UNIVERSIDAD NACIONAL DEL LITORAL

\title{
Facultad de Bioquímica y Ciencias Biológicas
}

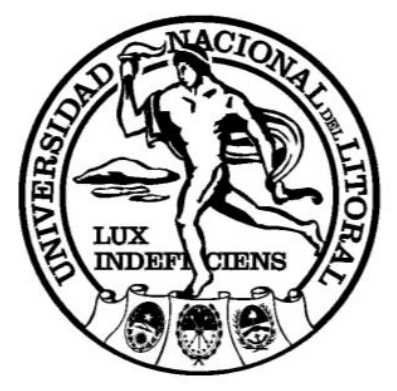

Tesis para la obtención del Grado Académico de Doctor en Ciencias Biológicas

“Determinación por métodos multiresiduo de plaguicidas y micotoxinas en alimentos vegetales y lácteos mediante técnicas cromatográficasespectrométricas de masa"

Lic. Nicolás Michlig

Ing. Horacio R. Beldoménico

Director de Tesis

Dr. Juan C. Basílico

Co-director de Tesis

Programa de Investigación y Análisis de Residuos y Contaminantes Químicos (PRINARC) Facultad de Ingeniería Química - Universidad Nacional del Litoral 


\section{AGRADECIMIENTOS}

Quiero agradecer a todo el grupo del PRINARC que acompañó la realización de esta tesis durante estos siete años. Estudiar, trabajar e investigar como estando en familia o con amigos es un gran privilegio y un enorme placer. Gracias a Lucila, Mirna, Negro, Darío C., Silvia, Florencia, Melina, Luisina, Daiana, Ivana, Jonatan, Micaela, Guillermo, Darío M., Miguel y Vepi. Aunque todos, los que estuvieron y los que están, merezcan igual crédito en estas líneas, quiero agradecer especialmente a dos integrantes del grupo sin los cuales no estaría escribiendo esto:

Al Profesor Horacio Beldoménico (a.k.a Lacho o Patrón), no por la formalidad de haber dirijido con gran dedicación esta tesis sino por su enorme y constante compromiso con mi formación.

A María Rosa Repetti, quien sin las responsabilidades formales tuvo un rol preponderante en cada una de las etapas de desarrollo de esta tesis, tanto en la enseñanza como en el acompañamiento.

Al Dr. Juan Carlos Basílico y su grupo de la Cátedra de Microbiología de la FIQ por haber introducido el mundo de las micotoxinas que resultó en uno de los contenidos principales de esta tesis.

También quiero agradecer a los investigadores de la Estación Experimental INTA de Rafaela por su contribución en la ejecución de los estudios de campo que formaron parte de este trabajo.

A la Universidad Nacional del Litoral, a la Facultad de Bioquímica y Ciencias Biológicas, a la Facultad de Ingeniería Química y a todo el Sistema Científico Nacional (ANPCyT, CONICET), por acompañar, respaldar y financiar la relización de esta tesis y mi formación doctoral.

A TODOS, MUCHAS GRACIAS.

Esta tesis está especialmente dedicada a Mamá y a Papá 


\section{PUBLICACIONES REALIZADAS DURANTE EL DESARROLLO DE LA PRESENTE TESIS}

Multiclass Compatible Sample Preparation for UHPLC-MS/MS Determination of Aflatoxin M1 in Raw Milk; Nicolás Michlig, María R. Repetti, Carolina Chiericatti, Silvia R. García, Mónica Gaggiotti, JuanC. Basílico, Horacio.R. Beldoménico. Chromatographia 79 (2015), 1091-1100.

Risk factors associated with the presence of aflatoxin M1 in raw bulk milk from Argentina; Nicolás Michlig, Marcelo Signorini, Mónica Gaggiotti, Carolina Chiericatti, Juan C. Basílico, María R. Repetti, Horacio R. Beldomenico. Food Control 64 (2016) 151-156.

Comprehensive estimate of the theoretical maximum daily intake of pesticide residues for chronic dietary risk assessment in Argentina; Darío A. Maggioni, Marcelo L. Signorini, Nicolás Michlig, María R. Repetti, Mirna E. Sigrist, Horacio R. Beldomenico. Journal of Environmental Science and Health, Part B (2017) 52 (4) 256-266.

National short-term dietary exposure assessment of a selected group of pesticides in Argentina; Darío A. Maggioni, Marcelo L. Signorini, Nicolás Michlig, María R. Repetti, Mirna E. Sigrist \& Horacio R. Beldomenico. Journal of Environmental Science and Health, Part B (2018) 1-13.

Determination of glyphosate, AMPA and glufosinate in dairy farm water from Argentina using a simplified UHPLC-MS/MS method; Luisina D. Demonte, Nicolás Michlig, Monica Gaggiotti, Claudia G. Adam, Horacio R. Beldoménico, Maria R. Repetti. Science of the Total Environment 645 (2018) 34-43. 


\section{ÍNDICE}

Contenido

ABREVIATURAS Y SÍMBOLOS 1

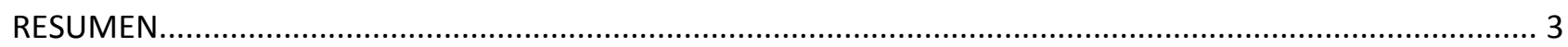

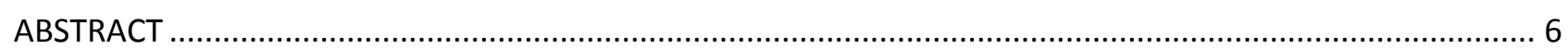

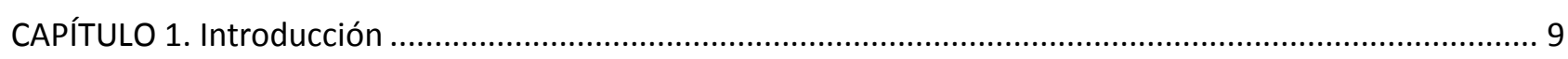

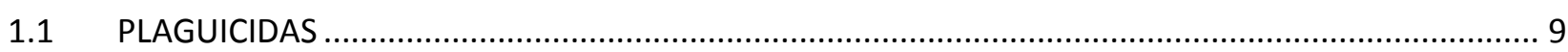

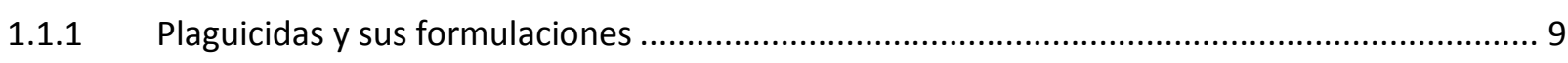

1.1.2 Identificación y clasificaciones de los plaguicidas .................................................................. 11

1.1.3 Propiedades físicas y químicas de los plaguicidas ............................................................. 17

1.1.4 Características toxicológicas asociadas a la residualidad de plaguicidas ............................... 19

1.1.5 Residuos de plaguicidas. Definición y caracterización. ....................................................... 20

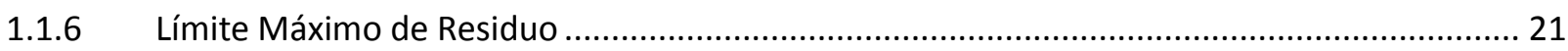

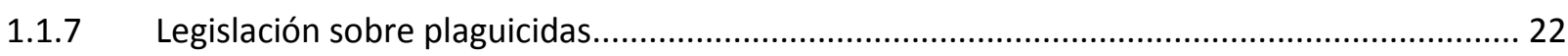

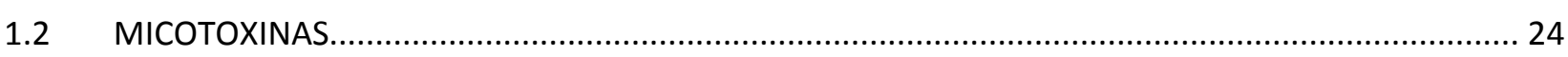

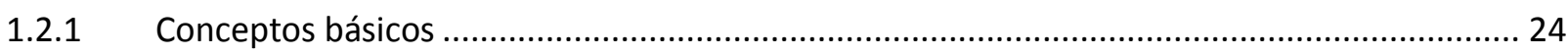

1.2.2 Crecimiento fúngico y producción de micotoxinas ............................................................. 24

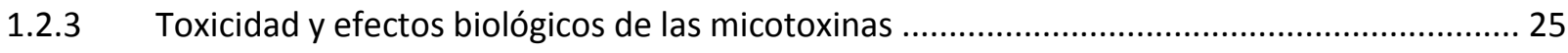

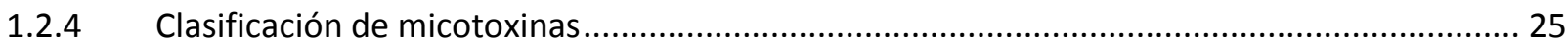

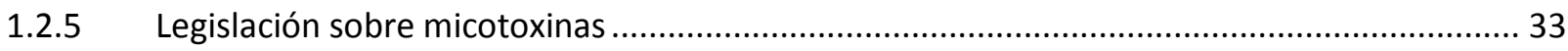

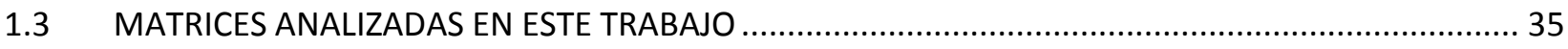

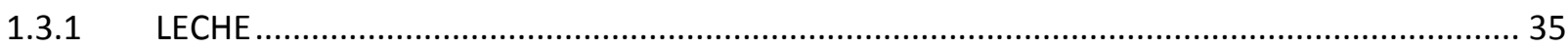

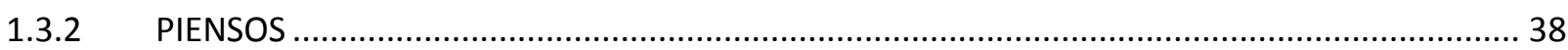

1.4 MÉTODOS MULTI-RESIDUO MULTI-CLASE PARA PLAGUICIDAS Y MICOTOXINAS.......................... 41

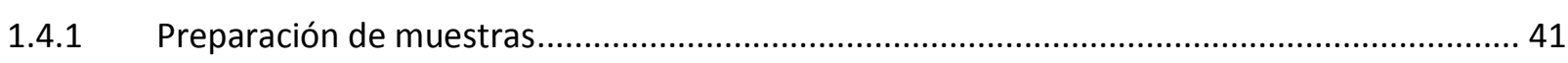

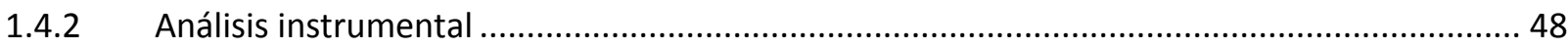

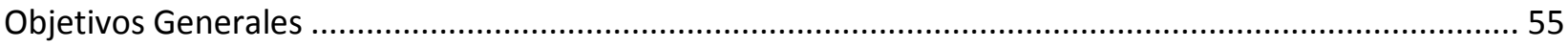

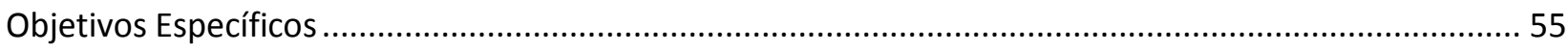

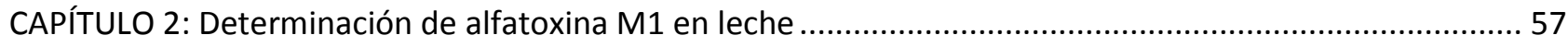

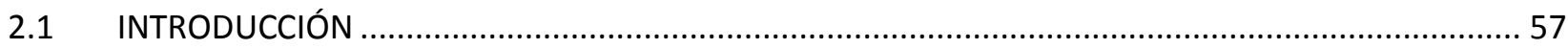

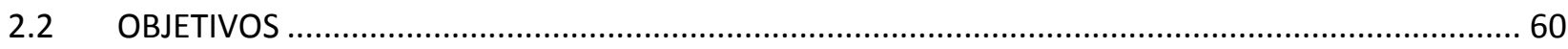

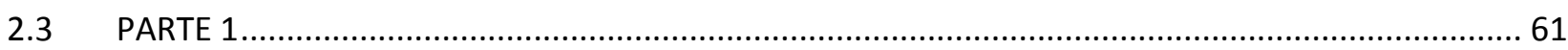

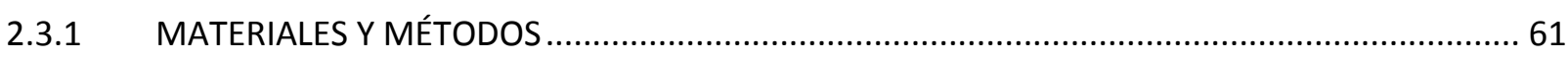

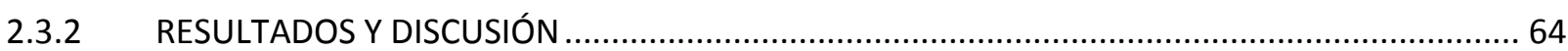




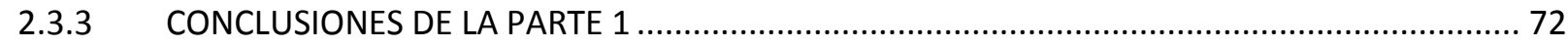

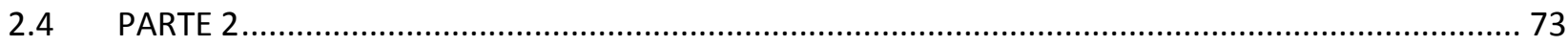

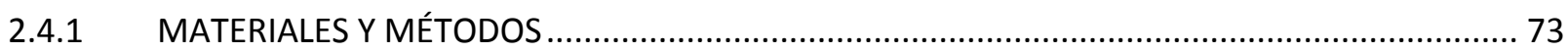

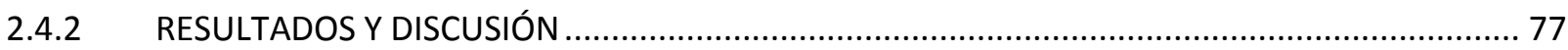

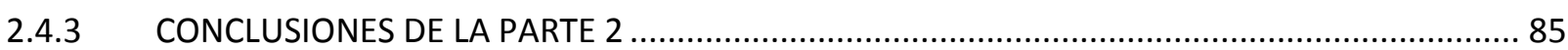

CAPÍTULO 3: Determinación de residuos de plaguicidas en leche............................................................ 87

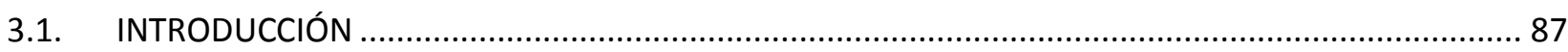

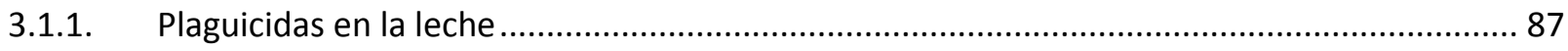

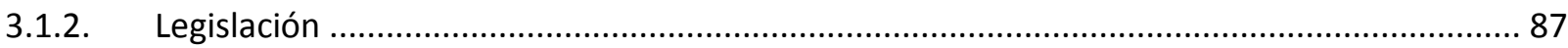

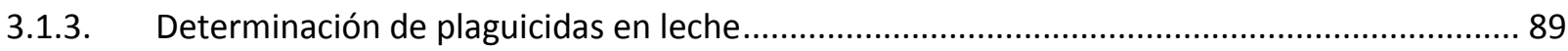

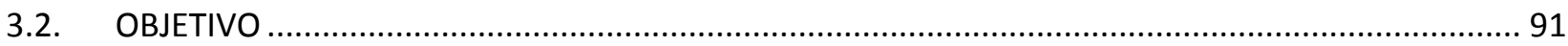

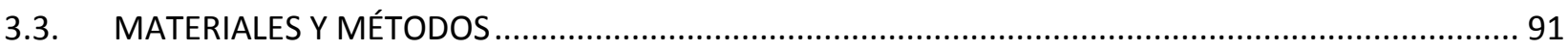

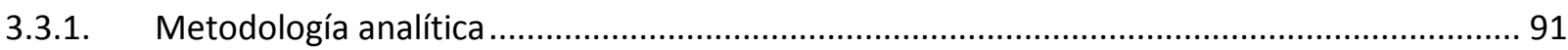

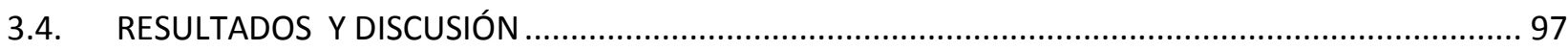

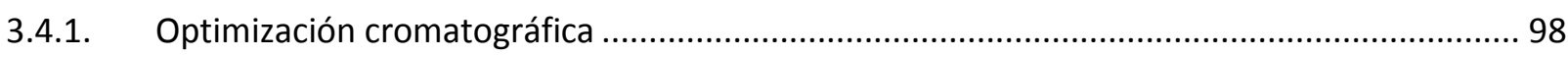

3.4.2. Optimización del método de extracción QuEChERS........................................................... 103

3.4.3. Validación del método QuEChERS aplicado a plaguicidas y otras micotoxinas .................... 105

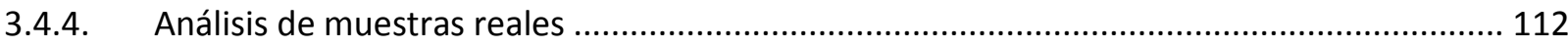

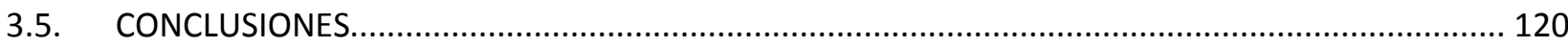

CAPÍTULO 4: Determinación de residuos de plaguicidas en piensos ........................................................ 123

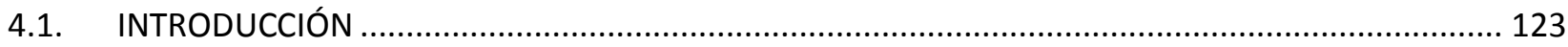

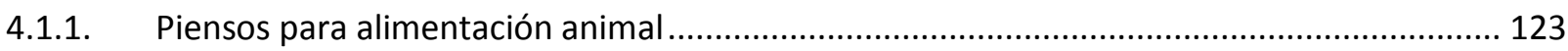

4.1.2. Legislación para piensos en Argentina y el mundo ........................................................... 124

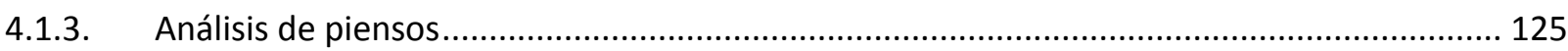

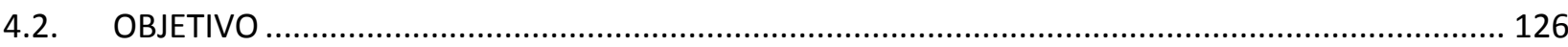

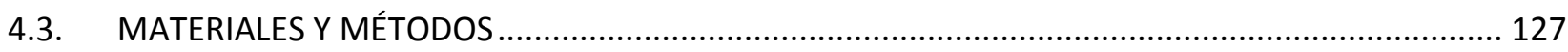

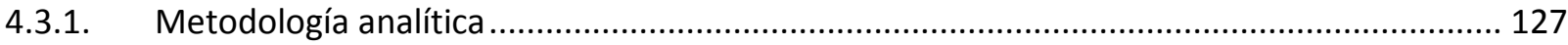

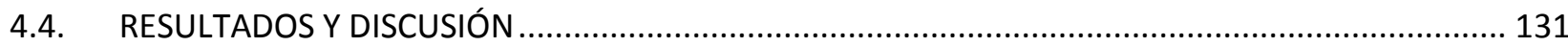

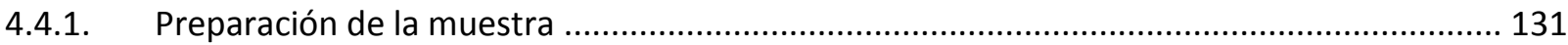

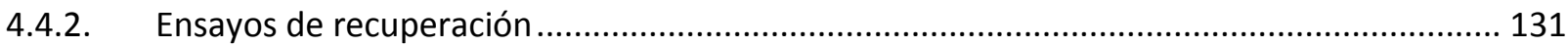

4.4.3. Residuos de plaguicidas encontrados en muestras analizadas ............................................ 132

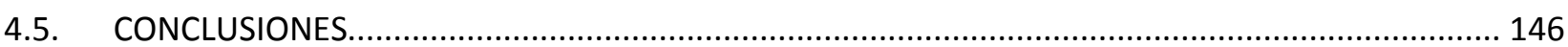

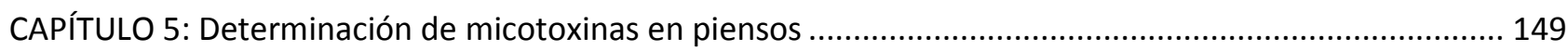

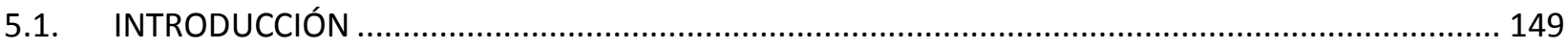

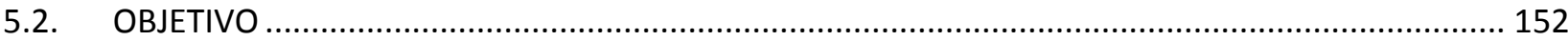




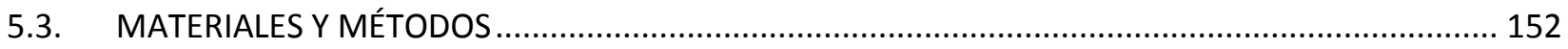

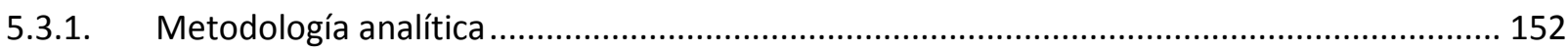

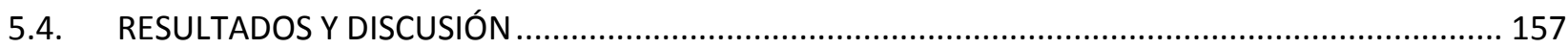

5.4.1. Evaluación de la recuperación del método y estimación de los límites de cuantificación ... 157

5.4.2. Micotoxinas halladas en muestras similares de Argentina ................................................. 159

5.4.3. Hallazgos en las muestras analizadas en nuestro trabajo .................................................... 160

5.4.4. Ocurrencia de las micotoxinas más importantes en los distintos tipos de muestra............. 163

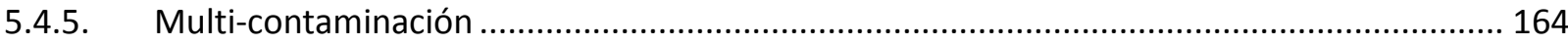

5.4.6. Relación entre el contenido de micotoxinas y el de plaguicidas......................................... 165

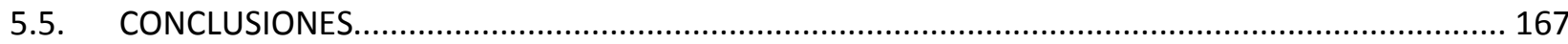

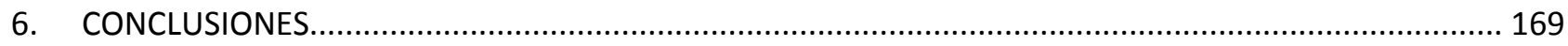

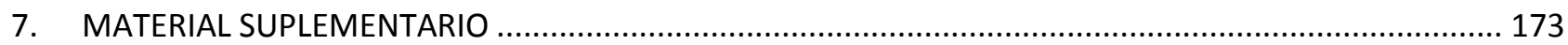

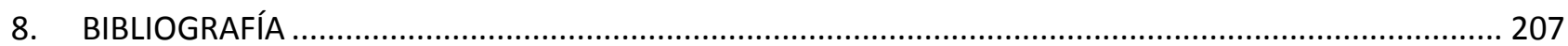




\section{ABREVIATURAS Y SÍMBOLOS}

\begin{tabular}{|c|c|}
\hline$\%$ REC & Porcentaje de recuperación \\
\hline$\mu \mathrm{g} / \mathrm{kg}$ & Microgramo/kilogramo \\
\hline $15-A D O N$ & 15-acetildeoxinivalenol \\
\hline 3-ADON & 3-acetildeoxinivalenol \\
\hline $\mathrm{ACL}$ & Agroclavina \\
\hline AFB1 & Aflatoxina B1 \\
\hline AFB2 & Aflatoxina B2 \\
\hline AFG1 & Aflatoxina G1 \\
\hline AFG2 & Aflatoxina G2 \\
\hline AFM1 & Aflatoxina M1 \\
\hline AME & Alternariol-metileter \\
\hline $\mathrm{AOH}$ & Alternariol \\
\hline BEA & Beauvericina \\
\hline $\mathrm{CIT}$ & Citrinina \\
\hline CPA & Ácido Ciclopiazónico \\
\hline DAS & Diacetoxiscirpenol \\
\hline DER & Desviación estándar relativa \\
\hline DON & Deoxinivalenol \\
\hline DON-3-GLU & Deoxinivalenol-3-glucosido \\
\hline d-SPE & Extracción en fase sólida dispersiva \\
\hline E-cor & Ergocornina \\
\hline E-corN & ErgocornININA \\
\hline E-crip & Ergocriptina \\
\hline E-cripN & ErgocriptININA \\
\hline E-cris & Ergocristina \\
\hline E-crisN & ErgocristININA \\
\hline E-met & Ergometrina \\
\hline ENA & Eniatina A \\
\hline ENA1 & Eniatina A1 \\
\hline ENB & Eniatina B \\
\hline ENB1 & Eniatina B1 \\
\hline ESI & Electrospray ionization \\
\hline$E-\sin$ & Ergosina \\
\hline$E-\sin N$ & ErgosININA \\
\hline E-tam & Ergotamina \\
\hline E-taN & ErgotamININA \\
\hline FB1 & Fumonisina B \\
\hline FB2 & Fumonisina B2 \\
\hline FB3 & Fumonisina B3 \\
\hline FUS-X & Fusarenon $\mathrm{X}$ \\
\hline GC-MS/MS & Cromatografía gaseosa acoplada a espectrometría de masa en tándem \\
\hline GLIO & Gliotoxina \\
\hline HRMS & Espectrometría de masa de alta resolución \\
\hline HT2 & Toxina HT-2 \\
\hline IAC & Columna de inmunoafinidad \\
\hline LC-MS/MS & Cromatografía líquida acoplada a espectrometría de masa en tándem \\
\hline LLE & Extracción líquido-líquido \\
\hline
\end{tabular}




\begin{tabular}{|c|c|}
\hline LM & Límite máximo (micotoxinas) \\
\hline LMR & Límite máximo de residuo (plaguicidas) \\
\hline $\mathrm{m} / \mathrm{z}$ & Relación masa/carga \\
\hline MEA & Meleagrina \\
\hline MMM & Método multi-residuo multi-clase \\
\hline MPA & Ácido Micofenólico \\
\hline MRM & Método multi-residuo \\
\hline MRM & Multiple Reaction Monitoring (modo de espectrometría de masa) \\
\hline MS & Espectrometría de masa \\
\hline MS/MS & Espectrometría de masa en tándem \\
\hline NEO & Neosolaniol \\
\hline NIV & Nivalenol \\
\hline OCP & Plaguicida organoclorado \\
\hline OPP & Plaguicida organofosforado \\
\hline OTA & Ocratoxina A \\
\hline PAT & Patulina \\
\hline PAX & Paxilina \\
\hline PenA & Ácido Penicílico \\
\hline PEN-A & Penitrem \\
\hline PM-A & Phomopsina A \\
\hline $\mathrm{ppb}$ & Parte por billón \\
\hline$q$ & Transición de confirmación \\
\hline$Q$ & Transición de cuantificación \\
\hline $\mathrm{QqQ}$ & Triple cuadrupolo \\
\hline QuEChERS & Quick, Easy, Cheap, Effective, Rugged, Safe \\
\hline Q-Trap & Cuadrupolo-trampa de iones (analizador MS) \\
\hline ROQ-C & Roquefortina C \\
\hline $\mathrm{S} / \mathrm{N}$ & Relación señal/ruido \\
\hline SPE & Extracción en fase sólida \\
\hline STACH & Stachybotrylactam \\
\hline STE & Esterigmatocistina \\
\hline $\mathrm{T} 2$ & Toxina T-2 \\
\hline TeA & Ácido tenuazónico \\
\hline TEN & Tentoxina \\
\hline TOF & Tiempo de vuelo (analizador MS) \\
\hline UHPLC & Cromatografía líquida de ultra alta resolución \\
\hline VRGN & Verruculogen \\
\hline VRL & Verrucarol \\
\hline ZEA & Zearalenona \\
\hline$\alpha-Z O L$ & $\alpha$-zearalenol \\
\hline$\beta-Z O L$ & $\beta$-zearalenol \\
\hline
\end{tabular}




\section{RESUMEN}

La calidad de los alimentos consumidos por el ser humano y por los animales está determinada, entre otros, por dos factores que tienen lugar al inicio de la cadena de producción. Por un lado, la expansión agrícola influye como consecuencia del gran número de plaguicidas que se utilizan en la agricultura como herramientas para el control de plagas y para incrementar los rendimientos de los cultivos. Por otro lado, los procesos de intensificación de la producción animal requieren de disponer gran cantidad de alimentos conservados que se almacenan en condiciones muy variables y son propensos al desarrollo fúngico y la producción de un gran número de micotoxinas. La combinación de ambos, los plaguicidas y las micotoxinas, puede afectar no solamente la salud y la producción de los animales que son los primeros expuestos, sino eventualmente también a las personas que consumen alimentos producidos por esos animales, como la leche. El control de materias primas y productos en la etapa inicial de la cadena de producción es, por lo tanto, de importancia fundamental.

Las actividades desarrolladas para la concreción de la presente tesis estuvieron enmarcadas en dos proyectos de investigación interdisciplinares. Uno denominado "Residuos y contaminantes en cadenas de agroalimentos prioritarias de la región central santafesina" (Proyecto ANPCyT-PICT) cuyo objetivo principal era generar y perfeccionar métodos avanzados para la determinación de plaguicidas y contaminantes fúngicos, y aplicarlos en estudios de residualidad en muestras de leche cruda y alimentos vegetales para ganado. El otro fue un proyecto de cooperación binacional Argentina-República Checa denominado "Técnicas analíticas innovadoras para la evaluación de inocuidad de alimentos y piensos" (Proyecto MINCYT-MEYS) uno de cuyos objetivos era la aplicación de metodologías multi-residuo multi-clase de amplio espectro para efectuar estudios de campo sobre la transferencia de micotoxinas y plaguicidas desde los alimentos consumidos por el ganado hacia la leche.

En ese contexto, luego de una introducción general el presente manuscrito se organizó en 4 capítulos principales. Los Capítulos 2 y 3 tienen una componente principal de índole químico-analítica centrada en la matriz leche destinada a la obtención de métodos multi-residuo multi-clase para la determinación de micotoxinas y plaguicidas en ese alimento y su aplicación en un estudio de campo (Proyecto ANPCyT-PICT). Los Capítulos 4 y 5, centrados en piensos como matrices de estudio, no focalizan en el desarrollo de metodologías analíticas sino en la aplicación de métodos de amplio espectro para evaluar la incidencia de la residualidad de dichos contaminantes en una diversidad de alimentos que componen la dieta del ganado lechero en la zona central de Argentina (Proyecto MINCYT-MEYS).

El Capítulo 2 describe, en una primera parte, la optimización y validación de una metodología basada en columnas de inmunoafinidad con cromatografía líquida acoplada a espectrometría de masa (IAC-UHPLCMS/MS) para la determinación de aflatoxina M1 en leche y su aplicación para el análisis de 160 muestras de leche tomadas de 40 establecimientos productores de la zona central de la Provincia de Santa Fe durante 4 
estaciones climáticas a lo largo de un año. Se encontró una prevalencia de AFM1 en las muestras analizadas cercana al $50 \%$ con niveles medios de concentración de 0,038 y un máximo de 0,293 $\mu \mathrm{g} / \mathrm{L}$. Aunque no se registraron excesos en el límite máximo establecido en Argentina $(0,5 \mu \mathrm{g} / \mathrm{L})$ se verificaron violaciones al $\mathrm{LM}$ de la Unión Europea $(0,05 \mu \mathrm{g} / \mathrm{kg})$ en el $8 \%$ de las muestras. En la segunda parte del Capítulo se describe la optimización de una metodología alternativa al método IAC basada en el enfoque QuEChERS para integrar la determinación de AFM1 con la de residuos de plaguicidas en un mismo método de extracción. Tras varias etapas de optimización, el método propuesto mostró un desempeño analítico con cifras de mérito compatibles con las normativas de Mercosur y la Unión Europea.

El Capítulo 3 describe la optimización y validación de una metodología QuEChERS-UHPLC-MS/MS para la determinación multi-residuo multi-clase de residuos de plaguicidas y micotoxinas en leche, y su posterior aplicación en al análisis de 80 muestras de leche tomadas de los mismos establecimientos referidos anteriormente durante dos períodos climáticos. El método optimizado demostró parámetros de desempeño que satisfacen los requerimientos de las normativas de Argentina y de otros países. En el análisis de muestras de leche se encontró mayor prevalencia de insecticidas organofosforados como clorpirifos y diazinon, y en menor medida otros como atrazina, acetamiprid, carbendazim, pirimifos-metilo, entre otros. Adicionalmente, la posterior incorporación de un instrumento GC-MS/MS en las instalaciones del PRINARC permitió analizar los extractos de las mismas muestras ampliando así el conjunto de compuestos determinados. De esa forma, se encontraron también residuos de plaguicidas organoclorados como heptacloro o isómeros de DDT, prohibidos hace más de dos décadas, y una alta ocurrencia de endosulfán-sulfato, de prohibición más reciente en Argentina.

En el Capítulo 4 se describe la determinación de residuos de plaguicidas en una amplia variedad de piensos que componen las dietas del ganado lechero. La estrategia analítica orientada a enfoques de amplio espectro consistió en la determinación de 350 compuestos mediante una metodología analítica QuEChERSUHPLC-MS/MS (análisis realizado en República Checa) y la posterior determinación de 160 plaguicidas en las mismas muestras replicando el procedimiento de extracción pero con determinación por GC-MS/MS (análisis realizado en Argentina). De los 420 plaguicidas estudiados en total 50 se encontraron en las muestras analizadas, siendo el $62 \%$ insecticidas, el $20 \%$ herbicidas y el $18 \%$ restante fungicidas. Clorpirifos, metolacloro y difenilamina fueron los plaguicidas de mayor ocurrencia entre los insecticidas, herbicidas y fungicidas, respectivamente. Respecto al análisis de muestras, en el $72 \%$ de las mismas se encontraron residuos de plaguicidas $(n=54)$, siendo los alimentos balanceados y las semillas de algodón las matrices con mayor cantidad de compuestos detectados. La concentración más alta de un plaguicida hallado fue para el insecticida piretroide deltametrina en un alimento balanceado $(532 \mu \mathrm{g} / \mathrm{kg})$.

En el Capítulo 5 se describe la determinación de micotoxinas en el mismo set de muestras de alimentos vegetales analizadas en el Capítulo 4 y a partir del mismo procedimiento de extracción, integrando así la 
determinación simultánea de gran cantidad de compuestos (multi-residuo) de diferente origen (multiclase). A partir del mismo extracto QuEChERS utilizado en el análisis de residuos de plaguicidas, se determinó un conjunto de 56 metabolitos fúngicos incluyendo micotoxinas tradicionales, conjugadas o enmascaradas, y micotoxinas emergentes. Se encontró que el 100\% de las muestras analizadas contenía al menos 1 micotoxina, y del total de compuestos incluidos en el alcance del método se identificaron 38 (68\%). Además de las micotoxinas con incidencia histórica en este tipo de alimentos en la región (aflatoxinas, fumonisinas, zearalenona, deoxinivalenol), se hallaron micotoxinas emergentes como eniantinas, toxinas de Alternaria y beauvericina que no habían sido previamente estudiadas. En algunos casos de verificaron excesos a los límites máximos establecidos por la UE para micotoxinas en piensos, como AFB1 en granos de maíz ( $L M=5 \mu \mathrm{g} / \mathrm{kg}$ ), FB1 en gluten de trigo ( $\mathrm{LM}=6000 \mu \mathrm{g} / \mathrm{kg}$ ) y ZEA en silaje de maíz (LM=3000 $\mu \mathrm{g} / \mathrm{kg})$.

Los resultados obtenidos en este trabajo constituyen un aporte importante para un mayor conocimiento sobre la residualidad de plaguicidas y micotoxinas en la primer etapa de la cadena de producción, y pueden ayudar a asistir a los productores respecto al mejoramiento del manejo de sus cultivos y productos almacenados destinados a la alimentación animal, para perfeccionar los programas de monitoreo y control necesarios para la evaluación de riesgo, y para asegurar las medidas de protección de la salud tanto animal como humana relacionadas con la inocuidad de los alimentos. 


\section{ABSTRACT}

Among several factors, food and feed quality for human and livestock consumption is determined by two main circumstances occurring at the beginning of the food chain. On one hand, agricultural expansion demands a high number of pesticides to be used for crop protection and to improve crops yields and this might impact on food and feed quality. On the other hand, farm feeding intensification in livestock production demands higher amounts of conserved forages and concentrated feeds which may be exposed to fungal development and mycotoxin contamination as a consequence of inappropriate storage conditions. Combination of both pesticide residues and mycotoxins could affect not only animal health and production, but eventually human health also, due to consumption of contaminated products of animal origin. The control of commodities and raw primary foods at the beginning of the food supply chain is, hence, of priority importance.

The activities involved in the realization of this thesis where framed under two interdisciplinary research projects. One of them, named "Residues and contaminants in priority agrifood supply chains from Santa Fe central region" (ANPCYT-PICT Project) was aimed to develop and perfect advanced analytical methods for the determination of pesticides and fungal contaminants, and to apply them in residuality studies on raw milk and feedstuff samples for dairy cattle. The second project named "Novel analytical techniques for food and feed safety assessment" was a binational cooperation project between Argentina and the Czech Republic and was aimed to the application of wide-scoped multi-residue multi-class methodologies for field studies assessments regarding mycotoxin and pesticide transfer from feed consumed by dairy cattle to milk.

In this context, this manuscript was organized in 4 main chapters after a general introduction about the different addressed topics. Chapters 2 and 3 have a main chemical-analytical component focused on milk as the studied matrix and are aimed to the development of multi-residue multi-class methods for the determination of mycotoxins and pesticide residues with further application to field studies (ANPCYT-PICT Project). Centered in vegetal origin feedstuffs analysis, Chapters 4 and 5 are not focused on analytical methodologies developments but on their application of wide-scoped approaches to assess mycotoxin and pesticide residuality on a great variety of typical feed that constitute dairy cattle diets in Argentinean central regions (MINCYT-MEYS Project).

Chapter 2 describes, at a first stage, the optimization and validation of an immunoaffinity-based extraction method with liquid chromatography-tandem mass spectrometry determination (IAC-UHPLC-MS/MS) for aflatoxin M1 determination in raw milk and its application for the analysis of 160 milk samples obtained from 40 different milk farms located in Santa Fe province central region throughout four climate season in a one-year field study. AFM1 prevalence in the analyzed samples was close to $50 \%$ with mean and maximum concentration levels of 0.038 and $0.293 \mu \mathrm{g} / \mathrm{L}$, respectively. Although no maximum limits violations to 
Argentinean legislation $(0.5 \mu \mathrm{g} / \mathrm{L})$ were observed, European Union $\mathrm{ML}(0.05 \mu \mathrm{g} / \mathrm{L})$ exceedances were observed in $8 \%$ of the cases. Chapter 2 second part describes the optimization of a QuEChERS-based approach as an alternative to the IAC method to integrate AFM1 and pesticide residues determination in a single extraction method. After several optimization steps, the proposed method was validated demonstrating appropriate analytical performance to fulfill Mercosur and European Union legislations.

Chapter 3 describes the optimization and validation process of a QuEChERS-UHPLC-MS/MS for the multiresidue multi-class determination of pesticides and mycotoxins in milk, and its later application to the analysis of 80 milk samples obtained from the same above mentioned dairy farms. The optimized method demonstrated good performance characteristics to fulfill analytical requirements set by legislation from Argentina and other countries. The analysis of milk samples revealed a higher prevalence of organophosphate insecticides (mainly chlorpyrifos and diazinon) and to a less extent other compounds such as atrazine, acetamiprid, carbendazim and pirimifos-methyl were also found. In addition, the later incorporation of a GC-MS/MS system to the PRINARC analytical platforms allowed the analysis of the same sample extracts to enhance the determined compounds scope. Thus, residues of some organochlorine pesticide that have been banned for over 2 decades were found such as heptachlor and DDT isomers, and also high occurrence of endosulfan-sulfate which has been more recently banned.

Chapter 4 describes the pesticide residues determination in a wide variety of feed samples used in dairy cattle diets. In this case the analytical strategy was focused on wide-scoped approaches and it implied the determination of 350 compounds my means of a QuEChERS-UHPLC-MS/MS analytical methodology (analysis performed in the Czech Republic) together with the further determination of 160 pesticides in the same samples by replicating the extraction procedure but with final determination by GC-MS/MS (analysis performed in Argentina). From the total 420 different pesticides studied 50 of them were found in the analyzed samples, being $62 \%$ of them insecticides, $20 \%$ herbicides and $18 \%$ fungicides. Chlorpyrifos, metholachlor and diphenylamine were the pesticides with major occurrence from the insecticide, herbicide and fungicide families, respectively. Regarding sample analysis, pesticide residues were found in $72 \%$ of them $(n=54)$, being compound feeds and cotton seeds the feed types with higher amount of detected compounds. The highest concentration of a single pesticide in an individual sample was due to the pyrethroid insecticide deltamethrin in a compound feed sample $(532 \mu \mathrm{g} / \mathrm{kg})$.

Chapter 5 describes the mycotoxin determination in the same set of feed samples analyzed in Chapter 4, using the same extraction procedure thus integrating simultaneous determination of a great amount of compounds (multi-residue) from different classes and origin (multi-class). From the same sample extracts used for pesticide residues analysis, 56 fungal origin metabolites were determined, including traditional mycotoxins, conjugated or masked mycotoxins and emerging mycotoxins. All of the analyzed samples $(100 \%)$ evidenced contamination with at least one mycotoxin, and from the total compound included in the 
analytical scope 38 different mycotoxins were identified (68\%). Besides mycotoxins with historical incidence in this types of feed from the studied region (like aflatoxins, fumonisins, zearalenone and deoxynivalenol), other emerging mycotoxins that had not previously been studied were found, such as enniatins, Alternaria toxins and beauvericin. In some cases violations to EU maximum levels for mycotoxins in feeds were observed, as the case of AFB1 in maize grains ( $M L=5 \mu \mathrm{g} / \mathrm{kg}$ ), FB1 in wheat gluten (ML=6000 $\mu \mathrm{g} / \mathrm{kg})$ and ZEA in maize silage $(\mathrm{ML}=3000 \mu \mathrm{g} / \mathrm{kg})$.

The results obtained from this work constitute an important contribution for a better knowledge about mycotoxin and pesticide residuality in the first stage of the food production chain, and can help to assist producers on the improvement of crops and feed managements, to improve monitoring and control programs for risk assessment and to guarantee safe food and feeds for human and animal health protection. 
CAPITULO 1

Introducción 


\section{CAPÍTULO 1. Introducción}

Las personas estamos expuestas a los plaguicidas y a las micotoxinas en forma directa a través de los productos de origen agrícola que consumimos (cereales y derivados, frutas, vegetales, etc.), y en forma indirecta cuando consumimos alimentos (como la leche) que son producidos por animales que estuvieron expuestos a estos contaminantes durante su alimentación. Además de los evidentes riesgos para la salud humana que estos peligros representan, son también un problema para la salud de los animales, afectan su capacidad de producción y, en consecuencia, causan pérdidas económicas muy importantes.

\subsection{PLAGUICIDAS}

A nivel mundial, las plantas que producen alimentos son afectadas por más de 10.000 especies de insectos predadores, 30.000 especies de malezas, 100.000 enfermedades (causadas por hongos, virus y bacterias) y unas 1.000 especies de nematodos [1]. Los plaguicidas son considerados herramientas tecnológicas utilizadas en la agricultura moderna para disminuir los efectos destructivos ocasionados por las plagas y enfermedades.

\subsubsection{Plaguicidas y sus formulaciones}

El término "plaga" fue creado por el hombre y está determinado en función de la pérdida económica que el daño producido por la especie en cuestión genera. Se lo define como "toda especie, variedad o biotipo vegetal, animal o agente patógeno dañino para las plantas y productos, materiales o entornos vegetales: comprenden los vectores de parásitos o patógenos de las enfermedades de seres humanos y animales, así como los animales que causan perjuicio a la salud pública" [2,3]. En general, el concepto más actual de plaga es análogo al de enfermedad, pero el problema no es el organismo en sí mismo sino un desarrollo descontrolado de su población. Una población animal o vegetal es el conjunto de individuos de la misma especie que se relacionan entre sí, controlada por factores ambientales o biológicos. Cuando los factores ambientales como la disponibilidad de recursos o las características del hábitat se modifican, su número puede disminuir o crecer descontroladamente afectando a otras poblaciones que, por competencia, pueden a su vez alterarse [4].

En ese contexto, un "plaguicida", según una definición abarcativa del Codex Alimentarius, es "...cualquier sustancia destinada a impedir, destruir, atraer, repeler o combatir cualquier plaga, incluidas las especies indeseadas de plantas o animales, durante la producción, almacenamiento, transporte, distribución y elaboración de alimentos, productos agrícolas o piensos, o que pueda administrarse a los animales para combatir ectoparásitos. El término incluye las sustancias destinadas a utilizarse como reguladores del crecimiento de las plantas, defoliantes, desecantes, agentes para reducir la densidad de fruta o inhibidores de la germinación, y las sustancias aplicadas a los cultivos antes o después de la cosecha para proteger el producto contra el deterioro durante el almacenamiento y transporte. El término excluye normalmente los fertilizantes, nutrientes de origen vegetal o animal, aditivos alimentarios y medicamentos veterinarios" [5]. 
De este modo, los plaguicidas son preparados cuyo objetivo buscado es combatir plagas y que contienen sustancias activas biocidas contra el organismo que se desea controlar. Estas sustancias en un principio fueron productos naturales como la nicotina, el piretro, el azufre, las sales de cobre empleadas en la antigüedad, y que hoy no se utilizan masivamente aunque algunas de ellas están volviendo a ser utilizadas en prácticas agroecológicas. En su mayoría, estos principios son moléculas especialmente diseñadas y fabricados por el hombre por lo que se denominan genéricamente plaguicidas sintéticos [6].

Dichos preparados no están constituidos solamente por los principios activos sino que incorporan distintas sustancias que les confieren propiedades para optimizar su eficacia contra la plaga objetivo y favorecen las condiciones operativas de su aplicación [7]. La composición habitual de un formulado tiene como componente principal a la sustancia o principio activo (p.a.), también denominado ingrediente activo (i.a.) por su denominación más frecuente en la legislación de Estados Unidos (active ingredient, a.i.). Esta sustancia, que puede no ser única en un formulado, se encuentra en concentraciones que suelen ser muy variables, prácticamente de todo el rango de concentraciones. Además, los preparados están integrados por coadyuvantes o "ingredientes no activos" como humectantes, dispersantes, estabilizantes y emulsionantes, que son agentes tensoactivos que facilitan la penetración de la solución líquida en los objetivos y pueden ser compuestos aniónicos (benceno sulfonatos), catiónicos (sales de amonio cuaternario), anfóteros, no iónicos (fenoles etoxilados, copolímeros de óxido de polietileno) entre otros. También coexisten en los formulados hidrocarburos utilizados como solventes para solubilizar el activo cuando no es soluble en agua, vehículos o cargas minerales para mantener el p.a. en suspensión cuando es sólido, y otras sustancias con distinto uso como antiespumantes (dimeti polisiloxano), correctores de $\mathrm{pH}$ (soluciones buffer), acidificantes (ácido fosfórico, alquil aril polietilenglicol éter), secuestrantes (hidroxietanos, ortofosfatos), antiderivantes, penetrantes, compatibilizantes, etc. [8]. Se observa entonces que cuando una formulación es liberada al ambiente además de los ingredientes activos se libera otra gran cantidad de sustancias, algunas de las cuales tienen implicancias toxicológicas específicas para el hombre y el ambiente.

Para cumplir con la función para la que fueron diseñados, los plaguicidas deben atravesar una serie de procesos complejos que pueden resumirse en tres etapas [9]:

1) Penetrar el organismo que debe combatir: la velocidad y extensión de la penetración depende de la permeabilidad que presenta el organismo hacia el plaguicida, la cual difiere significativamente entre plantas e insectos. La habilidad de un plaguicida para penetrar en un organismo depende de su naturaleza, su estructura química y su formulación, y puede incrementarse en determinadas condiciones como altas temperaturas o en presencia de emulsificantes y solventes orgánicos en los preparados.

2) Transportarse al sito de acción: el movimiento del plaguicida desde su punto de ingreso al organismo hasta el sitio de acción involucra tanto la movilidad propia de la molécula como la 
rapidez con la que los mecanismos de transporte de la planta o animal la mueven a través de su sistema. Aquí se distinguen los plaguicidas sistémicos (aquellos que penetran a la planta y se transportan hacia todas sus partes a través de la savia) y los de contacto (que no se movilizan y ejercen su efecto tóxico en el sitio de aplicación).

3) Interrumpir o alterar alguna función vital: el modo de acción de un plaguicida es la forma en la que interfiere con algunas de las funciones fisiológicas vitales del organismo objetivo, que pueden estar asociadas con la respiración, el sistema nervioso, o el crecimiento, entre otras.

Cada una de estas etapas depende de una multiplicidad de interacciones plaguicida/organismo que deben verificarse, y que también determinan los procesos metabólicos, de acumulación y de eliminación de estas sustancias.

\subsubsection{Identificación y clasificaciones de los plaguicidas}

La identificación y caracterización de los numerosos principios activos que conforman el universo actual de plaguicidas, que se estima en más de 1000 a nivel global [10] y de los cuales unos 430 tienen usos autorizados en Argentina, puede encararse desde distintas ópticas según la disciplina desde la que se estudian los plaguicidas, clasificándolos según su aptitud y uso agronómico, su constitución química, su toxicidad aguda en términos del parámetro $\mathrm{DL}_{50}$, su modo de acción toxicológico, entre otras.

Se describirán aquí dos tipos de clasificaciones que atañen al contenido y encuadre de esta tesis. Por un lado, aquella que agrupa a los distintos plaguicidas según grupos de familias químicas y que permite inferir similitudes de los distintos principios activos en la tolerancia de los cultivos, en la sensibilidad de las plagas, en el mecanismo de acción, en el destino del suelo y en la toxicidad en los mamíferos. Por otro lado, la clasificación basada en el mecanismo de acción tóxica que permite, mediante el conocimiento de los mecanismos de acción bioquímica, una mejor predicción del efecto probable en los organismos blanco [11].

\section{Clasificación según la constitución química que poseen}

Los principios activos están diseñados según distintas estructuras moleculares en su mayoría de origen sintético y responden a una gran cantidad de clases químicas. En las Tablas 1-3 que siguen se ejemplifica mediante la descripción de las clases químicas a las que pertenecen los principales principios activos de insecticidas, herbicidas y fungicidas en la legislación de fitosanitarios de Argentina (SENASA 934/10) [12]. Las clases químicas incluidas se consultaron de las bases de datos PPDB y PAN $[13,14]$. 
Tabla 1. Clasificación de las principales familias químicas de INSECTICIDAS.

\begin{tabular}{|c|c|c|}
\hline Familia & Estructura molecular & Ejemplos de principios activos \\
\hline Organometal & Organo-Sn, met. pesado & Azociclotin, cyhexatin, fenbutatin óxido \\
\hline $\begin{array}{l}\text { Organoclorados } \\
\text { (no autorizados) }\end{array}$ & Aromático halogenado & DDT, HCB, metoxicloro \\
\hline (autorizados) & $\begin{array}{l}\text { Hexaclorociclohexano } \\
\text { Ciclodieno o cíclico } \\
\text { Aromático halogenado } \\
\text { Organohalogenado }\end{array}$ & $\begin{array}{l}\text { Lindano, } \alpha-\mathrm{HCH}, \beta-\mathrm{HCH} \\
\text { Clordano, heptacloro, aldrin, dieldrin, endrin, endosulfan, mirex } \\
\text { Dicofol } \\
\text { Bromuro de metilo }\end{array}$ \\
\hline Organofosforados & Organofosforado & $\begin{array}{l}\text { Acefato, clorpirifos metil, clorpirifos etil, diclorvos, dimetoato, etion, } \\
\text { etoprop, fenamifos, fenitrotion, fention, fentoato, fostiazate,fosmet, } \\
\text { malation, metamidofos, azinfos-metil, metidation, oxidemeton metil, } \\
\text { piridafention, pirimifos-metil, profenofos, triclorfon }\end{array}$ \\
\hline \multirow[t]{3}{*}{ Carbamatos } & N-Metil carbamato & $\begin{array}{l}\text { Formetanato, metiocarb, carbofuran, carbarilo, carbosulfan, metomilo, } \\
\text { pirimicarb, tiodicarb }\end{array}$ \\
\hline & Ditiocarbamato-MITC & Metam potasio, metam sodio \\
\hline & Otros carbamatos & Benfuracarb \\
\hline Piretroides & Piretroide & $\begin{array}{l}\text { Acrinatrina, alfametrina, betaciflutrina, betacipermetrina, bifentrin, } \\
\text { cipermetrina, cyflutrina, deltametrina, esfenvalerato, fenpropatrina, } \\
\text { fenvalerato, lambdacialotrina, permetrina, teflutrina, zetametrina }\end{array}$ \\
\hline Neonics & Neonicotinoide & $\begin{array}{l}\text { Clothianidin, imidacloprid, tiacloprid, tiametoxam, acetamiprid, } \\
\text { dinotefuran }\end{array}$ \\
\hline \multirow[t]{2}{*}{ Ureas } & Benzoilurea & $\begin{array}{l}\text { Flufenoxuron, bistriflurón, diflubenzuron, lufenuron, novaluron, } \\
\text { teflubenzuron, triflumuron }\end{array}$ \\
\hline & Sulfonilurea & Tifensulfuron metil \\
\hline Amidas & $\begin{array}{l}\text { Diamida antranílica } \\
\text { Carboxamida } \\
\text { Sulfonamida }\end{array}$ & $\begin{array}{l}\text { Clorantraniliprole, cyantraniliprole, flubendiamide } \\
\text { Carboxin, hexitiazox } \\
\text { Sulfluramida }\end{array}$ \\
\hline Hidrazinas & $\begin{array}{l}\text { Diacilhidracina } \\
\text { Hidrazina carboxilato }\end{array}$ & $\begin{array}{l}\text { Metoxifenocide, tebufenozide } \\
\text { Bifenazate }\end{array}$ \\
\hline Varios & $\begin{array}{l}\text { Aldehido } \\
\text { Benzilato } \\
\text { Ceto-enol } \\
\text { Difenilo enlazado } \\
\text { Fenilpirazol } \\
\text { Fenilpirrol } \\
\text { Formamidina } \\
\text { Lactona macrocíclica } \\
\text { Nereistoxina } \\
\text { Oxadiazina } \\
\text { Pirazol } \\
\text { Piridazinona } \\
\text { Piridina } \\
\text { Quinazolina } \\
\text { Sulfoximina } \\
\text { Sulfito ester } \\
\text { Tetrazina } \\
\text { Triazina } \\
\text { Xililalanina }\end{array}$ & $\begin{array}{l}\text { Metaldehido } \\
\text { Bromopropilato } \\
\text { Spiromesifen, spirodiclofen, spirotetramat } \\
\text { Tetradifon } \\
\text { Ethiprole } \\
\text { Fludioxonil } \\
\text { Amitraz } \\
\text { Benzoato de emamectina } \\
\text { Cartap } \\
\text { Indoxacarb } \\
\text { Clorfenapir, fenpiroximato, fipronil } \\
\text { Pyrldaben } \\
\text { Flonicamid } \\
\text { Fenazaquin } \\
\text { Sulfoxaflor } \\
\text { Propargite } \\
\text { Clofentezine } \\
\text { Pymetrozine } \\
\text { Metalaxil }\end{array}$ \\
\hline Naturales & $\begin{array}{l}\text { Espinosin } \\
\text { Botánico } \\
\text { Mimético de Hormona } \\
\text { Juvenil }\end{array}$ & $\begin{array}{l}\text { Spinetoram, spinosad } \\
\text { Piretrinas, rianodina, abamectina } \\
\text { Pyriproxyfen }\end{array}$ \\
\hline
\end{tabular}


Tabla 2. Clasificación de las principales familias químicas de HERBICIDAS.

\begin{tabular}{|c|c|c|}
\hline Familia & Estructura molecular & Ejemplos de principios activos \\
\hline Inorganicos & Inorgánico & Cianamida hidrogenada, cloropicrina \\
\hline Organometal & Organoarsenicales & MSMA, ácido cacodílico, ácido arsanílico \\
\hline \multirow[t]{5}{*}{$\begin{array}{l}\text { Acidos carboxilicos y } \\
\text { aromaticos }\end{array}$} & $\begin{array}{l}\text { Ác. ariloxifenoxi } \\
\text { propiónico }\end{array}$ & $\begin{array}{l}\text { Cialofop-But, clodinafop, propargil, fenoxaprop-Et, fluazifop-p-But, } \\
\text { haloxyfop-p-Me, propaquizafop, quizalofop-Et, quizalofop-p-tefuril }\end{array}$ \\
\hline & Clorofenoxiácido o éster & 2,4-D, 2,4-DB, diclorprop, MCPA, diclofop metil \\
\hline & Ác. benzoico & Dicamba \\
\hline & Ác. piridinocarboxílico & Aminopyralid, clopiralid, fluroxipir, picloran \\
\hline & Ác. quinolinocarboxilico & Quinclorac \\
\hline Heterociclicos & Benzotiazolona & Benazolin etil, bentazon \\
\hline \multirow{5}{*}{$\begin{array}{l}\text { Nitrogenados y } \\
\text { otros ciclicos }\end{array}$} & Dinitroanilina & Flumetralin, butralin, oryzalin, pendimetalin, trifluralin, dinitramina \\
\hline & Ciclohexanodiona & Cletodim \\
\hline & Deriv. de ciclohexenona & Butroxidim, profoxidim /clefoxidim, sethoxidim, tralkoxydim \\
\hline & Benzoilciclohexanodiona & Mesotrione \\
\hline & Benzoilpirazol & Tolpyralate \\
\hline \multirow[t]{4}{*}{ Ureas } & Sulfonilurea & $\begin{array}{l}\text { Clorimuron-etil, clorsulfuron, nicosulfuron, } \\
\text { foramsulfuron, halosulfuron, halosulfuron-metil, iodosulfuron-meti } \\
\text { sodio, metsulfuron-metil, oxasulfuron, primisulfuron, prosulfuron, } \\
\text { rimsulfuron, sulfometurón-metil, triasulfuron, trifloxisulfuron }\end{array}$ \\
\hline & Fenilurea & Tiadiazuron, fluometuron \\
\hline & Urea & Diuron, linuron, metabenztiazuron, tebutiuron \\
\hline & Uracilo & Butafenacil, bromacil, lenacil, terbacil \\
\hline Bipiridilo & Bipiridilo & Diquat dibromuro, paraquat (dicloruro) \\
\hline Triazinas & $\begin{array}{l}\text { Triazina } \\
\text { Triazinona }\end{array}$ & $\begin{array}{l}\text { Terbutilazina, ametrina, atrazina, prometrina, simazina, terbutrina } \\
\text { Hexazinona, metribuzin }\end{array}$ \\
\hline \multirow[t]{3}{*}{ Triazoles } & Triazol & Aminotriazol \\
\hline & Triazolona & Carfentrazone-Et, flucarbazone, sulfentrazone, tiencarbazone-Me \\
\hline & Triazolpirimidina & Cloransulam-Me, diclosulam, flumetsulam, penoxulam, piroxsulam \\
\hline Acetanilidas & Cloroacetanilida & Acetoclor, alaclor, metolacloro /s- metolacloro \\
\hline \multirow{6}{*}{$\begin{array}{l}\text { Amidas, éteres, } \\
\text { cetonas aldehidos }\end{array}$} & Amida & Dimetenamida, napropamida, naptalan, propizamida, saflufenacil \\
\hline & Oxiacetamida & Isoxaflutole, topramezone, oxadiazon \\
\hline & $\begin{array}{l}\text { N-tenilftalımıdas } \\
\text { Anilida }\end{array}$ & $\begin{array}{l}\text { Hlumıoxazım } \\
\text { Diflufenican, flufenacet, propanil }\end{array}$ \\
\hline & Tricetona & Biciclopirona \\
\hline & Aldehido & Acroleina \\
\hline & Hidroxibenzonitrilo & Bromoxinil, ioxinil octanoato \\
\hline \multirow[t]{2}{*}{ Imidazolinonas } & Imidazolinona & Imazamox, imazapic, imazapir, imazaquin, imazetapir \\
\hline & Isoxazolidinona & Clomazone \\
\hline OCs, OPs, & Organoclorados & Dalapon /acido 2,2 dicloropropionico \\
\hline \multirow[t]{5}{*}{ carbamatos } & HC halogenado & 1,3 diclopropeno \\
\hline & Organofosforados & Tribufos, etefon \\
\hline & Bis-carbamato & Fenmedifan \\
\hline & Tiocarbamato & Molinato \\
\hline & Otros carbamatos & Clorprofam, asulam \\
\hline Glicinas/ácidos & Fosfonoglicina & Glifosato/glifosato acido \\
\hline fosfinicos & Ácido fosfínico & Glufosinato de amonio \\
\hline \multirow[t]{7}{*}{ Otros } & Pirazolilfenil & Piraflufen-etilo \\
\hline & Piridazina & Hidrazida maleica \\
\hline & Piridazinona & Cloridazon/pirazon \\
\hline & Pirimidinil-tio-benzoato & Bispiribac sódico \\
\hline & Amonio cuaternario & Cloromecuato, mepiquat cloruro \\
\hline & Malonanilato & Cyclanilide \\
\hline & Oxima éter & Fluxofenim \\
\hline
\end{tabular}


Tabla 3. Clasificación de las principales familias químicas de FUNGICIDAS.

\begin{tabular}{|c|c|c|}
\hline Familia & Estructura molecular & Ejemplos de principios activos \\
\hline Inorgánicos & $\begin{array}{l}\text { Sal de Cobre } \\
\text { Azufre }\end{array}$ & $\begin{array}{l}\text { Oxicloruro de cobre, oxido cuproso, sulfato cúprico pentahidratado, sulfato } \\
\text { tribásico de cobre, hidróxido de cobre } \\
\text { Azufre }\end{array}$ \\
\hline Organometal & $\begin{array}{l}\text { Organo estaño } \\
\text { Sal de Zinc }\end{array}$ & $\begin{array}{l}\text { Trifenil acetato de estaño } \\
\text { Nafteno de zinc }\end{array}$ \\
\hline $\begin{array}{l}\text { Amidas/ } \\
\text { imidas }\end{array}$ & $\begin{array}{l}\text { Amida } \\
\text { Benzamida } \\
\text { Carboxamida/ Anilida/ } \\
\text { Pirazol } \\
\text { Fenilamida } \\
\text { Mandelamida } \\
\text { Dicarboximidas } \\
\text { Cianoacetamida oxima } \\
\text { Tioftalimida }\end{array}$ & $\begin{array}{l}\text { Benzovindiflupir } \\
\text { Fluopicolide, zoxamide } \\
\text { Boscalid, fenhexamid, sedaxane, fluxapyroxad, pentiopirad, pydiflumetofen, } \\
\text { isopyrazam } \\
\text { Metalaxil, furalaxil } \\
\text { Mandipropamid. } \\
\text { Famoxadone, iprodione, procimidone } \\
\text { Cymoxanil } \\
\text { Captan, folpet }\end{array}$ \\
\hline Azoles & $\begin{array}{l}\text { Imidazol } \\
\text { Bencimidazol } \\
\text { Tiazol } \\
\text { Triazolintiona }\end{array}$ & $\begin{array}{l}\text { Difenoconazole, prothioconazole, bitertanol, diniconazole, fenbuconazole, } \\
\text { fluquinconazole, flusilazole, flutriafol, hexaconazole, ipoconazole, } \\
\text { metconazole, myclobutanil, penconazole, propiconazole, tebuconazole, } \\
\text { fenetrazole, tetraconazole, triadimefon, cyproconazole, triadimenol, } \\
\text { triticonazole, epoxiconazole } \\
\text { Cyazofamid, imazalil, procloraz } \\
\text { Carbendazim, tiabendazol, benomil, metil tiofanato } \\
\text { Ethaboxam } \\
\text { Prothioconazole }\end{array}$ \\
\hline Estrobinas & Estrobilurina & $\begin{array}{l}\text { Dimoxistrobin, fluoxastrobin, piraclostrobin, metominostrobin, kresoxim-Me, } \\
\text { picoxystrobin, trifloxistrobin, azoxistrobina }\end{array}$ \\
\hline Carbamatos & $\begin{array}{l}\text { Ditiocarbamato } \\
\text { Carbamato }\end{array}$ & $\begin{array}{l}\text { Tiram, propineb, ziram, ferbam, mancozeb metiram, zineb } \\
\text { Iprovalicarb, propamocarb clorhidrato, dazomet }\end{array}$ \\
\hline Fenoles & $\begin{array}{l}\text { Dinitrofenol } \\
\text { Fenol }\end{array}$ & $\begin{array}{l}\text { Meptyldinocap } \\
\text { Ortofenilfenato de sodio }\end{array}$ \\
\hline Pirimidinas & $\begin{array}{l}\text { Pirimidina } \\
\text { Triazolpirimidina }\end{array}$ & $\begin{array}{l}\text { Bupirimato, cyprodinil, fenarimol, pyrimetanil } \\
\text { Ametoctradin }\end{array}$ \\
\hline Varios & $\begin{array}{l}\text { 2,6-Dinitroanilina } \\
\text { Benceno sustituido } \\
\text { Benzofenona } \\
\text { Fenilpirrol } \\
\text { Guanidina } \\
\text { Morfolina } \\
\text { Organofosforado } \\
\text { Piperazina } \\
\text { Quinolina } \\
\text { Quinona } \\
\text { Sulfamida } \\
\text { Urea } \\
\text { Xililalanina }\end{array}$ & $\begin{array}{l}\text { Fluazinam } \\
\text { Clorotalonil, PCNB } \\
\text { Metrafenone } \\
\text { Fludioxanil } \\
\text { Guazatine } \\
\text { Dimetomorf } \\
\text { Tolclofos metil, fosetil aluminio } \\
\text { Triforine } \\
\text { Quinoxyfen } \\
\text { Ditianon } \\
\text { Tolyfluanid } \\
\text { Pencycuron } \\
\text { Benalaxil, metalaxil-m-isómero }\end{array}$ \\
\hline
\end{tabular}

\section{Clasificación según su acción toxicológica respecto al organismo blanco o diana.}

La mayoría de los ingredientes activos son productos de diseño que afectan los procesos fisiológicos, bioquímicos, morfológicos y energéticos, entre otros, de los sistemas biológicos en los organismos que se proponen combatir o controlar. A continuación se describen los principales modos y mecanismos de acción de los insecticidas, herbicidas y fungicidas más difundidos incluyendo muchos considerados en este 
estudio. Los insecticidas son clasificados y agrupados por el Comité de Acción contra la Resistencia a Insecticidas (IRAC, Insecticide Resistence Action Committee) en 29 grupos de acuerdo al modo de acción sobre los objetivos (Tabla 4) [15].

Tabla 4. Clasificación IRAC de los INSECTICIDAS agrupados según su modo de acción.

\begin{tabular}{|c|c|c|c|}
\hline Grupo & Modo de acción & Grupo químico & p.a. ejemplo \\
\hline & Acción sobre el Sistema Nervioso o Muscular & & \\
\hline \multirow[t]{2}{*}{1} & Inhibidor de la acetilcolinesterasa & Carbamatos & bendiocarb, carbarilo \\
\hline & & Organofosforados & clorpirifos, pirimifos-metil \\
\hline 2 & $\begin{array}{l}\text { Bloqueador de canal de cloruro activado por } \\
\text { GABA }\end{array}$ & $\begin{array}{l}\text { Ciclodienos, } \\
\text { organoclorados }\end{array}$ & clordano, endosulfan \\
\hline 3 & Modulador del canal de sodio & Piretroides, piretrinas & bifentrin, deltametrina \\
\hline 4 & $\begin{array}{l}\text { Modulador competitivo del receptor } \\
\text { nicotínico de la acetilcolina }\end{array}$ & Neonicotinoides & imidacloprid, tiametoxam \\
\hline 5 & $\begin{array}{l}\text { Modulador alostérico del receptor nicotínico } \\
\text { de la acetilcolina }\end{array}$ & Espinosinas & spinetoram, spinosad \\
\hline 6 & $\begin{array}{l}\text { Modulador alostérico del canal de cloro } \\
\text { dependiente de glutamato }\end{array}$ & Avermectinas & abamectina \\
\hline 9 & $\begin{array}{l}\text { Modulador del canal TRPV de los órganos } \\
\text { cordotonales }\end{array}$ & Derivados de piridina & pimetrozina \\
\hline 14 & $\begin{array}{l}\text { Bloqueador del canal de los receptores } \\
\text { nicotínicos de acetilcolina }\end{array}$ & $\begin{array}{l}\text { Análogos de } \\
\text { neteistoxina }\end{array}$ & bensultap, tiocyclam \\
\hline 19 & Agonista del receptor de octopamina & Formamidina & amitraz \\
\hline 22 & $\begin{array}{l}\text { Bloqueador del canal de sodio dependiente } \\
\text { del voltaje }\end{array}$ & Oxadiazinas & indoxicarb \\
\hline 28 & Modulador del receptor de la rianodina & Diamidas & clorantraniliprole, flubendiamida \\
\hline \multirow[t]{2}{*}{29} & $\begin{array}{l}\text { Modulador de los órganos cordotonales - sin } \\
\text { punto de acción definido }\end{array}$ & Piridinas & flonicamid \\
\hline & Acción sobre el Crecimiento y Desarrollo & & \\
\hline 7 & Mimético de la hormona juvenil & - & metopreno, pyriproxyfen \\
\hline \multirow[t]{2}{*}{10} & Inhibidor del crecimiento de ácaros & Tetrazinas & clofentezina \\
\hline & & Carboxamidas & hexitiazox \\
\hline 15 & Inhibidor de la biosíntesis de quitina, Tipo 0 & Benzoilureas & diflubenzuron, lufenuron \\
\hline 16 & Inhibidor de la biosíntesis de quitina, Tipo 1 & - & buprofezin \\
\hline 17 & Disruptor de la muda, dípteros & - & ciromazina \\
\hline 18 & Agonista del receptor de ecdisona & Diacilhidrazina & metoxifenozide \\
\hline \multirow[t]{2}{*}{23} & Inhibidor de la acetil CoA carboxilasa & $\begin{array}{l}\text { Derivados de ácido } \\
\text { tetrónico y tetrámico }\end{array}$ & Spirodiclofen, spirotetramat \\
\hline & Acción sobre la Respiración & & \\
\hline 12 & Inhibidor de la ATP-sintetasa mitocondrial & - & propargita, tetradifon \\
\hline 13 & $\begin{array}{l}\text { Desacoplador de la fosforilación oxidativa por } \\
\text { disrupción delgradiente de protones }\end{array}$ & Pirroles, dinitrofenoles & clorfenapyr, DNOC \\
\hline 20 & $\begin{array}{l}\text { Inhibidor del transporte de electrones en el } \\
\text { complejo mitocondrial iii }\end{array}$ & - & acequinocil, bifenazato \\
\hline 21 & $\begin{array}{l}\text { Inhibidor del transporte de electrones en el } \\
\text { complejo mitocondrial i }\end{array}$ & - & fenazaquin, piridabeno \\
\hline 24 & $\begin{array}{l}\text { Inhibidor del transporte de electrones en el } \\
\text { complejo mitocondrial iv }\end{array}$ & $\begin{array}{l}\text { Fosfuros y cianuros } \\
\text { metálicos }\end{array}$ & fosfuro de $\mathrm{Ca}$, cianuro de $\mathrm{Na}$ \\
\hline \multirow[t]{2}{*}{25} & $\begin{array}{l}\text { Inhibidor del transporte de electrones en el } \\
\text { complejo mitocondrial ii }\end{array}$ & Carboxilanilidas & piflubumida \\
\hline & Acción sobre el Sistema Digestivo & & \\
\hline \multirow[t]{2}{*}{11} & $\begin{array}{l}\text { Disruptor microbiano de las membranas } \\
\text { digestivas de insectos }\end{array}$ & Bacillus thuringiensis & $\begin{array}{l}\text { Bacillus thuringiensis subsp. } \\
\text { israelensis }\end{array}$ \\
\hline & Modo de Acción desconocido o incierto & & \\
\hline 8 & Inhibidores multi-sitio inespecíficos & Haluros de alquilo, & bromuro de metilo \\
\hline UN & Acción desconocida o targets inespecífico & - & dicofol, chinometionato \\
\hline
\end{tabular}


Por su lado, la Sociedad Americana de Ciencias de Malezas (WSSA, Weed Science Society of America) agrupa a los herbicidas en 30 clases químicas y los clasifica según su modo de acción en 16 grupos (Tabla 5) [16].

Tabla 5. Clasificación WSSA de los HERBICIDAS agrupados según su modo de acción.

\begin{tabular}{|c|c|c|c|}
\hline Clase & Modo de acción (grupo) & Grupo químico & p.a. ejemplo \\
\hline 1 & $\begin{array}{l}\text { Inhibidor de acetyl CoA carboxylasa } \\
\text { (ACCasa) }\end{array}$ & $\begin{array}{l}\text { Ariloxifenoxipropionatos; } \\
\text { ciclohexanodionas }\end{array}$ & $\begin{array}{l}\text { Cialofop-butil, haloxifop-p-metil; } \\
\text { cletodim }\end{array}$ \\
\hline 2 & $\begin{array}{l}\text { Inhibidor acetolactato sintasa (ALS) o } \\
\text { Acetohidroxi ácido sintasa (AHAS) }\end{array}$ & $\begin{array}{l}\text { Imidazolinonas; } \\
\text { sulfonilureas }\end{array}$ & $\begin{array}{l}\text { imazapic, imazapir; } \\
\text { clorimuron-etil, metsulfuron-metil }\end{array}$ \\
\hline $\begin{array}{l}3,15 \\
23\end{array}$ & Inhibidor de mitosis & $\begin{array}{l}\text { Ác. benzoico; } \\
\text { Dinitroanilinas }\end{array}$ & $\begin{array}{l}\text { dicamba; } \\
\text { pendimetalin }\end{array}$ \\
\hline 4 & Auxinas sintéticas & $\begin{array}{l}\text { Ác. piridincarboxílicos; } \\
\text { quinolincarboxílicos; } \\
\text { clorofenoxiácidos }\end{array}$ & picloran; quinclorac; $2,4-D$ \\
\hline $5,6,7$ & Inhibidor fotosistema II & Triazinas; triazinonas; ureas & Atrazina; metribuzin; linuron \\
\hline 8,16 & $\begin{array}{l}\text { Inhibidor de biosíntesis de ácidos } \\
\text { grasos y lípidos }\end{array}$ & Tiocarbamatos; benzofuranos & Molinato \\
\hline 9 & $\begin{array}{l}\text { Inhibidor de la enzima enolpiruvil } \\
\text { shikimato-3-fosfato sintasa (EPSP) }\end{array}$ & Glicinas & glifosato \\
\hline 10 & Inhibidor de glutamina sintasa & Ácidos fosfínicos & glufosinato de amonio \\
\hline $\begin{array}{l}11,12 \\
13,27\end{array}$ & $\begin{array}{l}\text { Inhibidor de la biosíntesis de } \\
\text { carotenoides }\end{array}$ & $\begin{array}{l}\text { Amidas; piridiazinonas; } \\
\text { isoxazoles }\end{array}$ & $\begin{array}{l}\text { dimetenamida; cloridazon; } \\
\text { clomazone }\end{array}$ \\
\hline 14 & $\begin{array}{l}\text { Inhibidor de protoporfirinogeno } \\
\text { oxidasa (PPG oxidase o protox) }\end{array}$ & N-fenilftalimidas; tiadizoles & flumioxazim \\
\hline $\begin{array}{l}17,25 \\
26\end{array}$ & $\begin{array}{l}\text { Inhibidor potencial de ácido nucleico } \\
\text { o modo de acción no descripto }\end{array}$ & $\begin{array}{l}\text { Organoarsenicales; } \\
\text { ác. arilaminopropiónicos }\end{array}$ & MSMA; \\
\hline 18 & Inhibidor de dihidropteroato sintasa & Carbamato & azulam \\
\hline 19 & Inhibidor del transporte de auxina & Ftalamatos; semicarbazonas & naptalam; diflufenzopir \\
\hline $\begin{array}{l}20,21 \\
28,29\end{array}$ & Inhibidor de celulosa & $\begin{array}{l}\text { Benzamidas; nitrilos; } \\
\text { alquilazinas }\end{array}$ & Propizamida; \\
\hline 22 & Inhibidor fotosistema I & Bipiridilos & diquat, paraquat \\
\hline 24 & $\begin{array}{l}\text { Desacopladores de fosforilación } \\
\text { oxidativa }\end{array}$ & Dinitrofenoles & DNP \\
\hline
\end{tabular}

Adaptado de Ref. [16].

Finalmente, el Comité de Acción contra Resistencia a Fungicidas (FRAC, Fungicide Resistance Action Committee) agrupa a los fungicidas según su modo de acción en 12 grupos (Tabla 6) [17].

Tabla 6. Clasificación FRAC de los FUNGICIDAS agrupados según su modo de acción.

\begin{tabular}{|c|c|c|c|}
\hline Grupo & Modo de acción & Grupo químico & p.a. ejemplo \\
\hline A & $\begin{array}{l}\text { Inhibidor de la síntesis de ácidos } \\
\text { nucleicos }\end{array}$ & $\begin{array}{l}\text { Fenilamidas; } \\
\text { Hidroxi-(2 amino)-pirimidinas }\end{array}$ & Metalaxil; bupirimato \\
\hline B & $\begin{array}{l}\text { Inhibidor de la mitosis y la división } \\
\text { celular }\end{array}$ & Bencimidaloes; benzamidas & $\begin{array}{l}\text { Carbendazim, tiabendazol; } \\
\text { fluopicolide }\end{array}$ \\
\hline C & Inhibidor de la respiración & $\begin{array}{l}\text { Pirimidinamidas; } \\
\text { carboxamidas }\end{array}$ & $\begin{array}{l}\text { Diflumetorin; carboxin, } \\
\text { boscalid, flutolanil }\end{array}$ \\
\hline $\mathrm{D}$ & $\begin{array}{l}\text { Inhibidor de la síntesis de } \\
\text { aminoácidos y proteínas }\end{array}$ & Anilino-pirimidinas; & Cyprodinil, pirimetanil \\
\hline $\mathrm{E}$ & $\begin{array}{l}\text { Inhibidor de la transducción de la } \\
\text { señales }\end{array}$ & Quinolonas; fenil-pirroles & Quinoxyfen; fludioxonil \\
\hline $\mathrm{F}$ & $\begin{array}{l}\text { Inhibidor de la síntesis de lípidos y } \\
\text { membrana }\end{array}$ & $\begin{array}{l}\text { Fosforotiolatos; carbamatos; } \\
\text { heteroaromáticos }\end{array}$ & Pyrazofos; protiocarb; dicloran \\
\hline G & $\begin{array}{l}\text { Inhibidor de la biosíntesis del } \\
\text { ergosterol }\end{array}$ & $\begin{array}{l}\text { Imidazoles; pirimidinas; } \\
\text { ditiocarbamatos }\end{array}$ & $\begin{array}{l}\text { Imazalil, procloraz; fenarimol, } \\
\text { pirimetanil; thiram }\end{array}$ \\
\hline $\mathrm{H}$ & Inhibidor de la biosíntesis de la & Amidas del ácido carboxílico; & dimetomorph \\
\hline
\end{tabular}




\begin{tabular}{|c|c|c|c|}
\hline Grupo & Modo de acción & Grupo químico & p.a. ejemplo \\
\hline & pared celular & ácidos cinámicos & \\
\hline I & $\begin{array}{l}\text { Inhibidor de la síntesis de melanina } \\
\text { la pared celular }\end{array}$ & $\begin{array}{l}\text { Isobenzofuranona; } \\
\text { carboxamidas; propionamidas }\end{array}$ & Ftalida; capropamid; fenoxanil \\
\hline$P$ & Inductor de las defensas en la planta & Benzotiadizol & Acibenzolar-S-metil \\
\hline- & Fungicidas de actividad multisitio & $\begin{array}{l}\text { Sales inorgánicas; ftalimidas; } \\
\text { cloronitrilos; sulfamidas }\end{array}$ & $\begin{array}{l}\text { Óxido cuproso; captan, folpet; } \\
\text { clorotalonil; tolyfluanid }\end{array}$ \\
\hline- & $\begin{array}{l}\text { Fungicidas de mecanismo de acción } \\
\text { desconocido }\end{array}$ & $\begin{array}{l}\text { Cianoacetamida-oximas; } \\
\text { fosfonatos }\end{array}$ & Cymoxanil \\
\hline
\end{tabular}

Adaptado de Ref. [17].

En las Tablas S1-1 a S1-3 del material suplementario se brinda información adicional sobre los distintos mecanismos de acción de los distintos grupos de insecticidas, herbicidas y fungicidas clasificados en las tablas precedentes.

\subsubsection{Propiedades físicas y químicas de los plaguicidas}

El conocimiento de ciertas características físico-químicas cuantificables para los plaguicidas contribuye notablemente a orientar evaluaciones muy importantes para describir su destino o distribución en el ambiente una vez que son liberados, a obtener información sobre la residualidad en alimentos y también a los fines de la práctica químico-analítica, dado que en el proceso analítico para su determinación los analitos son sometidos a múltiples etapas en las que se aplica temperatura, solventes y particiones que dependen fuertemente de aquellas propiedades de los compuestos. En relación a esto se debe considerar que la molécula de plaguicida no permanece intacta por tiempo indefinido en el medio ambiente o en los alimentos, ya que con el tiempo sufre cierto grado de degradación influenciada por microorganismos, actividad química, pH, clima, y contenido de materia orgánica del suelo, entre otros [18].

\section{Solubilidad}

Cantidad de soluto disuelto en agua o solventes orgánicos. Desde el punto de vista de la distribución ambiental, valores de solubilidad en agua $>500 \mathrm{mg} / \mathrm{L}$ implican peligro de movilización en suelos, contaminación de acuíferos y acumulación en ecosistemas acuáticos. Tiene implicancia en los procesos de extracción/medición analítica.

\section{Presión de vapor}

Es una medida de volatilidad del plaguicida puro hacia la atmósfera o el aire. Valores de $\mathrm{P}_{\text {vap }}<1 \times 10^{-8} \mathrm{mmHg}$ indican bajo potencial para volatilizarse y valores $>1 \times 10^{-3} \mathrm{mmHg}$ indican que el plaguicida se puede considerar volátil.

\section{Constante de la Ley de Henry}

Describe la tendencia de un plaguicida a volatilizarse desde el agua o suelo húmedo. Refleja el coeficiente de partición aire-agua $\left(H_{c}\right)$ expresado como la constante de la Ley de Henry. Desde el punto de vista de la distribución ambiental compuestos con Constante de Ley de Henry $>10^{-3}\left(\mathrm{~Pa} \mathrm{~m}^{3} \mathrm{~mol}^{-1}\right)$ pueden considerarse volátiles, con riesgo de contaminación de aire. También permite considerar potenciales pérdidas en el procesamiento analítico. 


\section{Constante de acidez $\left(K_{a}, p K_{a}\right)$}

Definida como la constante de acidez (o basicidad $K_{\mathrm{b}}$ ) es la constante de equilibrio de la disociación de una reacción ácido-base. Es importante para definir el estado de ionización de una molécula en función del pH del medio en que se encuentra, por lo que tiene mucha implicancia en los procesos de extracción analítica.

\section{Coeficiente de Partición Octanol-Agua ( $K_{\text {ow }}$ )}

Una medida de cómo se distribuye en el equilibrio un soluto en las fases octanol y agua. Da una idea de la polaridad del compuesto. Sirve para tener una referencia de la afinidad de las sustancias para penetrar las barreras lipídicas celulares, y también para predecir comportamiento analítico en los procesos de extracción con solventes. Compuestos con $\mathrm{K}_{\mathrm{ow}}>1000\left(\log \mathrm{K}_{\mathrm{ow}}>3\right)$ son no polares con potencial de bioacumulación.

\section{Coeficiente de adsorción de Carbono orgánico $\left(K_{o c}\right)$}

Coeficiente de partición de suelo y agua estandarizado en función del contenido de $\mathrm{C}_{\text {org. }}$. Es una medida de la tendencia de las sustancias a ser adsorbidas por el suelo. El $\mathrm{K}_{\mathrm{oc}}$ es específico de la sustancia química e independiente de las propiedades del suelo. Desde el punto de vista de la distribución ambiental, compuestos con Log $\mathrm{K}_{\mathrm{oc}}<2$ implican alta movilidad en suelo, contaminación de acuíferos.

En la Tabla 7 se muestran ejemplos de propiedades fisicoquímicas para un grupo de plaguicidas seleccionado. Se puede observar el amplio espectro de valores de las propiedades más características de los compuestos según las distintas clases químicas. Esto es un punto de gran consideración al momento de definir estrategias de medición simultánea de multicomponentes en matrices complejas alimentarias o ambientales.

Tabla 7. Ejemplos de propiedades fisicoquímicas de plaguicidas seleccionados.

\begin{tabular}{|c|c|c|c|c|c|c|}
\hline Plaguicida & $\begin{array}{l}\text { Solubilidad } \\
\text { en agua } \\
\left(\mathrm{mg} \mathrm{L}^{-1}\right) 20^{\circ} \mathrm{C}\end{array}$ & $\begin{array}{l}\text { P. Vapor } \\
(\mathrm{mPa}) 20^{\circ} \mathrm{C}\end{array}$ & $\begin{array}{l}\text { Cte. Henry } \\
\left(\mathrm{Pa} \mathrm{m}^{3} \mathrm{~mol}^{-1}\right) \\
25^{\circ} \mathrm{C}\end{array}$ & $\begin{array}{l}\mathrm{pK}_{\mathrm{a}} \\
25^{\circ} \mathrm{C}\end{array}$ & $\begin{array}{l}\text { Log } \mathrm{K}_{\text {ow }} \\
\mathrm{pH} 7 \text { y } 20{ }^{\circ} \mathrm{C}\end{array}$ & $\log K_{o c}$ \\
\hline DDT & 0,006 & 0,03 & 0,84 & - & 6,91 & 5,18 \\
\hline Ciflutrina & 0,007 & $3,010^{-4}$ & 0,05 & n.a. & 6,00 & 5,04 \\
\hline Propoxur & 1800 & 1,3 & $1,510^{-4}$ & - & 0,14 & 1,48 \\
\hline Metiocarb & 27 & 0,015 & $1,210^{-4}$ & n.a. & 3,18 & - \\
\hline Fenamifos & 345 & 0,07 & $2,810^{-5}$ & n.a. & 3,30 & 2,65 \\
\hline Metamidofos & 200000 & 0,07 & $1,610^{-6}$ & - & $-0,79$ & 0 \\
\hline Azinfos metilo & 28 & $5,010^{-4}$ & $5,710^{-6}$ & 5 & 2,96 & 3,05 \\
\hline Imidacloprid & 610 & $4,010^{-7}$ & $1,710^{-10}$ & n.a. & 0,57 & - \\
\hline Malatión & 148 & 3,1 & $110^{-3}$ & n.a. & 2,75 & 3,25 \\
\hline Pirimifos metilo & 11 & 0,002 & $6,010^{-2}$ & 43 & 3,90 & 3,04 \\
\hline Clorpirifós & 1 & 1,4 & 0,48 & n.a. & 4,7 & 3,74 \\
\hline Diazinon & 60 & 11,9 & 0,06 & 2,6 & 3.69 & 2,78 \\
\hline Deltametrina & 0,0002 & $1,110^{-7}$ & $8,510^{-5}$ & n.a & 4,60 & 7,01 \\
\hline Bendiocarb & 280 & 4,6 & $4,010^{-3}$ & 8,8 & 1,70 & 2,60 \\
\hline Atrazina & 35 & 0,04 & $1,510^{-4}$ & 1,7 & 2,70 & 2,00 \\
\hline Metolacloro & 530 & 1,7 & $2,410^{-3}$ & n.a. & 3,40 & 2,08 \\
\hline Metalaxil & 8400 & 0,75 & $1,610^{-5}$ & 0 & 1,75 & 2,21 \\
\hline Difenilamina & 26 & 0,85 & 0,32 & 1,03 & 3,82 & 3,61 \\
\hline Cipermetrina & 0,009 & $6,810^{-3}$ & 0,31 & n.a. & 5,55 & 5,49 \\
\hline$\lambda$-cihalotrina & 0,005 & $2,010^{-4}$ & 0,02 & n.a. & 5,50 & 5,45 \\
\hline
\end{tabular}




\subsubsection{Características toxicológicas asociadas a la residualidad de plaguicidas}

El balance del uso de los agroquímicos, y en particular de los plaguicidas, en la agricultura moderna está constantemente sujeto a interpretaciones basadas en el concepto de riesgo-beneficio. Es decir que se puntualiza en la necesidad del apoyo en estas herramientas tecnológicas para posibilitar la producción de alimentos mediante la mejora de la productividad y el rendimiento, disminuyendo en gran medida los efectos destructivos ocasionados por plagas y enfermedades. Sin embargo, el equilibrio buscado se refiere a que se debe tener gran consideración con los múltiples riesgos ocasionados por efectos indeseados en la salud y en el ambiente atribuibles al uso de estos agentes técnicos en la agricultura. Entre los aspectos negativos se deben computar los riesgos existentes provenientes de la fabricación industrial, el transporte, el depósito y la aplicación de estas sustancias peligrosas. Como efectos generales se pueden computar el desequilibrio de ecosistemas, la afectación de la biodiversidad global como la mortandad de especies no blanco, el desarrollo de resistencia en todas las plagas que se combaten, y efectos agudos mortales en salud humana. Finalmente, se deben computar los efectos crónicos potenciales provocados por la exposición prolongada a pequeñas concentraciones, como los efectos alergénicos, mutagénicos, teratogénicos, carcinogénicos y de perturbación endócrina, ampliamente tratados en la literatura científica $[11,19,20]$.

\section{Neurotoxicidad de los plaguicidas}

El sistema nervioso es particularmente susceptible a muchos plaguicidas de diferentes clases químicas [21]. La neurotoxicidad se asocia a los modos y mecanismos de acción de muchos plaguicidas y específicamente a una gran cantidad de insecticidas (Tablas 4-6). Varios estudios han informado que la exposición prenatal y en la primera infancia a los insecticidas OPPs, incluido el clorpirifos, se asocia con indicadores de retraso en el neurodesarrollo [22-25], mientras que otros han asociado a los OCPs, OPPs y otros plaguicidas con demencias tales como la enfermedad de Alzheimer, o con la enfermedad de Parkinson [26,27].

\section{Perturbación endócrina}

Numerosos plaguicidas han sido estudiados y comprobados de alterar la función del sistema endócrino y consecuentemente causar efectos adversos para la salud en un organismo intacto, en su progenie o en subpoblaciones [28]. Se han propuesto al menos tres mecanismos de alteración de los procesos endócrinos: mimetizando la acción de hormonas producidas naturalmente, bloqueando los receptores hormonales de las células diana e imposibilitando la acción de hormonas normales y, finalmente, interfiriendo en la síntesis, el transporte, el metabolismo y la secreción de hormonas, con la consiguiente alteración de las concentraciones hormonales naturales [29]. Se ha determinado que de 60 sustancias con alto nivel de exposición para los humanos y la fauna, con evidencias de producir efectos de perturbación endócrina, hay 20 plaguicidas de los cuales 10 son organoclorados (p.ej. clordano, DDT y lindano), 4 son ditiocarbamatos (p. ej. tiram y zineb), 2 cloroacetamidas (acetoclor y alaclor) y los 4 restantes (vinclozolin, fentinacetato, atrazina y linuron) pertenecen a cuatro grupos químicos diferentes [30]. 


\section{Mutagenicidad, teratogenicidad}

La exposición humana a plaguicidas se ha asociado con modificaciones genéticas/epigenéticas y enfermedades crónicas [27], mientras que los estudios epidemiológicos han revelado asociaciones de exposición prenatal y postnatal a plaguicidas con el aumento en la cantidad de abortos espontáneos, déficits neurológicos, cáncer infantil, restricción del crecimiento intrauterino, nacimiento prematuro y defectos de nacimiento [31,32].

\section{Carcinogenicidad}

Resulta difícil probar en humanos una relación causal directa entre un plaguicida específico y un tipo de cáncer ya que son diversas las sustancias cancerígenas a las cuales estamos expuestos. Sin embargo, revisiones recientes sobre estudios epidemiológicos y experimentales dan evidencias de los efectos cancerígenos de la exposición a plaguicidas [33]. La Organización Mundial de la Salud (OMS), a través de la Agencia Internacional para la Investigación del Cáncer (IARC, International Agency for Research on Cancer) utiliza cuatro categorías para clasificar sustancias con relación a su carcinogenicidad, siendo su estatus actual respecto a sustancias en general el siguiente:

- Clase 1: Carcinogénico para humanos (120 agentes).

- Clase 2A: Probablemente carcinogénico para humanos (81 agentes).

- Clase 2B: Posiblemente carcinogénico para humanos (299 agentes).

- Clase 3: No clasificable por su carcinogenicidad para humanos (502 agentes).

- Clase 4: Probablemente no carcinogénico para humanos (1 agente).

En las monografías científicas de la IARC no se incluye a ningún plaguicida en la clase 1, habiendo sí varios compuestos incluidos en las clases $2 \mathrm{~A}$ y $2 \mathrm{~B}$ [34]. En general, puede decirse que este tópico de la toxicidad de los plaguicidas es uno de los más controversiales porque, a pesar de que la IARC no clasifica como carcinógeno en humanos a ningún plaguicida, existen trabajos científicos que aportan evidencias relacionando la exposición a plaguicidas con la aparición de distintos tipos de cáncer [35-37], y por el contrario otros autores desestiman la potencialidad de los plaguicidas sintéticos para producir muchos de los efectos adversos que les atribuyen, entre ellos la carcinogenicidad [38].

\subsubsection{Residuos de plaguicidas. Definición y caracterización.}

Un residuo es cualquier sustancia específica presente en o sobre los alimentos, productos agrícolas y otros tipos de productos o alimentos para animales, así como en el medio ambiente, en particular en el suelo, el aire y el agua, como consecuencia del uso de un plaguicida. El término incluye cualquier derivado de un plaguicida, como productos de conversión, metabolitos, productos de descomposición, productos de reacción e impurezas consideradas de importancia toxicológica o ecotoxicológica. El término "residuo de plaguicidas" incluye tanto los residuos de procedencias desconocidas o inevitables (por ejemplo, la 
contaminación ambiental), como los derivados de usos conocidos y autorizados de la sustancia química $[3,5]$.

Para cada plaguicida se establece lo que se denomina "definición de residuo" que es requerida para establecer el compuesto o los compuestos de interés en la estimación de los riesgos de la ingesta alimentaria asociada a la presencia de residuos en alimentos o piensos, y también para proporcionar la base para el control/monitoreo del cumplimiento de los LMR. Existen dos tipos diferentes de definiciones de residuos. La primera de ellas es la definición de residuos para evaluación del riesgo dietario, la cual incluye el compuesto original, sus metabolitos, derivados y compuestos relacionados que poseen implicancias toxicológicas. La segunda es la definición de residuos para control/monitoreo, la cual comprende aquellos compuestos que son indicadores del uso del plaguicida y que pueden analizarse fácilmente durante la rutina de monitoreo en los laboratorios.

Las condiciones que debe cumplir cada una de estas definiciones son distintas porque sus fines son distintos. De hecho, ambas coinciden en muchos casos aunque también en otros tantos no son iguales $[39,40]$. Hay casos de algunos compuestos que pueden tener una definición de residuos diferente según se trate de alimentos de origen animal o vegetal, o si se trata de un alimento procesado o sin procesar, incluso para algunos compuestos la definición de residuos para evaluación de riesgo aguda o crónica es diferente $[41,42]$.

En resumen, las definiciones y el establecimiento de lo que debe considerarse como residuo de plaguicida son aspectos que poseen una gran complejidad y que necesitan del soporte de mucha información científica respecto al comportamiento químico, bioquímico y toxicológico de los compuestos madre y sus productos de transformación.

\subsubsection{Límite Máximo de Residuo}

El Límite Máximo de Residuo es la concentración máxima de residuos de un plaguicida (expresada en $\mathrm{mg} / \mathrm{kg}$ ), que la Comisión del Codex Alimentarius recomienda se permita legalmente en la superficie o la parte interna de productos de alimentación para consumo humano y de piensos. Este valor se refiere al residuo remanente en el alimento de un agente terapéutico aplicado en condiciones de cumplimiento de las Buenas Prácticas Agrícolas (BPA). Este concepto de BPA, que según FAO/WHO "consisten en la aplicación del conocimiento disponible a la utilización sostenible de los recursos naturales básicos para la producción, en forma benévola, de productos agrícolas alimentarios y no alimentarios, inocuos y saludables, a la vez que se procura la viabilidad económica y la estabilidad social" se asocia a la estrategia sostenida respecto al uso seguro recomendado de plaguicidas, es reconocido y adoptado internacionalmente $[3,43]$. Los LMR se basan entonces en datos agronómicos obtenidos mediante buenas prácticas agrícolas y tienen por objeto lograr que los alimentos derivados de productos agrícolas puedan ser producidos eficientemente y con riesgos toxicológicos aceptables. Los LMR del Codex, que se destinan principalmente para ser aplicados a productos que circulan en el comercio internacional, se obtienen basándose en 
estimaciones hechas por el JMPR (Joint FAO/WHO Meeting on Pesticides Residues), cumpliendo dos etapas distintas:

a) La evaluación toxicológica del plaguicida y su residuo, que pretende proteger la salud de los consumidores, ya que la ingesta diaria del plaguicida a lo largo de toda una vida no debe provocar ningún efecto adverso sobre la salud. Para la evaluación se consideran parámetros toxicológicos como el Nivel sin Efecto Adverso Observable (NOAEL, Non Observed Adverse Effects Level) y la Ingesta Diaria Admisible (IDA).

b) El examen de datos de residuos obtenidos en ensayos de uso a campo, en particular usos que se ajustan a las prácticas agrícolas nacionales, denominados genéricamente "Ensayos Supervisados de Campo" que brindan información sobre los modelos de depleción o disipación a campo que tiene el agroquímico aplicado, mediante el registro de la variación de la concentración del mismo con el tiempo. Esto permite establecer con relativa exactitud, en condiciones experimentales, el tiempo requerido para que las concentraciones residuales disminuyan su valor hasta que se consideren inocuas.

Cabe destacar que así como existen LMRs recomendados por Codex, también los distintos países o bloques económicos como es el caso de Argentina o la Unión Europea, establecen sus propios límites máximos de residuo. En ese sentido se debe tener claro que el LMR es un parámetro de índole administrativa fijado por entes que velan por la producción, y no es un parámetro toxicológico, aunque por la forma en que está definido siempre respeta los límites de riesgo toxicológico aplicables.

Respecto al concepto de LMR, es importante también considerar la incertidumbre en las mediciones analíticas (MU, Measurement Uncertainty) a la hora de interpretar legalmente si la concentración de un principio activo hallada en una muestra cumple o no con el límite máximo de residuos establecido. Esta incertidumbre podría considerarse como una "tolerancia", la cual debe ser fijada por cada país. En la Unión Europea, la EFSA asume una MU del $50 \%$ a la hora de interpretar los resultados analíticos y determinar si hay cumplimiento o no de los LMR $[44,45]$.

\subsubsection{Legislación sobre plaguicidas}

Dado que los plaguicidas, como se ha planteado, son sustancias generalmente peligrosas cuyo uso en agricultura y en hogares revisten riesgos importantes para la salud de la población y del ambiente, están sometidos a legislaciones específicas que regulan tanto su uso como así también la gestión respecto a los residuos que producen en los alimentos y en ambiente.

En Argentina, en referencia solamente al ámbito de la producción agropecuaria, los productos fitosanitarios se inscriben en el Registro Nacional de Terapéutica Vegetal de acuerdo a lo establecido por el Decreto № 3489/58 y el Decreto № 5769/59, en los términos del “Manual de Procedimientos, Criterios y Alcances para el Registro de Productos Fitosanitarios en la República Argentina" el cual ha sido aprobado por resolución 
de la ex Secretaría de Agricultura, Ganadería, Pesca y Alimentación (SAGPyA), actualmente Secretaría de Agroindustria, a través de la Resolución № 350 del año 1999 [46].

EI SENASA (Servicio Nacional de Sanidad y Calidad Agroalimentaria) dependiente de la Secretaría de Agroindustria de la Nación, es el organismo responsable de autorizar el uso de los plaguicidas, así como también establecer los LMR para cada combinación plaguicida-alimento. Estas acciones son llevadas a cabo por la Dirección de Agroquímicos y Biológicos la cual depende de la Dirección Nacional de Agroquímicos, Productos Veterinarios y Alimentos (DNAPVyA), ambas pertenecientes al SENASA. Las normativas más recientes sobre especificaciones de LMR son la Resoluciones SENASA N 934, 559 y 608 emitidas en el año 2010, 2011 y 2012, respectivamente $[12,47,48]$.

Cabe aclarar que también existe normativa del Mercado Común del Sur (MERCOSUR) que establece LMR para algunos plaguicidas en diversos cultivos a través de la Resolución № 23 del año 1994 [49]. Además de lo establecido por el SENASA, Argentina cuenta con legislaciones de otros organismos que establecen límites para determinados plaguicidas en alimentos y aguas. Así, el Ministerio de Salud de la Nación a través de la Administración Nacional de Alimentos, Medicamentos y Tecnología Médica (ANMAT) ha fijado tolerancias para leche y agua de consumo en los capítulos 8 y 10 del Código Alimentario Argentino (CAA), respectivamente[50,51]. También, en el caso de agua, la Provincia de Santa Fe cuenta con la Ley $N^{\circ} 11.220$ que establece valores máximos para un grupo de plaguicidas en el agua de consumo [52].

En los Estados Unidos, la Agencia de Protección Ambiental (EPA, Environmental Protection Agency) es la encargada de autorizar el uso de los plaguicidas y fijar los límites máximos de residuos para dichas sustancias en ese país, donde se denominan "tolerancias". Además de estas actividades, la EPA tiene a su cargo la realización del proceso de evaluación de riesgo, tanto para los nuevos compuestos los cuales deben evaluarse antes de que ingresen al mercado, como para los plaguicidas ya autorizados los cuales deben re-evaluarse periódicamente para asegurar que siguen cumpliendo con las normas de seguridad e inocuidad [53].

A nivel Europeo, la autorización y uso de plaguicidas, así como también la gestión de sus residuos en los alimentos, está regulada principalmente en dos reglamentos: i) El Reglamento (CE) N 1107/2009 del Parlamento Europeo y del Consejo de la Unión Europea del 21 de Octubre de 2009, relativo a la comercialización de productos fitosanitarios [54]; ii) El Reglamento (CE) Nº 396/2005 del Parlamento Europeo y del Consejo del 23 de febrero de 2005 relativo a los límites máximos de residuos de plaguicidas en alimentos y piensos de origen vegetal y animal [55]. Esta última reglamentación ha podido armonizar en todos los países de la Unión Europea LMR de uso común para los productos agrícolas destinados a la alimentación humana y a piensos animales. El Reglamento N³96/2005 se refiere a los compuestos actual o previamente utilizados en la agricultura dentro o fuera de la UE (alrededor de 1.100 plaguicidas). Si un plaguicida no se menciona específicamente, se aplica un LMR general por defecto de $0,01 \mathrm{mg} / \mathrm{kg}$. Este 
Reglamento también hace referencia a la seguridad de todos los grupos de consumidores, incluyendo, bebés, niños y vegetarianos.

\subsection{MICOTOXINAS}

\subsubsection{Conceptos básicos}

Las micotoxinas son compuestos naturales de bajo peso molecular producidos como metabolitos secundarios por algunos mohos filamentosos (toxicogénicos) y se los considera como tales porque son el producto de procesos metabólicos primarios que no intervienen en el crecimiento del moho, por lo que no son directamente necesarios para los procesos vitales del organismo productor, pero pueden influir profundamente en otros organismos del ambiente que los consuman o que tengan contacto casual con ellos. Estos compuestos poseen una estructura química y actividad toxicológica muy variada y se distinguen principalmente porque por sí mismos o por sus productos metabólicos pueden causar enfermedades o muerte en los seres humanos y otros vertebrados expuestos en diferentes formas. De acuerdo a la literatura, más de 400 micotoxinas son producidas por unas 350 especies de mohos, al tiempo que se han encontrado alrededor de 1000 metabolitos bioactivos de mohos tóxicos, siendo una misma cepa toxicogénica capaz de producir diferentes micotoxinas, y una determinada micotoxina sintetizada por diferentes mohos [56].

\subsubsection{Crecimiento fúngico y producción de micotoxinas}

Los mohos pueden invadir, colonizar y producir micotoxinas a campo durante la pre-cosecha o en las etapas posteriores de post-cosecha tanto en el almacenamiento, el transporte y la producción, para lo cual utilizan los sustratos sólidos penetrándolos profundamente mediante la secreción de enzimas que descomponen los productos complejos de las matrices. Los mohos productores de micotoxinas pueden desarrollarse en casi todas las condiciones climáticas del mundo y sobre cualquier tipo de soporte, si se dan las condiciones ambientales adecuadas. En general, las especies de Aspergillus y Penicillium pueden crecer a baja actividad acuosa $\left(a_{w}\right)$ y en temperaturas más altas que las especies de Fusarium, que suelen requerir mayor $a_{w} y$ menor temperatura. El crecimiento fúngico sobre cualquier sustrato no es requisito previo para que el moho produzca micotoxinas, por lo que la producción de éstas por parte de una especie en particular depende enteramente de la disponibilidad de condiciones óptimas. La naturaleza y la cantidad de micotoxinas producidas están influenciadas por la interacción de varios factores como el tipo y la humedad del sustrato, los nutrientes disponibles, la temperatura y humedad del ambiente, la presencia de otros mohos, la competencia con otros microorganismos, factores de estrés y daños físicos del sustrato ocasionados por la actividad de insectos, entre otros. Una vez producidas, las micotoxinas están presentes en toda la colonia fúngica (hifas, micelio y esporas) y en el sustrato sobre el cual crece la colonia [57]. 


\subsubsection{Toxicidad y efectos biológicos de las micotoxinas}

En general las micotoxinas producen efectos adversos en un amplio rango de sistemas biológicos, incluyendo microorganismos, plantas, animales y seres humanos. Los efectos tóxicos en animales y humanos son dependientes de la dosis y pueden incluir: (1) toxicidad aguda seguida de muerte como consecuencia de la exposición a grandes cantidades de micotoxinas, (2) disminución en la producción de leche, huevos, o pérdidas de peso en animales productores de alimentos debido a exposiciones subcrónicas, (3) estimulación o supresión de las funciones inmunológicas y reducción de la resistencia a infecciones por exposiciones crónicas a bajos niveles de toxinas, y (4) formación de tumores, cánceres y otras enfermedades crónicas como consecuencia de la exposición prolongada a muy bajos niveles de una micotoxina. Adicionalmente, las micotoxinas son capaces de inducir mutaciones en células y organismos susceptibles (mutagénicas), y de causar deformidades en embriones en etapa de desarrollo (teratogénicas) [58].

Las micotoxinas afectan a determinados tejidos $\mathrm{u}$ órganos dependiendo del compuesto particular involucrado. En general, están específicamente asociadas con una alimentación especial y no son transmisibles de organismo a organismo (excepto en casos especiales como la producción de leche para el consumo humano o la lactancia). Los animales se ven afectados por las micotoxinas a través de la interferencia con la absorción de nutrientes y el metabolismo, afectando las funciones endócrinas y neuroendocrinas o la supresión del sistema inmunológico. En los seres humanos, sin embargo, la presencia de estos contaminantes puede ser acumulativa provocando diferentes tipos de cáncer (de hígado, de riñon, de tracto digestivo, de sistema reproductivo) o enfermedades inmunodeficientes [56]. Desde el punto de vista económico, en los sistemas productivos la presencia de micotoxinas puede afectar a la cadena de alimentos a través de la disminución en el crecimiento del ganado y otros animales productores junto con incrementos en los problemas reproductivos de los mismos [58].

\subsubsection{Clasificación de micotoxinas}

Debido a las diferentes estructuras químicas que presentan, a sus orígenes biosintéticos, a sus diferentes efectos biológicos y a su producción por diferentes especies fúngicas, la clasificación de las micotoxinas no es sencilla y tiende a reflejar el área del conocimiento desde donde se le dio origen. Así, de acuerdo al órgano que afectan pueden clasificarse como hepatotoxinas, nefrotoxinas, neurotoxinas, inmunotoxinas, inmunotoxinas, etcétera. Por otro lado, de acuerdo a sus estructuras químicas pueden clasificarse en lactonas, cumarinas, piranos, etc., mientras que por su actividad biológica es posible hacerlo en grupos genéricos como teratógenos, mutágenos, agentes cancerígenos, alérgenos, etc. Finalmente, cabe también su clasificación según el género de mohos que las producen, como toxinas de Fusarium, de Aspergillus, de Alternaria, etc. A modo de ejemplo, la aflatoxina B1 (AFB1) es una toxina producida por especies del género Aspergillus que es hepatotóxica, mutagénica, cancerígena, su biosíntesis proviene del ciclo policétido y es un derivado furano [56]. 
Como se ha dicho, el número de micotoxinas que se conocen es elevado, derivado de la gran cantidad de hongos que pueden desarrollarse en una también amplia variedad de sustratos y producir estos compuestos bajo diferentes condiciones ambientales. Por ello, la clasificación y descripción de los distintos grupos y familias de micotoxinas que se presenta a continuación está focalizada en aquellas que tuvieron implicancia en el desarrollo de esta tesis.

\subsubsection{Principales micotoxinas}

La cadena alimentaria puede verse contaminada por numerosas micotoxinas producidas por diversos hongos toxicogénicos, dando como resultados graves pérdidas económicas y problemas de salud en el ganado y los seres humanos. Desde el punto de vista agronómico, las principales micotoxinas de distribución mundial son: aflatoxinas, tricotecenos (DON, toxina T-2), zearalenona, fumonisinas, y ocratoxina $A$, pudiendo todas ellas ser encontradas en las etapas de pre- y post-cosecha, de preparación de alimentos y en los piensos.

\section{Aflatoxinas}

Las aflatoxinas (AFs) son derivados de la difuranocumarina producidos principalmente por mohos del género Aspergillus como A. flavus, y A. parasiticus, presentes normalmente en suelos y diversos materiales orgánicos. Los hongos productores de AFs crecen en una gran variedad de alimentos como cereales (maíz, cebada, avena, arroz y sorgo), en maní, nueces, almendras y semillas de algodón. Además, la leche puede contaminarse con aflatoxina M1 (AFM1), que es el metabolito principal de la AFB1, biotransformado por el citocromo microsomal hepático P450 en vacas que han sido alimentadas con piensos contaminados con AFB1. Las AFs presentan efectos teratogénicos, hepatotóxicos, mutagénicos e inmunosupresores, siendo el hígado el principal órgano afectado. Los efectos de toxicidad de las AFs están asociados, especialmente en la AFB1, con la posibilidad de epoxidación de la porción furano en carbonos 8-9 de la molécula, y la reacción del epóxido con las proteínas del ADN [59]. Estas micotoxinas se asocian tanto con la toxicidad aguda como con la carcinogenicidad crónica en poblaciones animales y humanas. La AFB1 es el más potente carcinógeno natural conocido y es generalmente la AF más importante producida por cepas toxicogénicas. Este compuesto ha sido clasificado por la IARC como carcinógeno Grupo 1, con alto riesgo de carcinoma hepatocelular en individuos expuestos a aflatoxinas, mientras que la AFM1 está listada como Grupo 2B (posible carcinógeno en humanos) [60].

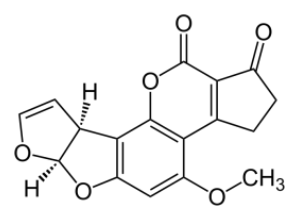

AFB1

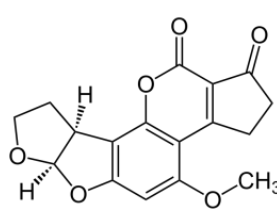

AFB2

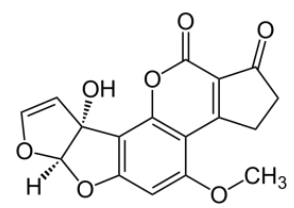

AFM1

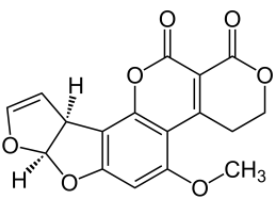

AFG1

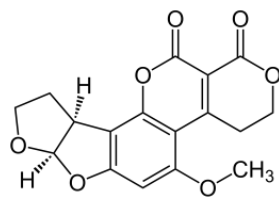

AFG2

Figura 1: Estructuras químicas de las principales aflatoxinas. 


\section{Tricotecenos}

Los tricotecenos (TCTC) constituyen una familia de más de 180 metabolitos sesquiterpernoides producidos por especies de varios géneros de mohos como Fusarium, Acremonium, Cylindrocarpon, Trichoderma, Trichothecium, y Stachybotrys, entre otros. Los más relevantes de estos metabolitos, por su interacción en la producción y la salud humada y animal, son deoxinivalenol (DON), nivalenol (NIV), las toxinas T-2 y HT-2 y el diacetoxiscirpenol (DAS). Las especies de Fusarium que producen TCTC generalmente infectan las cosechas a campo y colonizan cereales como trigo, cebada, centeno, avena, maíz y arroz, pudiendo encontrarse estas micotoxinas también en porotos de soja, semillas de algodón y en alimentos procesados derivados de esos cereales (pan, fideos, cerveza). Estos compuestos evidencian su toxicidad penetrando fácilmente la bicapa lipídica de la membrana celular y reaccionando con el ADN, ARN y organelas celulares. La toxicidad de los TCTC es sin embargo dependiente del tipo de compuesto que se trate, siendo por ejemplo la toxina T-2 10 veces más tóxica que el DON, que además de ser el tricoteceno más común y mayormente estudiado es el menos tóxico[56,60].

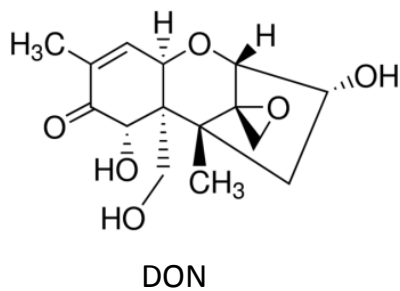

Figura 2. Estructuras químicas de los tricotecenos deoxinivelenol y toxina T-2.

\section{Zearalenona}

La zearalenona (ZEA) es una lactona del ácido resorcílico producida por cepas toxicogénicas de Fusarium principalmente $F$. graminearum, $F$. culmorum y $F$. semitectum, que son hongos de suelo que contaminan cereales en todo el mundo y producen ZEA en condiciones de elevada humedad y bajas temperaturas. Clasificada como no cancerígeno en humanos (IARC Grupo 3), esta micotoxina es frecuentemente hallada en cereales como maíz, trigo, sorgo, cebada y centeno en la etapa de precosecha, produciéndose también en la postcosecha si los cultivos no son manejados y secados correctamente, y además en productos como harina, malta y cerveza. La ZEA es considerada una micotoxina con actividad estrogénica por su similitud estructural con los estrógenos naturales, uniéndose competitivamente a los receptores hormonales y causando alteraciones reproductivas. En el ganado, el consumo de piensos contaminados con zearalenona está asociado con infertilidad y con la disminución de la producción de leche. Esta micotoxina es metabolizada, tanto en las plantas como en el hígado de los animales, en sus derivados $\alpha$-zearalenol y $\beta$ zearalenol que poseen igual actividad estrogénica [56,60,61]. 


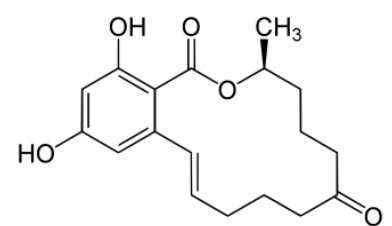

ZEA

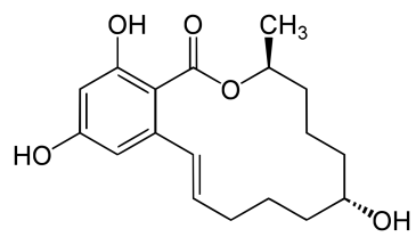

$\alpha-Z E A$<smiles>C[C@H]1CCC[C@H](O)CCC/C=C/c2cc(O)cc(O)c2C(=O)O1</smiles>

$\beta$-ZEA

Figura 3. Estructuras químicas de zearalenona y sus derivados $\alpha$-zearalenol y $\beta$-zearalenol.

\section{Fumonisinas}

Las fumonisinas (FBs) son un grupo de micotoxinas producidas por especies del género Fusarium, principalmente $F$. verticillioides, el cual crece como endófito en los tejidos vegetativos y reproductivos del maíz y en condiciones ambientales adecuadas o presencia de daños por insectos puede producir estas toxinas. Además de este cereal, las fumonisinas pueden ocurrir en sorgo, trigo, cebada y en soja. Estructuralmente las FBs son diferentes del resto de las micotoxinas, caracterizadas por la presencia de cuatro grupos carboxílicos e hidroxilos, lo que les confiere una alta polaridad e hidofilicidad evitando, por ejemplo, su transferencia hacia la leche en el ganado. Se han descubierto hasta aquí unos 28 homólogos de las FBs clasificados en 4 grupos (A, B, C y P), siendo la fumonisina B1 (FB1) la más relevante ya que representa el $70-80 \%$ de las fumonisinas producidas. El mecanismo de toxicidad de las FBs está relacionado con que interfieren con el metabolismo de los esfingolípidos interrumpiendo la biosíntesis de sus metabolitos, debido a la similitud estructural de estas micotoxinas con la esfinganina. En animales, las FBs afectan órganos como hígado y riñones causando diversos efectos tóxicos, y en humanos se las ha asociado con el desarrollo de cáncer de esófago, por lo que la IARC las ha clasificado como agentes probablemente cancerígenos (Grupo 2B) [56,60].<smiles>CCCCC(C)C(OC(=O)CC(CC(=O)O)C(=O)O)C(CC(C)CC(O)CCCCC(O)CC(O)C(C)N)OC(=O)CC(CCC(=O)O)C(=O)O</smiles>

FB1

Figura 4. Estructura química de fumonisina B1.

\section{Ocratoxina A}

La ocratoxina A (OTA) es un pentaquétido derivado de hidrocumarinas unido por un enlace amida a una molécula de fenilalanina y representa la micotoxina más importante de la familia de las ocratoxinas, producidas por varias especies de mohos de los géneros Penicillium y Aspergillus. Estos mohos colonizan gran variedad de cultivos como maíz, trigo, cebada, arroz, habas, café, uvas y frutas, produciendo ocratoxinas en todos ellos y pudiendo estar presentes también en productos elaborados debido a su alta 
estabilidad térmica y resistencia a los procesos de preparación de alimentos. Debido a su solubilidad en grasas, la OTA puede ser encontrada en leche y otros tejidos animales, aunque la mayor contribución a su ingesta está relacionada con el consumo de café y vinos. Uno de los mecanismos de toxicidad de la OTA está asociado con su similitud estructural con el amonoácido fenilalanina, interfiriendo con la actividad de la enzima hidroxilasa relacionada que resulta en la inhibición de la síntesis proteica. Se ha reportado también que OTA es una toxina causante de inmunotoxicidad, genotoxicidad, neurotoxicidad y teratotoxicidad en animales y humanos, por lo que IARC la ha clasificado como posible cancerígeno humano (Grupo 2B) [56,60].

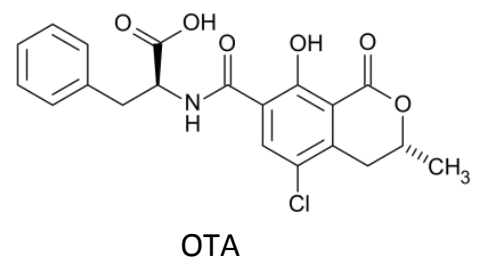

Figura 5. Estructura química de ocratoxina A.

\section{Alcaloides del ergot}

Los alcaloides del ergot (AE) son amidas del ácido D-lisérgico derivado del triptófano producidos por mohos del género Claviceps, especialmente C. purpurea, que atacan a gramíneas susceptibles como el centeno, trigo, cebada y avena produciendo membranas oscuras en la superficie de granos y semillas (ergot o cornezuelo) que presentan en su interior cócteles tóxicos de estos alcaloides. Los AE están presentes también en un hongo endófito de la festuca (Festuca arundinacea) que es un pasto común para el forraje, lo que aumenta la exposición del ganado a este tipo de micotoxinas. Existen más de 50 alcaloides que han sido aislados del ergot, siendo los más importantes la ergotamina, ergometrina, ergosina, ergocriptina, ergocornina y ergocristina. Los efectos farmacológicos de los AE son debidos a su similitud estructural con el sistema de anillos tetracíclicos de neurotransmisores como la noradrenalina, dopamina y serotonina, interactuando con los múltiples receptores involucrados en los sistemas nerviosos.

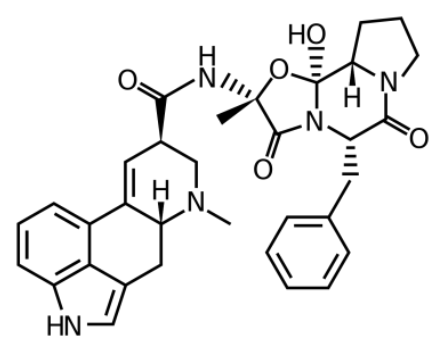

Ergotamina

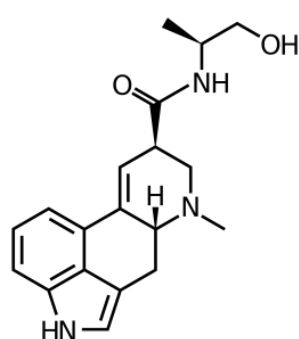

Ergometrina

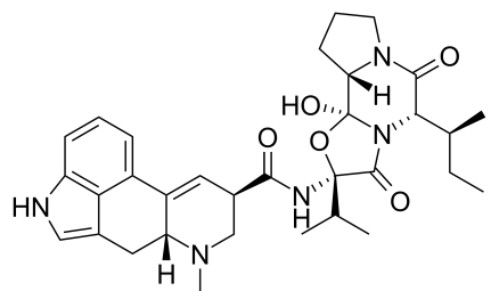

Ergocriptina

Figura 6. Estructuras químicas de tres alcaloides del ergot. 
Además de la clasificación descripta anteriormente, las micotoxinas pueden clasificarse desde el punto de vista analítico o de su ocurrencia en micotoxinas conjugadas y micotoxinas emergentes, según la forma en la que se presenten en la naturaleza y los nuevos descubrimientos que se van realizando de la mano de los avances en la química analítica de contaminantes.

\subsubsection{Micotoxinas enmascaradas o conjugadas}

El término "micotoxina enmascarada" surgió en la década de 1980 cuando tras confirmarse síntomas de micotoxicosis en animales afectados que no se correlacionaban con la baja cantidad de micotoxinas que se detectaban en los alimentos analizados comenzó a sospecharse de la presencia de otras formas de micotoxinas. De este modo, la elevada toxicidad observada comenzó a atribuirse a formas no detectadas de estos metabolitos. Recientemente, con la posibilidad para estos compuestos de ser detectados, el término "enmascarada" se ha reemplazado por "modificada" o "conjugada" para referir a las micotoxinas que fueron biológica o químicamente modificadas por asociación con otras moléculas [62,63].

Para protegerse de los efectos negativos causados por xenobióticos como las micotoxinas, las plantas pueden llevar a cabo 3 procesos bioquímicos principales: transformación (fase I), conjugación (fase II) y compartimentalización (fase III). Durante los procesos de fase I, las micotoxinas son convertidas en metabolitos menos hidrofóbicos y generalmente menos tóxicos por medio de reacciones de oxidación, reducción o hidrólisis. En la fase II, las micotoxinas o sus metabolitos de fase I son conjugados directamente con glucosa, glutatión, azúcares, ácidos grasos o aminoácidos para producir compuestos hidrofílicos que son excretados más fácilmente. Finalmente, en la fase III los metabolitos previamente conjugados son depositados en el interior de las vacuolas o de las paredes celulares. Ejemplos típicos de estas micotoxinas "enmascaradas" o conjugadas son las formas glucosídicas de algunas de las micotoxinas más conocidas, como deoxinivalenol-3-glucósido (DON-3-G), zearalenon-14-glucósido (ZEN-14-G) y glucósidos de las toxinas T-2 y HT-2, o formas acetiladas como 3-acetil-deoxinivalenol (3-ADON) y 15-acetil-deoxinivalenol (15-ADON) [64].

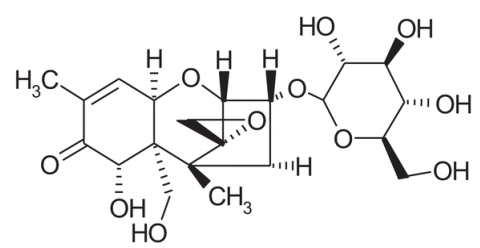

DON-3-gluc

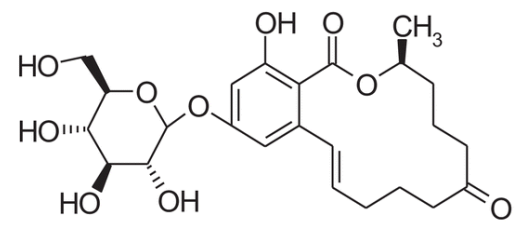

ZEA-14-gluc

Figura 7. Estructuras químicas de las micotoxinas enmascaradas DON-3-glucósido y zearalenona-14-glucósido.

Además de la ocurrencia en plantas, el fenómeno de la metabolización de las micotoxinas conjugadas se verifica también en hongos, mamíferos e incluso tras el procesamiento de alimentos, en procesos como calentamiento o fermentación. El proceso de conjugación metabólica con moléculas polares se considera comúnmente como una reacción de inactivación porque la aglicona por lo general pierde su actividad 
biológica. Sin embargo, durante la digestión de los mamíferos es posible que se produzca la hidrólisis de la micotoxina conjugada hacia su precursor tóxico aumentando el riesgo toxicológico hacia el hombre y los animales [65]. Por ejemplo, el riesgo de contaminación por DON-3-G ha sido señalado el Comité Mixto de Expertos en aditivos alimentarios de la FAO/WHO concluyendo que esa micotoxina conjugada podría ser una importante fuente de exposición dietaria [64].

La definición de micotoxina enmascarada implicaba que en el análisis de muestras que contenían estos compuestos se producía una subestimación del contenido de micotoxinas presentes, como consecuencia del cambio en las propiedades fisicoquímicas de las moléculas que modifican el comportamiento cromatográfico, la porción molecular reconocida por los anticuerpos utilizados para la detección, o por deficiencias en la extracción causada por el aumento de polaridad de los compuestos cuando se utilizan solventes de menor polaridad para la extracción de las micotoxinas no modificadas. Si bien con las técnicas instrumentales actuales es posible la identificación de estas micotoxinas, su inclusión en los métodos de análisis puede dificultarse debido a la falta de disponibilidad de los estándares analíticos de los compuestos conjugados $[64,66]$.

\subsubsection{Micotoxinas emergentes}

El término "micotoxinas emergentes" se refiere a aquellos metabolitos fúngicos que no son determinados rutinariamente ni regulados normativamente, pero que las evidencias sobre su incidencia han ido incrementando rápidamente. Aunque en un principio se denominaban dentro de esta categoría a ciertas micotoxinas producidas por el género Fusarium, lo cierto es que la mayoría de los géneros fúngicos producen micotoxinas consideradas como emergentes. Tal es el caso de los metabolitos de Aspergillus esterigmatocistina (STE) o emodina (EMO), los de Penicillium como el ácido micofenólico (MPA), de Alternaria como alternariol ( $\mathrm{AOH})$, alternariol metil éter (AME) y ácido tenuazónico (TeA), y los del género Fusarium eniatinas (ENNs), beauvericina (BEA), moniliformina (MON), fusaproliferina (FP), culmorina (CUL), entre otros (Gruber-Droninger, 2016). Se describen a continuación algunas de estas micotoxinas que tuvieron relevancia en este trabajo.

\section{Eniatinas y Beauvericina}

Las eniatinas (ENNs) y la beauvericina (BEA) son hexadepsipéptidos cíclicos de estructura similar producidos por varias especies de mohos del género Fusarium como F. avenaceum, F. poace y F. proliferatum que crecen principalmente en cereales. Respecto las ENNs, se conocen unos 29 tipos distintos de eniatinas, siendo los compuestos A, A1, B y B1 los detectadas más frecuentemente en alimentos y piensos [67]. Estas micotoxinas se han encontrado en niveles de concentración de hasta $\mathrm{mg} / \mathrm{kg}$ y con alta ocurrencia en distintos cereales y productos derivados en Europa sugiriéndose incluso su existencia ubicua en ese tipo de alimentos [68]. La toxicidad de las ENNs y la BEA está relacionada con sus propiedades ionóforas facilitando el transporte de iones como $\mathrm{K}^{+}$y $\mathrm{Ca}^{+2}$ a través de las membranas celulares, alterando sus concentraciones 
fisiológicas normales. En una opinión científica emitida en 2014 la EFSA concluyó que no existe riesgo de exposición aguda de las ENNs y BEA en humanos, al tiempo que por falta de datos relevantes sobre toxicidad in vivo no pudo emitir opinión sobre la exposición crónica [69].

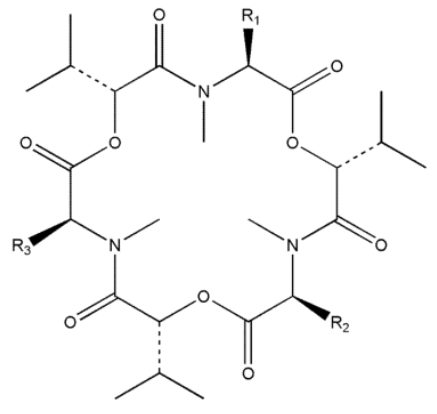

ENNS

\begin{tabular}{llll}
\hline & $\mathrm{R}_{1}$ & $\mathrm{R}_{2}$ & $\mathrm{R}_{3}$ \\
\hline ENA & s-But & s-But & s-But \\
ENA1 & i-Pr & s-But & s-But \\
ENB & i-Pr & i-Pr & i-Pr \\
ENB1 & i-Pr & i-Pr & s-But \\
\hline
\end{tabular}

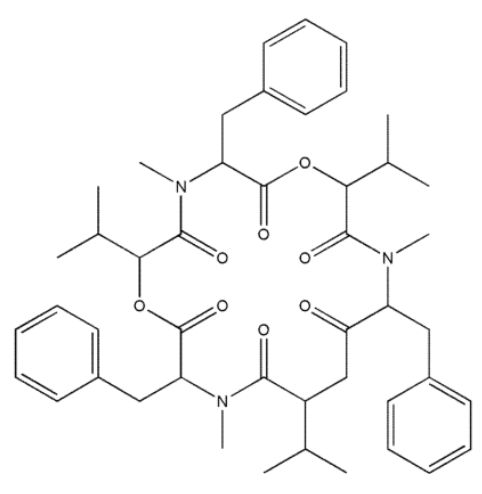

BEA

Figura 8. Estructuras químicas de eniatinas y beauvericina.

\section{Esterigmatocistina}

La esterigmatocistina (STE) es una micotoxina producida por especies de diversos géneros fúngicos, siendo las de Aspergillus (A. flavus, A. parasiticus, A. versicolor) las principales productoras. Estructuralmente, está muy relacionada con la aflatoxina B1 de la cual es precursora en su ruta biosintética y es precisamente esa similitud estructural la que le otorga a STE efectos tóxicos similares a los de AFB1, mediados por el anillo furofurano de su estructura que forma aductos con el ADN luego de ser metabólicamente transformado en epóxido. Aunque, al igual que AFB1, la STE presenta efectos tóxicos que incluyen genotoxicidad y carcinogenicidad, su toxicidad es considerada cerca de 200 veces menor que la de la aflatoxina. En ese sentido, la IARC ha clasificado a la esterigmatocistina como un posible cancerígeno para humanos (Grupo 2B) $[67,70]$.

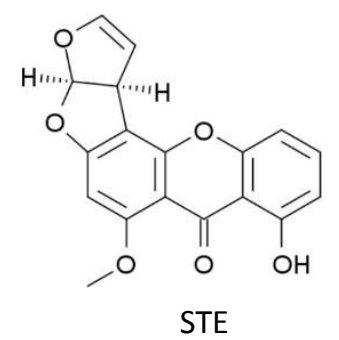

Figura 9. Estructura química de esterigmatocistina.

Toxinas de Alternaria

Estas micotoxinas están representadas fundamentalmente por alternariol $(\mathrm{AOH})$ y alternariol-metil-éter (AME), que químicamente son derivados de dibenzopironas, y por el ácido tenuazónico (TeA), que estructuralmente es derivado del ácido tetrámico. Son metabolitos secundarios producidos por algunas especies de mohos del género Alternaria, como A. alternata, A. citrii y A. tenuissima, que requieren alta humedad para su desarrollo y colonizan comúnmente frutas, vegetales y granos de trigo, sorgo y cebada 
previo a su cosecha $[58,67]$. Las especies de Alternaria producen más de 70 fitotoxinas pero sólo una pequeña porción de ellas han sido químicamente caracterizadas como micotoxinas con efectos en animales y humanos, y se ha descripto que algunas de estas toxinas, como AOH, AME y TeA, ejercen efectos fetotóxicos y teratogénicos en animales, y efectos mutagénicos en algunos sistemas estudiados in vivo, razón por la cual revisten interés para la salud pública [71].<smiles>Cc1cc(O)cc2oc(=O)c3c(O)cc(O)cc3c12</smiles>

$\mathrm{AOH}$<smiles>COc1cc(O)c2c(=O)oc3cc(O)cc(C)c3c2c1</smiles>

AME<smiles>CC[C@H](C)[C@H]1NC(=O)C(C(C)=O)=C1O</smiles>

TeA

Figura 10. Estructuras químicas de alternariol, alternariol-metil-éter y ácido tenuazónico.

Todas o una gran cantidad de estas familias de micotoxinas, que de manera resumida se describieron hasta aquí, pueden co-existir en un mismo sustrato si se dan las condiciones adecuadas. El impacto de la presencia de cócteles de estos metabolitos secundarios en los alimentos y piensos, y los efectos aditivos y sinérgicos que estas sustancias pueden tener sobre la salud de las personas y los animales es aún desconocido [72].

\subsubsection{Legislación sobre micotoxinas}

Distintos bloques comerciales y agencias de control a nivel internacional han establecido límites máximos a la presencia de las principales clases de micotoxinas en alimentos y piensos, teniendo en cuenta los riesgos potenciales para la salud de los seres humanos y los animales que presentan estos contaminantes, además de su implicancia en la productividad animal y agrícola, con consecuencias económicas en el comercio de los productos. En nuestra región, el MERCOSUR establece como bloque comercial, a través de la Resolución Mercosur/GMC/N²5/02, límites máximos solamente para aflatoxinas (AFM1 y AFs totales) en leche, maní y productos derivados, granos de maíz y productos derivados para consumo humano [73]. Algunos países miembros poseen, además, regulaciones internas que fijan límites para el contenido de otras micotoxinas en alimentos. En Brasil, por ejemplo, existen límites establecidos para AFs, OTA, DON y ZEA en una gran variedad de alimentos que incluyen cereales, frutas, vinos, quesos y café, entre otros [74]. Por otro lado Uruguay, además de regular en alimentos las mismas micotoxinas que Brasil establece límites máximos para DON y alcaloides del ergot en piensos para animales [75].

En la Unión Europea se encuentra la regulación más extendida y detallada para micotoxinas en alimentos, donde existen límites armonizados para, por ejemplo, aflatoxinas totales en diversos tipos de alimentos, AFM1 en leche, ocratoxina $A$ en cereales y frutos secos, patulina en manzana y productos derivados, AFB1 en diversos alimentos, toxinas T-2 y HT-2 en cereales y derivados $[75,76]$. Además de regular límites en 
alimentos para consumo humano, este bloque comercial ha fijado también niveles máximos para distintas micotoxinas (DON, ZEA, OTA, T-2, HT-2, FBs, AFB1) en piensos y productos para alimentación animal $[77,78]$.

En los Estado Unidos, por su parte, la FDA ha establecido límites máximos para AFM1, aflatoxinas totales, fumonisinas, DON y patulina en distintos tipos de alimentos lácteos y de origen vegetal para consumo humano, fijando también niveles permitidos para las mismas micotoxinas en piensos $[75,76]$.

Vale aquí traer a colación lo expuesto anteriormente sobre la inexistencia de límites máximos para las micotoxinas emergentes a nivel mundial, principalmente por la falta de información que aún se verifica sobre ocurrencia, niveles de contaminación y toxicidad de estos compuestos en alimentos y piensos [79]. 


\subsection{MATRICES ANALIZADAS EN ESTE TRABAJO}

\subsubsection{LECHE}

\subsubsection{Importancia económica}

La producción de leche primaria en Argentina en el año 2017 fue de 11.097 millones de litros producidos por un total de 11.326 tambos distribuidos en todo el país. La distribución de estos establecimientos productores se da en la región centro del país, estando localizados principalmente en las provincias de Santa Fe (35,1\%), Córdoba (30,0\%), Buenos Aires $(22,1 \%)$ y Entre Ríos $(7,6 \%)[80,81]$.

El 93\% de la producción total de leche del País se destina a la industria para su procesamiento, siendo el 18,4\% finalmente consumido como leches fluidas, y un $74,6 \%$ destinado a la elaboración de productos (55\% para la producción de quesos y 28\% para la elaboración de leche en polvo). En el año 2015 Argentina participó, aproximadamente, en el 1,9\% de la producción mundial de leche cruda, habiendo sido el tercer exportador mundial de leche en polvo entera [82].

Estos números reflejan la importancia que tiene el sector lácteo en nuestro país, y especialmente en la provincia de Santa Fe que se posiciona como la principal cuenca de producción de leche de la Argentina. En ese contexto, resulta imperioso que todo el sistema productivo asegure un producto con la calidad adecuada para que tenga un impacto positivo tanto a nivel económico-comercial para el desarrollo de los pueblos y ciudades como, por supuesto, para la salud de los consumidores siendo que la leche es el alimento básico primordial.

\subsubsection{Caracterización como matriz}

Desde el punto de vista fisicoquímico, la leche es un fluido complejo en el que sus constituyentes se presentan en tres fases. Cuantitativamente, la mayor parte de la masa de la leche es una solución de lactosa que coexiste con proteínas en dispersión y con lípidos en estado de emulsión [83,84]:

- Lactosa: es el carbohidrato distintivo de la leche y es un disacárido constituido por glucosa y galactosa. En la misma solución acuosa se encuentran sales inorgánicas (principalmente de $\mathrm{K}, \mathrm{Na}$, $\mathrm{Ca}, \mathrm{Mg}, \mathrm{Cl}$ ), sales orgánicas (en su mayoría citratos), vitaminas y otros nutrientes menores.

- Proteínas: el $80 \%$ del contenido proteico de la leche lo conforman las caseínas que se encuentran formando agregados coloidales, y el resto por proteínas del suero como $\beta$-lactoglobulina y otras proteínas menores y enzimas que se encuentran a nivel molecular.

- Lípidos: la parte grasa de la leche forma glóbulos grasos de entre 0,1 y $20 \mu \mathrm{m}$ de diámetro que se componen en gran parte de triglicéridos cuyos ácidos grasos varían ampliamente tanto en longitud (cadenas de 2 a 20 átomos de carbono) como en saturación (de 0 a 4 dobles enlaces), y también de otros lípidos como fosfolípidos, colesterol, ácidos grasos libres, y otros mono- y diglicéridos. 
En la Tabla 8 se describen la composición típica y algunas propiedades físicas de la leche de vaca. Si bien las cantidades de cada componente varían con la raza de los animales, su dieta, la época del año, la frecuencia de ordeñe, entre otros factores, las composiciones allí especificadas están aceptadas como las características para la leche bovina.

Tabla 8. Composición típica y propiedades físicas de la leche de vaca.

\begin{tabular}{|c|c|c|c|}
\hline \multicolumn{2}{|l|}{ Composición típica } & \multicolumn{2}{|c|}{$\mathrm{g} / \mathrm{L}$} \\
\hline Agua & & 905 & \\
\hline Glúcidos: lactosa & & 49 & \\
\hline Lípidos & & 35 & \\
\hline \multicolumn{2}{|l|}{ Materia grasa propiamente dicha } & & 34 \\
\hline \multicolumn{2}{|l|}{ Lecitina (fosfolípidos) } & & 0,5 \\
\hline \multicolumn{2}{|c|}{ Parte no saponificable (esteroles, carotenos, tocoferoles) } & & 0,5 \\
\hline \multicolumn{2}{|l|}{ Proteínas } & 34 & \\
\hline \multicolumn{2}{|l|}{ Caseína } & & 27 \\
\hline \multicolumn{2}{|c|}{ Proteínas solubles (globulinas, albúminas) } & & 5,5 \\
\hline \multicolumn{2}{|c|}{ Sustancias nitrogenadas no proteicas } & & 1.5 \\
\hline \multicolumn{2}{|l|}{ Sales } & 9 & \\
\hline \multicolumn{2}{|l|}{ Del ácido cítrico (en ácido) } & & 2 \\
\hline \multicolumn{2}{|l|}{ Del ácido fosfórico $\left(\mathrm{P}_{2} \mathrm{O}_{5}\right)$} & & 2.6 \\
\hline \multicolumn{2}{|l|}{ Del ácido clorhídrico ( $\mathrm{NaCl})$} & & 1.7 \\
\hline \multicolumn{2}{|c|}{$\begin{array}{l}\text { Componentes diversos } \\
\text { (vitaminas, enzimas, gases disueltos) }\end{array}$} & trazas & \\
\hline \multicolumn{2}{|l|}{ Extracto seco (total) } & 127 & \\
\hline \multicolumn{2}{|l|}{ Extracto seco desengrasado } & & 92 \\
\hline \multicolumn{4}{|l|}{ Propiedades físicas } \\
\hline Densidad de la leche completa: & 1,032 & & \\
\hline Densidad de la leche descremada: & 1,036 & & \\
\hline Densidad de la materia grasa: & 0,940 & & \\
\hline Poder calórico (por litro): & 700 & & \\
\hline $\mathrm{pH}:$ & $6,6-6,8$ & & \\
\hline Viscosidad relativa (específica): & $1,6-2,15$ & & \\
\hline Punto de congelación: & $-55^{\circ} \mathrm{C}$ & & \\
\hline
\end{tabular}

Adaptado de Charles Alais (1988) Ciencia de la leche [85].

Se observa entonces que la leche es una matriz compleja desde el punto de vista analítico, pues los completos y variados constituyentes que la componen conforman las distintas interferencias que se deben eliminar para el análisis de cantidades traza de residuos y contaminantes.

\subsubsection{La leche como vector de contaminantes}

La ocurrencia de contaminantes químicos en la leche es un tema que concierne a la salud pública ya que es el alimento basal de la primera infancia, y como tal o en forma de derivados lácteos es consumida por gran cantidad de niños y adultos en todo el mundo. Las características composicionales antes detalladas la convierten además en un medio en el que una variedad amplia de sustancias químicas pueden disolverse: muchos compuestos no polares como los plaguicidas organoclorados pueden encontrarse en leche 
asociados a la fracción lipídica de este alimento, al tiempo que por ser una solución acuosa con una constante dieléctrica casi tan alta como la del agua otras sustancias polares como plaguicidas organofosforados o micotoxinas pueden disolverse bien también.

Los residuos y contaminantes químicos pueden ingresar a la cadena de producción primaria a través de la ingesta de piensos que contengan estas sustancias como consecuencia de las prácticas agrícolas, producto de la contaminación ambiental cuando los animales pastorean en suelos contaminados, o por contacto directo cuando son administrados con compuestos que actúan como endo o ectoparasitarios.

De esta forma, las sustancias que son absorbidos por el animal por alguna de estas vías son metabolizadas y eventualmente excretadas en la leche del animal. La transferencia a la leche se da cuando el plaguicida o la micotoxina atraviesan la barrera sangre-leche de la glándula mamaria, siendo la eficacia de este proceso dependiente de las propiedades fisicoquímicas de las moléculas (lipo- o hidrofilicidad, peso molecular, afinidad por proteínas transportadoras, etc.) [86].

Diversas clases de plaguicidas pueden encontrarse en leche debido a su difundido uso agrícola. Así, a pesar de haber sido prohibidos o restringido su uso, los plaguicidas organoclorados son comúnmente hallados por su persistencia ambiental y su solubilidad en grasa. Los organofosforados y carbamatos, por su parte, son muy utilizados por su gran espectro de acción como insecticidas y por presentar menor persistencia ambiental y poder de acumulación. También los insecticidas piretroides han encontrado amplio uso por su similitud estructural y de poder de acción con las piretrinas naturales [87]. De este modo, los animales están expuestos a una amplia variedad de plaguicidas comúnmente utilizados haciendo probable su presencia en leche. Sin embargo, la ocurrencia de plaguicidas en esta matriz ha estado siempre más asociada a la familia de los compuestos organoclorados, por un lado debido a su alta lipofilicidad y persistencia ambiental, y por el otro porque los compuestos de las demás familias, especialmente organofosforados y carbamatos, son más polares e hidofílicos y tienen mayor probabilidad de sufrir procesos metabólicos de degradación (principalmente en el hígado) y ser excretados [88].

En el caso de las micotoxinas, su presencia en leche está relacionada exclusivamente con la transferencia desde los alimentos potencialmente contaminados con estas sustancias que consuman los animales. La flora del rumen es considerada una defensa contra las micotoxinas por el hecho de que algunas de ellas (ocratoxina A, deoxinivalenol, aflatoxina B1 y zearalenona) son allí metabolizadas a compuestos de menor toxicidad, aunque otras micotoxinas como patulina o las fumonisinas atraviesan la barrera del rumen sin sufrir cambios, aunque esto no implica su posterior transferencia a la leche [89]. Aunque la presencia en leche de distintas clases micotoxinas como FB1, ZEA, OTA, AFB1 y sus metabolitos se ha reportado con variados niveles de ocurrencia [89-91], la micotoxina de mayor importancia en leche ha sido siempre la aflatoxina M1 [92]. Este compuesto es el derivado hidroxilado de la aflatoxina B1 que comúnmente contamina las materias primas que se utilizan en la alimentación del ganado, y tal es su importancia que es la única micotoxina para la cual existen límites máximos permitidos en leche. 


\subsubsection{PIENSOS}

\subsubsection{Contexto productivo y caracterización de alimentos}

La producción de leche depende fuertemente de la nutrición y del tipo de alimentación que reciben los animales, que está condicionado a su vez por los sistemas de producción que adoptan los distintos establecimientos. En algunos países, los sistemas de producción extensivos basados en pastoreos de pasturas naturales o mejoradas y cultivos forrajeros han cambiado a sistemas de producción más intensivos, suplementando la alimentación con granos, forrajes conservados, subproductos industriales o alimentos balanceados para aumentar el crecimiento, la composición corporal o la producción de leche [93].

En la actualidad, los tambos argentinos dejaron de ser típicamente pastoriles, pues el pastoreo directo con forrajes frescos apenas satisface el 20-40 \% de las necesidades nutritivas del ganado. El resto de los nutrientes es aportado por el uso de forrajes conservados (silajes, henos) y concentrados energéticos y proteicos (balanceados comerciales, grano de maíz, derivados de soja, etc.). El incremento en el consumo de alimentos concentrados y el mayor uso de silajes ha contribuido al proceso de intensificación verificado en los últimos años, que consistió básicamente en un aumento de la carga animal y de la producción individual de leche [94]. Esta estrategia de alimentación es la que actualmente más se utiliza en toda la región pampeana de Argentina, y en especial en la región central de la provincia de Santa Fe donde las dietas tienen un componente fuerte de alimentos concentrados. En la Figura 11 se clasifican los principales tipos de alimentos que componen los piensos utilizados en la producción de leche, ejemplificándose los de uso principal en la región central santafesina.

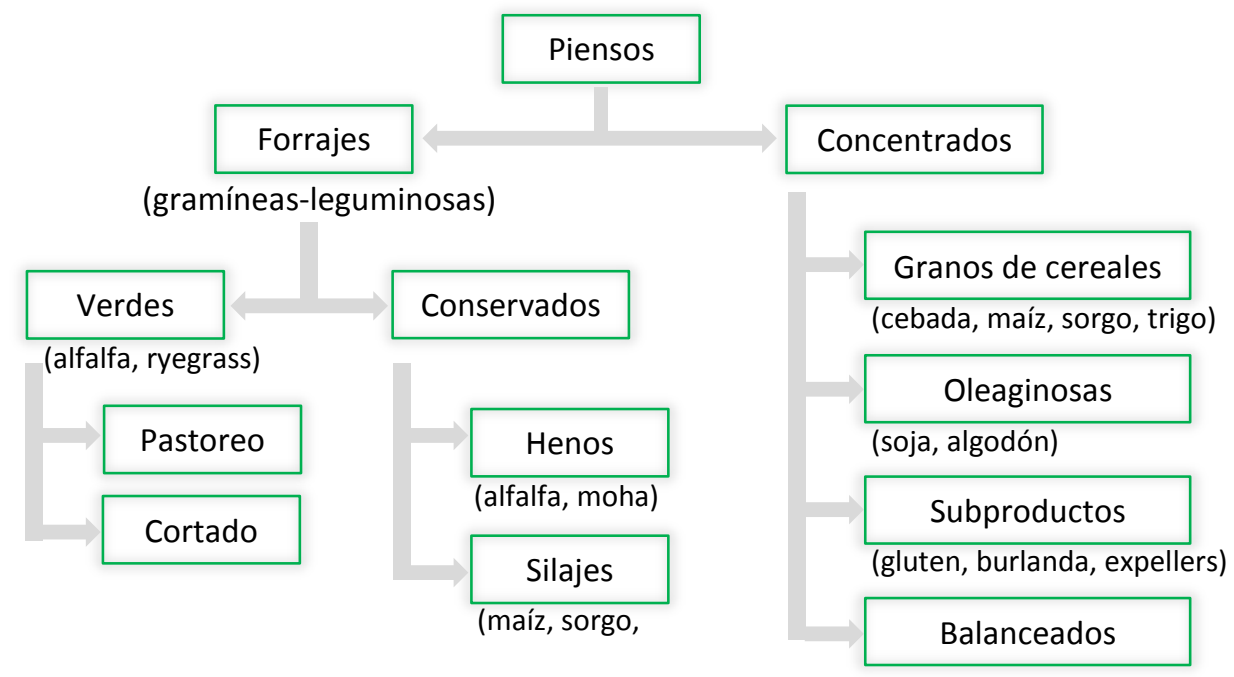

Figura 11. Clasificación de los tipos de piensos más utilizados en la alimentación del ganado lechero.

La gran variedad de alimentos vegetales que constituyen los piensos utilizados en la alimentación del ganado lechero determinan una composición química de estos sustratos también variada. Las pasturas y otros tipos de forrajes varían su calidad en las distintas etapas de crecimiento y en las diferentes fracciones 
de la planta. Estas diferencias de deben, además, a la amplitud de las condiciones ambientales (suelo, clima), al material genético, al manejo (riego, fertilización) y, en el caso de los forrajes conservados, al sistema de conservación y el tipo de almacenamiento. Por su parte, en los alimentos concentrados y suplementos (expellers, afrechillos, etc.), las características del proceso industrial del que derivan definen en gran medida su calidad [95]. En la Tabla 12 se resumen las composiciones químicas de algunos piensos característicos que se utilizan habitualmente en los sistemas productivos lecheros de Santa Fe.

Tabla 12. Composición química de alimentos utilizados comúnmente para el ganado lechero.

\begin{tabular}{llllllll}
\hline & \multicolumn{7}{c}{$\%$ (g/100 g MS) } \\
\cline { 2 - 8 } Alimento & MS & PB & FDN & FDA & LDA & EE & CEN \\
\hline Forrajes verdes & & & & & \\
Alfalfa (aprovechamiento óptimo - verano) & 23 & 22 & 39 & 30 & 7 & 4 & 10 \\
Avena (primer pastoreo) & 17 & 18 & 44 & 23 & 4 & 5 & - \\
Soja (R4) & 34 & 54 & 34 & 9 & 4 & - & 16 \\
Forrajes conservados & & & & & & & \\
Alfalfa heno & 88 & 19 & 46 & 31 & 9 & 3 & 11 \\
Alfalfa silaje (MS $\geq 50 \%)$ & 56 & 20 & 46 & 35 & 9 & 5 & 13 \\
Maíz silaje (planta entera MS $\geq 35 \%)$ & 41 & 8 & 49 & 29 & 4 & 5 & 7 \\
Sorgo silaje (planta entera MS $\geq 35 \%)$ & 39 & 8 & 56 & 35 & 7 & 5 & 11 \\
Concentrados & & & & & & & \\
Algodón semilla (entera) & & & & & & \\
Balanceado comercial (PB $\geq 18 \%)$ & 90 & 22 & 47 & 34 & 9 & 20 & 5 \\
Maíz grano & 91 & 20 & 26 & 10 & 3 & 6 & 8 \\
Soja expeller & 89 & 9 & 11 & 5 & 1 & 6 & 3 \\
Trigo grano & 94 & 40 & 17 & 9 & 1 & 9 & 8 \\
\hline
\end{tabular}

MS (materia seca): expresa indirectamente el contenido de humedad.

PB (proteína bruta): expresa el contenido de nitrógeno total del alimento (proteína verdadera y nitrogenados no proteicos).

FDN (fibra detergente neutro): compuesta por celulosa, hemicelulosa, lignina y sílice (denominada pared celular).

FDA (fibra detergente ácido): compuesta por celulosa, lignina y sílice (está inversamente relacionada con la digestibilidad).

LDA (lignina detergente ácido): expresa el contenido de lignina.

EE (extracto etéreo): expresa el contenido de grasa.

CEN (cenizas): expresa la materia inorgánica mineral del alimento

Fuente: Ref. [95]

Puede observarse entonces que los alimentos vegetales que constituyen los piensos utilizados para alimentar al ganado presentan una gran heterogeneidad en lo que respecta a su tipificación y composición química. Esto representa, desde el punto de vista analítico, una complejidad que se debe abordar a la hora de tener que analizar este tipo de matrices en la búsqueda de compuestos que se encuentran en niveles traza, dado el elevado contenido de hidratos de carbono, grasas y proteínas vegetales, taninos, clorofilas, vitaminas, etc.

\subsubsection{Problemática de plaguicidas y micotoxinas en piensos}

Los piensos e ingredientes que los componen deben producirse y conservarse en condiciones que los protejan de la acción de las plagas, de peligros físicos, peligros microbiológicos y de contaminantes 
químicos que casi inevitablemente estarán asociados. La contaminación de piensos por sustancias químicas puede incluir tanto a los compuestos que ocurren naturalmente (micotoxinas) como a los compuestos tóxicos sintéticos derivados de su uso común en la agricultura (plaguicidas) [96].

El control de plagas en la agricultura intensiva implica el tratamiento de los cultivos tanto en las etapas de precosecha como en la postcosecha. Así, y como consecuencia de la gran variedad de plagas y de la también amplia diversidad de cultivos, muchas clases químicas diferentes de insecticidas, herbicidas y fungicidas son utilizadas a nivel de campo para evitar que insectos, malezas y hongos ataquen los cultivos comprometiendo la producción. La posible ocurrencia de residuos de plaguicidas en los piensos utilizados para la alimentación del ganado no solamente deriva de la aplicación directa de estas sustancias sobre los cultivos, sino que puede provenir también de suelos previamente contaminados con compuestos orgánicos persistentes como los plaguicidas organoclorados, utilizados en el pasado pero que por su alta estabilidad y bajo poder de degradación siguen estando presentes y pueden ser tomados por las plantas. Un tercer factor de exposición a plaguicidas puede verificarse durante el almacenamiento de los piensos cosechados o adquiridos comercialmente, como consecuencia del uso de sustancias químicas para el control de insectos, hongos o roedores en las instalaciones.

La contaminación de cultivos por micotoxinas también puede ocurrir en las etapas de precosecha (en campo) y de poscosecha (en el almacenamiento). Las plantas de cereales, por ejemplo, pueden contaminarse con micotoxinas por dos vías: por crecimiento del hongo como un patógeno sobre la planta en pie, o cuando crece de manera saprófita en la planta almacenada [97]. Las distintas especies fúngicas pueden desarrollarse y producir micotoxinas en diferentes estadios del sustrato que colonizan. Así, mientras que las especies de Aspergillus y Penicillium se encuentran generalmente como contaminantes de los alimentos durante el secado y almacenado, otras como Fusarium y Alternaria spp. pueden producir micotoxinas antes o inmediatamente después de la cosecha [98]. Es muy reconocida la relación que existe entre la contaminación con micotoxinas y las condiciones de almacenamiento inadecuadas de las materias primas y alimentos para animales. La limpieza de los locales junto con un adecuado control de la temperatura y la humedad son factores determinantes para el crecimiento fúngico y la producción de micotoxinas. En los granos de cereales, por ejemplo, esto se da cuando se combina una elevada humedad del grano (16-30\%) con condiciones ambientales de temperaturas cálidas $\left(25-32^{\circ} \mathrm{C}\right)$ y una humedad relativa del aire elevada (80-100\%) [99].

Como se ve, la calidad de los piensos con que se alimenta el ganado lechero y los animales en general está determinada, desde el punto de vista de la residualidad y contaminación con plaguicidas y micotoxinas, por diversos factores que confluyen en una característica común: gran variedad de matrices y gran variedad de compuestos. 


\subsection{MÉTODOS MULTI-RESIDUO MULTI-CLASE PARA PLAGUICIDAS Y MICOTOXINAS}

\subsubsection{Preparación de muestras}

\subsubsection{Métodos multi-residuo}

Cuando hablamos de preparación de muestras, un método multi-residuo es aquel con la capacidad de extraer la mayor cantidad de plaguicidas posible de una muestra sometida a ensayo utilizando un único procedimiento analítico. El término "multi-residuo" deriva del carácter residual que presentan los plaguicidas en los alimentos o materias primas analizadas, como consecuencia de su uso en las prácticas agronómicas. Sin embargo, ese término pierde exactitud cuando se quieren determinar cantidades traza de otros contaminantes como las micotoxinas que por su origen natural no son consideradas residuos, por lo que hablaríamos en ese caso de métodos multi-contaminante o multi-toxina, y cuando el objetivo es determinar un conjunto amplio de residuos y contaminantes en un único proceso se trata entonces de métodos multi-residuo multi-clase (MMM).

En la actualidad es posible determinar de manera simultánea un gran número de compuestos de diferentes clases (plaguicidas y micotoxinas, en lo que respecta a los estudiados en esta tesis) mediante métodos de preparación de muestra multi-residuo y multi-clase, sobre la base de etapas comunes involucradas y que son compartidas para una y otra clase de compuestos: una primera etapa de extracción de los analitos para separarlos de la matriz de la sustancia que se quiere analizar, y una posterior etapa de purificación o cleanup para aumentar la selectividad y sensibilidad del método de determinación final eliminando coextractivos interferentes.

Se trate de la determinación de residuos de plaguicidas o de micotoxinas, la primera etapa implica una extracción sólido-líquido (SLE), si la muestra es un sólido como un pienso, o líquido-líquido (LLE) si es un fluido como la leche, con un solvente o mezcla de solventes elegidos de acuerdo a la naturaleza tanto de los analitos a extraer como de la matriz implicada. Dependiendo de su naturaleza química, los plaguicidas son altamente solubles en diferentes solventes orgánicos como n-hexano, diclorometano, acetato de etilo, acetona, acetonitrilo y metanol. Del mismo modo lo son las micotoxinas, y a pesar de que en general son insolubles en agua (a excepción de las fumonisinas que tienen en sus estructuras varios grupos polares libres), las mezclas de agua con un solvente orgánico como metanol o acetonitrilo son muy eficaces para la extracción de estos contaminantes.

La etapa de clean-up para la purificación de los extractos también comparte estrategias comunes en el caso de los plaguicidas y las micotoxinas. La principal de ellas es la extracción en fase sólida (SPE), que además de eliminar componentes de la matriz co-extraidos permite la concentración de extractos para alcanzar límites de detección que en algunas regulaciones suelen ser muy bajos, y el cambio de solvente por uno adecuado al instrumento de determinación y detección final. También es posible utilizar extracción LLE con distintos tipos de solventes para la purificación de extractos de plaguicidas y de micotoxinas. 
La combinación de estas dos etapas esenciales en la preparación de muestras para el análisis de residuos y contaminantes se vio enormemente simplificada en el año 2003 con la publicación por parte de Anastassiades y col. de un método multi-residuo para la determinación de plaguicidas en matrices vegetales al que llamaron QuEChERS, acrónimo de quick (rápido), easy (fácil), cheap (económico), effective (efectivo), rugged (robusto) y safe (seguro). La aplicación de este método fue tan exitosa que pronto su uso se adaptó a los más variados tipos de muestras y a otros contaminantes como las micotoxinas, fármacos veterinarios, etc., convirtiéndose en un verdadero método multi-residuo-multi-clase. Es así que el método QuEChERS fue parte central en el diseño y concreción de las actividades desarrolladas en esta tesis.

Antes de continuar con la descripción del QuEChERS como método MMM para la determinación de plaguicidas y micotoxinas, es propicio introducir aquí una breve reseña de cómo se determinaban en cantidad estos residuos y contaminantes antes de la revolución, si se me permite, causada por este método de preparación de muestras.

\subsubsection{Plaguicidas pre-2003}

No se pretende aquí hacer una revisión exhaustiva de los métodos de preparación de muestras que se utilizaban antes de las primeras aplicaciones del QuEChERS, sino repasar en forma general las características de los principales enfoques metodológicos para la medición multi-residuo de plaguicidas. Hasta el año 2003, estos métodos eran derivaciones y adaptaciones de los primeros procedimientos que se fueron diseñando desde la década de 1960, e implicaban gran número de etapas operativas y el uso de grandes volúmenes de solventes poco amigables con la salud y el ambiente, junto con etapas de secado y salting-out con sales inorgánicas. El primero de estos métodos fue el método de Mills (1963) para la determinación de plaguicidas organoclorados (OCP) utilizando acetonitrilo como solvente de extracción y particiones con éter de petróleo para la separación del agua previo a etapas de clean-up en columna. Luego del uso cada vez más expandido de los plaguicidas organofosforados (OPP) en la década de 1970, los métodos multi-residuo debieron incluir en sus alcances analíticos a compuestos de estas familias (más polares) y surgió el método de Luke (1975) como método de referencia que utilizaba acetona como solvente extractor, particiones con mezclas de éter de petróleo y diclorometano (DCM), y multiples etapas de secado y evaporaciones en presencia de DCM y acetona hasta llegar al extracto final. Ya en la década de 1990 surgieron métodos basados en el uso de acetato de etilo como solvente de extracción que, a pesar de no involucrar el uso de solventes clorados cuyo uso extendido fue disminuyendo para esos años por los perjuicios para la salud y el medio ambiente que ocasionan, introducían etapas de secado con grandes cantidades de sales para eliminar agua y otras etapas de clean-up adicionales para la eliminación de coextractivos (Figura 13) Los métodos tradicionales como el del acetato de etilo o el de Luke modificado (miniaturización e introducción de salting-out) no fueron reemplazados por el método QuEChERS sino que continúan siendo utilizados en distintas aplicaciones, por ejemplo en el análisis de residuos de plaguicidas y 
drogas veterinarias en leche [100], de plaguicidas en frutas y vegetales [101] y plaguicidas en leche y piensos [102].

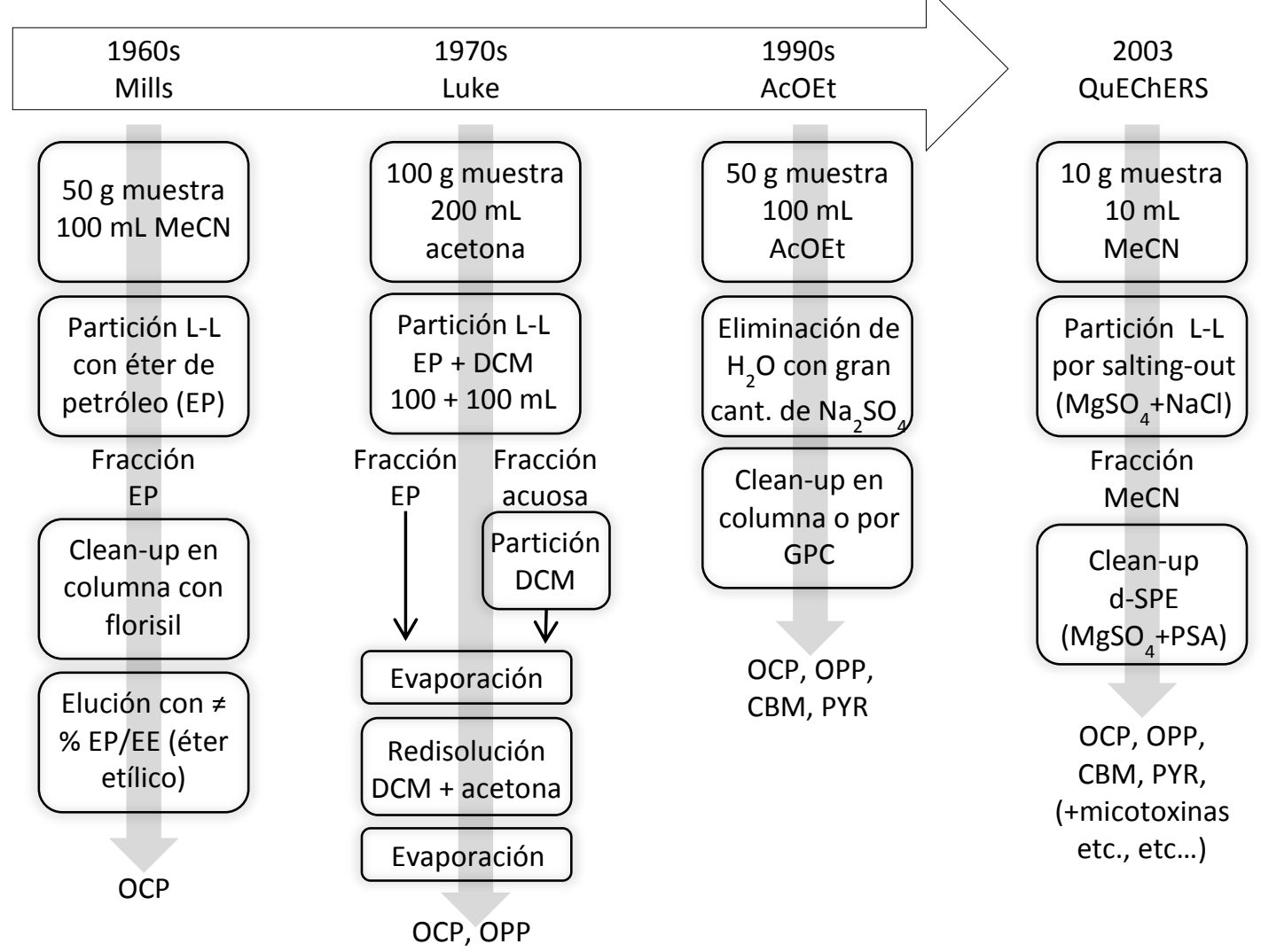

Figura 13. Principales características de los métodos multi-residuo clásicos para la determinación de residuos de plaguicidas y su evolución a los métodos actuales. [MeCN: acetonitrilo; DCM: diclorometano; AcOEt: acetato de etilo; GPC: cromatografía de permeación en gel; d-SPE: extracción en fase sólida dispersiva; OCP: plaguicidas organoclorados; OPP: plaguicidas organofosforados; CBM: carbamatos; PYR: piretroides].

\subsubsection{Micotoxinas pre-2003}

Los métodos de preparación de muestra para micotoxinas no presentaron la evolución de los métodos de plaguicidas, por cuanto la etapa de extracción con un solvente adecuado, según la estructura de la micotoxina o familia de micotoxinas de que se trate, ha sido mayoritariamente seguida por una de dos etapas de clean-up principales: extracción en fase sólida (SPE) con diversos adsorbentes o columnas de afinidad (IAC) [103]. Los adsorbentes SPE más utilizados para el análisis de micotoxinas son silicagel, octadecilsilano (C18), florisil, fenil, aminopropil y fases ligadas de intercambio iónico para toxinas que se ionizan, como las fumonisinas. Por la naturaleza de las interacciones micotoxina/absorbente, la SPE tiene la desventaja de no tener la capacidad de ser un método universal multi-toxinas, más que frente a familias estructuralmente relacionadas como el conjunto de aflatoxinas, o el de tricotecenos, o el de fumonisinas [59]. Las IAC, por otro lado, son columnas empacadas con una fase sólida activada que posee un anticuerpo inmovilizado que se une específicamente a una determinada micotoxina. Cuando el extracto pasa a través de la columna, la micotoxina se une selectivamente al anticuerpo mientras el resto de componentes de la 
matriz es removido en una etapa de lavado posterior, y la micotoxina finalmente se eluye con un solvente miscible como por ejemplo el metanol. Existen comercialmente columnas IAC para todas las micotoxinas de interés (AFs, FBs, OTA, ZEA, y algunos tricotecenos) y el carácter como método multi-toxina puede ser brindado por reactividad cruzada del anticuerpo frente a micotoxinas estructuralmente parecidas, o bien por la inmovilización de más de un tipo de anticuerpo para ampliar la capacidad de retención de distintas familias de toxinas [104]. Las columnas de inmunoafinidad tienen la superior ventaja de la alta selectividad que presentan los anticuerpos para purificación de los extractos de muestra permitiendo obtener, de la mano del poder de concentración que tienen como toda SPE, métodos con la sensibilidad suficiente para lograr los muy bajos límites máximos que en algunos casos establecen las regulaciones $(0,1 \mu \mathrm{g} / \mathrm{kg}$ para AFB1 en alimentos infantiles, o 0,05 $\mu \mathrm{g} / \mathrm{kg}$ para AFM1 en leche, en la Comunidad Europea) [76]. Por otro lado, la principal desventaja de las IAC es su elevado costo y la imposibilidad de ser re-utilizadas en mediciones cuantitativas debido a la desnaturalización de los anticuerpos que se produce en la etapa de elución con solvente orgánico.

\subsubsection{El método QuEChERS}

Este procedimiento de preparación de muestra fue pensado y desarrollado sobre la base de los principales métodos multi-residuo mencionados anteriormente, esto es, una extracción con un solvente orgánico apropiado y una partición L-L. Esta partición se logra a través de una separación de fases inducida por el agregado de sales inorgánicas $\left(\mathrm{MgSO}_{4}\right.$ y $\left.\mathrm{NaCl}\right)$ que, además de forzar la separación entre el agua de la matriz de la muestra y el solvente extractor, satura la fase acuosa induciendo a los analitos polares a migrar hacia la fracción orgánica (acetonitrilo). De este modo, se logra separar a los compuestos de interés de los interferentes de la matriz que, por tener un carácter generalmente más polar, quedan en la fase acuosa que se descarta. La segunda etapa del procedimiento QuEChERS consiste en el clean-up del extracto acetonitrilo separado en el paso anterior para remover interferencias de la matriz como lípidos, ácidos orgánicos, azúcares y pigmentos que no se separaron en la partición. Esta etapa se logra mediante una dispersión en fase sólida dispersiva (d-SPE) en la que el extracto se pone en contacto por agitación con distintos adsorbentes previamente pesados en un tubo cónico de centrífuga [105]. Estos adsorbentes pueden incluir $\mathrm{MgSO}_{4}$ para remoción de restos de agua, PSA (amina primaria/secundaria) para remover ácidos orgánicos, ácidos grasos, azúcares y pigmentos, octadecilsilano (C18) para remover grasas y otras interferencias no polares, carbono grafitizado negro (GCB) para remover clorofila y otros pigmentos, y actualmente se utilizan también fases de sílica enlazadas con óxido de circonio $\left(\mathrm{ZrO}_{2}\right)$ como alternativa o complemento al C18 y el PSA en la remoción de grasas y pigmentos [106]. La facilidad de ejecución de este clean-up dispersivo y la posibilidad de utilizar todos estos adsorbentes solos o mezclados en distintas composiciones hace que el método QuEChERS sea compatible con casi cualquier tipo de muestra.

Al método QuEChERS original publicado por Anastassiades y col. en 2003 le siguieron luego modificaciones que introducían cambios en la composición de las sales de partición para el control del pH del medio, con el 
fin de mejorar las condiciones de extracción de compuestos pH-dependientes. Así, Lehotay y col. (2005) propusieron un ajuste del $\mathrm{pH}$ a 4,8 con un buffer acetato cambiando el $\mathrm{NaCl}$ por $\mathrm{AcNa}$ en las sales de partición e introduciendo un 1\% de ácido acético al acetonitrilo para la extracción [107]. Por otro lado, Anastassiades y col. (2007) propusieron ajustar el pH en un valor similar pero levemente superior de 5,0-5,5 empleando un buffer con sales citrato [108]. Estas 2 modificaciones introducidas por los mismos autores del QuEChERS original se convirtieron en métodos oficiales AOAC 2007.01 y European Standard EN 15662, respectivamente $[109,110]$ (Figura 14).
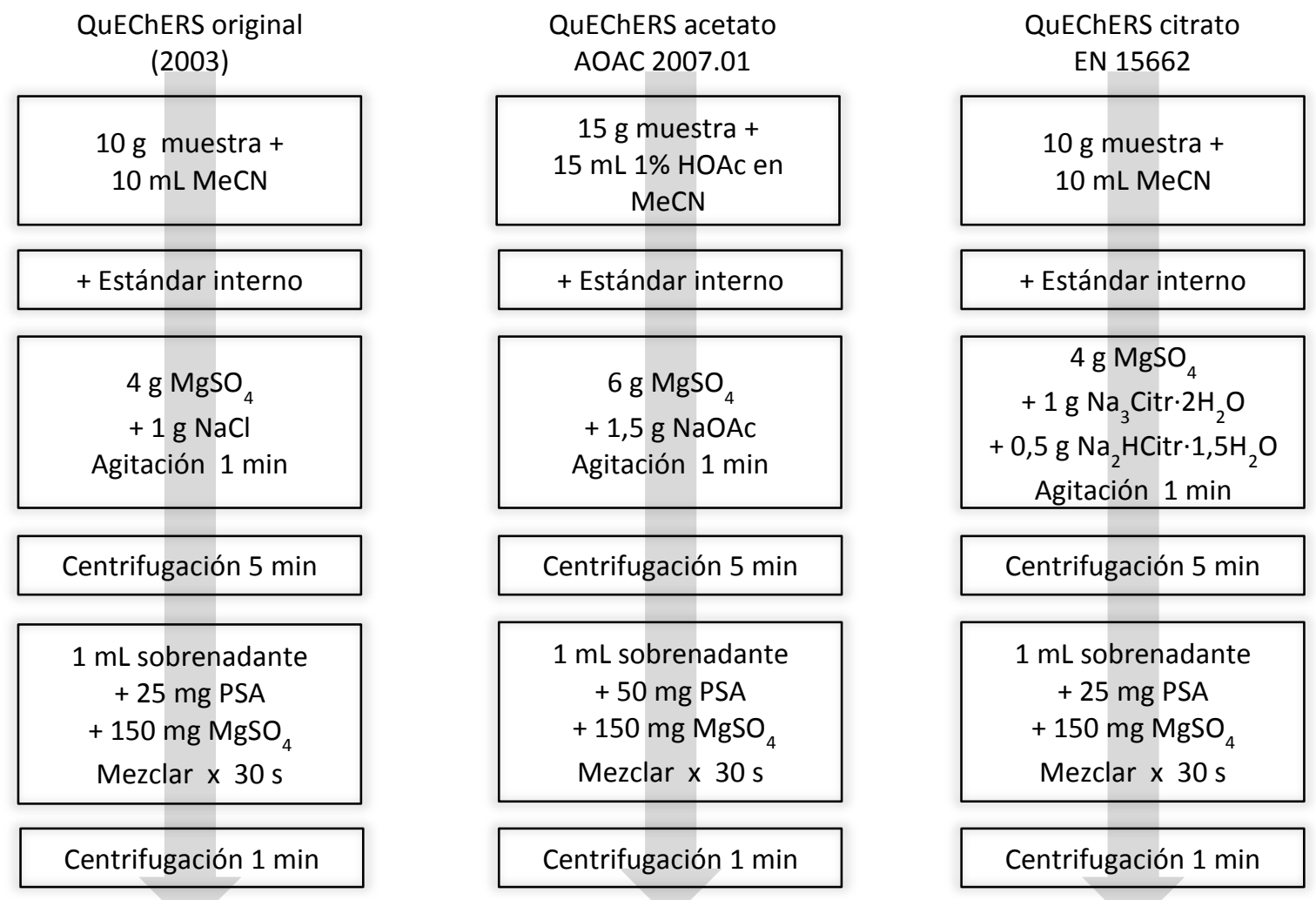

Figura 14. Comparación de las características principales del método QuEChERS original y sus variantes bufferizadas con acetato y citrato.

Otro aspecto a considerar del QuEChERS es que si bien se desarrolló como un método para analizar matrices vegetales con contenido acuoso como frutas y hortalizas, pronto se adaptó a todo tipo de muestra incluyendo matrices secas como cereales (introduciendo una etapa de hidratación con agua antes de la extracción) e incluso líquidas como la leche.

\section{QUEChERS como método multi-residuo multi-clase}

Dos aspectos se complementan en el establecimiento del QuEChERS como MMM. Por un lado, la rápida y sencilla ejecución de pasos para su aplicación, la capacidad que presenta de extraer grandes cantidades de compuestos simultáneamente, y la versatilidad para adaptarse a distintas matrices y distintos tipos de compuestos de interés, sean estos plaguicidas, micotoxinas, fármacos veterinarios y otros contaminantes. 
Por otro lado, si bien el origen de esos distintos tipos de compuestos químicos es diferente (los residuos de plaguicidas derivan de su aplicación directa o indirecta sobre alimentos y piensos, y las micotoxinas son producidas naturalmente por hongos que colonizan esos sustratos) todos pueden estar eventualmente presentes en un mismo tipo de muestra. Esto lleva a la necesidad de simplificar los procesos de preparación de muestra y contar con una única metodología analítica que permita abarcar a todos los tipos de analitos de interés de manera efectiva. La principal herramienta que actualmente tiene ese enfoque es el método QuEChERS. En la Tabla 9 se resumen algunas aplicaciones de este método de preparación de muestras que se han publicado en la bibliografía reciente en sus distintas variantes para el análisis de leche y piensos para ganado, los dos grandes tipos de alimentos que son objeto de estudio de esta tesis. Se destacan allí las distintas opciones de clean-up que pueden adoptarse cuando se analiza una matriz compleja como la leche, donde los principales co-extractivos a eliminar son los lípidos, explorándose alternativas con $\mathrm{C} 18, \mathrm{ZrO}_{2}$ y etapas de freeze-out. Con este tipo de matriz, el QuEChERS ha cobrado importancia como método MMM introduciendo en el alcance analítico a los contaminantes que derivan del uso veterinario junto con los residuos de plaguicidas y las micotoxinas, dando cuenta una vez más del amplio espectro de compuestos químicos que pueden ser determinados simultáneamente con un mismo procedimiento simplificado. La misma variedad de alternativas de clean-up y de ampliación del espectro analítico en la determinación simultánea de residuos y contaminantes se verifica en el análisis de una también amplia variedad de cereales, forrajes, ensilados y balanceados compuestos, entre otros, destinados a la alimentación animal. El gran poder multi-residuo multi-clase que tiene este procedimiento de extracción y preparación de muestras no es aprovechado, sin embargo, si no se dispone de la instrumentación con la selectividad y el poder de separación adecuados para la identificación individual de la gran cantidad de analitos de interés implicados. 
Tabla 9. Resumen de diferentes metodologías analíticas que utilizan la extracción QuEChERS para la determinación de residuos de plaguicidas, micotoxinas y otros contaminantes en leche y alimentos destinados a la alimentación animal.

\begin{tabular}{|c|c|c|c|c|c|}
\hline Tipo de matriz & Alcance analítico & Extracción & Instrumentación & País & Referencia \\
\hline \multicolumn{6}{|l|}{ LECHE } \\
\hline \multirow{2}{*}{$\begin{array}{l}\text { Leche entera } \\
\text { comercial }\end{array}$} & \multirow{2}{*}{$\begin{array}{l}32 \text { plaguicidas de } \\
\text { diversas familias }\end{array}$} & \multirow{2}{*}{$\begin{array}{l}\text { QuEChERS acetato/ } \\
\text { d-SPE }\left(\mathrm{MgSO}_{4}+\mathrm{PSA}+\mathrm{C} 18\right)\end{array}$} & GC-MS (single Q) & \multirow[t]{2}{*}{ EEUU } & \multirow{2}{*}{$\begin{array}{l}\text { Lehotay } \\
\text { (2005) [107] }\end{array}$} \\
\hline & & & LC-MS/MS (triple Q) & & \\
\hline $\begin{array}{l}\text { Leche entera } \\
\text { comercial }\end{array}$ & $\begin{array}{l}118 \text { (plag, alcaloides, } \\
\text { drogas veterinarias) }\end{array}$ & $\begin{array}{l}\text { QuEChERS acetato/ } \\
\text { sin clean-up }\end{array}$ & LC-MS/MS (Orbitrap) & EEUU & $\begin{array}{l}\text { Filigenzi } \\
\text { (2011) [111] }\end{array}$ \\
\hline \multirow[t]{2}{*}{ Leche } & 77 plaguicidas & \multirow{2}{*}{$\begin{array}{l}\text { QuEChERS citrato/ } \\
\text { sin clean-up }\end{array}$} & \multirow[t]{2}{*}{ LC-MS/MS (triple Q) } & \multirow[t]{2}{*}{ España } & Aguilera \\
\hline & 8 micotoxinas & & & & (2011) [112] \\
\hline \multirow[t]{2}{*}{ Leche comercial } & 14 plaguicidas de & \multirow{2}{*}{$\begin{array}{l}\text { QuEChERS acetato/ } \\
\text { d-SPE }\left(\mathrm{MgSO}_{4}+\mathrm{PSA}+\mathrm{C} 18\right)\end{array}$} & GC-ECD & \multirow[t]{2}{*}{ Corea } & Jeong \\
\hline & diversas familias & & GC-MS (single Q) & & $(2012)[113]$ \\
\hline Leche comercial & $\begin{array}{l}36 \text { (plaguicidas, } \\
\text { micotoxinas, drogas } \\
\text { veterinarias) }\end{array}$ & $\begin{array}{l}\text { QuEChERS acetato/ } \\
\text { d-SPE }\left(\mathrm{MgSO}_{4}+\mathrm{PSA}+\mathrm{C} 18\right)\end{array}$ & LC-MS/MS (Orbitrap) & Italia & $\begin{array}{l}\text { Dominicis } \\
(2012)[114]\end{array}$ \\
\hline \multirow[t]{2}{*}{ Leche cruda } & 15 plaguicidas & \multirow{2}{*}{$\begin{array}{l}\text { QuEChERS original/ } \\
\text { d-SPE }\left(\mathrm{MgSO}_{4}+\mathrm{PSA}+\mathrm{C} 18\right)\end{array}$} & \multirow[t]{2}{*}{ LC-MS/MS (triple Q) } & \multirow[t]{2}{*}{ Brazil } & dos Anjos \\
\hline & 1 micotoxina(AFM1) & & & & $(2016)[115]$ \\
\hline \multirow[t]{2}{*}{ Leche cruda } & 167 plaguicidas de & QuEChERS acetato/ & \multirow[t]{2}{*}{ LC-MS/MS (triple Q) } & Turquía & Golge \\
\hline & diversas familias & $\mathrm{d}-\mathrm{SPE}\left(\mathrm{MgSO}_{4}+\mathrm{PSA}+\mathrm{C} 18\right)$ & & & (2017) [116] \\
\hline Leche cruda & 30 plaguicidas de & QuEChERS original/ & LC-DAD & Polonia & Rejczak \\
\hline & diversas familias & d-SPE & & & (2017) [106] \\
\hline & & $\left(\mathrm{MgSO}_{4}+\mathrm{PSA}+\mathrm{ZrO}_{2}\right)$ & & & \\
\hline Leche comercial & 238 plaguicidas & QuEChERS original/ & LC-MS/MS (Q-trap) & India & Jadhav \\
\hline & 78 drogas veterin. & $\mathrm{d}-\mathrm{SPE}\left(\mathrm{MgSO}_{4}+\mathrm{C} 18\right)$ & GC-MS/MS (triple Q) & & (2018) [117] \\
\hline Leche materna & $\begin{array}{l}28 \text { micotoxinas y } \\
\text { metabolitos }\end{array}$ & $\begin{array}{l}\text { QuEChERS original/ } \\
\text { freeze-out }\end{array}$ & LC-MS/MS (triple Q) & Austria & $\begin{array}{l}\text { Braun } \\
(2018)[118]\end{array}$ \\
\hline PIENSOS & & & & & \\
\hline Heno de alfalfa, pajas & 150 plaguicidas de & QuEChERS citrato/ & LC-MS/MS (triple Q) & Grecia & Tsiplakou \\
\hline $\begin{array}{l}\text { de trigo, pasturas y } \\
\text { concentrados }\end{array}$ & $\begin{array}{l}\text { diversas familias y } \\
\text { metabolitos }\end{array}$ & $\begin{array}{l}\text { freeze-out + d-SPE } \\
\left(\mathrm{MgSO}_{4}+\mathrm{PSA}\right)\end{array}$ & GC-MS/MS (triple Q) & & (2010) [119] \\
\hline Ensilado de maíz & $\begin{array}{l}118 \text { (plaguicidas, } \\
\text { alcaloides, drogas } \\
\text { veterin.) }\end{array}$ & $\begin{array}{l}\text { QuEChERS acetato/ } \\
\text { sin clean-up }\end{array}$ & LC-MS/MS (Orbitrap) & EEUU & $\begin{array}{l}\text { Filigenzi } \\
\text { (2011) [111] }\end{array}$ \\
\hline Trigo & $\begin{array}{l}90 \text { (plaguicidas, } \\
\text { micotoxinas) }\end{array}$ & $\begin{array}{l}\text { QuEChERS acetato/ } \\
\text { sin clean-up }\end{array}$ & LC-MS/MS (triple Q) & España & $\begin{array}{l}\text { Romero } \\
(2011)[120]\end{array}$ \\
\hline $\begin{array}{l}\text { Maíz y soja sin } \\
\text { procesar }\end{array}$ & $\begin{array}{l}9 \text { plaguicidas OPP y } 1 \\
\text { piretroide }\end{array}$ & $\begin{array}{l}\text { QuEChERS citrato/ } \\
\text { freeze-out + d-SPE } \\
\left(\mathrm{MgSO}_{4}+\mathrm{PSA}+\mathrm{C} 18\right)\end{array}$ & GC-MS (single Q) & Italia & $\begin{array}{l}\text { Marchis } \\
(2012)[121]\end{array}$ \\
\hline $\begin{array}{l}\text { Granos de cereal, } \\
\text { balanceados y soja }\end{array}$ & $\begin{array}{l}167 \text { plaguicidas de } \\
\text { diversas familias }\end{array}$ & $\begin{array}{l}\text { QuEChERS citrato/ } \\
\text { d-SPE (C18+PSA) }\end{array}$ & GC-MS/MS (triple Q) & Polonia & $\begin{array}{l}\text { Walorczyk } \\
(2012)[122]\end{array}$ \\
\hline Trigo, balanceados, & 56 micotoxinas & QuEChERS original/ & LC-MS/MS (Q-trap) & Rep. & Dzuman \\
\hline ensilado de maíz & & & LC-MS/MS (Orbitrap) & & (2014) [123] \\
\hline Pajas (cebada, trigo, & 219 plaguicidas de & QuEChERS original/ & LC-MS/MS & Países & Mol \\
\hline colza) & diversas familias & dil.\& shoot (LC), & GC-MS/MS & Bajos & (2014) [124] \\
\hline Henos & & d-SPE (C18+PSA)(GC) & & & \\
\hline $\begin{array}{l}\text { Forrajes, cereales, } \\
\text { balanceados, } \\
\text { concentrados }\end{array}$ & 56 micotoxinas & $\begin{array}{l}\text { QuEChERS original/ } \\
\text { sin clean-up }\end{array}$ & LC-MS/MS (Q-trap) & $\begin{array}{l}\text { Rep. } \\
\text { Checa }\end{array}$ & $\begin{array}{l}\text { Zachariasova } \\
(2014)[125]\end{array}$ \\
\hline Trigo & 323 plaguicidas & QuEChERS original/ & LC-MS/MS & Rep. & Dzuman \\
\hline & 55 micotoxinas & $\mathrm{d}-\mathrm{SPE}\left(\mathrm{MgSO}_{4}+\mathrm{C} 18\right)$ & (Q-Orbitrap) & Checa & (2015) [126] \\
\hline Pajas de trigo y arroz & $\begin{array}{l}11 \text { alcaloides } \\
69 \text { plaguicidas de } \\
\text { diversas familias }\end{array}$ & $\begin{array}{l}\text { QuEChERS modificado/ } \\
\text { d-SPE }\left(\mathrm{MgSO}_{4}+\mathrm{PSA}+\mathrm{C} 18\right)\end{array}$ & LC-MS/MS (triple Q) & China & $\begin{array}{l}\text { Zhang } \\
(2016)[127]\end{array}$ \\
\hline $\begin{array}{l}\text { Piensos no } \\
\text { especificados }\end{array}$ & $\begin{array}{l}77 \text { (micotoxinas, } \\
\text { drogas veterin.) }\end{array}$ & $\begin{array}{l}\text { QuEChERS citrato/ } \\
\text { dilute \& shoot }\end{array}$ & LC-MS/MS (Orbitrap) & España & $\begin{array}{l}\text { Leon } \\
(2016)[128]\end{array}$ \\
\hline Granos de trigo & $\begin{array}{l}8 \text { micotoxinas } \\
4 \text { fungicidas }\end{array}$ & $\begin{array}{l}\text { QuEChERS acetato/ } \\
\text { d-SPE }\left(\mathrm{MgSO}_{4}+\mathrm{PSA}\right)\end{array}$ & LC-MS/MS (Q-ToF) & Brasil & $\begin{array}{l}\text { da Luz } \\
(2017)[129]\end{array}$ \\
\hline
\end{tabular}




\subsubsection{Análisis instrumental}

La manera con que en la actualidad se miden confiablemente plaguicidas y micotoxinas en el mundo es a través de las metodologías basadas en cromatografía-espectrometría de masa. Con estos sistemas se unen la capacidad de separar grandes cantidades de compuestos que tiene la cromatografía moderna mediante columnas capilares de GC y columnas de ultra resolución de LC, con el alto poder de identificación y confirmación que tienen los analizadores de masa actuales, dando como resultado configuraciones instrumentales únicas adaptables para medir todo tipo de residuos y contaminantes en niveles traza. Es el poder de identificación y confirmación inequívoca de los compuestos analizados el que ha colocado a estos sistemas en la proa de la medición instrumental moderna en lo que respecta a la determinación de residuos de plaguicidas, micotoxinas y otros contaminantes.

\subsubsection{Medición clásica de residuos y contaminantes}

La forma clásica de medir instrumentalmente plaguicidas antes de las innovaciones introducidas por la espectrometría de masa era a través de sistemas cromatográficos, principalmente GC, acoplados con detectores selectivos de captura electrónica (ECD), de nitrógeno-fósforo (NPD) o fotométricos de llama (FPD). Si bien estos detectores tienen la selectividad y sensibilidad adecuada para medir cantidades traza de plaguicidas, carecen de la capacidad de confirmación del analito detectado, para lo cual es necesario repetir la medición en un sistema diferente (cambiando el tipo de columna cromatográfica, o a través de GC-MS, por ejemplo). Por otro lado, los plaguicidas que por su inestabilidad térmica o baja volatilidad son difíciles de determinar por GC, eran medidos por cromatografía líquida utilizando detectores clásicos de absorción ultravioleta (UV) o emisión de fluorescencia (FD), que además de tener menor selectividad presentan el mismo inconveniente frente a la confirmación de los compuestos detectados. En ese sentido, la introducción de detectores de arreglos de diodos (DAD) en acoplamientos con sistemas LC permitió obtener mayor selectividad mediante la posibilidad de obtener espectros de emisión UV de los compuestos separados como criterios de identificación adicional. A pesar de esto, las aplicaciones de la cromatografía líquida con detección espectroscópica se vieron reducidas a métodos single ( 1 único analito) o con bajo número de compuestos.

La medición de micotoxinas, por su lado, se ha basado principalmente en la aplicación de métodos cromatográficos clásicos y en métodos rápidos de screening. En el primer caso, las más comunes han sido las aplicaciones de cromatografía en capa delgada (TLC), la cromatografía líquida (HPLC) y en menor medida la cromatografía gaseosa (GC). La TLC fue tradicionalmente el método más popular para la determinación cuantitativa y semi-cuantitativa de micotoxinas aunque con la desventaja de tener un pobre poder de separación y visualización que limita la sensibilidad de la medición y su aplicación como método multitoxina $[59,130]$. En su lugar, por ser las micotoxinas compuestos que generalmente tienen baja volatilidad, ha tenido amplia aplicación la técnica HPLC con detectores UV y FD, permitiendo gracias al poder de resolución la determinación en métodos multi-toxina. La cromatografía gaseosa, por otro lado, ha estado 
limitada a un número reducido de micotoxinas, principalmente tricotecenos y zearalenona, que pueden ser determinadas por detectores ECD convencionales, no sin antes pasar por una etapa previa de derivatización. Los métodos rápidos de screening para micotoxinas individuales o familias de micotoxinas se basan en técnicas inmunoquímicas que utilizan anticuerpos que reconocen específicamente a los analitos reaccionando con ellos para producir su medición. El más común de estos métodos es el ensayo por inmunoabsorción ligado a enzimas (enzyme-linked immunosorbent assay, ELISA) cuyo uso se expandió con el desarrollo de anticuerpos para las micotoxinas más importantes, y se afianzó como método rápido para el análisis de estos compuestos en muestras de toda la cadena alimentaria. A pesar de que los métodos ELISA tienen buena sensibilidad (en el orden de los $\mu \mathrm{g} / \mathrm{kg}$ ), tienen como desventaja la posibilidad de dar falsos positivos por reacciones cruzadas, por lo que son necesarios etapas de confirmación con métodos instrumentales.

En la Tabla 10 se resumen algunas aplicaciones de métodos instrumentales clásicos para la determinación de residuos de plaguicidas y micotoxinas.

Tabla 10. Resumen de diferentes métodos de determinación multi-residuo o multi-contaminantes de plaguicidas y micotoxinas en leche y alimentos destinados a la alimentación animal, con base en técnicas instrumentales no-espectrométricas de masa.

\begin{tabular}{|c|c|c|c|c|c|}
\hline Tipo de matriz & Alcance analítico & Instrumentación & Confirmación & País & Referencia \\
\hline \multicolumn{6}{|l|}{ PLAGUICIDAS } \\
\hline \multirow[t]{2}{*}{ Leche } & 22 clorados & GC-ECD (OCP) & no & EEUU & Schenck \\
\hline & 45 fosforados & GC-FPD (OPP) & & & (1999) [131] \\
\hline Porotos de soja & 6 plaguicidas & HPLC-UV/DAD & no & Brasil & $\begin{array}{l}\text { Maldaner } \\
\text { (2008) [132] }\end{array}$ \\
\hline $\begin{array}{l}\text { Leche y otros } \\
\text { alimentos }\end{array}$ & $\begin{array}{l}3 \text { fosforados } \\
4 \text { piretroides }\end{array}$ & GC-ECD & $\begin{array}{l}\text { GC-MS } \\
\text { (sector magnético) }\end{array}$ & EEUU & $\begin{array}{l}\text { Hunter } \\
\text { (2010) [133] }\end{array}$ \\
\hline Piensos & $\begin{array}{l}25 \text { plaguicidas OPP y } \\
\text { carbamatos }\end{array}$ & GC-ECD & no & Brasil & $\begin{array}{l}\text { Fagnani } \\
\text { (2011) [134] }\end{array}$ \\
\hline Leche & 12 clorados & GC-ECD & GC-MS (single Q) & India & $\begin{array}{l}\text { Selvi } \\
\text { (2012) [135] }\end{array}$ \\
\hline \multicolumn{6}{|l|}{ MICOTOXINAS } \\
\hline Cereal base maíz & 5 micotoxinas & HPLC-UV/DAD & no & Italia & $\begin{array}{l}\text { Aresta } \\
(2003)[136]\end{array}$ \\
\hline Maíz & $4 \mathrm{AFs}+\mathrm{OTA}$ & HPLC-FD & no & UK & $\begin{array}{l}\text { Chan } \\
(2004) \text { [137] }\end{array}$ \\
\hline Granos de trigo & 4 tricotecenos & GC-ECD & no & España & $\begin{array}{l}\text { V-Algarra } \\
(2005)[138]\end{array}$ \\
\hline Leche & AFM1 & TLC & HPLC-FD & Brasil & $\begin{array}{l}\text { Shundo } \\
\text { (2006) [139] }\end{array}$ \\
\hline \multirow[t]{2}{*}{ Granos de trigo } & $\begin{array}{l}5 \text { (DON, NIV, ZEA, } \\
\text { 3-ADON, 15-ADON) }\end{array}$ & HPLC-UV/DAD & no & Bélgica & $\begin{array}{l}\text { Pussemier } \\
(2006) \text { [140] }\end{array}$ \\
\hline & 2 (OTA, CIT) & HPLC-FLD & no & & \\
\hline Forraje de maíz & DON & ELISA & LC-MS & & $\begin{array}{l}\text { Oldenburg } \\
(2006)[141]\end{array}$ \\
\hline
\end{tabular}




\subsubsection{Medición moderna de residuos y contaminantes}

En la actualidad existe la necesidad de medir en simultáneo un gran número de compuestos, sean estos plaguicidas y/o micotoxinas, en niveles de concentración cada vez más bajos, y con la certeza necesaria en la identificación y cuantificación, para dar cumplimiento con los límites máximos que establecen las distintas regulaciones para la protección de la salud, los cuales a su vez constituyen parámetros de aptitud para el comercio internacional. Esa demanda ha sido impulsada, a su vez, por los desarrollos instrumentales de los analizadores de masa que, acoplados a sistemas LC o GC, conforman las configuraciones modernas con las que hoy en día se miden residuos y contaminantes, constituyendo plataformas analíticas muy sensibles y específicas, con alto rendimiento y con la rapidez suficiente como para medir, por ejemplo, 389 compuestos en 30 minutos [126].

Los cromatógrafos líquidos o gaseosos pueden acoplarse a distintos analizadores de masa que se fueron desarrollando para conformar configuraciones aptas para la medición de cantidades traza de plaguicidas y micotoxinas. Estos incluyen sistemas de cuadrupolo simple (Q), triple cuadrupolo (TQ), trampas de iones (IT) y trampas de iones lineales (LIT). Sin embargo, el analizador de triple cuadrupolo, y en especial su acoplamiento a sistemas LC, ha sido la opción más ampliamente elegida en el desarrollo de métodos MMM debido a su alta eficiencia, selectividad y sensibilidad, y es de hecho considerado el "gold-standard" para la identificación y cuantificación de micotoxinas y residuos de plaguicidas en alimentos y piensos, en análisis de rutina en los laboratorios de control.

\subsubsection{El analizador de triple cuadrupolo}

Un cuadrupolo (Q) consiste básicamente en cuatro barras metálicas dispuestas de manera espacial perpendicularmente entre sí, sobre las que se aplican voltajes variables de corriente continua (CC) y de radiofrecuencia (RF). Cuando una determinada combinación de voltajes CC/RF es aplicada, solo los iones con una relación masa/carga específica $(\mathrm{m} / \mathrm{z})$ tendrán una trayectoria estable a través del camino entre las barras llegando al detector, produciéndose así la separación de iones. Los analizadores de triple cuadrupolo (TQ) son configuraciones en las que 3 de estos $Q$ están dispuestos consecutivamente pero el segundo no actúa como un filtro de masa sino como una celda de colisión, y tienen una gran versatilidad de operación combinando distintos modos de escaneos o selección de masas según el análisis que se quiera realizar. El modo más importante para el análisis de cantidades traza de residuos y contaminantes es denominado monitoreo de reacción múltiple (MRM) o monitoreo de reacción seleccionada (SRM), en el que Q1 selecciona los iones con una $\mathrm{m} / \mathrm{z}$ específica, que luego son disociados en Q2 por colisión con un gas y una energía determinada, y esos fragmentos son filtrados en Q3 donde nuevamente solo los iones de una relación $\mathrm{m} / \mathrm{z}$ específica atraviesan con una trayectoria estable el sistema y llegan al detector. Se dice entonces que el analizador realiza un análisis target (de objetivo específico) de los analitos de interés. 
Este proceso de selección del ion precursor antes de la colisión elimina cualquier incertidumbre en el origen de los iones fragmentados y es lo que hace que el TQ operado en modo MRM sea altamente específico y selectivo [142]. Además, la eliminación en las distintas etapas de filtrado de iones y compuestos neutros interferentes provenientes de la matriz contribuye a aumentar significativamente la relación señal/ruido y en consecuencia la sensibilidad de la medición.

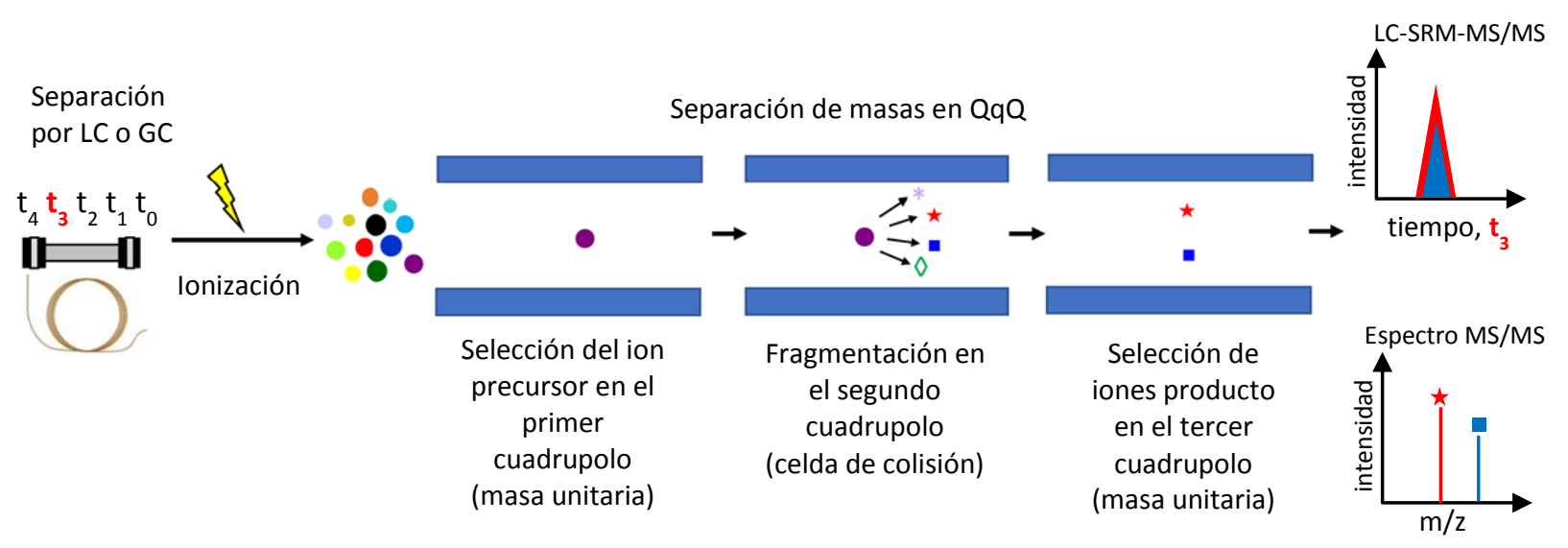

Figura 15. Esquema de operación de un analizador de triple cuadrupolo en modo monitoreo de reacción múltiple (MRM) (Imagen adaptada de Ref. [143])

La excepcional selectividad, especificidad y sensibilidad del triple cuadrupolo operado en modo MRM lo ha convertido en la técnica de elección para analizar y cuantificar plaguicidas, micotoxinas y otros contaminantes en alimentos, piensos y ambiente.

Las configuraciones de LC-MS/MS y GC-MS/MS basadas en el analizador de triple cuadrupolo son enfoques que requieren información y manejo de parámetros cromatográficos y espectrométricos de los analitos, como tiempos de retención, conocimiento de los iones precursores y las posibles transiciones producto con sus energías de colisión asociadas. La necesidad de contar con esta información previa para incluir a los compuestos de interés en listas de búsqueda para su detección y análisis target impide el uso de estos sistemas para la búsqueda de otros compuestos que puedan estar igualmente presentes en la muestra a analizar, como metabolitos de plaguicidas, micotoxinas conjugadas, o compuestos de cuya presencia se tiene certeza pero que simplemente no se dispone de los estándares de calibración respectivos. Otros aspectos negativos de este tipo de analizadores son que por tener una resolución de masa unitaria a veces se hace imposible la identificación inequívoca de analitos que presentan transiciones isobáricas [143], que la determinación de un gran número de compuestos es un proceso que insume mucho tiempo, y que el número de transiciones MRM que pueden ser analizadas en una misma corrida está limitado por el tiempo que lleva medir una transición (el dwell time), el ancho del pico cromatográfico, el número de puntos por pico necesarios y la cantidad de analitos que co-eluyen $[65,144]$. 


\section{Espectrometría de masa de alta resolución HRMS}

La necesidad de analizar exhaustivamente un número cada vez más grande de residuos y contaminantes ha llevado al desarrollo de espectrómetros de masa de alta resolución como los analizadores de tiempo de vuelo (ToF) y el de trampa iónica orbital (Orbitrap), que permiten hacer screening de compuestos mediante la adquisición de espectros full-scan (escaneo completo) de alta sensibilidad, combinado con una alta exactitud de masa (típicamente $<5 \mathrm{ppm}$ ), rápida adquisición de datos, con la posibilidad de realizar análisis non-target (no específicos, de compuestos desconocidos) y análisis retrospectivo de compuestos que inicialmente no fueron considerados a partir de los espectros full-scan obtenidos, permitiendo de este modo la determinación, en base a su masa exacta, de casi cualquier compuesto ionizable presente en el extracto de muestra $[65,145]$.

Adicionalmente, la implementación de sistemas HRMS híbridos como el cuadrupolo-tiempo de vuelo (QToF) y el cuadrupolo-Orbitrap (Q-Orbitrap) amplían el alcance de los métodos ya que además de medir masa exacta con análisis full-scan de alta resolución, ofrecen la posibilidad de realizar análisis target (MS/MS) para confirmación [143]. Esto permite conformar verdaderas plataformas analíticas multi-residuo multi-clase para la medición a gran escala de plaguicidas, micotoxinas, y otros contaminantes en aplicaciones cuantitativas o de screening de compuestos.

Algunas aplicaciones de la HRMS reportadas en la bibliografía para la determinación de multi-residuo multiclase de plaguicidas y micotoxinas en leche, piensos y alimentos relacionados incluyen la confirmación de la presencia de metabolitos glicosidados de las toxinas HT-2 y T-2 en trigo, avena y cebada contaminados naturalmente utilizando UHPLC-Q-ToF [146], la determinación de 59 micotoxinas en leche y productos lácteos utilizando UHPLC-Q-Orbitrap [147], la identificación de 119 compuestos (plaguicidas, micotoxinas, drogas veterinarias) en leche, tejido animal y ensilado de maíz mediante UHPLC-Orbitrap [111], la determinación de 492 residuos y contaminantes (plaguicidas, micotoxinas y drogas veterinarias) en leche, piensos y otros alimentos empleando configuración UHPLC-Q-ToF [148], y la determinación de 323 residuos de plaguicidas, 55 micotoxinas y 11 alcaloides en trigo y otras matrices vegetales utilizando UHPLC-QOrbitrap [126]. 



\section{OBJETIVOS}




\section{OBJETIVOS}

\section{Objetivos Generales}

Efectuar estudios para obtener una o más metodologías analíticas para determinar niveles traza de micotoxinas y plaguicidas en matrices agroalimentarias (leche y vegetales seleccionados), basadas en la experimentación con técnicas avanzadas cromatográficas y espectrométricas de masa, con métodos innovativos de preparación de muestras y su aplicación en estudios de campo orientados a obtener conocimientos sobre niveles de concentración y comportamiento químico de los compuestos en sistemas de producción de agro-alimentos de las cadenas en estudio, conducentes a mejorar las prácticas de producción y la evaluación de riesgos involucrada.

\section{Objetivos Específicos}

- Adquirir conocimientos teóricos y prácticos en el marco de la práctica analítica de laboratorio y actividades de investigación, sobre las problemáticas de residuos y contaminantes (plaguicidas y micotoxinas) en alimentos y sus soluciones; sobre tópicos de las ciencias químicas y de la separación involucradas en sus aspectos analíticos, y ganar experiencia en el empleo de metodologías con base en instrumentación analítica especialmente cromatográficas y espectrométricas de masa.

- Estudiar formas avanzadas de preparación de muestras en base a la simplificación de etapas, miniaturización de la escala e integración con las nuevas tecnologías de detección disponibles de cromatografía con detectores de masa. Estudiar la integración de métodos de extracción y limpieza para la determinación simultánea de micotoxinas y plaguicidas.

- Estudiar con especial énfasis el desempeño bajo diferentes condiciones experimentales, de sistemas de cromatografía de líquidos con detección de espectrometría de masa (UHPLC MS/MS), para establecer métodos específicos para la detección, identificación y cuantificación de mezclas de analitos de amplio espectro (conjuntos de plaguicidas, de micotoxinas y combinaciones).

- Contribuir mediante aplicaciones de las metodologías avanzadas disponibles a la generación de conocimientos e información sobre la presencia y las condiciones de origen de micotoxinas en matrices vegetales destinadas a la alimentación de animales de lechería de la Provincia de Santa Fe. Establecer bases para el análisis de riesgo por exposición al contaminante en leche de consumo.

- Contribuir a la evaluación de estrategias para el uso eficiente y sustentable de fitosanitarios en la cadena fruti-hortícola regional (criterios de selección de compuestos, procedimiento de uso, evaluación de residualidad y degradación, seguridad del aplicador, estudios selectivos a campo de los resultados en la producción de los principales cultivos). 
CAPÍTULO 2

Determinación de aflatoxina M1 en leche 


\section{CAPÍTULO 2: Determinación de alfatoxina M1 en leche}

\section{$2.1 \quad$ INTRODUCCIÓN}

Las aflatoxinas son metabolitos secundarios producidos por hongos filamentosos específicos, principalmente del género Aspergillus (A. flavus y $A$. parasiticus, por ejemplo) que comúnmente contaminan a los productos agrícolas [97]. Son compuestos químicamente derivadas de ciclopentanonas altamente solubles en agua (10-30 mg/L), insolubles en solventes no polares y altamente solubles en solventes orgánicos de polaridad moderada (cloroformo, metanol, acetonitrilo, acetona y dimetilsulfóxido, por ejemplo). Estos contaminantes están clasificados genéricamente por la Agencia Internacional para la Investigación del Cáncer (IARC) como sustancias cancerígenas Tipo I [149]. La aflatoxina B1 (AFB1) es de particular interés debido a que es una de las toxinas de origen natural más potentes que se conocen y es bio-transformada en el hígado de los mamíferos a su metabolito hidroxilado, la aflatoxina M1 (AFM1), que puede encontrarse en leche como resultado directo de la ingesta de alimentos contaminados por parte de los mamíferos que los consumen [150-152]. Cuando animales mamíferos como las vacas consumen en sus raciones alimentos contaminados con AFB1, este contaminante puede acumularse en los músculos y órganos internos o ser excretado en los fluidos corporales como orina o leche, pudiendo en este último caso llegar vía ingesta a los consumidores. De manera aproximada, el 0,3-6,2\% de AFB1 inicialmente presente en el alimento consumido por los animales podría ser encontrado en la leche en la forma de AFM1 $[150,153]$. La presencia de AFM1 en leche y productos derivados representa un riesgo particular en humanos como consecuencia de los efectos negativos que provoca en adultos y en niños, especialmente [152]. Aunque es menos mutagénica que su precursora AFB1, la aflatoxina M1 provoca efectos nocivos al organismo tales como daños al ADN, anormalidades cromosómicas, mutación genética y transformación celular, dependiendo del nivel de exposición $[152,154,155]$. Su presencia en leche depende de la presencia de AFB1 en los alimentos consumidos por el ganado, la cual a su vez depende, como se describió en el Capítulo 1, de diversos factores como las condiciones climáticas que favorecen el crecimiento fúngico y la producción de la toxina [154].

La exposición de los consumidores a la aflatoxina M1 en leche está estrictamente regulada a nivel mundial, estableciéndose niveles máximos permitidos de $0,5 \mu \mathrm{g} / \mathrm{L}$ por Argentina y el MERCOSUR [73] y 0,05 $\mathrm{\mu g} / \mathrm{kg}$ (con niveles de 0,025 $\mathrm{mg} / \mathrm{kg}$ en alimentos infantiles) por la Unión Europea [76].

En nuestro país se evidencia una incidencia constantemente alta de AFM1 en las leches analizadas en distintos estudios, con niveles de concentración encontrados que se ajustan a la regulación local del MERCOSUR pero que en algunos casos son controversiales respecto a los establecidos por la Unión Europea. En un análisis de riesgo cuantitativo realizado en la Provincia de Santa Fe por Signorini y col. en 2012 evidenció que los silos de maíz, las semillas de algodón y los alimentos balanceados eran las principales fuentes de AFM1 encontrada en muestras de leche cruda tomada en tanques de almacenamiento de los tambos muestreados [156]. En el mismo trabajo se demostró mediante una 
simulación estocástica que aproximadamente el $0,81 \%$ de las leches de tanque excederían el límite máximo aceptado para AFM1 por regulaciones del MERCOSUR (0,5 $\mathrm{gg} / \mathrm{L})$.

Respecto al análisis de muestras reales, en Argentina no se han publicado muchos estudios sobre la prevalencia de AFM1 en leche, pudiendo mencionarse el trabajo de Alonso y col. que reportó una ocurrencia del 64\% (niveles ND-0,07 $\mu \mathrm{g} / \mathrm{L}$ ) en 94 muestras de leche de 47 regiones distintas del país con un nivel medio encontrado de AFM1 de 0,028 $\mathrm{\mu g} / \mathrm{L}$ [157]; el estudio publicado por López y col. en el que se reportó una incidencia del $23 \%$ en 77 leches de distintos tipos (leche cruda de tanque, fluida comercial y en polvo) con un nivel medio encontrado de AFM1 de 0,016 $\mu \mathrm{g} / \mathrm{L}$ [151]; y el trabajo de García Londoño y col. (2013) en el que se reporta una ocurrencia del 100\% en 21 muestras de leche en polvo comerciales con una media de $0,41 \mu \mathrm{g} / \mathrm{kg}$ y un valor máximo de $0,92 \mu \mathrm{g} / \mathrm{kg}$ [158]. En ninguno de estos casos se verificaron concentraciones superiores al límite máximo aceptable establecido por el MERCOSUR (0,5 $\mu \mathrm{g} / \mathrm{L}$ para fluida y $5,0 \mu \mathrm{g} / \mathrm{kg}$ para leche en polvo).

En otros estudios de la región se evaluó también la presencia de aflatoxina M1 en leche: por ejemplo, Scaglioni y col. (2014) analizaron en Brasil 40 muestras de leche de distinto tipo (cruda, pasteurizada, UHT y en polvo) y reportaron la presencia de esta micotoxina en el $29 \%$ de las leches crudas en todas las cuales se excedía el límite establecido por MERCOSUR con un nivel medio de 0,835 $\mu \mathrm{g} / \mathrm{L}$ [159]. En otro análisis realizado en Brasil por Picinin y col. (2013) se reportó 100\% de ocurrencia de AFM1 en 129 muestras de leche cruda, aunque en niveles de concentración todos por debajo del permitido por MERCOSUR (valores hallados entre 0,0002 y 0,1057 $\mu \mathrm{g} / \mathrm{L}$ ) [160]. Por otra parte, Santili y col. (2015) hallaron AFM1 en el 53\% de un total de 635 muestras de leche cruda obtenidas en tres regiones del estado de Sao Paulo, Brasil, con una concentración media de 0,021 $\mu \mathrm{g} / \mathrm{kg}$ y un valor máximo de 0,72 $\mu \mathrm{g} / \mathrm{kg}$ [161]. También en la región, Díaz y Espitia (2006) informaron que de un total de 241 muestras de leche comercial de Colombia el 74\% contenía trazas de AFM1 con una media de $0,033 \mu \mathrm{g} / \mathrm{L}$ y un valor máximo de 0,288 $\mu \mathrm{g} / \mathrm{L}$ [162]. Estos hallazgos reflejan que la ocurrencia de AFM1 en leches de nuestra región es importante, implicando riesgo potencial para los consumidores y pérdidas económicas eventuales a nivel comercial cuando se exceden los límites establecidos por las regulaciones internacionales, por ejemplo, el nivel 0,05 $\mu \mathrm{g} / \mathrm{kg}$ establecido por la Unión Europea. La presencia de AFM1 en leche no ocurre únicamente en las leches de nuestra región sino que es un problema que se ha evidenciado desde hace mucho tiempo en todo el mundo. En un breve repaso de los trabajos bibliográficos publicados en los últimos dos años (2017-2018), se ha informado incidencia de este contaminante en leches de distintos países como China, Croacia, España, Italia, Malasia, y Pakistán, entre otros [163-168].

Medir analíticamente estos niveles regulados en valores de concentración tan bajos requiere de metodologías selectivas y de elevada sensibilidad que involucren etapas de clean-up exhaustivas para atender las interferencias propias de una matriz tan compleja como la leche. La principal técnica analítica empleada para la determinación de AFM1 en leche y productos derivados que se ha reportado en la 
literatura es el ensayo por inmunoabsorción ligado a enzimas (ELISA) que presenta como desventaja la posibilidad de dar falsos positivos como resultado $[169,170]$. Por eso, para la identificación precisa de este contaminante y la confirmación de resultados positivos se requieren técnicas analíticas instrumentales, entre las cuales la cromatografía es la que tiene el mayor potencial. La cromatografía líquida de alta resolución (HPLC) acoplada con detectores de fluorescencia es la segunda técnica analítica más reportada en la literatura [169] y es de hecho el Método Oficial AOAC para la determinación de AFM1 en leche [170]. La cromatografía de ultra-alta performance acoplada a espectrometría de masa en tándem (UHPLC-MS/MS) ha adquirido importancia en el análisis de aflatoxina M1 y otras micotoxinas debido a su alta sensibilidad y selectividad que proporcionan certeza en la identificación así como también menores límites de detección y cuantificación [112,130,171-173]. En ese sentido, las aplicaciones de técnicas UHPLC-MS/MS para el análisis de micotoxinas en leche se han ido desarrollando en los últimos años $[90,171,174,175]$.

Para aprovechar la posibilidad de alcanzar bajos límites de determinación que ofrece este tipo de técnicas instrumentales, se ha propuesto una gran variedad de etapas de purificación o clean-up de muestras que minimicen los efectos interferentes que puedan producir los componentes de la matriz. El método más difundido para la purificación y pre-concentración de AFM1 en leche y productos derivados emplea columnas de inmunoafinidad (IAC) con anticuerpos monoclonales altamente específicos para la retención del analito de interés (AFM1 en este caso) permitiendo la remoción de interferencias de la matriz previo a la determinación por LC-MS/MS $[90,157,172,176]$. Si bien el método de purificación por IAC es el más confiable y más extensamente utilizado, su uso requiere de columnas específicas de elevado costo que limitan o impiden la realización de análisis en países económicamente limitados [177]. La extracción en fase sólida (SPE) también se ha utilizado como método de preparación de muestras para la determinación de micotoxinas en forma individual y múltiple o por familias [112,130,171,178-180]. También se han propuesto otros métodos tales como la extracción líquido-líquido (LLE) [181], microextracción dispersiva líquido-líquido (DLLME) [182], dispersión de la matriz en fase sólida (MSPD) [183], métodos de dilución isotópica [184], e incluso técnicas de dilución e inyección directa sin preparación previa [112,185].

Como se describió anteriormente, el método QuEChERS es una alternativa de preparación de muestra que involucra una extracción con acetonitrilo, separación de fases y posterior clean-up SPE dispersivo con amina primaria-secundaria (PSA). Esta metodología fue propuesta inicialmente para la extracción y purificación de residuos de plaguicidas en frutas y vegetales y luego fue adaptado para usarse también con matrices con mayor contenido graso [107]. A pesar de que el método QuEChERS también puede ser aplicado en la determinación de micotoxinas en el mismo tipo de matrices, su empleo en la determinación de AFM1 en leche ha sido muy limitado. Algunos autores como Aguilera-Luiz y col. (2011) propusieron metodologías con base QuEChERS para la terminación de residuos de plaguicidas y micotoxinas en leche, pero cuyas condiciones no eran apropiadas para la extracción de AFM1 en los niveles bajos requeridos por la Unión Europea [112], y otros como Rubert y col. (2014) aplicaron un procedimiento QuEChERS para 
extraer AFM1 y otras micotoxinas en muestras de leche humana para su determinación por UHPLC-MS/MS [186].

La búsqueda de métodos de preparación de muestra simplificados y compatibles con las avanzadas técnicas instrumentales de la actualidad para la determinación de AFM1 en leche continúa siendo un desafío para la química analítica de residuos y contaminantes. En ese sentido, el resultado final debe ser una metodología simple, de sensibilidad adecuada y bajo costo que permita obtener resultados lo suficientemente confiables como para ser aplicados en actividades extensivas de monitoreo y control.

\subsection{OBJETIVOS}

El objetivo principal de esta primer etapa del trabajo de tesis consistió en optimizar metodologías analíticas para la extracción de aflatoxina M1 en leche cruda y su posterior determinación mediante cromatografía líquida acoplada a espectrometría de masa en tándem, cumpliendo los requerimientos de detección establecidos por las regulaciones locales y europeas.

En ese marco, se plantearon a su vez 2 objetivos específicos:

- Optimizar una metodología de extracción de aflatoxina M1 en leche cruda utilizando en el método de referencia basado en columnas de inmunoafinidad (IAC) con posterior determinación por UHPLC-MS/MS, y aplicarla en un estudio de campo estacional a lo largo de 1 año que comprendió el análisis de muestras de leche cruda provenientes de la región central de la Provincia de Santa Fe.

- Optimizar una metodología alternativa al método IAC siguiendo las estrategias de los métodos multi-residuo multi-clase como el QuEChERS para la determinación de AFM1 y otros residuos y contaminantes en leche cruda, para su posterior aplicación en el análisis de plaguicidas y micotoxinas en muestras de la misma región de estudio.

Dado que las actividades que dieron cumplimiento a los objetivos propuestos se llevaron a cabo en etapas distintas del trabajo de tesis, resulta propicio plantear este capítulo en dos partes, desarrollando en cada una las actividades y resultados obtenidos en la consecución de cada objetivo. 


\subsection{PARTE 1}

Aplicación de una metodología analítica basada en extracción IAC y UHPLC-MS/MS para la determinación de AFM1 en leche cruda, en un estudio de ocurrencia de este contaminante en leches de la Provincia de Santa Fe.

\subsubsection{MATERIALES Y MÉTODOS}

\subsubsection{Muestreo}

El muestreo comprendió 40 tambos situados en la zona central de la Provincia de Santa Fe, en los departamentos Castellanos y Las Colonias (Figura 16) y se llevó a cabo a lo largo de las cuatro estaciones climáticas entre Septiembre de 2012 y Agosto de 2013, tomando una muestra de leche de los tanques de enfriamiento de los tambos involucrados por cada estación, totalizando así 160 muestras que se congelaron inmediatamente después de obtenidas para su posterior análisis.

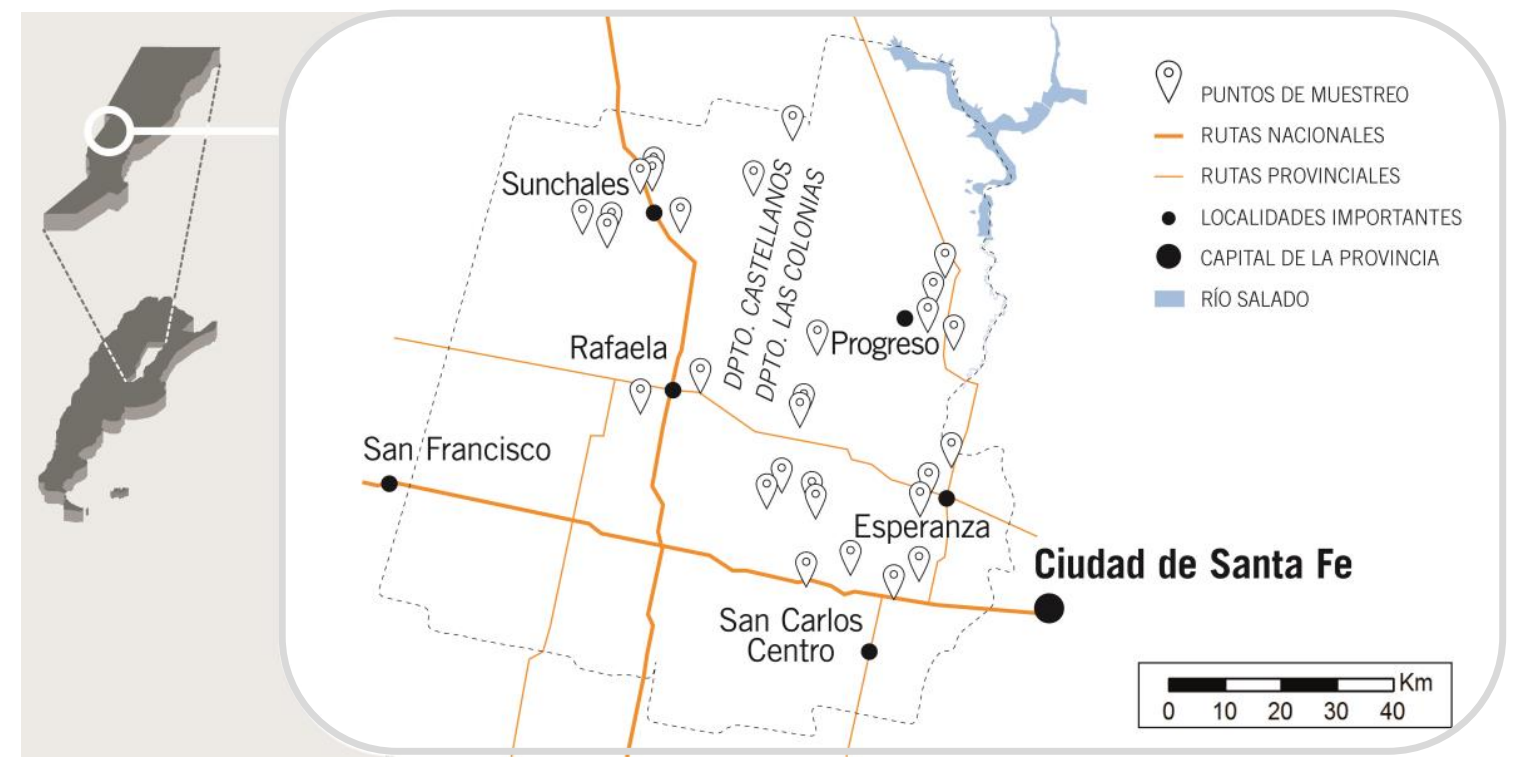

Figura 16. Localización geográfica de la zona de estudio y de los puntos de muestreo. Adaptado de Demonte y col. (2018) [187].

\subsubsection{Metodología analítica}

\section{Reactivos}

Como solución patrón madre se utilizó una solución estándar de aflatoxina M1 de $10 \mathrm{mg} / \mathrm{L}$ en acetonitrilo de $98,5 \%$ de pureza (Supelco, Sigma-Aldrich, Bellefonte, PA, USA). Como componentes de fase móvil cromatográfica se utilizó agua, metanol y acetonitrilo de calidad Óptima ${ }^{\circledR}$ de Fisher Scientific (Fair Lawn, NJ, USA). Como promotores de ionización para la fase móvil se utilizaron acetato de amonio $\left(\mathrm{AcHN}_{4}\right)$ de $98 \%$ de pureza (Anedra, Argentina) y ácido fórmico 96\% marca Tedia (Fairfield, OH, USA). Las columnas de inmunoafinidad utilizadas para la extracción y concentración de AFM1 de las muestras de leche (AFLAPREP ${ }^{\circledR}$ M) se obtuvieron de R-Biopharm Rhône (Glasgow, Escocia). 
A partir de la solución patrón madre de AFM1 se preparó una solución estándar intermedia de $1 \mathrm{mg} / \mathrm{L}$ en acetonitrilo, y partiendo de ésta se prepararon soluciones estándar de trabajo de 100 y $50 \mu \mathrm{g} / \mathrm{L}$ para utilizar en los ensayos de recuperación y calibración. Todas las soluciones estándar de AFM1 se almacenaron en viales color ámbar a $-18^{\circ} \mathrm{C}$.

\section{Equipamiento y condiciones analíticas}

Para la separación cromatográfica se utilizó un cromatógrafo líquido de ultra alta resolución ACQUITY UPLC'M (Waters, Milford, MA, USA) acoplado a un espectrómetro de masa de triple cuatrupolo Micromass TQD (Waters, Manchester, UK) a través de una fuente ortogonal de ionización por electro-spray. La columna utilizada fue una ACQUITY UPLC ${ }^{\mathrm{TM}}$ BEH C18 RP Shield $(1,7 \mu \mathrm{m}, 2,1 \times 100 \mathrm{~mm})$ de Waters con un caudal de $0,3 \mathrm{~mL} / \mathrm{min}$ y una temperatura de trabajo de $40^{\circ} \mathrm{C}$.

La fase móvil utilizada consistió de un componente acuoso $\mathrm{A}\left(0,5 \mathrm{mM} \mathrm{AcNH}_{4}+0,1 \%\right.$ de ácido fórmico) y un componente orgánico B (Metanol 100\%), y se empleó un programa de gradiente comenzando con $20 \%$ de B durante 1 minuto, incrementado linealmente a $100 \%$ B en 1,6 minutos $y$, tras permanecer en esas condiciones durante 2,4 minutos, regresando a condiciones iniciales en 1 minuto. Antes de la siguiente inyección la columna se re-equilibró durante 1 minuto en las condiciones iniciales de gradiente, totalizando así un tiempo de corrida de 7 minutos. El volumen de inyección fue de $10 \mu \mathrm{L}$.

Los parámetros instrumentales operativos para la ionización y análisis en el espectrómetro de masa fueron individualmente optimizados por inyección directa de una solución estándar de AFM1 de $1 \mathrm{mg} / \mathrm{L}$ de concentración, y los valores óptimos finales utilizados se presentan en la Tabla 11.

Tabla 11. Parámetros operativos de ionización y análisis para la determinación de AFM1 por UHPLC-MS/MS

\begin{tabular}{lll}
\hline & Parámetro & Valor \\
\hline Ionización & Polaridad & Positiva (ESI+) \\
& Temperatura de fuente & $120^{\circ} \mathrm{C}$ \\
& Voltaje capilar & $3,2 \mathrm{kV}$ \\
& Gas de desolvatación & $\mathrm{N}_{2}, 900 \mathrm{~L} / \mathrm{h}$ \\
& Temperatura de desolvatación & $390^{\circ} \mathrm{C}$ \\
& Gas de cono & $\mathrm{N}_{2}, 48 \mathrm{~L} / \mathrm{h}$ \\
& Voltaje de cono & $40 \mathrm{~V}$ \\
Analizador & lon padre (m/z) & 329 \\
& lones hijos (m/z) & $273(Q), 259(q)$ \\
& Gas de colisión & $\operatorname{Argón~} 0,14 \mathrm{~mL} / \mathrm{min}(1,3 \mathrm{e}-5 \mathrm{mbar})$ \\
& Energía de colisión & $25 \mathrm{~V}(Q), 30 \mathrm{~V}(q)$ \\
\hline
\end{tabular}

\subsubsection{Preparación de las muestras}

Las muestras de leche conservadas en freezer desde el momento de su obtención se descongelaron a temperatura ambiente y se calentaron durante algunos minutos en baño de agua a $37^{\circ} \mathrm{C}$ para su 
homogeneización. Luego, la leche fue transferida a tubos de polipropileno de $50 \mathrm{~mL}$ para la separación de la grasa por centrifugación a $3500 \mathrm{rpm}$ y $4^{\circ} \mathrm{C}$ durante 15 minutos. La leche desgrasada fue tomada cuidadosamente mediante jeringa y aguja desde la parte media de los tubos y filtrada a través de papel de filtro común con la ayuda de vacío.

Para los ensayos de recuperación la leche descremada se adicionó con soluciones estándar de trabajo de AFM1 de modo de obtener concentraciones de analito de 0,05 y 0,10 $\mu \mathrm{g} / \mathrm{L}$. La leche así adicionada se agitó suavemente durante 2 horas para una completa integración de la aflatoxina con la matriz.

Procedimiento de clean-up mediante columnas de inmunoafinidad (IAC): un volumen de $50 \mathrm{~mL}$ de leche descremada se colocó en un cilindro de jeringa de $60 \mathrm{~mL}$ situado en la parte superior de las columnas de inmunoafinidad. Con la ayuda de vacío, la muestra de pasó a través de las columnas a razón de 1-2 gotas por segundo. Luego, para eliminar componentes de la matriz no adheridos a los anticuerpos, las columnas se lavaron pasando dos alícuotas de $10 \mathrm{~mL}$ de agua destilada, y posteriormente se secaron haciendo pasar aire durante 30 segundos para evitar la dilución de la aflatoxina adherida. En un paso posterior, la AFM1 se eluyó de las columnas IAC haciendo pasar por las mismas dos alícuotas de 1,25 mL de solvente de elución (MeCN:MeOH; 60:40) (Figura 17). Finalmente, el extracto obtenido se filtró mediante filtros de jeringa con membrana de nylon de $0,2 \mu \mathrm{m}$ se inyectó al sistema cromatográfico.

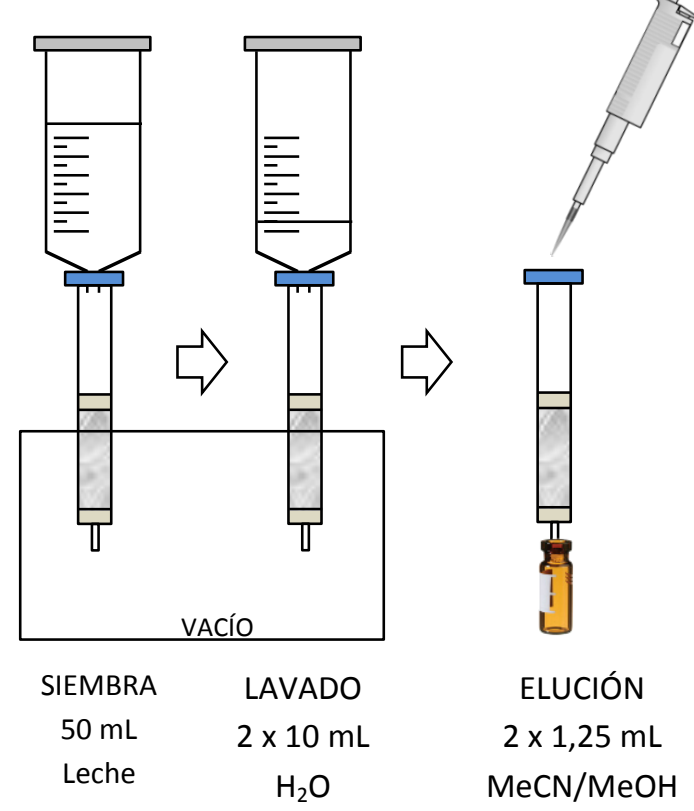

Figura 17. Esquema del procedimiento IAC para la extraccion de AFM1 de leche.

\section{Análisis estadístico}

A los responsables de cada establecimiento de muestreo se les realizó una encuesta orientada a conocer potenciales eventos de contaminación. Dicha encuesta consistió de un cuestionario de 18 preguntas dividido en dos secciones: a) características generales del tambo (p.ej. producción de leche, número de 
animales, litros producidos por animal, entre otras), y b) factores potenciales asociados con la presencia de AFM1 en leche (consumo de diferentes tipos de piensos, grado de conocimiento de los productores sobre las micotoxinas, utilización de agentes secuestrantes, entre otros).

Para cuantificar el riesgo asociado con la presencia de AFM1 en las muestras de leche analizadas se llevó a cabo un análisis estadístico bivariado en el que todas las preguntas generales y específicas (variables independientes) se compararon con la presencia de AFM1 a nivel detectado/no-detectado (variable dependiente). Las comparaciones se realizaron mediante test de T-student, test de Mann-Whitney, $\chi^{2}$ o test de Fisher teniendo en cuenta las características de la variable independiente, y los análisis estadísticos se realizaron utilizando el software InfoStat (Universidad Nacional de Córdoba) [188].

\subsubsection{RESULTADOS Y DISCUSIÓN}

\subsubsection{Optimización de la determinación instrumental UHPLC-MS/MS}

Para la separación cromatográfica se escogió una columna de fase reversa C18 que es el tipo de fase estacionaria utilizado más extensamente en la separación de plaguicidas y micotoxinas en alimentos. En cuanto a la selección de la fase móvil, inicialmente se probaron varias combinaciones agua-acetonitrilo y agua-metanol obteniéndose mejor resolución del pico cromatográfico y mayor sensibilidad para AFM1 cuando se utiliza agua y metanol como constituyentes de la fase móvil. También se evaluó el uso conjunto de ácido fórmico (AF) y acetato de amonio $\left(\mathrm{AcNH}_{4}\right)$ como promotores de la ionización, resultando que con una solución 0,5mM de $\mathrm{AcNH}_{4}$ se producía una señal de AFM1 7 veces más intensa que cuando se utilizaba solamente $\mathrm{AF}$, por lo que la fase móvil utilizada para continuar con el resto del análisis consistió en un componente acuoso constituido por una solución $0,5 \mathrm{mM}$ de $\mathrm{AcNH}_{4}$ con $0,1 \%$ AF (A) y un componente orgánico constituido por MeOH 100\% (B) (Figura 18).

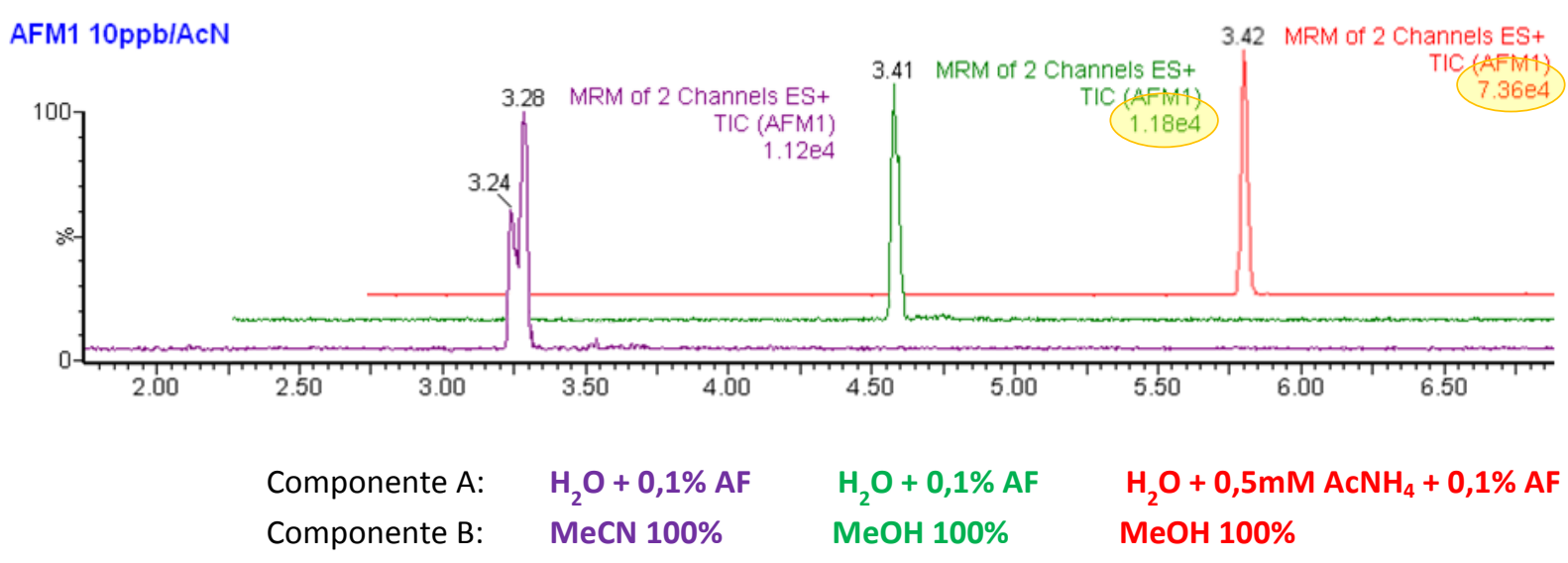

Figura 18. Cromatogramas de iones totales resultantes de las pruebas de distintas composiciones de fase móvil para determinación de AFM1 por UHPLC-MS/MS. 
Las condiciones de ionización y análisis en modo MRM (monitoreo de reacciones múltiples) de la molécula de AFM1 se optimizaron por infusión de una solución estándar directamente al sistema MS/MS, modificando cada variable de manera independiente y verificando su efecto sobre la intensidad de la señal (Tabla 11). En cuanto a la polaridad de la ionización, si bien el modo negativo $[\mathrm{M}-\mathrm{H}]^{-}$ha sido utilizado por algunos autores [176] en nuestras pruebas se obtuvo considerablemente mayor sensibilidad empleando la molécula de AFM1 ionizada positivamente $[\mathrm{M}+\mathrm{H}]^{+}$como ion precursor. Si bien en la fase móvil se introdujo acetato de amonio como promotor de ionización, la formación del aducto $\left[\mathrm{M}+\mathrm{NH}_{4}\right)^{+}$no se verificó. De las 2 transiciones analizadas la más sensible se escogió como transición de cuantificación ( $Q, \mathrm{~m} / \mathrm{z} 329>273$ ) y la de menor sensibilidad como confirmación ( $q$, m/z 329>259). Estas mismas transiciones han sido utilizadas por otros autores en métodos instrumentales para la determinación de AFM1 en leche $[171,172]$.

\subsubsection{Validación del procedimiento analítico}

El procedimiento IAC descripto anteriormente fue básicamente el mismo que el recomendado por el fabricante de las columnas, con la única modificación de utilizar agua en lugar de buffer fosfato salino (PBS) en la etapa de lavado luego de la siembra en las columnas. Esto se debió a que cuando se eluye la AFM1 con la mezcla acetonitrilo-metanol se produce un precipitado en el vial recolector cuando el lavado se realiza con buffer PBS, por insolubilidad de las sales en esos solventes orgánicos. Cuando, en su lugar, el lavado se realiza con agua destilada tal precipitación al momento de la elución no se observa. En cuanto al volumen de elución ( 2 alícuotas de 1,25 mL), se verificó que era suficiente para eluir completamente la aflatoxina unida a los anticuerpos del material de relleno. Para ello, se pasó un volumen extra de $1 \mathrm{~mL}$ de solvente de elución que se recogió en un vial independiente y se inyectó al sistema UHPLC-MS/MS, no observándose señal alguna en el tiempo de retención de la AFM1 e indicando así la completa elución del analito con las dos alícuotas indicadas. Además, se verificó que para mejorar los valores de recuperación de AFM1 se debe practicar un backflush de solvente para asegurar la completa ruptura del enlace aflatoxinaanticuerpo en la etapa de elución. Esto consiste en hacer pasar las primeras fracciones del solvente de elución en ambos sentidos de flujo de la columna IAC, con la ayuda de una pera de goma.

\section{Exactitud y precisión}

La performance del método IAC se evaluó mediante estudios de recuperación adicionando muestras de leche cruda descremada con estándar de AFM1 en los niveles 0,1 y 0,05 $\mu \mathrm{g} / \mathrm{L}$, haciendo hincapié en el nivel más bajo ya que es el límite máximo establecido por la Unión Europea. La precisión del método se determinó mediante la desviación estándar relativa (DER) de ensayos realizados en condiciones de repetibilidad (precisión intra-día) y reproducibilidad (precisión inter-día). Todos los valores de recuperación y DER obtenidos estuvieron dentro de los niveles aceptables establecidos por las guías de calidad analítica para determinación de micotoxinas [189] (Tabla 12). 
Tabla 12. Resultados del ensayo de exactitud y precisión realizado en la validación del método IAC para la determinación de AFM1 en leche por UHPLC-MS/MS

\begin{tabular}{lll}
\hline & \multicolumn{2}{l}{ Nivel adicionado $(\mu \mathrm{g} / \mathrm{L})$} \\
\hline Recuperación & $0,05(\mathrm{n})$ & $0,10(\mathrm{n})$ \\
media & $98 \%(10)$ & $99 \%(3)$ \\
DER intra-día & $7,5 \%(4)$ & $1,4 \%(3)$ \\
DER inter-día & $18 \%(10)$ & $15 \%(2)$ \\
\hline DER = Desviación estándar relativa & \\
$\mathrm{n}=$ número de réplicas independientes
\end{tabular}

\section{Linealidad y efecto matriz}

La calibración se analizó utilizando estándares de AFM1 tanto en solvente como en presencia de componentes de la matriz (extractos IAC de leche blanco). La linealidad en solvente se evaluó en el rango 0,1-10 $\mu \mathrm{g} / \mathrm{L}$ y en matriz en el rango 0,5-10 $\mu \mathrm{g} / \mathrm{L}$, obteniéndose coeficientes de regresión $\left(r^{2}\right)$ mayores de 0,990 en ambos casos. El efecto matriz (EM) se analizó comparando las pendientes de ambas curvas de calibración (EM = pendiente-matriz/pendiente-solvente $\times 100$ ), obteniéndose en promedio un $\mathrm{EM}=85 \%$ ( $n=10$ ensayos de calibración distintos), lo que indica una disminución de la señal del 15\% en presencia de matriz respecto a la curva en solvente y demuestra la alta especificidad hacia la AFM1 que el método IAC posee, en detrimento de otros componentes de la matriz.

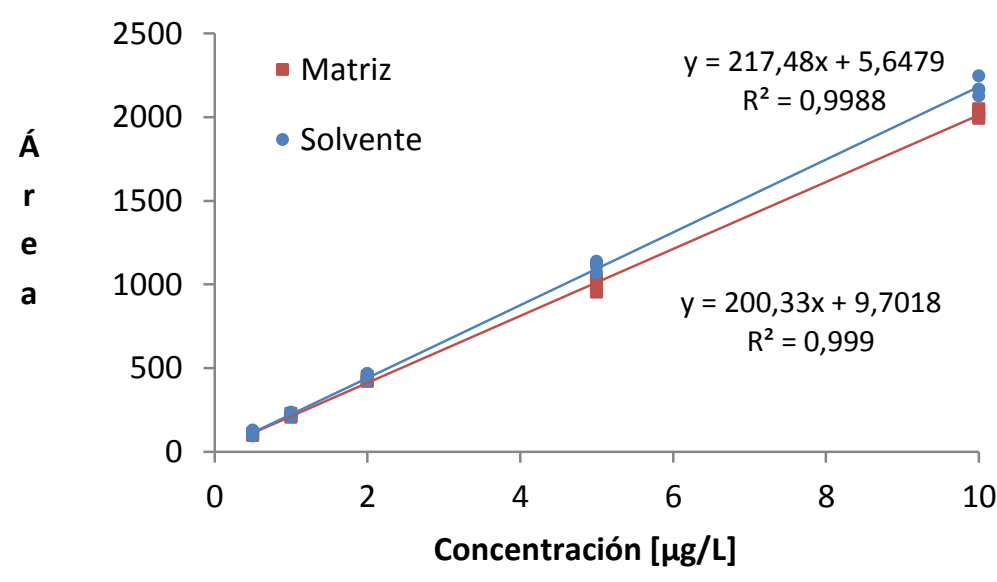

Figura 19. Calibraciones de AFM1 en solvente y matriz.

\section{Límites de determinación}

Los límites de detección (LD) y de cuantificación (LC) se estimaron como la menor concentración de analito que producía una relación señal/ruido $S / N=3$ y $S / N=10$ para la transición de cuantificación $(Q)$, respectivamente. Adicionalmente, para la selección de tal concentración debía verificarse una $S / N \geq 3$ en la transición de confirmación ( $q$ ) en ambos casos. Con estos criterios, el LD estimado fue de 0,001 $\mu \mathrm{g} / \mathrm{L}$ y el LC fue de $0,003 \mu \mathrm{g} / \mathrm{L}$. Estos límites dan clara muestra de la excelente capacidad del método IAC seguido de la determinación por UHPLC-MS/MS para verificar el cumplimiento de los límites máximos permitidos para 
AFM1 en leche establecidos por distintas regulaciones $(0,5 \mu \mathrm{g} / \mathrm{L}$ en MERCOSUR, Estados Unidos y China, y $0,05 \mu \mathrm{g} / \mathrm{kg}$ en la Unión Europea).

\section{Criterios de identificación en muestras reales}

Para la identificación y cuantificación de AFM1 en las muestras de leche analizadas por UHPLC-MS/MS se estableció una serie de criterios que los eventuales positivos debían cumplir: a) las dos transiciones de cuantificación ( $Q: 329>273$ ) y de confirmación ( $q$ : 329 > 259) debían estar presentes; b) tolerancia de $\pm 0,2$ min en los tiempos de retención de AFM1 en el extracto de la muestra con relación al tiempo de retención de un estándar de calibración en matriz; c) $S / N \geq 10$ para la transición $Q$ y, al mismo tiempo, $S / N \geq 3$ para la transición $q ;$ d) tolerancia de hasta $\pm 30 \%$ en la relación $q / Q$ del extracto de muestra comparado con un estándar en matriz de una concentración similar [190].

\subsubsection{Análisis de muestras}

En cuanto a la AFM1 hallada en las muestras analizadas, 62 de las 160 leches $(38,8 \%)$ se encontraron contaminadas con esta micotoxina en niveles entre $0,003 \mu \mathrm{g} / \mathrm{L}$ (el límite de cuantificación) y 0,293 $\mu \mathrm{g} / \mathrm{L}$, con un valor medio de 0,037 $\mathrm{\mu g} / \mathrm{L}$. Cincuenta de las 62 muestras (80,6\%) en las que se detectó AFM1 presentaron concentraciones por debajo de límite máximo establecido por la regulación europea (0,05 $\mu \mathrm{g} / \mathrm{L}$ [ [76], pero sin embargo ningún valor excedió el límite de 0,5 $\mu \mathrm{g} / \mathrm{L}$ establecido por el MERCOSUR [73]. Respecto a la ocurrencia observada en los muestreos de las distintas estaciones, el período en que más resultados positivos se hallaron fue verano con 19 detecciones, seguido por otoño con 16 y primavera e invierno con 14 detecciones cada una (Tabla 13). En la Figura 20 se representa la distribución de resultados obtenidos en las 4 estaciones según los niveles de concentración de AFM1 hallados. Se observó que, en promedio, en el 55\% de las muestras en todas las estaciones no se verificó la presencia de AFM1 (ND), el $32 \%$ en promedio dio valores entre el límite de cuantificación $(0,003 \mu \mathrm{g} / \mathrm{L})$ y el nivel máximo permitido por la Unión Europea $(0,05 \mu \mathrm{g} / \mathrm{L})$, y alrededor del 8\% presentó AFM1 en concentraciones que exceden ese límite máximo. Además, se evidenciaron casos en los que se observaron las señales características de AFM1 en sus respectivos cromatogramas pero que no satisficieron completamente los criterios de identificación y confirmación descriptos anteriormente, por lo que a fines descriptivos se los consideraron como <LD.

Tabla 13. Resumen de resultados de la determinación de AFM1 en las 160 muestras de leche analizadas por extracción IAC y UHPLC-MS/MS.

\begin{tabular}{lllllll} 
& & & & \multicolumn{3}{c}{ Concentraciones halladas $(\mu \mathrm{g} / \mathrm{L})$} \\
\cline { 6 - 7 } & Cuantificados & $<$ LD & ND & mínima & media & máxima \\
\hline $\begin{array}{l}\text { Primavera } \\
(\mathrm{n}=40)\end{array}$ & 14 & 6 & 20 & 0,003 & 0,031 & 0,185 \\
$\begin{array}{l}\text { Verano } \\
(\mathrm{n}=40)\end{array}$ & 19 & 0 & 21 & 0,004 & 0,024 & 0,126 \\
$\begin{array}{l}\text { Invierno } \\
(\mathrm{n}=40)\end{array}$ & 14 & 2 & 24 & 0,009 & 0,063 & 0,293 \\
$\begin{array}{l}\text { Otoño } \\
(\mathrm{n}=40)\end{array}$ & 16 & 2 & 22 & 0,009 & 0,034 & 0,128 \\
\hline
\end{tabular}


En la Tabla S1-1 del material suplementario se muestran en detalle los valores de aflatoxina M1 hallados en todas las muestras individuales analizadas.

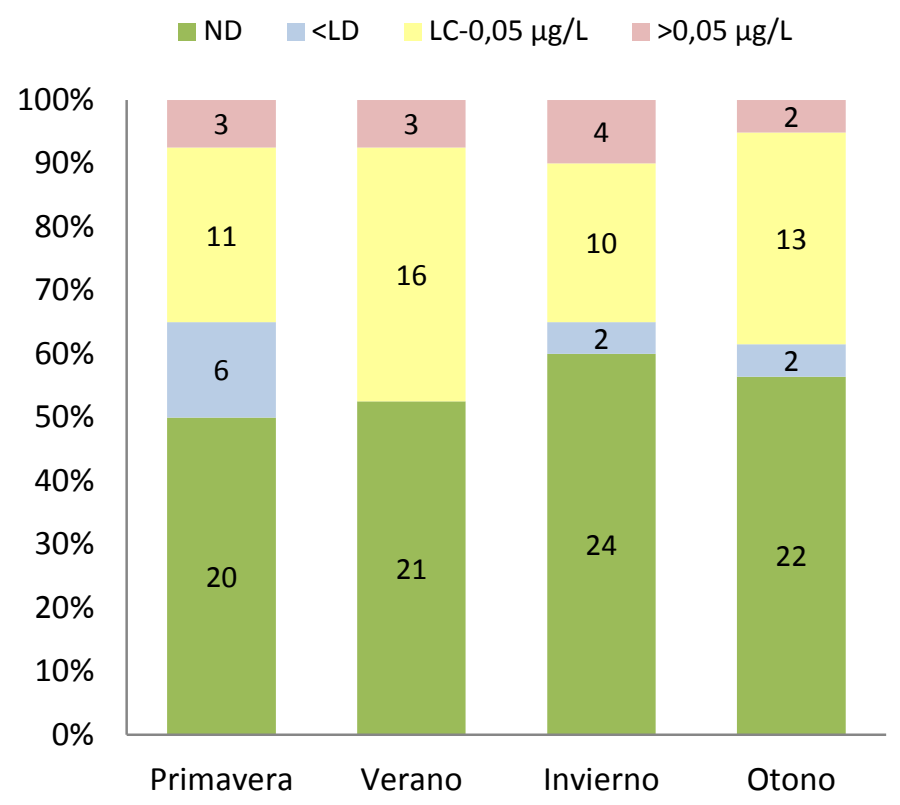

Figura 20. Distribución de resultados del análisis de las 40 muestras de leche analizadas en los distintos períodos estacionales. El valor dentro de cada barra indica el número de muestras de cada nivel de concentración.

(a) Muestra ND

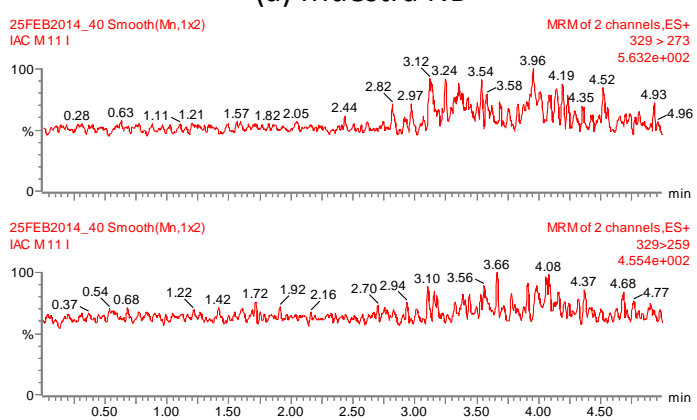

(c) Muestra positiva 0,009 $\mathrm{\mu g} / \mathrm{L}$

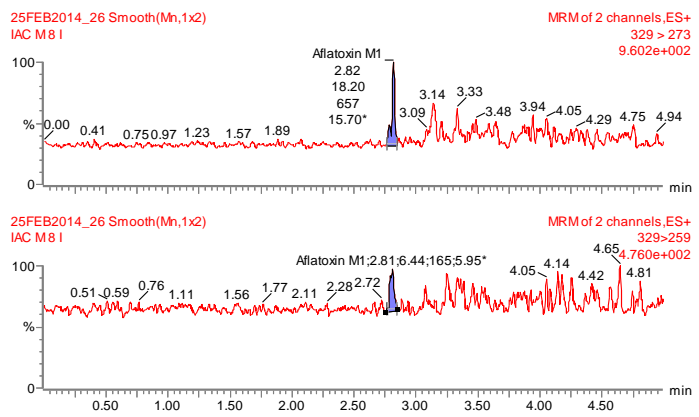

(b) Recuperado $0,05 \mu \mathrm{g} / \mathrm{L}$

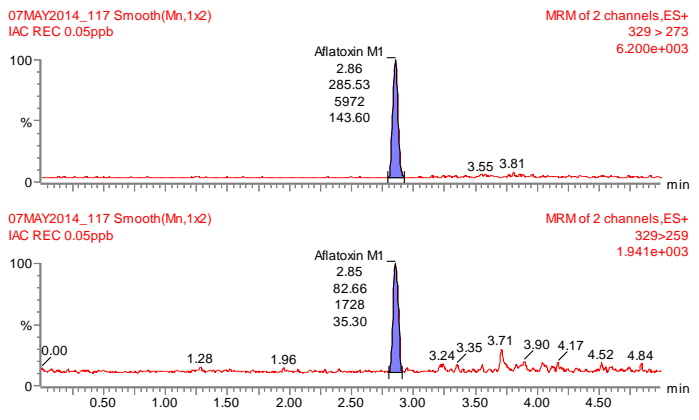

(d) Muestra positiva $0,293 \mu \mathrm{g} / \mathrm{L}$

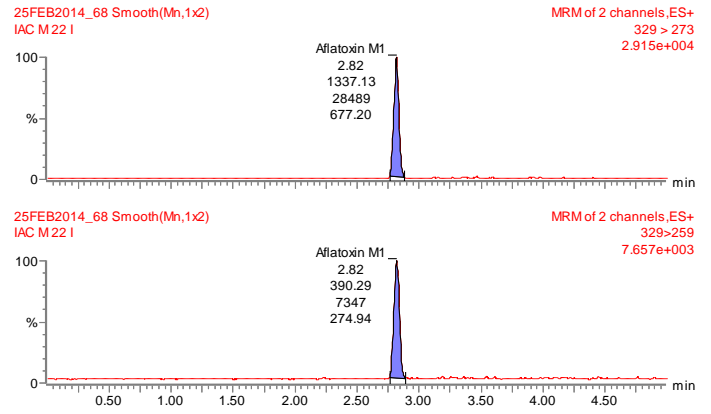

Figura 21. Cromatogramas obtenidos en el análisis de (a) una muestra blanco, (b) una muestra adicionada en nivel 0,05 $\mathrm{\mu g} / \mathrm{L}$, (c) una muestra con concentración de AFM1 próxima al LC del método y (d) una muestra contaminada con alto nivel de concentración de AFM1. 


\section{Análisis descriptivo del ensayo experimental}

Las muestras de leche $(n=160)$ se obtuvieron de 40 tambos en cada estación climática a lo largo del año de muestreo, y cada establecimiento estaba compuesto por un promedio de 161 vacas lecheras (rango 70-407 vacas) con una producción diaria promedio de 3623 L (rango 1400-11800 L). La producción diaria promedio por animal, en cambio, fue de 21,8 L (rango 15-32 L). En los diferentes tambos el ganado recibió una dieta rica en pasturas (esencialmente de alfalfa y de avena), ensilado de maíz y distintos granos (maíz, sorgo, semillas de algodón) como fuente de proteínas y carbohidratos, henos de alfalfa y sorgo como fuentes de fibra, y como fuente de proteínas y energía los ingredientes más utilizados fueron porotos de soja y semillas de algodón.

\section{Análisis bivariado}

A partir de los datos ocurrencia de AFM1 en las muestras analizadas (detectado/no detectado) se realizó un análisis estadístico bivariado para evaluar la potencial asociación entre la presencia de AFM1 en las leches (variable dependiente) y las características técnicas y operativas de los tambos involucrados como la caracterización de la producción, el tipo de alimento utilizado, la cantidad de leche producida, la cantidad de alimento suministrado, etc. (variables independientes categóricas y continuas) (Tablas 14 y 15 ). Se encontró que la prevalencia de AFM1 en las muestras de leche de tanque de almacenamiento analizadas no se modificó por la estación climática $(p=0,617)$. Esto es un reflejo del cambio que se ha producido hacia sistemas de alimentación constantes durante todo el año y que ha modificado la estacionalidad histórica que se verificaba al analizar AFM1 en las leches de la zona de estudio. Por otro lado, la probabilidad de hallar AFM1 no estuvo relacionada con las características de los establecimientos, ni con el número de animales $(p=0,183)$, ni la cantidad total de leche producida $(p=0,213)$ por tambo, y tampoco por la producción de leche por vaca $(p=0,498)$. Sin embargo, se encontró que en los tambos con producciones diarias mayores a 21,5 L por vaca tenían mayor probabilidad de presentar AFM1 en la leche $(p=0,084)$.

Respecto a los diferentes alimentos consumidos por los animales en cada establecimiento, no se encontró una asociación entre la presencia de AFM1 en los tanques de almacenamiento y el uso de ensilados de pasturas $(p=0,648)$, avena $(p=0,897)$, henos $(p=0,771)$, granos de maíz o sorgo $(p=0,338)$, ensilado de maíz $(p=0,915)$ y expeller de soja $(p=0,198)$. Sin embargo, hubo 3 tipos de alimentos cuyo consumo estuvo asociado con la ocurrencia de esta micotoxina en la leche siendo éstos pasturas de alfalfa $(p=$ $0,121)$, balanceados comerciales ( $p=0,017)$, y semillas de algodón $(p=0,030$ ) (Tabla 14). En estos casos la presencia de AFM1 en leche no estuvo asociada solamente con el mero consumo de ese tipo de alimentos sino también con la cantidad de los mismos en las dietas, obteniéndose relaciones para expeller de soja $(p=$ 0,082 ) y semillas de algodón $(p=0,023)$ (Tabla 15), por lo que las cantidades de estos dos ingredientes se incluyeron también como variables categóricas en el análisis (Tabla 14). 
Tabla 14. Definición y distribución de las variables explicativas (categóricas) incluidas en el análisis bivariado para evaluar su potencial asociación con la presencia de AFM1 en leche cruda ( $n=160$ muestras)

\begin{tabular}{|c|c|c|c|c|}
\hline Variable & Nivel & Tamaño & $\%$ positivos & Valor-P \\
\hline \multirow[t]{4}{*}{ Estación } & Primavera & 40 & 35,0 & 0,617 \\
\hline & Verano & 40 & 47,5 & \\
\hline & Otoño & 40 & 37,5 & \\
\hline & Invierno & 40 & 35,0 & \\
\hline \multirow[t]{2}{*}{ Producción de leche por animal } & $<21,5 \mathrm{~L} / \mathrm{vaca}$ & 75 & 32,0 & 0,084 \\
\hline & $>21,5 \mathrm{~L} / \mathrm{vaca}$ & 79 & 45,6 & \\
\hline \multirow[t]{2}{*}{ Producción de leche total } & $<3000 \mathrm{~L}$ & 77 & 35,1 & 0,426 \\
\hline & $>3000 \mathrm{~L}$ & 75 & 41,3 & \\
\hline \multirow[t]{2}{*}{ Consumo de alfalfa } & No & 16 & 56,3 & 0,121 \\
\hline & Sí & 127 & 36,2 & \\
\hline \multirow[t]{2}{*}{ Ensilados de pasturas } & No & 107 & 37,4 & 0,648 \\
\hline & Sí & 36 & 41,7 & \\
\hline \multirow[t]{2}{*}{ Consumo de avena } & No & 128 & 38,3 & 0,897 \\
\hline & Sí & 15 & 40,0 & \\
\hline \multirow[t]{2}{*}{ Permeado de suero } & No & 133 & 39,8 & 0,213 \\
\hline & Sí & 10 & 20,0 & \\
\hline \multirow[t]{2}{*}{ Heno } & No & 68 & 39,7 & 0,771 \\
\hline & Sí & 75 & 37,3 & \\
\hline \multirow[t]{2}{*}{ Granos } & No & 63 & 42,9 & 0,338 \\
\hline & Sí & 80 & 35,0 & \\
\hline \multirow[t]{2}{*}{ Ensilados } & No & 24 & 37,5 & 0,915 \\
\hline & Sí & 119 & 38,7 & \\
\hline \multirow[t]{2}{*}{ Expeller de soja } & No & 95 & 34,7 & 0,198 \\
\hline & Sí & 48 & 45,8 & \\
\hline \multirow[t]{2}{*}{ Consumo de expeller por animal } & $<0,95 \mathrm{~kg} \mathrm{MS} / \mathrm{vaca}$ & 108 & 35,2 & 0,082 \\
\hline & $>0,95 \mathrm{~kg} \mathrm{MS} / \mathrm{vaca}$ & 37 & 51,4 & \\
\hline \multirow[t]{2}{*}{ Balanceado comercial } & No & 70 & 28,6 & 0,017 \\
\hline & Sí & 73 & 47,9 & \\
\hline \multirow[t]{2}{*}{ Semilla de algodón } & No & 110 & 33,6 & 0,030 \\
\hline & Sí & 33 & 54,5 & \\
\hline \multirow[t]{2}{*}{ Consumo S, de algodón por animal } & $<1,5$ kg MS/vaca & 128 & 35,9 & 0,023 \\
\hline & $>1,5 \mathrm{~kg} \mathrm{MS} / \mathrm{vaca}$ & 17 & 64,7 & \\
\hline
\end{tabular}

Tabla 15. Definición y distribución de las variables explicativas (continuas) incluidas en el análisis bivariado para evaluar su potencial asociación con la presencia de AFM1 en leche cruda ( $n=160$ muestras)

\begin{tabular}{llll}
\hline Variable independiente & $\begin{array}{l}\text { Media en tambos } \\
\text { negativos }\end{array}$ & $\begin{array}{l}\text { Media en tambos } \\
\text { positivos }\end{array}$ & Valor-P \\
\hline Número de animales & 155,03 & 171,76 & 0,183 \\
Producción de leche por tambo (L) & 3460,81 & 3886,83 & 0,213 \\
Producción de leche por vaca (L) & 21,66 & 22,04 & 0,498 \\
Consumo de alfalfa (kg MS/vaca) & 3,34 & 3,10 & 0,656 \\
Consumo de avena (kg MS/vaca) & 0,19 & 0,28 & 0,557 \\
Consumo de henos (kg MS/vaca) & 0,82 & 0,65 & 0,280 \\
Consumo de grano de maíz (kg MS/vaca) & 2,57 & 2,09 & 0,268 \\
Consumo de ensilados (kg MS/vaca) & 2,69 & 2,98 & 0,572 \\
Consumo de ensilados de pastura (kg MS/vaca) & 1,19 & 1,71 & 0,311 \\
Consumo de expeller (kg MS/vaca) & 0,58 & 0,92 & 0,123 \\
Consumo de balanceados (kg MS/vaca) & 2,05 & 2,96 & 0,049 \\
Consumo de semilla de algodón (kg MS/vaca) & 0,24 & 0,49 & 0,036 \\
\hline
\end{tabular}




\section{Prevalencia y factores de riesgo asociados}

Se evidenció una importante ocurrencia de aflatoxina M1 $(38,8 \%)$ en leches de tanques de almacenamiento de un conjunto de tambos seleccionados en la principal zona de producción láctea de Argentina, en el centro de la Provincia de Santa Fe. Al respecto, el nivel medio encontrado de concentración de AFM1 en leche $(0,038 \mu \mathrm{g} / \mathrm{L})$ se halló muy por debajo del nivel máximo aceptado por la regulación del MERCOSUR $(0,5$ $\mu \mathrm{g} / \mathrm{L})$, mientras que el $80,6 \%$ de las muestras analizadas evidenciaron niveles menores que el límite establecido por la regulación Europea (0,05 $\mu \mathrm{g} / \mathrm{L})$.

Respecto a la presencia de esta micotoxina en leche cruda de nuestro país los estudios reportados han sido dispares. Algunos autores informaron contaminación con AFM1 en el $64 \%$ de muestras de leche de tanque analizadas con concentraciones medias de $0,028 \mu \mathrm{g} / \mathrm{L}$ [157], mientras que otros reportaron incidencia en el 10,7\% de leches de granja con una concentración media de 0,016 $\mu \mathrm{g} / \mathrm{L}$ [151]. En otro estudio llevado a cabo en la zona central santafesina se encontró este contaminante en niveles por encima de $1 \mu \mathrm{g} / \mathrm{L}$ en 2 de 33 muestras de leche cruda analizadas (6,1\%) [156]. Cabe destacar que estos estudios se llevaron a cabo en distintas regiones geográficas de Argentina, por lo que estas diferencias en los porcentajes de ocurrencia y en los niveles hallados de AFM1 podrían ser consecuencia de las distintas composiciones de ingredientes de las dietas, tanto en sus tipos (especialmente alimentos concentrados y pasturas) como en sus cantidades. La proporción en la que los distintos tipos de alimentos y piensos son utilizados en las dietas del ganado lechero varían considerablemente de acuerdo a diferencias geográficas regionales, al estadio productivo en el que se encuentra el animal y a las prácticas de manejo de los establecimientos de producción [91]. Los estudios antes mencionados coinciden con nuestros hallazgos, sin embargo, en que la AFM1 se encontró en todos los casos en bajos niveles de concentración. Así, en el estudio de Alonso y col. (2010) se reportaron niveles hasta $0,07 \mu \mathrm{g} / \mathrm{L}$, y en el estudio llevado a cabo por López y col. (2003) se encontró una concentración media de AFM1 de 0,016 $\mathrm{\mu g} / \mathrm{L}$. Por otro lado, en un relevamiento realizado en Argentina entre 2003 y 2014 en el marco del Plan Nacional de Control de Residuos e Higiene en Alimentos (CREHA) se encontraron niveles detectables de AFM1 en el 40,5\% de un total de 2862 muestras de leche cruda con niveles entre $0,025 \mu \mathrm{g} / \mathrm{L}$ y $0,5 \mu \mathrm{g} / \mathrm{L}$ (CREHA, 2012).

La selección genética para producir mayores cantidades de leche ha llevado a la necesidad de introducir en las dietas mayores cantidades de ingredientes ricos en energía [91] que a al mismo tiempo presentan mayores riesgos de contaminación por aflatoxina B1, precursora de AFM1 [157]. Los tambos productores de leche localizados en la zona central de Argentina, en la Provincia de Santa Fe, utilizan comúnmente sistemas de alimentación semi-intensivos integrando a las dietas una proporción importante de alimentos concentrados (como ser expellers de soja y semillas de algodón) y ensilados de maíz. En nuestro caso los expellers de soja, las semillas de algodón y lo balanceados comerciales se identificaron como factores de riesgo de presencia de AFM1 en leche cruda, y adicionalmente verificó que los tambos en los que se utiliza 
ese tipo de alimentos en las dietas de sus animales se caracterizan por una producción intensiva presentando por ende mayor riesgo de contaminación de las leches.

Los alimentos concentrados referidos en el párrafo precedente han sido altamente correlacionados con los niveles de micotoxinas hallados en leche vacuna en un análisis de riesgo cuantitativo realizado previamente en la región de estudio [156]. En base a predicciones con modelos matemáticos, en ese estudio se estimó que aproximadamente el $0,66 \%$ de la leche producida en la región excede el límite máximo permitido en el MERCOSUR al tiempo que el porcentaje de muestras que pueden exceder el límite de las regulaciones Europeas se estimó en $32,7 \%$. Estas estimaciones realizadas en análisis de riesgo cuantitativo podrían considerarse confiables al compararlas con la información que emerge de estudios de campo, siendo que en nuestro estudio ninguna de las muestras analizadas excedió el límite MERCOSUR y solo el 7,5\% de las mismas presentó niveles de AFM1 por encima del límite Europeo.

\subsubsection{CONCLUSIONES DE LA PARTE 1}

La prevalencia y los niveles de AFM1 hallados en leche producida fue relativamente alta aunque los niveles de concentración representan riesgos de menor consideración, habida cuenta que no se verificaron violaciones a las tolerancias de Mercosur $(0,5 \mu \mathrm{g} / \mathrm{L})$ aunque sí se comprobaron algunos excesos de los LMs de la Unión Europea $(0,05 \mu \mathrm{g} / \mathrm{kg})$.

Los ingredientes utilizados como alimentos en la dieta del ganado lechero que parecieran presentar el mayor riesgo para la ocurrencia de AFM1 son semillas de algodón, expellers de soja y balanceados comerciales.

Dado que los requerimientos de calidad para el comercio internacional son cada vez más rigurosos, cualquier reducción en los límites actualmente regulados podría tener un fuerte impacto en la producción y el comercio local. 


\subsection{PARTE 2}

Optimización de una metodología de extracción alternativa a las columnas de inmunoafinidad basada en el método QuEChERS para la determinación de AFM1 en leche.

\subsubsection{MATERIALES Y MÉTODOS}

\subsubsection{Metodología analítica}

\section{Reactivos}

Como solución patrón madre se utilizó un estándar en acetonitrilo de 10 mg/L (pureza 98,5\%) provisto por Supelco (Sigma-Aldrich, Bellefonte, PA, EE.UU.). Como solventes para la fase móvil cromatográfica se utilizaron agua, metanol y acetonitrilo de calidad Óptima ${ }^{\circledR}$ de Fisher Scientific (Fair Lawn, NJ, EE.UU.). Como modificadores de fase móvil se emplearon acetato de amonio $\left(\mathrm{AcNH}_{4},>98 \%\right)$ y acetato de sodio (NaAc, 99,7\%) marca Anedra (Argentina), formiato de amonio ( $\mathrm{FNH}_{4},>97 \%$ ) marca Alfa Aesar (Ward Hill, MA, EE.UU.) y ácido fórmico (96\%) de marca Tedia (Fairfield, OH, EE.UU.). Las sales empleadas en el método QuEChERS fueron sulfato de magnesio anhidro $\left(\mathrm{MgSO}_{4}\right.$, grado reactivo) marca Cicarelli (Argentina), adsorbente C18 Selectrasorb ${ }^{\text {TM }}$ y amina primaria-secundaria PSA Enviro-Clean ${ }^{\circledR}$ ambos de marca UCT (Brockville, Canadá). Las columnas de inmunoafinidad IAC fueron adquiridas de R-Biopharm Rhône (Glasgow, Escocia).

A partir de la solución patrón madre de AFM1 se preparó una dilución intermedia de 1 mg/L de concentración empleando acetonitrilo como diluyente, la cual se almacenó a $-18^{\circ} \mathrm{C}$ para su empleo en consecutivos análisis. Del mismo modo, a partir de la dilución intermedia se prepararon soluciones de trabajo de 100 y $50 \mu \mathrm{g} / \mathrm{L}$ las cuales se utilizaron para adicionar las muestras en estudios de recuperación y para la preparación de curvas de calibrado.

\section{Muestras}

Se tomaron muestras de leche cruda bovina de los tanques de enfriamiento de tambos seleccionados localizados en la zona central de la Provincia de Santa Fe y se congelaron inmediatamente hasta el momento del análisis. Como muestra blanco para los ensayos de adición y optimización del método se utilizó una leche obtenida en un establecimiento específico a la cual se le verificó previamente la ausencia de aflatoxina M1 mediante extracción IAC.

\section{Acondicionamiento de muestra}

Tras su descongelamiento en heladera, las muestras de leche se calentaron en un baño de agua a $37^{\circ} \mathrm{C}$ invirtiendo los recipientes suavemente de forma manual de tanto en tanto. Las muestras de leche así homogeneizadas se centrifugaron durante 15 minutos a $4^{\circ} \mathrm{C}$ y $3000 \mathrm{rpm}(1300 \mathrm{~g})$ para separar la grasa. La leche desgrasada se tomó cuidadosamente por medio de una jeringa desde la parte media de los tubos de centrífuga y se filtró por medio de papeles de filtro con ayuda de vacío. Para los ensayos de recuperación, porciones de leche entera y desgrasada se adicionaron con las soluciones estándar de trabajo de AFM1 
para obtener concentraciones de 0,$03 ; 0,05$ y $0,100 \mu \mathrm{g} / \mathrm{L}$. Las muestras adicionadas se agitaron suavemente durante 4 horas a temperatura ambiente para permitir un adecuado contacto analito-matriz.

\section{Procedimiento QuEChERS optimizado}

En tubos de polipropileno de $50 \mathrm{~mL}$ se colocó un volumen de $10 \mathrm{~mL}$ de leche, agregando luego $1 \mathrm{~mL}$ de solución $\mathrm{Na}_{2}$ EDTA $1 \mathrm{M}, 10 \mathrm{~mL}$ de acetonitrilo y agitando posteriormente en vórtex durante 30 segundos. Luego, se agregaron $4 \mathrm{~g}$ de sulfato de magnesio anhidro y $1 \mathrm{~g}$ de acetato de sodio y se agitó vigorosamente de forma manual durante 3 minutos para producir la separación de fases y la partición de los analitos entre las mismas. Luego las fases se separaron mediante centrifugación durante 6 minutos a $3000 \mathrm{rpm}$ o $1000 \mathrm{~g}$ a temperatura ambiente. Para realizar el clean-up se tomó una alícuota de $8 \mathrm{~mL}$ de la fase acetonitrilo superior y se transfirió a un tubo de centrífuga de $15 \mathrm{~mL}$ de capacidad con $200 \mathrm{mg}$ de $\mathrm{MgSO}_{4}, 67 \mathrm{mg}$ de PSA y $180 \mathrm{mg}$ de C18 pesados previamente. Tras una agitación manual durante 2 minutos, los tubos se centrifugaron durante 2 minutos a $3000 \mathrm{rpm}$. Finalmente, una alícuota de $5 \mathrm{~mL}$ del extracto limpio se llevó a sequedad bajo corriente suave de nitrógeno a $50-55^{\circ} \mathrm{C}$, se reconstituyó con posterioridad con $0,5 \mathrm{~mL}$ de una mezcla agua-metanol $(80: 20 \mathrm{v} / \mathrm{v})$ y se filtró a través de filtros de jeringa de nylon de 0,2 $\mu \mathrm{m}$ previo a la inyección al sistema UHPLC-MS/MS.

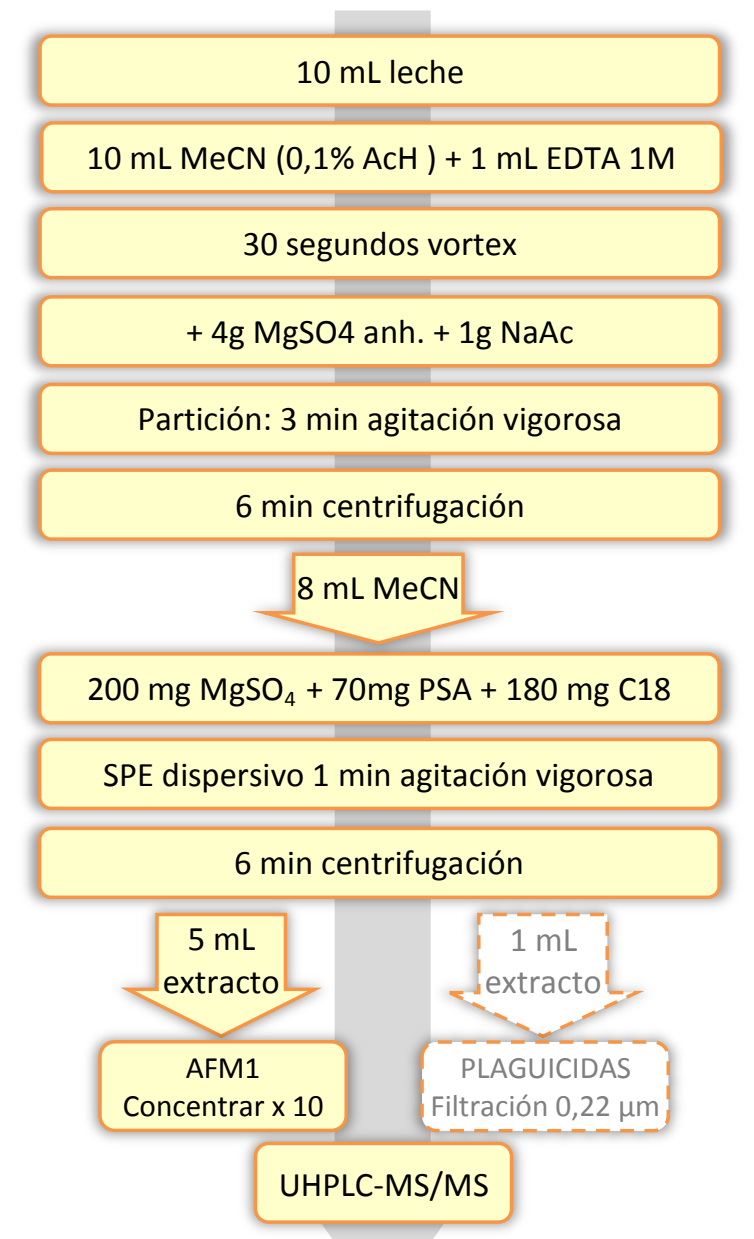

Figura 22. Esquema de extracción del procedimiento QuEChERS optimizado para la determinación de AFM1 en leche. 


\subsubsection{Optimización mediante diseños experimentales}

Optimización de la fase móvil

Se realizó un diseño factorial $3^{2}$ (dos factores estudiados en tres niveles, involucrando 9 experimentos) para optimizar la composición de la fase móvil de modo de incrementar la sensibilidad de AFM1 en términos del área del pico cromatográfico. Las variables seleccionadas fueron la concentración de $\mathrm{FNH}_{4}$ (niveles estudiados 0,5, 5,25 y $10 \mathrm{mM}$ ) y la concentración de ácido fórmico (niveles estudiados 0, 0,25 y 0,5\%) en ambos componentes de la fase móvil, el acuoso (A) y el orgánico (B).

\section{Optimización de la recuperación de AFM1}

Tomando como base el método propuesto por Mertzig y col. (2012) para la determinación de residuos de plaguicidas en leche [191], se propusieron modificaciones para aplicar la metodología a la determinación de AFM1 en el mismo tipo de muestra. Para ello se hizo uso de un diseño experimental para estudiar el modo en que las principales variables del método (factores) influencian la recuperación de AFM1 y determinar las condiciones óptimas para una adecuada recuperación. Como variables más relevantes a estudiar se seleccionaron el tiempo de agitación de la etapa de extracción/partición (factor A) y la cantidad de adsorbente $\mathrm{C} 18$ en la etapa de clean-up (factor B), estudiando estos dos factores en tres niveles mediante un diseño factorial $3^{2}$ (9 experimentos implicados) y analizando los resultados mediante la metodología de superficie de respuesta para obtener las condiciones óptimas. El factor A se estudió en 3, 6,5 y 10 minutos y el factor B se estudió en 50, 125 y 200 mg. En todas las experiencias la muestra de leche fue adicionada en nivel 0,1 $\mu \mathrm{g} / \mathrm{L}$ de AFM1 y como respuesta estudiada se analizó su \% de recuperación. Para realizar el análisis estadístico en ambas experiencias de optimización se utilizó el software Statgraphics ${ }^{\circledR}$ XV Centurion (StatPoint Technologies Inc., Warrenton, VA, EE.UU).

Teniendo en cuenta la interacción que se ha reportado que existe entre las moléculas de AFM1 y las micelas de caseína de la leche [192], se realizó un ensayo de optimización de la etapa inicial de extracción del método QuEChERS (el mezclado de la muestra con el solvente acetonitrilo) previo a la adición de sales de partición, de modo de lograr una extracción más efectiva. Para ello se evaluaron 3 modos de extracción diferentes: (a) extracción en vórtex durante 30 segundos, (b) extracción vigorosa manual durante 3 minutos y (c) extracción en ultrasonido durante 3 minutos. Para determinar la efectividad de extracción, en los ensayos se utilizó una muestra de leche naturalmente contaminada con AFM1, que fue en paralelo extraída con el método IAC como referencia. Además de esa muestra, se evaluó la recuperación de una muestra adicionada en nivel $0,05 \mu \mathrm{g} / \mathrm{L}$ con cada modo de extracción.

\subsubsection{Ensayos de validación}

La metodología optimizada se validó de acuerdo a la directiva europea 2002/657/EC que aplica al funcionamiento de los métodos analíticos para residuos orgánicos y contaminantes [189], y al documento SANTE/11945/2015 [190] sobre procedimientos de validación y control de calidad analítico para el análisis 
de residuos de plaguicidas en alimentos y piensos. Los parámetros analizados fueron los siguientes: exactitud, precisión, linealidad, especificidad, efecto matriz, límite de detección (LD) y límite de cuantificación (LC).

La exactitud y precisión se evaluaron por medio de estudios de recuperación adicionando muestras blanco (leche entera o descremada cuando correspondiera) con estándar de AFM1 en 3 niveles de concentración: 0,03, 0,05 y 0,1 $\mu \mathrm{g} / \mathrm{L}$. La linealidad se determinó usando calibración matrix-matched (en presencia de matriz) en niveles $0-0,25-0,5-1,0-5,0-10 \mu \mathrm{g} / \mathrm{L}$ que de acuerdo a la concentración que se realiza en el método representan niveles 10 veces más bajos en muestra. El efecto matriz se calculó como la relación de las pendientes de las curvas de calibración en solvente y matrix-matched (\%EM = pendiente matrix-matched /pendiente solvente $\times 100$ ). La especificidad del método se analizó comparando cromatogramas de muestras blanco con aquellos de las muestras adicionadas, y los límites de detección (LD) y cuantificación (LC) se estimaron usando una relación señal/ruido $\mathrm{S} / \mathrm{N}$ de 3 y 10 , respectivamente.

Finalmente, el método optimizado se aplicó en el análisis de muestras de leche cruda naturalmente contaminadas con AFM1, cuya concentración se determinó previamente utilizando la extracción IAC como método de referencia.

\subsubsection{Condiciones experimentales y analíticas}

Para la determinación analítica de la aflatoxina M1 se utilizó un cromatógrafo líquido de ultra-alta performance ACQUITY UPLC ${ }^{\mathrm{TM}}$ (Waters, Milford, MA, EE.UU.) acoplado a un espectrómetro de masa de triple cuadrupolo Micromass TQ Detector (Waters, Manchester, UK) por medio de una fuente de ionización electrospray (Waters ortogonal-Z-spray). La separación se realizó con una columna de fase reversa ACQUITY UPLC'M BEH RP Shield C18 (1,7 $\mu \mathrm{m} ; 2,1 \times 100 \mathrm{~mm})$ de Waters con un flujo de fase móvil de 0,3 mL/min y una temperatura de $40^{\circ} \mathrm{C}$. La fase móvil consistió en un componente acuoso $\mathrm{A}\left(5 \mathrm{mM} \mathrm{FNH}_{4}+0,1 \%\right.$ ácido fórmico en agua) y un componente orgánico $\mathrm{B}\left(5 \mathrm{mM} \mathrm{FNH}_{4}+0,1 \%\right.$ ácido fórmico en metanol), utilizando un programa de gradiente que comienza con $20 \%$ B durante 1 minuto, se incrementa linealmente durante 2 minutos hasta $100 \%$ B donde se mantiene durante 2 minutos para luego retornar a las condiciones iniciales en 1 minuto y re-equilibrar la columna durante otros 60 segundos antes de la próxima inyección, dando un tiempo total de corrida de 7 minutos. El volumen de inyección fue de $10 \mu \mathrm{L}$.

Los parámetros instrumentales operativos del espectrómetro de masa fueron los mismos que se utilizaron en la primer parte de este trabajo y se presentan en la Tabla 11. 


\subsubsection{RESULTADOS Y DISCUSIÓN}

\subsubsection{Optimización de la determinación instrumental UHPLC-MS/MS}

Durante el análisis de las muestras de leche extraídas por el método IAC se verificaron situaciones en las que no todos los criterios establecidos para la identificación y confirmación de AFM1 se satisficieron, implicando esto, en algunos casos, que no era detectable la transición de confirmación $(q)$. Esto hizo pensar que el sistema cromatográfico podía optimizarse aún más para obtener mayor sensibilidad en la detección. En ese sentido, se evaluó el uso de un tercer tipo de promotor de ionización en la fase móvil como el formiato de amonio, además del acetato de amonio y el ácido fórmico ensayados en la primer parte de este capítulo. Hasta el momento en que se realizó este trabajo, el uso de modificadores como $\mathrm{FNH}_{4}$ y $\mathrm{AF}$ en ambos componentes de la fase móvil (agua y metanol) había sido frecuentemente reportado en la literatura para el análisis multi-residuo de plaguicidas y otras micotoxinas y no así en la determinación de AFM1 en leche.

En esta etapa de nuestro estudio se evaluó el efecto en la sensibilidad cromatográfica de la AFM1 del uso de $\mathrm{AcNH}_{4}$ y $\mathrm{FNH}_{4}$ en ambos componentes de la fase móvil (acuoso y orgánico). Se observó un incremento del $70 \%$ en las áreas de las dos transiciones analizadas cuando se cambiaba de una solución 0,5 mM de $A c \mathrm{NH}_{4}$ a una de $\mathrm{FNH}_{4}$ de igual concentración. Así mismo, un incremento de la concentración de formiato de amonio de 0,5 a $5 \mathrm{mM}$ producía un incremento adicional de alrededor del $40 \%$ en los valores de área, con el respectivo aumento en los valores de relación S/N (Figura 23). Similares aumentos en la sensibilidad cromatográfica de AFM1 han sido reportados en aplicaciones relacionadas de métodos multi-toxinas $[186,193]$.

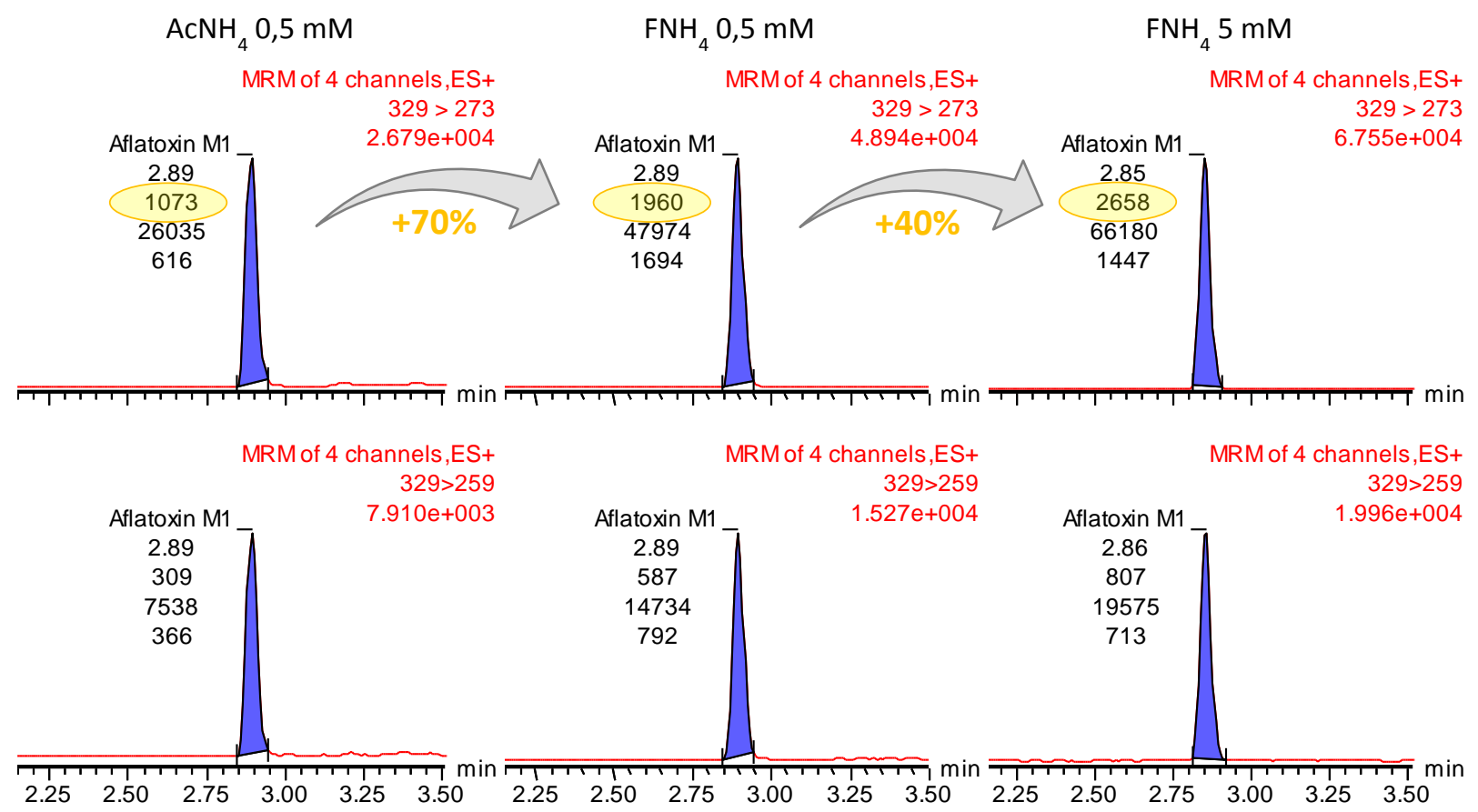

Figura 23. Cromatogramas de las transiciones MRM de AFM1 obtenidos empleando fases móviles con distintos promotores de ionización. 
El incremento en la sensibilidad cromatográfica de la AFM1 utilizando formiato en lugar de acetato de amonio se vio reflejado también las pendientes de curvas de calibrado tanto en solvente como en extractos de leche obtenidos por los métodos en estudio (IAC y QuEChERS) (Figura 24).

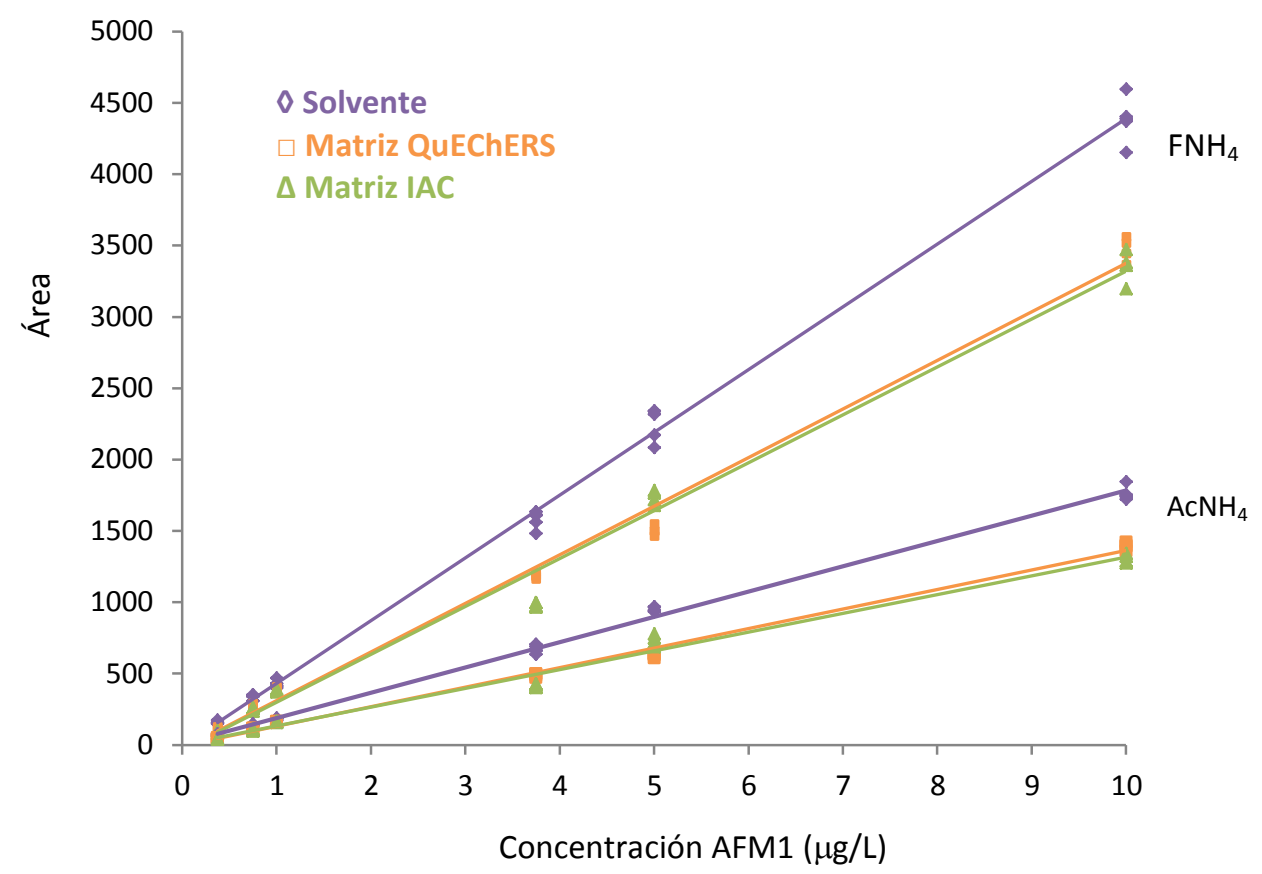

Figura 24. Curvas de calibrado de AFM1 en solvente y matriz (leche, IAC-QuEChERS) obtenidas utilizando fases móviles con formiato y acetato de amonio $0,5 \mathrm{mM}$ como promotores de ionización.

Con los resultados anteriores se propuso optimizar la composición de la fase móvil a través de un diseño de experimento utilizando formiato de amonio y ácido fórmico como modificadores. El nivel menor de $\mathrm{FNH}_{4}$ estudiado $(0,5 \mathrm{mM})$ se eligió por ser la concentración más baja que se había ensayado en las pruebas previas, y el nivel mayor $(10 \mathrm{mM})$ por ser la concentración máxima recomendada para modificadores cuando se trabaja en sistemas MS/MS. En cuanto al ácido fórmico, su concentración se seleccionó como segunda variable de estudio debido a la gran discordancia en los valores utilizados en la bibliografía consultada. En este diseño, el nivel menor (0\%) se eligió para estudiar si su presencia tiene efecto significativo y el nivel máximo $(0,5 \%)$ se seleccionó de manera arbitraria.

El análisis ANOVA indicó que ninguno de los factores estudiados exhibían efectos significativamente distintos de cero ( $p=0,088$ para la concentración de $\mathrm{FNH}_{4}$ y $p=0,932$ para \% de AF), para un nivel de confianza del 95\%, aunque la gráfica de efectos principales evidenció que la respuesta cromatográfica de AFM1 presentaba cierta linealidad en la relación con la concentración de $\mathrm{FNH}_{4}$ (Material suplementario). Basados en los resultados obtenidos con el diseño de experimentos se decidió continuar trabajando con la fase móvil ensayada previamente: $5 \mathrm{mM} \mathrm{FNH}_{4}+0,1 \% \mathrm{AF}$ en agua (A) y $5 \mathrm{mM} \mathrm{FNH}+4,1 \% \mathrm{AF}$ en metanol (B). 


\subsubsection{Optimización del procedimiento de preparación de muestras (QuEChERS)}

La extracción de compuestos de elevada o mediana polaridad de matrices complejas como la leche representa siempre un desafío, especialmente cuando se requieren metodologías multi-clase orientadas a gran cantidad y variedad de compuestos. Si bien en esta etapa inicial del trabajo de tesis el foco estuvo puesto en optimizar un método alternativo al IAC para la extracción de AFM1 en leche, para la optimización del mismo se tuvo en cuenta la aptitud que debía tener el método para extenderlo a otros tipos de compuestos de interés, como plaguicidas y otras micotoxinas. En ese sentido, la extracción QuEChERS se basó en el método propuesto por Mertzig y col. (2013) para la determinación de plaguicidas en leche [191]. Aunque en todos los métodos de extracción de micotoxinas el solvente de elección es el metanol, en este caso se eligió el acetonitrilo por su capacidad de solubilizar compuestos de un amplio rango de polaridades, lo que lo hace idealmente compatible con métodos multi-residuo. Se adoptó entonces una extracción QuEChERS bufferizada con adición de $10 \mathrm{~mL}$ de acetonitrilo (1\% ácido acético) como solvente extractor sobre la muestra de leche seguida de una partición líquido-líquido inducida por el agregado de sales $\left(\mathrm{MgSO}_{4}\right.$ y $\left.\mathrm{AcNa}\right)$. Debido a que la AFM1 puede ligarse a la caseína de la leche se agregó también entre los reactivos $1 \mathrm{~mL}$ de solución de $\mathrm{Na}_{2}$ EDTA $1 \mathrm{M}$ para facilitar la disolución de las micelas de caseína y favorecer la liberación y extracción de la micotoxina de interés, por el efecto secuestrante del fosfato de calcio coloidal por parte del EDTA [194].

Como se mencionó anteriormente, el proceso de extracción fue optimizado mediante la aplicación de un diseño de experimentos con el cual se estudió el efecto de dos variables (el tiempo de agitación en la etapa de extracción/partición y la cantidad de adsorbente C18 en la etapa del clean-up) sobre la recuperación de AFM1. La importancia de la agitación durante la extracción y partición líquido-líquido con acetonitrilo en todo método QuEChERS es bien conocida, como también lo es el tiempo durante el cual se realiza esa agitación por lo que esta última variable se incluyó como factor de estudio en el diseño de experimento. Por otro lado, en la mayoría de los protocolos de análisis de residuos la leche se clasifica típicamente como una matriz de bajo contenido graso (2-20\%), pero que sin embargo puede transferirse a la fase orgánica extractiva e interferir en la respuesta analítica del sistema LC-MS/MS o afectar el comportamiento y mantenimiento del sistema cromatográfico. Por eso se han propuesto adaptaciones a la etapa de clean-up original del QuEChERS mediante el agregado de adsorbente C18 que presenta afinidad por compuestos poco polares [107]. La cantidad de C18 en esta etapa fue entonces seleccionada como segunda variable de estudio en el diseño de experimento. Los factores y niveles estudiados en el DDE fueron entonces: tiempo de extracción (3, 6,5 y 10 minutos) y cantidad de $C 18(50,125$ y $200 \mathrm{mg})$, analizando como respuesta la recuperación de AFM1 (\%REC) (Material suplementario).

La recuperación de AFM1 (\%REC) en todos los experimentos varió entre 59 y $109 \%$ y el análisis de la varianza ANOVA indicó que la cantidad de C18 era la única variable con efecto significativo sobre la respuesta, con un nivel de confianza del $95 \%(p=0,032)$, no siendo significativos el otro factor estudiado o 
sus interacciones para el mismo nivel de confianza $(p>0,05)$. De acuerdo a los datos cargados en el diseño, la optimización de la respuesta ( $\mathrm{REC}=100 \%$ ) se obtenía con un tiempo de agitación de 3 minutos y $180 \mathrm{mg}$ de C18, valores que se adoptaron como los definitivos.

\subsubsection{Optimización adicional}

Adicionalmente, la efectividad en la extracción inicial previa a la separación de fases se evaluó mediante 3 mecanismos: agitación con vórtex, agitación vigorosa manual y extracción en ultrasonido. Para la evaluación se adicionó una muestra de leche con 0,05 $\mu \mathrm{g} / \mathrm{L}$ de AFM1 y en paralelo se analizó con los tres mecanismos una muestra naturalmente contaminada cuya concentración se determinó utilizando columnas IAC como referencia. El análisis de la varianza indicó que no existía diferencia significativa entre las medias de las concentraciones obtenidas por los 3 mecanismos de extracción, siendo además aceptables los niveles de recuperación obtenidos en cada caso (Tabla 16 y Figura 25).

Tabla 16. Performance de la extracción de AFM1 por 3 mecanismos previo a la partición utilizando la metodología QuEChERS.

\begin{tabular}{lll}
\hline Mecanismo de extracción & $\begin{array}{l}\text { AFM1 en muestra } \\
\text { incurrida } \\
\left(\mu \mathrm{g} \mathrm{L}^{-1}\right)^{*, * *}\end{array}$ & $\begin{array}{l}\text { Recuperación } \\
\left(0,05 \mu \mathrm{g} \mathrm{L}^{-1}\right)^{*}\end{array}$ \\
\hline a) Vórtex 30 segundos & 0,184 & $84 \%$ \\
b) Agitación manual 3 minutos & 0,180 & $106 \%$ \\
c) Ultrasonido 3 minutos & 0,178 & $75 \%$ \\
IAC (método de referencia) & 0,187 & $111 \%$ \\
\hline *Valores medios ( $\mathrm{n}=3$ 3) & & \\
${ }^{* *}$ ANOVA $p=0,58$ (nivel de confianza 95\%).
\end{tabular}

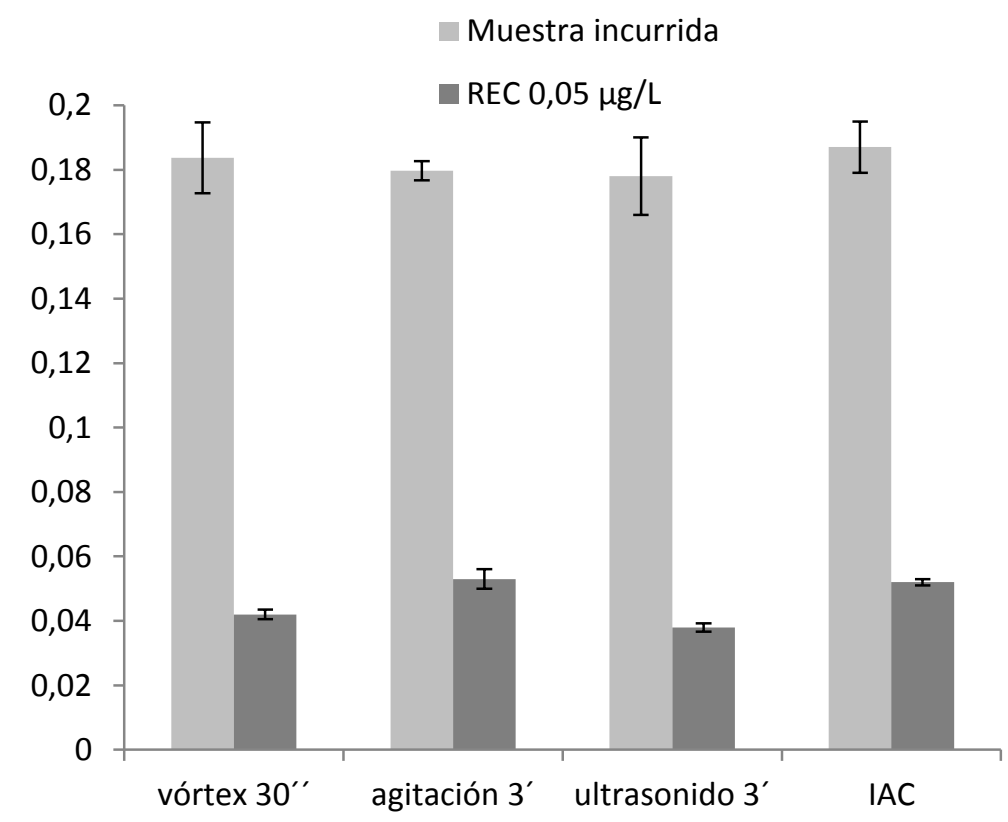

Figura 25. Concentración de AFM1 hallada en una muestra incurrida naturalmente $(0,187 \mu \mathrm{g} / \mathrm{L})$ y en ensayo de recuperación $(0,05 \mu \mathrm{g} / \mathrm{L})$ aplicando el método QUEChERS mediante 3 alternativas de extracción distintas. 
Por razones prácticas (menor tiempo de análisis y menor manipulación de la muestra) se optó finalmente por la extracción con vórtex durante 30 segundos como mecanismo de contacto inicial entre la muestra de leche y el solvente acetonitrilo.

La técnica IAC requiere que la muestra de leche sea desgrasada antes de pasarla por la columna debido a que los glóbulos de grasa pueden ocluir los sitios de adsorción de AFM1. En ese sentido, se evaluó la performance del método QuEChERS optimizado en la extracción de AFM1 en leche entera y desgrasada, obteniéndose recuperaciones dentro de los niveles aceptables en análisis de micotoxinas (Tabla 17).

Tabla 17. Comparación de recuperaciones obtenidas aplicando el método QuEChERS optimizado a leche desgrasada y entera.

\begin{tabular}{|c|c|c|c|c|c|c|}
\hline & \multicolumn{6}{|c|}{ Nivel de adición $\left(\mu \mathrm{g} \mathrm{L}^{-1}\right)$} \\
\hline & \multicolumn{2}{|l|}{0,03} & \multicolumn{2}{|l|}{0,05} & \multicolumn{2}{|l|}{0,1} \\
\hline & $\% \operatorname{Rec}$ & $\operatorname{DER}^{a}(n)$ & $\% \operatorname{Rec}$ & $\operatorname{DER}^{b}(n)$ & $\% \operatorname{Rec}$ & $\operatorname{DER}^{\mathrm{a}}(\mathrm{n})$ \\
\hline Leche desgrasada & 66 & $4(3)$ & 96 & $11(9)$ & 98 & $13(3)$ \\
\hline Leche entera & 83 & $10(3)$ & 81 & $15(6)$ & 70 & $13(3)$ \\
\hline
\end{tabular}

A pesar de la presencia de grasa en la leche entera que podría pasar al acetonitrilo, no se observaron diferencias apreciables en los perfiles de los cromatogramas y en el nivel de ruido de los mismos. En consecuencia, como muestra sometida al análisis se adoptó el uso de la leche entera tal cual, sin etapa de desgrasado previa como requiere la técnica IAC, asegurando también la compatibilidad del procedimiento QuEChERS optimizado como método multi-clase multi-residuo para el análisis de plaguicidas. Esto último se discutirá en el Capítulo 3 de la presente tesis.

\subsubsection{Validación del método}

\section{Linealidad}

Los parámetros de regresión lineal obtenidos con las calibraciones en solvente acentonitrilo y matrixmatched se resumen en la Tabla 18. Los criterios de aceptación para la evaluación de la linealidad se basaron en la inspección visual de las curvas trazadas, en valores de coeficientes de regresión $\left(r\right.$ y $\left.r^{2}\right)$ cercanos a la unidad, y verificando que en todo el rango de calibración los residuos no superaran el $\pm 20 \%$. En el caso que los residuos sobrepasaran dicho rango se reemplazó el modelo de regresión lineal simple por el modelo de regresión lineal ponderada $(1 / x)$, de acuerdo a lo establecido por la directiva SANTE/11945/2015. 
Tabla 18. Parámetros de regresión de AFM1 obtenidos en el estudio de calibración en matriz (leche cruda entera) y en solvente (acetonitrilo) utilizando el método de extracción QuEChERS optimizado.

\begin{tabular}{lclllllll}
\hline & $\mathrm{t}_{\mathrm{R}}$ & $\begin{array}{l}\text { Pendiente } \\
\left(\mathrm{S}_{\mathrm{s}}\right)\end{array}$ & $\begin{array}{l}\text { Intercepto } \\
\left(S_{\mathrm{i}}\right)\end{array}$ & $\mathrm{r}^{2}$ & $\begin{array}{l}\mathrm{RL} \\
\left(\mu \mathrm{g} \mathrm{L}^{-1}\right)\end{array}$ & $\begin{array}{l}\mathrm{EM}^{\mathrm{a}} \\
\%\end{array}$ & $\begin{array}{l}\mathrm{LD} \\
\left(\mu \mathrm{g} \mathrm{L}^{-1}\right)\end{array}$ & $\begin{array}{l}\mathrm{LC} \\
\left(\mu \mathrm{g} \mathrm{L}^{-1}\right)\end{array}$ \\
\hline Calibración-matriz & 2,86 & 218,282 & $-5,629$ & 0,9998 & $0,25-10$ & 75 & 0,002 & 0,007 \\
& & $(1,211)$ & $(3,516)$ & & & & & \\
Calibración-solvente & 2,85 & $\begin{array}{l}288,833 \\
\text { (1,731) }\end{array}$ & $\begin{array}{l}5,751 \\
(9,689)\end{array}$ & 0,9996 & $0,25-10$ & & & \\
& & & & & & \\
\hline
\end{tabular}

$\mathrm{t}_{\mathrm{R}}$ : tiempo de retención; $\mathrm{S}_{\mathrm{s}}$ : error estándar de la pendiente; $\mathrm{S}_{\mathrm{i}}$ : error estándar del intercepto; RL: rango lineal; $\mathrm{EM}$ : efecto matriz; LD: límite de detección; LC: límite de cuantificación.

${ }^{\mathrm{a}}$ Efecto Matriz \% calculado como (pendiente-matriz/pendiente-solvente)*100

\section{Efecto matriz}

Se observó un efecto de supresión iónica significativa por parte de la matriz leche al comparar curvas de calibración matrix-matched y en solvente preparadas en el mismo rango de concentraciones $(0,25,0,5,1,5$ y $10 \mu \mathrm{g} / \mathrm{L}$ ), reduciéndose la señal alrededor de un $25 \%$ en el caso del QuEChERS de leche entera. El efecto matriz calculado relacionando las pendientes de ambas curvas de calibración resultó ser de un 75\% (Tabla 18). Esta supresión de la señal del método QuEChERS fue más elevada que la observada con la extracción IAC que exhibió un efecto matriz del 85\% (es decir, una reducción del 15\% en la intensidad de la señal). En el caso de utilizar leche desgrasada como muestra de análisis no se observó un comportamiento diferenciado de la matriz en relación con la supresión de señal respecto a la leche entera, lo que refleja que más que la presencia de grasa es la heterogeneidad propia de la matriz lo que influencia en gran medida el mecanismo de ionización por electrospray (ESI) debido a la co-elución del analito con los distintos componentes de la matriz. Para compensar esta interferencia de la matriz se emplearon curvas de calibración matrix-matched para la cuantificación de AFM1 en extractos de leche cruda obtenidos con el método QuEChERS optimizado.

\section{Límites de determinación}

El límite de detección (LD) fue estimado como la menor concentración de analito que producía un pico cromatográfico con una relación $\mathrm{S} / \mathrm{N}$ igual a 3 para la transición de cuantificación $(Q)$. En tanto, el límite de cuantificación (LC) se estimó como la menor concentración de analito que producía una relación S/N igual a 10 para la misma transición al mismo tiempo que la transición de confirmación $(q)$ debía presentar una relación $\mathrm{S} / \mathrm{N}$ igual a 3. Así, para la metodología QuEChERS optimizada los LD y LC calculados para AFM1 en leche cruda entera resultaron ser 0,002 y $0,007 \mu \mathrm{g} / \mathrm{L}$, respectivamente. Estos valores dan muestra de la aptitud que presenta el método optimizado para verificar el cumplimiento de los niveles máximos de AFM1 permitidos en leche establecidos por distintas regulaciones a nivel mundial $(0,5 \mu \mathrm{g} / \mathrm{L}$ en MERCOSUR, Estados Unidos, China y otros países, y 0,05 $\mu \mathrm{g} / \mathrm{kg}$ en la Unión Europea). 


\section{Exactitud y precisión}

La exactitud del método se estimó a partir de los valores medios de recuperación obtenidos de la adición AFM1 en leche cruda entera e incluyendo en el diseño de los ensayos réplicas independientes por triplicado en cuatro niveles de concentración $(0,03,0,05,0,1$ y $0,5 \mu \mathrm{g} / \mathrm{L})$, con el foco puesto en el nivel máximo permitido por la Unión Europea $(0,05 \mu \mathrm{g} / \mathrm{kg})$. Los resultados obtenidos fueron satisfactorios, con valores entre 70 y $95 \%$ (Tabla 19).

Tabla 19. Parámetros de exactitud y precision del método QuEChERS optimizado obtenidos de la adición de AFM1 en muestras de leche cruda entera.

\begin{tabular}{|c|c|c|c|c|}
\hline & \multicolumn{4}{|c|}{ Nivel adicionado $\left(\mu \mathrm{g} \mathrm{L}^{-1}\right)$} \\
\hline & 0,03 & 0,05 & 0,1 & 0,5 \\
\hline Recuperación media & $70 \%$ & $95 \%$ & $83 \%$ & $78 \%$ \\
\hline DER intra-día & $13 \%$ & $15 \%$ & $10 \%$ & $14 \%$ \\
\hline DER inter-día & NE & $16 \%$ & NE & NE \\
\hline $\mathrm{n}$ & 3 & 10 & 3 & 3 \\
\hline
\end{tabular}

La precisión en términos de repetibilidad se evaluó a través de la desviación estándar relativa (DER) de los valores de recuperación obtenidos en réplicas de adición realizadas el mismo día de análisis (intra-día). Para los 4 niveles de concentración evaluados y presentados en la Tabla 19 los valores de DER fueron menores del 15\%. La variabilidad inter-día, evaluada a partir de mediciones repetidas del nivel 0,05 $\mathrm{\mu g} / \mathrm{L}$ en distintos días de análisis, fue del 16\%. Estos valores se encuentran dentro de los niveles establecidos por los criterios de aceptación de las guías y documentos para el análisis de residuos y contaminantes $[189,190]$.

Finalmente, la especificidad del método se evaluó analizando los cromatogramas obtenidos a partir de extractos blancos de reactivos y de leches blanco confirmando la ausencia de señales interferentes en la zona cercana al tiempo de retención de AFM1.

\subsubsection{Análisis de muestras reales}

Para evaluar la efectividad del método en muestras contaminadas naturalmente, se analizó una selección de 20 muestras en las que la presencia de AFM1 se había determinado previamente mediante el método IAC-LC-MS/MS descripto anteriormente en este capítulo. La selección de muestras se hizo de manera de abarcar un rango amplio de concentraciones, entre $\angle \mathrm{LD}$ y $0,187 \mu \mathrm{g} / \mathrm{L}$. Como resultado, se observó una concordancia aceptable entre los valores hallados mediante los 2 métodos, en especial cuando la concentración de AFM1 es superior a 0,025 $\mathrm{g} / \mathrm{L}$ (Figura 26). Esto se verificó también mediante un test de comparación de muestras pareadas en el que se verificó que la diferencia entre las concentraciones de los dos métodos no era significativa ( $p=0,316)$ (Material Suplementario). 


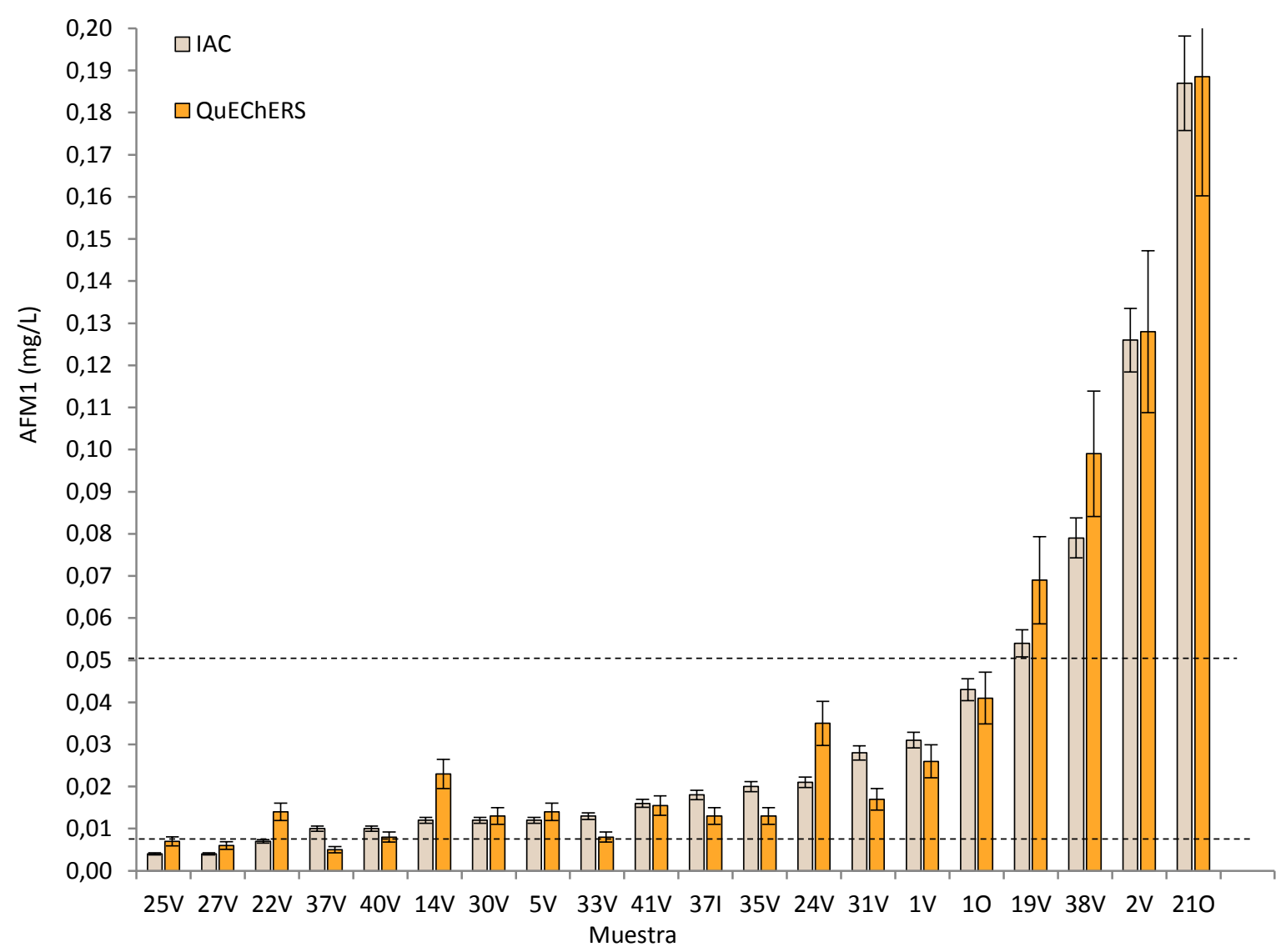

Figura 26. Comparación de la concentración de AFM1 obtenida en 20 muestras naturalmente contaminadas analizadas por el método IAC (referencia) y el método QuEChERS optimizado. En líneas punteadas se marcan el límite máximo de Unión Europea y el límite de cuantificación del segundo método.

Estos resultados cumplen con las especificaciones establecidas por la guía EC/657/2002 sobre la exactitud que deben tener los métodos cuantitativos de análisis. En los niveles de concentración más bajos $(<0,025$ $\mu \mathrm{g} / \mathrm{L}$ ) se observó mayor variabilidad en los resultados probablemente debido a deficiencias en la ionización de AFM1 en tan bajas concentraciones en presencia de la gran cantidad de compuestos interferentes provenientes de una matriz tan compleja como la leche cruda. En la Figura 27 se muestran cromatogramas representativos de AFM1 obtenidos aplicando el método QuEChERS en muestras de leche adicionadas y naturalmente contaminadas. 


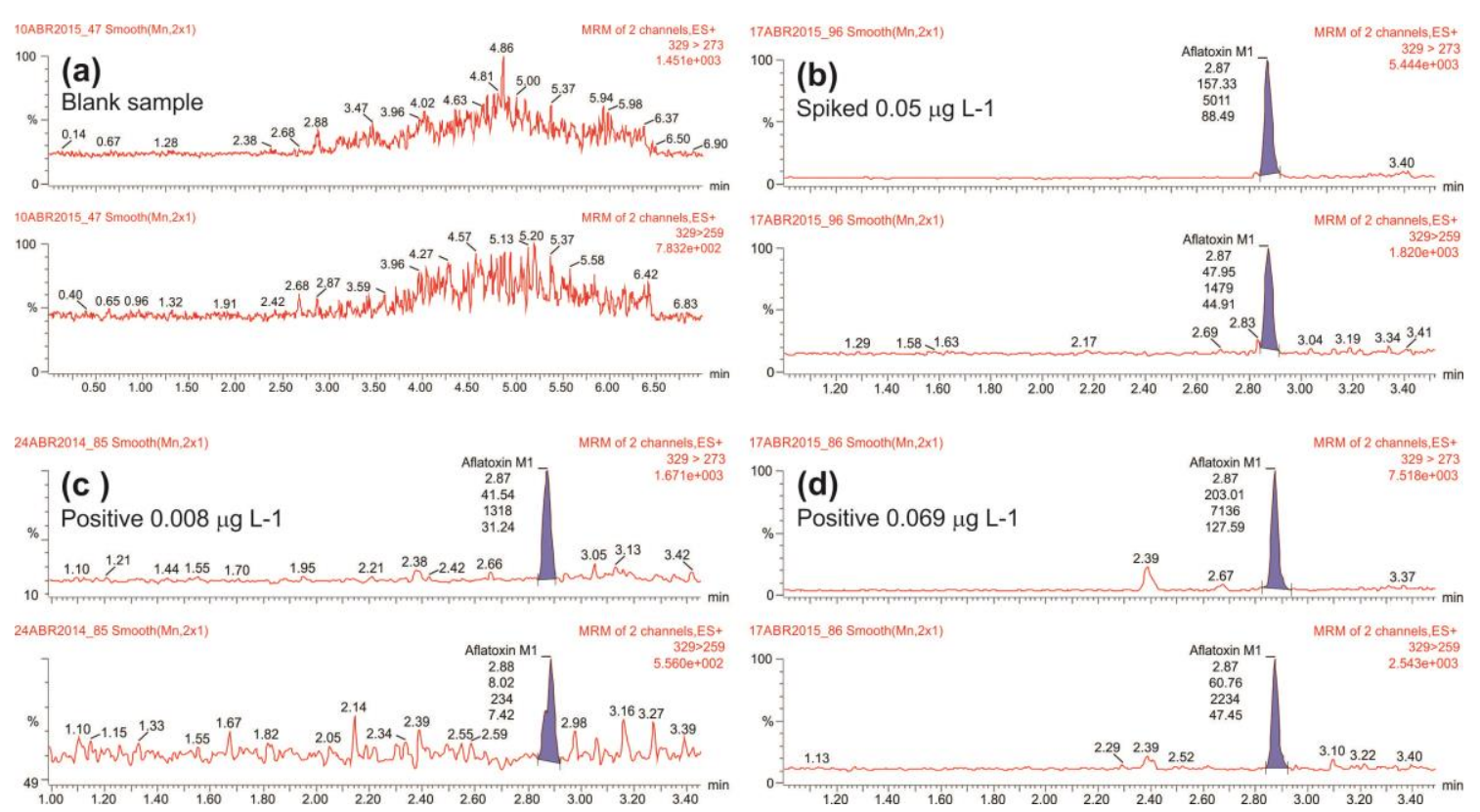

Figura 27. Cromatogramas resultantes de la aplicación de la metodología QuEChERS optimizada al análisis de: (a) muestra blanco, (b) leche adicionada en el LMR establecido por la UE, (c) muestra positiva con concentración próxima el límite de cuantificación $(0,007 \mu \mathrm{g} / \mathrm{L})$ y (d) muestra positiva con concentración próxima al LMR de la UE.

\subsubsection{CONCLUSIONES DE LA PARTE 2}

Se propuso una metodología alternativa basada en la extracción QuEChERS para la determinación de AFM1 en leche cruda con resultados satisfactorios. Mediante los ensayos de optimización planificados se lograron mejoras en el desempeño analítico, especialmente en la etapa instrumental alcanzándose cifras de mérito compatibles con las normativas vigentes de Mercosur y EU.

Se alcanzó así el objetivo principal de optimizar un procedimiento de extracción basado en estrategias multi-residuo-multi-clase actuales, no suficientemente desarrollado en la bibliografía existente.

Debido a la simplicidad que presentan las estrategias basadas en el método QuEChERS, el procedimiento aquí optimizado podría reemplazar o complementar el método IAC que es extensamente utilizado debido a su alta confiabilidad, pero que presenta limitaciones en cuanto al elevado costo de las columnas y al tiempo de uso de las mismas producto de la estabilidad de los anticuerpos involucrados.

Esto es una contribución de interés para aumentar el rendimiento y disminuir el costo analítico de los laboratorios de control de residuos, aportando así al mejoramiento de los sistemas de monitoreo de AFM1 en leche. 
CAPÍTULO 3

Determinación de residuos de plaguicidas en leche 


\section{CAPÍTULO 3: Determinación de residuos de plaguicidas en leche.}

\subsection{INTRODUCCIÓN}

\subsubsection{Plaguicidas en la leche}

El análisis de residuos de plaguicidas en leche representa un gran desafío por la complejidad del tipo de matriz y por el amplio espectro de compuestos a determinar, derivados de la utilización de cantidades cada vez más grandes de agroquímicos como herramientas necesarias para la intensificación de la producción. Por eventual contacto directo o por vía de la ingesta durante la alimentación, diversos plaguicidas pueden ingresar al organismo del ganado lechero y ser distribuidos metabólicamente alcanzando tejidos y glándulas mamarias desde donde pasan a la leche para llegar finalmente al consumidor.

La leche bovina es uno de los alimentos de origen natural más completos que existen debido a que es fuente rica de proteínas, grasas, vitaminas y minerales (Tabla 8 Cap.1). Desde el punto de vista químico, es el líquido ideal para disolver contaminantes ambientales como los plaguicidas debido a que la mayoría de éstos son solubles en lípidos. Este alimento puede contener niveles considerables de residuos de plaguicidas como resultado de la acumulación de éstos en los tejidos de los animales, como consecuencia de su exposición al consumir piensos o agua contaminados [195].

Los plaguicidas son diseñados para infligir daños biológicos serios en el control de las plagas, y del mismo modo pueden afectar seriamente la actividad biológica de enzimas similares presentes en los organismos de los seres humanos infantes y adultos.

Para evitar el riesgo potencial que presentan los residuos de plaguicidas en la leche y sus productos derivados, es importante que los productores, las agencias de regulación y los mismos consumidores establezcan medidas apropiadas para eliminar o minimizar la presencia de estos residuos [196].

\subsubsection{Legislación}

Con el fin de promover la seguridad alimentaria, las agencias de regulación de distintos países y bloques comerciales han establecido a través de diferentes legislaciones límites máximos de residuo de plaguicidas en leche, cuyo cumplimiento protege a los consumidores de la exposición a estas sustancias en niveles perjudiciales y propicia el intercambio comercial. A nivel internacional la Comisión del Codex Alimentarius, organismo subsidiario de la Organización de las Naciones Unidas para la Agricultura y la Alimentación (FAO) y de la Organización Mundial de la Salud (OMS), ha establecido, hasta su $39^{\circ}$ período de sesiones inclusive (julio de 2016), los LMR para 141 plaguicidas en leche [197]. En Argentina, el Código Alimentario Argentino (CAA) en su capítulo VIII establece límites máximos de residuos para 71 plaguicidas en leches para ser consumidas como tal o destinadas a la elaboración de productos lácteos [198]. Cabe destacar que estos límites establecidos por el CAA son adoptados del Códex Alimentarius en sus versiones de 1993 y 1995, y no han sido actualizados hasta la fecha. Complementariamente, el Servicio Nacional de Sanidad y Calidad Agroalimentaria (SENASA) ha establecido por Resolución 559 del año 2011 LMRs para una serie de 21 
plaguicidas autorizados como antiparasitarios de uso externo, algunos de los cuales no son contemplados en la legislación del CAA y otros presentan valores máximos permitidos distintos respecto a éste (Tabla 20).

Tabla 20. Límites máximos de residuo $(\mu \mathrm{g} / \mathrm{kg}$ ) de plaguicidas en leche adoptados por la legislación Argentina y por el Codex Alimentarius.

\begin{tabular}{ll}
\hline LMR & Legislación Argentina $^{\text {a }}$ \\
\hline 0 & aldicarb, aldrin, dieldrin, heptacloro \\
$<10$ & metidation (1), clordano (2), fenitrotion (2), \\
& endosulfan (4), abamectina (5), bifentrin (5)
\end{tabular}

amitraz, anilazina, ciflutrina, ciromazina, chinometionat, clofentezina, clorpirifosmetilo, diquat, disulfoton, flusilazol, mecarbam, metamidofos, miclobutanil, paraquat, penconazol, profenofos, propiconazol, tebuconazole, terbufos, triadimenol, triazofos amitraz, ciromazina, fenitrotion, pirimifosmetilo

20 clorpirifos, DDT, diazinon, diclorvos, fosmet, imidacloprid, metomilo clorpirifos, diazinon, diclorvos, fipronil,

30-40 cialotrina (30), ciflutrina (40), flumetrina (30)

50 2,4-D, azociclotin, bendiocarb, bentazona, carbofuran, cihexatin, cipermetrina, cletodim, deltametrina, diflubenzurón, ditiocarbamatos, etefon, fenobutatin óxido, fention, flumetrin, flutolanil, forato, metopreno, pirimicarb, pirimifos-metilo, propoxur, triadimefon, vinclozolin carbarilo, deltametrina, triclorfon

100 acefato, carbarilo, carbendazim, dicofol, fenpropatrin, fenvalerato, glifosato, permetrin, procloraz, propargita cipermetrina, imidacloprid, metopreno, permetrina

>200 piperonil-butóxido (200), spinosad (1000)
Codex Alimentarius ${ }^{b}$

aldrin (6), benzoato de emamectina (2), ciprodinil $(0,4)$,

clordano (2), dieldrin (6), fenamifos (5), heptacloro (6), lindano (1), metidation (1), paraquat (5), protioconazol (4), spirodiclofen (4), spirotetramat (5), trinexapac-etilo (5) 2,4-D, aldicarb, amitraz, azoxistrobina, bentazona, benzovindiflupir, bifenazato, buprofezin, ciflumetofeno, ciflutrina, ciproconazol, ciromazina, clorpirifos-metilo, clorprofam, diclobenil, diclorvos, difenilamina, dimetenamid-P, dimetipin, dimetomorf, diquat, ditianon, endosulfan, espinetoram, etefon, etoprofos, etoxazole, fenamidona, fenbuconazol, fenhexamide, fenitrotion, fenpiroximato, fenpropatrin, fenpropimorf, fludioxonil, flufenoxurón, flutriafol, forato, imazamox, imazapir, isopyrazam, isoxaflutol, kresoxim-metilo, mesotriona, metaflumizone, metrafenona, miclobutanilo, oxidemetónmetilo, pirimetanil, pirimicarb, pirimifos-metilo, profenofos, propamocarb, propiconazol, quinoxyfen, saflufenacil, sedaxane, tebuconazol, tebufenozida, terbufos, triadimefon, triadimenol, triforina acefato, acetoclor, aminociclopiraclor, aminopiralid, cicloxidim, clotianidin, DDT, diazinon, difenoconazol, diflubenzuron, etofenprox, flumioxazin, fluopicolide, fluxapiroxad, fosmet, glufosinato-amonio, metamidofos, metomilo, oxamilo, trifloxistrobin, triflumizol

famoxadona (30), piraclostrobin (30), MCPA (40), pentiopirad (40)

bitertanol, carbarilo, carbendazim, cipermetrin, cletodim, clofentezina, clorantraniliprol, deltametrina, ditiocarbamatos, fenbutatin-óxido, flusilazol, flutolanil, glifosato, hexitiazox, metoxifenozida, piperonil-butóxido, procloraz, tiacloprid, tiametoxam clorotalonil (70)

boscalid, dinotefuran, fenvalerato, flubendiamide, imazapic, imidacloprid, indoxacarb, lufenuron, metopreno, propargita

acetamiprid (200), bifentrin (200), cialotrin-lambda (200), ciantraniliprol (600), dicamba (200), fluopyram (600), haloxifop (300), novaluron (400), sulfoxaflor (200)

${ }^{a}$ En letra normal, LMRs según Código Alimentario Argentino, adoptados de Codex Alimentarius (Vol. II - Supl 1-1993 y Vol. II B 1995). En letra cursiva, compuestos autorizados como antiparasitarios externos con LMRs según Resolución SENASA 559/2011. ${ }^{\mathrm{b}} \mathrm{ML} 0106$ - Leches. Actualización 2016 [197]

Por otra parte, la Unión Europea establece límites máximos de residuo para alrededor de 1100 plaguicidas de uso actual y pasado en la agricultura en 315 clases de alimentos frescos de origen vegetal y animal entre 
los que se incluye la leche bovina [199], y en Estados Unidos la Administración de Alimentos y Medicamentos (FDA) ha fijado límites individuales para 179 plaguicidas en leche cruda [200].

\subsubsection{Determinación de plaguicidas en leche}

Una de las mayores dificultades asociadas con la determinación de residuos de plaguicidas en leche es el elevado contenido de grasas y proteínas de la matriz que pueden interferir en la determinación analítica. Por esta razón, la extracción de muestras resulta en procedimientos extensos y tediosos que involucran varias etapas de clean-up para remover los componentes co-extraídos de la matriz [112].

En el diseño de metodologías analíticas para la determinación de residuos de plaguicidas en matrices con contenido graso, Lehotay y col. (2005) propusieron una clasificación de los alimentos en tres grupos: no grasos (<2\% de contenido lipídico), bajos en grasa (2-20\%) y alimentos de alto contenido graso (>20\%). Cuando se trata de alimentos bajos en grasa como la leche, los métodos analíticos deben idearse para la extracción de compuestos en un amplio rango de polaridades ya que pueden estar presentes tanto plaguicidas lipofílicos como hidrofílicos [107].

Antes de la primera publicación del método QuEChERS en el año 2003, los métodos más universalizados para la extracción de plaguicidas de alimentos de origen animal eran la extracción en fase sólida (SPE) y la extracción líquido-líquido (LLE). Este último consiste en varias etapas de agitación de la muestra en presencia de una variada selección de solventes orgánicos que extraen a los plaguicidas del seno de la leche, y cuya elección depende de las clases de compuestos que se quieren determinar derivando en la mayoría de los casos en la necesidad de utilizar más de un tipo de solvente, en especial en métodos multiresiduo. Así, la LLE ha sido el método de elección para el análisis de leche fluida, antes e incluso después del 2003, utilizando distintas etapas de extracción con solventes como etanol, acetato de etilo, acetona, hexano y acetonitrilo para la determinación de plaguicidas organoclorados, organofosforados, carbamatos y piretroides [201-206]. Este tipo de enfoque clásico cuenta con las desventajas de ser laborioso, requerir grandes cantidades de tiempo de ejecución, de volúmenes de solventes y de materiales, además de necesitar posteriores etapas de limpieza o clean-up de los extractos por medio de extracción en fase sólida (SPE) con adsorbentes como C18, aminopropil, alúmina o silicagel, e incluso mediante precipitación a baja temperatura (freeze-out). Adicionalmente, la evaporación de grandes volúmenes de solvente es fuente de posibles pérdidas de analitos y de contaminación ambiental [207]. Otros métodos efectivos y quizás menos utilizados para la determinación de residuos de plaguicidas en leche incluyen la extracción soxhlet, microextracción en fase sólida (SPME), dispersión de la matriz en fase sólida (MSPD) y extracción acelerada con solventes (ASE) [195].

Desde el advenimiento del QuEChERS tras su publicación por Anastassiades, Lehotay y colaboradores en 2003, este método se ha convertido en el método de elección para la determinación de residuos de plaguicidas y otros contaminantes en alimentos. Si bien su desarrollo se produjo para el análisis de frutas y vegetales, pronto su uso se expandió a todo tipo de alimentos incluso de origen animal con contenido 
graso, como la leche. La primera publicación de un método QuEChERS para la determinación de residuos de plaguicidas en leche la realizó Lehotay con colaboradores dos años después del método original para vegetales, introduciendo modificaciones como el uso de buffer acetato para la estabilidad de compuestos pH-dependientes, y adsorbente C18 en el clean-up para la retención de compuestos lipídicos co-extraídos de la matriz [107]. Otros métodos basados en la metodología QuEChERS fueron publicados posteriormente para la determinación de plaguicidas y otros contaminantes como micotoxinas y drogas veterinarias en leche bovina, algunos de los cuales se resumen en la Tabla 21.

Tabla 21. Resumen de metodologías QuEChERS reportadas en la bibliografía destinadas a la determinación de residuos de plaguicidas y otros contaminantes en leche.

\begin{tabular}{|c|c|c|c|c|c|c|}
\hline $\begin{array}{l}\text { Compuestos } \\
\text { analizados }\end{array}$ & Muestra & Extracción & Partición & Clean-up & Instrumental & Referencia \\
\hline $\begin{array}{l}32 \\
\text { (plaguicidas) }\end{array}$ & $\begin{array}{l}15 g \\
\text { leche }\end{array}$ & $\begin{array}{l}15 \mathrm{~mL} \\
\text { MeCN 1\% ác. } \\
\text { acético }\end{array}$ & $\begin{array}{l}6 \mathrm{~g} \mathrm{MgSO}_{4} \\
1,5 \mathrm{~g} \mathrm{AcNa}\end{array}$ & $\begin{array}{l}\text { dSPE: } \\
\mathrm{MgSO}_{4}+ \\
\mathrm{PSA}+\mathrm{C} 18\end{array}$ & $\begin{array}{l}\text { GC-MS } \\
\text { LC-MS/MS }\end{array}$ & $\begin{array}{l}\text { Lehotay } \\
2005 \text { [107] }\end{array}$ \\
\hline $\begin{array}{l}118 \\
\text { (plaguicidas, } \\
\text { alcaloides, } \\
\text { drogas vet.) }\end{array}$ & $\begin{array}{l}10 \mathrm{~mL} \\
\text { leche }\end{array}$ & $\begin{array}{l}12 \mathrm{~mL} \\
\text { MeCN 1\% ác. } \\
\text { fórmico }\end{array}$ & $\begin{array}{l}6 \mathrm{~g} \mathrm{MgSO}_{4} \\
1,5 \mathrm{~g} \mathrm{AcNa}^{-}\end{array}$ & no & LC-MS/MS & $\begin{array}{l}\text { Filigenzi } \\
2011[111]\end{array}$ \\
\hline $\begin{array}{l}85 \\
\text { (plaguicidas, } \\
\text { micotoxinas) }\end{array}$ & $\begin{array}{l}10 \mathrm{~mL} \\
\text { leche }\end{array}$ & $\begin{array}{l}10 \mathrm{~mL} \\
\text { MeCN 1\% ác. } \\
\text { acético }\end{array}$ & $\begin{array}{l}4 \mathrm{~g} \mathrm{MgSO}_{4} \\
1 \mathrm{~g} \mathrm{NaCl} \\
1 \mathrm{~g} \mathrm{NaCit} \\
0,5 \mathrm{~g} \mathrm{diNaCit} \\
4 \mathrm{~g} \mathrm{MgSO}_{4} \\
1 \mathrm{~g} \mathrm{NaAc}\end{array}$ & no & LC-MS/MS & $\begin{array}{l}\text { Aguilera- } \\
\text { Luiz 2011 } \\
{[112]}\end{array}$ \\
\hline $\begin{array}{l}14 \\
\text { (plaguicidas) }\end{array}$ & $\begin{array}{l}15 \mathrm{~g} \\
\text { leche }\end{array}$ & $\begin{array}{l}15 \mathrm{~mL} \\
\text { MeCN 1\% ác. } \\
\text { acético }\end{array}$ & $\begin{array}{l}6 \mathrm{~g} \mathrm{MgSO}_{4} \\
1,7 \mathrm{~g} \mathrm{AcNa}^{-}\end{array}$ & $\begin{array}{l}\text { dSPE: } \\
\mathrm{MgSO}_{4}+ \\
\mathrm{PSA}+\mathrm{C} 18\end{array}$ & $\begin{array}{l}\text { GC-ECD } \\
\text { GC-MS }\end{array}$ & $\begin{array}{l}\text { Jeong } 2012 \\
{[113]}\end{array}$ \\
\hline $\begin{array}{l}36 \\
\text { (plaguicidas, } \\
\text { micotoxinas, } \\
\text { drogas vet.) }\end{array}$ & $\begin{array}{l}10 \mathrm{~g} \\
\text { leche }\end{array}$ & $\begin{array}{l}10 \mathrm{~mL} \\
\text { MeCN 1\% ác. } \\
\text { acético }\end{array}$ & $\begin{array}{l}\mathrm{Na}_{2} \mathrm{SO}_{4} \\
\mathrm{NaCl} \\
\text { (cantidades no } \\
\text { especificadas) }\end{array}$ & $\begin{array}{l}\text { dSPE: } \\
\mathrm{MgSO}_{4}+ \\
\mathrm{PSA}+\mathrm{C} 18\end{array}$ & LC-MS & $\begin{array}{l}\text { Dominicis } \\
2012[114]\end{array}$ \\
\hline $\begin{array}{l}30 \\
\text { (plaguicidas) }\end{array}$ & $\begin{array}{l}20 \mathrm{~mL} \\
\text { leche }\end{array}$ & $\begin{array}{l}16 \mathrm{~mL} \\
\mathrm{MeCN}\end{array}$ & $\begin{array}{l}8 \mathrm{~g} \mathrm{MgSO}_{4} \\
2 \mathrm{~g} \mathrm{NaCl}\end{array}$ & $\begin{array}{l}\text { dSPE: } \\
\mathrm{PSA}+\mathrm{ZrO}_{2}\end{array}$ & LC-DAD & $\begin{array}{l}\text { Rejczak } \\
2017 \text { [106] }\end{array}$ \\
\hline $\begin{array}{l}316 \\
\text { (plaguicidas, } \\
\text { drogas vet.) }\end{array}$ & $\begin{array}{l}5 \mathrm{~g} \\
\text { leche }\end{array}$ & $\begin{array}{l}15 \mathrm{~mL} \\
\mathrm{MeCN}\end{array}$ & $\begin{array}{l}2 \mathrm{~g} \mathrm{MgSO}_{4} \\
0,5 \mathrm{~g} \mathrm{NaCl}^{-}\end{array}$ & $\begin{array}{l}\text { dSPE: } \\
\mathrm{MgSO}_{4}+ \\
\mathrm{C} 18\end{array}$ & $\begin{array}{l}\text { LC-MS/MS } \\
\text { GC-MS/MS }\end{array}$ & $\begin{array}{l}\text { Jadhav } \\
2018 \text { [117] }\end{array}$ \\
\hline $\begin{array}{l}28 \\
\text { (micotoxinas) }\end{array}$ & $\begin{array}{l}2 \mathrm{~mL} \\
\text { leche }\end{array}$ & $\begin{array}{l}2 \mathrm{~mL} \\
\text { MeCN 1\% ác. } \\
\text { fórmico }\end{array}$ & $\begin{array}{l}0,8 \mathrm{~g} \mathrm{MgSO}_{4} \\
0,2 \mathrm{~g} \mathrm{NaCl}\end{array}$ & freeze-out & LC-MS/MS & $\begin{array}{l}\text { Braun } 2018 \\
{[118]}\end{array}$ \\
\hline
\end{tabular}

Como puede observarse, la versatilidad del método QuEChERS ha permitido la determinación de gran variedad de residuos y contaminantes en leche siendo su etapa distintiva la del clean-up, que permite adoptar distintas alternativas de eliminación de los componentes de la matriz co-extraídos. Como se mencionó antes, el elevado contenido lipídico y proteico de la leche puede dar lugar a interferencias en la determinación final de los analitos de interés, por lo que se deben explorar diferentes alternativas de eliminación como ser la extracción en fase sólida dispersiva (d-SPE) con diversos tipos de adsorbentes (C18, $\left.\mathrm{PSA}, \mathrm{ZrO}_{2}, \mathrm{GCB}\right)$, la precipitación de grasas y proteínas a bajas temperaturas por freeze-out que favorece la 
partición de los plaguicidas en la fase acetonitrilo, o incluso etapas adicionales de LLE con solventes apolares como n-hexano. Todas estas alternativas dependen finalmente del tipo de compuestos que se quieran analizar. Así, por ejemplo, el uso de PSA como adsorbente puede retener algunos plaguicidas ácidos como 2,4-D, el carbono grafitizado negro (GCB) retener compuestos de estructura planar como tiabendazol y hexaclorobenceno, $\mathrm{o}$ en la partición con $\mathrm{n}$-hexano pueden transferirse hacia esa fase la mayor parte de los plaguicidas no polares. Esto marca que el planteo una estrategia de extracción y cleanup para la determinación de residuos de plaguicidas y otros contaminantes en leche debe hacerse teniendo en presente cuáles son los compuestos comprendidos en el alcance del método.

\subsection{OBJETIVO}

El objetivo de este trabajo fue optimizar una metodología analítica basada en los conceptos multi-residuo multi-clase para la determinación de residuos de plaguicidas y micotoxinas (aflatoxinas) en leche, y aplicarla al análisis de muestras tomadas de los tanques de almacenamiento de 40 establecimientos productores seleccionados localizados en la zona central de la Provincia de Santa Fe.

\subsection{MATERIALES Y MÉTODOS}

\subsubsection{Metodología analítica}

\section{Reactivos}

Los estándares individuales de los plaguicidas utilizados en este trabajo fueron adquiridos de diferentes marcas comerciales como AccuStandard (New Haven, CT, EE.UU.), ChemLab (Zedelgem, Bélgica), Dr. Ehrenstorfer (Augsburg, Alemania), Fluka, HCP y Riedel-de-Haën Sigma-Aldrich (St. Louis, MO, EE.UU.), todos con purezas superiores al 98\%. Los estándares de aflatoxina B1 y aflatoxina B2 utilizados fueron de marca Trilogy Analytical Standards (Washington, MO, EEUU), también con purezas superiores al 98\%. El agua, el metanol y el acetonitrilo de calidad Óptima ${ }^{\circledR}$ utilizados como solventes cromatográficos al igual que el ácido fórmico se adquirieron de Fisher Scientific (Fair Lawn, NJ, EE.UU.). Como modificador de fase móvil se empleó además formiato de amonio $\left(\mathrm{FNH}_{4},>97 \%\right)$ marca Alfa Aesar (Ward Hill, MA, EE.UU). Las sales empleadas en el método QuEChERS fueron sulfato de magnesio anhidro ( $\mathrm{MgSO}_{4}$ ) marca UCT (Bristol, PA, EE.UU.), acetato de sodio (NaAc, 99,7\%) marca Anedra (Argentina) y adsorbente C18 Selectrasorb ${ }^{\text {TM }}$ con amina primaria-secundaria PSA Enviro-Clean ${ }^{\circledR}$ ambos de marca UCT (Brockville, Canadá). A partir de las soluciones madres individuales de cada compuesto se preparó un mix conjunto en solvente acetonitrilo conteniendo los 63 plaguicidas y las 2 aflatoxinas con una concentración de $1 \mathrm{mg} / \mathrm{L}$, el cual se utilizó en todos los ensayos tanto de calibración como de adición de muestras.

\section{Compuestos comprendidos en el alcance del método}

En el desarrollo de esta tesis, el perfil de búsqueda analítica de residuos en leche estuvo más orientado a medir en cantidad muchos plaguicidas, y no así grupos específicos como pueden ser fármacos veterinarios regulados como ectoparasitarios por SENASA (clorpirifos, diazinon, pirimifos metilo, por ejemplo), o el 
grupo clásico de compuestos orgánicos persistentes conformado por los plaguicidas organoclorados. La definición del scope analítico estuvo entonces orientada a la multiresidualidad, razón por la cual la mayoría de los compuestos incluidos están aprobados en nuestro país como fitosanitarios. Además, dado que el listado de compuestos contemplados en el Código Alimentario Argentino se encuentra desactualizado, se buscó incluir dentro del perfil de búsqueda nuevos compuestos que están siendo utilizados, e incluso su determinación en leche demandada, como el caso del clorantraniliprole. Finalmente, en el scope analítico se incluyeron dos micotoxinas como representantes de ese grupo distinto de contaminantes de origen agronómico que presentan potencialidad de ser encontrados en leche. En las Tablas 22 y 23 se listan los compuestos comprendidos en el método validado para su determinación por UHPLC-MS/MS y aquellos que a modo de screening se analizaron con posterioridad en los extractos de las muestras por GC-MS/MS.

\section{Muestreo}

El muestreo de leches para el análisis de residuos de plaguicidas fue el mismo que el descripto en el capítulo anterior. En este caso la unidad de muestra fue independiente de la utilizada para la determinación de aflatoxina $M 1$, aunque ambas tomadas en el mismo momento, y al igual que en ese caso la leche muestreada se congeló inmediatamente a $-18^{\circ} \mathrm{C}$ hasta el momento de su análisis. El análisis de residuos de plaguicidas se realizó en 80 muestras de leche cruda obtenida de los tanques de almacenamiento de 40 tambos seleccionados, obtenidas durante los meses de verano 2012 e invierno 2013.

Tabla 22. Listado de compuestos comprendidos en el alcance analítico del método validado para la determinación de plaguicidas en leche por UHPLC-MS/MS.

\begin{tabular}{|c|c|c|c|c|c|}
\hline Compuesto & Tipo & Grupo Químico & Compuesto & Tipo & Grupo Químico \\
\hline $2,4-D$ & $\mathrm{H}$ & Alquilclorofenoxi & Flonicamid & I & Piridina \\
\hline $2,4-D B$ & $\mathrm{H}$ & Ác. ariloxialcanoico & Fludioxonil & $\mathrm{F}$ & Fenilpirrol \\
\hline Abamectina & 1 & - & Flusilazole & $\mathrm{F}$ & Triazol \\
\hline Acefato & 1 & Organofosfato & Flutolanil & $\mathrm{F}$ & Oxatiina \\
\hline Acetamiprid & 1 & Neonicotinoide & Fosmet & I & Organofosfato \\
\hline AFB1 & $M$ & Aflatoxina & Imidacloprid & I & Neonicotinoide \\
\hline AFB2 & $\mathrm{M}$ & Aflatoxina & Linuron & $\mathrm{F}$ & Urea \\
\hline Amitraz & 1 & Amidina & Mecarbam & 1 & Organofosfato \\
\hline Anilazina & $\mathrm{F}$ & Triazina & Metalaxil & $\mathrm{F}$ & Fenilamida \\
\hline Atrazina & $\mathrm{H}$ & Triazina & Metamidofos & 1 & Organofosfato \\
\hline Azinfos-Me & 1 & Organofosfato & Metidation & I & Organofosfato \\
\hline Azoxistrobina & $\mathrm{F}$ & Strobilurina & Metomilo & I & Carbamato \\
\hline Bendiocarb & 1 & Carbamato & Metopreno & I & Terpeno \\
\hline Bentazona & $\mathrm{H}$ & Benzotiazinona & Metoxifenocide & I & Diacilhidrazina \\
\hline Carbarilo & 1 & Carbamato & Metribuzin & $\mathrm{H}$ & Triazinona \\
\hline Carbendazim & $\mathrm{F}$ & Benzimidazol & Metsulfuron-Me & $\mathrm{H}$ & Sulfonilurea \\
\hline Carboxin & $\mathrm{F}$ & Oxatiina & Nitenpyram & 1 & Neonicotinoide \\
\hline Chinometionat & $\mathrm{F}$ & Carbamato & Piraclostrobin & $\mathrm{F}$ & Strobilurina \\
\hline Ciromazina & 1 & Triazina & Pirimicarb & 1 & Carbamato \\
\hline Cletodim & $\mathrm{H}$ & Ciclohexanodiona & Pirimifos-Me & I & Organofosfato \\
\hline Clofentezina & 1 & Tetrazina & Procloraz & $\mathrm{F}$ & Imidazol \\
\hline Clorantraniliprole & 1 & Diamida & Profenofos & I & Organofosfato \\
\hline Clorimuron-Et & $\mathrm{H}$ & Sulfonilurea & Propargite & I & Éster sulfito \\
\hline Clorpirifos & 1 & Organofosfato & Propiconazole & $\mathrm{F}$ & Triazol \\
\hline Clorprifos-Me & 1 & Organofosfato & Tebuconazole & $\mathrm{F}$ & Triazol \\
\hline Clotianidin & I & Neonicotinoide & Terbufos & 1 & Organofosfato \\
\hline
\end{tabular}




\begin{tabular}{llllll}
\hline Compuesto & Tipo & Grupo Químico & Compuesto & Tipo & Grupo Químico \\
\hline Diazinon & $\mathrm{I}$ & Organofosfato & Tiabendazol & $\mathrm{F}$ & Benzimidazol \\
Diclorvos & $\mathrm{I}$ & Organofosfato & Tiacloprid & $\mathrm{I}$ & Neonicotinoide \\
Diflubenzuron & $\mathrm{I}$ & Benzoilurea & Tiametoxam & $\mathrm{I}$ & Neonicotinoide \\
Dinotefuran & $\mathrm{I}$ & Neonicotinoide & Triadimefon & $\mathrm{F}$ & Triazol \\
Fenpropatrin & $\mathrm{I}$ & Piretroide & Triadimenol & $\mathrm{F}$ & Triazol \\
Fention & $\mathrm{I}$ & Organofosfato & Triazofos & $\mathrm{I}$ & Organofosfato \\
Fipronil & $\mathrm{I}$ & Fenilpirazol & & & \\
\hline
\end{tabular}

F: fungicida; $\mathrm{H}$ : herbicida; I: insecticida; M: micotoxina.

Tabla 23. Listado de compuestos determinados en modo screening en los extractos de muestras de leche por GC-MS/MS.

\begin{tabular}{llllll}
\hline Compuesto & Tipo & Grupo Químico & Compuesto & Tipo & Grupo Químico \\
\hline Aldrin & I & Organoclorado & Endosulfan-sulfato & I & Organoclorado \\
Bifentrin & I & Piretroide & Endrin & I & Organoclorado \\
Captan & F & Ftalimida & Etion & I & Organofosfato \\
Cipermetrina & I & Piretroide & Fenitrotion & I & Organofosfato \\
Clordano-alfa & I & Organoclorado & Fenvalerato & I & Piretroide \\
Clordano-gama & I & Organoclorado & Heptacloro & I & Organoclorado \\
Clorotalonil & $\mathrm{F}$ & Cloronitrilo & Heptacloro endo-epoxido & I & Organoclorado \\
Clorpirifos & I & Organofosfato & Heptacloro exo-epoxido & I & Organoclorado \\
Clorpirifos-metil & I & Organofosfato & Hexaclorobenceno & F & Organoclorado \\
DDD o,p' & I & Organoclorado & Hidroxiclordano & I & Organoclorado \\
DDD p,p' & I & Organoclorado & Lambdacialotrina & I & Piretroide \\
DDE o,p' & I & Organoclorado & Lindano & I & Organoclorado \\
DDE p,p' & I & Organoclorado & Malation & I & Organofosfato \\
DDT o,p' & I & Organoclorado & Metoxicloro & I & Organoclorado \\
DDT p,p' & I & Organoclorado & Mirex & I & Organoclorado \\
Deltametrina & I & Piretroide & Oxiclordano & I & Organoclorado \\
Diazinon & I & Organofosfato & Paration-metil & I & Organofosfato \\
Dieldrin & I & Organoclorado & Permetrina & I & Piretroide \\
Dliclorvos & I & Organofosfato & Procimidona & F & Dicarboxiamida \\
Endosulfan-alfa & I & Organoclorado & Tetrametrina & I & Piretroide \\
Endosulfan-beta & I & Organoclorado & Vinclozolina & F & Oxazol \\
\hline & & & &
\end{tabular}

\section{Preparación y extracción de muestra}

La noche anterior a su análisis las muestras de leche fueron retiradas del freezer y dejadas a temperatura ambiente para su descongelamiento. Antes de tomar la alícuota analítica, los recipientes que contenían a las muestras se agitaron manualmente por inversión para integración y homogeneización de la muestra descongelada, y en los casos en que se observó que la leche estaba cortada el recipiente se agitó vigorosamente para re-emulsionar u homogeneizar el fluido. En los ensayos de recuperación, la adición del mix de estándares se realizó sobre la leche blanco homogeneizada y se agitaron suavemente durante 4 horas a temperatura ambiente para permitir un adecuado contacto analito-matriz. En tubos de polipropileno de $50 \mathrm{~mL}$ se colocó un volumen de $10 \mathrm{~mL}$ de leche y se agregaron luego $1 \mathrm{~mL}$ de solución $\mathrm{Na}_{2}$ EDTA $1 \mathrm{M}$ y $10 \mathrm{~mL}$ de acetonitrilo (0,1\% ácido acético), agitando posteriormente en vórtex durante 30 segundos. Luego, se agregaron $4 \mathrm{~g}$ de $\mathrm{MgSO}_{4}$ y $1 \mathrm{~g}$ de NaAc agitando vigorosamente de forma manual durante 3 minutos para producir la separación de fases y la partición de los analitos entre las mismas. Luego, las fases se separaron por centrifugación durante 6 minutos a $3000 \mathrm{rpm}$ o $1000 \mathrm{~g}$ a temperatura 
ambiente. Para realizar el clean-up se tomó una alícuota de $8 \mathrm{~mL}$ de la fase acetonitrilo superior y se transfirió a un tubo de centrífuga de $15 \mathrm{~mL}$ de capacidad conteniendo $200 \mathrm{mg}$ de $\mathrm{MgSO}_{4}, 67 \mathrm{mg}$ de PSA y $180 \mathrm{mg}$ de C18 pesados previamente. Tras una agitación manual durante 2 minutos, los tubos se centrifugaron durante 2 minutos a $3000 \mathrm{rpm}$. Finalmente, una alícuota de $1 \mathrm{~mL}$ del extracto limpio se filtró a través de filtros de jeringa de nylon de 0,22 $\mu \mathrm{m}$ para la inyección al sistema UHPLC-MS/MS.

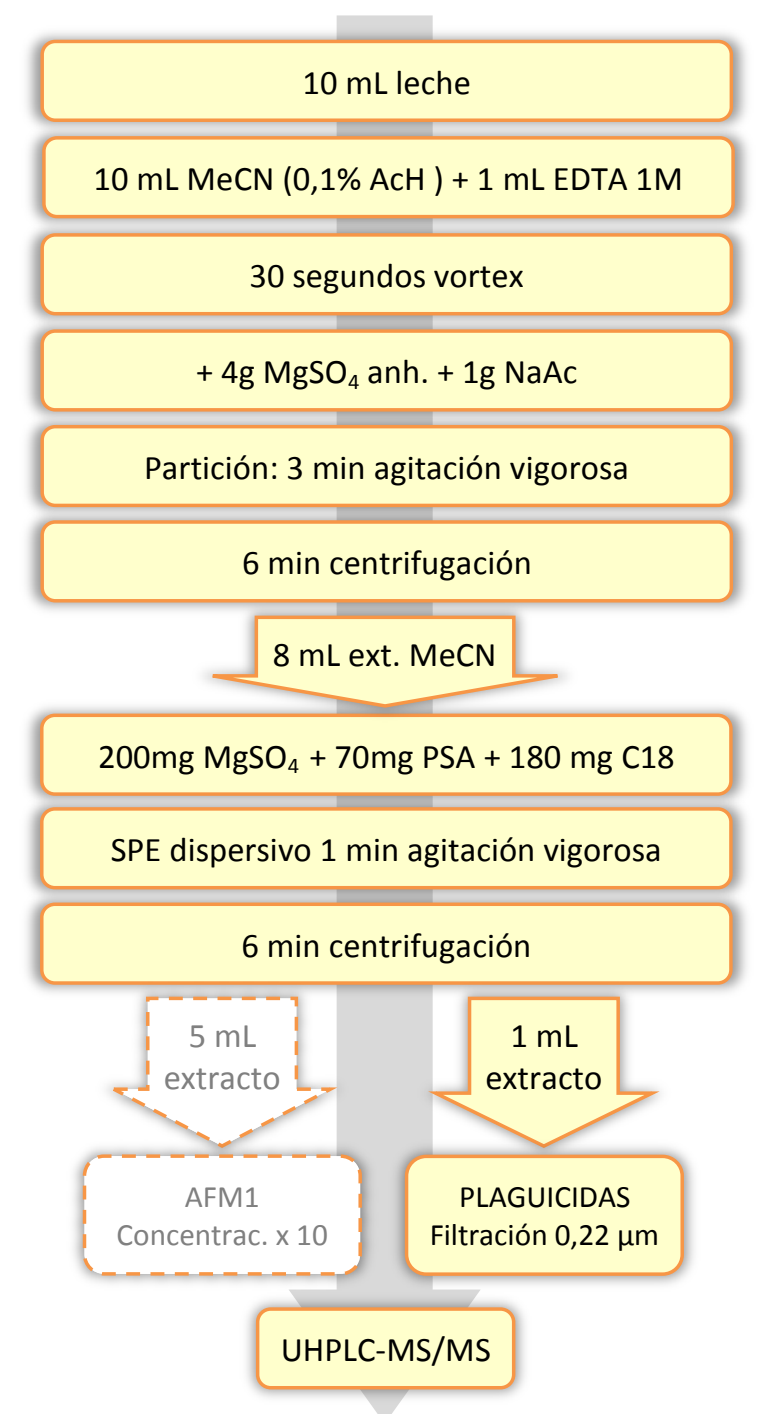

Figura 28. Esquema del procedimiento de extracción QuEChERS optimizado para la determinación de residuos de plaguicidas y micotoxinas en leche.

Equipamiento y condiciones instrumentales de análisis

UHPLC-MS/MS

La separación de las especies extraídas se realizó con una columna de fase reversa ACQUITY UPLC ${ }^{\mathrm{TM}}$ BEH RP Shield C18 $(1,7 \mu \mathrm{m} ; 2,1 \times 100 \mathrm{~mm})$ de Waters instalada en un cromatógrafo líquido de ultra-alta performance ACQUITY UPLC'M (Waters, Milford, MA, EE.UU.). La fase móvil consistió en soluciones 5 mM de $\mathrm{FNH}_{4}+0,1 \%$ de ácido fórmico en agua (componente A) y Metanol (componente B) con una velocidad de flujo de $0,35 \mathrm{~mL} / \mathrm{min}$. Las separaciones se realizaron a una temperatura de $40^{\circ} \mathrm{C}$ a través de un gradiente comenzando con $5 \%$ de componente B incrementado linealmente a $100 \%$ B durante 7 minutos y volviendo 
escalonadamente a las condiciones iniciales en 2 minutos, permaneciendo así por 1 minuto adicional para re-equilibrio de la columna antes de la siguiente inyección. El tiempo total de la corrida cromatográfica fue de 10 minutos y el volumen de inyección $2 \mu \mathrm{L}$ con llenado de loop a $10 \mu \mathrm{L}$ con fase móvil.

La determinación de las especies separadas se realizó mediante un espectrómetro de masa de triple cuadrupolo Micromass TQ Detector (Waters, Manchester, UK) acoplado al cromatógrafo mediante una fuente de ionización electrospray (Waters ortogonal-Z-spray). Los parámetros operativos del sistema MS/MS y la información de los iones $\mathrm{m} / \mathrm{z}$ utilizados en el análisis de los 65 compuestos estudiados se resumen en las Tablas 24 y 25.

Tabla 24. Parámetros operativos de ionización y análisis MS/MS del método empleado para la determinación de 63 plaguicidas y 2 aflatoxinas por UHPLC.

\begin{tabular}{lll}
\hline & Parámetro & \\
\hline Ionización & Polaridad: & Positiva (ESI+) y negativa (ESI-) \\
& Temperatura de fuente: & $145^{\circ} \mathrm{C}$ \\
& Voltaje capilar: & $3 \mathrm{kV}$ \\
& Gas de desolvatación: & $\mathrm{N}_{2}, 800 \mathrm{~L} / \mathrm{h}$ \\
& Temperatura de desolvatación: & $400^{\circ} \mathrm{C}$ \\
& Gas de cono: & $\mathrm{N}_{2}, 10 \mathrm{~L} / \mathrm{h}$ \\
\multirow{3}{*}{ Analizador } & Voltaje de cono: & $30 \mathrm{~V}$ \\
& Modo de operación: & MRM \\
& Gas de colisión: & Argón 0,15 mL/min $\left(5,7 \mathrm{e}^{-3} \mathrm{mbar}\right)$ \\
& lones padre, hijos, energías de colisión & Independientes para cada \\
& y dwell times: & compuesto (Tabla 25) \\
\hline
\end{tabular}

Tabla 25. Iones $(\mathrm{m} / \mathrm{z})$, energías de colisión y tiempos asociados empleados en el método MS/MS para la determinación de 63 plaguicidas y 2 aflatoxinas por UHPLC.

\begin{tabular}{lllllllll}
\hline Compuesto & $\begin{array}{l}\text { Padre } \\
(\mathrm{m} / \mathrm{z})\end{array}$ & $\begin{array}{l}\text { Cono } \\
(\mathrm{V})\end{array}$ & $\begin{array}{l}\text { Hijo } 1 \\
(\mathrm{~m} / \mathrm{z}) \mathrm{Q}\end{array}$ & $\begin{array}{l}\mathrm{EC} 1 \\
(\mathrm{eV})\end{array}$ & $\begin{array}{l}\text { Hijo } 2 \\
(\mathrm{~m} / \mathrm{z}) q\end{array}$ & $\begin{array}{l}\text { EC } 2 \\
(\mathrm{eV})\end{array}$ & $\begin{array}{l}\text { dwell } \\
(\mathrm{seg})\end{array}$ & $\begin{array}{l}\mathrm{t}_{\mathrm{R}} \\
(\mathrm{min})\end{array}$ \\
\hline 2,4 D & 219 & 25 & 161 & 15 & 125 & 30 & 0,02 & 5,37 \\
2,4 DB & 247 & 20 & 161 & 15 & 125 & 30 & 0,02 & 6,10 \\
Abamectina & 890,7 & 18 & 305,1 & 22 & 567,2 & 10 & 0,01 & 7,17 \\
Acefato & 184 & 14 & 143 & 8 & 125 & 12 & 0,02 & 1,45 \\
Acetamiprid & 223 & 28 & 126 & 20 & 56 & 15 & 0,07 & 3,52 \\
AFB1 & 313 & 40 & 285 & 22 & 241 & 40 & 0,02 & 4,49 \\
AFB2 & 315 & 50 & 287 & 25 & 259 & 29 & 0,01 & 4,27 \\
Amitraz & 294 & 25 & 163 & 18 & 122 & 35 & 0,01 & 7,15 \\
Anilazina & 274,9 & 40 & 153 & 26 & 178 & 24 & 0,01 & 6,06 \\
Atrazina & 216,1 & 33 & 174,1 & 18 & 96,01 & 23 & 0,01 & 5,22 \\
Azinfos-Me & 318 & 20 & 160 & 8 & 261 & 8 & 0,01 & 5,59 \\
Azoxistrobina & 404 & 22 & 372 & 15 & 329 & 30 & 0,01 & 5,52 \\
Bendiocarb & 224,1 & 20 & 167 & 8 & 109 & 18 & 0,02 & 4,54 \\
Bentazona & 241,1 & 15 & 199,1 & 12 & 107,2 & 26 & 0,02 & 4,81 \\
Carbarilo & 202 & 28 & 145 & 22 & 117 & 28 & 0,02 & 4,93 \\
Carbendazim & 192,1 & 33 & 160,1 & 30 & 132,1 & 28 & 0,07 & 2,34 \\
Carboxin & 236 & 28 & 143 & 16 & 87 & 22 & 0,02 & 4,91 \\
Chinometionat & 235 & 22 & 207 & 15 & 163 & 20 & 0,01 & 7,00 \\
Ciromazina & 167 & 32 & 60,2 & 19 & 108,1 & 19 & 0,02 & 1,03
\end{tabular}




\begin{tabular}{|c|c|c|c|c|c|c|c|c|}
\hline Compuesto & $\begin{array}{l}\text { Padre } \\
(\mathrm{m} / \mathrm{z})\end{array}$ & $\begin{array}{l}\text { Cono } \\
\text { (V) }\end{array}$ & $\begin{array}{l}\text { Hijo } 1 \\
(\mathrm{~m} / \mathrm{z}) Q\end{array}$ & $\begin{array}{l}\text { EC } 1 \\
(\mathrm{eV})\end{array}$ & $\begin{array}{l}\text { Hijo } 2 \\
(\mathrm{~m} / \mathrm{z}) q\end{array}$ & $\begin{array}{l}\text { EC } 2 \\
(\mathrm{eV})\end{array}$ & $\begin{array}{l}d w e l l \\
\text { (seg) }\end{array}$ & $\begin{array}{l}t_{R} \\
(\min )\end{array}$ \\
\hline Cletodim & 359,9 & 27 & 164 & 20 & 268 & 12 & 0,01 & 6,66 \\
\hline Clofentezina & 303 & 22 & 138 & 22 & 102 & 35 & 0,01 & 6,74 \\
\hline Clorantraniliprole & 482 & 23 & 284 & 10 & 451 & 15 & 0,01 & 5,47 \\
\hline Clorimuron-Et & 414,9 & 30 & 186 & 17 & 119 & 20 & 0,01 & 5,82 \\
\hline Clorpirifos & 352 & 30 & 199,9 & 16 & 323,8 & 11 & 0,07 & 6,99 \\
\hline Clorpirifos-Me & 321,8 & 28 & 125 & 20 & 290 & 16 & 0,01 & 6,65 \\
\hline Clotianidin & 250 & 18 & 169 & 12 & 132 & 18 & 0,07 & 3,37 \\
\hline Diazinon & 305,1 & 31 & 169 & 22 & 96,9 & 35 & 0,01 & 6,23 \\
\hline Diclorvos & 221 & 28 & 109 & 22 & 79 & 34 & 0,01 & 4,38 \\
\hline Diflubenzuron & 311,1 & 26 & 158,1 & 12 & 141,1 & 22 & 0,01 & 6,37 \\
\hline Dinotefuran & 203 & 20 & 129 & 12 & 157 & 8 & 0,05 & 1,97 \\
\hline Fenpropatrin & 350,1 & 18 & 97 & 34 & 125 & 14 & 0,02 & 7,12 \\
\hline Fention & 279,1 & 30 & 169,1 & 16 & 247,1 & 13 & 0,01 & 6,39 \\
\hline Fipronil & 435 & 30 & 330 & 18 & 250 & 28 & 0,01 & 6,29 \\
\hline Flonicamid & 230 & 30 & 203 & 18 & 148 & 25 & 0,1 & 2,61 \\
\hline Fludioxonil & 246,7 & 45 & 180,1 & 25 & 169,1 & 30 & 0,02 & 6,07 \\
\hline Flusilazole & 316 & 30 & 247 & 18 & 165 & 28 & 0,01 & 6,10 \\
\hline Flutolanil & 324,1 & 28 & 242 & 25 & 262,1 & 18 & 0,01 & 5,89 \\
\hline Fosmet & 318 & 22 & 160,01 & 10 & 77 & 22 & 0,01 & 5,60 \\
\hline Imidacloprid & 256,1 & 25 & 175,1 & 17 & 209,1 & 15 & 0,07 & 3,22 \\
\hline Linuron & 248,8 & 30 & 159,9 & 18 & 181,9 & 14 & 0,01 & 5,89 \\
\hline Mecarbam & 330 & 15 & 227,1 & 8 & 97 & 35 & 0,01 & 5,95 \\
\hline Metalaxil & 280,1 & 26 & 220,1 & 13 & 192,1 & 17 & 0,01 & 4,94 \\
\hline Metamidofos & 142 & 28 & 93,9 & 13 & 124,9 & 13 & 0,02 & 1,17 \\
\hline Metidation & 303 & 12 & 85,1 & 20 & 145 & 10 & 0,01 & 5,42 \\
\hline Metomilo & 163 & 20 & 88 & 10 & 106 & 10 & 0,1 & 2,38 \\
\hline Metopreno & 311 & 14 & 279 & 5 & 191 & 9 & 0,01 & 7,31 \\
\hline Metoxifenozide & 369,1 & 28 & 149,1 & 18 & 313,2 & 8 & 0,01 & 5,92 \\
\hline Metribuzin & 214,9 & 35 & 187 & 18 & 74 & 30 & 0,01 & 4,52 \\
\hline Metsulfuron-Me & 382 & 33 & 167 & 15 & 199 & 25 & 0,01 & 4,67 \\
\hline Nitenpyram & 271,1 & 25 & 224,9 & 12 & 125,9 & 25 & 0,05 & 2,16 \\
\hline Piraclostrobin & 388,1 & 25 & 193,9 & 12 & 163 & 25 & 0,01 & 6,48 \\
\hline Pirimicarb & 239,1 & 28 & 72 & 18 & 182 & 15 & 0,1 & 3,51 \\
\hline Pirimifos-Me & 306,1 & 36 & 108,1 & 32 & 164,1 & 22 & 0,01 & 6,33 \\
\hline Procloraz & 376 & 16 & 70 & 34 & 308 & 16 & 0,01 & 6,29 \\
\hline Profenofos & 372,9 & 30 & 127,9 & 40 & 302,6 & 20 & 0,01 & 6,69 \\
\hline Propargita & 368 & 15 & 231 & 10 & 175 & 15 & 0,01 & 7,05 \\
\hline Propiconazole & 342 & 40 & 69 & 22 & 159 & 34 & 0,01 & 6,23 \\
\hline Tebuconazole & 308 & 34 & 70,1 & 22 & 125 & 40 & 0,01 & 6,28 \\
\hline Terbufos & 289 & 12 & 57,2 & 22 & 103 & 8 & 0,02 & 6,77 \\
\hline Tiabendazol & 202,1 & 55 & 175 & 25 & 131 & 31 & 0,05 & 2,87 \\
\hline Tiacloprid & 253 & 35 & 126 & 20 & 90 & 40 & 0,02 & 3,96 \\
\hline Tiametoxam & 292 & 22 & 132 & 22 & 181 & 12 & 0,1 & 2,71 \\
\hline Triadimefon & 294,1 & 25 & 197,2 & 15 & 141 & 20 & 0,01 & 5,78 \\
\hline Triadimenol & 296,1 & 15 & 70,2 & 10 & 99,1 & 15 & 0,01 & 5,90 \\
\hline Triazofos & 314,1 & 25 & 161,9 & 18 & 118,9 & 35 & 0,01 & 5,92 \\
\hline
\end{tabular}

EC: energía de colisión; $Q$ : transición de cuantificación; $q$ : transición de confirmación; $t_{R}$ : tiempo de retención. 


\section{GC-MS/MS}

El análisis de extractos por GC-MS/MS se realizó utilizando un cromatógrafo gaseoso Agilent 7890B acoplado a un espectrómetro de masa de triple cuadrupolo Agilent $7000 \mathrm{C}$ (Agilent Technologies, Santa Clara, CA, EE.UU.) operado en modo de análisis MRM (monitoreo de reacciones múltiples). La separación se realizó en una columna capilar HP-5MS 5\% Fenil Metil Siloxano (30 m x $250 \mu \mathrm{m} \times 0,25 \mu \mathrm{m}$, Agilent Technologies). El programa de temperatura del horno comenzó en $60^{\circ} \mathrm{C}$ manteniéndose durante 1 minuto antes de aumentar linealmente a $170^{\circ} \mathrm{C}$ en 3,7 minutos a razón de $40^{\circ} \mathrm{C} / \mathrm{min}$, y posteriormente a $310^{\circ}$ en 14 minutos a $10^{\circ} \mathrm{C} / \mathrm{min}$, donde se mantuvo durante 3 minutos antes de retornar a las condiciones iniciales, resultando en una corrida final de 20,75 minutos. Los extractos $(1 \mu \mathrm{L})$ se inyectaron a través de un inyector multimodo operado en modo splitless a $280^{\circ} \mathrm{C}$, y como gas carrier se empleó helio de alta pureza $(99,999 \%)$ en un flujo constante de $1 \mathrm{~mL} / \mathrm{min}$. La línea de transferencia al espectrómetro de masa se mantuvo a una temperatura de $280^{\circ} \mathrm{C}$ y la fuente de ionización de impacto electrónico se operó a 70eV. Las transiciones MRM de cada compuesto y sus condiciones de análisis instrumental fueron obtenidas de la base de datos de Agilent G9250AA. Todas las operaciones de comando instrumental y análisis e interpretación de cromatogramas se realizaron utilizando los softwares MassHunter Workstation, Qualitative Analysis y Quantitative Analysis (Agilent Technologies).

\section{Validación}

La validación del método QuEChERS para el análisis de leche cruda se realizó siguiendo los criterios establecidos por el Documento SANTE 11945/2015 para el control de calidad y validación de procedimientos analíticos destinados al análisis de residuos de plaguicidas en alimentos y piensos [190]. Se evaluaron la exactitud y precisión del método, la linealidad, el efecto matriz y los límites de cuantificación de la metodología optimizada. La exactitud se analizó en dos niveles de concentración ( 10 y 100 g/L) adicionando las cantidades respectivas del mix de estándar sobre una leche cruda utilizada como blanco en ensayos por triplicado que se repitieron en 3 días distintos. El diseño de los ensayos de recuperación permitió al mismo tiempo evaluar la precisión en términos de repetibilidad a través del Desvío Estándar Relativo intra-día, y en términos de reproducibilidad a partir del Desvío Estándar Relativo inter-día. Para evaluar la linealidad y el efecto matriz se prepararon sendas curvas de calibrado del mix de estándar en solvente (acetonitrilo) y matriz (extracto QuEChERS) en los niveles 0,1-0,2-0,5-1-1,5-2-10-20-100 ng/mL. Finalmente, tal como establece la mencionada Directiva SANTE, los límites de cuantificación se estimaron como la mínima concentración analizada en un ensayo de recuperación que diera valores aceptables de los parámetros de \% Recuperación (70-120\%) y DER ( $\leq 20 \%)$.

\subsection{RESULTADOS Y DISCUSIÓN}

En primer lugar se definió el listado de compuestos a ser incluidos en el alcance del método analítico. Sobre la base del listado de plaguicidas con un límite máximo de residuo establecido para leche en el Código 
Alimentario Argentino y los compuestos disponibles en el laboratorio en el momento de realizar estas experiencias, se definió un lista de 63 plaguicidas de diferentes familias a la que se le agregaron 2 aflatoxinas (AFB1 y AFB1) totalizando así 65 compuestos. Si bien en leche no es esperable la presencia de estas dos aflatoxinas, se incluyeron en el alcance del método como representantes de otra familia de contaminantes, las micotoxinas, que típicamente se analizan en conjunto con los plaguicidas mediante métodos multi-residuo multi-componente como los que son objeto de estudio en esta tesis.

\subsubsection{Optimización cromatográfica}

En el capítulo anterior se describió la optimización de las condiciones cromatográficas para la determinación de aflatoxina M1, que al tratarse de un único compuesto (single method) permitió analizar distintas variantes de fase móvil tanto en el tipo de componente orgánico (metanol, acetonitrilo) como incluso el uso de un diseño de experimento para analizar el comportamiento de variables que afectan tanto a la cromatografía como al proceso de ionización posterior, como modo de seleccionar la combinación de variables que brinden la mayor sensibilidad para el analito en cuestión. En el caso de los métodos multiresiduos multi-componentes no es factible una optimización tan pormenorizada por el lógico hecho de que al tratarse de un conjunto de compuestos de distinta naturaleza y con muy variadas propiedades fisicoquímicas, las condiciones que favorezcan la mejor separación e ionización de los distintos compuestos serán muy variables. Lo que sí puede hacerse, sin embargo, es evaluar fases móviles de distinta composición y analizar el comportamiento general de los diferentes compuestos con cada una de ellas, seleccionando aquella que brinde las mejores condiciones para la mayor cantidad de compuestos posibles. En ese sentido, la selección de la fase móvil para la determinación de los 63 plaguicidas y 2 aflatoxinas incluidos en el alcance del método se hizo sobre la base del comportamiento de estos compuestos con 3 fases móviles distintas:

- $\quad F M 1: \mathrm{H}_{2} \mathrm{O}+0,1 \%$ AF (A1) / MeCN 0,1\% FA (B1)

- FM 2: $\mathrm{H}_{2} \mathrm{O} 10 \mathrm{mM} \mathrm{FNH}_{4}(\mathrm{~A} 2) / \mathrm{MeOH} 100 \%$ (B2)

- $\quad F M 3: \mathrm{H}_{2} \mathrm{O} 5 \mathrm{mM} \mathrm{FNH}_{4}+0,1 \% \mathrm{AF}(\mathrm{A} 3) / \mathrm{MeOH} 5 \mathrm{mM} \mathrm{FNH}_{4}+0,1 \% \mathrm{AF}(\mathrm{B} 3)$

La FM 1 es una composición típica de fase móvil utilizada en métodos multi-residuo, y era de hecho la que estaba siendo utilizada rutinariamente en nuestro laboratorio. La FM 2 es la que fuera optimizada en este trabajo para la determinación de AFM1, y la FM 3 es una composición típica también utilizada en métodos multi-residuo pero en este caso utilizando formiato de amonio además de ácido fórmico como promotores de la ionización. La sensibilidad de los distintos compuestos con las 3 fases móviles se analizó inyectando en los diferentes sistemas una curva de calibrado de 9 niveles en el rango 0,1-100 ng/mL a partir de un mix en acetonitrilo de los 65 compuestos. Para cada compuesto y por cada fase móvil se calculó el factor de respuesta como la razón entre el área del pico cromatográfico y la concentración inyectada $\left(\mathrm{f}_{\mathrm{R}}=\right.$ área/concentración), considerando entonces como mejor fase móvil aquella que diera los $\mathrm{f}_{\mathrm{R}}$ más altos para 
la mayor cantidad de compuestos. En la Figura 29 se comparan las relaciones entre los factores de respuesta de las fases móviles 1 y 2 en las que los promotores de ionización eran ácido fórmico y formiato de amonio, respectivamente. Hacer la relación de los factores permite cuantificar el incremento $\left(f_{R}>1\right) \circ$ disminución $\left(f_{R}<1\right)$ de la sensibilidad de una fase móvil respecto de la otra. Como puede verse en la figura, la respuesta cromatográfica de la mayoría de los compuestos (71\%) se vio favorecida con la fase móvil con $\mathrm{FNH}_{4}$ como modificador (FM 2). Los factores de respuesta obtenidos para cada compuesto con las 3 fases móviles ensayadas se muestran en la Tabla 26 donde puede verse también que la FM 3, con ambos promotores de ionización tanto en el componente acuoso como en el orgánico y con una concentración de $\mathrm{FNH}_{4}$ menor, dio valores de $\mathrm{f}_{\mathrm{R}}$ similares a los de la FM 2 por lo que se seleccionó a FM 3 como la fase móvil definitiva para el análisis de plaguicidas y micotoxinas en leche. El uso de fases móviles constituidas por combinaciones de formiato de amonio y ácido fórmico en métodos multi-clase multi-residuo ha sido reportado previamente en la bibliografía $[193,208]$. 
Tabla 26: Factores de respuesta cromatográfica $\left(f_{R}\right)$ de los plaguicidas y micotoxinas estudiados obtenidos con 3 fases móviles de distinta composición.

\begin{tabular}{|c|c|c|c|c|c|c|c|}
\hline \multirow[b]{2}{*}{ Compuesto } & \multicolumn{3}{|c|}{$f_{R}^{a}$} & \multirow[b]{2}{*}{ Compuesto } & \multicolumn{3}{|c|}{$f_{R}^{a}$} \\
\hline & FM 1 & FM 2 & FM 3 & & FM 1 & FM 2 & FM 3 \\
\hline $2,4-D$ & 6 & 2 & 1 & Flonicamid & 266 & 93 & 112 \\
\hline 2,4-DB & 1 & 1 & 0 & Fludioxonil & 11 & 44 & 49 \\
\hline Abamectina & 2 & 4 & 5 & Flusilazole & 2068 & 1107 & 704 \\
\hline Acefato & 262 & 546 & 283 & Flutolanil & 1119 & 3298 & 3217 \\
\hline Acetamiprid & 393 & 3649 & 3946 & Fosmet & 26 & 2953 & 3109 \\
\hline AFB1 & 461 & 1078 & 775 & Imidacloprid & 96 & 468 & 523 \\
\hline AFB2 & 313 & 1027 & 816 & Linuron & 237 & 1072 & 1019 \\
\hline Amitraz & 8378 & 3509 & 1325 & Mecarbam & 656 & 4815 & 2376 \\
\hline Anilazina & 167 & 18 & 16 & Metalaxil & 2510 & 4204 & 4068 \\
\hline Atrazina & 4187 & 2432 & 2179 & Metamidofos & 167 & 228 & 213 \\
\hline Azinfos-Me & 45 & 2600 & 2969 & Metidation & 254 & 1979 & 1316 \\
\hline Azoxistrobina & 2710 & 6614 & 5716 & Metomil & 1327 & 1106 & 1051 \\
\hline Bendiocarb & 841 & 2812 & 2243 & Metopreno & 295 & 676 & 269 \\
\hline Bentazona & 47 & 4 & 8 & Metoxifenocide & 175 & 520 & 337 \\
\hline Carbarilo & 101 & 318 & 341 & Metribuzin & 1404 & 721 & 343 \\
\hline Carbendazim & 292 & 1529 & 1316 & Metsulfuron-Me & 149 & 82 & 57 \\
\hline Carboxin & 1602 & 5674 & 4825 & Nitenpyram & 182 & 261 & 220 \\
\hline Chinomethionat & 115 & 5 & 2 & Piraclostrobin & 1191 & 2611 & 2365 \\
\hline Ciromazina & 509 & 93 & 34 & Pirimicarb & 5611 & 7638 & 7176 \\
\hline Cletodim & 178 & 305 & 122 & Pirimifos-Me & 6079 & 3647 & 3838 \\
\hline Clofentezine & 221 & 420 & 134 & Procloraz & 501 & 708 & 669 \\
\hline Clorantraniliprole & 46 & 219 & 183 & Profenofos & 63 & 280 & 576 \\
\hline Clorpirifos & 13 & 232 & 12575 & Propargite & 126 & 1642 & 1373 \\
\hline Clorprifos-Me & 4 & 86 & 85 & Propiconazole & 3722 & 1256 & 1290 \\
\hline Clotianidin & 102 & 350 & 437 & Tebuconazole & 4114 & 4510 & 4103 \\
\hline Diazinon & 8204 & 5507 & 10580 & Terbufos & 88 & 460 & 664 \\
\hline Diclorvos & 212 & 441 & 293 & Tiabendazol & 665 & 2503 & 2282 \\
\hline Diflubenzuron & 240 & 440 & 652 & Tiacloprid & 786 & 4986 & 5050 \\
\hline Dinotefuran & 447 & 859 & 1157 & Tiametoxam & 71 & 359 & 408 \\
\hline Fenpropatrin & 6 & 79 & 229 & Triadimefon & 755 & 501 & 375 \\
\hline Fention & 6 & 236 & 119 & Triadimenol & 860 & 215 & 126 \\
\hline Fipronil & 43 & 147 & 150 & Triazofos & 2845 & 8193 & 6659 \\
\hline
\end{tabular}

${ }^{a} f_{R}$ promedio de todos los niveles de concentración ensayados. $\mathrm{f}_{\mathrm{R}}=$ área/concentración.

FM 1: $\mathrm{H}_{2} \mathrm{O} 2 \% \mathrm{MeCN}+0,1 \%$ AF (A1) / MeCN 0,1\% FA (B1)

FM 2: $\mathrm{H}_{2} \mathrm{O} 10 \mathrm{mM} \mathrm{FNH}_{4}$ (A2) / $\mathrm{MeOH} 100 \%$ (B2)

FM 3: $\mathrm{H}_{2} \mathrm{O} 5 \mathrm{mM} \mathrm{FNH}_{4}+0,1 \%$ AF (A3) / $\mathrm{MeOH}_{5} \mathrm{mM} \mathrm{FNH}_{4}+0,1 \% \mathrm{AF}$ (B3) 


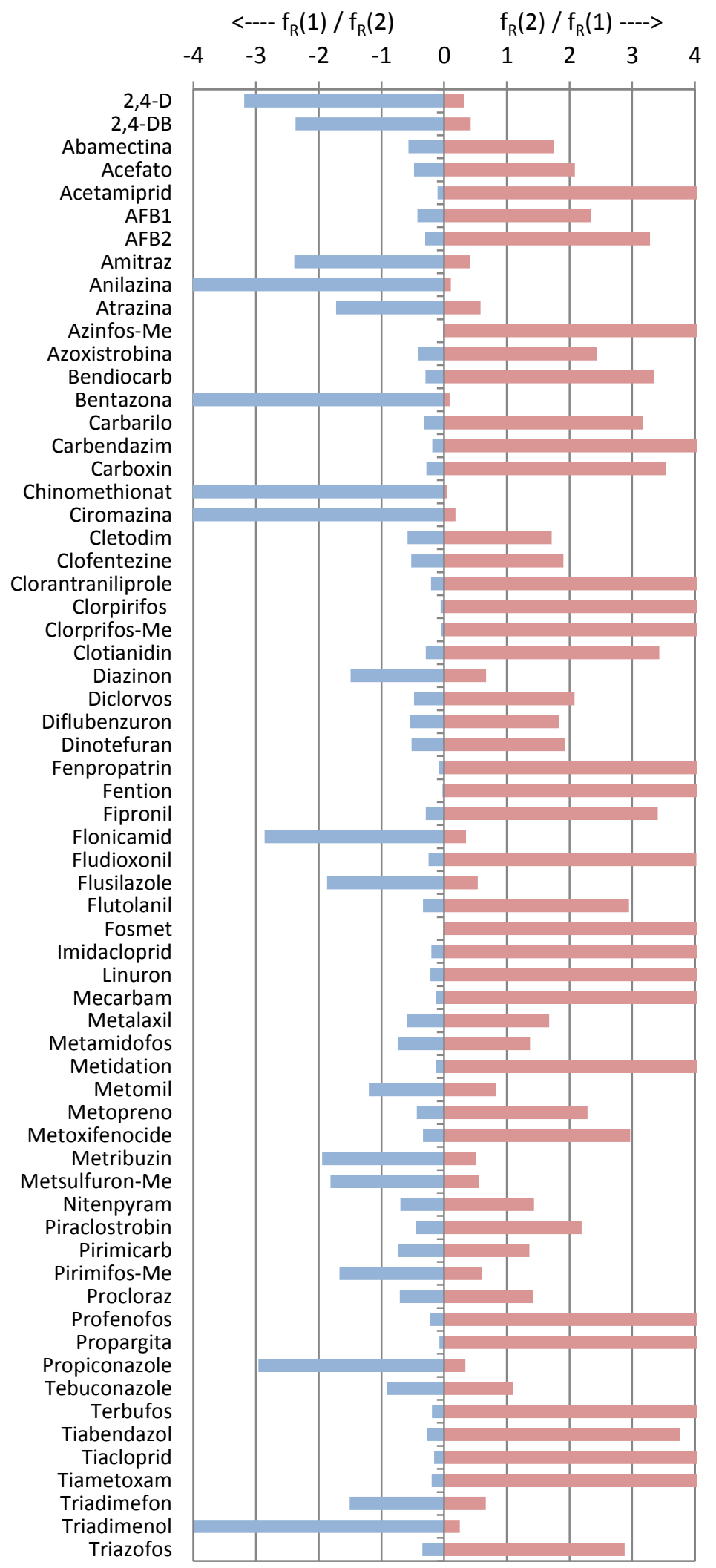

Figura 29: Comparación de la relación entre los factores de respuesta $\left(f_{R}\right)$ de las fases móviles con ácido fórmico (1) y formiato de amonio (2) como promotores de la ionización. 


\section{Determinación MS/MS}

La separación y detección de los compuestos eluidos de la columna cromatográfica se realizó operando el espectrómetro de masa en modo MRM. Las condiciones operativas de la zona de ionización del instrumento (temperatura de fuente, voltaje capilar, flujo y temperatura del gas de desolvatación) fueron adoptadas de métodos previamente optimizados en nuestro laboratorio para análisis multi-residuo de plaguicidas. Si bien la ionización de cada compuesto es dependiente de estos parámetros, en métodos multi-residuo no es posible ajustarlos para cada analito individual por lo que se utilizan condiciones genéricas en las que los distintos compuestos que se quieren analizar se ionizan lo suficiente como para tener una buena sensibilidad de detección. Para armar el método de adquisición de iones se recabó información sobre las transiciones MRM de cada compuesto a ser buscadas por el analizador (voltaje de cono, ion padre, iones hijos, energía de colisión, dwell times). En la mayoría de los casos esta información surgió, nuevamente, de métodos previamente optimizados en el laboratorio mientras que para compuestos nuevos que se agregaron al método, como el caso de las 2 aflatoxinas, la información se obtuvo por sintonización manual de las condiciones mediante infusión directa de los compuestos individuales. Los parámetros de detección de cada compuesto se muestran en la Tabla 25. De acuerdo a los tiempos de retención de los compuestos, sus transiciones MRM se distribuyeron en segmentos o ventanas de adquisición, ajustándose en cada una de ellas la cantidad de transiciones y los dwell times (o tiempos de escaneo) para obtener los picos con mejor forma y sensibilidad posibles. De esta forma, los 65 compuestos incluidos en el alcance del método se analizaron a lo largo de 16 segmentos de adquisición en una corrida total de 8 minutos (Figura 30).

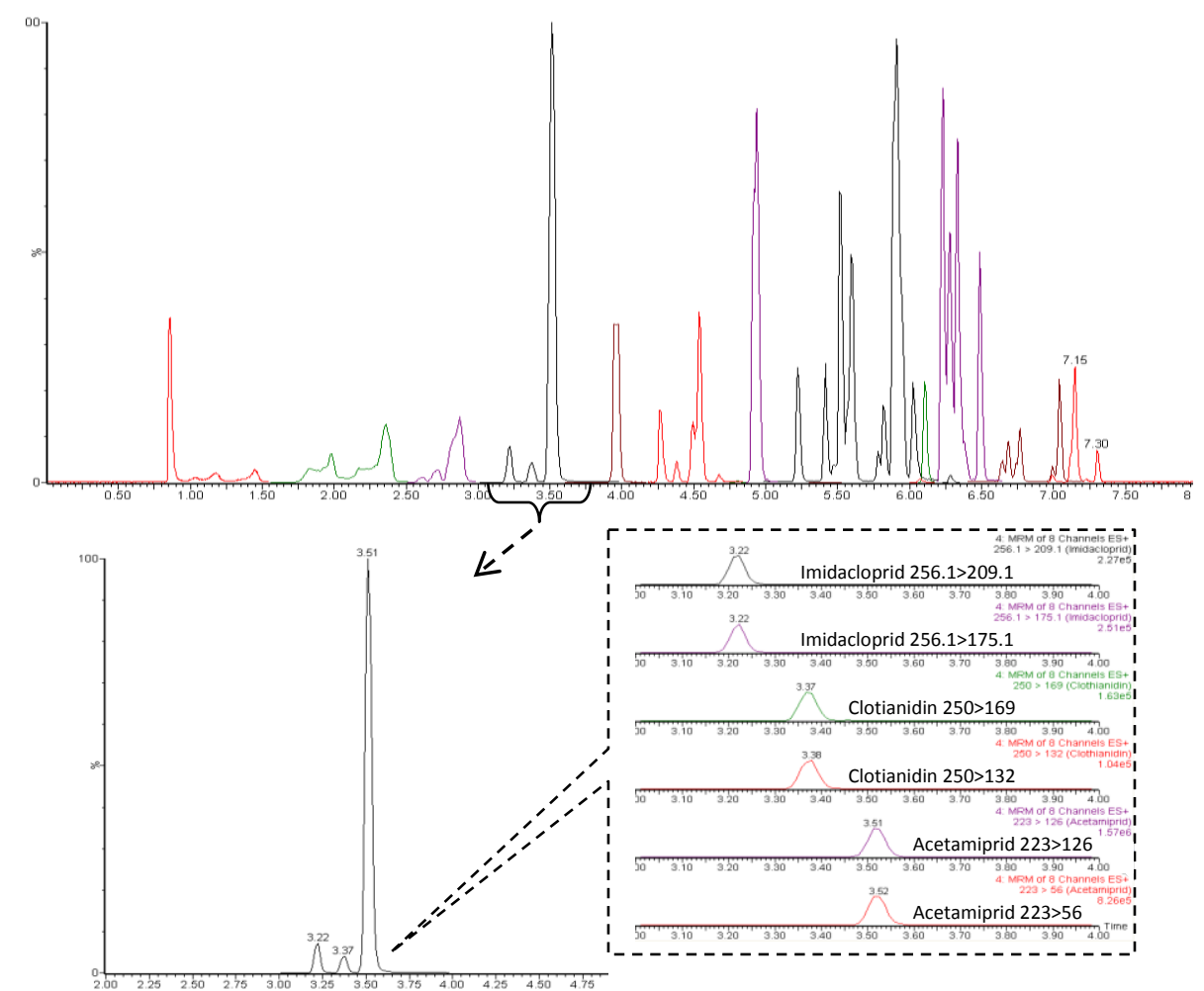

Figura 30. Cromatograma resultante de la inyección de un estándar en solvente de 65 compuestos, adquirido con el método MRM optimizado. Cromatograma de iones totales del conjunto de segmentos (arriba), de un segmento particular (abajo izquierda) y deconvolución de las transiciones específicas del segmento (abajo derecha). 


\subsubsection{Optimización del método de extracción QuEChERS}

Para la determinación de micotoxinas y residuos de plaguicidas en leche cruda se empleó el método QuEChERS optimizado previamente para la extracción de aflatoxina M1 en la misma matriz. Dado que ese método fue pensado como un método multi-residuo multi-componente para la extracción simultánea de AFM1, plaguicidas y otras micotoxinas, para el caso de los plaguicidas no se plantearon etapas de optimización adicionales a las descriptas en el capítulo anterior, sino que directamente se evaluó la performance de aquel método en la extracción del conjunto de plaguicidas y micotoxinas incluidos en el alcance analítico.

Cabe destacar que el único ensayo de optimización del método QuEChERS relacionado con estos últimos compuestos fue la evaluación de alternativas de extracción previa a la partición que se realizó para la determinación de AFM1, que incluyó la adición conjunta de plaguicidas a la leche que iba a ser sometida a las distintas variantes de extracción. Se llevó a cabo entonces la experiencia adicionando el mix de 63 plaguicidas y 2 aflatoxinas a la leche cruda en un nivel de concentración de $10 \mu \mathrm{g} / \mathrm{L}$. Las opciones estudiadas fueron:

Opción 1: agitación en vórtex durante 30 segundos.

Opción 2: extracción manual vigorosa durante 3 minutos.

Opción 3: extracción en ultrasonido durante 3 minutos.

Como resultado, se encontró que los compuestos 2,4-D, 2,4-DB, abamectina, chinometionat y fludioxonil no se recuperaron con ninguna opción de extracción en el nivel de concentración evaluado, mientras que las recuperaciones obtenidas para los demás compuestos no difirieron sustancialmente entre los tres métodos evaluados. En general, para la mayoría de los compuestos se obtuvieron recuperaciones más cercanas a 100\% con la opción 1 (vórtex 30 segundos) y valores más bajos con la opción 3 (ultrasonido 3 minutos), aunque por encima del valor aceptable de 70\% (Figura 31). A la luz de estos resultados, y considerando que para en caso de AFM1 (que fue el compuesto para el cual se pensó la prueba de las 3 extracciones) tampoco se vieron diferencias en las recuperaciones por las distintas vías, se decidió continuar en las experiencias posteriores con la forma de extracción con la que se venía trabajando: 30 segundos en vórtex. 


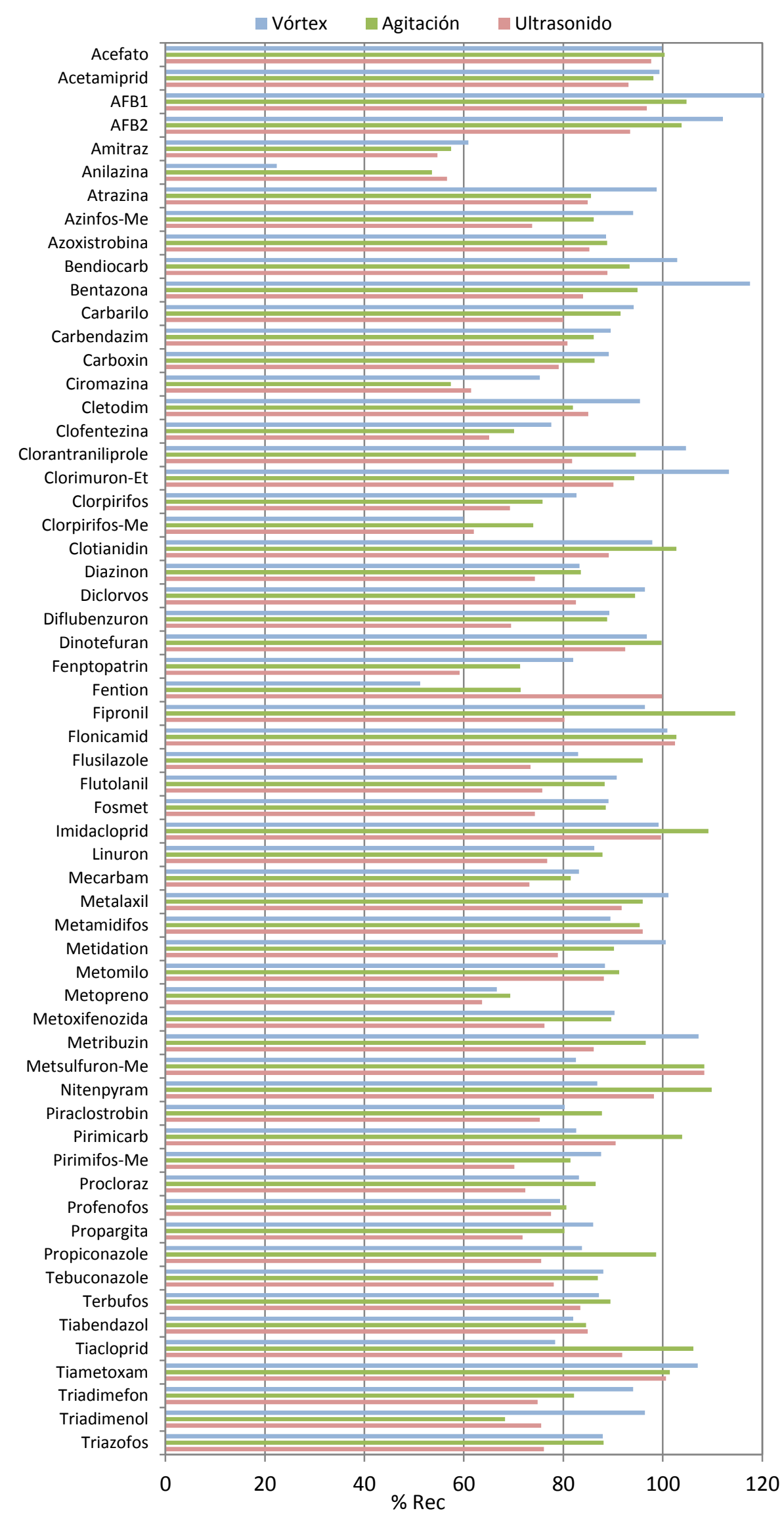

Figura 31. Porcentajes de recuperación de 63 plaguicidas y 2 aflatoxinas obtenidos con el método QuEChERS mediante 3 alternativas de extracción previa a la partición. 
Se analizó entonces la efectividad de extracción del método, en relación con los plaguicidas y las 2 aflatoxinas, ensayando la recuperación en 3 niveles de concentración adicionada (10, 100 y $200 \mu \mathrm{g} / \mathrm{L})$, verificándose que para la mayoría de los compuestos los niveles de recuperación estuvieron dentro del rango aceptable (70-120\%) (Figura 32).

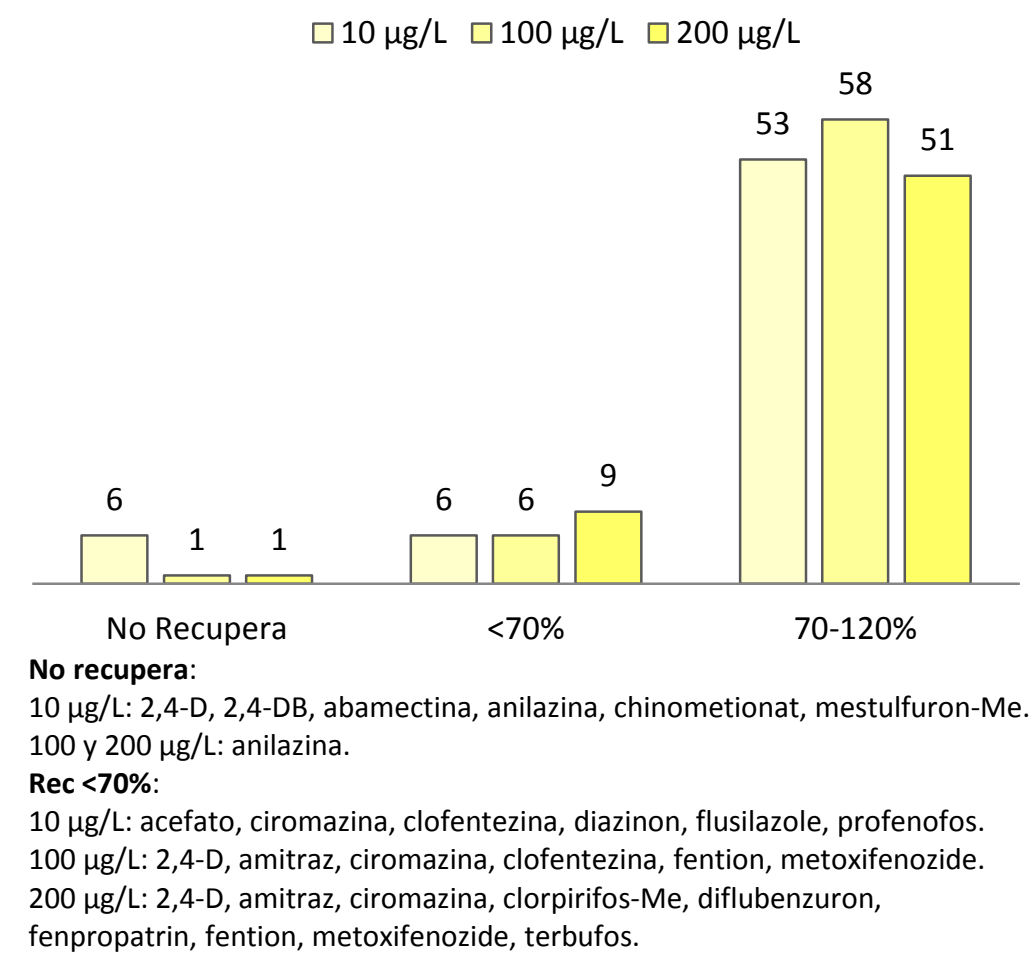

Figura 32: Número de compuestos recuperados $(\mathrm{N}=65)$ mediante el método QuEChERS en 3 niveles de concentración.

El 81,89, y $78 \%$ de los compuestos se extrajeron dentro del rango aceptable de recuperaciones (70-120\%) en los niveles de concentración de 10, 100 y 200 Mg/L, respectivamente. Tal como ocurriera en el ensayo de las alternativas de extracción, algunos compuestos como 2,4-D, 2,4-DB o chinometionat, entre otros, no dieron recuperaciones en el nivel más bajo analizado pero sí en los más altos, mientras que otros plaguicidas como amitraz y ciromazina dieron \%REC consistentemente por debajo del nivel óptimo de $70 \%$ en todos los niveles de adición. Por otra parte, el único compuesto que no se recuperó en ninguno de los niveles probados fue el fungicida anilazina. Dado que estos compuestos, por sus características iónicas (ácidos o bases) o su elevada polaridad, son comúnmente difíciles de ser satisfactoriamente extraídos mediante métodos multi-residuo como el QuEChERS se optó por no introducir modificaciones probando nuevas variantes para mejorar sus \%REC y se continuó con la validación del método planteado hasta el momento, incluyendo de todos modos a estos plaguicidas problemáticos en todos los ensayos.

\subsubsection{Validación del método QuEChERS aplicado a plaguicidas y otras micotoxinas}

La verificación de la aptitud del método para la determinación de plaguicidas y micotoxinas en leche cruda entera fue realizada de acuerdo al documento SANTE 11945/2015 que establece directivas de calidad para 
la validación de métodos analíticos para la determinación de residuos de plaguicidas en alimentos y piensos. Siguiendo las directivas de ese documento se evaluó la linealidad, el efecto matriz, la exactitud, la precisión y los límites de cuantificación del método QuEChERS optimizado para la determinación de plaguicidas y micotoxinas en leche.

\section{Linealidad y efecto matriz}

La linealidad fue analizada en ensayos de calibración con el mix de estándares tanto en solvente (MeCN) como en matriz (extracto QuEChERS de leche cruda blanco), y en ambos casos los niveles de concentración evaluados fueron: 0,1-0,2-0,5-1-1,5-2-10-20-100 ng/mL. La mayoría de los compuestos presentó calibraciones lineales con coeficientes de determinación $\left(r^{2}\right)$ mayores a 0,999 (Tabla 27), aunque con niveles mínimos de calibración (NMC) variables dependiendo de la sensibilidad de los distintos plaguicidas en el sistema. Respecto a la calibración matrix-matched, se verificaron altos NMC (10-20 ng/mL) solo en 6 compuestos (2,4-D, 2,4-DB, abamectina, anilazina, ciromazina y chinometionat), los cuales todos menos abamectina tienen menor sensibilidad en fases móviles con formiato de amonio como promotor de ionización (Figura 29). El resto de los compuestos presentó, por otro lado, NMC en los niveles de concentración más bajos analizados. El incremento o supresión de la señal que puede producirse durante la ionización de los compuestos por interferencias de componentes de la matriz co-extraídos se evaluó para cada plaguicida calculando el efecto matriz como la relación de las pendientes de la curva de calibración en matriz y en solvente $(E M=$ pendiente-matriz/pendiente-solvente x100). La Directiva SANTE 11945 establece un criterio de aceptación de $\pm 20 \%$ para el efecto matriz, situación que se verificó para 54 de los 65 compuestos analizados (Tabla 27). Se verificó que la presencia de matriz producía incrementos en la ionización (EM>120\%) en plaguicidas como ciromazina y metamidofos, mientras que en otros compuestos como AFB1, amitraz, clofentezina, fenpropatrin, fention y metopreno provocaba supresión de señal $(E M<80 \%)$. Esto significa que para estos los cálculos de concentración en muestras deben realizarse utilizando la curva de calibrado matrix-matched para compensar estas variaciones en el proceso de ionización. Sin embargo, este criterio de cálculo se adoptó para la totalidad de los compuestos independientemente de que el efecto matriz analizado durante la validación del método hubiera sido significativo o no.

\section{Exactitud y precisión}

La directiva SANTE 11945 establece entre sus criterios de validación que la exactitud debe evaluarse en al menos dos niveles de concentración, siendo uno de ellos el nivel del límite de cuantificación esperado y el otro un nivel en el rango 2-10xLC. Siguiendo ese criterio la evaluación de la exactitud del método se realizó mediante ensayos de recuperación adicionando a muestras de leche blanco el mix de estándar en dos niveles de concentración: 10 y 100 mg/L. En el nivel de concentración más bajo, 58 de los 65 compuestos (89\%) obtuvieron recuperaciones dentro del rango aceptable de 70-120\% y 6 compuestos no se recuperaron en absoluto verificando el comportamiento de los ensayos previos (2,4-D, 2,4-DB, abamectina, 
anilazina, chinometionat, ciromazina). En tanto, en el nivel de concentración de $100 \mu \mathrm{g} / \mathrm{L}$ el $94 \%$ de los compuestos tuvo recuperaciones en niveles aceptables, al tiempo que algunos de los plaguicidas que no se recuperaban en el nivel más bajo en este caso lo hicieron aunque con recuperaciones por debajo del 70\% (Figura 33) y desvíos estándares relativos $>30 \%$ lo que evidencia la dificultad en la extracción de estos compuestos. En la Tabla 27 se resumen los valores de \%REC de todos los compuestos obtenidos en el ensayo de validación.

\section{$10 \mu \mathrm{g} / \mathrm{L}$}

NR $\quad<70 \% \quad-70-120 \%$

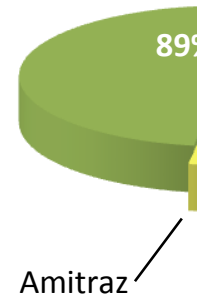

$(1 \%)$

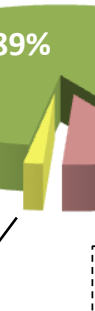

abamectina, anilazina,
chinometionat,

ciromazina
$100 \mu \mathrm{g} / \mathrm{L}$

$<70 \%-70-120 \%$

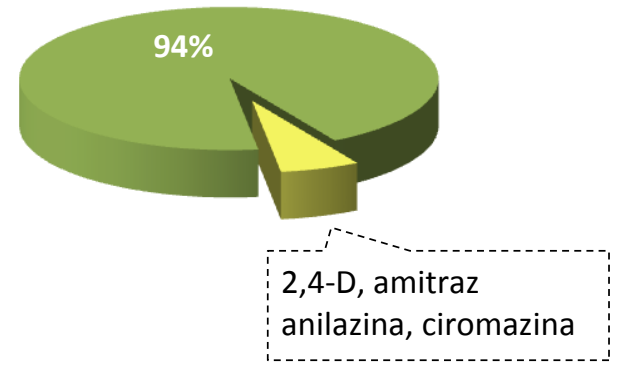

Figura 33. Porcentaje de compuestos $(n=65)$ con valores aceptables de recuperación en los dos niveles de concentración evaluados (NR: no recupera).

La precisión se analizó mediante la evaluación de la desviación estándar relativa (DER) de los valores de recuperación obtenidos en cada nivel de concentración ensayado. En términos de repetibilidad se evaluó la DER intra-día a partir de los valores de recuperación de un ensayo en el que se analizaron 5 réplicas de cada nivel de adición en un mismo día. Todos los compuestos presentaron DER $\leq 20 \%$ en los 2 niveles de concentración, excepto fention en el nivel más bajo y chinometionat en el más alto (Tabla 27). La precisión en términos de reproducibilidad se evaluó mediante los DER-inter día obtenidos a partir de las recuperaciones obtenidas en ensayos realizados en 3 días diferentes, dos en días consecutivos y el tercero en una semana posterior. En este caso, en el nivel $10 \mu \mathrm{g} / \mathrm{L}$ el $17 \%$ de los compuestos presentó valores de DER $>20 \%$ de los cuales sólo 2 , acefato y cletodim, tuvieron valores mayores al 30\%, y en el nivel $100 \mu \mathrm{g} / \mathrm{L}$ el $18 \%$ de los compuestos dio valores de DER por encima del nivel aceptable, de los cuales nuevamente los que dieron DER $>30 \%$ fueron aquellos compuestos de difícil extracción con el método analizado (Tabla 27).

\section{Límites de cuantificación}

De acuerdo a la directiva SANTE 11945 el límite de cuantificación del método es la mínima concentración ensayada en un estudio de recuperación que satisface los criterios de aceptación para la exactitud y la precisión (valores de \%REC entre $70-120 \%$ y DER $\leq 20 \%$ ). De acuerdo a estos criterios, 57 compuestos (el 88\%) presentaron un límite de cuantificación de $10 \mu \mathrm{g} / \mathrm{L}$, que fue el nivel de adición más bajo ensayado, 
mientras que 3 plaguicidas presentaron un LC de $100 \mu \mathrm{g} / \mathrm{L}$ (abamectina, clorpirifos-metil y metsulfuronmetil) y 5 no recuperaron en ningún nivel ensayado y se les asignó un valor arbitrario >100 $\mu \mathrm{g} / \mathrm{L}$ (2,4-D, 2,4$\mathrm{DB}$, amitraz, anilazina y chinometionat). Con estos resultados, el método propuesto no demostró suficiente aptitud para la determinación de los siguientes plaguicidas que están regulados para leche en el Código Alimentario Argentino (CAA): 2,4-D (LMR $50 \mu \mathrm{g} / \mathrm{L}$ ), abamectina (LMR $5 \mu \mathrm{g} / \mathrm{L}$ ), amitraz, anilazina, chinometionat y clorpirifos-metil (todos con LMR $10 \mu \mathrm{g} / \mathrm{L}$ ). Por otro lado, el herbicida metsulfuron-metil no se encuentra regulado en leche por el CAA ni por el Codex. 
Tabla 27. Parámetros obtenidos en la validación del método QuEChERS para la determinación de residuos de 63 plaguicidas y 2 micotoxinas en leche cruda por UHPLC-MS/MS.

\begin{tabular}{|c|c|c|c|c|c|c|c|c|c|c|c|c|c|c|c|c|}
\hline & \multicolumn{7}{|c|}{ Exactitud y precisión } & \multicolumn{9}{|c|}{ Calibraciones } \\
\hline & \multicolumn{3}{|c|}{$10 \mu \mathrm{g} / \mathrm{L}$} & \multicolumn{3}{|c|}{$100 \mu \mathrm{g} / \mathrm{L}$} & \multirow[b]{2}{*}{$L C^{d}$} & \multicolumn{4}{|l|}{ Matriz } & \multicolumn{4}{|c|}{ Solvente } & \multirow[b]{2}{*}{$\begin{array}{l}\mathrm{EM}^{\mathrm{h}} \\
(\%)\end{array}$} \\
\hline & $\begin{array}{l}\operatorname{Rec} \\
(\%)^{a}\end{array}$ & $\begin{array}{l}\mathrm{DER}_{1 \text { día }} \\
(\%)^{\mathrm{b}}\end{array}$ & $\begin{array}{l}\mathrm{DER}_{3 \text { días }} \\
(\%)^{\mathrm{c}}\end{array}$ & $\begin{array}{l}\operatorname{Rec} \\
(\%)^{\mathrm{a}}\end{array}$ & $\begin{array}{l}\mathrm{DER}_{1 \text { día }} \\
(\%)^{\mathrm{b}}\end{array}$ & $\begin{array}{l}\mathrm{DER}_{3 \text { días }} \\
(\%)^{\mathrm{c}}\end{array}$ & & $\mathrm{MNC}^{\mathrm{e}}$ & $b^{\dagger}$ & $a^{g}$ & $r^{2}$ & $\mathrm{MNC}^{\mathrm{e}}$ & $b^{f}$ & $a^{g}$ & $r^{2}$ & \\
\hline $2,4 \mathrm{D}$ & & & & 52 & 25 & 31 & $>100$ & 10 & 4 & -4 & 0,9997 & 10 & 4 & -4 & 0,9997 & 120 \\
\hline $2,4 \mathrm{DB}$ & & & & 103 & 21 & 30 & $>100$ & 10 & 2 & -1 & 0,9980 & 10 & 1 & -1 & 0,9994 & 79 \\
\hline Abamectina & & & & 80 & 37 & 32 & 100 & 10 & 16 & -14 & 0,9995 & 10 & 15 & -11 & 0,9995 & 110 \\
\hline Acefato & 71 & 19 & 58 & 105 & 5 & 18 & 10 & 2 & 474 & -261 & 0,9998 & 2 & 620 & -166 & 0,9995 & 118 \\
\hline Acetamiprid & 109 & 2 & 7 & 105 & 2 & 9 & 10 & 0,1 & 3122 & 1747 & 0,9992 & 0,1 & 3329 & 2344 & 0,9988 & 86 \\
\hline AFB1 & 107 & 5 & 24 & 118 & 3 & 28 & 10 & 0,1 & 706 & 85 & 0,9999 & 0,1 & 771 & 97 & 0,9999 & 65 \\
\hline AFB2 & 110 & 4 & 23 & 123 & 3 & 29 & 10 & 0,1 & 831 & 173 & 0,9998 & 0,1 & 845 & 148 & 0,9998 & 82 \\
\hline Amitraz & 60 & 8 & 27 & 51 & 3 & 13 & $>100$ & 0,5 & 1891 & -247 & 1,0000 & 0,2 & 1426 & 336 & 0,9997 & 49 \\
\hline Anilazina & & & & 24 & & 53 & $>100$ & 10 & 38 & -35 & 0,9997 & 10 & 44 & -4 & 0,9924 & 93 \\
\hline Atrazina & 93 & 6 & 11 & 95 & 3 & 10 & 10 & 0,1 & 1619 & 416 & 0,9998 & 0,1 & 1948 & 704 & 0,9996 & 89 \\
\hline Azinfos-Me & 86 & 7 & 14 & 91 & 3 & 12 & 10 & 0,2 & 2677 & 174 & 1,0000 & 0,2 & 3174 & 978 & 0,9996 & 89 \\
\hline Azoxistrobina & 92 & 4 & 11 & 93 & 2 & 7 & 10 & 0,1 & 4780 & 1240 & 0,9998 & 0,1 & 5141 & 1662 & 0,9998 & 86 \\
\hline Bendiocarb & 109 & 4 & 20 & 110 & 3 & 18 & 10 & 0,1 & 1723 & 180 & 0,9999 & 0,1 & 2184 & 514 & 0,9997 & 93 \\
\hline Bentazona & 102 & 14 & 27 & 114 & 6 & 26 & 10 & 1 & 12 & 3 & 0,9996 & 1 & 10 & 4 & 0,9994 & 83 \\
\hline Carbarilo & 88 & 6 & 12 & 92 & 3 & 11 & 10 & 0,1 & 310 & 75 & 0,9997 & 0,5 & 418 & 131 & 0,9994 & 98 \\
\hline Carbendazim & 99 & 6 & 13 & 95 & 2 & 14 & 10 & 0,2 & 1319 & -90 & 1,0000 & 0,2 & 1549 & -59 & 1,0000 & 81 \\
\hline Carboxin & 87 & 2 & 8 & 88 & 2 & 8 & 10 & 0,1 & 3867 & 1613 & 0,9995 & 0,1 & 4323 & 2313 & 0,9991 & 87 \\
\hline Chinometionat & & & & 78 & 23 & 34 & $>100$ & 20 & 10 & -12 & 0,9836 & 20 & 13 & -33 & 0,9897 & 97 \\
\hline Ciromazina & & & & 69 & 4 & 13 & 10 & 10 & 80 & -220 & 0,9868 & 10 & 104 & -77 & 0,9996 & 199 \\
\hline Cletodim & 115 & 21 & 32 & 84 & 6 & 8 & 10 & 1 & 211 & -68 & 0,9999 & 1 & 215 & -65 & 1,0000 & 80 \\
\hline Clofentezine & 79 & 20 & 24 & 82 & 6 & 29 & 10 & 0,5 & 203 & -61 & 0,9999 & 0,5 & 136 & 177 & 0,9930 & 68 \\
\hline Clorantraniliprole & 88 & 18 & 21 & 95 & 6 & 16 & 10 & 0,5 & 203 & 22 & 0,9995 & 0,5 & 201 & 148 & 0,9980 & 81 \\
\hline Clorimuron-Et & 89 & 10 & 12 & 85 & 3 & 5 & 10 & 0,2 & 1258 & -231 & 0,9999 & 0,2 & 1267 & -466 & 0,9997 & 115 \\
\hline
\end{tabular}




\begin{tabular}{|c|c|c|c|c|c|c|c|c|c|c|c|c|c|c|c|c|}
\hline & \multicolumn{7}{|c|}{ Exactitud y precisión } & \multicolumn{9}{|c|}{ Calibraciones } \\
\hline & \multicolumn{3}{|c|}{$10 \mu \mathrm{g} / \mathrm{L}$} & \multicolumn{3}{|c|}{$100 \mu \mathrm{g} / \mathrm{L}$} & \multirow[b]{2}{*}{$L C^{d}$} & \multicolumn{4}{|l|}{ Matriz } & \multicolumn{4}{|c|}{ Solvente } & \multirow[b]{2}{*}{$\begin{array}{l}E^{h}{ }^{h} \\
(\%)\end{array}$} \\
\hline & $\begin{array}{l}\operatorname{Rec} \\
(\%)^{a}\end{array}$ & $\begin{array}{l}\mathrm{DER}_{1} \text { dia } \\
(\%)^{b}\end{array}$ & $\begin{array}{l}D^{D^{2} R_{3 \text { dias }}} \\
(\%)^{\text {col }}\end{array}$ & $\begin{array}{l}\text { Rec } \\
(\%)^{a}\end{array}$ & $\begin{array}{l}\mathrm{DER}_{1} \text { dia } \\
(\%)^{\mathrm{b}}\end{array}$ & $\begin{array}{l}D^{D E R_{3} \text { dias }} \\
(\%)^{c}\end{array}$ & & $\mathrm{MNC}^{\mathrm{e}}$ & $b^{f}$ & $a^{g}$ & $r^{2}$ & $\mathrm{MNC}^{\mathrm{e}}$ & $b^{f}$ & $a^{g}$ & $r^{2}$ & \\
\hline Clorpirifos & 99 & 8 & 15 & 81 & & 5 & 10 & 0,2 & 178 & 5 & 1,0000 & 0,1 & 184 & 6032 & 0,9987 & 79 \\
\hline Clorpirifos-Me & 81 & 15 & 23 & 86 & 6 & 13 & 100 & 1,5 & 118 & -61 & 0,9993 & 1 & 127 & -1 & 0,9997 & 83 \\
\hline Clotianidin & 109 & 4 & 11 & 105 & 3 & 14 & 10 & 0,1 & 340 & 110 & 0,9997 & 0,1 & 427 & 93 & 0,9999 & 92 \\
\hline Diazinon & 77 & 7 & 18 & 81 & 3 & 8 & 10 & 0,1 & 3819 & 1571 & 0,9998 & 0,1 & 4089 & 3257 & 0,9999 & 83 \\
\hline Diclorvos & 100 & 11 & 20 & 100 & 2 & 16 & 10 & 0,5 & 377 & -52 & 1,0000 & 1 & 455 & -50 & 0,9999 & 89 \\
\hline Diflubenzuron & 78 & 12 & 14 & 73 & 6 & 8 & 10 & 0,2 & 535 & 6 & 0,9999 & 0,1 & 703 & -132 & 0,9999 & 99 \\
\hline Dinotefuran & 98 & 4 & 12 & 101 & 4 & 12 & 10 & 0,5 & 1203 & 78 & 0,9999 & 0,2 & 1306 & 32 & 0,9999 & 84 \\
\hline Fenpropatrin & 106 & 9 & 15 & 88 & 4 & 12 & 10 & 1,5 & 408 & -159 & 0,9999 & 1,5 & 455 & -199 & 0,9999 & 76 \\
\hline Fention & 82 & 22 & 17 & 74 & 12 & 18 & 10 & 0,5 & 278 & -53 & 0,9999 & 1 & 180 & -46 & 0,9991 & 71 \\
\hline Fipronil & 92 & 15 & 15 & 86 & 3 & 4 & 10 & 0,1 & 85 & 162 & 0,9976 & 0,2 & 78 & 136 & 0,9967 & 88 \\
\hline Flonicamid & 109 & 7 & 20 & 103 & 2 & 10 & 10 & 0,5 & 100 & -18 & 1,0000 & 0,2 & 125 & 16 & 0,9998 & 95 \\
\hline Fludioxonil & 95 & 17 & 26 & 89 & 8 & 10 & 10 & 0,5 & 47 & 26 & 0,9990 & 0,2 & 51 & 23 & 0,9993 & 87 \\
\hline Flusilazole & 85 & 12 & 20 & 87 & 3 & 10 & 10 & 0,2 & 949 & 63 & 0,9999 & 0,1 & 891 & -287 & 0,9999 & 78 \\
\hline Flutolanil & 78 & 6 & 15 & 79 & 3 & 17 & 10 & 0,1 & 2576 & 333 & 0,9999 & 0,1 & 3037 & 925 & 0,9996 & 88 \\
\hline Fosmet & 86 & 5 & 13 & 87 & 3 & 10 & 10 & 0,2 & 2886 & 89 & 1,0000 & 0,2 & 3419 & 751 & 0,9997 & 90 \\
\hline Imidacloprid & 110 & 7 & 14 & 105 & 3 & 14 & 10 & 0,1 & 463 & 181 & 0,9997 & 0,1 & 483 & 143 & 0,9998 & 84 \\
\hline Linuron & 79 & 11 & 25 & 83 & 3 & 23 & 10 & 0,1 & 802 & 279 & 0,9996 & 0,1 & 978 & 405 & 0,9994 & 91 \\
\hline Mecarbam & 92 & 7 & 18 & 89 & 4 & 12 & 10 & 0,1 & 1930 & 431 & 0,9998 & 0,1 & 2338 & 413 & 0,9999 & 89 \\
\hline Metalaxil & 101 & 4 & 10 & 99 & 3 & 10 & 10 & 0,1 & 3548 & 874 & 0,9998 & 0,1 & 3990 & 602 & 0,9999 & 86 \\
\hline Metamidofos & 109 & 4 & 9 & 98 & 7 & 16 & 10 & 1,5 & 293 & -194 & 0,9998 & 1,5 & 456 & -345 & 0,9996 & 151 \\
\hline Metidation & 94 & 8 & 22 & 99 & 5 & 18 & 10 & 0,1 & 1113 & 269 & 0,9998 & 0,1 & 1330 & 272 & 0,9996 & 88 \\
\hline Metomilo & 94 & 4 & 8 & 95 & 3 & 9 & 10 & 0,1 & 1078 & 94 & 1,0000 & 0,1 & 1055 & 24 & 0,9999 & 79 \\
\hline Metopreno & 99 & 14 & 15 & 79 & 3 & 11 & 10 & 0,5 & 400 & -3 & 1,0000 & 0,5 & 381 & -354 & 0,9956 & 71 \\
\hline Metoxifenozide & 79 & 21 & 18 & 77 & 4 & 10 & 10 & 0,2 & 442 & -168 & 0,9998 & 0,2 & 474 & -292 & 0,9993 & 84 \\
\hline
\end{tabular}




\begin{tabular}{|c|c|c|c|c|c|c|c|c|c|c|c|c|c|c|c|c|}
\hline & \multicolumn{7}{|c|}{ Exactitud y precisión } & \multicolumn{9}{|c|}{ Calibraciones } \\
\hline & \multicolumn{3}{|c|}{$10 \mu \mathrm{g} / \mathrm{L}$} & \multicolumn{3}{|c|}{$100 \mu \mathrm{g} / \mathrm{L}$} & \multirow[b]{2}{*}{$L C^{d}$} & \multicolumn{4}{|c|}{ Matriz } & \multicolumn{4}{|c|}{ Solvente } & \multirow[b]{2}{*}{$\begin{array}{l}\mathrm{EM}^{\mathrm{h}} \\
(\%)\end{array}$} \\
\hline & $\begin{array}{l}\begin{array}{l}\text { Rec } \\
(\%)^{a}\end{array}\end{array}$ & $\begin{array}{l}\mathrm{DER}_{1 \text { dia }} \\
(\%)^{\mathrm{b}}\end{array}$ & $\begin{array}{l}\mathrm{DER}_{3} \text { dias } \\
(\%)^{c}\end{array}$ & $\begin{array}{l}\operatorname{Rec} \\
(\%)^{a}\end{array}$ & $\begin{array}{l}\mathrm{DER}_{1 \text { dia }} \\
(\%)^{\mathrm{b}}\end{array}$ & $\begin{array}{l}D^{D^{2} R_{3} \text { dias }} \\
(\%)^{c}\end{array}$ & & $M N C^{e}$ & $b^{f}$ & $a^{g}$ & $r^{2}$ & $\mathrm{MNC}^{\mathrm{e}}$ & $b^{\dagger}$ & $a^{9}$ & $r^{2}$ & \\
\hline Metribuzin & 106 & 10 & 30 & 112 & 4 & 22 & 10 & 0,5 & 333 & 56 & 0,9997 & 0,5 & 427 & 86 & 0,9995 & 91 \\
\hline Metsulfuron-Me & 89 & 19 & 23 & 92 & 5 & 12 & 100 & 2 & 137 & -79 & 0,9997 & 2 & 141 & -82 & 0,9997 & 85 \\
\hline Nitenpyram & 96 & 11 & 11 & 93 & 4 & 10 & 10 & 0,5 & 236 & -22 & 1,0000 & 0,5 & 281 & -43 & 1,0000 & 89 \\
\hline Piraclostrobin & 80 & 13 & 14 & 80 & 3 & 6 & 10 & 0,1 & 2202 & 412 & 0,9997 & 0,1 & 2314 & 612 & 0,9996 & 82 \\
\hline Pirimicarb & 97 & 3 & 12 & 96 & 3 & 11 & 10 & 0,1 & 6265 & 1163 & 0,9999 & 0,1 & 7010 & 526 & 1,0000 & 87 \\
\hline Pirimifos-Me & 74 & 2 & 9 & 74 & 3 & 12 & 10 & 0,1 & 3280 & 249 & 1,0000 & 0,1 & 3737 & 499 & 0,9999 & 85 \\
\hline Procloraz & 79 & 6 & 11 & 81 & 4 & 6 & 10 & 0,1 & 607 & 41 & 0,9999 & 0,1 & 671 & 93 & 0,9998 & 86 \\
\hline Profenofos & 84 & 11 & 18 & 82 & 4 & 11 & 10 & 0,2 & 532 & -35 & 1,0000 & 0,1 & 616 & -24 & 1,0000 & 86 \\
\hline Propargite & 91 & 8 & 21 & 81 & 4 & 8 & 10 & 0,1 & 1239 & -64 & 1,0000 & 0,1 & 1404 & -190 & 0,9999 & 79 \\
\hline Propiconazole & 83 & 12 & 13 & 84 & 4 & 8 & 10 & 0,5 & 1148 & 350 & 0,9997 & 0,2 & 1281 & 425 & 0,9996 & 92 \\
\hline Tebuconazole & 84 & 5 & 13 & 86 & 4 & 8 & 10 & 0,1 & 2796 & 573 & 0,9999 & 0,1 & 3077 & 1149 & 0,9997 & 87 \\
\hline Terbufos & 86 & 13 & 13 & 79 & 4 & 9 & 10 & 0,5 & 437 & 60 & 1,0000 & 0,2 & 509 & 155 & 1,0000 & 85 \\
\hline Tiabendazol & 91 & 5 & 11 & 90 & 3 & 9 & 10 & 0,1 & 2059 & -191 & 1,0000 & 0,1 & 2195 & 157 & 0,9999 & 85 \\
\hline Tiacloprid & 123 & 4 & 23 & 116 & 12 & 22 & 10 & 0,1 & 4062 & 1815 & 0,9990 & 0,1 & 4560 & 3163 & 0,9986 & 88 \\
\hline Tiametoxam & 106 & 5 & 11 & 108 & 4 & 14 & 10 & 0,2 & 392 & 193 & 0,9993 & 0,2 & 425 & 147 & 0,9996 & 85 \\
\hline Triadimefon & 93 & 10 & 14 & 86 & 5 & 13 & 10 & 0,5 & 446 & -44 & 1,0000 & 0,5 & 522 & -74 & 1,0000 & 87 \\
\hline Triadimenol & 88 & 20 & 20 & 85 & 15 & 11 & 10 & 1,5 & 207 & 144 & 0,9967 & 1,5 & 214 & 16 & 0,9984 & 85 \\
\hline Triazofos & 87 & 4 & 9 & 87 & 3 & 7 & 10 & 0,1 & 5641 & 1497 & 0,9998 & 0,1 & 6357 & 2333 & 0,9995 & 88 \\
\hline
\end{tabular}

${ }^{a}$ Recuperación, media de 3 réplicas en 3 días distintos $(n=6)$.

${ }^{\mathrm{b}}$ Desvío estándar relativo- repetibilidad, 5 réplicas en un día ( $\left.\mathrm{n}=5\right)$.

'Desvío estándar relativo- reproducibilidad, 3 réplicas en 3 días distintos $(n=6)$.

¿Límite de cuantificación $(\mu \mathrm{g} / \mathrm{L})$

${ }^{\mathrm{e}}$ Mínimio nivel de calibración $(\mu \mathrm{g} / \mathrm{L})$

${ }^{\mathrm{f} P e n d i e n t e ~ d e ~ l a ~ c u r v a ~ d e ~ c a l i b r a c i o ́ n ; ~}{ }^{\mathrm{g}}$ ordenada al origen de la curva de calibración.

${ }^{\mathrm{h}}$ Efecto matriz $=$ pendiente-matrix/pendiente-solvente $\times 100$. 


\section{Criterios para la identificación y cuantificación por UHPLC-MS/MS}

Para la identificación, confirmación y cuantificación de los compuestos en los extractos de leches analizados en el sistema UHPLC-MS/MS se consideraron los siguientes criterios: a) presencia de al menos 2 transiciones escaneadas, una para cuantificación $(Q)$ y la otra para confirmación $(q) ;$ b) tolerancia de $\pm 0,2$ min en los tiempos de retención del compuesto en el extracto de la muestra con relación al tiempo de retención de un estándar de calibración en matriz; c) relación $\mathrm{S} / \mathrm{N} \geq 10$ para la transición $Q$ y, al mismo tiempo, $S / N \geq 3$ para la transición $q$; d) tolerancia de hasta $\pm 30 \%$ en la relación $q / Q$ del extracto de muestra comparado con un estándar en matriz de una concentración similar. Aquellas señales cromatográficas de compuestos que cumplieron los mencionados criterios se cuantificaron a través de las respectivas curvas de calibrado en matriz, y en aquellos casos en los que la ecuación de la curva no permitía el cálculo de la concentración esta última se estimó por comparación puntual con el nivel de calibración más próximo.

\subsubsection{Análisis de muestras reales}

Utilizando el método de extracción QuEChERS validado y la determinación por UHPLC-MS/MS optimizada se analizaron las muestras de leche cruda correspondientes a las estaciones de verano e invierno, que hasta el momento del análisis permanecieron congeladas a $-18^{\circ} \mathrm{C}$ desde su obtención. En vista de los resultados obtenidos que se muestran en la Tabla 28, cabe mencionar, como primer comentario, que los plaguicidas hallados en las muestras de leche analizadas se encontraron todos a niveles traza, por debajo de los respectivos límites de cuantificación del método. Los plaguicidas más frecuentemente encontrados fueron diazinon y clorpirifos, en el $16 \%$ y $14 \%$ de las 80 muestras, respectivamente, seguidos con menor nivel de ocurrencia por pirimifos-metilo (4\%), piraclostrobin (3\%), azoxistrobina (3\%) y detecciones únicas de acetamiprid, atrazina, bendiocarb, carbendazim, cletodim, fention, fipronil y metalaxil (Tablas 28 y 29). Los valores estimados de concentración más altos correspondieron a fipronil $(2,6 \mu \mathrm{g} / \mathrm{L})$, clorpirifos $(2,5 \mu \mathrm{g} / \mathrm{L}) \mathrm{y}$ atrazina $(2,4 \mu \mathrm{g} / \mathrm{L})$, mientras que para el resto de los compuestos se estimaron concentraciones por debajo de $1 \mu \mathrm{g} / \mathrm{L}$. 
Tabla 28. Compuestos hallados del análisis de 80 muestras de leche cruda mediante extracción QuEChERS y determinación UHPLC-MS/MS.

\begin{tabular}{|c|c|c|c|c|c|c|c|}
\hline & \multirow[b]{2}{*}{ Compuesto } & \multirow[b]{2}{*}{ Detecciones } & \multicolumn{5}{|c|}{ Concentración $\mu \mathrm{g} / \mathrm{L}$} \\
\hline & & & Min. & Máx. & Media & LC & MNC \\
\hline \multirow{8}{*}{$\begin{array}{l}\text { Muestreo Verano } \\
(n=40)\end{array}$} & Acetamiprid & 1 & & 0,1 & & 10 & 0,1 \\
\hline & Clorpirifos & 11 & 0,5 & 2,5 & 1,4 & 10 & 0,2 \\
\hline & Cletodim & 1 & & 1,6 & & 10 & 1 \\
\hline & Diazinon & 13 & 0,4 & 1,4 & 0,7 & 10 & 0,1 \\
\hline & Fention & 1 & & 0,9 & & 10 & 0,5 \\
\hline & Fipronil & 1 & & 2,6 & & 10 & 0,1 \\
\hline & Piraclostrobin & 2 & 0,1 & 0,1 & 0,1 & 10 & 0,1 \\
\hline & Pirimifos-Me & 3 & 0,1 & 0,1 & 0,1 & 10 & 0,1 \\
\hline \multirow{5}{*}{$\begin{array}{l}\text { Muestreo Invierno } \\
(n=40)\end{array}$} & Atrazina & 1 & & 2,4 & & 10 & 0,1 \\
\hline & Azoxistrobina & 2 & 0,2 & 0,2 & 0,2 & 10 & 0,1 \\
\hline & Bendiocarb & 1 & & 0,2 & & 10 & 0,1 \\
\hline & Carbendazim & 1 & & 0,9 & & 10 & 0,2 \\
\hline & Metalaxil & 1 & & 0,2 & & 10 & 0,1 \\
\hline
\end{tabular}

Mín.: concentración mínima; Máx.: concentración máxima.

LC: límite de cuantificación; MNC: mínimo nivel de calibración matrix-matched

La ocurrencia de plaguicidas organofosforados en leche puede ser causada por la aplicación directa de estos compuestos sobre el ganado para control de ectoparásitos, por el tratamiento de plantas vegetales que luego son usadas en forma de pasturas, forrajes o piensos para alimentación animal, o por el uso de estos insecticidas para el control de plagas en instalaciones y fábricas [206]. Además, su persistencia en leche puede deberse a que poseen la habilidad de unirse covalentemente a las proteínas como la caseína, al tiempo que la naturaleza lipofílica de la mayoría de ellos favorece su acumulación en la parte grasa de esa matriz [203]. En este trabajo, los 3 compuestos más encontrados en las leches analizadas por UHPLCMS/MS fueron precisamente los insecticidas organofosforados clorpirifos, diazinon y pirimifos-metilo. La presencia de esta familia de plaguicidas en leche ha sido reportada también en la literatura reciente. Por ejemplo, Fagnani y col. (2011) analizaron 30 muestras de leche en la región de Pernambuco (Brasil), hallando fention como el compuesto de mayor prevalencia (34\%) seguido por dimetoato (25\%), cumafos y malation ( $9 \%$ cada uno), todos en niveles traza y con una concentración media máxima de 0,16 $\mu \mathrm{g} / \mathrm{L}$ para cumafos [134]. También en Brasil, Ciscatto y col. (2018) hallaron residuos de clorpirifos en el 68\% de un total de 28 muestras comerciales de leche UHT de San Pablo, encontrando a la vez alta ocurrencia (54\%) de el insecticida piretroide cipermetrina (Brazil) [209]. Salas y col. (2003), por otro lado, analizaron 93 muestras de leche comercializadas en México y de los compuestos hallados en nuestro trabajo reportaron residuos de clorpirifos en una sola muestra $(13 \mu \mathrm{g} / \mathrm{L})$, al tiempo que diclorvos fue el plaguicida más frecuente (6 detecciones) con una concentración media de $20 \mu \mathrm{g} / \mathrm{L}$ [206]. Por otro lado, Pagliuca y col. (2006) encontraron residuos de clorpirifos en 16 de 135 muestras de leche cruda (12\%, concentración máxima $5 \mu \mathrm{g} / \mathrm{L}$ ) obtenidas en tanques de plantas de procesamiento en Italia, además de trazas no cuantificables de pirimifos-metilo y diazinon en 2 y 1 muestra, respectivamente [203]. También Bedi y col. 
(2018) verificaron la presencia de clorpirifós a niveles promedio de 2,6 $\mu \mathrm{g} / \mathrm{kg}$ en 6 de 55 muestras de leche cruda $(10,1 \%)$ en un estudio realizado en India en el que además de leche analizaron alimentos concentrados, pasturas y agua suministradas al ganado. En el mismo trabajo reportaron, junto con clorpirifos, la presencia de otros plaguicidas endosulfan sulfato, cipermetrina, etion, p, $p^{\prime}-D D E$, lindano, malation y fenvalerato [102].

Tabla 29. Plaguicidas hallados por UHPLC-MS/MS y GC-MS/MS en las 80 muestras de leche analizadas por la metodología QuEChERS optimizada. Resultados de las muestras tomadas en verano e invierno en los tambos 1-20.

\begin{tabular}{|c|c|c|c|c|c|c|c|c|c|c|c|c|c|c|c|c|c|c|c|c|}
\hline \multirow[b]{2}{*}{ Compuesto } & \multicolumn{20}{|c|}{$\mathrm{N}^{\circ}$ de tambo } \\
\hline & 1 & 2 & 3 & 4 & 5 & 6 & 7 & 8 & 9 & 10 & 11 & 12 & 13 & 14 & 15 & 16 & 17 & 18 & 19 & 20 \\
\hline VERANO & & & & & & & & & & & & & & & & & & & & \\
\hline UHPLC-MS/MS & & & & & & & & & & & & & & & & & & & & \\
\hline Acetamiprid & & & 0,1 & & & & & & & & & & & & & & & & & \\
\hline Clorpirifos & 2,5 & 0,5 & & & & & 2 & & & & & & & & & & & & & \\
\hline Cletodim & & & & & & & & & & & & & & & & & & & & \\
\hline Diazinon & 0,5 & 0,6 & 0,8 & & 1,3 & & & & & & 0,7 & 1,4 & & & & 1 & & 0,6 & & \\
\hline Fention & & & & & & & & & & & & & & & & & & & & \\
\hline Fipronil & & & & & & & 2,6 & & & & & & & & & & & & & \\
\hline Piraclostrobin & & & & & & & & & & & & & & & & 0,1 & & & & \\
\hline Pirimifos-Me & & & & & & & & 0,1 & & & & 0,1 & & & & & & & & 0,1 \\
\hline GC-MS/MS & & & & & & & & & & & & & & & & & & & & \\
\hline Clorpirifos & & & & & & & & & & 0,7 & & & & & 0,5 & & & & & \\
\hline$\lambda$-cialotrina & 2,8 & 6 & & 3,5 & 11,1 & & & & & 9,8 & 6,9 & 6,8 & & & & & & & & \\
\hline Cipermetrina & & & & & & & & & & & & & & & & & & & & \\
\hline DDD-p,p' & & & & & & & & & & & & & & & & & & & & \\
\hline DDE-o,p' & & & & & & & & & & & & & & & & & & & & \\
\hline DDE-p,p' & & & & & & & & & & & & & & & 0,1 & & & & & \\
\hline DDT-o,p' & & & & & & & & & & & & & & & & & & & & \\
\hline Diazinon & & & 0,4 & & & & & & & & 0,7 & 0,6 & & & & & & & & \\
\hline Endosulfan $\mathrm{SO}_{4}{ }^{=}$ & 0,4 & 0,3 & 1,3 & 1,5 & 0,4 & 0,9 & 0,5 & 0,7 & 0,5 & 1 & 0,5 & 0,3 & 1,8 & 0,6 & 2,2 & 0,8 & 1,9 & 0,7 & 3,6 & 0,5 \\
\hline Heptacloro & & & & & & & & & & & & & & & & & & & & \\
\hline Metoxicloro & & & & & & & & & & & & & & & 1,5 & & & & & \\
\hline Mirex & & & & & & & & & & & & & & & & & & & & \\
\hline INVIERNO & & & & & & & & & & & & & & & & & & & & \\
\hline UHPLC-MS/MS & & & & & & & & & & & & & & & & & & & & \\
\hline Atrazina & & & & & & & & & & & & & 2,6 & & & & & & & \\
\hline Azoxistrobina & & & & & & & & & & & & & & & & & & & & \\
\hline Bendiocarb & & & & & & & & & & & & & & & & & & & & \\
\hline Carbendazim & & & & & & & & & & & & & & & & & & & & \\
\hline Diazinon & & 0,3 & 0,5 & & & & & & & & & & & & & & & & & \\
\hline Metalaxil & & & & & & & & & & & & & & & & & & & & \\
\hline GC-MS/MS & & & & & & & & & & & & & & & & & & & & \\
\hline$\lambda$-cialotrina & 1,1 & & & & & & & & & & & & & & & & & & & \\
\hline Endosulfan $\mathrm{SO}_{4}{ }^{=}$ & & & & & & 3,1 & & & 0,1 & & 0,2 & & & & & & & 0,5 & 0,4 & \\
\hline Heptacloro & & & & 0,2 & & & & & & & & & & & & & & & & \\
\hline
\end{tabular}


Tabla 29 (cont.). Plaguicidas hallados por UHPLC-MS/MS y GC-MS/MS en las 80 muestras de leche analizadas por la metodología QuEChERS optimizada. Resultados de las muestras tomadas en verano e invierno en los tambos 21-40.

\begin{tabular}{|c|c|c|c|c|c|c|c|c|c|c|c|c|c|c|c|c|c|c|c|c|}
\hline \multirow[b]{2}{*}{ Compuesto } & \multicolumn{20}{|c|}{$\mathrm{N}^{\circ}$ de tambo } \\
\hline & 21 & 22 & 23 & 24 & 25 & 26 & 27 & 28 & 29 & 30 & 31 & 32 & 33 & 34 & 35 & 36 & 37 & 38 & 39 & 40 \\
\hline VERANO & & & & & & & & & & & & & & & & & & & & \\
\hline UHPLC-MS/MS & & & & & & & & & & & & & & & & & & & & \\
\hline Acetamiprid & & & & & & & & & & & & & & & & & & & & \\
\hline Clorpirifos & & 1,2 & 1,4 & & & & & 0,8 & & & 1 & 1,1 & & 2,2 & & 0,9 & & & & 1,5 \\
\hline Cletodim & & & & & & & & & & 1,6 & & & & & & & & & & \\
\hline Diazinon & & & & 0,8 & & 0,6 & & 0,5 & & & & & & & & 0,4 & & & 0,4 & \\
\hline Fention & & & & & & & & & & & & & & & & & & & 0,9 & \\
\hline Fipronil & & & & & & & & & & & & & & & & & & & & \\
\hline Piraclostrobin & & & & & & & & & & 0,1 & & & & & & & & & & \\
\hline Pirimifos-Me & & & & & & & & & & & & & & & & & & & & \\
\hline$G C-M S / M S$ & & & & & & & & & & & & & & & & & & & & \\
\hline Clorpirifos & & & & & & & & & & & & & & & & & & & & \\
\hline$\lambda$-cialotrina & & & 25 & & 2 & & & & 7,2 & & 8 & 6,9 & & 2,1 & 1,2 & 1,5 & & & & \\
\hline Cipermetrina & & & & & & & & & 19 & & & & & & & & & & & \\
\hline DDD-p, $p^{\prime}$ & & & & & & & & & & & & & & & & & & 0,1 & & \\
\hline DDE-o,p' & & & & & & & & & & & & & & & & & & 1,8 & & \\
\hline DDE-p,p' & & & 0,1 & & & & & & & & & & 0,1 & & & & & 0,1 & & \\
\hline DDT-o,p' & & & & & & & & & & & & & & & & & & 0,1 & & \\
\hline Diazinon & & & & 0,5 & & 0,6 & 0,5 & 0,4 & & & & & & & & 0,2 & 0,2 & & 0,2 & \\
\hline Endosulfan $\mathrm{SO}_{4}=$ & 0,3 & 0,5 & 2 & 2,8 & 1,7 & 1,1 & 0,8 & 0,3 & 2,3 & 1 & 1,6 & 0,8 & 1,3 & 1 & 1,1 & 0,8 & 1,3 & 1,1 & 1 & 0,2 \\
\hline Heptacloro & & & 0,1 & & & & & & & & & & & & & & & & & \\
\hline Metoxicloro & & & 0,4 & & & & & & & & & 0,3 & & & & & & & & \\
\hline Mirex & & & & & & & & & & & & & & & & & & 0,1 & & \\
\hline INVIERNO & & & & & & & & & & & & & & & & & & & & \\
\hline UHPLC-MS/MS & & & & & & & & & & & & & & & & & & & & \\
\hline Atrazina & & & & & & & & & & & & & & & & & & & & \\
\hline Azoxistrobina & & & & & & & 0,1 & & & & & & & & & & & & & \\
\hline Bendiocarb & & & & & & & & & & & & & & & & & & 1,3 & & \\
\hline Carbendazim & & & & & & & & & & & & & & & & & & & & \\
\hline Diazinon & 0,3 & & & & & & 0,3 & & & & & & & & & & & & & \\
\hline Metalaxil & & & & & & & & & & & & & & & & & & 0,4 & & \\
\hline$G C-M S / M S$ & & & & & & & & & & & & & & & & & & & & \\
\hline$\lambda$-cialotrina & & & & 1 & & & & & & & & & & & & & 1,9 & & 0,8 & \\
\hline $\begin{array}{l}\text { Endosulfan } \mathrm{SO}_{4}= \\
\text { Heptacloro }\end{array}$ & & 0,4 & & & & & & & & & & & & & & & & & 0,3 & \\
\hline
\end{tabular}

A pesar de la menor persistencia y poder de acumulación en el ambiente que presentan los plaguicidas organofosforados, razón por la cual su uso se ha expandido frente a los organoclorados, sus residuos son igualmente encontrados en leche y en toda la cadena de producción. Como se verá en el Capítulo 4 de esta Tesis, clorpirifos y pirimifos-metilo han presentado alta ocurrencia en alimentos vegetales utilizados en la alimentación del ganado lechero, lo que resulta coherente con estos hallazgos en leche. 
Además de plaguicidas organofosforados, otros compuestos como los analizados y hallados en este trabajo han sido reportados en la bibiliografía. Por ejemplo, Aguilera-Luiz y col. (2011) analizaron 15 muestras de leche comercializadas en España y detectaron trazas de acetamiprid (4 muestras en niveles 0,5-3,6 $\mu \mathrm{g} / \mathrm{L}$ ), bendiocarb (1 muestra, $2,2 \mu \mathrm{g} / \mathrm{L}$ ) y carbenzadim (1 muestra 3,4 $\mu \mathrm{g} / \mathrm{L}$ ) [112].

Respecto a los plaguicidas principalmente hallados por UHPLC-MS/MS, se debe mencionar que en Argentina clorpirifos, diazinon y pirimifos-metilo además de estar autorizados como fitosanitarios están permitidos como antiparasitarios externos $[12,47]$ por lo que la llegada de estos plaguicidas a la leche podría darse por vía de la ingesta de alimentos o por vía del contacto dérmico directo. Se observa además falta de armonización entre las regulaciones puesto que en el caso del pirimifos-metilo, por ejemplo, la Resolución SENASA 559 que fija LMRs para alimentos de origen animal establece un límite de $10 \mu \mathrm{g} / \mathrm{L}$ en leche mientras que el Código Alimentario Argentino lo fija en 50 mg/L.

Plaguicidas hallados en las en muestras analizadas por GC-MS/MS

Con el propósito de ampliar la base de información sobre la presencia de residuos de plaguicidas en las 80 muestras de leche analizadas por UHPLC-MS/MS, los mismos extractos se inyectaron con posterioridad en un sistema de cromatografía gaseosa (GC-MS/MS) analizando 42 compuestos organoclorados, organofosforados y piretroides. Si bien la mayoría de estos compuestos estuvieron fuera del alcance analítico del método de extracción validado, la información obtenida es valiosa desde el punto de vista cualitativo. De todos modos, las concentraciones de los plaguicidas identificados se calcularon mediante curva de calibración en matriz $(1-500 \mathrm{ng} / \mathrm{mL})$ preparada en el momento e inyectada en la misma secuencia que los extractos. Además se verificó la concentración en los extractos de 4 plaguicidas incluidos en el método GC-MS/MS y que habían sido adicionados a la leche en los ensayos de recuperación en ocasión del análisis por UHPLC-MS/MS. Estos compuestos fueron clorpirifos, clorpirifos-metilo, diazinon y diclorvos, para los que se obtuvieron recuperaciones de $94,62,78$ y $154 \%$ en el nivel adicionado en $10 \mu \mathrm{g} / \mathrm{L}$, y de 119 , 64,73 y $165 \%$ en el nivel de $100 \mu \mathrm{g} / \mathrm{L}$, respectivamente.

El compuesto con mayor ocurrencia en los extractos fue endosulfan sulfato, que se encontró en el 59\% las muestras verificándose su presencia en la totalidad de las 40 muestras de verano y en 7 de igual cantidad de invierno. También dentro de la familia de los organoclorados se encontraron residuos de DDE-p,p' (4 muestras), metoxicloro (3 muestras), heptacloro (2 muestras), y con ocurrencia en una sola muestra se encontraron DDD-p,p', DDE-o,p', DDT-o,p' y mirex. En relación a los plaguicidas organofosforados se encontraron residuos de diazinon en el 13\% de las muestras (10 detecciones) y clorpirifos en 2 de ellas. Respecto al clorpirifos fueron llamativas las menores detecciones por GC que por UHPLC, probablemente debido a un comportamiento diferencial de la combinación analito-matriz en los procesos de ionización por impacto electrónico y electrospray, respectivamente. No se debe dejar de recordar, sin embargo, que los extractos de muestras analizados por GC se sometieron a un proceso de freezado prolongado durante el cual pudieron precipitar proteínas co-extraídas por las que los compuestos organofosforados, como se 
mencionó anteriormente, presentan afinidad. Finalmente, entre los piretroides se encontraron residuos de lambdacialotrina en el $24 \%$ de las muestras ( 15 de verano y 4 de invierno) y cipermetrina en una muestra (Tabla 30).

Tabla 30. Compuestos hallados por GC-MS/MS en los extractos de leche previamente analizados por UHPLC-MS/MS.

\begin{tabular}{|c|c|c|c|c|c|}
\hline & \multirow[b]{2}{*}{ Compuesto } & \multirow[b]{2}{*}{ Detecciones } & \multicolumn{3}{|c|}{ Concentraciones $\mu \mathrm{g} / \mathrm{L}$} \\
\hline & & & Mín. & Máx. & Media \\
\hline \multirow{12}{*}{$\begin{array}{l}\text { Muestras verano } \\
(n=40)\end{array}$} & Cipermetrina & 1 & & 19 & \\
\hline & Clorpirifos & 2 & 0,5 & 0,7 & 0,6 \\
\hline & DDD-p, $p^{\prime}$ & 1 & & 0,1 & \\
\hline & DDE-o, $p^{\prime}$ & 1 & & 1,8 & \\
\hline & DDE-p,p' & 4 & 0,1 & 0,1 & 0,1 \\
\hline & DDT-o,p' & 1 & & 0,1 & \\
\hline & Diazinon & 10 & 0,2 & 0,7 & 0,4 \\
\hline & Endosulfan sulfato & 40 & 0,2 & 3,6 & 1,1 \\
\hline & Heptacloro & 1 & & 0,0004 & \\
\hline & Lambdacialotrina & 15 & 1,2 & 25 & 6,7 \\
\hline & Metoxicloro & 3 & 0,3 & 1,5 & 0,7 \\
\hline & Mirex & 1 & & 0,1 & \\
\hline \multirow{3}{*}{$\begin{array}{l}\text { Muestras invierno } \\
(n=40)\end{array}$} & Endosulfan sulfato & 7 & 0,1 & 3,1 & 0,7 \\
\hline & Heptacloro & 1 & & 0,2 & \\
\hline & Lambdacialotrina & 4 & 0,8 & 1,9 & 1,2 \\
\hline
\end{tabular}

Mín.: concentración mínima; Máx.: concentración máxima.

LC: límite de cuantificación; MNC: mínimo nivel de calibración matrix-matched

Los insecticidas organoclorados son compuestos orgánicos en su mayoría con cinco o más átomos de cloro y fueron de los primeros plaguicidas orgánicos sintéticos en ser utilizados en la agricultura y la salud pública [210]. La presencia de residuos de estos compuestos ha sido reportada en muestras de leche en todo el mundo durante las últimas décadas. Incluso en los últimos 20 años se han publicado estudios en los que se verifica la ocurrencia de estos compuestos, a pesar de que el uso de la mayoría de ellos ha estado prohibido desde hace varias décadas. En Argentina, los plaguicidas organoclorados son los que más se han estudiado históricamente. En una revisión realizada por Villamil Lepori y col. (2013) sobre la contaminación por plaguicidas en nuestro país se reporta que los compuestos con mayor frecuencia de aparición en alimentos son hexaclorociclohexano $(\mathrm{HCH})$ y DDT, seguidos por heptacloro, clordano, aldrin y endosulfan, siendo los residuos más abundantes en lácteos los de DDT y $\mathrm{HCH}$, siguiendo tendencias históricas [211]. En la misma revisión se consigna que las concentraciones reportadas de plaguicidas clorados en alimentos decrecen en el orden DDT $>\mathrm{HCH}>$ aldrin heptacloro $>$ dieldrin, y que los niveles hallados son muy inferiores a los

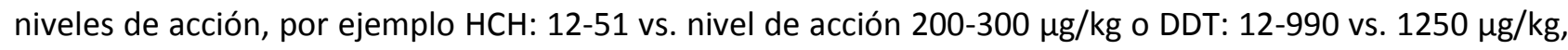
como consecuencia de las restricciones de uso de estos plaguicidas en las décadas de 1980 y 1990. También en Argentina Lorenzatti y col. $(2003,2016)$ hallaron $\mathrm{HCH}$ (isómeros a y $\beta$ ), aldrin, dieldrin, clordano (isómeros $\alpha$ y Y), endosulfan (I y II) e isómeros de DDT a niveles por debajo de $11 \mu \mathrm{g} / \mathrm{kg}$-grasa en 
48 muestras de leche comercial de la provincia de Santa Fe [212,213], y Ruiz y col. (2008) encontraron residuos de endosulfan, $\mathrm{Y}-\mathrm{HCH}$ (lindano), heptacloro-exoepóxido, endrin, clordano-trans (valor máximo del estudio, 4,8 $\mu \mathrm{g} / \mathrm{kg}$ ) e isómeros del DDT en 20 muestras de leche cruda obtenidas de establecimientos productores de la provincia de Jujuy [214]. Los residuos de plaguicidas organoclorados en leche se han reportado también en otros países de la región y del mundo. Por ejemplo en Brasil, Avancini y col. (2013) reportaron alta incidencia de aldrin (44\%), isómeros del DDT (36\%), mirex (34\%), endosulfan (I y II, 32\%), clordano (17\%) y heptacloro (11\%), ente otros, en el análisis de 100 muestras de leche pasteurizadas obtenidas de los tanques de almacenamiento de diversas industrias del estado de Mato Gorsso do Sul, con niveles de concentración entre 0,1 y 14,7 $\mu \mathrm{g} / \mathrm{kg}$-grasa (valor máximo del estudio correspondiente a dieldrin) [215]. En España, Luzardo y col. (2012) analizaron muestras de leche convencional $(n=16)$ y orgánica $(n=10)$ comercializadas en las Islas Canarias y encontraron residuos de plaguicidas organoclorados a nivel de trazas en el $100 \%$ de las mismas, siendo los más frecuentes $\alpha-\mathrm{HCH}$, clordano-cis, heptacloro, DDE-p,p' y dieldrin con ocurrencias en el $87,5 \%, 87,5 \%, 87,5 \%, 81,3 \%$ y $68,8 \%$ de leches convencionales y en el $80 \%, 70 \%, 70 \%$, $80 \%$ y $50 \%$ de leches orgánicas, respectivamente. El residuo de mayor concentración reportado en ese mismo trabajo corresponde al metabolito DDE-p, $p^{\prime}$ con niveles de 30,2 $\mu \mathrm{g} / \mathrm{kg}$-grasa en leche convencional y 20,5 $\mu \mathrm{g} / \mathrm{kg}$-grasa en leche orgánica [216]. En un monitoreo de una región de India, Nag y Raikwar (2008) reportaron la presencia de clorados en 63 \% de un total de 325 muestras de leche fresca, siendo los isómeros totales del $\mathrm{HCH}$ los más encontrados en 128 muestras (38\%) con una media de 0,16 mg/kg, seguidos por los isómeros de DDT en 114 muestras (35\%) con una media de 0,17 mg/kg y los endosulfanes ( $\alpha, \beta$, sulfato) en 89 muestras con una media de $0,05 \mathrm{mg} / \mathrm{kg}$ [217].

En las muestras de leche analizadas en este trabajo fue llamativa la aparición masiva de endosulfan sulfato, que es el principal metabolito de degradación del endosulfán, igualmente tóxico y más resistente en el medio ambiente que su compuesto de origen (Figura 34). El endosulfán es un insecticida organoclorado sintético usado para controlar insectos en una gran variedad de cultivos agrícolas, habiéndose publicado amplia información técnica sobre su toxicidad, destino y concentración ambiental, residuos en alimentos y en el forraje. Por procesos de oxidación mediada biológicamente, el endosulfan se transforma en su principal metabolito, que luego se degrada lentamente a los metabolitos más polares endosulfan-diol, endosulfan-lactona y endosulfan-éter [218]. Este insecticida se introdujo en el mercado a mediados de 1950 y todavía forma parte de los plaguicidas usados en algunos países. En Argentina, la comercialización y uso del endosulfan fue prohibida a partir del 1 de julio de 2013, fecha que fue contemporánea con el muestreo de las leches analizadas en este trabajo (verano 2012-2013 e invierno 2013), situación que podría explicar la presencia de residuos de este plaguicida hoy en día prohibido. Sin embargo, la aparición en niveles de concentración recurrentemente tan bajos puede estar relacionada al carácter altamente lipofílico del endosulfan y su metabolito, con capacidad de acumulación en el tejido graso de los animales 
desde donde eventualmente pase a la parte grasa de la leche, conduciendo a la aparición de trazas de este insecticida a pesar de que su uso ha sido discontinuado.

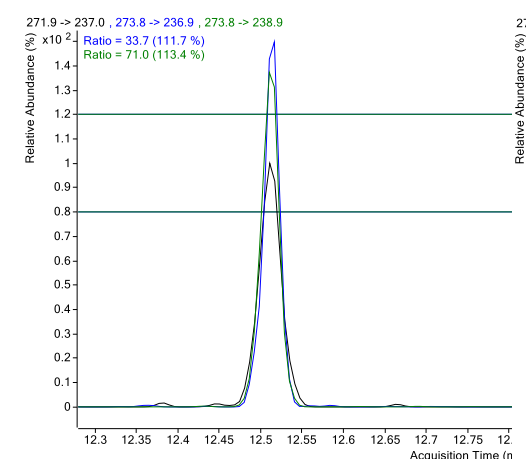

(a)

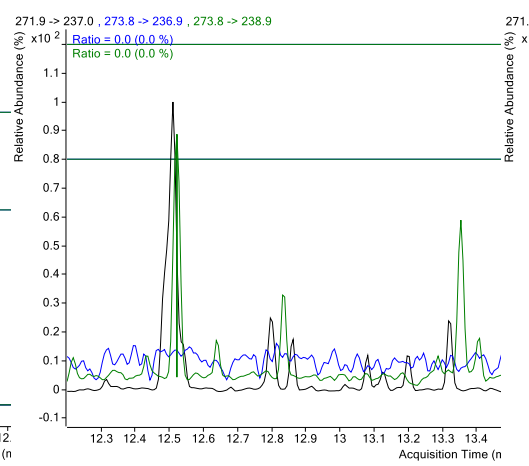

(b)

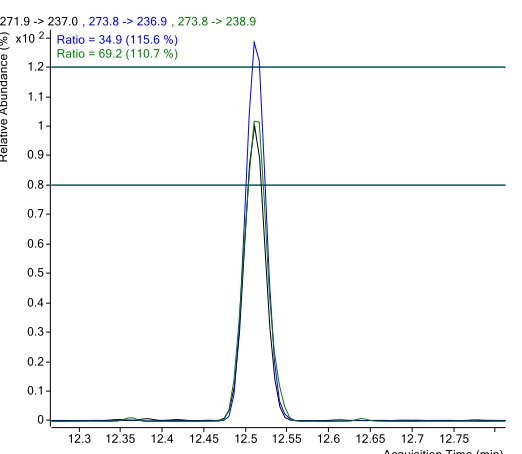

(c)

Figura 34. Cromatogramas del insecticida endosulfán-sulfato obtenidos por GC-MS/MS en la inyección de (a) extracto de muestra de leche de tambo 5-verano, (b) extracto de leche blanco, (c) estándar en matriz de concentración $1 \mathrm{ng} / \mathrm{mL}$.

Lambdacialotrina fue otro de los compuestos de mayor ocurrencia que pudieron detectarse en los extractos de muestras por GC-MS/MS. Este insecticida pertenece a la familia de los piretroides, que son compuestos lipofílicos de baja polaridad que debido al metabolismo que atraviesan en los animales tienden a bioacumularse en los compartimientos lipídicos desde donde pueden pasar a la leche convirtiéndose así en potenciales fuentes de exposición humana [207].

Teniendo en cuenta el conjunto de hallazgos verificado en este estudio cabe una observación sobre los resultados y el estatus actual que presenta la estructura de control de residuos de plaguicidas en leche en nuestro país. Desde la década del 80 el SENASA desarrolla el Plan Nacional de Control de Residuos e Higiene en Alimentos (CREHA) mediante la Coordinación de Vigilancia y Alerta de Residuos y Contaminantes. En su versión orientada a alimentos de origen animal, el total de muestras analizadas en 2017 para el ítem leche fue de 142 muestras y los resultados que se informan para el rubro contaminantes/plaguicidas fueron de 0 (ningún) resultados no conformes [219]. En otros informes del sitio web del organismo se desprende que se han verificado casos de excesos a la normativa en muestras de leche de los compuestos endosulfán sulfato ( 3 casos en 2004 y uno en 2005), semicarbazida ( 2 casos en 2010), cialotrina (1 caso en 2012), y meloxycam (un caso en 2016), no especificándose las concentraciones halladas [220]. Cabe observar que este Plan abarca adecuadamente el control mediante el análisis químico periódico de un listado que puede considerarse completo de los plaguicidas clorados y de 7 piretroides de uso difundido. Sin embargo el plan restringe su alcance, en el caso de los plaguicidas fosforados, a un grupo de nueve compuestos (diazinon, bromofos, etilbromofos, clorfenvinfos, fenitrotion, clorpirifos, etion, fention, cumafos) sin tener en cuenta que esta familia de compuestos es de muy amplio uso en el país y para los cuales rigen un gran número de autorizaciones. Considerando los hallazgos observados en nuestro estudio esto implica que el Plan no considera un conjunto de compuestos cuya presencia vestigial en leche resulta indicadora de la exposición 
potencial, siendo los casos observados más llamativos los de pirimifos-metilo fipronil, cletodim, acetamiprid, piraclostrobin, azoxistrobin, atrazina, bendiocarb, carbendazim, metalaxil. Estas observaciones también ponen en relieve la escasa información que existe respecto a la ocurrencia de plaguicidas en leche, tanto de trabajos científicos publicados como de informes elaborados por organismos de control.

La mejora de los sistemas de monitoreo y control es indispensable para perfeccionar todas las actividades que conforman en análisis de riesgo de acuerdo a los estándares actuales (riesgo de largo y de corto término, y riesgo acumulativo), que se encuentran en un estadio incipiente en nuestro país. En ese sentido, la comunicación del status actual respecto a los riesgos existentes por residuos de plaguicidas es una de las actividades que conforman el análisis de riesgo. Esto además cobra cada vez mayor importancia dado el significativo rol que se le ha asignado a la inocuidad alimentaria, especialmente química, en el comercio internacional de leche donde las tendencias son favorables y promisorias para los países productores con potencial de exportación como Argentina [87].

\subsection{CONCLUSIONES}

Se optimizó una metodología para determinar residuos de plaguicidas en leche cruda compatible con la determinación simultánea de micotoxinas (aflatoxinas), con parámetros de desempeño que satisfacen los requerimientos de las normativas de Argentina y de otros países.

Esta metodología resulta un aporte de gran interés ya que no existen muchos antecedentes en la bibliografía sobre métodos simplificados basados en QuEChERS consolidados para el análisis de leche para plaguicidas y micotoxinas, incluyendo AFM1.

Respecto a la ocurrencia, se verificó en total la presencia de 23 plaguicidas distintos en las leches analizadas, con una prevalencia de mayor significación para los insecticidas organofosforados, principalmente clorpirifos y diazinon. También se detectaron algunos insecticidas piretroides y herbicidas de amplio uso en Argentina como lambdacialotrina, atrazina y metolacloro. Fue llamativa la recurrencia de aparición de compuestos organoclorados cuyo uso ha estado discontinuado desde hace más de dos décadas, como heptacloro e isómeros del DDT. La incidencia alta de otro organoclorado hallado en leches como endosulfán-sulfato podría explicarse porque el endosulfán fue recientemente prohibido en el país.

Sobre el sistema regulatorio vigente cabe observar que se han detectado casos de falta de armonización entre las legislaciones tanto respecto a los valores de tolerancias fijadas para el mismo alimento como así también respecto a la composición y actualización de los listados de compuestos contemplados por distintos organismos (CAA y SENASA por ejemplo). Aspecto que también demanda revisiones por parte de las autoridades competentes. 

CAPÍTULO 4

Determinación de residuos de plaguicidas en piensos para el ganado lechero 


\section{CAPÍTULO 4: Determinación de residuos de plaguicidas en piensos para el ganado lechero}

\subsection{INTRODUCCIÓN}

\subsubsection{Piensos para alimentación animal}

La calidad de los piensos utilizados en la alimentación del ganado lechero está asociada con el gran número de plaguicidas utilizados en la agricultura actual, como herramientas tanto para el control de plagas como para la intensificación de los cultivos y la expansión de la producción. El uso inadecuado de estos plaguicidas, incluyendo la selección incorrecta, su uso excesivo en los cultivos y commodities agrícolas o la cosecha temprana sin respetar los períodos de carencia luego de su aplicación, pueden conducir a la presencia de grandes cantidades de residuos en alimentos y piensos aumentando el riesgo de exposición de humanos y del propio ganado a través de sus respectivas dietas [221].

Los piensos tradicionales que se utilizan en las dietas del ganado lechero consisten en forrajes y alimentos concentrados. Los primeros contemplan las partes vegetativas de gramíneas y leguminosas y son suministrados a los animales en pastoreo directo o preservados como henos o ensilados luego de ser cosechados. Por su lado, los concentrados complementan a los forrajes aportando fuentes adicionales de energía y proteínas, siendo representativos los cereales (maíz, trigo, sorgo, cebada), las oleaginosas (girasol, soja, semillas de algodón) y diversos subproductos de la industria cervecera y aceitera [222]. Por lo tanto, el término "pienso" es una definición genérica cuando se trata de la nutrición animal, y más específicamente del ganado lechero, ya que están involucradas una gran variedad de matrices. En la literatura científica reciente se han reportado determinaciones de residuos de plaguicidas en una amplia variedad de matrices vegetales utilizadas como piensos en la alimentación animal, como cereales, oleaginosas, henos, pajas y raciones mezcladas (TMRs), entre otros (Tabla 31).

Tabla 31. Resumen de trabajos publicados en la literatura científica dedicados al análisis de distintos tipos de piensos.

\begin{tabular}{|c|c|c|c|c|c|c|}
\hline Tipo de pienso & $\mathrm{n}$ & Alcance analítico & Extracción & Det. Instrumental & País & Referencia \\
\hline $\begin{array}{l}\text { Henos de alfalfa, pajas } \\
\text { de trigo, pasturas y } \\
\text { concentrados }\end{array}$ & 40 & $\begin{array}{l}150 \text { plaguicidas de } \\
\text { diversas familias y } \\
\text { metabolitos }\end{array}$ & $\begin{array}{l}\text { QuEChERS citrato / } \\
\text { freezeout + d-SPE } \\
\text { (PSA) }\end{array}$ & $\begin{array}{l}\text { LC-MS/MS (triple Q) } \\
\text { GC-MS/MS (triple Q) }\end{array}$ & Grecia & $\begin{array}{l}\text { Tsiplakou } \\
\text { (2010)[119] }\end{array}$ \\
\hline $\begin{array}{l}\text { Pasturas, pajas y } \\
\text { concentrados }\end{array}$ & 109 & $\begin{array}{l}15 \text { Fosforados y } 8 \\
\text { carbamatos }\end{array}$ & $\begin{array}{l}\text { Extracción y } \\
\text { partición con } \\
\text { solventes }\end{array}$ & GC-ECD & Brasil & $\begin{array}{l}\text { Fagnani } \\
(2011)[134]\end{array}$ \\
\hline $\begin{array}{l}\text { Maíz y soja sin } \\
\text { procesar }\end{array}$ & 45 & $\begin{array}{l}9 \text { plaguicidas } \\
\text { fosforados y } 1 \\
\text { piretroide }\end{array}$ & $\begin{array}{l}\text { QuEChERS citrato / } \\
\text { freezeout + d-SPE } \\
\text { (C18+PSA) }\end{array}$ & GC-MS (single Q) & Italia & $\begin{array}{l}\text { Marchis } \\
(2012)[121]\end{array}$ \\
\hline $\begin{array}{l}\text { Granos de cereal, } \\
\text { balanceados y soja }\end{array}$ & 900 & $\begin{array}{l}167 \text { plaguicidas de } \\
\text { diversas familias }\end{array}$ & $\begin{array}{l}\text { QuEChERS citrato / } \\
\text { d-SPE (C18+PSA) }\end{array}$ & GC-MS/ & Polonia & $\begin{array}{l}\text { Walorczyk } \\
(2012)[122]\end{array}$ \\
\hline $\begin{array}{l}\text { Raciones totales } \\
\text { mezcladas (TMRs) }\end{array}$ & 25 & $\begin{array}{l}20 \text { plaguicidas } \\
\text { clorados }\end{array}$ & $\begin{array}{l}\text { Extracción y } \\
\text { partición con } \\
\text { solventes }\end{array}$ & $\begin{array}{l}\text { GC-MS/MS } \\
\text { (trampa de iones) }\end{array}$ & Italia & $\begin{array}{l}\text { Panseri } \\
(2013)[223]\end{array}$ \\
\hline $\begin{array}{l}\text { Pajas (cebada, trigo, } \\
\text { colza), henos }\end{array}$ & 192 & $\begin{array}{l}219 \text { plaguicidas de } \\
\text { diversas familias }\end{array}$ & $\begin{array}{l}\text { QuEChERS original/ } \\
\text { dil.\& shoot (LC), } \\
\text { d-SPE (C18+PSA)(GC) }\end{array}$ & $\begin{array}{l}\text { LC-MS/MS } \\
\text { GC-MS/MS }\end{array}$ & $\begin{array}{l}\text { Países } \\
\text { Bajos y } \\
\text { Europa }\end{array}$ & $\begin{array}{l}\text { Mol } \\
(2014)[124]\end{array}$ \\
\hline Pajas de trigo y arroz & NE & $\begin{array}{l}69 \text { plaguicidas de } \\
\text { diversas familias }\end{array}$ & $\begin{array}{l}\text { QuEChERS } \\
\text { modificado }\end{array}$ & LC-MS/MS (triple Q) & China & $\begin{array}{l}\text { Zhang } \\
(2016)[127]\end{array}$ \\
\hline
\end{tabular}




\subsubsection{Legislación para piensos en Argentina y el mundo}

La acumulación de residuos de plaguicidas en los distintos alimentos que son proporcionados al ganado para su alimentación representa un riesgo para la salud de los propios animales y de los humanos, que están expuestos a los mismos contaminantes al consumir los productos derivados que los primeros producen. Es por esto que no solo los alimentos consumidos por el hombre sino también los piensos están sujetos a distintas regulaciones que fijan las cantidades permitidas de plaguicidas en los mismos.

En Argentina, se han establecido límites máximos de residuo para 431 plaguicidas en 274 commodities vegetales de distinto origen, de las cuales 38 ítems (14\%) comprenden piensos destinados a la alimentación animal, incluyendo distintos tipos de forrajes, henos, cereales y pasturas [12].

A nivel internacional, la Comisión de Codex Alimentarius ha adoptado, hasta su actualización de Julio de 2016, 4844 LMRs para distintas combinaciones plaguicida/commodity, incluyendo alimentos para animales clasificados como "Materias primas de origen vegetal para piensos", subdivididos en 91 ítems distintos de los cuales sólo 18 presentan límites máximos permitidos para un total de 140 plaguicidas distintos [197]. La Agencia de Protección Ambiental de Estados Unidos (EPA) ha fijado también tolerancias máximas para la presencia de residuos de plaguicidas en materias primas agrícolas de origen vegetal sin procesar para uso específico como piensos, distinguiéndose 16 tipos de henos, forrajes, granos y semillas de diversos cultivos en los que se fijaron límites para 247 principios activos distintos [224].

En la Unión Europea, por otro lado, sólo los plaguicidas organoclorados están regulados de forma genérica en piensos para animales definidos como "productos de origen vegetal o animal en estado natural, frescos o conservados, y los derivados de su transformación industrial, así como las sustancias orgánicas o inorgánicas, simples o en mezclas, con o sin aditivos, destinados a la alimentación animal por vía oral", sin clasificarlos o diferenciarlos en distintos tipos como en las regulaciones antes mencionadas [225] (Tabla 32). Cabe destacar que las distintas regulaciones de LMRs en piensos se han establecido sobre productos primarios en su mayoría como forrajes y en algunos casos como cultivos verdes para pastoreo, y que los alimentos balanceados, por ejemplo, que son una base importante en la nutrición del ganado en algunas regiones de alta producción como en la Provincia de Santa Fe no se encuentran contemplados como ítems específicos dentro de los piensos. En ese sentido, el único país que a nuestro conocimiento incluye la categoría de alimento balanceado ("compound feed") en su regulación de LMRs en piensos es Japón [226]. 
Tabla 32. Distintos tipos de alimentos de origen vegetal regulados como piensos por las legislaciones de Argentina, del Codex Alimentarius, de EEUU y de la Unión Europea.

\begin{tabular}{|c|c|}
\hline Regulador & Número de piensos y principios activos regulados \\
\hline Argentina & 38 tipos de piensos distintos: \\
\hline Res. 934/2017 & $\begin{array}{l}\text { Alfalfa (forraje), alfalfa (heno), algodón (torta), alpiste (forraje), arroz (forraje seco), arroz (heno), } \\
\text { avena (forraje verde/seco), cebada (forraje verde/seco), cebada (grano), cebada (heno), centeno } \\
\text { (grano), centeno (forraje verde/seco), colza (forraje), lino (forraje seco), lino (grano), lino (heno), } \\
\text { lino (torta), maíz (forraje verde/seco), maíz (grano), maíz (heno), maíz (silaje), maní (forraje), mijo } \\
\text { (forraje), mijo (grano), mijo (heno), pasturas (leguminosas), pasturas (gramíneas), soja (forraje), } \\
\text { soja (heno), sorgo (forraje verde/seco), sorgo (grano), sorgo (heno), trébol (blanco forraje), trébol } \\
\text { (rojo forraje), trigo (forraje verde/seco), trigo (grano), trigo (heno) } \\
\text { Límites para } 163 \mathrm{p.a.} \text { diferentes } \\
\text { Mínimo: } 0,005 \mathrm{mg} / \mathrm{kg} \text { (fipronil en pasturas leguminosas y gramíneas) } \\
\text { Máximo: } 100 \mathrm{mg} / \mathrm{kg} \text { (carbarilo en todos los tipos de forrajes) }\end{array}$ \\
\hline CODEX & $\begin{array}{l}18 \text { tipos de piensos distintos: } \\
\text { Alfalfa (forraje), algodón (semilla), almendra (cascarillas), arveja (heno), avena (paja y forraje seco), } \\
\text { caña de azúcar (forraje), cebada (paja y forraje seco), centeno (paja y forraje seco), cereales } \\
\text { (granos), cereales (paja y forraje seco), gramíneas (heno y forraje seco), maíz (forraje seco), maní } \\
\text { (forraje), menta (heno), soja (forraje), sorgo (paja y forraje seco), trébol (heno y forraje), trigo (paja } \\
\text { y forraje seco) } \\
\text { Límites para } 140 \text { p.a. diferentes } \\
\text { Mínimo: } 0,01 \mathrm{mg} / \mathrm{kg} \text { (p.ej. bentazona en granos de cereales) } \\
\text { Máximo: } 80 \mathrm{mg} / \mathrm{kg} \text { (pentiopirad en todos los forrajes y pajas) }\end{array}$ \\
\hline EEUU & 16 tipos de piensos distintos: \\
\hline EPA & $\begin{array}{l}\text { Alfalfa (forraje), alfalfa (heno), alfalfa (semilla), algodón (semilla), cebada (grano), centeno (grano), } \\
\text { cereales (granos), girasol (semilla), grano (cultivo), leguminosas (forraje), leguminosas (heno), } \\
\text { leguminosas (semillas), maíz (grano), oleaginosas, soja (poroto), trigo (grano) } \\
\text { Límites para } 247 \mathrm{p.a.} \text { diferentes } \\
\text { Mínimo: } 0,01 \mathrm{mg} / \mathrm{kg} \text { (p.ej. abamectina en soja) } \\
\text { Máximo: } 210 \mathrm{mg} / \mathrm{kg} \text { (paraquat en heno de leguminosas) }\end{array}$ \\
\hline Unión & Clasificación genérica como "piensos" \\
\hline Europea & $\begin{array}{l}\text { Límites para } 16 \text { p.a. diferentes (organoclorados) } \\
\text { Mínimo: 0,005 mg/kg ( } \beta-\mathrm{HCH}) \\
\text { Máximo: } 0,5 \mathrm{mg} / \mathrm{kg} \text { (endosulfán) }\end{array}$ \\
\hline
\end{tabular}

\subsubsection{Análisis de piensos}

El análisis de la gran variedad de matrices que constituyen las mezclas complejas utilizadas como fuente de alimentos para el ganado y del gran número de plaguicidas derivados de las prácticas agrícolas que pueden encontrarse, requiere de métodos analíticos de amplio espectro que involucren etapas de extracción y determinación instrumental con la suficiente confiabilidad y sensibilidad para alcanzar los bajos niveles de concentración implicados. En ese sentido, el método QuEChERS ha sido el método de elección utilizado en la determinación multi-residuo de plaguicidas en piensos $[96,119,121,122,124,127]$ al tiempo que por su versatilidad también se ha empleado en determinaciones multi-clase de plaguicidas, micotoxinas y otros contaminantes en piensos y matrices relacionadas $[126,128]$.

No todos los plaguicidas se pueden determinar de la misma manera debido a que las propiedades fisicoquímicas individuales de los distintos compuestos gobiernan su comportamiento, ya sea en la naturaleza o durante el análisis químico. Aunque la gran mayoría de los plaguicidas pueden ser determinados mediante técnicas de cromatografía líquida, todavía existen cientos de compuestos que 
requieren de la cromatografía gaseosa para ser analizados. Sin embargo, independientemente de la técnica cromatográfica que se trate, es el acople con analizadores de espectrometría de masa (especialmente las configuraciones de triple cuadrupolo) lo que permite determinaciones multi-residuo de plaguicidas a gran escala y con la selectividad y sensibilidad necesarias. Esto es aún más importante en el análisis de piensos debido a la complejidad intrínseca que presenta este tipo de matrices. La mayoría de los trabajos consultados respecto a la determinación de residuos de plaguicidas en este tipo de alimentos han reportado técnicas de GC-MS/MS $[96,121,122,223,227]$, y en menor medida técnicas de LC-MS/MS o combinaciones de GC y LC-MS/MS $[119,124,127]$. Para el análisis de piensos para alimentación animal se han reportado también metodologías analíticas con configuraciones más tradicionales basadas en GC con detectores de captura electrónica y de fósforo-nitrógeno, aunque con la limitación de estar acotadas a un menor número de compuestos a determinar $[134,228]$.

\subsection{OBJETIVO}

El objetivo de este trabajo fue analizar la ocurrencia de residuos de plaguicidas en los alimentos consumidos por el ganado lechero en los sistemas de producción de Argentina, específicamente en la cuenca lechera santafesina. Para ese propósito, y con la intención de medir la mayor cantidad posible de plaguicidas, una gran variedad de piensos típicos de origen vegetal fueron analizados, utilizando estrategias analíticas multi-clase multi-residuo de amplio alcance basadas en la extracción QuEChERS en combinación con técnicas de determinación por cromatografía líquida y gaseosa acoplada a espectrometría de masa en tándem (LC-MS/MS, GC-MS/MS). 


\subsection{MATERIALES Y MÉTODOS}

\subsubsection{Metodología analítica}

\section{Reactivos}

Los estándares analíticos de los 358 plaguicidas analizados se obtuvieron principalmente de Sigma-Aldrich (Praga, República Checa) y Merck (Praga, República Checa). Para realizar ensayos de calibración y recuperación, se prepararon soluciones de trabajo conteniendo todos los compuestos en $1000 \mathrm{ng} / \mathrm{mL}$ de concentración, las cuales se almacenaron en viales color ámbar a $-20^{\circ} \mathrm{C}$ hasta el momento de su uso.

Para la preparación de fase móvil cromatográfica se empleó formiato de amonio $\left(\mathrm{FNH}_{4}\right)$ y ácido fórmico (AF, 98\%) de Sigma-Aldrich (Praga, República Checa), metanol (MeOH) obtenido de Merck (Darmstadt, Alemania) y agua deionizada producida por un sistema Milli-Q (Millipore, Bedford, MA, EEUU). Para la extracción y preparación de las muestras se utilizaron sulfato de magnesio anhidro $\left(\mathrm{MgSO}_{4}\right)$, cloruro de sodio ( $\mathrm{NaCl}$ ) y acetonitrilo grado HPLC (MeCN) obtenidos de Sigma-Aldrich (Praga, República Checa).

\section{Muestras}

Las muestras comprendieron una gran variedad de piensos que son representativos de las mezclas utilizadas en las dietas del ganado en la zona de estudio, donde los sistemas de producción de leche no se basan solamente en el pastoreo de los animales sino en el suplemento de las dietas con alimentos concentrados que aportan los componentes nutricionales que las pasturas por sí solas no logran suplir. Así, distintos tipos de alimentos vegetales utilizados como piensos se obtuvieron de varios tambos situados en la zona central de la Provincia de Santa Fe, en los departamentos Castellanos y Las Colonias. El muestreo se realizó durante el mes de agosto de 2016 y se obtuvieron 54 muestras que incluyeron pasturas, granos de cereales, ensilados, balanceados comerciales, y subproductos de la industria, todos los cuales se encontraban siendo utilizados para alimentar el ganado lechero en los distintos establecimientos al momento de realizar el muestreo. Los distintos piensos muestreados se agruparon de acuerdo al documento del CODEX para la clasificación de alimentos y piensos en 4 familias [229]: (i) forrajes. (ii) granos de cereales y derivados, (iii) oleaginosas y derivados, y (iv) alimentos balanceados y TMRs (Tabla 33). Una vez recolectada, cada muestra se secó hasta peso constante a $50^{\circ} \mathrm{C}$ en estufas con convección de aire, se trituró mediante molino mecánico con malla de $1 \mathrm{~mm}$ y se almacenó en bolsas herméticas al abrigo de la luz hasta el momento del análisis (Figura 35). 
Tabla 33. Clasificación de las 54 muestras analizadas siguiendo los criterios establecidos por el Codex Alimentarius.

\begin{tabular}{|c|c|c|c|c|}
\hline \multirow[b]{2}{*}{ Grupo $^{a}$} & \multicolumn{3}{|c|}{ Clasificación del CODEX para alimentos y piensos } & \multirow[b]{2}{*}{ Muestras analizadas $(\mathrm{n})$} \\
\hline & Clase & Tipo & Grupo & \\
\hline \multirow{5}{*}{$\begin{array}{l}\text { (i) Forrajes } \\
\text { (pasturas, henos, } \\
\text { ensilados) }\end{array}$} & \multirow[t]{5}{*}{$\mathrm{C}$} & \multirow{5}{*}{$\begin{array}{l}11 \text { Productos primarios } \\
\text { de origen vegetal }\end{array}$} & \multirow[t]{2}{*}{050 Leguminosas } & Pasturas de alfalfa (4) \\
\hline & & & & Henos de alfalfa (2) \\
\hline & & & \multirow{3}{*}{$\begin{array}{l}051 \text { Pajas y forrajes } \\
\text { de gramíneas }\end{array}$} & Pastura de cebada (1) \\
\hline & & & & Silos de maíz (9) \\
\hline & & & & Silos de sorgo (4) \\
\hline \multirow{4}{*}{$\begin{array}{l}\text { (ii) Granos de cereales } \\
\text { y derivados }\end{array}$} & \multirow[t]{2}{*}{ A } & \multirow[t]{2}{*}{03 Gramíneas } & \multirow[t]{2}{*}{020 Granos de cereal } & Granos de maíz (7) \\
\hline & & & & Granos de trigo (2) \\
\hline & \multirow[t]{2}{*}{$\mathrm{D}$} & \multirow{2}{*}{$\begin{array}{l}13 \text { Productos derivados } \\
\text { de origen vegetal }\end{array}$} & \multirow{2}{*}{$\begin{array}{l}065 \text { Fracciones de la } \\
\text { molienda de cereales }\end{array}$} & Gluten de trigo (1) \\
\hline & & & & Burlanda de maíz $(2)^{b}$ \\
\hline \multirow{4}{*}{$\begin{array}{l}\text { (iii) Oleaginosas } \\
\text { y derivados }\end{array}$} & \multirow[t]{2}{*}{ A } & \multirow{2}{*}{$\begin{array}{l}04 \text { Frutos secos y } \\
\text { semillas }\end{array}$} & \multirow{4}{*}{$\begin{array}{l}023 \text { Semillas } \\
\text { oleaginosas } \\
071 \text { Subproductos } \\
\text { utilizados para } \\
\text { alimentación animal }\end{array}$} & Semillas de algodón (4) \\
\hline & & & & Poroto de soja (1) \\
\hline & \multirow[t]{2}{*}{$\mathrm{D}$} & \multirow{2}{*}{$\begin{array}{l}13 \text { Productos derivados } \\
\text { de origen vegetal }\end{array}$} & & Expellers de soja (3) \\
\hline & & & & Expeller de girasol (1) \\
\hline (iv) Balanceados & & & & Balanceados $(10)^{\mathrm{b}}$ \\
\hline y TMRs & & & & $\operatorname{TMRs}(3)^{\mathrm{b}}$ \\
\hline
\end{tabular}

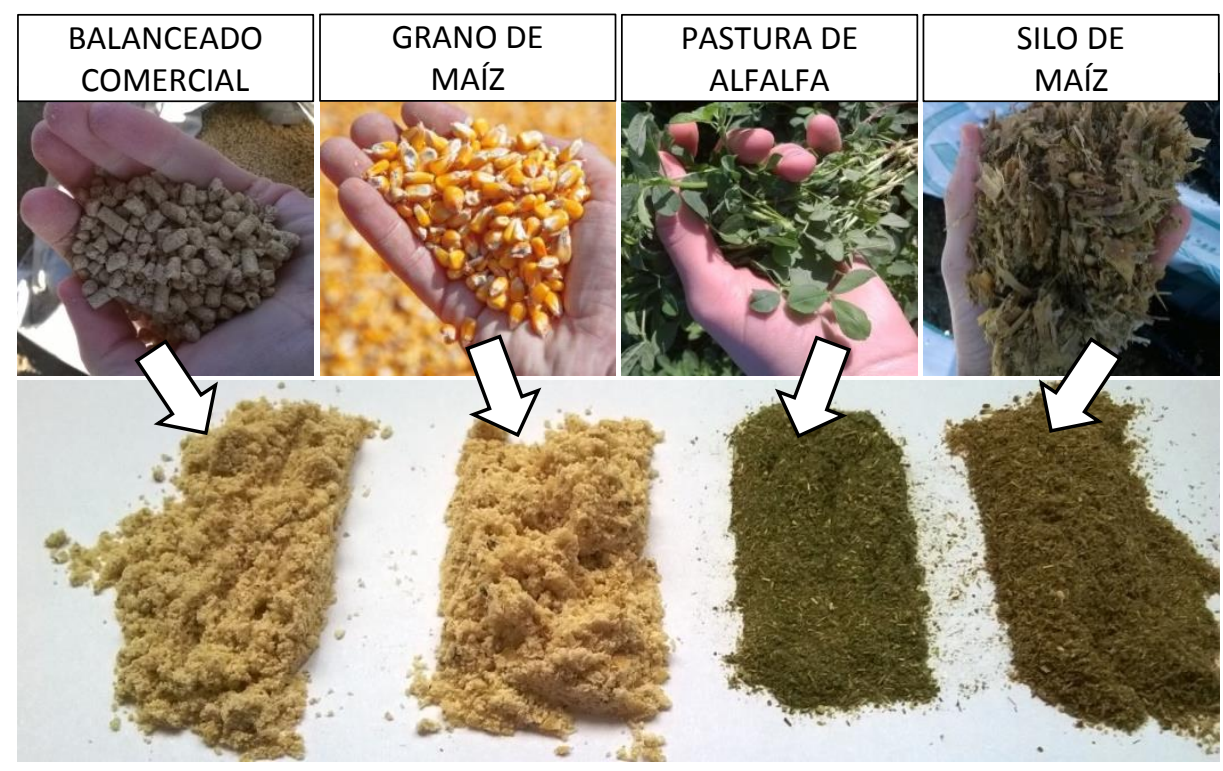

Figura 35. Ejemplos de la variedad muestras implicadas en el estudio, en su estado real muestreado y tras su procesamiento para el análisis.

\section{Extracción de muestras}

Para la extracción de las muestras secadas y trituradas se utilizó un método QuEChERS previamente optimizado y validado en el laboratorio donde se realizó el análisis (UCT Praga), empleado en el análisis rutinario de este tipo de muestras. Tanto para la determinación de residuos de plaguicidas como para la de micotoxinas (Capítulo 5 de esta Tesis) las muestras se extrajeron una sola vez mediante este método 
QuEChERS, utilizando el mismo extracto para su medición en dos plataformas instrumentales diferentes. Básicamente, se pesaron 2 gramos de muestra en tubos falcon de $50 \mathrm{~mL}$ de capacidad y se agregaron $10 \mathrm{~mL}$ de agua acidificada (2\% AF) para la hidratación, dejando que la misma ocurra durante 30 minutos, tras lo cual se agregaron $10 \mathrm{~mL}$ de acetonitrilo y se realizó la extracción durante 30 minutos en un agitador mecánico (IKA, Staufen, Alemania). Luego se agregó la mezcla de sales para inducir la separación de fases (4 $\mathrm{g} \mathrm{MgSO}_{4}+1 \mathrm{~g} \mathrm{NaCl}$ ), se realizó una agitación manual vigorosa durante 1 minuto para producir la partición de los analitos, y se agregó $0,1 \mathrm{~mL}$ de una solución $5 \mu \mathrm{g} / \mathrm{mL}$ de trifenil-fosfato (TPP) como estándar interno antes de centrifugar los tubos a $10000 \mathrm{rpm}$ durante 5 minutos. Finalmente, una alícuota de la fase acetonitrilo se transfirió a viales de $2 \mathrm{~mL}$ de capacidad para su determinación por LC y GC-MS/MS (Figura 36).

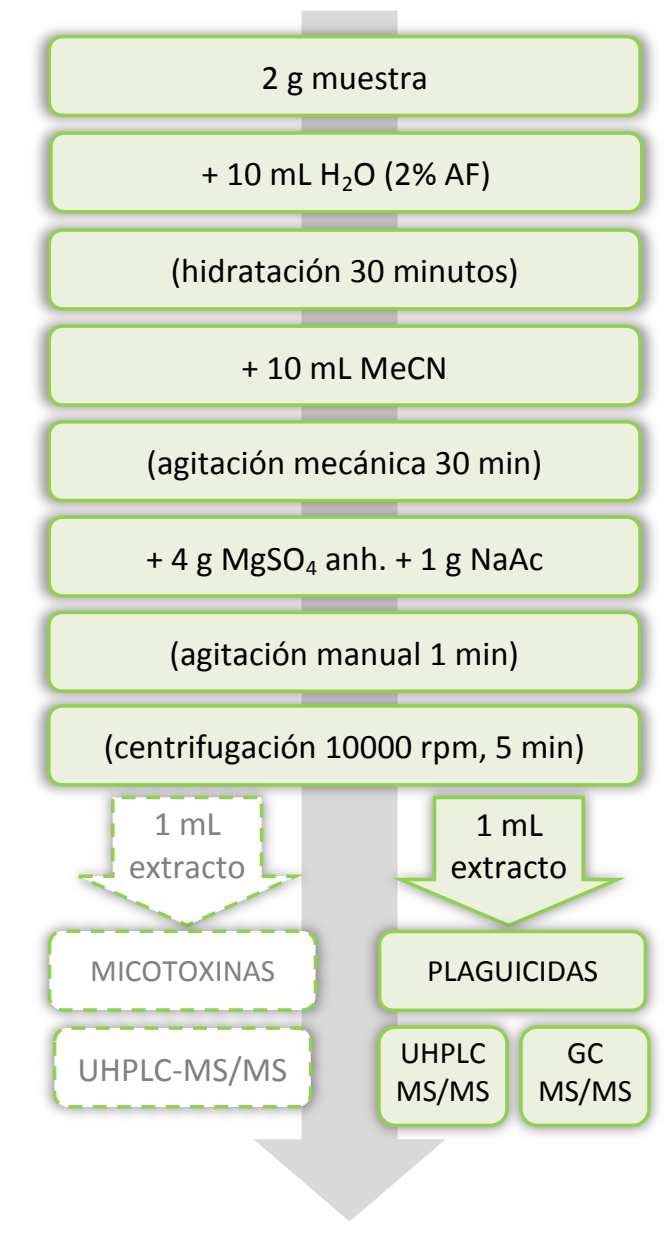

Figura 36. Esquema de extracción utilizado para la determinación de residuos y contaminantes.

\section{Ensayos de recuperación}

Para evaluar la eficiencia de extracción del método QuEChERS se adicionaron muestras con soluciones estándar de plaguicidas, en ensayos separados para el análisis por LC y por GC. Para el análisis por LCMS/MS (realizado en laboratorios de la Universidad UCT-Praga) la recuperación se evaluó utilizando como 
matriz blanco una muestra de trigo molido que fue adicionada con una solución estándar de 350 plaguicidas para dar concentraciones de 10 y $100 \mu \mathrm{g} / \mathrm{kg}$. Para el análisis por GC-MS/MS (realizado en instalaciones del PRINARC-FIQ-UNL) la recuperación se evaluó adicionando una muestra blanco de heno de alfalfa con un mix de estándar de 160 plaguicidas en niveles de concentración de 25, 50 y $100 \mu \mathrm{g} / \mathrm{kg}$. En ambos casos, luego de la adición de estándares al material blanco se permitió un tiempo de contacto de 30 minutos para la distribución de los analitos y su incorporación a la matriz antes de comenzar con el procedimiento de extracción descripto anteriormente.

La cuantificación de los plaguicidas hallados en las muestras se realizó mediante calibración externa utilizando curvas matrix-matched preparadas a partir del agregado de las soluciones estándar a los respectivos extractos del material blanco. Para el caso del análisis por LC, la curva se preparó en los niveles $500,100,50,10,5$ y $1 \mathrm{ng} / \mathrm{mL}$, y para la determinación por GC en niveles de 100, 50, 20, 5, 2 y $1 \mathrm{ng} / \mathrm{mL}$.

\section{Condiciones instrumentales de análisis}

UHPLC-MS/MS

La determinación de plaguicidas por LC-MS/MS se realizó utilizando un cromatógrafo líquido Acquity UPLC ${ }^{\circledR}$ (Waters, Milford, MA, EEUU) equipado con una columna Acquity UPLC ${ }^{\circledR}$ HSS T3 (100 x 2,1 mm x 1,8 $\mu \mathrm{m}$ ) mantenida a una temperatura de $40^{\circ} \mathrm{C}$. Como fase móvil se utilizó una solución $5 \mathrm{mM}$ de $\mathrm{FNH}_{4}$ con $0,1 \%$ de AF tanto en agua (componente A) como en metanol (componente B), y la separación se realizó aplicando un gradiente de fase móvil de la siguiente manera: las condiciones iniciales $(10 \% \mathrm{v} / \mathrm{v}$ de $B, 0,3 \mathrm{~mL} / \mathrm{min})$ se cambiaron a $50 \%$ (B) y $0,35 \mathrm{~mL} / \mathrm{min}$ durante el primer minuto, luego se incrementaron linealmente a $95 \%$ (B) y $0,45 \mathrm{~mL} / \mathrm{min}$ a lo largo de 10 minutos, y a continuación el flujo se aumentó a 0,7 $\mathrm{mL} / \mathrm{min}$ durante 1 minuto y se mantuvo la composición de la fase móvil en 95\% (B) durante 2 minutos para lavar la columna, retomando finalmente las condiciones iniciales durante 2 minutos adicionales. El volumen de inyección fue de $2,5 \mu \mathrm{L}$ y la temperatura del compartimento de muestras se mantuvo a $5^{\circ} \mathrm{C}$. Para la separación y análisis de masa se utilizó un analizador de triple cuadrupolo Xevo TQ-S (Waters, Milford, MA, EEUU) equipado con una fuente de ionización por electrostray (ESI) operada en modo positivo con un voltaje capilar de 0,6 kV, con temperaturas de fuente y de desolvatación de $120^{\circ}$ y $350^{\circ} \mathrm{C}$, respectivamente, y utilizando nitrógeno como gas de desolvatación ( $800 \mathrm{~L} / \mathrm{h}$ ) y gas de cono (150 L/h). El análisis de masa se realizó operando el analizador en modo MRM (monitoreo de reacciones múltiples) y la colisión de los iones padres se realizó utilizando un caudal de Argón de 0,14 mL/min.

\section{GC-MS/MS}

El análisis de muestras por cromatografía gaseosa se realizó utilizando el mismo sistema descripto en el capítulo anterior para la determinación de plaguicidas en leche. La única modificación fue en el método de adquisición, que en este caso contempló un número de compuestos mayor (160) respecto a los analizados en leche (42), que fue posible por la incorporación de estándares adicionales de plaguicidas entre un 
análisis y otro. La información sobre las transiciones analizadas y otros parámetros de detección asociados se listan en la Tabla S4-2 del material suplementario.

\subsection{RESULTADOS Y DISCUSIÓN}

En este estudio, se determinaron 400 plaguicidas de diversas clases y estructuras químicas, tanto compuestos susceptibles de ser determinados por Cromatografía Líquida (LC) como otros más afines a la Cromatografía Gaseosa (GC), que están incluidos en los programas de vigilancia para alimentos de la Unión Europea, estando 193 de los mismos (47\%) también regulados en la legislación argentina en diversos cultivos, de los cuales a su vez 92 principios activos tienen LMRs establecidos en diversos granos, pasturas y forrajes [12]. En la Tabla S4-1 del material suplementario se listan todos los compuestos comprendidos en este análisis.

\subsubsection{Preparación de la muestra}

Con fines de monitoreo, el análisis de una variedad de muestras tan amplia claramente puede lograrse solamente a través de métodos analíticos multi-clase y de amplio alcance. El objetivo en esta etapa del trabajo de tesis no estuvo puesto en la optimización de procedimientos de extracción y análisis instrumental, sino en determinar la mayor cantidad posible de compuestos en la amplia variedad de muestras seleccionadas para evaluar su calidad en términos del contenido de residuos de plaguicidas y de micotoxinas (estas últimas se analizarán en el siguiente capítulo). Para tal fin, se emplearon métodos multiclase, multi-residuo bien establecidos y validados para el análisis rutinario de este tipo de muestras en los laboratorios donde se realizaron los trabajos.

Como se mencionó anteriormente, los métodos QuEChERS se han utilizado ampliamente para la determinación simultánea de plaguicidas y otros contaminantes como las micotoxinas en alimentos y muestras relacionadas de origen agrícola. En nuestro caso, se empleó un método de extracción basado en QuEChERS propuesto por Dzuman y col. (2014) para la determinación de múltiples micotoxinas en piensos de matrices complejas (Figura 36) [123]. Dado que este método se optimizó originalmente para la determinación de micotoxinas, antes de realizar la extracción de las muestras se llevaron a cabo ensayos de recuperación para evaluar la capacidad multi-clase con respecto a los plaguicidas. La única modificación del método fue que se evitó la etapa de clean-up propuesta originalmente, priorizando la estabilidad de los plaguicidas en el extracto, ya que estos compuestos fueron los más numerosos del conjunto completo de analitos abarcado (plaguicidas + micotoxinas).

\subsubsection{Ensayos de recuperación}

Tanto para la determinación de plaguicidas por LC-MS/MS y como para la realizada por GC-MS/MS se hicieron ensayos de recuperación para evaluar la performance del método de extracción. Como matriz blanco para la determinación por LC se utilizó una muestra de trigo triturado, y para la determinación por GC se probaron 4 diferentes tipos de alimentos (ensilado de maíz, alimento balanceado comercial, soja y 
alfalfa) haciéndose la selección analizando los cromatogramas de exploración completa (full-scan) de sus extractos. El heno de alfalfa resultó el tipo de matriz que produjo la menor cantidad e intensidad de picos de compuestos interferentes y fue seleccionado como blanco. Para el análisis de plaguicidas por LC se evaluaron dos niveles de adición a 100 y $10 \mu \mathrm{g} / \mathrm{kg}$ ( 20 y $2 \mathrm{ng} / \mathrm{mL}$ ), obteniéndose recuperaciones en el rango del $70-120 \%$ para el $95 \%$ de los compuestos en el nivel alto y el $91 \%$ en el nivel bajo. En cuanto al análisis de plaguicidas por GC, se evaluaron tres niveles de adición a 100, 50 y $25 \mu \mathrm{g} / \mathrm{kg}(20,10$ y $5 \mathrm{ng} / \mathrm{mL})$, verificándose que un $74 \%, 50 \%$ y $27 \%$ de los compuestos cayeron en el rango de recuperación aceptable de 70-120\% respectivamente. Esta menor proporción de compuestos recuperados en niveles aceptables en el análisis por GC-MS/MS puede atribuirse más a cuestiones de comportamiento instrumental que a la extracción propiamente dicha, debido a que el mix de estándar utilizado incluía compuestos que típicamente no son bien analizados por cromatografía gaseosa. Por ejemplo, es sabido que muchos carbamatos (como bendiocarb, carbarilo o metiocarb) y triazinas (como simetrina) son mejor o únicamente analizados por LC [230], o que compuestos organofosforados como acefato y metamidofos presentan pobre forma de picos y resolución en columnas HP-5 [231], además del hecho de que plaguicidas como diclorvos, triclorfon o trifloxistrobina presentan temperaturas de degradación cercanas o inferiores a la temperatura utilizada en el puerto de inyección $\left(280^{\circ} \mathrm{C}\right)$ [13]. En la Tabla S4-1 del material suplementario se resumen los niveles de recuperación obtenidos de todos los compuestos analizados por LC y GC-MS/MS. Los resultados muestran que el procedimiento de extracción basado en QuEChERS utilizado fue adecuado para la mayoría de los plaguicidas, especialmente en los niveles de concentración más altos evaluados.

\subsubsection{Residuos de plaguicidas encontrados en muestras analizadas}

Del total de compuestos evaluados, se identificaron $12 \%$ (50 de 400 plaguicidas) en las 54 muestras analizadas, siendo el $62 \%$ en su mayoría insecticidas, el $20 \%$ herbicidas y el $18 \%$ restante fungicidas. La frecuencia de detección de los plaguicidas en el total de muestras analizadas se muestra en la Figura 37.

En la Tabla 34 se resume la información sobre los rangos de concentración y los tipos de muestra en los que se encontraron los plaguicidas hallados en el análisis. 


\section{Insecticidas}

\section{3}

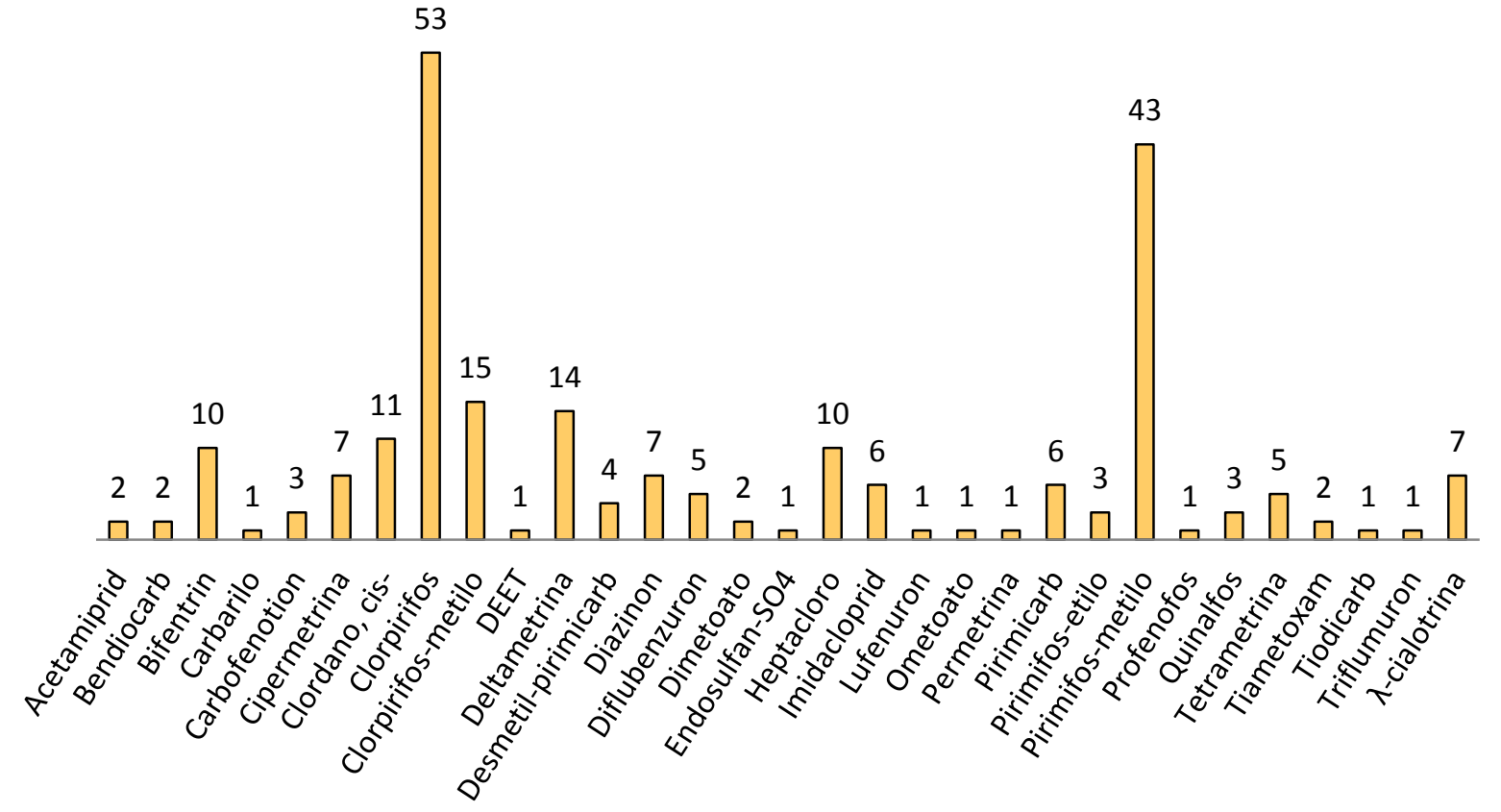

Herbicidas

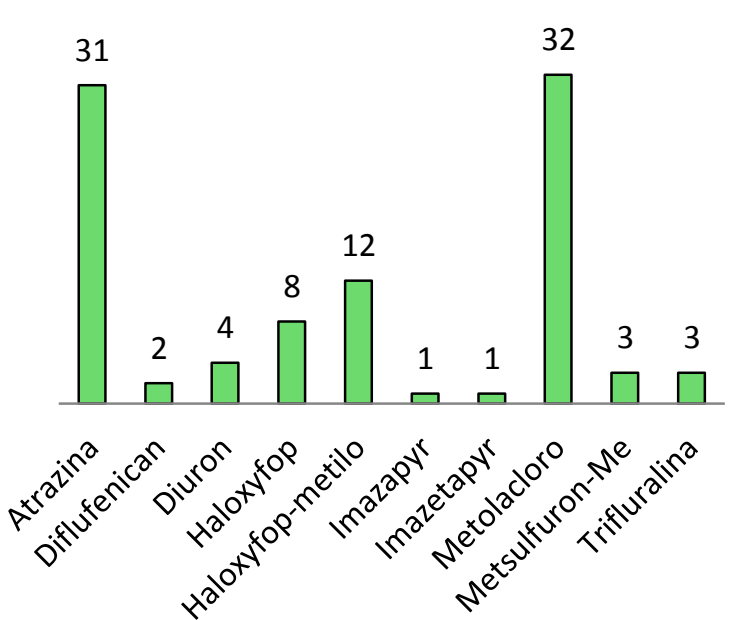

\section{Fungicidas}

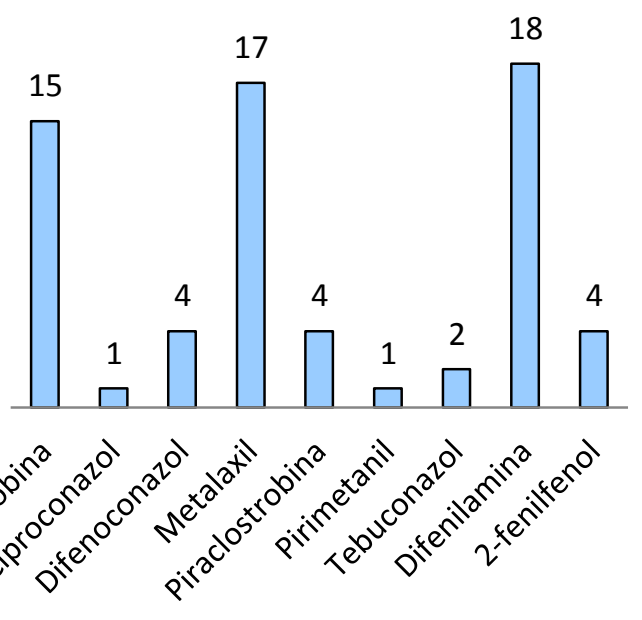

Figura 37. Frecuencias de detección de los plaguicidas hallados en las 54 muestras analizadas por LC-MS/MS y GC-MS/MS.

Tabla 34. Plaguicidas hallados en el análisis de las 54 muestras de piensos para ganado.

\begin{tabular}{|c|c|c|c|c|c|}
\hline \multirow[b]{2}{*}{ Compuesto $^{a}$} & \multirow[b]{2}{*}{ Detecciones $^{b}$} & \multicolumn{3}{|c|}{ Conc. $\mu \mathrm{g} / \mathrm{kg}$} & \multirow[b]{2}{*}{ Tipo de muestra ${ }^{d}$} \\
\hline & & $\mathrm{LC}^{\mathrm{C}}$ & Rango & Media & \\
\hline \multicolumn{6}{|l|}{ Insecticidas } \\
\hline Acetamiprid & $2(0)$ & 5 & & & alfalfa pastura (1), balanceado (1) \\
\hline Bendiocarb & $2(2)$ & 50 & $123-282$ & 203 & alfalfa pastura (1), silo de sorgo (1) \\
\hline Bifentrin & $10(0)$ & 5 & & & $\begin{array}{l}\text { alfalfa pastura (1), silo de maíz (2) silo de sorgo (3), TMR (1), } \\
\text { balanceado (2), gluten (1) }\end{array}$ \\
\hline Carbarilo & $1(0)$ & 5 & & & maíz molido \\
\hline Carbofenotion & $3(0)$ & 10 & & & maíz molido (1), burlanda (2) \\
\hline Clordano, cis- & $11(10)$ & 5 & $5-22$ & 11 & $\begin{array}{l}\text { alfalfa pastura (1), maíz molido (4), balanceado (4), sem. algodón (1), } \\
\text { expeller de soja (1) }\end{array}$ \\
\hline Clorpirifos & $53(17)$ & 10 & $10-167$ & 52 & $\begin{array}{l}\text { alfalfa pastura (6), cebada pastura (1), silo de maíz (9), silo de sorgo } \\
\text { (4), TMR (3), maíz molido (8), trigo molido (1), balanceado (10), } \\
\text { semilla de algodón (4), expeller de soja (3), expeller de girasol (1), } \\
\text { burlanda (2), gluten (1) }\end{array}$ \\
\hline Clorprifos-me & $10(5)$ & 25 & $25-128$ & 66 & $\begin{array}{l}\text { TMR (1), maíz molido (1), trigo molido (1), balanceado (6), semilla de } \\
\text { algodón (1) }\end{array}$ \\
\hline Cipermetrina & $7(6)$ & 50 & $50-211$ & 86 & maíz molido (2), balanceado (5) \\
\hline
\end{tabular}




\begin{tabular}{|c|c|c|c|c|c|}
\hline \multirow[b]{2}{*}{ Compuesto $^{a}$} & \multirow[b]{2}{*}{ Detecciones $^{b}$} & \multicolumn{3}{|c|}{ Conc. $\mu \mathrm{g} / \mathrm{kg}$} & \multirow[b]{2}{*}{ Tipo de muestra $^{d}$} \\
\hline & & $\mathrm{LC}^{\mathrm{C}}$ & Rango & Media & \\
\hline DEET & $1(0)$ & 10 & & & balanceado \\
\hline Deltametrina & $16(12)$ & 25 & $25-371$ & 148 & $\begin{array}{l}\text { alfalfa pastura (1), TMR (1), maíz molido (2), trigo molido (1), } \\
\text { balanceado (8), expeller de soja (1), burlanda (2) }\end{array}$ \\
\hline Desm-pirimicarb & $4(3)$ & 5 & $5-47$ & 20 & alfalfa pastura(2), cebada pastura (1), semilla de algodón (1) \\
\hline Diazinon & $7(0)$ & 5 & & & alfalfa pastura (1), TMR (2), balanceado (2), sem. de algodón (2) \\
\hline Diflubenzuron & $5(5)$ & 10 & $10-61$ & 43 & TMR (3), balanceado (2) \\
\hline Dimetoate & $2(0)$ & 5 & & & alfalfa pastura (1), semilla de algodón (1) \\
\hline Endosulfan-SO4 & $1(0)$ & 50 & & & balanceado (1) \\
\hline Heptacloro & $10(1)$ & 50 & 66 & - & TMR(1), maíz molido (3), balanceado (5), semilla algodón (1) \\
\hline Imidacloprid & $6(1)$ & 5 & 61 & - & silo maíz (2), balanceado (1), sem. algodón (2), expeller soja (1) \\
\hline$\lambda$-cialotrina & $7(0)$ & 250 & & & TMR (1), maíz molido (2), balanceado (4) \\
\hline Lufenuron & $1(1)$ & 10 & 115 & - & alfalfa pastura \\
\hline Ometoate & $1(0)$ & 5 & & & semilla de algodón \\
\hline Permetrina & $1(0)$ & 25 & & & alfalfa pastura \\
\hline Pirimicarb & $6(3)$ & 5 & $5-91$ & 36 & alfalfa pastura (2), cebada pastura (1), maíz molido (2), s. algodón(1) \\
\hline Pirimifos-et & $3(0)$ & 5 & & & maíz molido (2), balanceado (1) \\
\hline Pirimifos-me & 43 (19) & 5 & $5-324$ & 80 & $\begin{array}{l}\text { alfalfa pastura (4), cebada pastura (1), silo maíz (5), silo sorgo (4), TMR } \\
\text { (3), maíz molido (7), trigo molido (1), balanceado (9), sem. de algodón } \\
\text { (4), expeller soja (2), burlanda (2), gluten (1) }\end{array}$ \\
\hline Profenofos & $1(0)$ & 5 & & & alfalfa pastura \\
\hline Quinalfos & $3(3)$ & 25 & $37-54$ & 45 & silo de maíz (1), semilla de algodón (2) \\
\hline Tetrametrina & $5(2)$ & 10 & $10-94$ & 66 & alfalfa pastura (2), balanceado (1), burlanda (2) \\
\hline Tiametoxam & $2(1)$ & 10 & 64 & - & balanceado (1), expeller de soja (1) \\
\hline Tiodicarb & $1(0)$ & 10 & & & silo de maíz \\
\hline Triflumuron & $1(0)$ & 10 & & & semilla de algodón \\
\hline \multicolumn{6}{|l|}{ Herbicidas } \\
\hline Atrazina & $31(7)$ & 5 & $5-26$ & 20 & $\begin{array}{l}\text { alfalfa pastura (4), cebada pastura (1), silo de maíz (4), silo de sorgo } \\
\text { (2), TMR (2), maíz molido (2), trigo molido (1), balanceado (7), sem. de } \\
\text { algodón (3), expeller soja (3), burlanda (1), gluten (1) }\end{array}$ \\
\hline Diflufenican & $2(2)$ & 10 & $15-20$ & 17 & alfalfa pastura (1), semilla de algodón (1) \\
\hline Diuron & $4(2)$ & 10 & $10-23$ & 22 & silo de maíz (1), semilla de algodón (2) \\
\hline Haloxyfop & $8(8)$ & 10 & $10-59$ & 25 & $\begin{array}{l}\text { alfalfa pastura (2), silo de maíz (1), balanceado (1), semilla de algodón } \\
\text { (2), expeller de soja (2) }\end{array}$ \\
\hline Haloxyfop-me & $12(0)$ & 5 & & & $\begin{array}{l}\text { silo de maíz (2), maíz molido (1), balanceado (7), semilla de algodón } \\
\text { (1), expeller de soja (1) }\end{array}$ \\
\hline Imazapyr & $1(1)$ & 5 & 13 & - & TMR \\
\hline Imazetapyr & $1(0)$ & 5 & & & alfalfa pastura \\
\hline Metolacloro & $32(3)$ & 5 & $5-15$ & 12 & $\begin{array}{l}\text { alfalfa pastura (3), cebada pastura (1), silo de maíz (2), silo de sorgo } \\
\text { (2), TMR (2), maíz molido (6), trigo molido (1), balanceado (7), semilla } \\
\text { de algodón (4), expeller soja (1), expeller girasol (1), burlanda (2) }\end{array}$ \\
\hline Metsulfuron-me & $3(0)$ & 10 & & & silo de maíz (1), semilla de algodón (2) \\
\hline Trifluralina & $3(0)$ & 50 & & & balanceado (2), semilla de algodón (1) \\
\hline \multicolumn{6}{|l|}{ Fungicidas } \\
\hline Azoxistrobina & $15(0)$ & 5 & & & $\begin{array}{l}\text { alfalfa pastura (3), silo de maíz (3), silo de sorgo (3), TMR (1), } \\
\text { balanceado (4), poroto de soja (1) }\end{array}$ \\
\hline Ciproconazol & $1(0)$ & 10 & & & alfalfa pastura \\
\hline Difenoconazol & $4(0)$ & 5 & & & silo de maíz (1), silo de sorgo (1), balanceado (1), gluten (1) \\
\hline Difenilamina & $18(9)$ & 25 & $25-63$ & 41 & $\begin{array}{l}\text { alfalfa pastura (1), silo de maíz (3), maíz molido (2), trigo molido (1), } \\
\text { balanceado (6), semilla de algodón (2), expeller soja (1), burlanda (2) }\end{array}$ \\
\hline Metalaxil & $17(1)$ & 5 & $5-27$ & 27 & $\begin{array}{l}\text { alfalfa pastura (2), cebada pastura (1), silo maíz (1), silo sorgo (1), TMR } \\
\text { (1), maíz molido (3), trigo molido (1), balanceado (5), sem. algodón (2) }\end{array}$ \\
\hline Fenilfenol & $4(0)$ & 25 & & & balanceado (4) \\
\hline Piraclostrobina & $4(0)$ & 5 & & & Silo de maíz (1), silo de sorgo (1), sem. de algodón (1), expeller soja (1) \\
\hline Pirimethanil & $1(0)$ & 5 & & & silo de maíz \\
\hline Tebuconazol & $2(0)$ & 10 & & & alfalfa pastura (1), silo de maíz (1) \\
\hline
\end{tabular}

${ }^{a}$ Nombres en itálica refieren a compuestos determinados por GC-MS/MS; ${ }^{b}$ Entre paréntesis se indican hallazgos cuantificados (>LC); ${ }^{c}$ LC: límite de cuantificación; ${ }^{d}$ Entre paréntesis se indica la cantidad de muestras en las que se halló el compuesto. 


\subsubsection{Plaguicidas más recurrentes}

Se describen a continuación los plaguicidas de los tres tipos de familias (insecticidas, herbicidas y fungicidas) hallados más recurrentemente en las muestras analizadas. La información aquí descripta hace referencia a los resultados presentados en la Figura 37, en la Tabla 34, y a las Tablas S4-3 a S4-6 del material suplementario donde se proporcionan concentraciones individuales de plaguicidas/muestras.

\section{Insecticidas}

El clorpirifos y el pirimifos-metilo fueron los compuestos con mayor ocurrencia en todo el conjunto de muestras analizado, mostrando también altas tasas de cuantificación. El clorpirifos es el insecticida más utilizado en Argentina y su uso está autorizado en 39 artículos diferentes, incluidos 10 cultivos y forrajes relacionados con las muestras analizadas en este trabajo [12]. Este insecticida organofosforado de amplio espectro y acaricida de acción por contacto es ampliamente utilizado en diferentes tipos de tratamientos de semillas, aplicaciones de suelo y en cultivos extensivos e intensivos (alfalfa, algodón, girasol, maíz, sorgo, soja). En este estudio, el clorpirifos de detectó muy frecuentemente en las muestras analizadas por ambas técnicas instrumentales. Por LC-MS/MS se cuantificó en alrededor del 30\% de las muestras en las que se detectó (17 de 53 muestras) con una concentración máxima de $167 \mu \mathrm{g} / \mathrm{kg}$ en un maíz molido. Por GCMS/MS se cuantificó en 22 de 33 muestras en las que se halló, siendo la concentración máxima de 144 $\mu \mathrm{g} / \mathrm{kg}$ para la misma muestra. Como se mencionó en el capítulo anterior, el clorpirifos fue uno de los plaguicidas encontrados en muestras de leche cruda de tambos de la misma área en la provincia de Santa $\mathrm{Fe}$, detectándose en 8 de 40 muestras de leche con una concentración máxima de $3 \mu \mathrm{g} / \mathrm{L}$ (LMR para leche en nuestro país es de $20 \mu \mathrm{g} / \mathrm{L}$ ) [47,50]. En Argentina, este compuesto ha sido recurrentemente hallado e informado en muestras ambientales, alimenticias y biológicas [211], y aunque existe poca información publicada respecto a piensos se ha encontrado en semillas de algodón analizadas como alimento para ganado en niveles inferiores al LMR establecido [232]. La ocurrencia de este compuesto también se informó en varios estudios en otros alimentos en todo el mundo [102,134,203,206,233] incluyendo países de la Unión Europea en los que su uso está aprobado. De hecho, en el informe realizado por la EFSA en el año 2017 se indica a este insecticida como uno de los casos más frecuente de superación de la ARfD en la evaluación de riesgo de exposición dietaria de corto término para diversas frutas y vegetales [234].

La alta ocurrencia del clorpirifos, que lo distingue de otros residuos de plaguicidas, debe tenerse en cuenta con respecto a las acciones preventivas de control ya que a pesar de tener baja solubilidad acuosa y ser moderadamente persistente en el agua, es altamente tóxico para los peces e inverterbrados acuáticos, así como también para las aves y abejas melíferas. En general, es altamente tóxico para los mamíferos y se lo clasifica como tóxico de reproducción, inhibidor de acetilcolinesterasa y neurotóxico. Tales son los peligros asociados al clorpirifos que derivan de las evaluaciones de riesgo que recientemente la agencia de protección ambiental de EEUU (EPA) ha puesto en consideración pedidos expresos de revocación del registro para este compuesto en ese país [134]. 
Otro de los compuestos hallados en gran medida en este trabajo fue el pirimifos-metilo, cuyo uso está autorizado en Argentina para 13 artículos, incluidos los cereales (arroz, cebada, trigo, maíz, sorgo) y algunos de sus derivados (harinas y salvados). Este es un insecticida organofosforado de amplio espectro, de acción rápida fumigante y por contacto que se utiliza para controlar una gran variedad de insectos y ácaros en granos almacenados y en tratamientos de semillas, teniendo también usos no-agronómicos extendidos en establos, locales industriales y vehículos de transporte [13]. Al igual que el clorpirifos, en nuestro estudio el pirimifós-metilo fue muy frecuente en todos los tipos de muestra. Por LC-MS/MS se cuantificó en 19 de 43 detecciones con una concentración media y máxima de 36 y $324 \mu \mathrm{g} / \mathrm{kg}$, respectivamente. Los resultados de la determinación por GC-MS/MS fueron ligeramente diferentes, probablemente a causa de un comportamiento diferente en el sistema de detección, habiendo sido cuantificado en 5 de 29 muestras con media y máxima de 33 y $273 \mu \mathrm{g} / \mathrm{kg}$ respectivamente. La alta frecuencia de detecciones de pirimifos-metilo observada en el análisis de estas muestras confirmó cierta tendencia hacia la ubicuidad de este compuesto en piensos, evidenciada en los resultados de un estudio previo realizado por nuestro grupo, en el que de un total de 145 muestras similares de alimento para ganado de la misma zona este plaguicida se detectó en 127 casos con una media de $46 \mu \mathrm{g} / \mathrm{kg}$ y una concentración máxima de $1108 \mu \mathrm{g} / \mathrm{kg}$ (estos resultados de describirán brevemente al final de este capítulo). A pesar de la alta incidencia encontrada en los alimentos de ganado lechero, el pirimifos-metilo no se encontró con alta frecuencia en muestras de leche de la misma área de estudio, encontrándose en 3 de 80 muestras analizadas en concentraciones por debajo del LMR de $10 \mu \mathrm{g} / \mathrm{kg}$ establecido por la legislación argentina [47]. Desde el punto de vista toxicológico, recientes estudios efectuados también por nuestro grupo sobre evaluación de riesgo dietario en Argentina a través de la estimación de la ingesta diaria máxima teórica (TDMI) evidenciaron que el pirimifos-metilo supera el $100 \%$ de la ingesta diaria admisible recomendada (196\% IDA) para las dietas infantiles [235]. Se puede observar que este insecticida es uno de los compuestos permitidos tanto en la Argentina como en la Unión Europea (UE) y que presentan LMRs considerablemente diferentes, de 10 y 0,5 mg/kg para maíz, respectivamente. En la UE, pirimifós-metilo también evidencia problemas de ocurrencia en todo tipo de cereales, conduciendo a la reducción de LMRs establecidos, en algunos casos de 5 a $0,5 \mathrm{mg} / \mathrm{kg}$, después de una reevaluación del riesgo en 2009 [236]. La alta ocurrencia para este plaguicida también fue informada por la EFSA en 2017, siendo el segundo compuesto más frecuente encontrado en muestras de trigo con un alto porcentaje de violaciones del LMR [234]. En un informe anterior de la EFSA del año 2011 se vinculó la alta incidencia de pirimifos-metilo en muestras de origen agrícola con la probabilidad de que se produzca contaminación cruzada del maíz cuando se almacena en silos que anteriormente albergaron cereales tratados, derivado esto de los usos para los cuales este compuesto está autorizado en Europa por la directiva $C E / 52 / 2007$, que se limitan al tratamiento post-cosecha y de instalaciones de almacenamiento [237]. 


\section{Herbicidas}

En cuanto a los herbicidas, atrazina y metolacloro fueron los dos compuestos más frecuentes que se encontraron, siendo el primero uno de los herbicidas más utilizados en Argentina que incluso se fabrica en el país. Su uso está autorizado para 8 artículos, incluidos forrajes de maíz, sorgo y sus respectivos granos para consumo, y se detectó en 31 de 54 muestras analizadas, aunque solo 7 valores fueron cuantificables en el rango de 9-26 $\mu \mathrm{g} / \mathrm{kg}$. El resto de los valores detectados se distribuyeron en todo el conjunto de muestras en niveles $<2 \mu \mathrm{g} / \mathrm{kg}$. El metolacloro, por su parte, es un compuesto de la familia de las cloroacetanilidas ampliamente utilizado en nuestro país y está autorizado para 36 cultivos, incluidos 2 forrajes (maíz y sorgo), 4 granos para consumo (maíz, soja, sorgo y semillas de girasol) y el resto para frutas y verduras. En las muestras analizadas se evidenció una frecuencia de detección relativamente alta (60\%) pero a tasas de cuantificación muy bajas ( 3 de 32 detectadas) con un máximo de $15 \mu \mathrm{g} / \mathrm{kg}$. Para estos dos herbicidas, la baja incidencia de niveles cuantificados en piensos puede explicar la también baja ocurrencia verificada en la leche en nuestros estudios previos. No obstante, la alta frecuencia de detecciones de ambos compuestos puede sugerir que los suelos tienen contenido residual, y con respecto a esto debe prestarse especial atención a la posible contaminación del agua subterránea por lixiviación no controlada. En ese sentido, considerando los modos de producción argentinos una evaluación de impacto ambiental estableció que atrazina y acetocloro, otro herbicida de amplio uso, son los que tienen mayor impacto potencial de contaminación de acuíferos [238]. En Argentina prevalecen los estudios sobre contaminación de aguas superficiales con residuos de plaguicidas [211] y se han realizado seguimientos del estado de contaminación de acuíferos por atrazina y otras triazinas en estudios puntuales efectuados por el INTA [239-242] y otros centros de investigación [243,244]. Cabe mencionar que desde el año 2013 existe a nivel nacional una Guía de Calidad de Agua desarrollada para atrazina, que establece límites en niveles $\leq 1,5 \mu \mathrm{g} / \mathrm{L}$ para aguas subterráneas utilizadas como fuente de agua potable y $\leq 0,04-0,13 \mu \mathrm{g} / \mathrm{L}$ para agua de riego, en relación con las situaciones observables en campos agrícolas [245].

\section{Fungicidas}

Con respecto a los fungicidas, el metalaxil y la difenilamina fueron los dos compuestos más recurrentes. En Argentina, el metalaxil está exento de tener LMR para el tratamiento de granos y semillas destinados al consumo y en nuestro estudio se encontró solo a niveles traza $(<1 \mu \mathrm{g} / \mathrm{kg})$ en 17 de las 54 muestras y solo una pastura de cebada demostró un valor cuantificable de $27 \mu \mathrm{g} / \mathrm{kg}$. Estos valores pueden considerarse bajos aunque la incidencia refleja el uso de estos productos y una residualidad verificable. Otras reglamentaciones, por ejemplo la de EPA de EEUU, establecen los siguientes LMR para la cebada: grano 0,2 $\mathrm{mg} / \mathrm{kg}$, forrajes y pajas $2,0 \mathrm{mg} / \mathrm{kg}$ y fracciones de molienda $1,0 \mathrm{mg} / \mathrm{kg}$ [246]. Se debe mencionar que el metalaxil es el único fungicida del grupo de las amidas, que en general son de bajo riesgo, que está considerado como levemente peligroso [247]. En el caso de la difenilamina (DPA), en Argentina este compuesto solo tiene autorizaciones para dos alimentos, derivadas de su uso en la conservación de frutas 
en la post-cosecha ( $L M R=3 \mathrm{mg} / \mathrm{kg}$ para manzanas y peras). A pesar de esto, se encontró notablemente en niveles cuantificables en 10 de las 18 las muestras de distinto tipo en las que se detectó, con concentraciones en el rango de $25-63 \mu \mathrm{g} / \mathrm{kg}$. Si bien se considera un compuesto de bajo riesgo, presenta riesgos principalmente relacionados con la exposición del aplicador y de toxicidad para peces e invertebrados acuáticos. En nuestro caso, la aparición de DPA es llamativa debido a que no está autorizada para cultivos extensivos y su presencia en muestras tan variadas (como pastura de alfalfa, ensilados y grano molido de maíz, grano de trigo, balanceados, semilla de algodón, expeller de soja y burlanda) denota que puede estar originada o bien a partir de la transformación de otros compuestos o por algún uso no autorizado, por lo que su origen debería ser estudiado.

\subsubsection{Ocurrencia de otras familias de compuestos (piretroides, organofosforados, organoclorados)}

\section{Piretroides}

Los piretroides son reconocidos por su rápido efecto de derribo contra las plagas de insectos, la baja toxicidad de los mamíferos y la fácil biodegradación [210] lo que ha extendido su uso en tecnología agropecuaria, haciéndolos compatibles con muchas formulaciones modernas. Los piretroides están ampliamente autorizados en Argentina para una gran variedad de productos de origen vegetal, incluidos muchos granos y forrajes $(32,37,34$ y 37 ítems distintos para cipermetrina, deltametrina, lambdacihalotrina y permetrina, respectivamente). Todos estos insecticidas se detectaron en las muestras analizadas mediante determinación de LC-MS/MS o GC-MS/MS. Sin embargo, los resultados de ambas técnicas analíticas fueron discordantes para algunos piretroides: por ejemplo, la cipermetrina se detectó en una sola muestra por LC y en 7 muestras por GC. Esto se asocia con la alta afinidad por la cromatografía de gases que esta familia de compuestos tiene, principalmente debido a sus puntos de ebullición más altos $\left(130-200^{\circ} \mathrm{C}\right)$, a la buena estabilidad térmica y su más débil polaridad [248]. Por lo tanto, para el análisis se consideraron los resultados de GC-MS/MS.

La cipermetrina, la deltametrina y la lambda-cihalotrina se encontraron consistentemente a niveles cuantificables en los balanceados en concentraciones que oscilaron entre 53 y $532 \mu \mathrm{g} / \mathrm{kg}$, y también en algunas muestras de cereales y TMRs. De hecho, el valor más alto encontrado en todo el trabajo correspondió a deltametrina en una muestra de alimento balanceado $(532 \mu \mathrm{g} / \mathrm{kg}$ ). En cuanto a lambdacihalotrina, fue menos frecuente que los otros dos piretroides, pero se detectó en algunas muestras a pesar de su alto límite de cuantificación ( $L C=100 \mu \mathrm{g} / \mathrm{kg}$ ). Respecto a los otros piretroides, la tetrametrina fue notablemente identificada a niveles cuantificables en una pastura de alfalfa y en un alimento balanceado (39 y $94 \mu \mathrm{g} / \mathrm{kg}$, respectivamente), a pesar de que este compuesto no está autorizado para su uso en Argentina. Finalmente, en muy pocas muestras se detectaron residuos de bifentrin y permetrina, que también están autorizadas en Argentina, en niveles no cuantificables. En Argentina los LMR para deltametrina varían entre $0,1 \mathrm{mg} / \mathrm{kg}$ en semillas de algodón y girasol de consumo, 0,5 $\mathrm{mg} / \mathrm{kg}$ en forrajes (de alfalfa, maíz, soja y sorgo) y $1 \mathrm{mg} / \mathrm{kg}$ en granos de cereales para consumo. Los valores de LMR para la 
cipermetrina son de $5 \mathrm{mg} / \mathrm{kg}$ para pasturas y forrajes, y de entre 0,1 y $0,2 \mathrm{mg} / \mathrm{kg}$ para semillas y granos. En el caso de los LMR de lambda-cihalotrina, varían de 0,01 a $2 \mathrm{mg} / \mathrm{kg}$ para todos los artículos aplicables a la alimentación. Aunque en el análisis de piensos realizado en este trabajo no se observaron excesos de esos límites, en el caso del valor máximo registrado para alimento balanceado no hay ningún LMR especificado (puesto que se trata de mezclas de muchos productos), pero puede considerarse un valor relativamente alto con respecto al $L M R=0,5 \mathrm{mg} / \mathrm{kg}$ establecido para los forrajes o el $\mathrm{LMR}=0,1 \mathrm{mg} / \mathrm{kg}$ para las semillas. En general, la ocurrencia relativamente alta de estos compuestos corresponde al uso intenso de piretroides, si bien no se reflejó con un peso similar en las muestras de leche de nuestro estudio. Los residuos de estos compuestos conciernen sí muy fuertemente con la integridad de medio ambiente, teniendo un impacto potencial en la vida acuática, ya que esta familia de insecticidas es extremadamente tóxica para los peces, por ejemplo [249]. Además, si bien estos compuestos son muy poco tóxicos para mamíferos, son relativamente estables y han sido involucrados con efectos alergénicos, por lo que su presencia en forma de residuos en los alimentos es un aspecto de creciente preocupación.

\section{Organofosforados}

Aunque los insecticidas organofosforados son la familia de plaguicidas con más autorizaciones en Argentina, su incidencia en las muestras analizadas fue baja. Diazinon, dimetoato y profenofos se identificaron solo a nivel de trazas. Diazinon es un insecticida de uso general que se utiliza para controlar insectos chupadores y masticadores en una amplia gama de cultivos, incluida las frutas más importantes, teniendo también aplicaciones contra plagas del ganado incluidos ácaros, garrapatas, piojos y moscas mordedoras. Este compuesto se ha encontrado a niveles traza en las muestras de leche analizadas en el marco de esta tesis, aunque su presencia podría ser atribuible más a sus usos terapéuticos veterinarios que provenientes de las dietas para el ganado. El diazinón y el dimetoato son plaguicidas prohibidos para uso en la Unión Europa y ambos han sido informados como muy comprometidos con excesos de $100 \%$ de la IDA y 100\% del ARfD, en evaluaciones recientes en Argentina sobre riesgo dietario por exposiciones crónicas y agudas, respectivamente $[235,250]$. Por otro lado, pirimicarb y su metabolito desmetil-pirimicarb también se encontraron en concentraciones no cuantificables principalmente en pasturas. Finalmente, vale la pena señalar las detecciones de carbofenotion, ometoato y quinalfós, ya que son compuestos no autorizados en Argentina y sobre los que se deberían explorar sus posibles orígenes.

\section{Plaguicidas organoclorados}

Como en la mayoría de los países del mundo, los plaguicidas organoclorados (OCP) están prohibidos en Argentina desde hace varias décadas debido a su alta estabilidad química, alta toxicidad y potencial de bioacumulación. Actualmente, estos compuestos son solamente motivo de preocupación como contaminantes ambientales persistentes dado que sus residuos aún se encuentran en muchos productos de origen agrícola, ya sea por su persistencia ambiental o su uso indebido. En este trabajo, fue llamativa la detección de clordano en cereales, semillas de algodón y muestras de expeller de soja, ya que este 
plaguicida ha estado prohibido durante más de 20 años. También se encontraron en niveles de trazas no cuantificables heptacloro en alimentos balanceados y cereales, y endosulfán que fue encontrado como endosulfan sulfato en una muestra de alimento balanceado. En este caso no hay correspondencia con lo verificado en leches donde la incidencia fue un poco mayor, probablemente vinculado a la gran liposolubilidad y tendencia a la bioacumulación en tejidos animales que presenta esta familia de plaguicidas. Se debe considerar que el endosulfan fue completamente prohibido en 2013 en Argentina, cerca del período de muestreo de este trabajo. Como se mencionó en el capítulo anterior, estos dos insecticidas (heptacloro y endosulfan) y sus productos de transformación han sido encontrados por otros autores en muestras de leche bovina de establecimientos agrícolas en la misma área de producción en la provincia de Santa Fe [212]. Con respecto a los plaguicidas organoclorados en general, es notable la continuidad de informes actuales sobre su ocurrencia en gran variedad de matrices alimentarias y ambientales tanto en Argentina [211] como en muchas otras partes del mundo [102,251-253].

\subsubsection{Análisis con respecto a los diferentes tipos de muestra}

En la Figura 38 se presentan descriptivamente los porcentajes de detección de las 3 familias de plaguicidas (insecticidas, herbicidas y fungicidas) y los rangos de cuantificación del conjunto de plaguicidas hallados en los 4 grupos en los que se clasificaron las 54 muestras analizadas. Comparando los 4 grupos de muestras entre sí, se observa que las detecciones de insecticidas fueron mayores en los cereales y derivados (67\%), las de los herbicidas en oleaginosas y derivados (33\%), y la de los fungicidas en forrajes (22\%). También se observa que la mayor carga de plaguicidas la tuvo el grupo de los balanceados y TMRs con una concentración media de 80 y rango de $5-532 \mu \mathrm{g} / \mathrm{kg}$, y que las menores concentraciones se encontraron en el grupo de oleaginosas y derivados con media de 31 y rango de 6-82 $\mu \mathrm{g} / \mathrm{kg}$. Los resultados de los plaguicidas hallados en cada una de las muestras clasificadas por grupos se presentan en las Tablas S4-3 a S4-6 del material suplementario.

(a) Detecciones

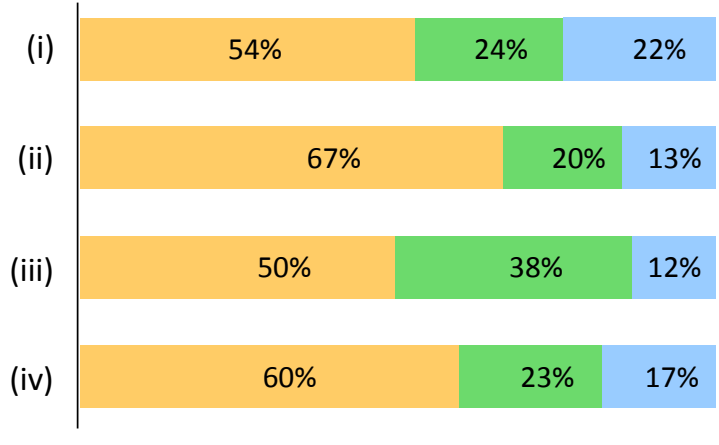

$\square$ Insecticidas $\square$ Herbicidas $\square$ Fungicidas (b) Rangos cuantificados

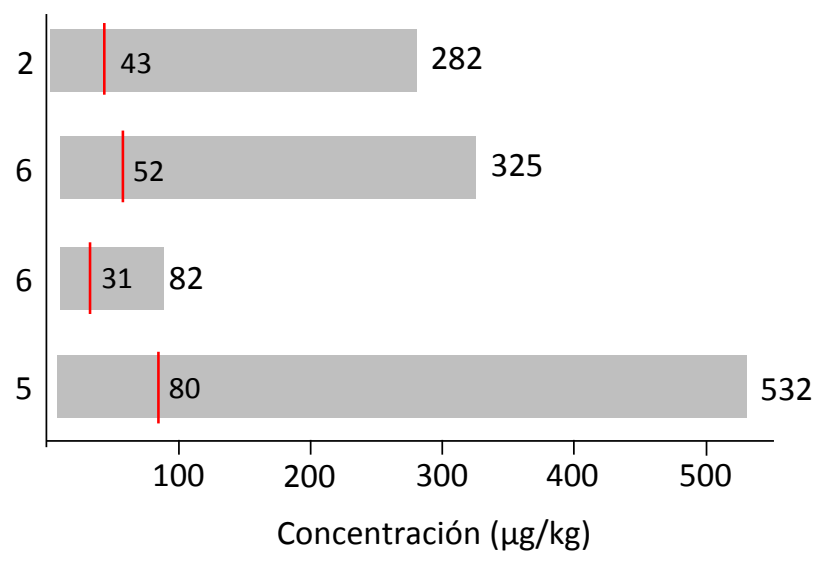

Figura 38. Análisis descriptivo de las detecciones y rangos de cuantificación de los plaguicidas determinados en los 4 grupos en los que se clasificaron las muestras analizadas. (i) forrajes, (ii) cereales y derivados, (iii) oleaginosas y derivados, (iv) balanceados y TMRs. 


\section{Forrajes}

Los forrajes son componentes esenciales de los sistemas de alimentación intensiva adoptados en Argentina para la producción de ganado lechero y son consumidos por pastoreo directo o suministrados como materiales frescos molidos, henos o ensilajes. En ese sentido la alfalfa es el componente base de la oferta de forraje en los establecimientos de producción en la zona central de la Provincia de Santa Fe. En este esquema un componente alimentario importante y común del ganado lechero en los sistemas de producción actuales son los ensilados, que consisten en la fermentación láctica anaeróbica de gramíneas trituradas (toda la planta, típicamente maíz y sorgo) y se utilizan como fuente de energía debido a su alto contenido de carbohidratos no fibrosos. Todas las muestras de este grupo contenían al menos un residuo de plaguicida y de las detecciones totales el $29 \%$ fueron cuantificables en el rango de $2-282 \mu \mathrm{g} / \mathrm{kg}$ con un valor medio de $43 \mu \mathrm{g} / \mathrm{kg}$ (Figura 38). Los valores más altos fueron para bendiocarb en una pastura de alfalfa y un ensilado de sorgo (282 y $123 \mu \mathrm{g} / \mathrm{kg}$, respectivamente) (Tabla S4-3 del material suplementario). Los hallazgos verificados de este insecticida de la familia de los carbamatos, con clasificación de extrema toxicidad para especies acuáticas, llaman la atención dado que no posee autorizaciones en cultivos vegetales por la Resolución 934/10 de SENASA [12], presentando sí un límite establecido en leche de acuerdo a su uso veterinario ( $\mathrm{LMR}=0,05 \mathrm{mg} / \mathrm{kg}$, Código Alimentario Argentino) [50]. Además, fue prohibido para usos domisanitarios en 2013 por Resolución del Ministerio de Salud de la Nación [254]. Este compuesto fue encontrado en una sola de las muestras de leche analizadas en este trabajo en niveles traza $(2,2 \mu \mathrm{g} / \mathrm{kg})$ (Capítulo 3). El de los forrajes fue el grupo en el que mayor cantidad de plaguicidas se encontraron, con 35 compuestos diferentes identificados. Ya se ha mencionado la gran ocurrencia de clorpirifos y pirimifos-metilo en todas las muestras, tendencia también hallada en este grupo aunque con relativamente pocos valores cuantificados, lo que indicaría que estos dos plaguicidas conciernen más al almacenamiento que al campo. Se destacó además la única detección en todo el trabajo de lufenuron en un heno de alfalfa con concentración $115 \mu \mathrm{g} / \mathrm{kg}$. Este compuesto es un insecticida de la familia de las benzoilureas con propiedades acaricidas y de uso veterinario, utilizado en cultivos de algodón y máiz [13], que en nuestro país no está autorizado para cultivos de alfalfa ni otros forrajes, presentando sí autorizaciones en algunos granos y semillas con LMRs tan bajos como $10 \mu \mathrm{g} / \mathrm{kg}$ en semillas de girasol o 50 $\mu \mathrm{g} / \mathrm{kg}$ en soja para consumo [12].

\section{Cereales y derivados}

Los cereales son ampliamente utilizados en los sistemas de alimentación del ganado lechero para complementar las dietas basadas en forraje debido a su alto contenido de energía y baja fibra. El maíz, el trigo y, en menor medida, el sorgo se utilizan principalmente como este tipo de alimento concentrado y se proporcionan como granos enteros, partidos o molidos. Además, se utilizan cada vez más en las dietas ganaderas algunos subproductos resultantes del procesamiento industrial de estos cereales, como el gluten de trigo y la burlanda de maíz (granos de destilería con solubles, DGS). Al contrario de los forrajes, el grupo 
de los cereales y derivados fue el que menor cantidad de plaguicidas diferentes presentó (22 compuestos), siendo el máximo valor hallado el correspondiente a pirimifos-metilo en un maíz molido con $325 \mu \mathrm{g} / \mathrm{kg}$. En este grupo se evidenció escasa presencia de herbicidas, detectándose todos ellos (atrazina, haloxyfopmetilo, metolacloro y trifluralina) sólo en niveles traza con un promedio de 1,5 $\mu \mathrm{g} / \mathrm{kg}$. En una muestra de maíz molido y en dos muestras de burlanda se identificaron las únicas 3 detecciones carbofenotion, en niveles cuantificados de entre 6 y $7 \mu \mathrm{g} / \mathrm{kg}$. Este insecticida de la familia de los organofosforados, con elevada toxicidad en mamíferos y especies terrestres y acuáticas, tiene usos principalmente en cultivos frutales aunque ya no está autorizado en la UE, en EEUU ni tampoco para ningún cultivo en nuestro país.

\section{Semillas oleaginosas y derivados}

Otro tipo de alimento concentrado son las semillas con alto contenido lipídico, como la soja, el girasol y el algodón, que se utilizan junto con algunos subproductos industriales, como las harinas de expeller, para complementar las dietas debido a su alto contenido de proteínas. En este grupo, el valor hallado más alto se debió a deltametrina en un expeller de soja, siendo de hecho la única detección de un piretroide en este tipo de muestras. También en un expeller de soja se encontró el insecticida neonicotinoide tiametoxam con una concentración de $64 \mu \mathrm{g} / \mathrm{kg}$, excediendo el LMR $=20 \mu \mathrm{g} / \mathrm{kg}$ establecido en Argentina para soja de consumo. En una muestra de semillas de algodón de este grupo se hallaron las concentraciones más altas de plaguicidas organoclorados de todo el trabajo ( $22 \mu \mathrm{g} / \mathrm{kg}$ de cis-clordano y $66 \mu \mathrm{g} / \mathrm{kg}$ de heptacloro), guardando relación, como ya se ha mencionado, con los hallazgos de heptacloro en leche.

\section{Balanceados y TMRs}

Los alimentos balanceados comerciales y los TMRs son mezclas equilibradas altamente nutritivas de diferentes ingredientes, como maíz o granos de sorgo, salvado de trigo, expellers de soja y girasol, sales, vitaminas y minerales como el calcio que se proporcionan al ganado como fuentes de energía y proteínas complementaria a la aportada por los forrajes. Este grupo de muestras evidenció el rango de concentraciones más amplio (5-532 $\mu \mathrm{g} / \mathrm{kg}$ ) con un valor medio de $80 \mu \mathrm{g} / \mathrm{kg}$, y fue el grupo en el que la carga de clorpirifos y pirimifos-metilo fue más importante (mayores valores cuantificados). Del mismo modo se observó elevada carga de deltametrina, presentando todas las detecciones valores altos y cuantificables y siendo el valor extremo el de $532 \mathrm{\mu g} / \mathrm{kg}$ en un balanceado comercial. Dado que no hay LMR en la legislación argentina este tipo de alimento, podría ser un valor exceso si se considera el valor máximo de $500 \mu \mathrm{g} / \mathrm{kg}$ establecido para la deltametrina en el forraje de maíz [12]. También en este grupo fueron importantes las detecciones de plaguicidas organoclorados, encontrándose por ejemplo heptacloro a niveles residuales en 6 de las 13 muestras de este grupo $(24-34 \mu \mathrm{g} / \mathrm{kg}$ ) y cis-clordano en 4 balanceados $(5-12 \mu \mathrm{g} / \mathrm{kg})$, al tiempo que la única identificación de endosulfán sulfato se dio en un balanceado de este grupo. Se destacó también la presencia de diflubenzuron, que no se halló en otros tipos de muestras, en 3 TMRs y 2 alimentos balanceados con una concentración media de 43 y rango de $28-61 \mu \mathrm{g} / \mathrm{kg}$. Este compuesto es un insecticida de la familia de las benzoilureas que presenta baja toxicidad para mamíferos y tiene autorizaciones y LMRs 
establecidos para piensos en la UE, EEUU y en Códex. En Argentina también está autorizado en algunos cultivos con LMRs de $50 \mathrm{\mu g} / \mathrm{kg}$ para granos de maíz y soja para consumo, por ejemplo.

\section{Multi-residualidad según el tipo de muestra}

Debido al alto número de plaguicidas utilizados en las prácticas agrícolas y los sistemas de rotación de cultivos empleados para la producción de alimentos y piensos, es esperable la co-existencia de múltiples residuos en una misma muestra, dependiendo de las condiciones de la práctica agronómica, la historia del suelo y las condiciones climáticas, entre algunas razones. En este trabajo, los niveles de contaminación múltiple variaron ampliamente desde 1 hasta 17 plaguicidas simultáneamente por muestra individual, con una media general de 7,3 compuestos detectados por muestra. No hubo ningún producto en todo el conjunto de muestras estudiado que estuviera libre de residuos de plaguicidas. Solo 8 muestras presentaron una cantidad relativamente baja, de uno a tres compuestos, a niveles de trazas no cuantificables: se detectó un único residuo de plaguicida en una muestra de soja, se identificaron 2 residuos en cuatro muestras (expeller de girasol, maíz y dos silajes de maíz), y 3 compuestos presentes simultáneamente se confirmaron en dos muestras (silaje de maíz y grano de maíz). En el otro extremo, una muestra de semilla de algodón presentó la mayor cantidad de plaguicidas diferentes co-existiendo en un ítem individual (17 compuestos). De hecho, las semillas de algodón, junto con los balanceados, fueron el tipo de muestras con mayor número de detecciones con un promedio de 11 residuos por muestra (Tabla 35). Esto es esperable en los alimentos balanceados ya que cada ingrediente individual en su composición heterogénea contribuye al contenido final de residuos. Resulta notable que se distinguen claramente a este respecto los distintos grupos considerados, siendo los alimentos compuestos (balanceados y TMR) el grupo con más contenido multiresidual con un promedio de 9,9 pesticidas por muestra, mientras que en el extremo opuesto los forrajes como era de esperar, constituyen el grupo con menos residuos con 5,8 plaguicidas por muestra promedio (Tabla 35).

Estos resultados conducen a resaltar la importancia que reviste la profundización del conocimiento sobre los múltiples efectos esperables de los residuos que co-existen en una misma matriz, posibilitando efectos sinérgicos en algunos casos, y en otros efectos aditivos o acumulativos cuando comparten los mismos objetivos moleculares o mecanismos de toxicidad. Los efectos de la coexistencia de distintas sustancias tóxicas en los alimentos y el ambiente constituyen una temática de gran relevancia actual, dado que la mayoría de los datos toxicológicos existentes corresponden a estudios efectuados en forma de sustancias individuales. 
Tabla 35. Multiresidualidad observada en los distintos tipos y grupos de muestras analizadas.

\begin{tabular}{|c|c|c|c|}
\hline Grupo & Tipos de muestra & $\begin{array}{l}\text { Residuos promedio } \\
\text { por tipo de muestra }\end{array}$ & $\begin{array}{l}\text { Residuos promedio } \\
\text { por grupo }\end{array}$ \\
\hline \multirow[t]{5}{*}{ (i) Forrajes } & 4 pasturas de alfalfa & 8 & 5,8 \\
\hline & 2 henos de alfalfa & 6 & \\
\hline & 1 pastura de cebada & 7 & \\
\hline & 9 ensilados de maíz & 4,8 & \\
\hline & 4 ensilados de sorgo & 5,5 & \\
\hline \multirow[t]{4}{*}{ (ii) Cereales y derivados } & 7 granos de maíz & 6,3 & 6,8 \\
\hline & 2 granos de trigo & 7,5 & \\
\hline & 2 burlandas de maíz & 8 & \\
\hline & 1 gluten de trigo & 6 & \\
\hline \multirow[t]{4}{*}{ (iii) Oleaginosas y derivados } & 4 semillas de algodón & 11 & 7,3 \\
\hline & 1 poroto de soja & 1 & \\
\hline & 3 expellers de soja & 6 & \\
\hline & 1 expeller de girasol & 2 & \\
\hline \multirow[t]{2}{*}{ (iv) Balanceados y TMRs } & 10 balanceados & 11 & 9,9 \\
\hline & 3 TMRs & 7,3 & \\
\hline
\end{tabular}

\section{Análisis previos en piensos}

Como se ha mencionado, este trabajo de tesis se enmarcó en las actividades de un proyecto ANPCyT-PICT que buscaba medir residualidad de plaguicidas y contaminantes de origen fúngico en leches y piensos para ganado de la cuenca lechera santafesina en un estudio anual a lo largo de 4 estaciones climáticas. Fue así que una de las actividades propuestas en esta tesis fue la medición de residuos de plaguicidas y micotoxinas en una selección de muestras del conjunto muy amplio alimentos vegetales (más de 700 muestras) implicadas en el plan de muestreo de ese proyecto. Las muestras seleccionadas comprendieron 145 piensos correspondientes al muestreo de verano, con las mismas características, composición general y origen que los analizados en la discusión precedente de este capítulo, y se analizaron con un scope reducido de 90 plaguicidas y 2 aflatoxinas con un método QuEChERS y con determinación por UHPLCMS/MS según la capacidad analítica con la que contaba nuestro laboratorio en ese momento.

Como el planteo de este capítulo de tesis, como así también del siguiente, se basó en la descripción y discusiones sobre la aplicación de métodos multi-clase y de alto scope analítico para medir grandes cantidades de plaguicidas y micotoxinas con fines de evaluación de ocurrencia de estos residuos y contaminantes, se decidió no focalizar en los resultados previos sobre las 142 muestras mencionadas. Sin embargo, es propicio comentar que aquellos resultados sustentan a los obtenidos en este nuevo estudio ampliado, por cuanto se verificaron las principales tendencias en la ocurrencia de residuos de plaguicidas en piensos destinados a la alimentación del ganado lechero en la zona de estudio. En la Tabla 36 se resumen los resultados obtenidos en aquel primer análisis de muestras, y en las Tablas S4-7 a S4-14 del material suplementario se presentan los resultados individuales de todas las muestras comprendidas en ese estudio. 
Tabla 36. Resumen de los plaguicidas hallados en el análisis previo de 142 muestras de alimentos para ganado mediante extracción QuEChERS y determinación por UHPLC-MS/MS.

\begin{tabular}{|c|c|c|c|c|c|c|c|}
\hline \multirow[b]{2}{*}{ Compuesto } & \multirow[b]{2}{*}{ Detecciones } & \multirow[b]{2}{*}{$\begin{array}{l}\text { \% Ocurrencia } \\
(n=142)\end{array}$} & \multirow[b]{2}{*}{$\begin{array}{l}\mathrm{N}^{\circ} \text { de } \\
\text { cuantificadas }\end{array}$} & \multicolumn{4}{|c|}{ Concentraciones $(\mu \mathrm{g} / \mathrm{kg})$} \\
\hline & & & & Mínima & Máxima & Media & LC \\
\hline Acetamiprid & 3 & 2 & 2 & 4 & 36 & 23 & 25 \\
\hline AFB1 & 15 & 11 & 2 & 1 & 12 & 2 & 5 \\
\hline Atrazina & 2 & 1,4 & 0 & 0,4 & 1,0 & 0,7 & 10 \\
\hline Azoxistrobina & 24 & 17 & 7 & 0,4 & 155 & 12 & 5 \\
\hline Bentazona & 3 & 2 & 0 & 9 & 20 & 13 & 25 \\
\hline Carbendazim & 13 & 9 & 8 & 14 & 119 & 39 & 25 \\
\hline Clorpirifos & 26 & 18 & 8 & 2 & 592 & 104 & 100 \\
\hline Clotianidina & 1 & $<1$ & 1 & 13 & 367 & 190 & 50 \\
\hline Diazinon & 3 & 2 & 2 & 2 & 11 & 6 & 5 \\
\hline Fipronil & 1 & $<1$ & 1 & 9 & 9 & 9 & 5 \\
\hline Flusilazol & 1 & $<1$ & 0 & 5 & 5 & 5 & 10 \\
\hline Haloxyfop & 1 & $<1$ & 1 & 1300 & 1300 & 1300 & 100 \\
\hline Imazalil & 1 & $<1$ & 0 & 1 & 1 & 1 & 5 \\
\hline Imidacloprid & 2 & 1,4 & 1 & 43 & 89 & 66 & 10 \\
\hline Metalaxil & 9 & 6 & 3 & 2 & 37 & 8 & 5 \\
\hline Methamidiphos & 1 & 1 & 0 & 24 & 24 & 24 & 50 \\
\hline Metoxifenocida & 4 & 3 & 2 & 21 & 503 & 150 & 50 \\
\hline Piraclostrobina & 9 & 6 & 4 & 1 & 34 & 7 & 5 \\
\hline Pirimifos-Me & 127 & 88 & 109 & 2 & 1108 & 46 & 5 \\
\hline Profenofos & 1 & $<1$ & 1 & 41 & 41 & 41 & 25 \\
\hline Propiconazol & 1 & $<1$ & 0 & 6 & 6 & 6 & 10 \\
\hline Tebuconazol & 2 & 1,4 & 0 & 10 & 24 & 17 & 50 \\
\hline Tiametoxam & 2 & 1,4 & 2 & 114 & 324 & 219 & 50 \\
\hline Tiofanato-metilo & 1 & $<1$ & 0 & 48 & 48 & 48 & $>100$ \\
\hline
\end{tabular}

LC: límite de cuantificación.

Se puede observar que en aquel primer análisis de piensos también se verificó que los plaguicidas con mayor ocurrencia son pirimifos-metilo y clorpirifos, aunque para el caso de este último con una incidencia mucho menor que la hallada en las 54 muestras posteriores.

Respecto a la determinación de clorpirifos, este es un compuesto que en el analizador ACQUITY TQD (PRINARC-FIQ-UNL) presenta relativamente poca sensibilidad comparada con la que tiene en el analizador Xevo $^{\text {TM }}$ TQ-S (UCT-Praga). Si bien ambos son configuraciones de triple cuadrupolo de la misma marca comercial (Waters), el más moderno Xevo ${ }^{\mathrm{TM}}$ TQ-S presenta un diseño optimizado con una tecnología denominada "Strep-wave" para transferencia de iones hacia los cuadrupolos que permite, entre otras características, eliminar iones neutros no ionizados con el consecuente aumento de la sensibilidad de detección. Este incremento en la sensibilidad de clorpirifos se evidenció en los límites de cuantificación obtenidos en ambos ensayos, con una diferencia de un orden de magnitud a favor de la sensibilidad en el

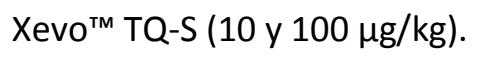




\subsection{CONCLUSIONES}

La información que surge de este estudio con respecto a la presencia de residuos de plaguicidas en piensos para el ganado lechero es sustancialmente más extensa que las obras reportadas anteriormente en Argentina, ya que se evidenció la presencia de gran cantidad de compuestos diferentes en una amplia variedad de alimentos de origen vegetal.

Se encontraron concentraciones variables de 50 plaguicidas con una prevalencia de mayor significación para los insecticidas organofosforados, siendo altamente frecuentes clorpirifós y pirimifós-metilo. También se detectaron insecticidas piretroides, herbicidas y fungicidas, siendo deltametrina, atrazina y difenilamina los de mayor incidencia de cada una de esas familias, respectivamente.

Aunque la comparación con los límites máximos de residuos específicos para cada tipo de muestra no es posible debido a la inexistencia de tales LMR específicos, los niveles de concentraciones hallados proporcionan información significativa para dimensionar preliminarmente los riesgos que representa la presencia de residuos de plaguicidas para la salud animal, humana y para el medioambiente.

Cabe remarcar que la mayoría de las detecciones corresponden a productos autorizados en el país y sobre los cuales no existen planes de control para este tipo de alimentos. También fue llamativa la aparición de compuestos no autorizados en el país como carbofenotion, ometoato y quinalfos.

Estos hallazgos evidencian la necesidad de realizar monitoreo y tareas de control en los productos de la dieta animal cubriendo un amplio espectro de compuestos, para preservar la salud del rodeo y también prevenir la contaminación de los alimentos de origen animal derivados en el eslabón primario de la cadena. 

CAPÍTULO 5

Determinación de micotoxinas en piensos para el ganado lechero 


\section{CAPÍTULO 5: Determinación de micotoxinas en piensos para el ganado lechero}

\subsection{INTRODUCCIÓN}

Las micotoxinas son metabolitos secundarios de bajo peso molecular producidos por hongos filamentosos de especies de Alternaria, Aspergillus, Claviceps, Fusarium, Penicillium, entre otros, cuya producción depende del tipo de moho, del tipo de sustrato que éste colonice, de factores climáticos y de prácticas agronómicas, incluidos el manejo de cultivos en períodos de pre-y post-cosecha y las condiciones de almacenamiento de los productos. El tipo y cantidad de micotoxinas que los mohos producen depende además de factores físicos (humedad relativa, temperatura, daños mecánicos), químicos (disponibilidad de oxígeno, dióxido de carbono, uso de plaguicidas) y biológicos (variedad de cultivos, estrés, insectos) [255]. En la actualidad se conocen cerca de 400 micotoxinas producidas por unas 350 especies de mohos. De ese universo, son pocas las que han sido siempre estudiadas en piensos debido a su ubicuidad y frecuencia de aparición, como por ejemplo aflatoxinas, zearalenona, tricotecenos (especialmente deoxinivalenol), fumonisinas y ocratoxina A [97]. Estas micotoxinas, junto con otras como citrinina, alcaloides del ergot, gliotoxina o esterigmatocistina, tienen además importancia en la alimentación animal por el efecto tóxico que pueden producir en los rumiantes [70]. En los últimos años también han suscitado interés en piensos las micotoxinas emergentes como eniatinas y beauvericina debido a su alta ocurrencia tanto en cereales como trigo, cebada y alimentos derivados [256-258] como en ensilados de pastura y de maíz [259].

La importancia de la presencia de micotoxinas en piensos para alimentación animal radica en la gran variedad de sustratos que conforman las dietas, que pueden ser afectados por hongos con la consecuente producción de micotoxinas bajo los factores antes mencionados. Por ejemplo, los hongos filamentosos pueden crecer en forrajes durante la etapa de pre-cosecha por lo que es frecuente la presencia de micotoxinas en henos y ensilados [260]. Por otro lado, las dietas para ganado se constituyen principalmente por granos de cereales (en especial maíz, sorgo y trigo) que pueden infectarse por mohos durante el período de floración, durante el cultivo o en el almacenamiento. A su vez, los cereales y sus productos derivados son los principales ingredientes de los alimentos balanceados que son ampliamente utilizados en dietas concentradas, constituyendo hasta el $48 \%$ de la composición de los mismos [261]. La compleja composición de muchos piensos, especialmente balanceados y TMRs, los hace especialmente proclives a presentar altas contaminaciones con micotoxinas provenientes de los distintos materiales mezclados para su elaboración. Esto, sumado a que los procesos de intensificación de los sistemas de producción actuales llevan a un uso mayor de alimentos cosechados, mezclados y almacenados en condiciones muy variables hace que la presencia de micotoxinas en piensos sea frecuente y casi inevitable. Las micotoxinas ingeridas por los animales con el alimento pueden causar efectos como disminución de la ingesta, rechazo al alimento, una pobre conversión del mismo, pérdida de peso, mayor incidencia de enfermedades por efectos de inmunosupresión, reducción de la capacidad reproductiva e incluso la muerte, todos efectos que 
terminan ocasionando pérdidas económicas a los productores [260]. Se estima que el 5-10\% de los cultivos producidos a nivel mundial se pierden como consecuencia de la contaminación por micotoxinas [262].

La regulación del contenido de micotoxinas mediante el establecimiento de límites máximos permitidos en piensos ha estado dirigida hacia las micotoxinas tradicionales (AFs, DON, ZEA, T-2 y HT-2, FBs). Mediante diferentes directivas, la Comisión Europea ha establecido límites máximos de estas micotoxinas en alimentos destinados al consumo humano y en piensos para alimentación animal. En la Tabla 37 se resumen algunos de estos límites fijados para materias primas que puedan derivar para uno u otro tipo de alimentos, junto con límites similares establecidos por otros organismos o bloques comerciales. La situación para alimentos destinados al consumo humano puede variar respecto a los piensos en términos de tener límites más bajos pero no en la cantidad y tipos de micotoxinas reguladas.

Tabla 37. Resumen de los límites máximos (L.M., $\mu \mathrm{g} / \mathrm{kg}$ ) para algunas micotoxinas en piensos para alimentación animal establecidos por distintas legislaciones.

\begin{tabular}{|c|c|c|}
\hline Micotoxina & L.M. & Tipo de pienso \\
\hline \multirow[t]{5}{*}{ Aflatoxinas (B1+B2+G1+G2) } & $5^{a}$ & Piensos completos para ganado lechero \\
\hline & $20^{\mathrm{a}}$ & $\begin{array}{l}\text { Semillas de algodón, maíz y derivados de su transformación } \\
\text { para alimentación animal }\end{array}$ \\
\hline & $20^{b}$ & Semillas de algodón, maíz, maní y otros piensos \\
\hline & $20^{c}$ & Maíz en grano (entero, partido) para consumo humano* \\
\hline & $300^{b}$ & Expeller de algodón para ganado \\
\hline Alcaloides del ergot & $1000^{\mathrm{a}}$ & Piensos y piensos compuestos conteniendo granos enteros \\
\hline Citrinina & $2000^{d}$ & Suplementos alimentarios para humanos de base arroz* \\
\hline \multirow[t]{7}{*}{ Deoxinivalenol (DON) } & $1750^{d}$ & Maíz, trigo duro y avena no elaborados* \\
\hline & $1250^{d}$ & Otros cereales no elaborados* \\
\hline & $5000^{e}$ & $\begin{array}{l}\text { Piensos complementarios y completos para alimentación } \\
\text { animal }\end{array}$ \\
\hline & $8000^{e}$ & $\begin{array}{l}\text { Cereales y productos a base de cereales (no maíz) para } \\
\text { alimentación animal }\end{array}$ \\
\hline & $10000^{b}$ & Granos y derivados para ganado lechero \\
\hline & $12000^{\mathrm{e}}$ & Subproductos de maíz para alimentación animal \\
\hline & $30000^{b}$ & Granos de destilería y piensos constituidos de gluten \\
\hline \multirow[t]{4}{*}{ Fumonisinas (FB1, FB2, FB3) } & $10000^{b}$ & (B1+B2+B3) Maíz y derivados para ganado lechero \\
\hline & $50000^{e}$ & (B1+B2) Piensos complementarios y completos para \\
\hline & & rumiantes mayores de 4 meses \\
\hline & $60000^{e}$ & (B1+B2) Maíz y productos base maíz para alim. animal \\
\hline \multirow[t]{2}{*}{ Ocratoxina A } & $5^{d}$ & Cereales no elaborados* \\
\hline & $250^{\mathrm{e}}$ & $\begin{array}{l}\text { Cereales y productos a base de cereales para alimentación } \\
\text { animal }\end{array}$ \\
\hline Toxinas HT-2 y T-2 & $500^{f}$ & $\begin{array}{l}\text { (HT-2+T-2) Productos a base de cereales en los piensos y los } \\
\text { piensos compuestos }\end{array}$ \\
\hline \multirow[t]{3}{*}{ Zearalenona } & $500^{\mathrm{e}}$ & Piensos complementarios y completos para ganado lechero \\
\hline & $2000^{\mathrm{e}}$ & $\begin{array}{l}\text { Cereales y productos a base de cereales (no maíz) para } \\
\text { alimentación animal }\end{array}$ \\
\hline & $3000^{\mathrm{e}}$ & Subproductos de maíz para alimentación animal \\
\hline
\end{tabular}

${ }^{*}$ En cursiva, LMs para alimentos para condumo humano. ${ }^{a}$ Directiva CE/32/2002 del Parlamento Europeo; ${ }^{\mathrm{b}} \mathrm{FDA}$ Mycotoxin Regulatory Guidance; ${ }^{c}$ Reg téc. MERCOSUR/ GMC/RES. N²5/02; ${ }^{d}$ Reg. CE/1881/2006 de la Comisión Europea; ${ }^{\mathrm{e}}$ Recomend. CE 576/2006 de la Comisión Europea; ${ }^{\mathrm{f}}$ Recomend. CE/165/2013 de la Comisión Europea 
Como ya se indicó, no se han establecido aún niveles máximos para las micotoxinas emergentes en alimentos. En ese sentido la EFSA se encuentra continuamente solicitando información a instituciones científicas, académicas, de industria y comercio de la Comunidad Europea sobre la ocurrencia de estas micotoxinas en alimentos, con el fin de evaluar el riesgo para el hombre y los animales ocasionado por su exposición a estos contaminantes y el eventual establecimiento de límites máximos.

El establecimiento de límites máximos para la presencia de micotoxinas en alimentos y piensos ha promovido el desarrollo de distintos métodos de extracción y determinación de estos contaminantes. Como se mencionó en el Capítulo 1, estos métodos han virado hacia enfoques multi-residuo o multi-clase apoyados en configuraciones instrumentales altamente selectivas y sensibles basadas en espectrometría de masa. Dado que los métodos multi-residuo presentan la capacidad de cubrir un amplio espectro de compuestos con gran variedad de propiedades físico-químicas, son la opción más razonable cuando se pretenden realizar estudios de monitoreo. En ese sentido, se han propuesto diversos enfoques combinando la extracción QuEChERS con métodos instrumentales UHPLC-MS/MS para la determinación simultánea de micotoxinas y plaguicidas en piensos y matrices relacionadas. Por ejemplo, Lacina y col. (2012) optimizaron un procedimiento basado en QuEChERS para la extracción de 288 plaguicidas y 38 micotoxinas de diferentes tipos de matrices (incluyendo granos de trigo y semillas de algodón) y su determinación por UHPLC-MS/MS (cuadrupolo-trampa de iones), obteniendo recuperaciones aceptables en el rango 70-120\% para la mayoría de los compuestos, excepto para algunos compuestos polares como las fumonisinas, y límites de cuantificación del orden de los $10 \mu \mathrm{g} / \mathrm{kg}$ para los plaguicidas y algunas micotoxinas [193]. Romero-González y col. (2011) emplearon un método QuEChERS para la determinación por UHPLC-MS/MS (triple cuadrupolo) de más de 90 compuestos incluyendo plaguicidas, bioplaguicidas y 7 micotoxinas en cereales como trigo y maíz, extrayendo confiablemente (REC 70-120\%) y con bajos límites de cuantificación (10 $\mu \mathrm{g} / \mathrm{kg}$ ) la mayoría de los compuestos [120]. Dzuman y col. (2015) validaron un método de extracción QUEChERS para la determinación de 323 plaguicidas, 55 micotoxinas y 11 alcaloides vegetales mediante UHPLC-MS/MS (alta resolución, cuadrupolo-orbitrap) en trigo verificando su aptitud en proficiency tests de otros cereales como cebada, maíz y alimentos infantiles [126]. Filigenzi y col. (2011) utilizaron la combinación de una extracción QuEChERS con determinación UHPLC-MS/MS (alta resolución, orbitrap) como método de screening de 118 compuestos entre plaguicidas, micotoxinas y drogas veterinarias en diversas matrices de interés agronómico incluyendo silos de maíz [111]. 


\subsection{OBJETIVO}

El objetivo de este trabajo fue analizar la ocurrencia de micotoxinas en los alimentos consumidos por el ganado lechero en los sistemas de producción de Argentina, específicamente en la cuenca lechera santafesina. Para ese propósito, y con la intención de medir la mayor cantidad posible de micotoxinas, una gran variedad de piensos típicos de origen vegetal fueron analizados, utilizando estrategias analíticas multiclase multi-residuo de amplio alcance basadas en la extracción QuEChERS con determinación por cromatografía líquida acoplada a espectrometría de masa en tándem (UHPLC-MS/MS).

\subsection{MATERIALES Y MÉTODOS}

\subsubsection{Metodología analítica}

\section{Estándares y reactivos}

Se utilizaron estándares analíticos de 57 micotoxinas adquiridos de Sigma-Aldrich (Praga, República Checa) y Biopure (Tulln, Austria). Para el estudio de recuperación se preparó una solución de trabajo conjunta de $1000 \mathrm{ng} / \mathrm{mL}$ de concentración conteniendo todos los analitos, conservada a $-20^{\circ} \mathrm{C}$ en viales color ámbar y traída a temperatura ambiente previo a su uso. Para la preparación de fases móviles cromatográficas se utilizó formiato de amonio $\left(\mathrm{FNH}_{4}\right)$, acetato de amonio $\left(\mathrm{ACNH}_{4}\right)$, ácido fórmico (98\%) de Sigma-Aldrich (Praga, República Checa), metanol $(\mathrm{MeOH})$ marca Merck (Darmstadt, Alemania) y agua deionizada producida por un sistema Milli-Q (Millipore, Bedford, MA, EEUU). Para la extracción de muestras se utilizó sulfato de magnesio anhidro $\left(\mathrm{MgSO}_{4}\right)$, cloruro de sodio $(\mathrm{NaCl})$ y acetonitrilo de grado $\mathrm{HPLC}(\mathrm{MeCN})$ obtenidos de Sigma-Aldrich (Praga, República Checa).

\section{Muestras analizadas}

Las muestras fueron obtenidas por personal entrenado del Instituto Nacional de Tecnología Agropecuaria (INTA, EEA Rafaela) como una de las actividades de sus rutinas oficiales de control siguiendo protocolos de muestreo establecidos en la institución. El conjunto de muestras analizado comprendió diferentes tipos de alimentos concentrados obtenidos en varios tambos distribuidos en la zona de mayor producción lechera de Argentina, en los departamentos Castellanos y Las Colonias de la Provincia de Santa Fe (Figura 16 Cap.2). El muestreo tuvo lugar durante el mes de agosto de 2016 y se seleccionaron 54 muestras que incluyeron: pasturas de alfalfa (4), henos de alfalfa (2), pastura de cebada (1), ensilados de maíz (9) y de sorgo (4), granos de maíz (7) y de trigo (3) triturados, balanceados comerciales (10), raciones totales mezcladas (3), semillas de algodón (4), expellers de soja (3), expeller de girasol (1), burlanda de maíz (2), gluten de trigo (1) y porotos de soja (1). Todos los piensos muestreados se encontraban siendo utilizados para alimentación del ganado al momento del muestreo. Para la preparación para el posterior análisis todas las muestras se secaron en estufas con circulación de aire a $50^{\circ} \mathrm{C}$ hasta peso constante, y luego fueron individualmente trituradas en molino mecánico con malla de $1 \mathrm{~mm}$ de tamaño. Las muestras fueron finalmente empacadas 
en bolsas con cierre hermético y almacenadas en un lugar fresco, seco y al abrigo de la luz hasta el momento del análisis.

Tabla 38. Listado de micotoxinas comprendidas en el alcance analítico. Clasificación según su tipo, familia y relevancia agronómica.

\begin{tabular}{|c|c|c|}
\hline Aflatoxinas & Eniatinas & Misceláneas \\
\hline Aflatoxina B1 (AFB1) & Eniatina $\mathrm{A}(\mathrm{ENA}) \bullet$ & Ácido Ciclopiazónico (CPA) \\
\hline Aflatoxina B2 (AFB2) & Eniatina $\mathrm{A} 1$ (ENA1) • & Ácido Micofenólico (MPA) • \\
\hline Aflatoxina G1 (AFG1) • & Eniatina $\mathrm{B}(\mathrm{ENB})$ & Ácido Penicílico (PenA) \\
\hline Aflatoxina G2 (AFG2) & Eniatina B1 (ENB1) • & Beauvericina (BEA) • \\
\hline Alcaloides del Ergot & Toxinas de Alternaria & Citrinina $(\mathrm{CIT})$ \\
\hline Agroclavina $(A C L)$ & Ácido tenuazónico $(\mathrm{TeA}) \bullet$ & Esterigmatocistina (STE) \\
\hline Ergocornina (E-cor) & Alternariol $(\mathrm{AOH})$ & Gliotoxina (GLIO) \\
\hline ErgocornININA (E-corN) • & Alternariol-metileter (AME) & Meleagrina (MEA) \\
\hline Ergocristina (E-cris) & Tentoxina (TEN) & Ocratoxina A (OTA) • \\
\hline ErgocristININA (E-crisN) • & Tricotecenos & Patulina (PAT) \\
\hline Ergocriptina (E-crip) & 15-acetildeoxinivalenol (15-ADON) & Paxilina (PAX) \\
\hline ErgocriptININA (E-cripN) & 3-acetildeoxinivalenol (3-ADON) • & Penitrem A (PEN-A) \\
\hline Ergometrina (E-met) & Deoxinivalenol (DON) & Phomopsina A (PM-A) \\
\hline Ergosina (E-sin) & DON-3-glucosido (DON-3-GLU) • & Roquefortina C (ROQ-C) \\
\hline ErgosININA (E-sinN) • & Diacetoxiscirpenol (DAS) & Stachybotrylactam (STACH) \\
\hline Ergotamina (E-tam) & Fusarenon X (FUS-X) & Verrucarol (VRL) \\
\hline ErgotamININA (E-tamN) • & Neosolaniol (NEO) & Verruculogen (VRGN) \\
\hline Fumonisinas & Nivalenol (NIV) & Zearalenona $(\mathrm{ZEA}) \bullet \bullet$ \\
\hline Fumonisina B1 (FB1) • & Toxina HT-2 (HT2) • & $\alpha$-zearalenol ( $\alpha$-ZOL) \\
\hline Fumonisina B2 (FB2) • & Toxina $\mathrm{T}-2(\mathrm{~T} 2) \bullet \bullet$ & $\beta$-zearalenol $(\beta$-ZOL) \\
\hline \multicolumn{3}{|l|}{ Fumonisina B3 (FB3)॰॰ } \\
\hline $\begin{array}{l}\text { Relevancia en piensos po } \\
\text { Relevancia toxicológica er } \\
\text { - Micotoxinas emergentes } \\
\text { - Micotoxinas enmascarad }\end{array}$ & $\begin{array}{l}\text { ecuencia de aparición } \\
\text { antes } \\
\text { etabolitos }\end{array}$ & \\
\hline
\end{tabular}

\section{Extracción de las muestras}

La extracción de muestras se realizó siguiendo el procedimiento QuEChERS desarrollado por Dzuman y col. (2014): se pesaron $2 \pm 0,1$ gramos de muestra en tubos de centrífuga de polipropileno de $50 \mathrm{~mL}$ de capacidad y se agregaron $10 \mathrm{~mL}$ de agua acidificada con $2 \%$ de ácido fórmico, dejando las muestras en reposo para su hidratación durante 30 minutos. Luego se agregaron $10 \mathrm{~mL}$ de acetonitrilo y los tubos se Ilevaron a un agitador mecánico (IKA, Staufen, Alemania) durante 30 minutos. Transcurrido el tiempo de extracción se agregaron las sales de partición (4 g de $\mathrm{MgSO}_{4}+1 \mathrm{~g}$ de $\mathrm{NaCl}$ ) y se realizó una agitación manual vigorosa durante 1 minuto, centrifugando posteriormente los tubos durante 5 min a $10000 \mathrm{rpm}$ para lograr la separación de fases. Finalmente, por medio de una pipeta pasteur se transfirieron alícuotas de la fase superior de acetonitrilo a viales de $2 \mathrm{~mL}$ de capacidad para su inyección en el sistema cromatográfico. 


\section{Ensayo de recuperación y curva de calibración}

La eficiencia de extracción del procedimiento QuEChERS empleado se verificó mediante un ensayo de recuperación adicionando con una solución estándar de todas las micotoxinas una muestra de brotes de cebada cuya aptitud como blanco analítico había sido previamente evaluada. El nivel de concentración adicionado fue de $500 \mu \mathrm{g} / \mathrm{kg}$, que representó una concentración final de $100 \mathrm{ng} / \mathrm{mL}$ en el extracto de inyección. Antes de proceder con la extracción, la muestra adicionada se dejó en reposo durante 30 minutos para la evaporación del solvente y para permitir la distribución e incorporación de los analitos a la matriz. Para calcular los porcentajes de recuperación de las micotoxinas y la concentración en las muestras analizadas se empleó una curva de calibrado matrix-matched (utilizando extracto blanco como medio de dilución) en los niveles de concentración $500,200,100,50,20,10,5,2,1,0,5,0,2$ y 0,1 ng/mL. El amplio rango de niveles utilizado en la calibración permitió realizar una estimación del límite de cuantificación instrumental de las micotoxinas en el análisis de las muestras.

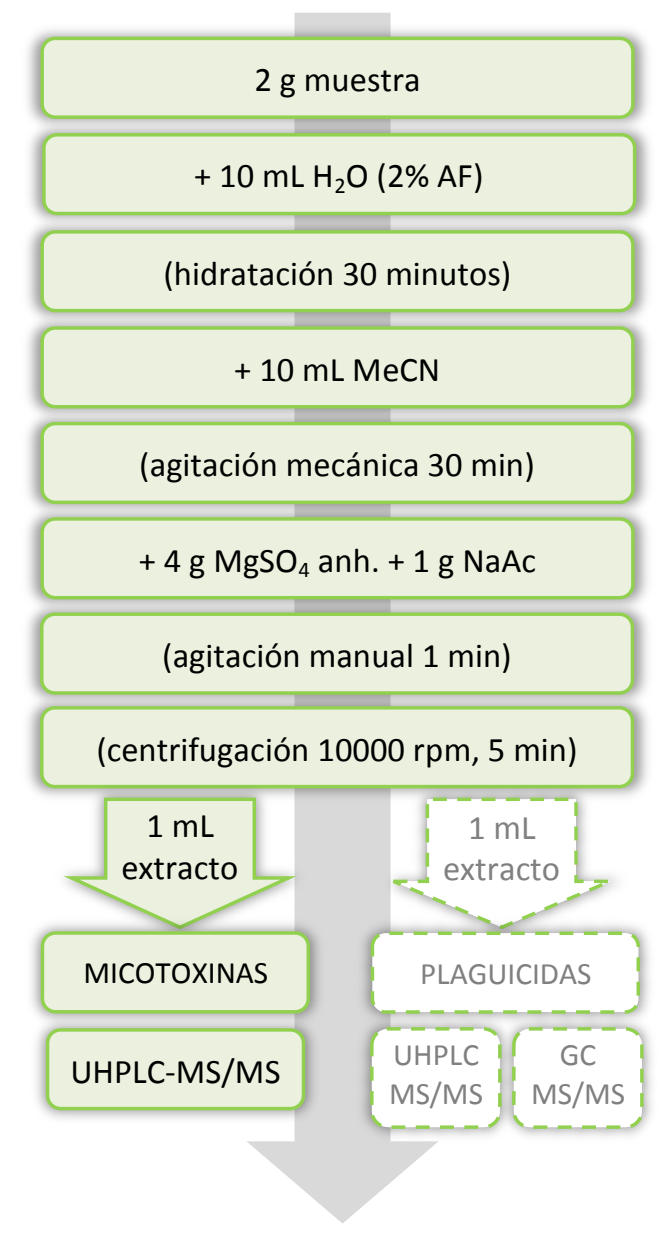

Figura 39. Esquema de extracción utilizado para la determinación de residuos y contaminantes.

\section{Condiciones instrumentales de análisis}

La separación cromatográfica de las micotoxinas determinadas se realizó utilizando un cromatógrafo líquido de ultra alta resolución ACQUITY UPLC ${ }^{\circledR}$ (Waters, Miliford, MA, EEUU) equipado con una columna 
analítica Kinetex ${ }^{\mathrm{TM}}$ C18 de dimensiones $100 \mathrm{~mm}$ x 2,1 mm y tamaño de partícula 2,6 $\mu \mathrm{m}$ (Phenomenex, EEUU) a una temperatura de $40^{\circ} \mathrm{C}$. La determinación de micotoxinas en los modos de ionización positiva (ESI+) y negativa (ESI-) se realizó en corridas separadas y con fases móviles de composición y los gradientes de elución diferentes. En modo ESI+, la fase móvil se compuso por una solución de $5 \mathrm{mM}$ de formiato de amonio en agua con $0,2 \%$ de ácido fórmico (solvente $\mathrm{A} 1$ ) y otra de metanol con $0,2 \%$ de ácido fórmico (solvente B1). El programa de gradiente comenzó con una composición de 10\% (v/v) de B1 a un caudal de 0,25 mL/min, seguido por un cambio de composición lineal hasta 50\% B1 durante 1 minuto. Luego, la composición de B1 se incrementó hasta 100\% durante 7 minutos con un simultáneo aumento del caudal a $0,5 \mathrm{~mL} / \mathrm{min}$, manteniendo esas condiciones durante 2 minutos adicionales para el lavado de la columna antes de regresar a la composición y caudal iniciales del programa. En modo ESI-, por otro lado, la fase móvil se compuso por una solución de $5 \mathrm{mM}$ de acetato de amonio en agua (solvente A2) y de metanol puro como (solvente B2). Las condiciones iniciales del gradiente fueron $10 \%$ (B2) a caudal $0,3 \mathrm{~mL} / \mathrm{min}$, incremento lineal de la composición hasta 100\% B2 durante 6,5 min con un simultáneo aumento de la velocidad de flujo hasta $0,5 \mathrm{~mL} / \mathrm{min}$. La columna se mantuvo en esas condiciones durante 2 minutos para su lavado y durante 2 minutos adicionales se retomaron las condiciones iniciales del programa de elución.

El sistema cromatográfico se acopló a un espectrómetro de masa cuadrupolo/trampa de iones QTRAP ${ }^{\circledR}$ 5500 (AB SCIEX, Toronto, ON, Canadá) equipado con una fuente de ionización por electrospray (ESI) operada en modos positivo y negativo. Los parámetros operativos de la fuente de iones en modo ESI+ fueron los siguientes: voltaje de aguja, $4,5 \mathrm{kV}$; gas cortina, $35 \mathrm{psi}$; temperatura de fuente, $600^{\circ} \mathrm{C}$; gas nebulizador (gas 1) y gas turbo (gas 2), 55 psi. En modo ESI- los parámetros operativos fueron los siguientes: voltaje de aguja, $-4,5 \mathrm{kV}$; gas cortina, $35 \mathrm{psi}$; temperatura de fuente $500^{\circ} \mathrm{C}$, gas nebulizador (gas 19 y gas turbo (gas 2), 55 psi. Para el análisis de las transiciones de todos los analitos el instrumento se operó en modo multiple reaction monitoring (MRM, monitoreo de reacciones múltiples) analizando dos transiciones para cada compuesto, una de cuantificación $(Q)$ y la otra de confirmación (q) (Tabla 39). Los parámetros como el potencial de declustering (DP), la energía de colisión (CE) y el potencial de salida de la celda de colisión (CXP) para el análisis de esas transiciones habían sido ya optimizados individualmente para cada compuesto mediante infusión directa de soluciones estándar de micotoxinas [123].

Tabla 39. Parámetros de ionización y detección instrumental utilizados en la determinación de las 57 micotoxinas en piensos por UHPLC-MS/MS.

\begin{tabular}{|c|c|c|c|c|c|c|}
\hline \multirow{2}{*}{ Micotoxina } & \multirow{2}{*}{$\begin{array}{l}t_{R}{ }^{a} \\
(\min )\end{array}$} & \multicolumn{2}{|c|}{ Iones analizados $(\mathrm{m} / \mathrm{z})$} & \multirow{2}{*}{$\begin{array}{l}D P^{b} \\
(V)\end{array}$} & \multirow{2}{*}{$\begin{array}{l}\mathrm{CE}^{\mathrm{C}} \\
(\mathrm{V})\end{array}$} & \multirow{2}{*}{$\begin{array}{l}\operatorname{CXP}^{d} \\
(V)\end{array}$} \\
\hline & & Precursor & Productos $Q$ / $q$ & & & \\
\hline 15-A-DON & 2,40 & $356,1\left[\mathrm{M}+\mathrm{NH}_{4}\right]^{+}$ & $321,0 / 137,1$ & 46 & $17 / 21$ & $32 / 18$ \\
\hline 3-A-DON & 2,15 & $397,1\left[\mathrm{M}+\mathrm{CH}_{3} \mathrm{COO}\right]^{-}$ & 336,9 / 306,9 & -55 & $-12 /-20$ & $-17 /-17$ \\
\hline A. Ciclopiazonico & 6,28 & $355,0\left[\mathrm{M}+\mathrm{NH}_{4}\right]^{+}$ & $267,1 / 154,3$ & 201 & $29 / 32$ & $12 / 10$ \\
\hline A. Micofenolico & 5,06 & $321,0\left[\mathrm{M}+\mathrm{NH}_{4}\right]^{+}$ & $207,0 / 159,0$ & 71 & $13 / 19$ & $12 / 14$ \\
\hline A. Penicillico & 2,14 & $171,1[\mathrm{M}+\mathrm{H}]^{+}$ & $153,1 / 125,0$ & 60 & $13 / 17$ & $10 / 8$ \\
\hline A. Tenuazonico & 3,50 & $198,1[\mathrm{M}+\mathrm{H}]^{+}$ & $153,3 / 125,1$ & 66 & $19 / 23$ & $10 / 8$ \\
\hline Aflatoxina B1 & 3,06 & $313,0[\mathrm{M}+\mathrm{H}]^{+}$ & $285,0 / 241,0$ & 136 & $33 / 51$ & $20 / 20$ \\
\hline
\end{tabular}




\begin{tabular}{|c|c|c|c|c|c|c|}
\hline \multirow{2}{*}{ Micotoxina } & \multirow{2}{*}{$\begin{array}{l}t_{R}{ }^{a} \\
(\min )\end{array}$} & \multicolumn{2}{|c|}{ Iones analizados $(\mathrm{m} / \mathrm{z})$} & \multirow{2}{*}{$\begin{array}{l}\mathrm{DP}^{\mathrm{b}} \\
(\mathrm{V})\end{array}$} & \multirow{2}{*}{$\begin{array}{l}C^{c}{ }^{c} \\
(V)\end{array}$} & \multirow{2}{*}{$\begin{array}{l}\operatorname{CXP}^{d} \\
(V)\end{array}$} \\
\hline & & Precursor & Productos $Q / q$ & & & \\
\hline Aflatoxina B2 & 2,85 & $315,0[\mathrm{M}+\mathrm{H}]^{+}$ & $287,1 / 259,0$ & 141 & $37 / 41$ & $20 / 24$ \\
\hline Aflatoxina G1 & 2,65 & $329,0[\mathrm{M}+\mathrm{H}]^{+}$ & $243,0 / 200,0$ & 138 & $34 / 51$ & $20 / 18$ \\
\hline Aflatoxina G2 & 2,51 & $331,1[\mathrm{M}+\mathrm{H}]^{+}$ & $313,0 / 189,0$ & 136 & $35 / 57$ & $18 / 12$ \\
\hline Agroclavina & 2,16 & $239,0[\mathrm{M}+\mathrm{H}]^{+}$ & $168,0 / 183,0$ & 71 & $47 / 27$ & $8 / 18$ \\
\hline Alternariol & 3,36 & $257,0[\mathrm{M}-\mathrm{H}]^{-}$ & $214,9 / 213,0$ & -130 & $-34 /-31$ & $-13 /-11$ \\
\hline Alternariol-metileter & 4,76 & $271,0[\mathrm{M}-\mathrm{H}]^{-}$ & $255,9 / 228,0$ & -176 & $-71 /-63$ & $-14 /-14$ \\
\hline Beauvericina & 7,19 & $801,3\left[\mathrm{M}+\mathrm{NH}_{4}\right]^{+}$ & $784,1 / 262,2$ & 116 & $27 / 43$ & $28 / 8$ \\
\hline Citrinina & 3,43 & $251,1[\mathrm{M}+\mathrm{H}]^{+}$ & $233,1 / 205,1$ & 96 & $23 / 37$ & $24 / 24$ \\
\hline Deoxinivalenol (DON) & 1,71 & $355,1\left[\mathrm{M}+\mathrm{CH}_{3} \mathrm{COO}\right]^{-}$ & $295,1 / 265,1$ & -45 & $-14 /-20$ & $-15 /-15$ \\
\hline Diacetoxiscirpenol & 3,18 & $384,0\left[\mathrm{M}+\mathrm{NH}_{4}\right]^{+}$ & 307,2 / 105,0 & 66 & $15 / 63$ & $16 / 12$ \\
\hline DON-3-glucosido & 1,65 & $517,1\left[\mathrm{M}+\mathrm{CH}_{3} \mathrm{COO}\right]^{-}$ & 456,9 / 426,9 & -60 & $-20 /-28$ & $-23 /-11$ \\
\hline Eniatina $\mathrm{A}$ & 7,39 & $699,3\left[\mathrm{M}+\mathrm{NH}_{4}\right]^{+}$ & 228,2 / 210,1 & 76 & $59 / 35$ & $16 / 14$ \\
\hline Eniatina A1 & 7,27 & $685,3\left[\mathrm{M}+\mathrm{NH}_{4}\right]^{+}$ & $214,1 / 210,1$ & 66 & $59 / 37$ & $10 / 8$ \\
\hline Eniatina B & 7,03 & $657,3\left[\mathrm{M}+\mathrm{NH}_{4}\right]^{+}$ & 213,9 / 196,1 & 51 & $59 / 39$ & $20 / 4$ \\
\hline Eniatina B1 & 7,15 & $671,2\left[\mathrm{M}+\mathrm{NH}_{4}\right]^{+}$ & $228,1 / 214,1$ & 66 & $57 / 61$ & $12 / 11$ \\
\hline Ergocornina & 2,95 & $562,1[\mathrm{M}+\mathrm{H}]^{+}$ & $223,2 / 268,2$ & 86 & $57 / 39$ & $10 / 12$ \\
\hline ErgocornININA & 3,62 & $562,1[\mathrm{M}+\mathrm{H}]^{+}$ & $223,2 / 268,2$ & 86 & $57 / 39$ & $10 / 12$ \\
\hline Ergocriptina & 3,46 & $576,1[\mathrm{M}+\mathrm{H}]^{+}$ & $223,1 / 268,1$ & 86 & $37 / 49$ & $8 / 10$ \\
\hline Ergocristina & 3,53 & $610,1[\mathrm{M}+\mathrm{H}]^{+}$ & $223,1 / 208,1$ & 86 & $57 / 75$ & $10 / 10$ \\
\hline ErgocristININA & 4,30 & $610,1[\mathrm{M}+\mathrm{H}]^{+}$ & $223,1 / 208,1$ & 86 & $57 / 75$ & $10 / 10$ \\
\hline ErgocrptININA & 4,16 & $576,1[\mathrm{M}+\mathrm{H}]^{+}$ & $223,1 / 268,1$ & 86 & $37 / 49$ & $8 / 10$ \\
\hline Ergometrina & 1,85 & $326,0[\mathrm{M}+\mathrm{H}]^{+}$ & $223,0 / 207,0$ & 131 & $33 / 33$ & $26 / 26$ \\
\hline Ergosina & 2,73 & $548,1[\mathrm{M}+\mathrm{H}]^{+}$ & $223,1 / 208,0$ & 86 & $65 / 67$ & $10 / 8$ \\
\hline ErgosININA & 2,78 & $548,1[\mathrm{M}+\mathrm{H}]^{+}$ & $223,1 / 208,0$ & 86 & $65 / 67$ & $10 / 8$ \\
\hline Ergotamina & 2,87 & $582,0[\mathrm{M}+\mathrm{H}]^{+}$ & $223,0 / 208,0$ & 116 & $59 / 47$ & $20 / 10$ \\
\hline ErgotamININA & 2,92 & $582,0[\mathrm{M}+\mathrm{H}]^{+}$ & $223,0 / 208,0$ & 116 & $59 / 47$ & $20 / 10$ \\
\hline Esterigmatocistina & 5,92 & $325,0[\mathrm{M}+\mathrm{H}]^{+}$ & $310,0 / 281,0$ & 106 & $35 / 51$ & $20 / 18$ \\
\hline Fumonisina B1 & 5,05 & $722,4[\mathrm{M}+\mathrm{H}]^{+}$ & $352,3 / 334,3$ & 165 & $49 / 55$ & $26 / 20$ \\
\hline Fumonisina B2 & 5,88 & $706,4[\mathrm{M}+\mathrm{H}]^{+}$ & 336,2 / 318,3 & 165 & $53 / 53$ & $16 / 18$ \\
\hline Fumonisina B3 & 5,62 & $706,4[\mathrm{M}+\mathrm{H}]^{+}$ & 336,2 / 318,3 & 165 & $53 / 53$ & $16 / 18$ \\
\hline Fusarenon X & 1,88 & $413,1\left[\mathrm{M}+\mathrm{CH}_{3} \mathrm{COO}\right]^{-}$ & $353,1 / 263,0$ & -50 & $-14 /-20$ & $-17 /-17$ \\
\hline Gliotoxina & 3,12 & $327,0[\mathrm{M}+\mathrm{H}]^{+}$ & $245,0 / 263,0$ & 121 & $17 / 15$ & $16 / 12$ \\
\hline Meleagrina & 2,97 & $415,0[\mathrm{M}+\mathrm{H}]^{+}$ & $403,0 / 261,0$ & 61 & $23 / 55$ & $30 / 10$ \\
\hline Neosolaniol & 2,14 & $400,0\left[\mathrm{M}+\mathrm{NH}_{4}\right]^{+}$ & $305,1 / 185,1$ & 66 & $17 / 23$ & $36 / 24$ \\
\hline Nivalenol & 1,49 & $402,0\left[\mathrm{M}+\mathrm{CH}_{3} \mathrm{COO}\right]^{-}$ & $311,1 / 281$ & -50 & $-14 /-20$ & $-15 /-17$ \\
\hline Ocratoxin A & 5,84 & $404,0[\mathrm{M}+\mathrm{H}]^{+}$ & $239,0 / 102,0$ & 91 & $97 / 35$ & $22 / 12$ \\
\hline Patulina & 1,46 & $213,0\left[\mathrm{M}+\mathrm{CH}_{3} \mathrm{COO}\right]^{-}$ & $152,9 / 109,0$ & -30 & $-8 /-16$ & $-11 /-5$ \\
\hline Paxillin & 6,69 & $436,0[\mathrm{M}+\mathrm{H}]^{+}$ & $182,0 / 167,0$ & 71 & $47 / 89$ & $10 / 10$ \\
\hline Penitrem A & 6,69 & $635,1[\mathrm{M}+\mathrm{H}]^{+}$ & 616,2 / 558,2 & 111 & $19 / 27$ & $26 / 24$ \\
\hline Phomopsin A & 2,30 & $790,1[\mathrm{M}+\mathrm{H}]^{+}$ & $226,0 / 162,0$ & 46 & $47 / 115$ & $14 / 12$ \\
\hline Roquefortina C & 3,92 & $390,1[\mathrm{M}+\mathrm{H}]^{+}$ & $322,1 / 193,0$ & 60 & $27 / 37$ & $14 / 2$ \\
\hline Stachybotrylactam & 6,32 & $387,0[\mathrm{M}+\mathrm{H}]^{+}$ & 178,0 / 179,1 & 1 & $47 / 49$ & $10 / 8$ \\
\hline Tentoxina & 4,80 & $415,0[\mathrm{M}+\mathrm{H}]^{+}$ & 312,0 / 256,0 & 156 & $29 / 43$ & $54 / 10$ \\
\hline Toxina HT-2 & 4,37 & $442,2\left[\mathrm{M}+\mathrm{NH}_{4}\right]^{+}$ & $263,0 / 215,1$ & 61 & $17 / 19$ & $30 / 28$ \\
\hline Toxina T-2 & 5,38 & $484,2\left[\mathrm{M}+\mathrm{NH}_{4}\right]^{+}$ & $305,2 / 215,1$ & 76 & $19 / 25$ & $20 / 26$ \\
\hline Verrucarol & 2,28 & $267,1[\mathrm{M}+\mathrm{H}]^{+}$ & $249,1 / 231,2$ & 60 & $11 / 13$ & $4 / 10$ \\
\hline Verruculogen & 6,23 & $512,1[\mathrm{M}+\mathrm{H}]^{+}$ & $494,1 / 352,1$ & 41 & $11 / 23$ & $6 / 6$ \\
\hline Zearalenona & 4,37 & $317,1[\mathrm{M}-\mathrm{H}]^{-}$ & $175,1 / 131,0$ & -85 & $-10 /-10$ & $-11 /-9$ \\
\hline
\end{tabular}




\begin{tabular}{lllllll}
\hline \multirow{2}{*}{ Micotoxina } & $t_{\mathrm{R}}{ }^{\mathrm{a}}$ & \multicolumn{2}{c}{ lones analizados $(\mathrm{m} / \mathrm{z})$} & $\mathrm{DP}^{\mathrm{b}}$ & $\mathrm{CE}^{\mathrm{c}}$ & $\mathrm{CXP}^{\mathrm{d}}$ \\
\cline { 3 - 4 } & $(\mathrm{min})$ & Precursor & Productos $Q / q$ & $(\mathrm{~V})$ & $(\mathrm{V})$ & $(\mathrm{V})$ \\
\hline$\alpha$-zearalenol & 4,20 & $319,1[\mathrm{M}-\mathrm{H}]^{-}$ & $275,0 / 174,0$ & -110 & $-30 /-36$ & $-5 /-9$ \\
$\beta$-zearalenol & 3,67 & $319,1[\mathrm{M}-\mathrm{H}]^{-}$ & $275,0 / 174,0$ & -110 & $-30 /-37$ & $-5 /-9$ \\
\hline
\end{tabular}

$\mathrm{t}_{\mathrm{R}}$ : tiempo de retención; DP: declustering potential; $\mathrm{CE}$ : collision energy; CXP: collision cell exit potential. Adaptado de Dzuman et al. (2014)

\subsection{RESULTADOS Y DISCUSIÓN}

Como se ha mencionado, el objetivo en esta etapa del trabajo de tesis fue realizar un amplio relevamiento sobre la presencia de micotoxinas en los diversos alimentos en los que se basan las dietas del ganado lechero en la zona de estudio, para lo cual se analizaron un total de 57 micotoxinas de 6 clases distintas (aflatoxinas, fumonisinas, alcaloides del ergot, toxinas de alternaria, eniatinas, tricotecenos) junto con un grupo de diversas micotoxinas de importancia agronómico como zearalenona. Entre los compuestos analizados se incluyeron micotoxinas relevantes desde el punto de visita de los alimentos para ganado por su elevada frecuencia de aparición y de su toxicidad en rumiantes, así como también micotoxinas emergentes, conjugadas y metabolitos.

\subsubsection{Evaluación de la recuperación del método y estimación de los límites de cuantificación}

Si bien para la extracción de las micotoxinas se utilizó una metodología QuEChERS previamente optimizada y validada, al momento de analizar las muestras se verificó la performance del método mediante un ensayo de recuperación. Sobre una muestra de brotes de cebada triturada y seca, que se seleccionó entre un conjunto de otros piensos analizados en un ensayo previo para verificar su aptitud como blanco analítico, se realizó la adición de un mix de estándar de 57 micotoxinas y metabolitos en el nivel $500 \mu \mathrm{g} / \mathrm{kg}$, implicando una concentración de $100 \mathrm{ng} / \mathrm{mL}$ al momento de la inyección. Para realizar los cálculos de recuperación (\%REC) se utilizó una curva de calibración matrix-matched en los niveles descriptos anteriormente e inyectada en la misma secuencia. Como resultado se obtuvo que el $88 \%$ de los compuestos dio valores de recuperación media aceptable dentro del rango $60-98 \%$, mientras que el 12\% restante obtuvo recuperaciones medias por debajo del 60\% (Figura 40). Entre estos últimos se encontraron nivalenol, paxilina, DON-3-glucósido, alternariol, ácido ciclopiazónico, verrucarol, 3-ADON y 15-ADON, siendo la recuperación más baja la del NIV en un 30\%. Estas bajas recuperaciones pueden deberse al carácter altamente polar de estos compuestos que los hace permanecer preferentemente en la fase acuosa y no particionar hacia la fase acetonitrilo. Es notable, en igual sentido, cómo los grupos polares acetilo y glucósido de DON-3-Glu, 3-ADON y 15-ADON hacen que estas micotoxinas evidencien un comportamiento diferenciado en la extracción respecto a la molécula "padre" de DON. El valor de referencia de 60\% para la evaluación de la extracción se eligió debido que la Unión Europea establece ese nivel de recuperación mínima entre los criterios de funcionamiento que debe tener un método analítico para la determinación de 
algunas micotoxinas tales como DON, ZEA, FB1 y FB1, toxina HT-2 y toxina T-2 para niveles de concentración entre 50 y 500 mg/kg [263].

\% Recuperación

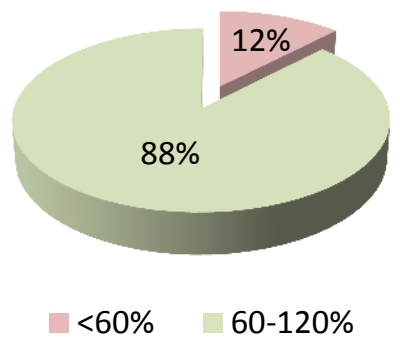

Límites de cuantificación

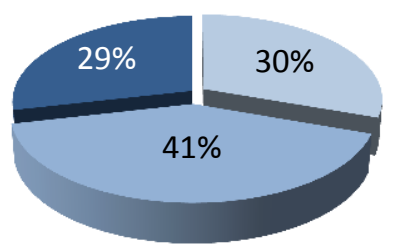

$\square 5 \mu \mathrm{g} / \mathrm{kg} \square 10-25 \mu \mathrm{g} / \mathrm{kg} \square 50-500 \mu \mathrm{g} / \mathrm{kg}$

Figura 40. Distribución porcentual del comportamiento analítico de las micotoxinas analizadas ( $n=57)$.

En líneas generales, además, los valores de recuperación obtenidos en el ensayo realizado se condicen con aquellos obtenidos en la validación del método (Tabla 4).

Tabla 40. Comparación de parámetros de performance entre los ensayos de validación y verificación del método QuEChERS utilizado para determinar micotoxinas en piensos.

\begin{tabular}{|c|c|c|c|c|c|c|}
\hline \multirow[t]{2}{*}{ Micotoxina } & \multicolumn{3}{|c|}{$\begin{array}{l}\text { Validación (cereal) } \\
500 \mu \mathrm{g} / \mathrm{kg}(\mathrm{n}=6)\end{array}$} & \multicolumn{3}{|c|}{$\begin{array}{l}\text { Verificación (brotes de cebada) } \\
500 \mu \mathrm{g} / \mathrm{kg}(\mathrm{n}=5)\end{array}$} \\
\hline & \%REC & RSD & $\mathrm{LC}^{\mathrm{a}}(\mu \mathrm{g} / \mathrm{kg})$ & \%REC & RSD & $\mathrm{LC}^{\mathrm{b}}(\mu \mathrm{g} / \mathrm{kg})$ \\
\hline 15-acetildeoxinivalenol & $76-91$ & 8 & 50 & $37-56$ & 14 & 250 \\
\hline 3-acetildeoxinivalenol & $94-99$ & 2 & 25 & $39-55$ & 12 & 50 \\
\hline Ácido Ciclopiazonico & $70-85$ & 8 & 1000 & $51-65$ & 9 & 5 \\
\hline Ácido Micofenolico & $71-78$ & 4 & 5 & $62-78$ & 9 & 10 \\
\hline Ácido Penicillico & $73-92$ & 5 & 50 & $60-76$ & 10 & 100 \\
\hline Ácido Tenuazónico & $71-79$ & 5 & 1000 & $73-50$ & 6 & 100 \\
\hline Aflatoxina B1 & $71-87$ & 9 & 1 & $62-77$ & 9 & 2,5 \\
\hline Aflatoxina B2 & $75-77$ & 1 & 1 & $63-79$ & 9 & 2,5 \\
\hline Aflatoxina G1 & $76-84$ & 4 & 1 & $67-79$ & 7 & 5 \\
\hline Aflatoxina G2 & $76-85$ & 5 & 1 & $61-70$ & 7 & 25 \\
\hline Agroclavina & $72-81$ & 5 & 5 & $74-92$ & 9 & 10 \\
\hline Alternariol & $95-100$ & 2 & 1 & $53-65$ & 8 & 25 \\
\hline Alternariol-metileter & $90-97$ & 3 & 1 & $58-74$ & 9 & 5 \\
\hline Beauvericina & $75-88$ & 6 & 2 & $64-81$ & 11 & 10 \\
\hline Citrinina & $109-112$ & 1 & 50 & $55-69$ & 9 & 25 \\
\hline Deoxinivalenol (DON) & $87-96$ & 3 & 50 & $62-85$ & 11 & 100 \\
\hline Diacetoxiscirpenol & $73-95$ & 11 & 10 & $52-70$ & 13 & 25 \\
\hline DON-3-glucósido & $41-50$ & 7 & 50 & $16-104$ & 76 & 100 \\
\hline Eniatina $\mathrm{A}$ & $79-86$ & 4 & 1 & $81-96$ & 7 & 2,5 \\
\hline Eniatina A1 & $81-89$ & 4 & 1 & 81-103 & 9 & 5 \\
\hline Eniatina B & $76-90$ & 7 & 1 & $69-84$ & 8 & 50 \\
\hline Eniatina B1 & $73-92$ & 9 & 1 & $74-87$ & 7 & 10 \\
\hline Ergocornina & $76-92$ & 9 & 25 & $68-77$ & 5 & 2,5 \\
\hline ErgocornININA & $75-93$ & 9 & 25 & $71-88$ & 10 & 5 \\
\hline Ergocriptina & $73-75$ & 1 & 25 & $69-87$ & 10 & 5 \\
\hline ErgocriptININA & $73-78$ & 3 & 25 & $74-84$ & 5 & 5 \\
\hline Ergocristina & $73-96$ & 11 & 25 & $70-85$ & 8 & 5 \\
\hline ErgocristININA & $75-102$ & 12 & 25 & 87-102 & 7 & 2,5 \\
\hline Ergometrina & $80-85$ & 2 & 5 & $55-77$ & 13 & 25 \\
\hline Ergosina & $72-82$ & 6 & 25 & $69-81$ & 7 & 2,5 \\
\hline
\end{tabular}




\begin{tabular}{|c|c|c|c|c|c|c|}
\hline \multirow[t]{2}{*}{ Micotoxina } & \multicolumn{3}{|c|}{$\begin{array}{l}\text { Validación (cereal) } \\
500 \mu \mathrm{g} / \mathrm{kg}(\mathrm{n}=6)\end{array}$} & \multicolumn{3}{|c|}{$\begin{array}{l}\text { Verificación (brotes de cebada) } \\
500 \mu \mathrm{g} / \mathrm{kg}(\mathrm{n}=5)\end{array}$} \\
\hline & \%REC & RSD & $\mathrm{LC}^{\mathrm{a}}(\mu \mathrm{g} / \mathrm{kg})$ & \%REC & RSD & $\mathrm{LC}^{\mathrm{b}}(\mu \mathrm{g} / \mathrm{kg})$ \\
\hline ErgosinININA & $75-80$ & 3 & 25 & $65-90$ & 13 & 25 \\
\hline Ergotamina & $89-93$ & 2 & 25 & $73-80$ & 8 & 25 \\
\hline ErgotamININA & $77-86$ & 5 & 25 & $74-89$ & 8 & 10 \\
\hline Esterigmatocistina & $70-78$ & 5 & 5 & $61-76$ & 9 & 0,5 \\
\hline Fumonisina B1 & $84-91$ & 3 & 100 & $77-96$ & 8 & 25 \\
\hline Fumonisina B2 & $87-91$ & 2 & 100 & $73-84$ & 6 & 100 \\
\hline Fumonisina B3 & $70-77$ & 5 & 100 & $79-98$ & 8 & 25 \\
\hline Fusarenon-X & $76-87$ & 4 & 100 & $80-92$ & 14 & 500 \\
\hline Gliotoxina & $71-79$ & 4 & 100 & $47-79$ & 20 & 100 \\
\hline Meleagrina & $81-83$ & 1 & 5 & $53-69$ & 10 & 1 \\
\hline Neosolaniol & $87-93$ & 3 & 25 & $65-87$ & 11 & 25 \\
\hline Nivalenol & $70-78$ & 4 & 100 & $20-39$ & 28 & 500 \\
\hline Ocratoxina A & $81-99$ & 8 & 2 & $64-83$ & 9 & 10 \\
\hline Patulina & $71-75$ & 2 & 100 & $60-75$ & 9 & 250 \\
\hline Paxillina & $100-109$ & 4 & 25 & $52-63$ & 7 & 25 \\
\hline Penitrem A & $71-71$ & 1 & 50 & $65-82$ & 9 & 10 \\
\hline Phomopsina A & $70-71$ & 1 & 2000 & $69-95$ & 13 & 100 \\
\hline Roquefortina C & $82-92$ & 5 & 5 & $54-70$ & 10 & 10 \\
\hline Stachybotrylactam & $75-93$ & 9 & 100 & $47-79$ & 18 & 50 \\
\hline Tentoxina & $82-97$ & 7 & 10 & $58-65$ & 5 & 5 \\
\hline Toxina HT-2 & $88-96$ & 4 & 25 & $68-76$ & 5 & 25 \\
\hline Toxina T-2 & $83-99$ & 8 & 5 & $65-79$ & 8 & 10 \\
\hline Verrucarol & $87-99$ & 6 & 500 & NR & NR & ND \\
\hline Verruculogen & $81-96$ & 7 & 100 & $67-92$ & 13 & 500 \\
\hline Zearalenona & $98-106$ & 3 & 1 & $63-89$ & 13 & 50 \\
\hline$\alpha$-zearalenol & $100-105$ & 3 & 5 & $64-73$ & 6 & 10 \\
\hline$\beta$-zearalenol & $94-97$ & 1 & 5 & $65-84$ & 10 & 25 \\
\hline
\end{tabular}

\%REC: \% de recuperación; RSD: desviación estándar relativa; LC: límite de cuantificación; NR: no recuperó; ND: no deteminado; ${ }^{\mathrm{a}}$ Calculado en la validación del método; ${ }^{\mathrm{b}}$ Estimado en el ensayo de verificación.

Lo mismo puede apreciarse en la Tabla 40 respecto a los límites de cuantificación de las micotoxinas en el ensayo realizado, aunque en este caso los LC se estimaron a partir del menor nivel de calibración en matriz detectado para cada compuesto, afectado por la dilución del método QuEChERS. Considerando los elevados límites máximos establecidos por las distintas regulaciones para micotoxinas en piensos destinados a la alimentación animal (Tabla 37), la aptitud del método empleado se ve reflejada en el hecho de que el $71 \%$ de los compuestos determinados presentaron límites de cuantificación por debajo de 25 $\mu \mathrm{g} / \mathrm{kg}$, y casi la mitad de ellos límites por debajo de $5 \mu \mathrm{g} / \mathrm{kg}$ que es el nivel regulado más bajo para aflatoxina B1 en piensos completos para ganado lechero (Figura 40).

\subsubsection{Micotoxinas halladas en muestras similares de Argentina}

Como se mencionó antes, del universo de más de $\mathbf{3 0 0}$ micotoxinas conocidas en la actualidad son pocas las estudiadas con más dedicación y que son relevantes en piensos para ganado. Entre éstas se encuentran las alfatoxinas, ocratoxina A, fumonisinas, zearalenona y algunos tricotecenos (toxinas T-2 y HT-2, deoxinivalenol), y son las que tanto en nuestro país como en otros se han estudiado y encontrado más 
frecuentemente en distintas materias primas utilizadas para la alimentación animal. Más aún, son las micotoxinas para las cuales existen límites máximos establecidos para este tipo de productos (Tabla 37). La mayor frecuencia de aparición de esas micotoxinas se ha reportado en Argentina en distintos ingredientes que componen la dieta del ganado lechero, similares a los analizados en este estudio. Amigot y col. (2009) analizaron AFs totales y DON mediante enzimo inmuno ensayos (ELISA) en 147 muestras de distintos tipos de silos (maíz, sorgo y alfalfa) de la zona de Rafaela (Dpto. Castellanos, Prov. de Santa Fe) y evidenciaron contaminación con micotoxinas en el $65 \%$ de los silos de maíz, el $24 \%$ de los silos de sorgo y en el 63\% de los silos de alfalfa, siendo las concentraciones promedio de AFs de 7,2 $\mu \mathrm{g} / \mathrm{kg}$ y de DON 365 mg/kg [264]. González Pereyra y col. (2008) analizaron AFB1, ZEA, DON y FB1 en silos de maíz de las provincias de San Luis y Córdoba mediante técnicas instrumentales y enzimáticas. Los niveles hallados de ZEA, DON y FB1 promediaron 18, 150 y $600 \mu \mathrm{g} / \mathrm{kg}$, respectivamente, mientras que no detectaron AFB1 en ninguna de las muestras en etapa de pre-fermentación [265]. El mismo autor reportó en 2012 la presencia de AFB1 y DON en el $43 \%$ y 33\%, respectivamente, de un total de 15 muestras de TMRs no detectándose en ese caso ZEA ni FB1 [266]. Signorini y col. (2012) reportaron alta frecuencia de contaminación por AFB1, DON y ZEA en 843 muestras de diversos alimentos para ganado lechero (pasturas frescas, silos, henos, alimentos concentrados, semillas de algodón, entre otros) de la provincia de Santa Fe, analizadas mediante método ELISA con ocurrencias del 79, 75 y 40\% para AFB1, ZEA y DON, respectivamente [156]. En igual sentido que nuestro trabajo respecto al amplio espectro de compuestos determinados y al buen alcance metodológico empleando LC-MS/MS, pero analizando tipos de muestras distintos (pastos naturales para pastoreo), Nichea y col. (2015) hallaron, por ejemplo, alta ocurrencia de toxinas T-2 y HT-2 (niveles de hasta $5000 \mu \mathrm{g} / \mathrm{kg}$ cada una), ZEA (hasta $2000 \mu \mathrm{g} / \mathrm{kg}$ ) y AOH (hasta $1000 \mu \mathrm{g} / \mathrm{kg}$ ), entre un total de 77 micotoxinas distintas en 174 muestras analizadas. En el mismo trabajo reportan, además, alta frecuencia de aparición de otras micotoxinas emergentes menos estudiadas como eninatina B, esterigmatocistina y equisteina [70].

\subsubsection{Hallazgos en las muestras analizadas en nuestro trabajo}

En la Tabla 41 se resumen las micotoxinas halladas en las 54 muestras de alimentos analizadas en el presente trabajo, indicándose el porcentaje de ocurrencia en el total de muestras, los valores mínimos, máximos y medios detectados, como así también la ocurrencia de cada micotoxina en los distintos tipos de muestras tales como se clasificaron anteriormente: (i) forrajes, (ii) cereales y derivados, (iii) oleaginosas y derivados, y (iv) balanceados y TMRs. Si bien, como era esperable, se corroboró la presencia de las micotoxinas anteriormente mencionadas, el amplio espectro de analitos abarcados permitió encontrar micotoxinas que no habían sido encontradas o reportadas en este tipo de alimentos previamente en la región. En las Tablas S5-1 a S5-4 del material suplementario se muestran los resultados completos de las combinaciones micotoxina/muestra hallados en las 54 muestras analizadas. 
Tabla 41. Micotoxinas y concentraciones halladas en las 54 muestras de alimentos para ganado clasificadas en 4 tipos de muestra.

\begin{tabular}{|c|c|c|c|c|c|c|c|c|c|}
\hline \multirow{2}{*}{ Micotoxina } & \multirow{2}{*}{$\begin{array}{l}\text { Ocurrencia } \\
\%\end{array}$} & \multicolumn{4}{|c|}{ Concentraciones $(\mu \mathrm{g} / \mathrm{kg})$} & \multicolumn{4}{|c|}{ Ocurrencia tipo de muestra } \\
\hline & & Mínimo & Máximo & Media* & LC & (i) & (ii) & (iii & (iv) \\
\hline & & & & & & $n=20$ & $\mathrm{n}=12$ & $\mathrm{n}=9$ & $n=13$ \\
\hline \multicolumn{10}{|l|}{ Eniatinas } \\
\hline Eniatina B & 59 & 0,2 & 308 & 16 & 50 & 8 & 7 & 6 & 11 \\
\hline Eniatina B1 & 24 & 2 & 419 & 47 & 10 & 2 & 1 & 4 & 6 \\
\hline Eniatina A & 13 & 0,8 & 117 & 18 & 2,5 & - & 1 & 1 & 5 \\
\hline Eniatina A1 & 26 & 2 & 373 & 36 & 5 & 1 & 1 & 4 & 8 \\
\hline \multicolumn{10}{|l|}{ Alcaloides del Ergot } \\
\hline A. Ciclopiazónico & 11 & 7 & 30 & 15 & 5 & - & 3 & - & 3 \\
\hline ErgocornININA & 2 & 3 & 3 & 3 & 5 & - & - & - & 1 \\
\hline ErgocristININA & 2 & 2 & 2 & 2 & 2,5 & - & - & - & 1 \\
\hline Ergocriptina & 2 & 6 & 6 & 6 & 5 & - & - & - & 1 \\
\hline Ergocristina & 2 & 5 & 5 & 5 & 5 & - & - & - & 1 \\
\hline Ergometrina & 2 & 3 & 3 & 3 & 25 & - & - & - & 1 \\
\hline Ergosina & 2 & 4 & 4 & 4 & 2,5 & - & - & - & 1 \\
\hline \multicolumn{10}{|l|}{ Tricotecenos } \\
\hline 15-ADON & 9 & 63 & 1175 & 396 & 50 & - & 3 & 1 & 1 \\
\hline 3-ADON & 9 & 54 & 276 & 116 & 50 & - & 2 & - & 3 \\
\hline Deoxinivalenol & 17 & 36 & 167 & 85 & 1000 & 1 & 6 & 1 & 1 \\
\hline Diacetoxiscirpenol & 7 & 10 & 29 & 20 & 25 & 2 & - & 2 & - \\
\hline Nivalenol & 6 & 232 & 682 & 461 & 500 & - & 1 & - & 2 \\
\hline Toxina HT-2 & 4 & 12 & 21 & 17 & 25 & 1 & - & - & 1 \\
\hline Toxina T-2 & 2 & 19 & 19 & 19 & 10 & - & - & - & 1 \\
\hline \multicolumn{10}{|l|}{ Fumonisinas } \\
\hline Fumonisina B1 & 81 & 9 & 27996 & 1962 & 25 & 14 & 12 & 6 & 12 \\
\hline Fumonisina B2 & 67 & 23 & 5557 & 697 & 100 & 10 & 12 & 3 & 11 \\
\hline Fumonisina B3 & 54 & 35 & 2099 & 292 & 25 & 6 & 12 & 1 & 10 \\
\hline \multicolumn{10}{|l|}{ Zearalenona } \\
\hline Zearalenona & 96 & 0,9 & 5015 & 429 & 50 & 19 & 12 & 8 & 13 \\
\hline$\alpha-Z O L$ & 13 & 36 & 1349 & 355 & 10 & - & 3 & 2 & 2 \\
\hline$\beta-Z O L$ & 15 & 14 & 326 & 145 & 25 & 1 & 4 & 2 & 1 \\
\hline \multicolumn{10}{|l|}{ Toxinas de Alternaria } \\
\hline Alternariol & 74 & 7 & 2857 & 274 & 25 & 11 & 9 & 7 & 13 \\
\hline Alternariol-metileter & 93 & 0,3 & 531 & 59 & 5 & 17 & 12 & 8 & 13 \\
\hline Tentoxina & 56 & 4 & 175 & 56 & 5 & 9 & 2 & 7 & 12 \\
\hline A. Tenuazónico & 19 & 233 & 9536 & 2472 & 100 & 3 & - & 3 & 4 \\
\hline \multicolumn{10}{|l|}{ Aflatoxinas } \\
\hline Aflatoxina B1 & 20 & 0,9 & 19 & 6 & 2,5 & - & 6 & - & 5 \\
\hline Aflatoxina B2 & 4 & 1 & 1 & 1 & 2,5 & - & 1 & 1 & - \\
\hline Aflatoxina G1 & 2 & 3 & 3 & 3 & 5 & - & 1 & - & - \\
\hline Aflatoxina G2 & 2 & 25 & 25 & 25 & 25 & 1 & - & - & - \\
\hline \multicolumn{10}{|l|}{ Misceláneas } \\
\hline A. Micofenólico & 6 & 10 & 22 & 15 & 10 & - & 1 & 1 & 1 \\
\hline Beauvericina & 96 & 4 & 6364 & 572 & 10 & 18 & 12 & 9 & 13 \\
\hline Citrinina & 6 & 28 & 68 & 50 & 25 & 1 & - & 1 & 1 \\
\hline Esterigmatocistina & 43 & 0,6 & 25 & 4 & 0,5 & 13 & 4 & 4 & 2 \\
\hline Gliotoxina & 2 & 162 & 162 & 162 & 100 & 1 & - & - & - \\
\hline Roquefortina C & 4 & 104 & 127 & 115 & 10 & 1 & - & - & 1 \\
\hline
\end{tabular}

*incluye valores <LC; LC: límite de cuantificación.

Tipos de muestra: (i) Forrajes, (ii), Cereales \& derivados, (iii) Oleaginosas y derivados, (iv) Balanceados y TMRs. 


\section{Fumonisinas}

Con respecto a las FBs, si bien su presencia en alimentos concentrados para ganado no se ha relevado en extenso en la zona de estudio, sí se ha reportado contaminación por esta clase de micotoxinas en otras regiones de Argentina con altos niveles de ocurrencia en granos de maíz, en silos de maíz y en trigo [267269]. Nuestros resultados en alimentos concentrados, mayoritariamente con base maíz, siguieron la misma tendencia de alta frecuencia de aparición de las 3 FBs determinadas con elevados niveles de concentración. En este caso, se encontraron en el 81\% de las muestras analizadas, con una concentración media de 2951 $\mu \mathrm{g} / \mathrm{kg}(\mathrm{FB} 1+\mathrm{FB} 1+\mathrm{FB} 3)$ y un valor máximo de $27996 \mu \mathrm{g} / \mathrm{kg}$ para una muestra de gluten, constituyendo una clara violación al límite máximo establecido para piensos complementarios (Tabla 41).

\section{Zearalenona}

Históricamente, ZEA fue la micotoxina más importante y de mayor ocurrencia tanto en pasturas como en alimentos concentrados de la región, situación que se vio reflejada en el presente estudio habiéndose detectado además sus metabolitos $\alpha$ - y $\beta$ - zearalenol. La ZEA se detectó en el $96 \%$ de las muestras con una concentración media de $429 \mu \mathrm{g} / \mathrm{kg}$ y un valor máximo de $5015 \mu \mathrm{g} / \mathrm{kg}$ en un alimento balanceado, excediendo los límites máximos aceptados para esta micotoxina en piensos ganado (Tabla 37).

\section{Tricotecenos}

Los tricotecenos más encontrados de esta familia fueron DON y sus formas acetiladas 15-ADON y 3-ADON, con baja ocurrencia en el $17 \%, 9 \%$ y $9 \%$ de las muestras, respectivamente. En otros países como los europeos DON es considerada una micotoxina marcadora de otras producidas por hongos de Fusarium, esto es, que la presencia de una evidencia la presencia de otras. En nuestro caso esto no se observó, ya que la baja ocurrencia de DON no se condice con la alta frecuencia de detección de las FBs, por ejemplo. La concentración máxima que se encontró de esta familia de micotoxinas fue de $1175 \mu \mathrm{g} / \mathrm{kg}$, debido a 15 ADON en una muestra de expeller de girasol.

\section{Toxinas de Alternaria}

La ocurrencia de toxinas de Alternaria fue relevante por la cantidad de detecciones, por las altas concentraciones halladas y porque compuestos de esta familia no habían sido estudiados en alimentos concentrados de este tipo en la región. Se encontraron con alta ocurrencia AME, AOH y TEN (93\%, 74\% y $56 \%$, respectivamente). En este caso el valor máximo hallado fue de $2857 \mu \mathrm{g} / \mathrm{kg}$ de alternariol en una muestra de semilla de algodón. Aunque con una ocurrencia menor en todo el conjunto de muestras (19\%), ácido tenuazónico fue la toxina de Alternaria que se encontró en mayor concentración en otra muestra de semilla de algodón $(9536 \mu \mathrm{g} / \mathrm{kg})$.

\section{Aflatoxinas}

Las AFs se encontraron en el $24 \%$ de las muestras analizadas con un valor máximo de $25 \mu \mathrm{g} / \mathrm{kg}$ para AFG2 en un heno de alfalfa. El nivel de ocurrencia de AFB1 fue menor que el $79 \%$ reportado en muestras del 
mismo tipo de la región por otros autores [156] pero mayor que el encontrado en un estudio previo de nuestro grupo donde sobre un total de 142 muestras de alimentos concentrados para ganado (ensilados, balanceados, granos de cereales, henos y pasturas, entre otros) muestreados en la misma zona de estudio en el año 2013 se encontró una ocurrencia de AFB1 del 11\% (Tabla 36, Capítulo 4).

\section{Otras micotoxinas}

Con relación a las micotoxinas emergentes, se identificaron eniatinas en los cuatro tipos de muestras con alta ocurrencia de ENB (59\%). En línea con nuestros resultados, estas micotoxinas se han reportado como ubicuas en cereales en Europa [68] y también se han encontrado con alta frecuencia en pasturas frescas de Argentina [70]. Beauvericina es otra micotoxina emergente que fue hallada con muy alta ocurrencia en todos los tipos de alimentos concentrados analizados, y que en estudios previos en maíz y trigo de la provincia de Santa Fe no había sido detectada [270,271]. En nuestro caso, se encontró en el 96\% de las muestras analizadas con una concentración media de $572 \mu \mathrm{g} / \mathrm{kg}$ y un valor máximo de $6364 \mu \mathrm{g} / \mathrm{kg}$ en una muestra de semilla de girasol. Otros valores altos de esta micotoxina fueron hallados en silo de maíz (4437 $\mu \mathrm{g} / \mathrm{kg})$, poroto de soja $(3117 \mu \mathrm{g} / \mathrm{kg}$ ) y alimento balanceado $(1392 \mu \mathrm{g} / \mathrm{kg})$, lo que explica el cierto grado de ubicuidad que mostró el conjunto de muestras analizado respecto de este contaminante (Figura 41).

Otra micotoxina emergente encontrada fue esterigmatocistina, presente en el $43 \%$ de las muestras analizadas con una media de $4 \mu \mathrm{g} / \mathrm{kg}$ y un valor máximo de $25 \mu \mathrm{g} / \mathrm{kg}$ en un silo de maíz. Esta micotoxina es un precursor tóxico de la biosíntesis de las aflatoxinas y dependiendo de la especie de hongos Aspergillus que colonice los sustratos pueden convertirla o no en AFs [70], lo que podría explicar la relativamente baja ocurrencia de esta última familia en las muestras analizadas. Además, se observó que en muestras en donde se encontraron AFs no se halló STE, y viceversa.

\subsubsection{Ocurrencia de las micotoxinas más importantes en los distintos tipos de muestra}

Lo primero que hay que decir al analizar la contaminación por micotoxinas de los distintos tipos de muestra es que, en todos, la cantidad de compuestos hallados fue muy importante, tanto en número como en concentración. Ninguno de los 4 grupos en los que se clasificaron los distintos tipos de muestra presentó menos de 20 metabolitos de origen fúngico diferentes $y$, con distinto grado de distribución, todos presentaron las micotoxinas más relevantes en alimentos para ganado (ZEA, FBs, AFs) y un grupo de micotoxinas emergentes (BEA y toxinas de Alternaría, principalmente). En la Figura 41 se muestra la distribución de las 4 familias de micotoxinas de mayor ocurrencia en los distintos tipos de muestra. Como se observa, el grupo de cereales y derivados se destacó claramente por la gran ocurrencia de fumonisinas, debido a que está constituido mayoritariamente por granos de maíz, que es el cereal más afectado por $F$. verticillioides, el principal hongo productor de estas micotoxinas, pudiendo existir incluso como un endófito en la planta [58]. Además, está aceptado que en maíz la produccion de FBs se da en forma masiva [57]. 
En la misma figura se destaca también el grupo de oleaginosas y derivados porque es el que presentó mayor carga de las micotoxinas emergentes beauvericina y toxinas de Alternaria. Los hallazgos respecto a esta última familia de toxinas siguen la tendencia observada en un informe de EFSA (2011) en el que se informa sobre la presencia de toxinas de Alternaria en piensos de tipo oleaginoso como semillas y expellers de girasol y porotos de soja [272]. En dicho informe no se reportan, sin embargo, datos de ocurrencia de esta familia de micotoxinas en semillas de algodón, que en nuestro trabajo constituyó el tipo de alimento que presentó mayor concentración de alternariol $(2857 \mu \mathrm{g} / \mathrm{kg})$, alternariol-metil-éter $(531 \mu \mathrm{g} / \mathrm{kg})$, tentoxina

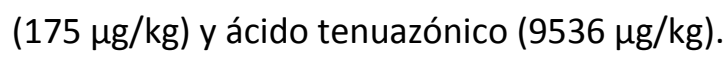

Finalmente, los forrajes fueron el tipo de muestra en el que la distribución de las micotoxinas fue más pareja, principalmente por la contribución de los ensilados de maíz y sorgo incluidos en esta categoría.

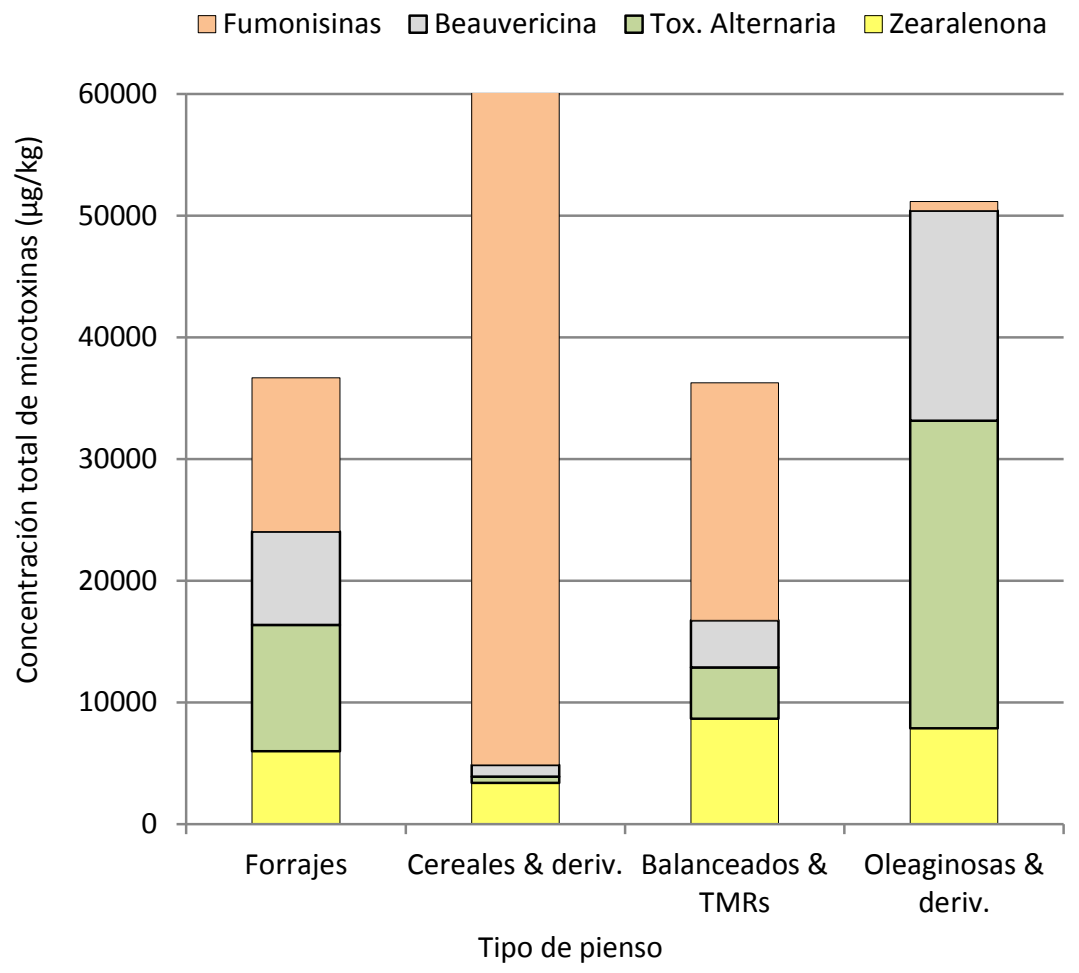

Figura 41. Distribución de concentraciones de las principales micotoxinas halladas en los distintos tipos de piensos analizados.

\subsubsection{Multi-contaminación}

Considerando que los hongos micotoxigénicos generalmente son capaces de producir más de una micotoxina, y que las materias primas utilizadas para la elaboración de piensos comúnmente pueden contaminarse con varias especies fúngicas al mismo tiempo, la ocurrencia de múltiples metabolitos fúngicos en una misma muestra es altamente probable [273]. La co-ocurrencia de micotoxinas es de gran interés debido a efectos aditivos o sinérgicos perjudiciales para la salud de los animales, para su capacidad de producción, y eventualmente para la seguridad alimentaria, considerando la posible transferencia de estos contaminantes a los alimentos de origen animal consumidos por el ser humano. A nivel global, se 
estima que entre el 30 y el 100\% de las muestras de alimentos y piensos presentan co-contaminación por micotoxinas [261]. En nuestro trabajo, el 100\% muestras se verificó estar contaminado con 3 o más micotoxinas, siendo la más afectada una muestra de alimento balanceado con 22 compuestos diferentes en niveles de concentración desde 0,8 $\mu \mathrm{g} / \mathrm{kg}$ (ENA) hasta $1685 \mu \mathrm{g} / \mathrm{kg}$ (FB1). En promedio, en los alimentos clasificados como forrajes se detectaron 7 micotoxinas por muestra, en cereales y derivados 11 , en oleaginosas y derivados 9, y en balanceados y TMRs se encontró un promedio de 12 micotoxinas por muestra (Tabla 42). Sobre la multi-contaminación debe tenerse presente que las distintas regulaciones para el control de alimentos y piensos no consideran los efectos combinados de las micotoxinas derivados de la exposición simultánea a múltiples compuestos, aspecto que puede conducir a incertidumbres en las evaluaciones de riesgo.

Tabla 42. Multicontaminación observada en los distintos tipos y grupos de muestras analizadas.

\begin{tabular}{|c|c|c|c|}
\hline Grupo & Tipos de muestra & $\begin{array}{l}\text { Residuos promedio } \\
\text { por tipo de muestra }\end{array}$ & $\begin{array}{l}\text { Residuos promedio } \\
\text { por grupo }\end{array}$ \\
\hline \multirow[t]{5}{*}{ (i) Forrajes } & 4 pasturas de alfalfa & 5 & 6,6 \\
\hline & 2 henos de alfalfa & 7,5 & \\
\hline & 1 pastura de cebada & 5 & \\
\hline & 9 ensilados de maíz & 7,6 & \\
\hline & 4 ensilados de sorgo & 8 & \\
\hline \multirow[t]{4}{*}{ (ii) Cereales y derivados } & 7 granos de maíz & 10,3 & 10,6 \\
\hline & 2 granos de trigo & 13 & \\
\hline & 2 burlandas de maíz & 11 & \\
\hline & 1 gluten de trigo & 8 & \\
\hline \multirow[t]{4}{*}{ (iii) Oleaginosas y derivados } & 4 semillas de algodón & 8,3 & 9,2 \\
\hline & 1 poroto de soja & 11 & \\
\hline & 3 expellers de soja & 10,3 & \\
\hline & 1 expeller de girasol & 7 & \\
\hline \multirow[t]{2}{*}{ (iv) Balanceados y TMRs } & 10 balanceados & 13,3 & 11,5 \\
\hline & 3 TMRs & 9,6 & \\
\hline
\end{tabular}

\subsubsection{Relación entre el contenido de micotoxinas y el de plaguicidas}

La síntesis de micotoxinas está determinada por una serie de factores que pueden ser físicos, biológicos, químicos, o interacciones entre ellos. Los principales factores que interactúan en forma compleja induciendo la síntesis de micotoxinas son el tiempo, la temperatura ambiental, la humedad y el daño físico causado por insectos. Como consecuencia de este último factor es posible considerar que también influyen en la producción de micotoxinas los efectos del uso de plaguicidas (insecticidas, fungicidas) para la protección de cultivos. Sería esperable que ocurriera una relación inversa entre el uso de plaguicidas como métodos de profilaxis, tanto a campo como en almacenamiento, y la producción de micotoxinas en las materias primas que componen los piensos. Es decir, que se produzca un menor desarrollo de hongos micotoxigénicos por efecto de la aplicación de un fungicida, y por el uso de insecticidas que eviten el daño 
producido por artrópodos en la superficie de granos donde luego tiene lugar el crecimiento fúngico. En ese sentido, se ha sugerido que la aplicación de un insecticida sólo o en combinación con un fungicida en la etapa de floración de maíz, por ejemplo, reduce significativamente los daños causados por insectos y en consecuencia el desarrollo de cepas de Fusarium productoras de fumonisinas [274]. Por otro lado, la menor producción de micotoxinas por uso de fungicidas no es tan directa puesto que se ha demostrado que la síntesis de micotoxinas puede incrementarse cuando ciertas cepas fúngicas son expuestas a dosis subletales de fungicidas [275].

Dado que el estudio de la afinidad específica de los fungicidas hallados en las muestras con las especies fúngicas productoras de las micotoxinas encontradas está fuera de los objetivos de esta tesis, se buscó correlacionar la concentración de algunas micotoxinas en las muestras analizadas con la carga total de plaguicidas de cada una (contenido total de insecticidas + contenido total de fungicidas). Se puede visualizar en la Figura 42 que existe una preliminar relación inversa entre la concentración de fumonisinas, zearalenona, toxinas de alternaría y beauvericina y la presencia de plaguicidas en las muestras. Esto es, las mayores concentraciones de micotoxinas se encontraron en aquellas muestras en las que la carga de plaguicidas fue menor, y viceversa.
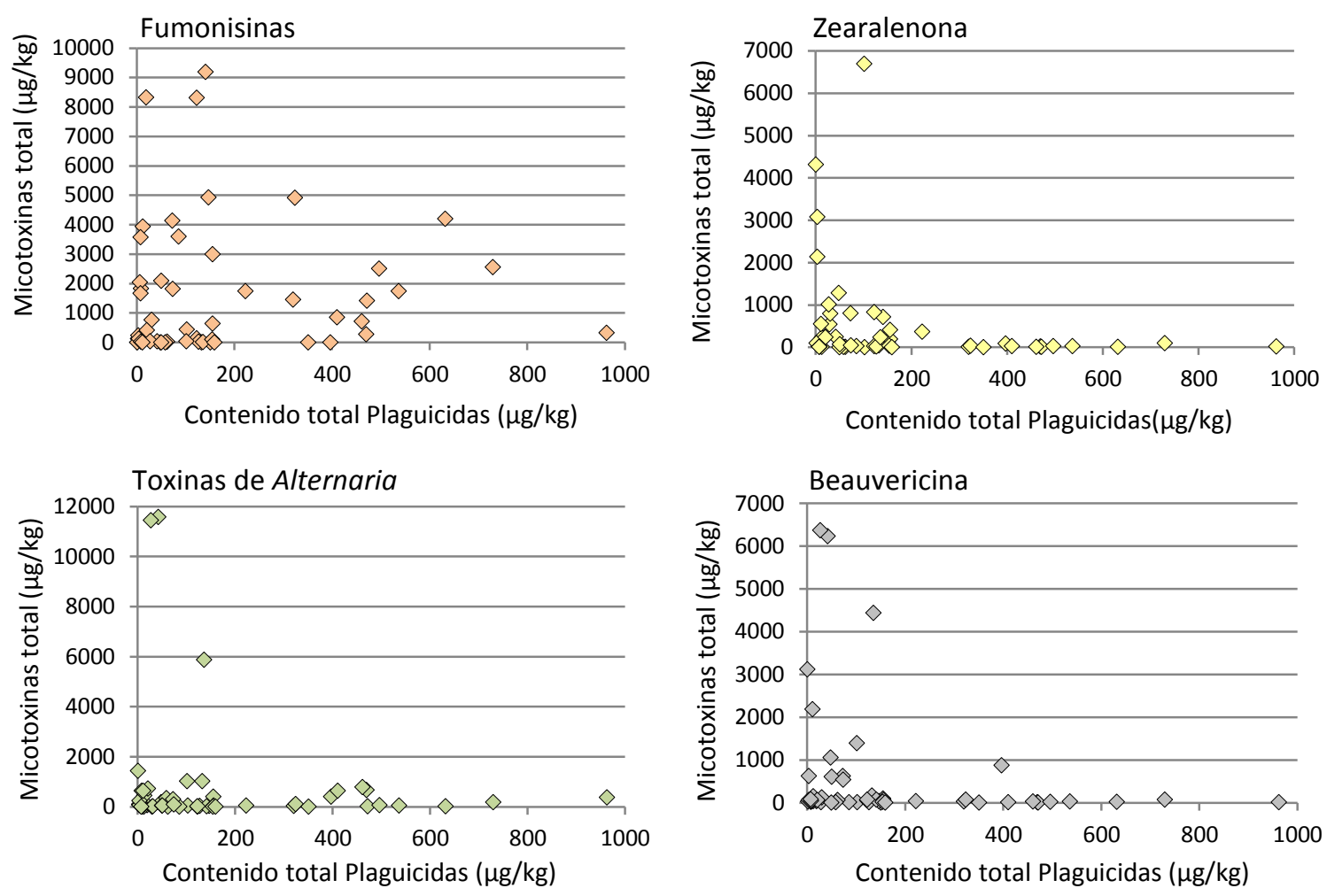

Figura 42. Relación entre el contenido total de las principales micotoxinas halladas y el contenido total de residuos de plaguicidas encontrados en las muestras de alimento para ganado analizadas. 


\subsection{CONCLUSIONES}

Los procesos actuales de intensificación de la producción llevan a un uso mayor de alimentos cosechados y almacenados en condiciones muy variables por lo que la presencia de las micotoxinas es más frecuente y casi inevitable. En estos términos, se analizó la calidad de una selección de diversos alimentos concentrados típicamente utilizados como ingredientes de la dieta del ganado lechero en la provincia de Santa Fe. La posibilidad de abarcar un amplio espectro de más de 50 contaminantes de origen fúngico y metabolitos permitió la detección de las micotoxinas analizadas más frecuentemente como zearalenona, aflatoxinas o deoxinivalenol, como así también un grupo de micotoxinas emergentes, como beauvericina, eninantinas y toxinas de Alternaria, no estudiadas previamente en este tipo de piensos en nuestra región y el país.

Los resultados mostraron una muy alta ocurrencia de micotoxinas en general, con elevados niveles de concentración de fumonisinas en alimentos a base de maíz y de toxinas de Alternaria (AOH, AME, TEN y TeA) en oleaginosas y sus derivados, principalmente semillas de algodón.

Fue muy llamativa también la elevada multi-contaminación observada en todas las muestras llegando al caso extremo de encontrar 22 micotoxinas diferentes en una sola muestra de un alimento balanceado.

El uso de métodos multi-residuo multi-clase abarcativos de una gran cantidad de compuestos, integrando el análisis de plaguicidas y micotoxinas, permitió realizar un análisis inédito sobre la ocurrencia de ese tipo de residuos y contaminantes en la región y en el país para este conjunto de alimentos.

La información aquí generada es relevante para orientar la asistencia a los productores en el mejoramiento del manejo de sus cultivos y productos almacenados destinados a la alimentación animal, para perfeccionar los programas de monitoreo y control necesarios en la evaluación de riesgo, y para asegurar las medidas de protección de la salud tanto animal como humana relacionadas con la inocuidad de los alimentos. 


\section{CONCLUSIONES}




\section{CONCLUSIONES}

Fruto del trabajo de optimización analítica asistido por herramientas estadísticas, se ha logrado experimentar con métodos multi-residuo multi-clase para la determinación de plaguicidas y micotoxinas siguiendo las tendencias analíticas actuales de amplio espectro, basadas en procesos de preparación de muestras simplificados (QuEChERS) y detección por técnicas cromatográficas-espectrométricas de masa (UHPLC-MS/MS, GC-MS/MS).

Se ha contribuido así con la validación de un método para la determinación de AFM1 en leche por IACUHPLC-MS/MS; un método para la determinación de AFM1 por QuEChERS-UHPLC-MS/MS; un método para la determinación de 63 plaguicidas de diversas familias y 2 aflatoxinas en leche por QuEChERS-UHPLCMS/MS; y un método para la determinación de plaguicidas y micotoxinas en piensos y forrajes por QuEChERS con detección por UHPLC-MS/MS y GC-MS/MS. También se ha experimentado con un método para la determinación de 400 plaguicidas y 56 micotoxinas y metabolitos en piensos y forrajes, que se ha incorporado a las herramientas disponibles en PRINARC.

Respecto a la residualidad en general, se ha evidenciado una ocurrencia importante tanto de plaguicidas (50 detectados de 400) como de micotoxinas (38 detectadas de 56), especialmente en los piensos y forrajes estudiados, siendo los mismos representativos de las dietas utilizadas en la práctica agrotécnica actual de la zona central de la Provincia de Santa Fe. No obstante, en leche la incidencia ha sido menor respecto a plaguicidas habiéndose verificado una alta frecuencia de aparición de AFM1.

Respecto a los plaguicidas en leche, los resultados de las concentraciones de los analitos hallados no indicaron excesos a los respectivos límites máximos de residuo. Clorpirifos y diazinon fueron los plaguicidas de mayor ocurrencia en el análisis por UHPLC-MS/MS, y endosulfán-sulfato y lambdacialotrina los más detectados por GC-MS/MS. Fue llamativa la presencia en leche, aunque en niveles traza, de heptacloro e isómeros de DDT que son compuestos que han estado prohibidos desde hace más de dos décadas en el país. Se observó también una tendencia a encontrar mayor cantidad de plaguicidas en las leches muestreadas durante el verano respecto de las obtenidas en meses de invierno.

Respecto a los plaguicidas en piensos, el espectro de compuestos detectados fue mayor en relación al análisis de leches, producto de la posibilidad de disponer de plataformas analíticas ampliadas desarrolladas para cumplir con los exigentes programas de monitoreo y control europeos. Entre los múltiples analitos detectados se verificó una alta ocurrencia de clorpirifos y pirimifos-metilo en el $98 \%$ y $80 \%$ de las muestras analizadas, respectivamente, aunque sin que se verificaran excesos a los LMRs. Entre algunos piretroides de uso difundido se destacó la elevada ocurrencia de deltametrina en alimentos balanceados (en el $80 \%$ de las muestras de este tipo) con concentraciones en algunos casos altas, con un máximo de $532 \mu \mathrm{g} / \mathrm{kg}$, por encima del LMR que en Argentina tiene deltametrina para algunos forrajes. Los herbicidas hallados más frecuentemente fueron atrazina y metolacloro, de amplio uso en nuestro país, aunque en muy bajos niveles 
de concentración. Azoxistrobina, metalaxil y difenilamina fueron los fungicidas de mayor frecuencia en los piensos analizados, también en concentraciones muy por debajo de los LMRs.

Respecto a micotoxinas en leche, las concentraciones de AFM1, que fue hallada en el $46 \%$ de las muestras con una media de 0,038 y máxima de 0,293 $\mu \mathrm{g} / \mathrm{L}$, no fueron violatorias de las tolerancias de la normativa Mercosur, aunque en el $8 \%$ de los casos se excedió la tolerancia de la Unión Europea.

La ocurrencia de micotoxinas en piensos fue del $100 \%$ en el conjunto de muestras analizadas, verificándose la presencia de los compuestos con incidencia histórica en este tipo de alimentos en la región (aflatoxinas, fumonisinas, zearalenona, deoxinivalenol), además de otro conjunto de micotoxinas emergentes como eniantinas, toxinas de Alternaria y beauvericina, siendo esta última la de mayor ocurrencia en el $96 \%$ de las muestras en niveles de concentración de hasta $6000 \mu \mathrm{g} / \mathrm{kg}$. Se verificaron también algunos casos en los que las concentraciones excedieron los límites máximos permitidos en piensos por la UE, como los casos de AFB1 en 3 muestras de granos de maíz (LM= $5 \mu \mathrm{g} / \mathrm{kg}$ ), FB1 en muestras de gluten y burlanda (LM= 6000 $\mu \mathrm{g} / \mathrm{kg}$ ) y ZEA en un silaje de maíz, un balanceado y una muestra de porotos de soja ( $L M=3000 \mu \mathrm{g} / \mathrm{kg}$ ). Otro aspecto distintivo de la determinación de micotoxinas en piensos fue el elevado nivel de multicontaminación, con casos de hasta 22 metabolitos presentes en una misma muestra, como en un balanceado con niveles entre $0,8 \mu \mathrm{g} / \mathrm{kg}$ (eniatina A) y $1685 \mu \mathrm{g} / \mathrm{kg}$ (FB1).

El estudio condujo a efectuar una consulta de las distintas legislaciones existentes en el país y a nivel global sobre las tolerancias o límites máximos permitidos, observándose que en nuestro país se verifica una falta de armonización entre las legislaciones aplicables en el caso de los plaguicidas, con diferencias tanto en las listas de compuestos regulados como en los niveles de concentración establecidos. También se verificó que la cantidad fitosanitarios que se someten a control en Argentina es reducida respecto al número de autorizados y a los que se controlan globalmente, que podrían estar contenidos potencialmente en productos de importación.

En relación al punto anterior, el estudio condujo también a la consulta de los sistemas de monitoreo y control vigentes en nuestro país, habiéndose observado que en el caso de leche el modelo seguido en el plan que lleva a cabo el SENASA (Plan CREHA animal) tiene incluido el seguimiento de AFM1 y controla un listado de plaguicidas centrado básicamente en el seguimiento de organoclorados y piretroides, siendo algo exiguo respecto al resto de los plaguicidas en uso en el país. En el caso de piensos y forrajes no existe plan de monitoreo y control sistemático ni de plaguicidas ni de micotoxinas. Sería recomendable prestar mayor atención al seguimiento de estos residuos y contaminantes en el eslabón primario, no solo para velar por los aspectos de sanidad animal sino también para prevenir la contaminación posterior de los productos alimenticios de origen animal.

Finalmente, en relación a lo institucional, el desarrollo de esta tesis permitió el fortalecimiento de vínculos colaborativos de fuerte contenido interdisciplinar entre diversos grupos de investigación como son el 
PRINARC (FIQ-UNL), el Laboratorio de Microbiología (FIQ-UNL) y la Estación Experimental INTA de Rafaela. Del mismo modo, cabe mencionar el fortalecimiento de los vínculos de cooperación internacional que dieron marco a actividades científicas directamente relacionadas con la tesis, como el caso del proyecto MINCYT-MEYS con República Checa que permitió concretar intercambios de investigadores entre UCTPraga y el PRINARC, incluyendo la realización directa de actividades de esta tesis en laboratorios de la institución checa. 
MATERIAL SUPLEMENTARIO 


\section{MATERIAL SUPLEMENTARIO}

\section{CAPÍTULO 1}

\section{1) Modos de acción toxicológica de inscticidas, herbicias y fungicidas.}

Tabla S1-1. Modo de acción toxicológica de insecticidas de acuerdo al Comité de Acción contra la Resistencia a Insecticidas (IRAC). Adaptado de Ref. [15].

Grupo. Modo de acción

Acción sobre el Sistema Nervioso o Muscular

La mayoría de los insecticidas actúan sobre el sistema niterasa

G1. Inhibidor de la acetilcolinesterasa

G2. Bloqueadores del canal de cloruro activado por GABA

G3. Modulador del canal de $\mathrm{Na}+$

G4. Modulador competitivo del receptor nicotínico de la acetilcolina (ACh)

G5. Modulador alostérico del receptor nicotínico de la ACh

G6. Modulador alostérico del canal de cloro dependiente de glutamato.

G9. Modulador del canal TRPV de los órganos cordotonales.

G14. Bloqueador del canal de los receptores nicotínicos de acetilcolina ( $\mathrm{nAChR}$ )

G19. Agonista del receptor de octopamina

G22. Bloqueador del canal de $\mathrm{Na}+$ dependiente del voltaje

G28. Modulador del receptor de la rianodina

G29. Modulador de los órganos cordotonales sin punto de acción definido

\section{Acción sobre el Crecimiento y Desarrollo}

El desarrollo de los insectos está controlado por el equilibrio de dos hormonas principales: la hormona juvenil y la ecdisona. Los reguladores del crecimiento de los insectos actúan imitando una de estas hormonas o perturbando directamente la formación/deposición de la cutícula o la biosíntesis de lípidos. Los insecticidas que actúan sobre los distintos objetivos de este sistema, son generalmente de acción lenta.

\section{G7. Mimético de la hormona juvenil}

G10. Inhib. del crecimiento de ácaros G15. Inhib. de la biosíntesis de quitina, tipo 0 G16. Inhib. de la biosíntesis de quitina, tipo 1

G17. Disruptor de la muda, dípteros G18. Agonista del receptor de ecdisona G23. Inhibidor de la acetil-CoA carboxilasa

\author{
Descripción del mecanismo
}

nervioso o muscular. Generalmente suelen ser de acción rápida.

Inhiben la AChE, causando hiperexcitación. La AChE es la enzima que finaliza la acción de excitación neurotransmisora de la ACh en la sinapsis nerviosa.

Bloquean el canal de cloruro activado por GABA causando hiperexcitación y convulsiones. GABA es el principal neurotransmisor inhibitorio en insectos.

Mantienen abiertos los canales de $\mathrm{Na}+$, causando hiperexcitación $\mathrm{y}$, en algunos casos, bloqueo nervioso. Los canales de $\mathrm{Na}+$ están implicados en la propagación de potenciales de acción a lo largo de los axones nerviosos.

Se unen al sitio de la ACh en el receptor, provocando una serie de síntomas desde hiperexcitación a letargia y parálisis. La ACh es el principal neurotransmisor excitador en el sistema nervioso central del insecto.

Activan alostéricamente los receptores, provocando la hiperexcitación del sistema nervioso. La ACh es el principal neurotransmisor excitador en el sistema nervioso central del insecto.

Activan alostéricamente el glutamato en canales de $\mathrm{Cl}$-, causando parálisis. El Glu es un importante neurotransmisor inhibidor en insectos.

Se unen e interrumpen la entrada de los complejos Nan-lav del canal TRPV (Receptor de potencial transitorio vaniloide) en órganos cordotonales receptores de estiramiento, que son críticos para los sentidos de la gravedad, el equilibrio, la propiocepción y la cinestesia. Esto provoca una alteración en la alimentación y otros comportamientos de los insectos.

Bloquean el nAChR resultando en bloqueo del sistema nervioso y parálisis. La ACh es el mayor neurotransmisor excitatorio en el sistema nervioso central del insecto. Activa receptores de octopamina conduciendo a hiperexcitación. La octopamina es en los insectos el equivalente de la adrenalina humana.

Bloquean los canales de $\mathrm{Na}+$, causando el colapso del sistema nervioso y parálisis. Los canales de $\mathrm{Na}+$ están implicados en la propagación de potenciales de acción a lo largo de los axones nerviosos.

Activan los receptores musculares de la rianodina, lo que provoca contracción y parálisis. Los receptores de la rianodina intervienen en la liberación de calcio en el citoplasma desde las reservas intracelulares.

Interrumpen la función de los órganos cordotonales receptores de estiramiento, que son críticos para los sentidos de la gravedad, el equilibrio, la propiocepción y la cinestesia. Esto interrumpe la alimentación y otros comportamientos de los insectos. Al contrario que el grupo 9, los insecticidas del grupo 29 no se unen al complejo Nan-lav del canal TRPV.

Aplicados en el estadio premetamórfico, estos compuestos interrumpen e impiden la metamorfosis.

MdA no completamente definido que provoca inhibición del crecimiento.

MdA no completamente definido que causa inhibición de la biosíntesis de quitina.

MdA no completamente definido que causa inhibición de la biosíntesis de quitina en una serie de insectos, incluyendo mosca blanca.

MdA no completamente definido que causa interrupción de la muda. Imitan la hormona de la muda, la ecdisona, induciendo una muda precoz. Inhiben la acetil-CoA carboxilasa, que forma parte del primer paso de la biosíntesis de los lípidos, causando la muerte del insecto. 


\section{Grupo. Modo de acción}

Descripción del mecanismo

\section{Acción sobre la Respiración}

La respiración mitocondrial produce ATP, la molécula que da energía a todos los procesos celulares vitales. En las mitocondrias, una cadena de transporte de electrones almacena la energía generada por la oxidación en forma de un gradiente de protones, lo que genera la síntesis de ATP. Varios insecticidas son conocidos por interferir en la respiración mitocondrial mediante la inhibición del transporte de electrones y/o la fosforilación oxidativa. Los insecticidas que actúan sobre los distintos puntos de este sistema son generalmente de acción rápida a moderadamente rápida.

G12. Inhibidor de la ATP-sintetasa mitocondrial Inhiben la enzima que sintetiza el ATP.

G13. Desacoplador de la fosforilación oxidativa Protonóforos que cortocircuitan el gradiente de protones mitocondrial para que el por disrupción del gradiente de protones G20. Inhib. del transporte de electrones en el complejo mitocondrial III

G21. Inhib. del transporte de electrones en el complejo mitocondrial I

G24. Inhib. del transporte de electrones en el ATP no se pueda sintetizar.

complejo mitocondrial IV

G25. Inhib. del transporte de electrones en el

complejo mitocondrial II

\section{Acción sobre el Sistema Digestivo}

Toxinas microbianas de lepidópteros específicos que se pulverizan o se expresan en variedades de cultivos transgénicos.

G11. Disruptor microbiano de las membranas digestivas de insectos

Inhiben el transporte de electrones en los complejos I, II, III y IV impidiendo el uso de la energía por las células.

\section{Modo de Acción desconocido o incierto}

Varios insecticidas que afectan a funciones o puntos de acción de un modo menos conocido, o actúan inespecíficamente sobre varios puntos. G8

Toxinas de proteínas que se unen a receptores en la membrana del intestino medio e inducen la formación de poros, provocando desequilibrio iónico y septicemia.

Diversos inhibidores no específicos (multi-sitio)

G.UN (desconocidos) Compuestos de modo de acción desconocido o incierto.

Tabla S1-2. Modo de acción toxicológica de herbicidas de acuerdo a la Sociedad Americana de Ciencias de las Malezas (WSSA). Adaptado de Ref.[16].

\begin{tabular}{l} 
Grupo. Modo de acción \\
\hline G1. Inhibidor de acetil-CoA \\
carboxilasa (ACCasa) \\
G2. Inhibidor acetolactato sintasa \\
(ALS) o Acetohidroxi acido sintasa \\
(AHAS)
\end{tabular}

G3,15,23. Inhibidor de mitosis

\section{Descripción}

Los herbicidas de las clases Arilofenoxipropionato (FOPs) ciclohexanodiona (DIMs) y fenilpirazolin (DENs) inhiben la enzima acetyl-CoA carboxylasa (ACCasa). Enzima que cataliza el primer paso de la síntesis de novo de la síntesis de ácidos grasos.

Las imidazolinonas, pirimidiniltiobenzoatos, sulfonilaminocarboniltriazolinonas, sulfonilureas, y triazolopirimidinas inhiben la enzima acetolactato sintasa (ALS), también llamada sintasa acetohidroxiacida (AHAS), clave en la biosíntesis de la cadena de los aminoácidos isoleucina, leucina, y valina.

Los herbicidas benzamida, acido benzoico (DCPA), dinitroanilina, fosforoamidato y piridina (pertenecen al grupo 2 WSSA) son ejemplos de acción por ligazón con tubulina, la más importante proteína microtubular. El complejo herbicida-tubulina inhibe la polimerización de microtubulos en uno de los extremos del microtubulo proteico sin afectar el otro extremo conduciendo a una pérdida de la estructura y funcionalidad. Como resultado se altera el alineamiento y separación de cromosomas durante la mitosis. Además la placa celular puede no formarse. Los microtúbulos intervienen en la formación de la pared celular. La pérdida de microtúbulos inducida por herbicidas puede causar la hinchazón observada de las puntas de las raíces ya que las células en esta región no se dividen ni se alargan. Los herbicidas carbámicos, carbetamida, cloroprofam y profam (Grupo 23), son ejemplos inhiben la división celular y la organización microtubular y la polimerización. Las acetamidas, cloroacetamidas, oxiacetamidas y trazolinonas (Grupo 15) se piensa inhiben la cadena larga de síntesis de ácidos grasos (VLCFA).

Los ácidos benzoico, fenoxicarboxílico, piridin- carboxílico y quinolin-carboxílicos (Grupo 4) son herbicidas que actúan en forma similar a auxina (IAA) endógena, aunque el mecanismo no está bien entendido todavía. El sitio de unión celular o molecular relevante para la acción IAA no se ha identificado. Sin embargo la acción primaria parece afectar la plasticidad de la pared celular y el metabolismo del ácido nucleico.

Los fenilcarbamatos, piridazinonas, triazinas, triazinonas, uracilos (Grupo 5), amidas, ureas (Grupo 7), benzotiadiazinonas, nitrilos, fenilpiridazinas (Grupo 6) inhiben la fotosíntesis por unión con el nicho QB en la proteína D1 del complejo del fotosistema II en las membranas del cloroplasto. La unión en esa ubicación de la proteína bloquea el transporte de electrones desde QA a QB y detiene la fijación de $\mathrm{CO} 2$ y producción de ATP y NADPH2 que se necesita para el crecimiento de la planta. Sin embargo ocurren otros varios fenómenos que conducen a la muerte de la planta involucrando reacciones con oxígeno, clorofila, lípidos y proteínas. 


\begin{tabular}{l} 
Grupo. Modo de acción \\
\hline G 8,16. Inhibidor de biosíntesis de \\
ácidos grasos y lipidos
\end{tabular}

Los benzofuranos (Grupo 16), los fosforditioatos y tiocarbamatos (Grupo 8) inhiben varios procesos: a) biosíntesis de ácidos grasos y lípidos que puede explicar las reducciones informadas en la deposición de cera cuticular. b) Biosíntesis de proteínas, isoprenoides (incluidas las giberelinas) y los flavonoides (incluidas las antocianinas). c) La inhibición de la síntesis de la giberelina que puede resultar de la inhibición de la síntesis de kaureno. La fotosíntesis también puede inhibirse.

G9. Inhibidor de la enzima enolpiruvil shikimato-3-fosfato sintasa (EPSP)

Las glicinas (glifosato) inhiben la enzima 5-enolpiruvilshikimato-3-fosfato sintasa (EPSP) que produce EPSP a partir de shikimato-3-fosfato y fosfoenolpiruvato en la ruta del ácido shikimico. La inhibición de EPSP afecta la producción de aminoácidos aromáticos (triptófano, tirosina y fenilalanina) todos necesarios para la síntesis de proteínas y el crecimiento.

G10. Inhibidor de glutamina sintasa Los ácidos fosfínicos (glufosinate y bialofos) inhiben la actividad de la glutamina sintasa la enzima que convierte el glutamato y amonio a glutamina. La acumulación de amonio en la planta destruye células y inhibe reacciones de ambos fotosistemas I y II.

G 11,12,13,27. Inhibidor de la biosíntesis de carotenoides Amidas, anilidex, furanonas, fenoxibutan-amidas, piridiazinonas y piridinas (Grupo 12) bloquean la biosíntesis de carotenoides por inhibición de la fitoeno desaturasa. Callistemonas, isoxazoles, pirazoles, y tricetonas (Group 27) inhiben la dihidroxifenill piruvato dioxigenasa (HPPD). Este es un paso clave en la biosíntesis de plastoquinona. Este es un paso clave en la biosíntesis de plastoquinona y su inhibición da lugar a síntomas de blanqueamiento en los nuevos crecimientos. Estos síntomas son el resultado de una inhibición indirecta de la síntesis de carotenoides debido a la participación de plastoquinona como cofactor de fitoeno desaturasa. Clomazona (Grupo 13) se metaboliza a la forma 5-ceto que es herbicida. Amitrol (Grupo 11) inhibe la acumulación de clorofila y carotenoides en la luz, aunque no se ha determinado el sitio de acción específico. Los precursores de la síntesis de carotenoides (fitoenos, fitofluenos, carotenos, licopenos) se acumulan por lo que se infiere la inhibición de las respectivas enzimas.

G14. Inhibidor de protoporfirinogeno oxidasa (PPG oxidase o protox)

Los difenileters, N-fenilftalimidas, oxadiazoles, oxazolidinadionas, fenilpirazoles, pirimidindionas, tiadiazoles y las triazolinonas son herbicidas que parecen inhibir la protoporfirinógeno oxidasa (PPG oxidasa o Protox), una enzima de la biosíntesis de clorofila y hemo que cataliza la oxidación del protoporfirinógeno IX (PPGIX) a protoporfirina IX (PPIX). La inhibición de Protox conduce a la acumulación de PPIX, el primer absorbente de luz precursor de clorofila.

$\mathrm{G} 17,25,26$. Inhibidor potencial de ácido nucleico o modo de acción no descripto

G18. Inhibidor de dihidropteroato sintasa

Se ha identificado que varios herbicidas tienen un modo de acción desconocido, incluidos los arsenicales orgánicos (Grupo 17), ácidos arilaminopropiónicos (Grupo 25) y otros herbicidas no clasificados (Grupo 26).

El herbicida carbamato, asulam, parece inhibir la división celular y la expansión en meristemos de plantas, tal vez por interferir con el ensamblaje o la función de los microtúbulos. También inhibe la 7,8-dihidropteroate sintasa, una enzima implicada en la síntesis de ácido fólico que se necesita para el nucleótido de biosíntesis de purina.

G19. Inhibidor del transporte de auxina

Los ftalamatos (naptalam) y las semicarbazonas (diflufenzopir) son compuestos que inhiben el transporte de auxinas. Estos compuestos inhiben el transporte polar de la auxina de origen natural, ácido indolacético (IAA) y de los herbicidas imitadores de auxinas en plantas sensibles. La inhibición del transporte de auxinas causa una acumulación anormal de IAA y agonistas de auxina sintéticos en regiones meristemáticas de brotes y raíces, alterando el equilibrio de auxinas necesario para el crecimiento de la planta.

G20,21,28,29. Inhibidor de celulosa Las benzamidas (Grupo 21), nitrilos (Grupo 20) y triazolocarboxamidas (Grupo 28) son herbicidas que inhiben la biosíntesis de la pared celular (celulosa) en malezas susceptible. Las alquilazinas (Grupo 29) inhiben la biosíntesis de la celulosa.

G22. Inhibidor fotosistema I Los bipiridilos son ejemplos de herbicidas que aceptan electrones del fotosistema I y se reducen para formar un radical herbicida. Este radical luego reduce el oxígeno molecular para formar radicales superóxido. Estos luego reaccionan consigo mismos en presencia de superóxido dismutasa para formar peróxidos de hidrógeno. El hidrógeno los peróxidos y los superóxidos reaccionan para generar radicales hidroxilo. Así pueden oxidar los grupos SH (sulfhidrilo) en varios compuestos orgánicos dentro de la célula. El radical hidroxilo es extremadamente reactivo y destruye fácilmente los lípidos insaturados, incluidos los ácidos grasos de membrana y clorofila. Producen radicales lipídicos que reaccionan con el oxígeno para formar hidroperóxidos lipídicos más otro radical lipídico para iniciar una reacción en cadena auto perpetuante de oxidación de lípidos. Dichos hidroperóxidos pueden destruir la integridad de las membranas celulares permitiendo que el citoplasma se filtre en los espacios intercelulares lo que conduce a una rápida marchitez y desecación de la hoja. Estos compuestos se pueden reducir/oxidar repetidamente.

G24.Desacopladores de fosforil. Los dinitrofenoles (dinoterb) son herbicidas que desacoplan el proceso de fosforilación oxidativa oxidativa causando casi interrupción y necrosis inmediatas de la membrana. 
Tabla S1-3. Modo de acción toxicológica de fungicidas de acuerdo al Comité de Acción contra la Resistencia a Fungicidas (FRAC). Adaptado de Ref. [17].

Grupo. Modo de acción
GA. Inhibidor de la síntesis de ácidos nucleicos

Descripción

GA. Inhibidor de la síntesis de ácidos nucleicos

Afectan la síntesis del ADN y ARN, reduciendo la producción de enzimas como: la ARN polimerasa I, adenosin-deaminasa o la ADN topoisomerasa. Grupos: Fenilamidas, hidroxi-(2-amino)pirimidas, heteroaromáticos, ácidos carboxílicos.

GB. Inhibidor de la mitosis y la división celular La tubulina (microtúbulos - citoesqueleto), es una molécula importante en la formación y segregación de cromosomas en la división celular. La alteración de esta afecta la mitosis a nivel de la metafase (el huso acromático es distorsionado y la separación del núcleo es suspendida, causando la muerte de la célula fungosa). Grupos: Metil-bencimidazol-carbamatos, N-fenil-carbamatos, benzamidas, fenilureas.

GC. Inhibidor de la respiración

GD. Inhibidor de la síntesis de aminoácidos y proteínas

GE. Inhibidor de la transducción de la señales

GF. Inhibidor de la síntesis de lípidos y membrana

GG. Inhibidor de la biosíntesis del ergosterol

GH. Inhibidor de la biosíntesis de la pared celular

GI. Inhibidor de la síntesis de melanina la pared celular

GP. Inductor de las defensas en la planta

Fungicidas de actividad multisitio
Inhibición mitocondrial de la respiración celular. Grupos: Pirimidinamidas, carboxamidas, inhibidores de la quinasa, compuestos órgano-tin.

Inhiben la biosíntesis de la metionina (gen cgs) y la secreción de enzimas hidrolíticas. Grupos: anilino-pirimidas, antibiótico hexopiranosil.

Lo forman sustancias que alteran la transducción de señales, inhibiendo los mecanismos metabólicos que permiten a la célula adaptarse a su entorno. MAP/ histidina-quinasa en la transducción de señales osmótica (OS-2, HOG1). Grupos: Quinolinas, fenil-pirroles.

Se engloban sustancias que alteran la síntesis de los lípidos y la integridad de las membranas celulares. Grupos: dicarboximidas, fosforotiolatos, ditiolatos, hidrocarbonos aromáticos, heteroaromáticos, carbamatos.

Presente en las membranas de ciertos hongos. Sustancias de espectros de actividad distintos; su característica común es su efecto antioídio. El ergosterol está presente en las membranas de ascomicetos y basidiomicetos, y no en bacterias ni oomicetos, a pesar de esto las bacterias gram + y los pythium son afectados por algunas de estas sustancias. Esto indica otro punto de acción. En los vegetales algunas sustancias afectan a la biosíntesis de los esteroles y la de las giberelinas. Grupos: Imidazoles, piperacinas, piridinas, pirimidinas, triazoles, morfolinas, piperidinas, espiroquetalaminas, tiocarbamatos, alilaminas.

Impiden la fijación de glucosamina a la quitina dentro de las paredes celulares. Grupos: ácidos cinámicos, amino ácidos, amido carbamatos, antibiótico glucopiranosil, polioxinas.

Reductasa en la biosíntesis de melanina deshidratasa.Grupos: isobenzofuranona, pirroloquinolinona, triazobenzotiazol, ciclopropanocarboxamida, propionamida Ruta del ácido salicílico. Grupos: benzo-tiadizol

Actividad de contacto multisitio. Grupos: inorgánicos (sales $\mathrm{Cu}, \mathrm{S}$ ), ditiocarbamatos y próximos, ftalimidas, cloronitrilos, sulfamidas, guanidinas, quinonas.

Fungicidas de mecanismo de acción desconocido Cianoacetamidaoxima, fosfonatos 


\section{CAPÍTULO 2}

\section{1) Resultados AFM1 en leche por método IAC-UHPLC-MS/MS}

Tabla S1. Resultados del análisis de aflatoxina M1 en las 160 muestras de leche analizadas por el método IAC y UHPLC-MS/MS.

\begin{tabular}{|c|c|c|c|c|}
\hline \multirow[b]{2}{*}{ Tambo } & \multicolumn{4}{|c|}{ Concentración AFM1 $\mu \mathrm{g} / \mathrm{L}$} \\
\hline & Primavera & Verano & Invierno & Otoño \\
\hline 1 & 0,006 & 0,031 & 0,025 & 0,043 \\
\hline 2 & 0,003 & 0,126 & $<\mathrm{LD}$ & 0,022 \\
\hline 3 & & & 0,015 & 0,033 \\
\hline 4 & & & & 0,042 \\
\hline 5 & & 0,012 & & \\
\hline 6 & 0,043 & & & \\
\hline 7 & & & & 0,009 \\
\hline 8 & $<L D$ & & 0,009 & 0,014 \\
\hline 9 & & & & 0,011 \\
\hline 10 & 0,006 & & $<L D$ & \\
\hline 11 & $<L D$ & & & \\
\hline 12 & 0,010 & & & \\
\hline 13 & 0,007 & & & \\
\hline 14 & 0,004 & 0,012 & 0,013 & 0,020 \\
\hline 15 & 0,009 & & 0,013 & \\
\hline 16 & 0,005 & & & \\
\hline \multicolumn{5}{|l|}{17} \\
\hline \multicolumn{5}{|l|}{18} \\
\hline 19 & & 0,051 & & \\
\hline 20 & & 0,005 & 0,039 & \\
\hline 21 & 0,056 & & 0,107 & 0,128 \\
\hline 22 & 0,010 & 0,007 & 0,293 & \\
\hline 23 & & & & 0,032 \\
\hline 24 & & 0,021 & & 0,028 \\
\hline 25 & & 0,004 & & \\
\hline \multicolumn{5}{|l|}{26} \\
\hline 27 & $<\mathrm{LD}$ & 0,004 & & \\
\hline 28 & 0,080 & & & \\
\hline 29 & $<L D$ & & & \\
\hline 30 & 0,015 & 0,012 & 0,014 & $<L D$ \\
\hline 31 & $<L D$ & 0,028 & & 0,013 \\
\hline 32 & $<\mathrm{LD}$ & & & \\
\hline 33 & 0,185 & 0,013 & 0,026 & $<L D$ \\
\hline 34 & & 0,005 & 0,105 & 0,078 \\
\hline 35 & & 0,020 & & \\
\hline 36 & & 0,011 & & \\
\hline 37 & & 0,010 & 0,018 & \\
\hline 38 & & 0,079 & 0,192 & 0,021 \\
\hline 39 & & & 0,016 & \\
\hline 40 & & 0,010 & & 0,018 \\
\hline
\end{tabular}

Celda vacía indica no detectado (ND). <LD: muestras en las que se observaron señales características de AFM1 pero que no satisficieron completamente los criterios de identificación y confirmación. 


\section{2) Diseño de experimento para optimización cromatográfica.}

Clase de diseño: Superficie de Respuesta

Nombre del Diseño: Factorial de 3 niveles: $3^{\wedge} 2$

\section{Diseño Base}

Número de factores experimentales: 2

Número de bloques: 1

Número de respuestas: 1

Número de corridas: 9

Grados de libertad para el error: 3

Aleatorizar: Sí

\begin{tabular}{|l|l|l|l|l|}
\hline Factores & Bajo & Alto & Unidades & Continuo \\
\hline Conc FNH4 & 0.5 & 10 & $\mathrm{mM}$ & Sí \\
\hline \% Ácido Fórmico & 0 & 0.5 & $\% \mathrm{v} / \mathrm{v}$ & Sí \\
\hline
\end{tabular}

\begin{tabular}{|c|c|c|c|c|c|c|c|c|c|}
\hline \multirow[b]{2}{*}{ PUNTO } & \multicolumn{4}{|c|}{ Composición Fase Móvil } & \multicolumn{5}{|c|}{ Respuesta cromatográfica* } \\
\hline & $\begin{array}{c}{\left[\mathrm{FNH}_{4}\right]} \\
\mathrm{mM}\end{array}$ & $\begin{array}{l}\% \mathrm{AF} \\
\% \mathrm{v} / \mathrm{v}\end{array}$ & $\mathrm{pH} \mathrm{A}$ & $\mathrm{pH} \mathrm{B}$ & Área & Altura & $\begin{array}{c}\text { Ancho } \\
\text { (seg) }\end{array}$ & $\mathrm{tR}(\mathrm{min})$ & $\mathrm{S} / \mathrm{N}$ \\
\hline 1 & 0,5 & 0 & 5 & 5 & 21503 & 500687 & 7,23 & 2,84 & 5487 \\
\hline 2 & 0,5 & 0,25 & 2 & 4 & 14065 & 322955 & 6,60 & 2,87 & 5003 \\
\hline 3 & 5,25 & 0,25 & 2 & 4 & 19438 & 450926 & 7,55 & 2,82 & 4714 \\
\hline 4 & 10 & 0 & 5 & 6 & 27463 & 660117 & 7,66 & 2,82 & 6204 \\
\hline 5 & 5,25 & 0 & 5 & $5-6$ & 28648 & 683715 & 7,77 & 2,83 & 9041 \\
\hline 6 & 0,5 & 0,5 & $2-3$ & 4 & 24140 & 567575 & 6,59 & 2,84 & 6915 \\
\hline 7 & 10 & 0,5 & $2-3$ & 4 & 26394 & 638227 & 6,38 & 2,81 & 8263 \\
\hline 8 & 5,25 & 0,5 & $2-3$ & 4 & 26296 & 635171 & 5,85 & 2,80 & 8614 \\
\hline 9 & 10 & 0,25 & 3 & $4-5$ & 27103 & 641037 & 8,09 & 2,82 & 7989 \\
\hline
\end{tabular}

* Parámetros cromatográficos del pico de la transición 329>273 (Q). Promedios de 4 inyecciones.

Análisis estadístico del diseño

\begin{tabular}{|c|c|c|c|c|c|c|c|c|}
\hline \multirow[b]{2}{*}{ Efecto } & \multicolumn{3}{|c|}{ Efectos estimados para Área AFM1 } & \multicolumn{5}{|c|}{ Análisis de Varianza para Área AFM1 } \\
\hline & Estimado & Error Estd. & V.I.F. & Suma de Cuadrados & $G l$ & Cuadrado Medio & Razón-F & Valor-P \\
\hline A:Conc FNH4 & 7084,0 & 2832,06 & 1,0 & 7,52746E7 & 1 & 7,52746E7 & 6,26 & 0,0876 \\
\hline B:\% Ácido Fórmico & $-261,333$ & 2832,06 & 1,0 & 102443, & 1 & 102443, & 0,01 & 0,9323 \\
\hline AA & $-2698,67$ & 4905,27 & 1,0 & 3,6414E6 & 1 & 3,6414E6 & 0,30 & 0,6205 \\
\hline $\mathrm{AB}$ & $-1853,0$ & 3468,55 & 1,0 & 3,43361E6 & 1 & $3,43361 \mathrm{E} 6$ & 0,29 & 0,6302 \\
\hline $\mathrm{BB}$ & 11077,3 & 4905,27 & 1,0 & $6,13537 \mathrm{E} 7$ & 1 & $6,13537 \mathrm{E} 7$ & 5,10 & 0,1091 \\
\hline Error total & & & & $3,60924 \mathrm{E} 7$ & 3 & $1,20308 \mathrm{E} 7$ & & \\
\hline Total (corr.) & & & & $1,79898 \mathrm{E} 8$ & 8 & & & \\
\hline promedio & 21101,6 & 2585,3 & & & & & & \\
\hline
\end{tabular}

R-cuadrada $=79,9373$ porciento

R-cuadrada (ajustada por g.l.) $=46,4994$ porciento

Error estándar del est. $=3468,55$

Error absoluto medio $=1740,25$

Estadístico Durbin-Watson $=1,47096(\mathrm{P}=0,1117)$

Autocorrelación residual de Lag $1=0,0593643$
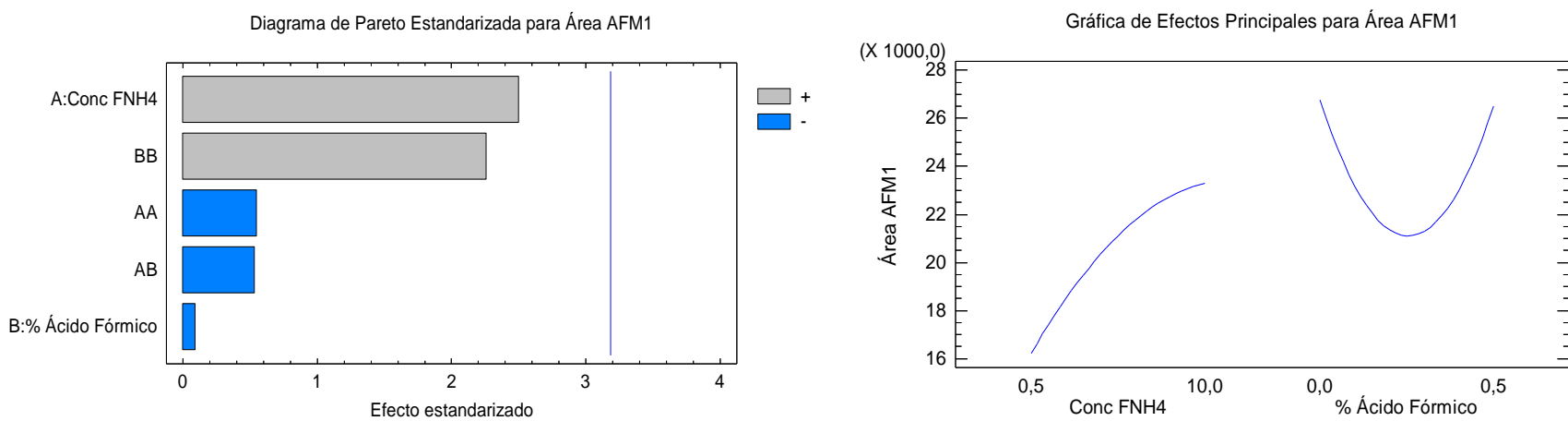


\section{3) Diseño de experimento para optimización de la extracción QuEChERS}

Clase de diseño: Superficie de Respuesta

Nombre del Diseño: Factorial de 3 niveles: $3^{\wedge} 2$

\section{Diseño Base}

Número de factores experimentales: 2

Número de bloques: 1

Número de respuestas: 1

Número de corridas: 9

Grados de libertad para el error: 3

Aleatorizar: Sí

\begin{tabular}{|l|l|l|l|l|}
\hline Factores & Bajo & Alto & Unidades & Continuo \\
\hline Tpo Agit & 3 & 10 & $\mathrm{~min}$ & Sí \\
\hline C18 & 50 & 200 & $\mathrm{mg}$ & Sí \\
\hline
\end{tabular}

\begin{tabular}{|l|l|l|l|l|}
\hline Respuestas & Unidades & & & \\
\hline Recuperacion & & & & \\
\hline
\end{tabular}

\begin{tabular}{cccc}
\hline $\begin{array}{c}\text { PUNTO } \\
\text { DDE }\end{array}$ & Tiempo agitación $(\mathrm{min})$ & Cantidad de C18 $(\mathrm{mg})$ & $\begin{array}{c}\text { Respuesta } \\
\text { (\%REC AFM1) }\end{array}$ \\
\hline 1 & 6,5 & 200,0 & 79.9 \\
2 & 10,0 & 125,0 & 108.6 \\
3 & 3,0 & 50,0 & 84.4 \\
4 & 6,5 & 125,0 & 101.5 \\
5 & 6,5 & 50,0 & 110.5 \\
6 & 3,0 & 125,0 & 80.9 \\
7 & 10,0 & 50,0 & 103.9 \\
8 & 10,0 & 200,0 & 58.8 \\
9 & 3,0 & 200,0 & 74.5 \\
\hline
\end{tabular}

Análisis estadístico del diseño

\begin{tabular}{|c|c|c|c|c|c|c|c|c|}
\hline \multirow[b]{2}{*}{ Efecto } & \multicolumn{3}{|c|}{ Efectos estimados para \% REC } & \multicolumn{5}{|c|}{ Análisis de Varianza para \%REC } \\
\hline & Estimado & Error Estd. & V.I.F. & Suma de Cuadrados & $G l$ & Cuadrado Medio & Razón-F & Valor- $P$ \\
\hline A:Tpo Agit & 10,5333 & 7,49436 & 1,0 & 166,427 & 1 & 166,427 & 1,98 & 0,2545 \\
\hline $\mathrm{B}: \mathrm{C} 18$ & $-28,5667$ & 7,49436 & 1,0 & 1224,08 & 1 & 1224,08 & 14,53 & 0,0318 \\
\hline AA & $-24,2$ & 12,9806 & 1,0 & 292,82 & 1 & 292,82 & 3,48 & 0,1591 \\
\hline $\mathrm{AB}$ & $-17,65$ & 9,17867 & 1,0 & 311,522 & 1 & 311,522 & 3,70 & 0,1502 \\
\hline BB & $-23,3$ & 12,9806 & 1,0 & 271,445 & 1 & 271,445 & 3,22 & 0,1705 \\
\hline Error total & & & & 252,744 & 3 & 84,2481 & & \\
\hline Total (corr.) & & & & 2519,04 & 8 & & & \\
\hline promedio & 105,067 & 6,84138 & & & & & & \\
\hline
\end{tabular}

R-cuadrada $=89,9666$ porciento

R-cuadrada (ajustada por g.l.) $=73,2444$ porciento

Error estándar del est. $=9,17867$

Error absoluto medio $=4,60741$

Estadístico Durbin-Watson $=1,5762(\mathrm{P}=0,5536)$

Autocorrelación residual de Lag $1=0,180518$
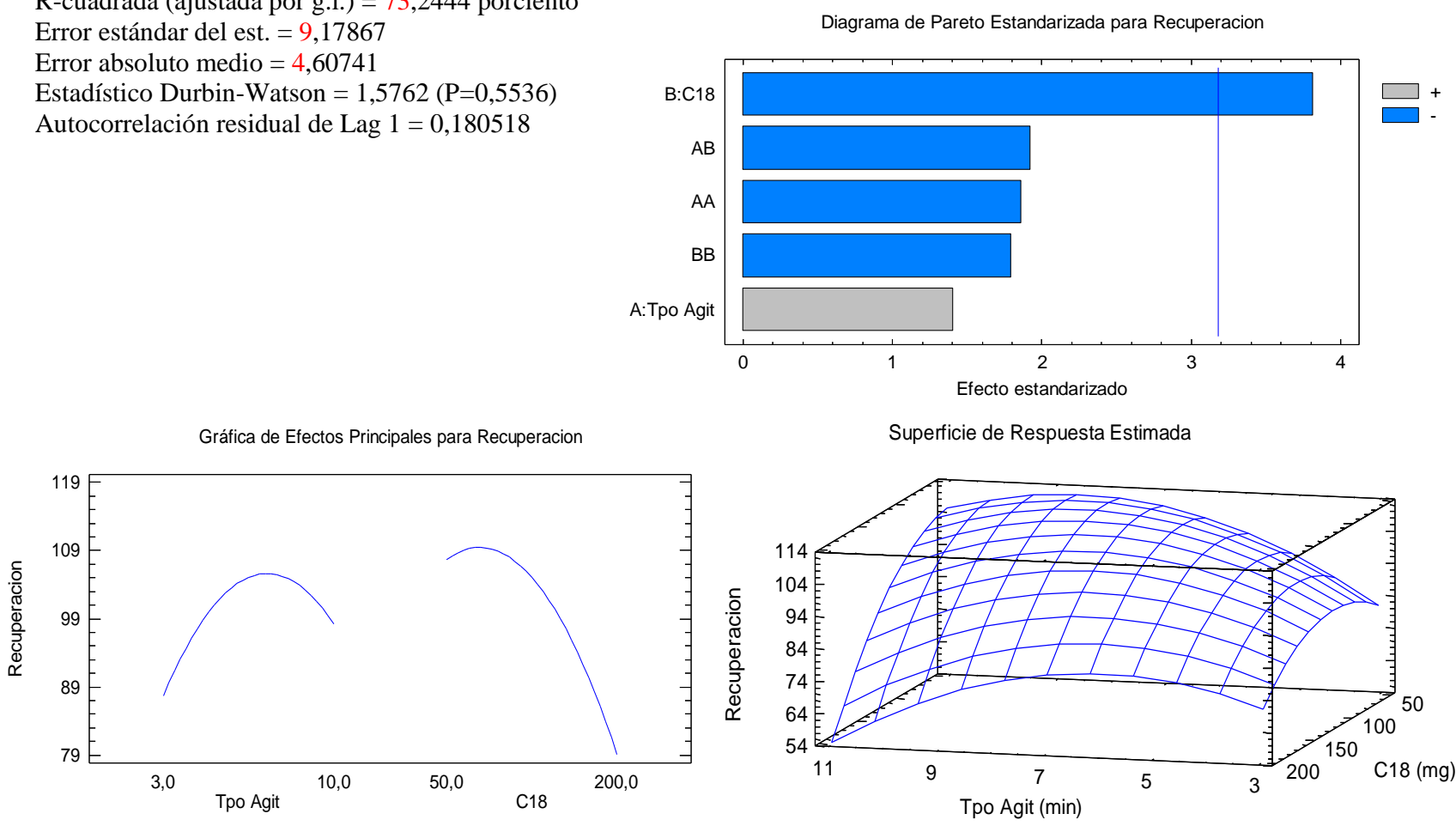
4) Verificación de la performance del método de extracción QuEChERS versus la del método IAC en la cuantificación de AFM1 en leche cruda.

\title{
-Test de comparación de muestras pareadas
}

Conjunto de datos:

\begin{tabular}{ccc}
\hline & \multicolumn{2}{c}{ Conc. AFM1 $(\mathrm{ppb})$} \\
\cline { 2 - 3 } Muestra & IAC & QuEChERS \\
\hline $25 \mathrm{~V}$ & 0,004 & 0,007 \\
$27 \mathrm{~V}$ & 0,004 & 0,006 \\
$22 \mathrm{~V}$ & 0,007 & 0,014 \\
$37 \mathrm{~V}$ & 0,010 & 0,005 \\
$40 \mathrm{~V}$ & 0,010 & 0,008 \\
$14 \mathrm{~V}$ & 0,012 & 0,023 \\
$30 \mathrm{~V}$ & 0,012 & 0,013 \\
$5 \mathrm{~V}$ & 0,012 & 0,014 \\
$33 \mathrm{~V}$ & 0,013 & 0,008 \\
$41 \mathrm{~V}$ & 0,016 & 0,016 \\
$37 \mathrm{I}$ & 0,018 & 0,013 \\
$35 \mathrm{~V}$ & 0,020 & 0,013 \\
$24 \mathrm{~V}$ & 0,021 & 0,035 \\
$31 \mathrm{~V}$ & 0,028 & 0,017 \\
$1 \mathrm{~V}$ & 0,031 & 0,026 \\
10 & 0,043 & 0,041 \\
$19 \mathrm{~V}$ & 0,054 & 0,069 \\
$38 \mathrm{~V}$ & 0,079 & 0,099 \\
$2 \mathrm{~V}$ & 0,126 & 0,128 \\
210 & 0,187 & 0,189 \\
\hline
\end{tabular}

\author{
Salidas Statgraphics \\ Prueba de Hipótesis para IAC-QuEChERS \\ Media Muestral $=-0,00185$ \\ Mediana Muestral $=-0,0015$ \\ Desviación Estándar de la Muestra = 0,00803463 \\ Prueba t \\ Hipótesis Nula: media $=0,0$ \\ Alternativa: no igual \\ Estadístico $\mathrm{t}=-1,02972$ \\ Valor-P $=0,316071$ \\ No se rechaza la hipótesis nula para alfa $=0,05$.
}

\section{El StatAdvisor}

Esta ventana muestra los resultados de las pruebas relativas a la población de la cual procede la muestra de IAC-QuEChERS. La prueba-t evalúa la hipótesis de que la media de IAC-QuEChERS es igual a 0,0 versus la hipótesis alterna de que la media de IACQuEChERS es no igual a 0,0. Debido a que el valor-P para esta prueba es mayor o igual a 0,05 , no se puede rechazar la hipótesis nula, con un nivel de confianza del 95,0\%.

-Modelo de Regresión Simple - QuEChERS vs. IAC

Variable dependiente: QuEChERS

Variable independiente: IAC

Lineal: $\mathrm{Y}=\mathrm{a}+\mathrm{b} * \mathrm{X}$

\section{Coeficientes}

\begin{tabular}{lllll}
\hline & Mín. Cuad. & Estándar & Estadístico & \\
\hline Parámetro & Estimado & Error & $T$ & Valor-P \\
Intercepto & 0,000704938 & 0,00230144 & 0,306303 & 0,7629 \\
Pendiente & 1,03239 & 0,0400936 & 25,7495 & 0,0000 \\
\hline
\end{tabular}

Análisis de Varianza

\begin{tabular}{llllll}
\hline Fuente & Suma de Cuad. & Gl & Cuad. Medio & Razón-F & Valor-P \\
\hline Modelo & 0,0435996 & 1 & 0,0435996 & 663,04 & 0,0000 \\
Residuo & 0,00118363 & 18 & 0,000065757 & & \\
Total (Corr.) & 0,0447832 & 19 & & & \\
\hline
\end{tabular}

Coeficiente de Correlación $=0,986696$

$\mathrm{R}$-cuadrada $=97,357$ porciento

R-cuadrado (ajustado para g.1.) $=97,2101$ porciento

Error estándar del est. $=0,00810908$

Error absoluto medio $=0,00621088$

Estadístico Durbin-Watson $=1,98491(\mathrm{P}=0,3922)$

Autocorrelación de residuos en retraso $1=-0,00401674$

\section{El StatAdvisor}

La salida muestra los resultados de ajustar un modelo lineal para describir la relación entre QuEChERS y IAC. La ecuación del modelo ajustado es

$$
\text { QuEChERS }=0,000704938+1,03239 * \text { IAC }
$$

Puesto que el valor-P en la tabla ANOVA es menor que 0,05 , existe una relación estadísticamente significativa entre QuEChERS y IAC con un nivel de confianza del 95,0\%.
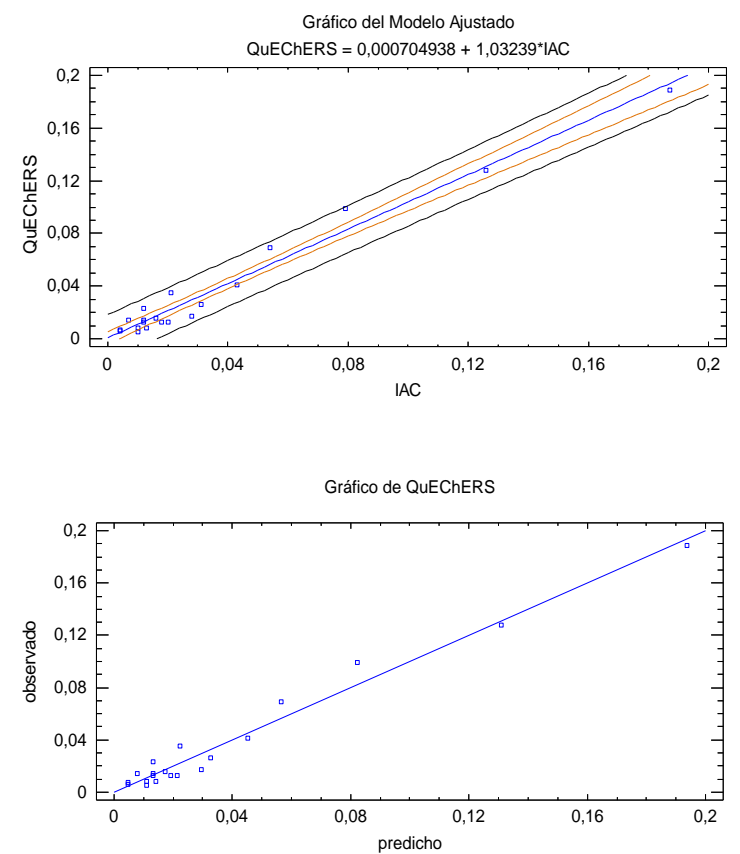


\section{CAPÍTULO 4}

1) Recuperaciones obtenidas para el total de compuestos determinados por LC-MS/MS y GCMS/MS.

Tabla S4-1. Porcentajes de recuperación de todos los compuestos analizados mediante extracción QuEChERS y determinación por UHPLC-MS/MS y GC-MS/MS.

\begin{tabular}{|llllllll|}
\hline & \multicolumn{3}{l|}{ Nivel adicionado $\mu \mathrm{g} / \mathrm{kg}$} \\
\cline { 2 - 3 } \cline { 5 - 6 } & \multicolumn{2}{l}{ LC-MS/MS } & & GC-MS/MS & \\
\hline Compuesto & 10 & 100 & & 25 & 50 & 100 \\
\hline
\end{tabular}

2,4-DB-Methylester

2-hydroxypropyl-

mepanipyrim

Acephate

Acetamiprid

Acetochlor

Aclonifen

Acrinathrin

Alachlor

Aldicarb

Aldicarb-sulfone

Aldicarb-sulfoxide

Aldrin

Ametryn

Aminopyralid

Asulam

Atrazine

Avermectin-B1a

Avermectin-B1b

Azadirachtin

Azinphos-ethyl

Azinphos-methyl

Azoxystrobin

Benalaxyl

Bendiocarb

Beta-cyfluthrin

BHC-alph isomer

BHC-beta isomer

BHC-delta isomer

Bifenthrin

Bitertanol

Bixafen

Boscalid

Bromacil

Bromophos-ethyl

Bromophos-methyl

Bromopropylate

Bromuconazole

Bupirimate
$81 \quad 102$

$89 \quad 107$

$86 \quad 119$

$88 \quad 107$

$76 \quad 100$

$70 \quad 80$

$80 \quad 107$

$87 \quad 105$

$91 \quad 106$

$82 \quad 108$

$\begin{array}{lllll}77 & 119 & 44 & 79 & 85\end{array}$

$66 \quad 90$

$68 \quad 93$

$82 \quad 105$

$91 \quad 95$

$74 \quad 90$

$72 \quad 88$

$81 \quad 116$

$82 \quad 108$

$86 \quad 103$

$77 \quad 116$

$83 \quad 113$

8191

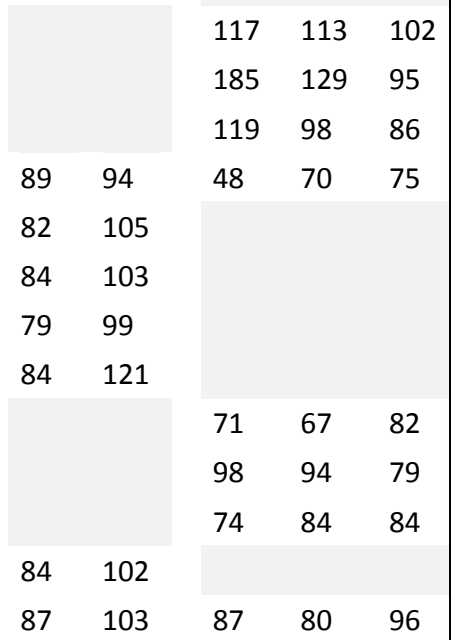

$\begin{array}{lllll}10 & 100 & 25 & 50 & 100 \\ - & 59 & & & \end{array}$

\begin{tabular}{|c|c|c|c|c|c|}
\hline \multirow[b]{3}{*}{ Compuesto } & \multicolumn{5}{|c|}{ Nivel adicionado $\mu \mathrm{g} / \mathrm{kg}$} \\
\hline & \multicolumn{2}{|c|}{ LC-MS/MS } & \multicolumn{3}{|c|}{ GC-MS/MS } \\
\hline & 10 & 100 & 25 & 50 & 100 \\
\hline Buprofezin & 83 & 105 & 24 & 21 & 66 \\
\hline Cadusafos & 83 & 102 & 101 & 120 & 113 \\
\hline Carbaryl & 86 & 109 & - & - & 97 \\
\hline Carbendazim & 96 & 109 & & & \\
\hline Carbofuran & 85 & 111 & & & \\
\hline Carbofuran-3-hydroxy & 91 & 116 & & & \\
\hline Carbophenothion & 80 & 92 & 47 & 73 & 73 \\
\hline Carbosulfan & 221 & 21 & - & - & - \\
\hline Carboxin & 68 & 90 & & & \\
\hline Chinomethionate & 82 & 93 & 45 & 40 & 38 \\
\hline Chlorantraniprole & 82 & 100 & & & \\
\hline Chlordane,cis- & & & 76 & 80 & 85 \\
\hline Chlordane,trans- & & & 90 & 79 & 80 \\
\hline Chlorfenapyr & & & 160 & 86 & 117 \\
\hline Chlorfenvinphos & 79 & 106 & 119 & 102 & 91 \\
\hline Chloridazon & 90 & 110 & & & \\
\hline Chlorobenzilate & & & 43 & 76 & 87 \\
\hline Chlorothalonil & & & - & - & - \\
\hline Chlorotoluron & 86 & 115 & & & \\
\hline Chloroxuron & 82 & 99 & & & \\
\hline Chlorpropham & 75 & 98 & 18 & 70 & 71 \\
\hline Chlorpyrifos & 79 & 93 & 76 & 90 & 87 \\
\hline Chlorpyrifos-methyl & 68 & 97 & 92 & 83 & 89 \\
\hline Chlorsulfuron & 70 & 91 & & & \\
\hline Cinerin-I & 89 & 94 & & & \\
\hline Cinerin-II & 101 & 95 & & & \\
\hline Clofentezine & 78 & 95 & & & \\
\hline Clomazone & 87 & 105 & & & \\
\hline Clopyralid & 113 & 86 & & & \\
\hline Clothianidin & 94 & 122 & & & \\
\hline Cyanazine & 72 & 93 & - & - & - \\
\hline Cyazofamid & 81 & 98 & & & \\
\hline Cycloxidim & 67 & 85 & & & \\
\hline Cyfluthrin(sum) & & & - & 127 & 102 \\
\hline CyhalothrinI(lambda) & & & - & - & - \\
\hline Cymoxanil & 89 & 113 & & & \\
\hline Cypermethrin & 69 & 83 & 148 & 116 & 92 \\
\hline Cyproconazole & 85 & 103 & & & \\
\hline Cyprodinyl & 78 & 76 & 47 & 72 & 85 \\
\hline DDD,o,p'- & & & 53 & 70 & 76 \\
\hline DDD,p, $p^{\prime}-$ & & & 87 & 80 & 74 \\
\hline DDE,o,p'- & & & 33 & 55 & 73 \\
\hline DDE,p,p'- & & & 43 & 73 & 88 \\
\hline DDT,o,p'- & & & 265 & 168 & 99 \\
\hline DDT,p,p'- & & & - & 230 & 121 \\
\hline Deet & 89 & 102 & & & \\
\hline Deltamethrin & 76 & 90 & 148 & 116 & 91 \\
\hline
\end{tabular}




\begin{tabular}{|c|c|c|c|c|c|c|c|c|c|c|c|}
\hline \multirow[b]{3}{*}{ Compuesto } & \multicolumn{5}{|c|}{ Nivel adicionado $\mu \mathrm{g} / \mathrm{kg}$} & & \multicolumn{5}{|c|}{ Nivel adicionado $\mu \mathrm{g} / \mathrm{kg}$} \\
\hline & \multicolumn{2}{|c|}{ LC-MS/MS } & \multicolumn{3}{|c|}{ GC-MS/MS } & \multirow[b]{2}{*}{ Compuesto } & \multicolumn{2}{|c|}{ LC-MS/MS } & \multicolumn{3}{|c|}{ GC-MS/MS } \\
\hline & 10 & 100 & 25 & 50 & 100 & & 10 & 100 & 25 & 50 & 100 \\
\hline Demeton-S-methyl & 83 & 117 & & & & Etofenprox & 79 & 94 & & & \\
\hline Demeton-S-methyl-sulfone & 90 & 116 & & & & Etrimfos & 81 & 103 & 2500 & 1352 & 749 \\
\hline Desmedipham & 83 & 104 & & & & Famoxadone & 81 & 105 & & & \\
\hline Desmethyl-pirimicarb & 84 & 116 & & & & Fenamidone & 77 & 100 & 74 & 81 & 79 \\
\hline Desmetryn & 80 & 110 & 45 & 76 & 82 & Fenamiphos & 74 & 108 & 137 & 103 & 94 \\
\hline Diazinon & 66 & 102 & 11 & 33 & 57 & Fenamiphos-sulfone & 76 & 113 & - & 211 & 131 \\
\hline Dibrom (Naled) & 80 & 87 & - & - & - & Fenamiphos-sulfoxide & 85 & 107 & & & \\
\hline Dichlobenil & & & 152 & 162 & 127 & Fenarimol & 82 & 98 & 97 & 87 & 83 \\
\hline Dichlofluanid & 78 & 95 & - & - & - & Fenazaquin & 51 & 89 & & & \\
\hline Dichlormid & 84 & 106 & & & & Fenbuconazole & 80 & 100 & & & \\
\hline Dichlorobenzophenone,4,4'- & & & 46 & 69 & 76 & Fenbutatin-oxide & 69 & 83 & & & \\
\hline Dichlorvos & 87 & 115 & 46 & 29 & 38 & Fenhexamid & 76 & 93 & & & \\
\hline Diclofop-methyl & 74 & 99 & 28 & 43 & 66 & Fenitrothion & & & 213 & 122 & 85 \\
\hline Dicloran(Dichloran)(DCNA) & & & 104 & 93 & 83 & Fenoxaprop & 66 & 91 & & & \\
\hline Dicrotophos & 96 & 116 & - & - & 111 & Fenoxaprop-ethyl & 68 & 102 & & & \\
\hline Dieldrin & & & - & 78 & 97 & Fenoxycarb & 70 & 103 & - & - & - \\
\hline Diethofencarb & 78 & 108 & & & & Fenpropathrin & 77 & 75 & & & \\
\hline Difenoconazole & 70 & 96 & 54 & 68 & 80 & Fenpropidin & 81 & 101 & & & \\
\hline Diflubenzuron & 81 & 102 & & & & Fenpropimorph & 81 & 102 & & & \\
\hline Diflufenican & 82 & 94 & & & & Fenpyroximate & 75 & 92 & & & \\
\hline Dimethachlor & 83 & 103 & & & & Fensulfothion & 81 & 105 & 204 & 122 & 89 \\
\hline Dimethenamid & 83 & 110 & & & & Fenthion & 76 & 100 & 91 & 96 & 78 \\
\hline Dimethoate & 96 & 117 & - & - & - & Fenthion-sulfone & 78 & 100 & - & - & 83 \\
\hline Dimethomorph & 71 & 102 & & & & Fenthion-sulfoxide & 82 & 110 & - & - & - \\
\hline Dimoxystrobin & 76 & 114 & & & & Fentin & 68 & 81 & & & \\
\hline Diniconazole & 83 & 101 & & & & Fenvalerate I & & & - & 111 & 91 \\
\hline Dinotefuran & 78 & 104 & & & & Fenvalerate II & & & 208 & 131 & 105 \\
\hline Diphenylamine & & & 94 & 109 & 99 & Fipronil & 84 & 95 & & & \\
\hline Disulfoton & 81 & 109 & - & 109 & 85 & Flonicamid & 89 & 109 & & & \\
\hline Disulfoton-sulfone & 82 & 106 & - & 101 & 80 & Florasulam & 73 & 95 & & & \\
\hline Disulfoton-sulfoxide & 89 & 116 & & & & Fluacrypyrim & 81 & 107 & & & \\
\hline Diuron & 84 & 106 & & & & Fluazifop & 81 & 97 & & & \\
\hline DMSA & 78 & 107 & & & & Fluazifop-P-butyl & 80 & 99 & & & \\
\hline DMST & 70 & 106 & & & & Flubendiamide & 80 & 101 & & & \\
\hline Dodine & 62 & 78 & & & & Flucythrinate I & 84 & 95 & 117 & 99 & 90 \\
\hline Endosulfan(alpha isomer) & & & 37 & 55 & 86 & Flucythrinate II & 84 & 95 & 92 & 87 & 87 \\
\hline Endosulfan(beta isomer) & & & - & - & 73 & Fludioxonil & & & 371 & 238 & 165 \\
\hline Endosulfan sulfate & & & - & 121 & 94 & Flufenacet & 88 & 109 & & & \\
\hline Endrin & & & - & - & 130 & Flufenoxuron & 79 & 100 & & & \\
\hline EPN & 79 & 94 & & & & Flumioxazin & 81 & 100 & & & \\
\hline Epoxiconazole & 80 & 108 & & & & Fluopicolide & 76 & 108 & & & \\
\hline Ethametsulfuron-methyl & 75 & 109 & & & & Fluopyram & 82 & 109 & & & \\
\hline Ethiofencarb & 72 & 99 & & & & Fluotrimazol & 80 & 66 & & & \\
\hline Ethion & 74 & 104 & 70 & 82 & 90 & Fluoxastrobin & 77 & 111 & & & \\
\hline Ethirimol & 80 & 114 & & & & Fluquinconazole & 83 & 100 & & & \\
\hline Ethofumesate & 77 & 108 & & & & Flurochloridone & 84 & 99 & & & \\
\hline Ethoprophos & 88 & 112 & 118 & 125 & 109 & Fluroxypyr & 87 & 96 & & & \\
\hline
\end{tabular}




\begin{tabular}{|c|c|c|c|c|c|c|c|c|c|c|c|}
\hline \multirow[b]{3}{*}{ Compuesto } & \multicolumn{5}{|c|}{ Nivel adicionado $\mu \mathrm{g} / \mathrm{kg}$} & & \multicolumn{5}{|c|}{ Nivel adicionado $\mu \mathrm{g} / \mathrm{kg}$} \\
\hline & \multicolumn{2}{|c|}{ LC-MS/MS } & \multicolumn{3}{|c|}{ GC-MS/MS } & \multirow[b]{2}{*}{ Compuesto } & \multicolumn{2}{|c|}{ LC-MS/MS } & \multicolumn{3}{|c|}{ GC-MS/MS } \\
\hline & 10 & 100 & 25 & 50 & 100 & & 10 & 100 & 25 & 50 & 100 \\
\hline Flusilazole & 79 & 104 & & & & Malaoxon & 90 & 109 & - & - & 72 \\
\hline Flutolanil & 80 & 114 & & & & Malathion & 80 & 111 & 113 & 96 & 94 \\
\hline Flutriafol & 84 & 105 & & & & Mandipropamide & 78 & 108 & & & \\
\hline Fluvalinate (sum) & 71 & 82 & - & - & 79 & Mecarbam & 86 & 119 & - & 98 & 93 \\
\hline Fluxapyroxad & 76 & 105 & & & & Mefenpyr-diethyl & 82 & 101 & & & \\
\hline Fonofos & 83 & 94 & & & & Mepanipyrim & 77 & 98 & & & \\
\hline Foramsulfuron & 71 & 101 & & & & Mepronil & 83 & 102 & & & \\
\hline Formetanate & 78 & 103 & & & & Metaflumizone & 66 & 90 & & & \\
\hline Formothion & 75 & 125 & & & & Metalaxyl & 83 & 113 & - & 23 & 83 \\
\hline Fosthiazate & 88 & 109 & & & & Metamitron & 99 & 126 & - & - & - \\
\hline Furathiocarb & 81 & 102 & & & & Metazachlor & 77 & 114 & 134 & 101 & 89 \\
\hline Haloxyfop & 82 & 100 & & & & Metconazole & 83 & 103 & & & \\
\hline Haloxyfop-2-ethoxyethyl & 82 & 100 & 24 & 33 & 78 & Methacrifos & 84 & 108 & 107 & 119 & 108 \\
\hline Haloxyfop-methyl & 78 & 111 & 39 & 47 & 78 & Methamidophos & 74 & 81 & - & - & - \\
\hline Heptachlor & & & 141 & 107 & 80 & Methidathion & 80 & 107 & 239 & 144 & 104 \\
\hline Heptachlor endoepoxide & & & 66 & 61 & 46 & Methiocarb & 77 & 107 & - & - & 59 \\
\hline Heptachlor exoepoxide & & & - & 92 & 73 & Methiocarb-sulfone & 91 & 121 & & & \\
\hline Heptenophos & 79 & 115 & 98 & 87 & 87 & Methiocarb-sulfoxide & 94 & 111 & & & \\
\hline Hexachlorobenzene(HCB) & & & 42 & 65 & 72 & Methomyl & 88 & 124 & & & \\
\hline Hexaconazole & 82 & 105 & & & & Methoxychlor & & & 5 & 57 & 78 \\
\hline Hexazinon & 85 & 103 & & & & Methoxyfenozide & 82 & 105 & & & \\
\hline Hexythiazox & 79 & 95 & - & - & 97 & Metobromuron & 85 & 106 & & & \\
\hline Imazalil & 64 & 104 & 57 & 84 & 84 & Metolachlor & 80 & 110 & & & \\
\hline Imazamethabenz-methyl & 80 & 117 & & & & Metolcarb & 76 & 90 & & & \\
\hline Imazamox & 83 & 104 & & & & Metominostrobin $-E+Z$ & 99 & 112 & & & \\
\hline Imazapyr & 85 & 106 & & & & Metosulam & 66 & 100 & & & \\
\hline Imazaquin & 81 & 107 & & & & Metoxuron & 82 & 113 & & & \\
\hline Imazethapyr & 84 & 106 & & & & Metrafenone & 80 & 104 & & & \\
\hline Imazosulfuron & 76 & 99 & & & & Metribuzin & 130 & 166 & & & \\
\hline Imidacloprid & 95 & 119 & & & & Metsulfuron-methyl & 69 & 95 & & & \\
\hline Indoxacarb & 82 & 98 & & & & Mevinphos & 30 & 101 & 154 & 108 & 89 \\
\hline Iodosulfuron-methyl & 76 & 93 & & & & Monocrotophos & 99 & 118 & - & - & 89 \\
\hline Iprodione & 84 & 99 & - & 192 & 100 & Monolinuron & 85 & 106 & & & \\
\hline Iprovalicarb & 88 & 109 & & & & Monuron & 81 & 115 & & & \\
\hline Isofenphos & 77 & 107 & 76 & 88 & 91 & Myclobutanil & 84 & 102 & 60 & 71 & 85 \\
\hline Isophenphos-methyl & 87 & 103 & 73 & 87 & 89 & Napropamide & 85 & 105 & & & \\
\hline Isoprocarb & 81 & 107 & & & & Neburon & 79 & 110 & & & \\
\hline Isoprothiolane & 82 & 104 & & & & Neoquassin & 74 & 89 & & & \\
\hline Isoproturon & 81 & 105 & & & & Nicosulfuron & 78 & 104 & & & \\
\hline Jasmolin-I & 71 & 87 & & & & Nitenpyram & 83 & 102 & & & \\
\hline Jasmolin-II & 91 & 97 & & & & Nitrofen & & & - & 218 & 133 \\
\hline Kresoxim-methyl & 76 & 106 & 78 & 90 & 94 & Norflurazon & 82 & 103 & & & \\
\hline Lambda-cyhalothrin & 75 & 93 & & & & Nuarimol & & & 67 & 84 & 87 \\
\hline Lenacil & 81 & 106 & & & & Omethoate & 80 & 104 & - & - & - \\
\hline Lindane $(\gamma-\mathrm{BHC}, \gamma-\mathrm{HCH})$ & & & 193 & 153 & 112 & Oxadixyl & 86 & 113 & - & 116 & 103 \\
\hline Linuron & 80 & 105 & & & & Oxamyl & 97 & 111 & & & \\
\hline Lufenuron & 83 & 100 & & & & Oxydemeton-methyl & 97 & 125 & & & \\
\hline
\end{tabular}




\begin{tabular}{|c|c|c|c|c|c|c|c|c|c|c|c|}
\hline \multirow[b]{3}{*}{ Compuesto } & \multicolumn{5}{|c|}{ Nivel adicionado $\mu \mathrm{g} / \mathrm{kg}$} & \multirow[b]{3}{*}{ Compuesto } & \multicolumn{5}{|c|}{ Nivel adicionado $\mu \mathrm{g} / \mathrm{kg}$} \\
\hline & \multicolumn{2}{|c|}{ LC-MS/MS } & \multicolumn{3}{|c|}{ GC-MS/MS } & & \multicolumn{2}{|c|}{ LC-MS/MS } & \multicolumn{3}{|c|}{ GC-MS/MS } \\
\hline & 10 & 100 & 25 & 50 & 100 & & 10 & 100 & 25 & 50 & 100 \\
\hline Oxyfluorfen & & & - & 99 & 82 & Proquinazid & 51 & 74 & & & \\
\hline Oxyfluorfen-druhy & 76 & 102 & & & & Prosulfocarb & 81 & 100 & & & \\
\hline Paclobutrazol & 82 & 106 & & & & Prothioconazole-desthio & 84 & 98 & & & \\
\hline Paraoxon & & & - & - & - & Prothiophos (Tokuthion) & 66 & 70 & 33 & 63 & 66 \\
\hline Paraoxon-methyl & & & - & - & - & Pymetrozine & 35 & 34 & & & \\
\hline Parathion & & & 268 & 155 & 107 & Pyraclostrobin & 76 & 110 & & & \\
\hline Parathion-methyl & & & - & 105 & 80 & Pyrazophos & 84 & 97 & 165 & 112 & 86 \\
\hline Penconazole & 82 & 103 & 32 & 65 & 79 & Pyrethrin-I & 78 & 76 & & & \\
\hline Pencycuron & 80 & 101 & 85 & 89 & 89 & Pyrethrin-II & 80 & 88 & & & \\
\hline Pendimethalin & 79 & 93 & 177 & 115 & 87 & Pyridaben & 53 & 68 & 78 & 81 & 81 \\
\hline Permethrin (sum) & 86 & 72 & 2 & 16 & 49 & Pyridaphenthion & & & 179 & 121 & 90 \\
\hline Pethoxamid & 83 & 106 & & & & Pyridate & 75 & 93 & & & \\
\hline Phenmedipham & 83 & 105 & & & & Pyrifenox & 88 & 104 & & & \\
\hline Phenothrin (sum) & 79 & 92 & - & 7 & 36 & Pyrimethanil & 78 & 91 & & & \\
\hline Phentoate & 78 & 108 & 84 & 97 & 87 & Pyriproxyfen & 79 & 98 & & & \\
\hline Phenylphenol,2-(OPP) & & & 87 & 95 & 105 & Quassin & 80 & 94 & & & \\
\hline Phorate & 80 & 105 & & & & Quinalphos & 79 & 101 & 93 & 96 & 89 \\
\hline Phorate-sulfone & 84 & 110 & & & & Quinclorac & 76 & 97 & & & \\
\hline Phorate-sulfoxide & 86 & 112 & & & & Quinmerac & 88 & 122 & & & \\
\hline Phosalone & 76 & 102 & 160 & 112 & 80 & Quinoclamine & 84 & 99 & & & \\
\hline Phosmet & 74 & 108 & - & - & - & Quinoxyfen & 75 & 94 & & & \\
\hline Phosphamidon I & 88 & 108 & - & - & 121 & Quintozene (PCNB) & & & 101 & 100 & 89 \\
\hline Phosphamidon II & 88 & 108 & - & - & 30 & Quizalofop & 78 & 96 & & & \\
\hline Phoxim & 77 & 98 & & & & Quizalofop-ethyl & 72 & 107 & & & \\
\hline Picloram & 59 & 92 & & & & Resmethrine (sum) & 73 & 76 & - & - & - \\
\hline Picolinafen & 77 & 103 & & & & Rimsulfuron & 59 & 95 & & & \\
\hline Picoxystrobin & 79 & 106 & & & & Ronnel (Fenchlorphos) & & & 92 & 79 & 83 \\
\hline Pinoxaden & 75 & 113 & & & & Rotenone & 80 & 97 & & & \\
\hline Piperonyl-butoxide & 85 & 109 & & & & Simazine & 79 & 117 & & & \\
\hline Pirimicarb & 82 & 116 & 94 & 108 & 108 & Simetryn & 83 & 105 & 33 & 60 & 77 \\
\hline Pirimiphos-ethyl & 80 & 101 & 86 & 84 & 84 & Spinosyn-A & 73 & 111 & & & \\
\hline Pirimiphos-methyl & 76 & 99 & 135 & 104 & 99 & Spinosyn-D & 79 & 101 & & & \\
\hline Prochloraz & 84 & 107 & & & & Spirodiclofen & 73 & 86 & & & \\
\hline Procymidone & & & 72 & 90 & 95 & Spiromesifen & 77 & 98 & & & \\
\hline Profenofos & 79 & 102 & 112 & 92 & 82 & Spirotetramat & 82 & 99 & & & \\
\hline Prometon & 83 & 114 & 27 & 78 & 82 & Spiroxamin & 82 & 106 & & & \\
\hline Prometryn & 81 & 109 & & & & Sulfosulfuron & 81 & 100 & & & \\
\hline Propachlor & 80 & 113 & & & & Sulfotep & 83 & 102 & 92 & 103 & 108 \\
\hline Propamocarb & 52 & 103 & & & & Tebuconazole & 103 & 114 & 37 & 78 & 81 \\
\hline Propaquizafop & 77 & 103 & & & & Tebufenozide & 79 & 104 & & & \\
\hline Propargite & 79 & 101 & - & - & 102 & Tebufenpyrad & 82 & 97 & & & \\
\hline Propazine & 83 & 107 & & & & Tecnazene (TCNB) & & & - & 107 & 106 \\
\hline Propham & 97 & 97 & - & - & 127 & Teflubenzuron & 75 & 101 & & & \\
\hline Propiconazole & 83 & 100 & & & & Tefluthrin,cis- & & & 66 & 96 & 95 \\
\hline Propoxur & 96 & 124 & 99 & 91 & 78 & Tepraloxydim & 77 & 98 & & & \\
\hline Propoxycarbazone & 84 & 96 & & & & Terbufos & 75 & 109 & 64 & 90 & 90 \\
\hline Propyzamide & 77 & 105 & & & & Terbufos-sulfone & 83 & 111 & - & 119 & 85 \\
\hline
\end{tabular}




\begin{tabular}{|c|c|c|c|c|c|}
\hline \multirow[b]{3}{*}{ Compuesto } & \multicolumn{5}{|c|}{ Nivel adicionado $\mu \mathrm{g} / \mathrm{kg}$} \\
\hline & \multicolumn{2}{|c|}{ LC-MS/MS } & \multicolumn{3}{|c|}{ GC-MS/MS } \\
\hline & 10 & 100 & 25 & 50 & 100 \\
\hline Terbufos-sulfoxide & 78 & 117 & & & \\
\hline Terbuthylazine & 82 & 103 & & & \\
\hline Terbutryn & 83 & 102 & & & \\
\hline Tetraconazole & 84 & 102 & 81 & 96 & 93 \\
\hline Tetradifon & & & - & 69 & 78 \\
\hline Tetrahydrophtalimide & & & - & - & 76 \\
\hline Tetramethrin & 84 & 101 & & & \\
\hline Thiabendazole & 77 & 110 & - & - & 60 \\
\hline Thiacloprid & 87 & 105 & & & \\
\hline Thiamethoxam & 98 & 119 & & & \\
\hline Thifensulfuron-methyl & 74 & 90 & & & \\
\hline Thiodicarb & 88 & 106 & & & \\
\hline Thiometon & - & 79 & - & 106 & 84 \\
\hline Thiophanate-methyl & 50 & 89 & & & \\
\hline Tolcofos-methyl & 86 & 94 & 79 & 98 & 91 \\
\hline Tolylfluanid & 76 & 102 & - & - & - \\
\hline Triadimefon & 83 & 101 & 76 & 88 & 98 \\
\hline Triadimenol & 82 & 105 & 4 & 64 & 84 \\
\hline Triasulfuron & 71 & 89 & & & \\
\hline Triazophos & 80 & 101 & 144 & 102 & 85 \\
\hline Tribenuron-methyl & 47 & 124 & & & \\
\hline Trichlorfon & 83 & 115 & - & - & 47 \\
\hline Tricyclazole & 78 & 107 & & & \\
\hline Trifloxystrobin & 81 & 102 & - & - & 18 \\
\hline Triflumuron & 82 & 103 & & & \\
\hline Trifluralin & & & 129 & 116 & 93 \\
\hline Triforine & 82 & 76 & & & \\
\hline Trinexapac-ethyl & 82 & 105 & & & \\
\hline Triphenylphosphate & & & - & - & - \\
\hline Triticonazole & - & 57 & & & \\
\hline Vamidothion & 94 & 114 & - & - & - \\
\hline Vinclozolin & & & 79 & 105 & 92 \\
\hline Zoxamide & 82 & 100 & & & \\
\hline
\end{tabular}

Las celdas con guión indican que el compuesto se analizó pero no se recuperó

(no se distinguió señal cromatográfica).

Las celdas color gris indican que el compuesto no se analizó en

la respectiva

determinación por LC o GC. 


\section{2) Parámetros intrumentales del análisis de 160 plaguicidas por GC-MS/MS}

Tabla S4-2. Parámetros instrumentales de detección y análisis de masa de plaguicidas por GC-MS/MS.

\begin{tabular}{|c|c|c|c|c|c|c|c|c|c|}
\hline \multirow[t]{2}{*}{ Compuesto } & \multicolumn{4}{|c|}{ Transiciones (m/z) } & \multicolumn{4}{|c|}{$\begin{array}{c}\text { Energía de colisión } \\
(\mathrm{eV})\end{array}$} & \multirow{2}{*}{$\begin{array}{l}\text { Dwell } \\
\text { (ms) }\end{array}$} \\
\hline & Q1 (cuantif.) & q2 (confirm.) & q3 (confirm.) & q4 (confirm.) & EC1 & $\mathrm{EC} 2$ & EC3 & EC4 & \\
\hline Acephate & $136,0>94,0$ & $142,0>96,0$ & $136,0>42,0$ & & 14 & 8 & 6 & & 8,7 \\
\hline Aldrin & $263,0>193,0$ & $298,0>263,0$ & $263,0>191,0$ & $257,0>222,0$ & 30 & 8 & 30 & 12 & 3,2 \\
\hline Ametryn & $227,0>185,0$ & $227,2>170,1$ & $227,2>152,1$ & $227,0>212,0$ & 5 & 20 & 20 & 8 & 3,6 \\
\hline Azinphos-ethyl & $160,0>132,0$ & $160,0>104,0$ & $132,0>104,0$ & $132,0>77,0$ & 8 & 8 & 12 & 12 & 8,2 \\
\hline Azinphos-methyl & $160,1>132,1$ & $160,1>102,1$ & $160,1>77,1$ & & 5 & 15 & 20 & & 4,7 \\
\hline Azoxystrobin & $344,0>329,0$ & $344,0>183,0$ & $344,0>156,0$ & & 15 & 20 & 25 & & 9,1 \\
\hline Bendiocarb & $166,0>151,0$ & $151,0>109,1$ & $151,0>107,0$ & $151,0>81,2$ & 10 & 10 & 10 & 10 & 3,7 \\
\hline $\mathrm{BHC}$ beta isomer & $181,0>145,0$ & $219,0>183,0$ & $219,0>145,0$ & $181,0>109,0$ & 15 & & & 30 & 2,8 \\
\hline $\mathrm{BHC}$ delta isomer & $219,0>183,0$ & $219,0>145,0$ & $181,0>109,0$ & $181,0>145,0$ & 10 & 20 & 15 & 15 & 3,3 \\
\hline BHC-alpha & $181,0>145,0$ & $219,0>145,0$ & $219,0>183,0$ & $181,0>109,0$ & 15 & 15 & 15 & 15 & 3,6 \\
\hline Bifenthrin & $181,0>165,0$ & $181,0>166,0$ & $166,0>165,0$ & & 25 & 25 & 16 & & 4,1 \\
\hline Bromophos methyl & $330,9>315,9$ & $330,9>285,9$ & $329,0>314,0$ & & 16 & 34 & 16 & & 3,9 \\
\hline Bromophos-ethyl & $359,0>303,0$ & $358,9>284,8$ & $358,7>331,0$ & & 14 & 35 & 4 & & 2,1 \\
\hline Bromopropylate & $341,0>185,0$ & $341,0>183,0$ & $183,0>155,0$ & & 20 & 20 & 15 & & 4,1 \\
\hline Bupirimate & $273,0>193,0$ & $316,1>208,2$ & $273,0>108,0$ & & 5 & 5 & 15 & & 2,7 \\
\hline Buprofezin & $105,0>77,0$ & $175,0>132,0$ & $105,0>104,0$ & & 20 & 10 & 8 & & 2,7 \\
\hline Cadusafos & $158,9>97,0$ & $159,0>97,0$ & $158,9>130,9$ & $158,9>78,9$ & 20 & 18 & 5 & 35 & 3,4 \\
\hline Carbaryl & $144,0>115,0$ & $144,0>116,0$ & $144,0>114,0$ & & 20 & 15 & 30 & & 3,6 \\
\hline Carbophenothion & $153,0>96,9$ & $199,0>143,0$ & $157,0>75,1$ & $153,0>79,0$ & 10 & 10 & 40 & 30 & 3,8 \\
\hline Carbosulfan & $164,0>149,2$ & $164,0>103,0$ & $149,0>77,1$ & & 10 & 25 & 32 & & 4,1 \\
\hline Chinomethionat & $206,0>148,0$ & $234,0>206,0$ & & & 15 & & & & 2,1 \\
\hline Chlordane, cis- & $272,0>237,0$ & $375,0>266,0$ & $372,7>266,1$ & & 16 & 25 & 25 & & 2,2 \\
\hline Chlordane, trans- & $372,7>266,1$ & $375,0>266,0$ & $272,0>237,0$ & & 25 & 25 & 16 & & 2,1 \\
\hline Chlorfenapyr & $247,0>227,0$ & $408,0>59,0$ & $247,0>200,0$ & $247,0>197,0$ & 15 & 10 & 25 & 20 & 2,9 \\
\hline Chlorfenvinphos & $267,0>159,0$ & $267,0>81,0$ & & & 20 & 40 & & & 2,8 \\
\hline Chlorobenzilate & $139,0>111,0$ & $139,1>111,0$ & $139,0>75,0$ & & 15 & 10 & 30 & & 2,9 \\
\hline Chlorothalonil & $265,9>230,9$ & $266,8>232,0$ & $266,8>239,8$ & & 20 & & & & 3,3 \\
\hline Chlorpropham (CIPC) & $171,0>127,0$ & $213,0>127,0$ & $213,0>171,0$ & & 10 & 5 & 5 & & 3,7 \\
\hline Chlorpyrifos & $196,9>169,0$ & $313,8>286,0$ & $313,8>258,0$ & $198,9>171,0$ & 15 & 14 & 14 & 15 & 3,2 \\
\hline Chlorpyrifos-methyl & $288,0>93,0$ & $287,9>272,7$ & $285,9>270,7$ & & 26 & 15 & & & 4,5 \\
\hline Cyanazine & $225,1>189,1$ & $212,1>151,1$ & $212,1>123,1$ & & 10 & 22 & 22 & & 3,2 \\
\hline Cyfluthrin (sum) & $163,0>127,0$ & $226,9>77,1$ & $206,0>151,0$ & $163,0>91,0$ & 5 & 30 & 25 & 15 & 6,8 \\
\hline Cyhalothrin I (lambda) & $181,1>152,1$ & $197,0>141,0$ & $197,0>161,0$ & $181,1>127,1$ & 30 & & & 35 & 10,9 \\
\hline Cypermethrin (sum) & $162,9>127,0$ & $181,1>127,1$ & $181,0>152,0$ & & 5 & 35 & 30 & & 6,8 \\
\hline Cyprodinil & $225,0>224,0$ & $224,0>118,0$ & $224,0>208,0$ & & 10 & 20 & 20 & & 2,8 \\
\hline DDD, o,p'- & $235,0>165,0$ & $237,0>165,0$ & $235,0>200,0$ & $235,0>199,1$ & 20 & 20 & 8 & 15 & 2,7 \\
\hline DDD, p,p'- & $235,0>165,0$ & $237,0>165,0$ & $235,0>200,0$ & $235,0>199,1$ & 20 & 20 & 8 & 15 & 3 \\
\hline DDE, o,p'- & $246,0>176,0$ & $248,0>176,0$ & $246,0>211,0$ & & 30 & 30 & 20 & & 2,1 \\
\hline DDE, p,p'- & $246,0>176,0$ & $248,0>176,0$ & $246,0>211,0$ & & 30 & 30 & 20 & & 3,6 \\
\hline DDT, o, p'- & $235,0>165,0$ & $237,0>165,0$ & $235,0>199,1$ & & 20 & 20 & 20 & & 3,7 \\
\hline DDT, p,p'- & $235,0>165,0$ & $237,0>165,0$ & $235,0>199,1$ & & 20 & 20 & 20 & & 4,3 \\
\hline Deltamethrin & $252,8>174,0$ & $252,8>172,0$ & $252,8>93,0$ & $181,0>152,0$ & 6 & 7 & 20 & 25 & 10,9 \\
\hline Desmetryn & $212,9>58,2$ & $212,9>198,3$ & $212,9>141,2$ & & 10 & 10 & 15 & & 4,8 \\
\hline
\end{tabular}




\begin{tabular}{|c|c|c|c|c|c|c|c|c|c|}
\hline \multirow[t]{2}{*}{ Compuesto } & \multicolumn{4}{|c|}{ Transiciones $(\mathrm{m} / \mathrm{z})$} & \multicolumn{4}{|c|}{$\begin{array}{c}\text { Energía de colisión } \\
(\mathrm{eV})\end{array}$} & \multirow{2}{*}{$\begin{array}{l}\text { Dwell } \\
\text { (ms) }\end{array}$} \\
\hline & Q1 (cuantif.) & q2 (confirm.) & q3 (confirm.) & q4 (confirm.) & EC1 & EC2 & EC3 & EC4 & \\
\hline Diazinon & $179,2>179,2$ & $304,0>179,0$ & $179,1>137,2$ & $137,1>84,0$ & 5 & 15 & 20 & 10 & 3,9 \\
\hline Dichlobenil & $173,0>100,0$ & $173,0>136,0$ & $171,0>136,0$ & & 28 & 12 & 15 & & 8,7 \\
\hline Dichlofluanid & $224,0>123,0$ & $167,0>96,7$ & $167,0>124,1$ & & 8 & 5 & 5 & & 3,1 \\
\hline $\begin{array}{l}\text { Dichlorobenzophenone } \\
4,4^{\prime} \text { - }\end{array}$ & $139,0>111,0$ & $249,9>215,1$ & $249,9>139,0$ & $139,0>75,0$ & 10 & 9 & 9 & 31 & 3,7 \\
\hline Dichlorvos & $109,0>79,0$ & $185,0>109,0$ & $185,0>93,0$ & $109,0>47,0$ & 5 & 15 & 15 & 15 & 8,7 \\
\hline Diclofop methyl & $253,0>162,0$ & $340,0>253,0$ & $281,0>120,0$ & & 22 & 14 & 12 & & 4,3 \\
\hline Dicloran (DCNA) & $206,1>176,0$ & $208,0>178,0$ & $178,0>150,0$ & $160,1>124,1$ & 10 & & 14 & 10 & 2,8 \\
\hline Dicrotofos & $127,0>95,0$ & $193,0>127,0$ & $127,0>109,0$ & & 17 & 8 & 12 & & 3,7 \\
\hline Dieldrin & $262,9>193,0$ & $277,0>241,0$ & $262,9>191,0$ & & 35 & 5 & 35 & & 2,7 \\
\hline Difenoconazol (sum) & $323,0>265,0$ & $325,0>267,0$ & $267,0>204,0$ & $265,0>202,0$ & 15 & 16 & 16 & 20 & 6,8 \\
\hline Dimethoate & $125,0>78,9$ & $229,0>87,0$ & $143,0>111,0$ & & 5 & & 10 & & 2,8 \\
\hline Diphenylamine & $168,0>167,2$ & $169,0>167,0$ & $169,0>77,0$ & $169,0>168,0$ & 15 & 15 & 15 & 15 & 3,7 \\
\hline Disulfoton & $88,0>60,0$ & $274,0>88,0$ & $186,0>142,0$ & & 5 & 5 & 5 & & 3,3 \\
\hline Disulfoton sulfone & $213,0>97,0$ & $213,0>125,0$ & $186,0>81,0$ & $186,0>97,1$ & 16 & 7 & 15 & 15 & 2 \\
\hline Endosulfan-alpha & $241,0>206,0$ & $238,8>204,0$ & $195,0>159,0$ & & 15 & 15 & 5 & & 2,2 \\
\hline Endosulfan-beta & $195,0>159,0$ & $241,0>206,0$ & $238,8>204,0$ & & 5 & 15 & 15 & & 3 \\
\hline Endosulfan-sulfate & $271,9>236,9$ & $387,0>217,0$ & $387,0>253,0$ & $271,9>116,9$ & 20 & 5 & 5 & 40 & 4,3 \\
\hline Endrin & $263,0>193,0$ & $281,0>245,0$ & $263,0>191,0$ & & 35 & 20 & 35 & & 3 \\
\hline Ethion & $152,9>96,9$ & $231,0>175,0$ & $231,0>129,0$ & & 10 & 25 & 25 & & 3 \\
\hline Ethoprophos & $158,0>97,1$ & $158,0>114,0$ & $158,0>80,9$ & & 15 & 5 & 15 & & 3,7 \\
\hline Etrimfos & $181,0>153,0$ & $292,0>153,0$ & $292,0>181,0$ & $277,0>125,0$ & 8 & 6 & 6 & 14 & 3,3 \\
\hline Fenamidone & $238,1>237,1$ & $268,1>180,1$ & $268,0>77,0$ & $238,1>103,0$ & 22 & 22 & 30 & 22 & 5 \\
\hline Fenamiphos & $303,1>154,0$ & $303,2>180,1$ & $303,2>217,1$ & $303,1>80,0$ & 20 & 20 & 20 & 40 & 2,9 \\
\hline Fenamiphos-sulfone & $320,0>292,0$ & $319,9>214,1$ & $292,0>213,0$ & $292,0>195,8$ & 10 & 15 & 15 & 15 & 4,1 \\
\hline Fenarimol & $139,0>111,0$ & $251,0>139,0$ & $219,0>107,0$ & $139,0>75,0$ & 15 & 15 & 10 & 35 & 12,5 \\
\hline Fenitrothion & $277,1>109,0$ & $277,1>124,9$ & $277,0>260,1$ & & 20 & 15 & 5 & & 3 \\
\hline Fenoxycarb & $255,0>186,0$ & $302,1>88,0$ & $186,0>109,0$ & & 10 & 30 & 15 & & 4,1 \\
\hline Fensulfothion & $293,0>97,1$ & $293,0>141,0$ & $293,0>125,0$ & & 25 & 10 & 10 & & 3 \\
\hline Fenthion & $278,0>109,0$ & $278,0>169,0$ & $278,0>125,0$ & & 22 & 18 & 15 & & 3,2 \\
\hline Fenthion sulfone & $124,9>47,0$ & $309,9>105,0$ & $309,8>108,9$ & $124,9>79,0$ & 10 & 10 & 20 & 5 & 3 \\
\hline Fenthion sulfoxide & $125,0>79,0$ & $279,0>109,0$ & $278,0>169,0$ & & 5 & 20 & 15 & & 3 \\
\hline Fenvalerate I & $167,0>125,0$ & $225,0>119,0$ & $167,1>89,1$ & & 10 & & 40 & & 6,8 \\
\hline Fenvalerate II & $167,0>125,0$ & $225,0>119,0$ & $167,1>89,1$ & & 10 & & 40 & & 6,8 \\
\hline Flucythrinate I & $199,0>157,0$ & $199,0>107,0$ & $157,0>107,0$ & & 5 & 30 & 15 & & 6,8 \\
\hline Flucythrinate II & $199,0>157,0$ & $199,0>107,0$ & $157,0>107,0$ & & 5 & 30 & 15 & & 6,8 \\
\hline Fludioxonil & $248,0>127,0$ & $248,0>182,0$ & $248,0>154,0$ & & 30 & 15 & 25 & & 3,2 \\
\hline Fluvalinate (sum) & $250,0>55,2$ & $250,0>200,0$ & $208,9>141,1$ & & 18 & 22 & & & 6,8 \\
\hline Haloxyfop-ethoxyethyl & $302,0>76,8$ & $316,0>287,9$ & $316,0>91,0$ & $302,0>274,1$ & 36 & 21 & 21 & 23 & 4,2 \\
\hline Haloxyfop-methyl & $316,0>91,0$ & $375,0>316,0$ & 0 & & 22 & 12 & & & 2,5 \\
\hline Heptachlor & $271,9>236,8$ & $274,0>239,0$ & $271,9>116,9$ & & 25 & 20 & 40 & & 3,6 \\
\hline Heptachlor endoepoxide & $352,9>262,9$ & $352,9>281,9$ & $217,0>182,0$ & $183,0>155,0$ & 10 & 15 & 15 & 20 & 2,3 \\
\hline Heptachlor exoepoxide & $353,0>263,0$ & $262,9>191,0$ & $262,9>193,0$ & $236,9>143,0$ & 35 & 35 & & 25 & 2,8 \\
\hline Heptenophos & $124,0>89,1$ & $215,0>89,0$ & $124,0>63,2$ & & 15 & 15 & 35 & & 9,7 \\
\hline Hexachlorobenzene & $283,9>213,9$ & $284,0>249,0$ & $284,0>142,0$ & $284,0>214,0$ & 35 & 30 & 30 & 30 & 3,6 \\
\hline Hexythiazox & $156,0>155,0$ & $227,0>149,0$ & $156,0>112,0$ & & 12 & 10 & 12 & & 2,1 \\
\hline Imazalil & $214,9>173,0$ & $217,0>175,0$ & $173,0>145,0$ & & 4 & 4 & 20 & & 3,3 \\
\hline
\end{tabular}




\begin{tabular}{|c|c|c|c|c|c|c|c|c|c|}
\hline \multirow[t]{2}{*}{ Compuesto } & \multicolumn{4}{|c|}{ Transiciones $(\mathrm{m} / \mathrm{z})$} & \multicolumn{4}{|c|}{$\begin{array}{c}\text { Energía de colisión } \\
(\mathrm{eV})\end{array}$} & \multirow{2}{*}{$\begin{array}{l}\text { Dwell } \\
\text { (ms) }\end{array}$} \\
\hline & Q1 (cuantif.) & q2 (confirm.) & q3 (confirm.) & q4 (confirm.) & EC1 & EC2 & EC3 & EC4 & \\
\hline Iprodione & $314,0>56,0$ & $314,0>245,0$ & $243,8>186,9$ & $187,0>124,0$ & 20 & 10 & 12 & 25 & 4,1 \\
\hline Isofenphos & $213,0>121,0$ & $255,0>121,0$ & $213,1>185,0$ & & 15 & 25 & 5 & & 2,8 \\
\hline Isofenphos-methyl & $199,0>121,0$ & $241,0>121,0$ & $241,0>199,0$ & $199,0>167,0$ & 11 & 5 & 5 & 5 & 2,8 \\
\hline Kresoxim-methyl & $116,0>89,0$ & $206,0>131,0$ & $206,0>116,0$ & & 15 & 5 & 5 & & 2,7 \\
\hline Lindane $(\nu-B H C)$ & $181,0>145,0$ & $219,0>145,0$ & $219,0>183,0$ & $181,0>109,0$ & 15 & 5 & 5 & 30 & 4,4 \\
\hline Malaoxon & $195,0>109,0$ & $268,0>99,0$ & $268,0>127,0$ & $195,0>125,0$ & 16 & 4 & 4 & 10 & 4,5 \\
\hline Malathion & $173,1>99,0$ & $173,0>127,0$ & $158,0>125,0$ & & 15 & 4 & 8 & & 3,1 \\
\hline Mecarbam & $158,9>131,0$ & $159,0>131,0$ & $130,9>74,0$ & $130,9>86,0$ & 5 & 10 & 10 & 10 & 2,8 \\
\hline Metalaxyl & $160,0>130,0$ & $249,0>146,0$ & $206,0>132,0$ & & 20 & 20 & 5 & & 3,6 \\
\hline Metamitron & $202,0>104,2$ & $202,0>173,1$ & & & 20 & 10 & 0 & & 2,9 \\
\hline Metazachlor & $209,0>132,1$ & $209,0>133,0$ & $133,0>117,0$ & & 20 & 10 & 25 & & 2,8 \\
\hline Methacrifos & $207,9>180,1$ & $179,9>93,0$ & $124,9>79,0$ & $124,9>47,1$ & 5 & 5 & 10 & 10 & 9,1 \\
\hline Methamidophos & $141,0>95,0$ & $141,0>79,0$ & $141,0>64,0$ & & 6 & 18 & 16 & & 8,7 \\
\hline Methidathion & $145,0>85,0$ & $302,0>145,0$ & $145,0>58,1$ & & 5 & & 15 & & 2,5 \\
\hline Methiocarb & $168,0>153,0$ & $168,0>109,0$ & $153,0>109,0$ & & 10 & 12 & & & 3 \\
\hline Methoxychlor & $227,0>141,1$ & $227,0>212,0$ & $227,0>169,0$ & $212,0>169,0$ & 40 & 16 & 28 & 15 & 4,3 \\
\hline Mevinphos & $127,0>109,0$ & $193,0>127,0$ & $192,0>127,0$ & $127,0>95,0$ & 10 & 10 & 10 & 15 & 8,7 \\
\hline Monocrotophos & $127,0>109,1$ & $192,0>127,0$ & $127,0>95,0$ & & 5 & & 15 & & 3,7 \\
\hline Myclobutanil & $179,0>125,0$ & $179,0>152,0$ & $179,0>90,0$ & & 14 & 6 & 25 & & 2,7 \\
\hline Naled & $109,0>79,0$ & $185,0>93,0$ & $145,0>109,0$ & $109,0>47,0$ & 5 & & & 15 & 3,7 \\
\hline Nitrofen & $282,9>253,0$ & $285,0>255,0$ & $282,9>202,1$ & $282,9>162,0$ & 10 & & 35 & 22 & 2,9 \\
\hline Nuarimol & $235,0>139,0$ & $314,0>139,0$ & $235,0>123,0$ & & 18 & 5 & 16 & & 4,3 \\
\hline Omethoate & $110,0>79,0$ & $156,0>110,0$ & $156,0>79,0$ & & 10 & 15 & 15 & & 3,7 \\
\hline Oxadixyl & $163,0>132,0$ & $163,0>117,0$ & $132,0>117,0$ & & 15 & 25 & 16 & & 3,7 \\
\hline Oxyfluorfen & $252,2>196,0$ & $361,0>300,0$ & $300,0>223,0$ & & 20 & 12 & 20 & & 2,7 \\
\hline Paraoxon & $149,0>102,1$ & $220,0>174,0$ & $149,0>119,0$ & & 10 & 10 & & & 3,6 \\
\hline Paraoxon-methyl & $230,0>200,1$ & $247,0>230,0$ & $230,0>136,1$ & & 5 & 0 & 5 & & 3,3 \\
\hline Parathion & $291,0>81,0$ & $291,0>137,0$ & $291,0>109,0$ & & 40 & 10 & 10 & & 3,2 \\
\hline Parathion methyl & $263,0>109,1$ & $263,0>246,0$ & $233,0>124,0$ & & 15 & 2 & 10 & & 4,5 \\
\hline Penconazole & $248,0>157,0$ & $248,0>192,0$ & & & 25 & 15 & & & 2,8 \\
\hline Pencycuron & $124,9>88,8$ & $209,0>125,0$ & $209,0>180,0$ & $124,9>62,6$ & 20 & 6 & 6 & 35 & 3,4 \\
\hline Pendimethalin & $252,1>161,2$ & $252,1>208,0$ & $252,1>191,0$ & & 20 & 2 & 4 & & 2,8 \\
\hline Permethrin (sum) & $183,1>168,1$ & $183,1>153,1$ & $163,0>127,0$ & & 15 & 15 & 5 & & 8,7 \\
\hline Phenothrin (sum) & $123,0>81,0$ & $183,1>153,1$ & $183,1>168,1$ & & 8 & 15 & 15 & & 5 \\
\hline Phenthoate & $274,0>121,0$ & $274,0>246,0$ & $274,0>125,0$ & & 10 & 4 & 16 & & 2,3 \\
\hline Phenylphenol, 2-o & $170,0>169,1$ & $170,0>141,2$ & $169,1>115,0$ & & 20 & 20 & 35 & & 9,1 \\
\hline Phosalone & $182,0>111,0$ & $367,0>182,0$ & $182,0>138,0$ & $182,0>75,1$ & 15 & 10 & 5 & 40 & 4,7 \\
\hline Phosmet & $160,0>77,1$ & $160,0>133,1$ & $160,0>105,0$ & & 30 & 15 & 15 & & 4,1 \\
\hline Phosphamidon I & $127,0>109,0$ & $264,0>127,0$ & $192,9>127,0$ & $127,0>95,0$ & 10 & 15 & 8 & 15 & 3,9 \\
\hline Phosphamidon II & $127,0>109,0$ & $264,0>127,0$ & $192,9>127,0$ & $127,0>95,0$ & 10 & 15 & 8 & 15 & 4,8 \\
\hline Pirimicarb & $238,0>166,0$ & $152,0>96,0$ & $152,0>55,0$ & & 10 & 15 & 15 & & 3,9 \\
\hline Pirimiphos-ethyl & $304,0>168,0$ & $318,1>182,0$ & $318,1>166,1$ & $152,1>69,0$ & 10 & 12 & 12 & 20 & 3,9 \\
\hline Pirimiphos-methyl & $290,1>125,0$ & $305,0>290,0$ & $305,0>180,0$ & & 25 & 5 & 5 & & 3 \\
\hline Procymidone & $283,0>96,0$ & $283,0>255,0$ & $283,0>67,1$ & & 10 & 10 & 40 & & 2,3 \\
\hline Profenofos & $208,0>63,1$ & $337,0>309,0$ & $337,0>267,0$ & & 38 & 16 & 16 & & 3,3 \\
\hline Prometon & $210,0>168,0$ & $210,2>94,2$ & $210,0>112,1$ & & 5 & 15 & 10 & & 2,8 \\
\hline Propargite & $135,1>107,1$ & $173,0>135,0$ & $135,1>77,1$ & & 15 & 15 & 25 & & 4,3 \\
\hline
\end{tabular}




\begin{tabular}{|c|c|c|c|c|c|c|c|c|c|}
\hline \multirow[t]{2}{*}{ Compuesto } & \multicolumn{4}{|c|}{ Transiciones $(\mathrm{m} / \mathrm{z})$} & \multicolumn{4}{|c|}{$\begin{array}{c}\text { Energía de colisión } \\
(\mathrm{eV})\end{array}$} & \multirow{2}{*}{$\begin{array}{l}\text { Dwel } \\
\text { (ms) }\end{array}$} \\
\hline & Q1 (cuantif.) & q2 (confirm.) & q3 (confirm.) & q4 (confirm.) & EC1 & $\mathrm{EC} 2$ & EC3 & $\mathrm{EC} 4$ & \\
\hline Propham & $93,0>66,0$ & $179,1>92,2$ & $93,0>65,0$ & & 15 & 30 & 25 & & 9,1 \\
\hline Propoxur & $110,0>63,0$ & $152,0>110,0$ & $110,0>92,0$ & $110,0>82,0$ & 32 & 6 & 10 & 8 & 3,7 \\
\hline Prothiophos & $162,0>63,1$ & $309,0>239,0$ & $266,9>239,0$ & $162,0>98,0$ & 40 & 15 & 5 & 20 & 3,3 \\
\hline Pyrazophos & $221,0>193,0$ & $232,0>204,0$ & $221,1>149,1$ & & 10 & 10 & 15 & & 8,2 \\
\hline Pyridaben & $147,0>117,0$ & $309,0>147,0$ & $147,0>132,0$ & & 20 & 10 & 10 & & 8,7 \\
\hline Pyridaphenthion & $340,0>199,2$ & $340,1>97,0$ & $340,0>109,0$ & $204,0>203,0$ & 8 & 35 & 22 & 10 & 4,1 \\
\hline Quinalphos & $146,0>118,0$ & $157,0>129,0$ & $146,0>91,0$ & & 10 & 15 & 30 & & 2,3 \\
\hline Quintozene & $295,0>237,0$ & $237,0>119,0$ & $237,0>143,0$ & & 20 & 30 & 30 & & 4,4 \\
\hline Resmethrine (sum) & $123,1>81,1$ & $171,0>143,0$ & $123,1>95,1$ & & 8 & 4 & 6 & & 4,2 \\
\hline Ronnel (Fenchlorphos) & $285,0>270,0$ & $287,0>272,0$ & $285,0>240,0$ & $270,0>240,0$ & 12 & 12 & 25 & 12 & 3,2 \\
\hline Simetryn & $213,0>170,0$ & $213,0>185,0$ & $213,0>155,0$ & & 8 & 6 & 20 & & 4,5 \\
\hline Sulfotep & $322,1>146,0$ & $322,1>174,0$ & $322,0>294,0$ & $322,0>202,0$ & 28 & 15 & 6 & 6 & 3,9 \\
\hline Tebuconazole & $250,0>125,0$ & $252,0>127,0$ & & & 25 & 25 & 0 & & 4,3 \\
\hline Tecnazene (TCNB) & $215,0>179,0$ & $203,0>83,1$ & $202,9>143,0$ & & 8 & 34 & 22 & & 3,7 \\
\hline Tefluthrin, cis- & $177,1>127,1$ & $197,0>141,1$ & $177,1>87,0$ & $177,0>137,0$ & 15 & 10 & 30 & 15 & 3,3 \\
\hline Terbufos & $231,0>128,9$ & $288,0>231,0$ & $231,0>174,9$ & & 25 & 4 & 10 & & 4,4 \\
\hline terbufos-sulfone & $153,0>96,9$ & $198,9>142,8$ & $153,0>125,0$ & & 10 & 10 & 2 & & 2,8 \\
\hline Tetraconazole & $336,0>204,0$ & $336,0>218,0$ & $336,0>164,0$ & $170,9>136,0$ & 34 & 20 & 35 & 10 & 3,7 \\
\hline Tetradifon & $353,7>159,0$ & $355,7>159,0$ & $229,0>199,0$ & & 10 & 10 & 15 & & 6 \\
\hline Tetrahydrophtalimide & $151,0>79,0$ & $151,0>122,1$ & $151,0>80,1$ & & 17 & 9 & 6 & & 9,1 \\
\hline Thiabendazole & $201,0>174,0$ & $174,0>103,0$ & $174,0>130,0$ & & 19 & 13 & 13 & & 2,3 \\
\hline Thiometon & $88,0>60,0$ & $246,0>88,0$ & $125,0>79,0$ & $125,0>47,0$ & 6 & 6 & 20 & 20 & 3,6 \\
\hline Tolclofos-methyl & $265,0>250,0$ & $265,0>220,0$ & $265,0>93,0$ & & 15 & 25 & 25 & & 3,6 \\
\hline Tolylfluanid & $137,0>91,0$ & $238,0>137,0$ & $137,0>65,0$ & & 18 & 8 & 30 & & 2,8 \\
\hline Triadimefon & $208,0>181,0$ & $210,0>113,0$ & $208,0>127,0$ & & 5 & 20 & 15 & & 3,7 \\
\hline Triadimenol & $168,0>70,0$ & $128,0>65,0$ & & & 10 & 20 & & & 2,3 \\
\hline Triazophos & $161,2>134,2$ & $257,0>162,1$ & $161,2>106,1$ & $161,2>91,0$ & 5 & 5 & 10 & 15 & 4,1 \\
\hline Trichlorfon & $109,0>79,1$ & $145,0>109,0$ & $109,0>92,7$ & & 5 & 8 & 5 & & 8,7 \\
\hline Trifloxystrobin & $131,0>116,1$ & $190,0>130,0$ & $131,0>89,2$ & & 15 & 6 & 10 & & 3,8 \\
\hline Trifluralin & $306,0>264,0$ & $306,0>160,0$ & $263,9>160,1$ & & 10 & 25 & 15 & & 3,7 \\
\hline Triphenyl phosphate & $326,0>77,0$ & $326,1>233,0$ & $326,0>169,0$ & & 30 & & 30 & & 4,2 \\
\hline Vamidothion & $144,9>87,1$ & $168,8>125,0$ & $87,0>58,0$ & & 25 & & & & 2 \\
\hline Vinclozolin & $212,0>172,0$ & $212,0>145,0$ & $212,0>109,0$ & & 15 & 15 & 40 & & 4,5 \\
\hline
\end{tabular}


3) Resultados de plaguicidas hallados en 54 muestras analizadas a través de métodos multiresiduo de alto scope con determinación por UHPLC-MS/MS y GC-MS/MS. Muestras Proyecto MINCyT-MEYS.

Tabla S4-3. Concentraciones ( $\mu \mathrm{g} / \mathrm{kg}$ mat.seca) de los plaguicidas detectados en las muestras clasificadas como forrajes. Proyecto MINCYT-MEYS.

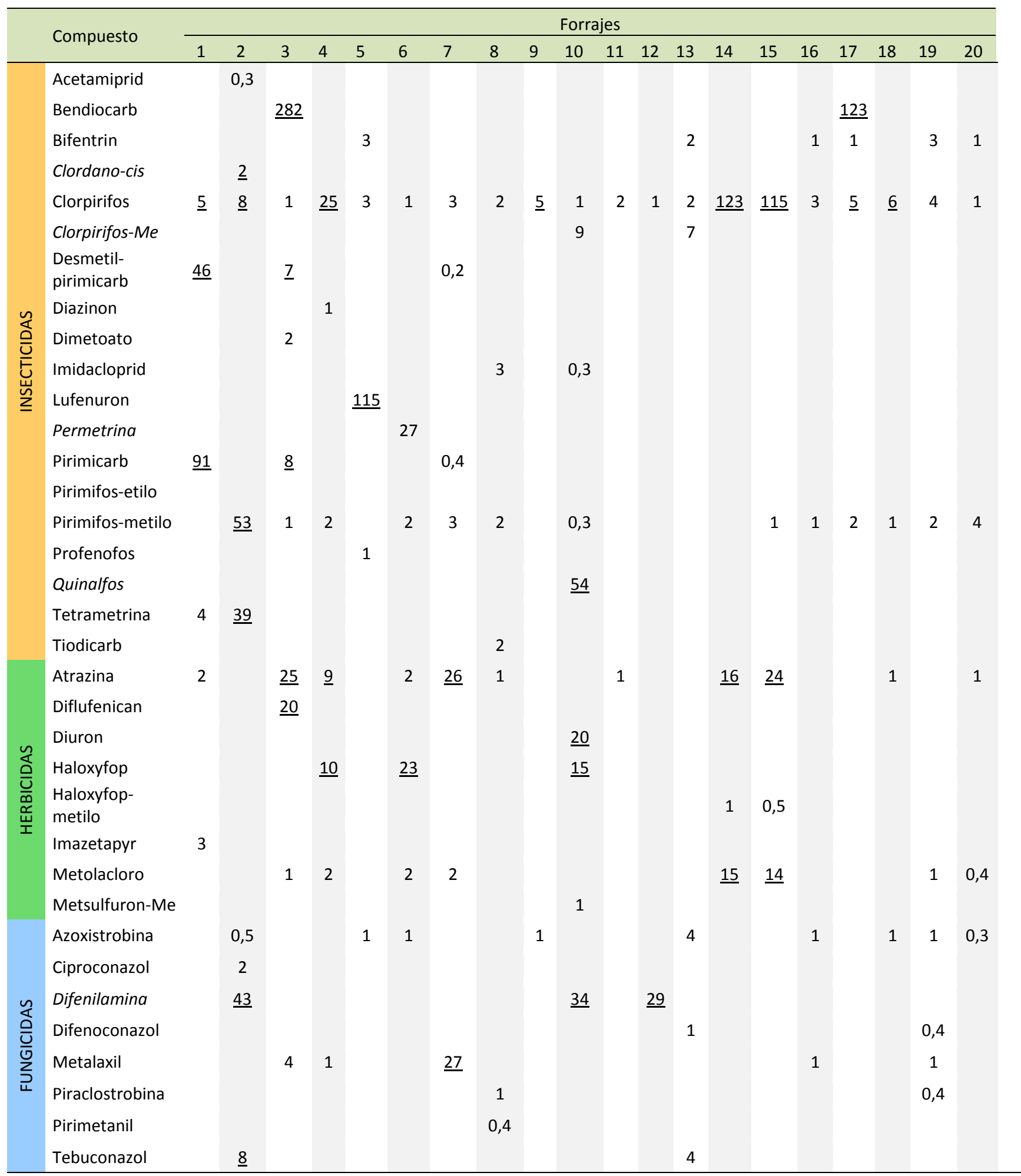

En cursiva, compuestos determinados por GC-MS/MS.

Celdas vacías indican ND (no detectado)

Subrayadas se muestran aquellas concentraciones calculadas que dieron valores por encima del límite de cuantificación.

Muestras: 1-4 (pasturas de alfalfa), 5-6 (henos de alfalfa), 7 (pastura de cebada), 8-16 (silos de maíz), 17-20 (silos de sorgo). 
Tabla S4-4. Concentraciones ( $\mu \mathrm{g} / \mathrm{kg}$ mat.seca) de los plaguicidas detectados en las muestras clasificadas como cereales y derivados. Proyecto MINCYT-MEYS.

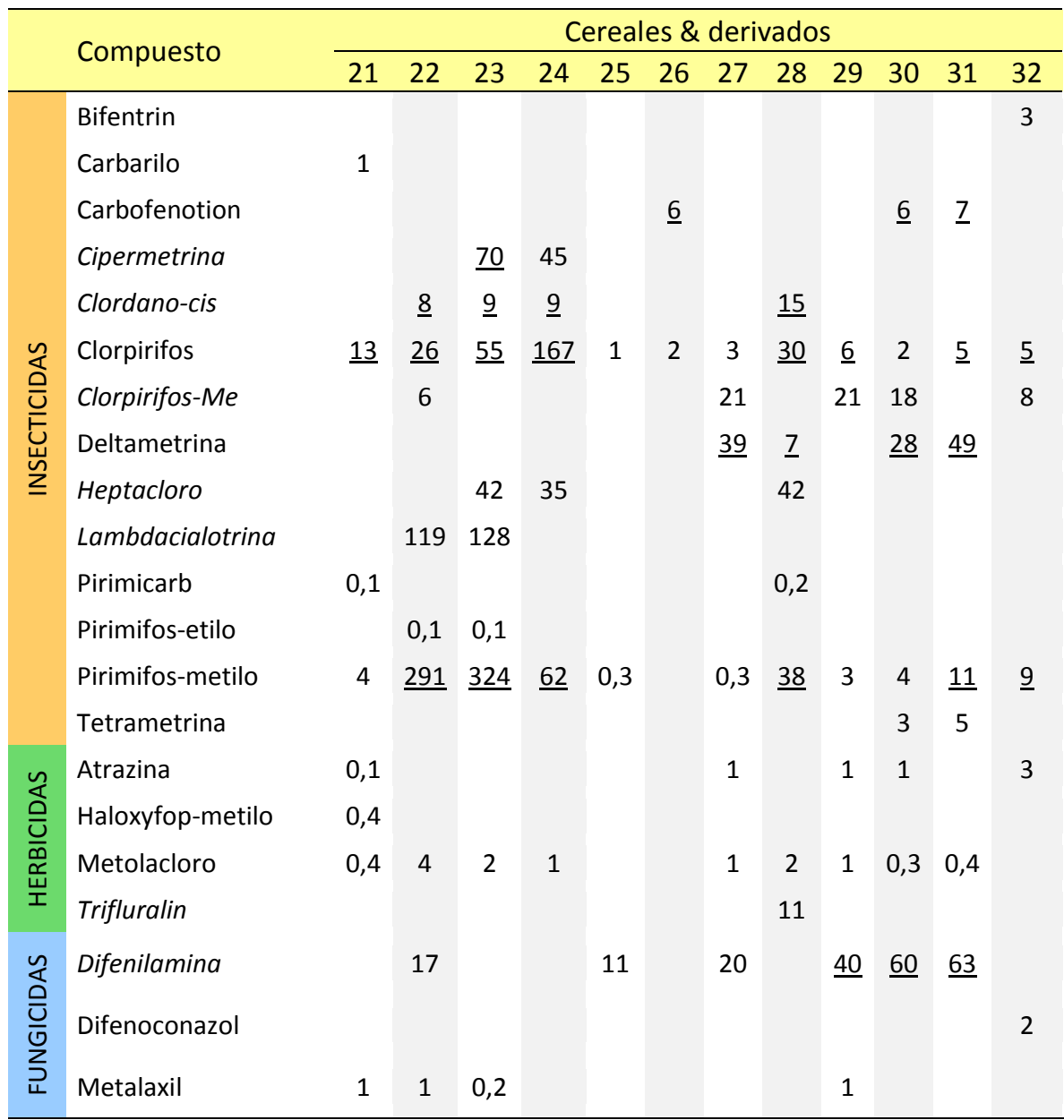

En cursiva, compuestos determinados por GC-MS/MS.

Celdas vacías indican ND (no detectado)

Subrayadas se muestran aquellas concentraciones calculadas que dieron valores por encima del límite de cuantificación.

Muestras: 21-27 (maíz molido),28-29 (trigo molido), 30-31 (burlanda de maíz), 32 (gluten de trigo). 
Tabla S4-5. Concentraciones ( $\mu \mathrm{g} / \mathrm{kg}$ mat.seca) de los plaguicidas detectados en las muestras clasificadas como balanceados y TMRs. Proyecto MINCYT-MEYS.

\begin{tabular}{|c|c|c|c|c|c|c|c|c|c|c|c|c|c|c|}
\hline & \multirow{2}{*}{ Compuesto } & \multicolumn{13}{|c|}{ Balanceados y TMRs } \\
\hline & & 33 & 34 & 35 & 36 & 37 & 38 & 39 & 40 & 41 & 42 & 43 & 44 & 45 \\
\hline \multirow{18}{*}{ 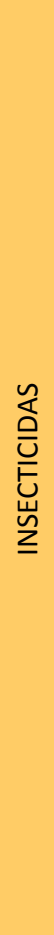 } & Acetamiprid & & & & & & & & & & 0,2 & & & \\
\hline & Bifentrin & & 2 & & & & & & & 1 & & & & 1 \\
\hline & Cipermetrina & $\underline{60}$ & $\underline{61}$ & $\underline{53}$ & $\underline{59}$ & $\underline{211}$ & & & & & & & & \\
\hline & Clordano-cis & $\underline{9}$ & $\underline{12}$ & $\underline{5}$ & $\underline{10}$ & & & & & & & & & \\
\hline & Clorpirifos & $\underline{34}$ & $\underline{132}$ & $\underline{17}$ & $\underline{35}$ & $\underline{28}$ & $\underline{7}$ & 1 & 2 & $\underline{17}$ & 4 & $\underline{30}$ & 3 & 3 \\
\hline & Clorpirifos-Me & 8 & $\underline{30}$ & 14 & & & $\underline{25}$ & & 9 & 6 & & & & \\
\hline & DEET & & & & $\underline{6}$ & & & & & & & & & \\
\hline & Deltametrina & $\underline{205}$ & $\underline{532}$ & $\underline{227}$ & $\underline{250}$ & $\underline{54}$ & $\underline{110}$ & & & $\underline{494}$ & $\underline{30}$ & $\underline{66}$ & & \\
\hline & Diazinon & & 0,3 & & & & & & & & 0,5 & & 4 & 4 \\
\hline & Diflubenzuron & & & & & $\underline{58}$ & $\underline{38}$ & & & & & $\underline{61}$ & $\underline{28}$ & $\underline{30}$ \\
\hline & Endosulfan- $\mathrm{SO}_{4}{ }^{=}$ & & & & 33 & & & & & & & & & \\
\hline & Heptacloro & 31 & 34 & 30 & 33 & & & & 25 & & & & & 24 \\
\hline & Imidacloprid & & & 1 & & & & & & & & & & \\
\hline & Lambdacialotrina & & 108 & & & 102 & 110 & & & & 108 & 115 & & \\
\hline & Pirimifos-etilo & 0,1 & & & & & & & & & & & & \\
\hline & Pirimifos-metilo & $\underline{118}$ & $\underline{34}$ & $\underline{44}$ & $\underline{21}$ & $\underline{9}$ & $\underline{17}$ & 1 & & $\underline{77}$ & $\underline{76}$ & $\underline{251}$ & $\underline{11}$ & $\underline{10}$ \\
\hline & Tetrametrina & & & & & & & & & $\underline{94}$ & & & & \\
\hline & Tiametoxam & & 5 & & & & & & & & & & & \\
\hline \multirow{6}{*}{ 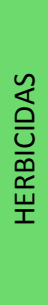 } & Atrazina & 0,5 & & & 1 & & 0,4 & 0,3 & 1 & $\underline{18}$ & 2 & & 2 & 1 \\
\hline & Haloxyfop & & & & & & & & $\underline{59}$ & & & & & \\
\hline & Haloxyfop-metilo & 0,5 & 0,3 & 0,4 & 0,3 & & & & 2 & 1 & 1 & & & \\
\hline & Imazapyr & & & & & & & & & & & $\underline{13}$ & & \\
\hline & Metolacloro & 2 & 1 & 1 & 2 & 0,2 & & & & 1 & 0,4 & 0,4 & & 0,4 \\
\hline & Trifluralin & & & 11 & & & & & & & & & & \\
\hline \multirow{5}{*}{ 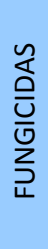 } & Azoxistrobina & 0,4 & 1 & & & 0,3 & 1 & & & & & & & 0,3 \\
\hline & Difenilamina & & & & 1 & 21 & 15 & $\underline{46}$ & 3 & 18 & & & & \\
\hline & Difenoconazol & & & & 1 & & & & & & & & & \\
\hline & Fenilfenol & & 10 & 6 & 11 & 11 & & & & & & & & \\
\hline & Metalaxil & & & 0,3 & & 1 & 0,3 & & & 3 & 0,5 & & 1 & \\
\hline
\end{tabular}


Tabla S4-6. Concentraciones ( $\mu \mathrm{g} / \mathrm{kg}$ mat.seca) de los plaguicidas detectados en las muestras clasificadas como oleaginosas y derivados. Proyecto MINCYT-MEYS.

\begin{tabular}{|c|c|c|c|c|c|c|c|c|c|c|}
\hline & \multirow{2}{*}{ Compuesto } & \multicolumn{9}{|c|}{ Oleaginosas \& derivados } \\
\hline & & 46 & 47 & 48 & 49 & 50 & 51 & 52 & 53 & 54 \\
\hline \multirow{15}{*}{ 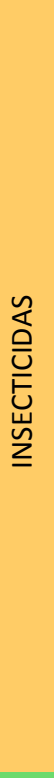 } & Clordano-cis & $\underline{22}$ & & & & $\underline{7}$ & & & & \\
\hline & Clorpirifos & $\underline{26}$ & 1 & 1 & $\underline{11}$ & $\underline{6}$ & 1 & 1 & 2 & \\
\hline & Clorpirifos-Me & 8 & 17 & & & & & & & \\
\hline & Deltametrina & & & & & & $\underline{82}$ & & & \\
\hline & Desmetil-pirimicarb & & $\underline{7}$ & & & & & & & \\
\hline & Diazinon & 0,5 & & & 0,2 & & & & & \\
\hline & Dimetoato & & 2 & & & & & & & \\
\hline & Heptacloro & $\underline{66}$ & & & & & & & & \\
\hline & Imidacloprid & $\underline{61}$ & & & 1 & & & 1 & & \\
\hline & Ometoato & & 1 & & & & & & & \\
\hline & Pirimicarb & & $\underline{8}$ & & & & & & & \\
\hline & Pirimifos-metilo & $\underline{71}$ & 1 & 1 & 1 & 4 & 0,2 & & & \\
\hline & Quinalfos & $\underline{37}$ & $\underline{45}$ & & & & & & & \\
\hline & Tiametoxam & & & & & $\underline{64}$ & & & & \\
\hline & Triflumuron & 0,4 & & & & & & & & \\
\hline \multirow{8}{*}{ 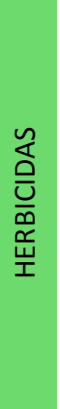 } & Atrazina & & $\underline{23}$ & 1 & 2 & 0,4 & 1 & 1 & & \\
\hline & Diflufenican & & $\underline{15}$ & & & & & & & \\
\hline & Diuron & 4 & & $\underline{23}$ & 1 & & & & & \\
\hline & Haloxyfop & $\underline{46}$ & & $\underline{12}$ & & $\underline{20}$ & $\underline{18}$ & & & \\
\hline & Haloxyfop-metilo & 1 & & & & 0,2 & & & & \\
\hline & Metolacloro & 3 & 1 & 1 & $\underline{6}$ & 0,5 & & & 0,5 & \\
\hline & Metsulfuron-Me & & & 1 & 5 & & & & & \\
\hline & Trifluralin & 16 & & & & & & & & \\
\hline \multirow{4}{*}{ 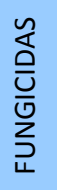 } & Azoxistrobina & & & & & & & & & 0,3 \\
\hline & Difenilamina & $\underline{34}$ & $\underline{35}$ & & & & $\underline{25}$ & & & \\
\hline & Metalaxil & 1 & 3 & & & & & & & \\
\hline & Piraclostrobina & 0,1 & & & & & & 1 & & \\
\hline
\end{tabular}

En cursiva, compuestos determinados por GC-MS/MS.

Celdas vacías indican ND (no detectado)

Subrayadas se muestran aquellas concentraciones calculadas que dieron valores por encima del límite de cuantificación.

Muestras: 46-49 (semillas de algodón), 50-52 (expellers de soja), 53

(expeller de gorasol), 54 (poroto de soja). 


\section{4) Resultados de plaguicidas hallados en 142 muestras analizadas a través de métodos multiresiduo con determinación UHPLC-MS/MS y GC-MS/MS. Muestras Proyecto ANPCyT-PICT.}

Tabla S4-7. Concentraciones ( $\mu \mathrm{g} / \mathrm{kg}$ mat.seca) de los plaguicidas detectados en las muestras clasificadas como forrajes. Proyecto ANPCYT-PICT.

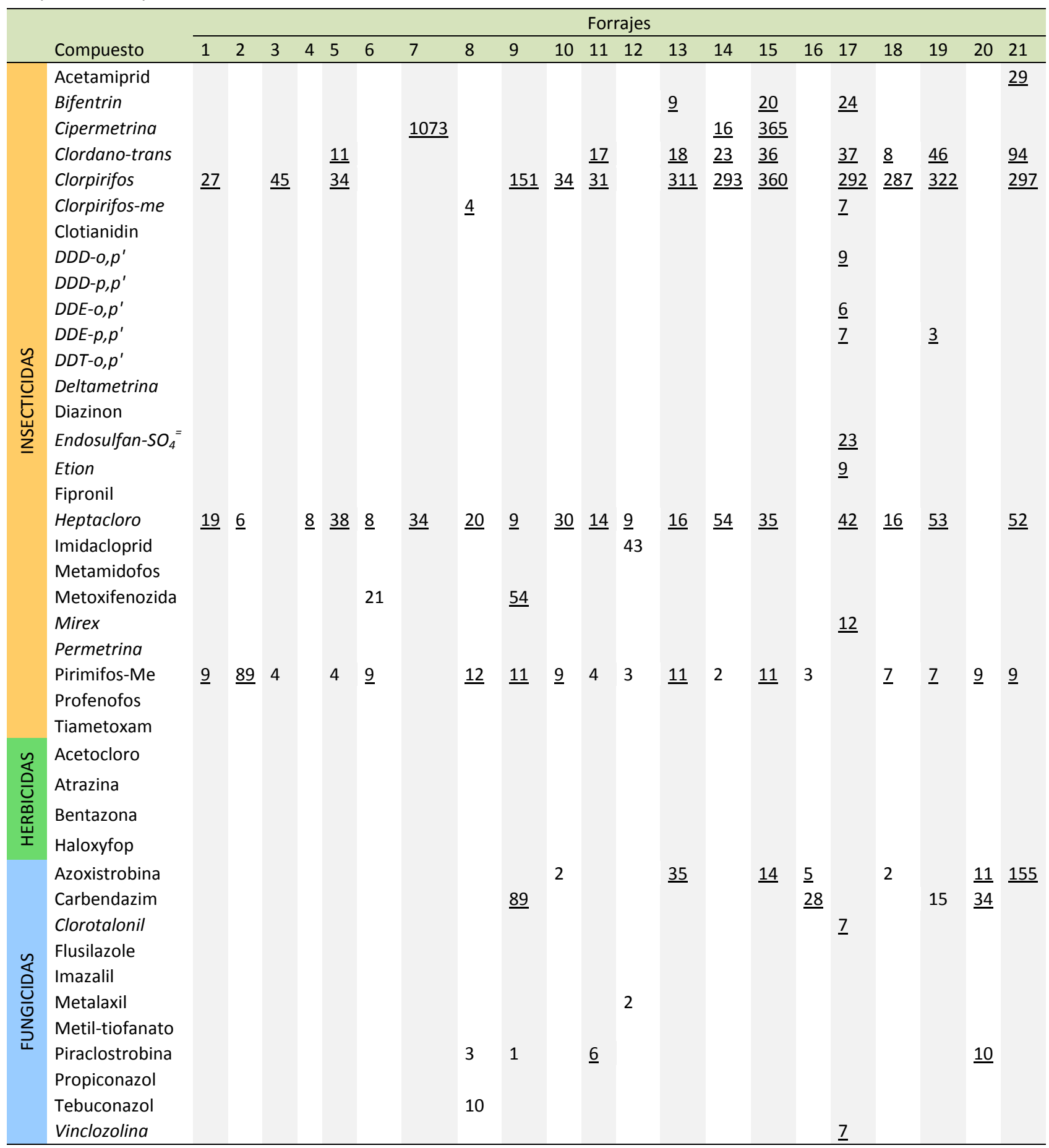

En cursiva, compuestos determinados por GC-MS/MS.

Celdas vacías indican ND (no detectado)

Subrayadas se muestran aquellas concentraciones calculadas que dieron valores por encima del límite de cuantificación. Muestras: 1-4 (henos de alfalfa); 5-21 (pasturas de alfalfa) 
Tabla S4-8. Concentraciones ( $\mu \mathrm{g} / \mathrm{kg}$ mat.seca) de los plaguicidas detectados en las muestras clasificadas como forrajes. Proyecto ANPCyT-PICT.

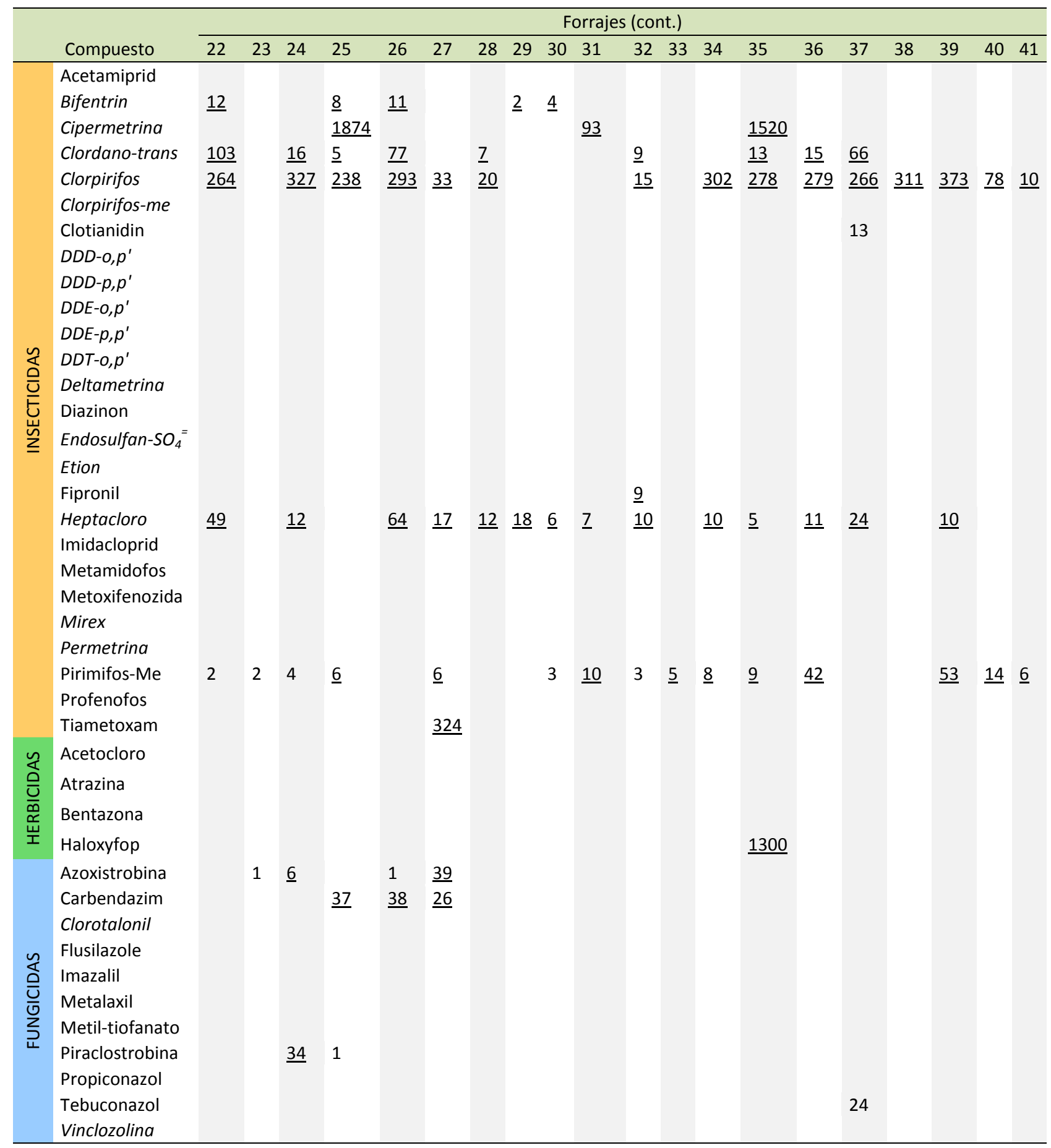

En cursiva, compuestos determinados por GC-MS/MS.

Celdas vacías indican ND (no detectado)

Subrayadas se muestran aquellas concentraciones calculadas que dieron valores por encima del límite de cuantificación. Muestras: 22-31 (pasturas de alfalfa); 32-41 (rollos de alfalfa). 
Tabla S4-9. Concentraciones ( $\mu \mathrm{g} / \mathrm{kg}$ mat.seca) de los plaguicidas detectados en las muestras clasificadas como forrajes. Proyecto ANPCYT-PICT.

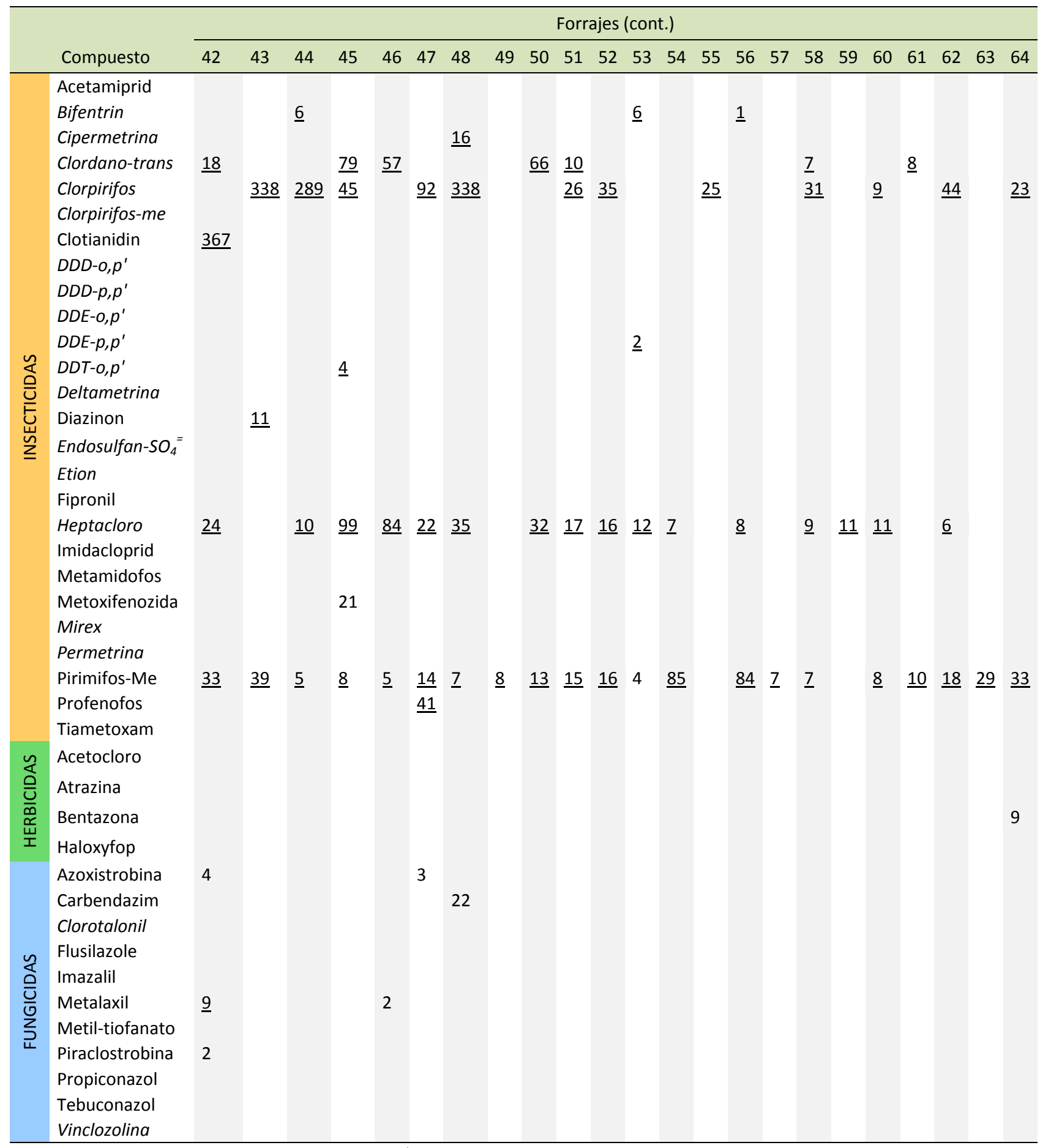

En cursiva, compuestos determinados por GC-MS/MS.

Celdas vacías indican ND (no detectado)

Subrayadas se muestran aquellas concentraciones calculadas que dieron valores por encima del límite de cuantificación.

Muestras: 42-44 (rollos de moha); 45-48 (pasturas); 49-54 (silos de alfalfa); 55 (silo de avena); 56-64 (silos de maíz) 
Tabla S4-10. Concentraciones ( $\mu \mathrm{g} / \mathrm{kg}$ mat.seca) de los plaguicidas detectados en las muestras clasificadas como forrajes. Proyecto ANPCyT-PICT.

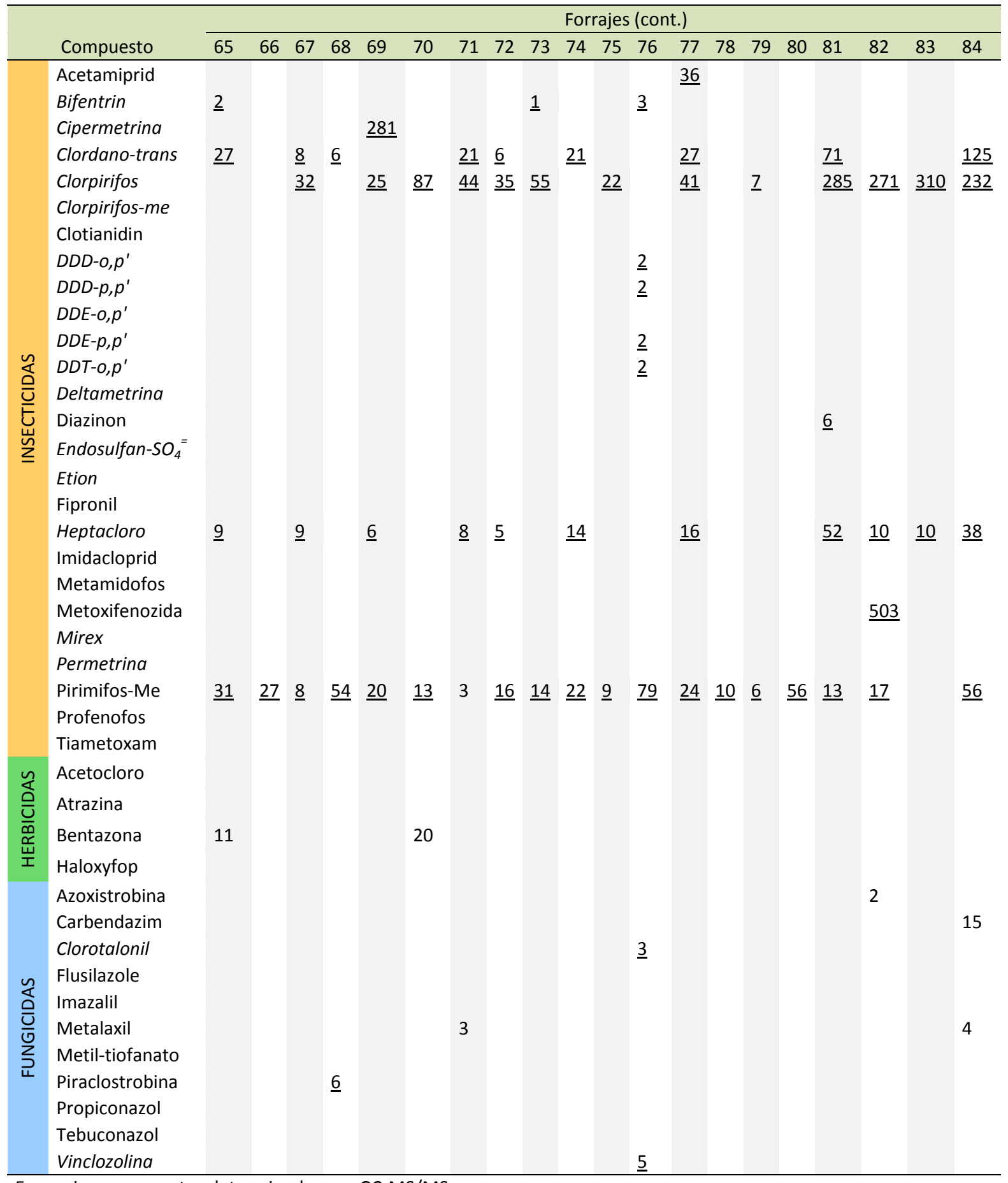

En cursiva, compuestos determinados por GC-MS/MS.

Celdas vacías indican ND (no detectado)

Subrayadas se muestran aquellas concentraciones calculadas que dieron valores por encima del límite de cuantificación. Muestras: $65-72$ (silos de maíz); 73 (silo de pastura); 74 (silo de soja); 75-79 (silos de sorgo); 80 (silo de trigo); 81-82 (soja pastoreo); 83 (pastura de sorgo); 84 (rollo de trigo) 
Tabla S4-11. Concentraciones ( $\mu \mathrm{g} / \mathrm{kg}$ mat.seca) de los plaguicidas detectados en las muestras clasificadas como cereales y derivados. Proyecto ANPCyT-PICT.

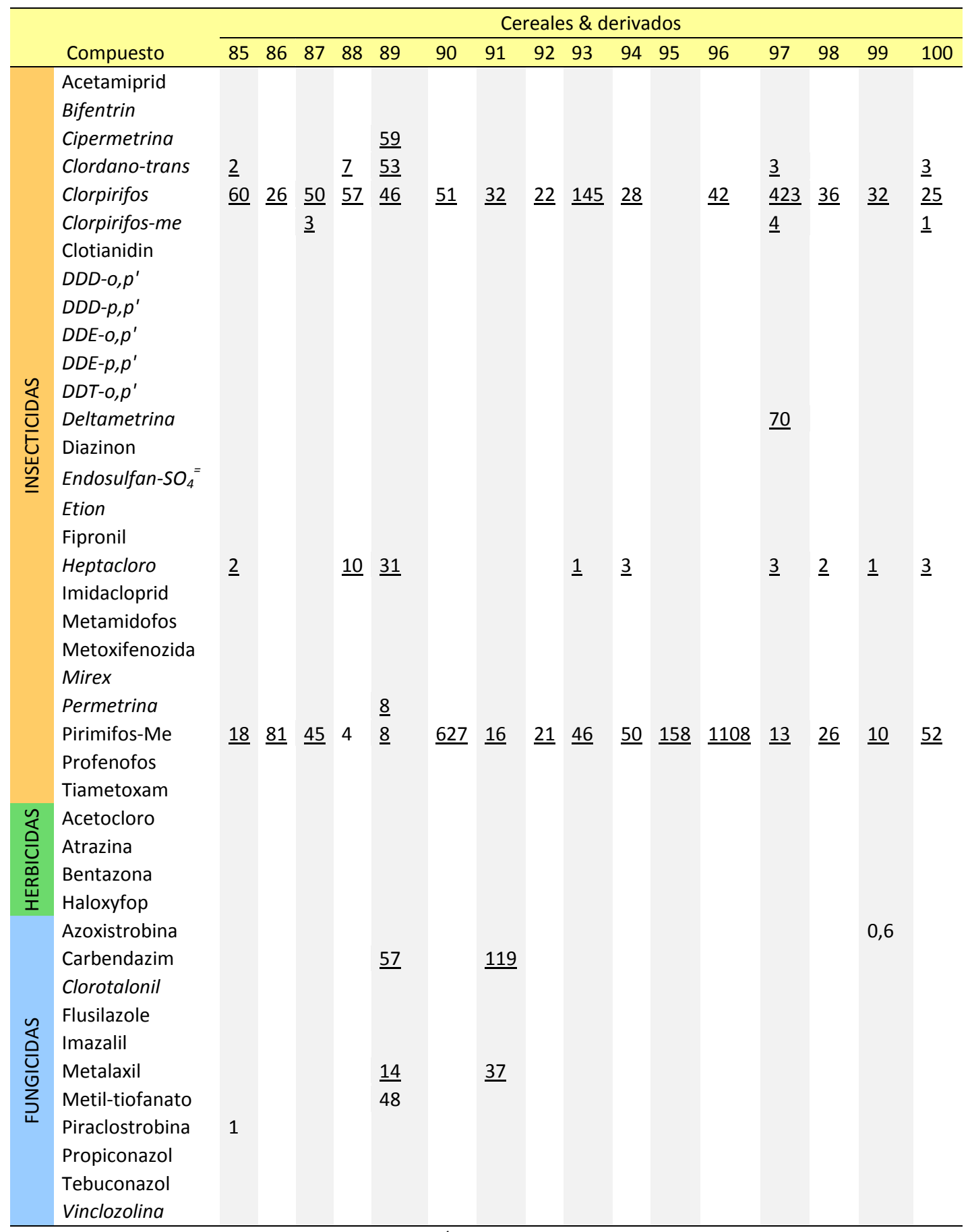

En cursiva, compuestos determinados por GC-MS/MS.

Celdas vacías indican ND (no detectado)

Subrayadas se muestran aquellas concentraciones calculadas que dieron valores por encima del límite de cuantificación.

Muestras: 85-98 (granos de maíz); 99 (grano de sorgo); 100 (grano de trigo) 
Tabla S4-12. Concentraciones ( $\mu \mathrm{g} / \mathrm{kg}$ mat.seca) de los plaguicidas detectados en las muestras clasificadas como balanceados y TMRs. Proyecto ANPCYT-PICT.

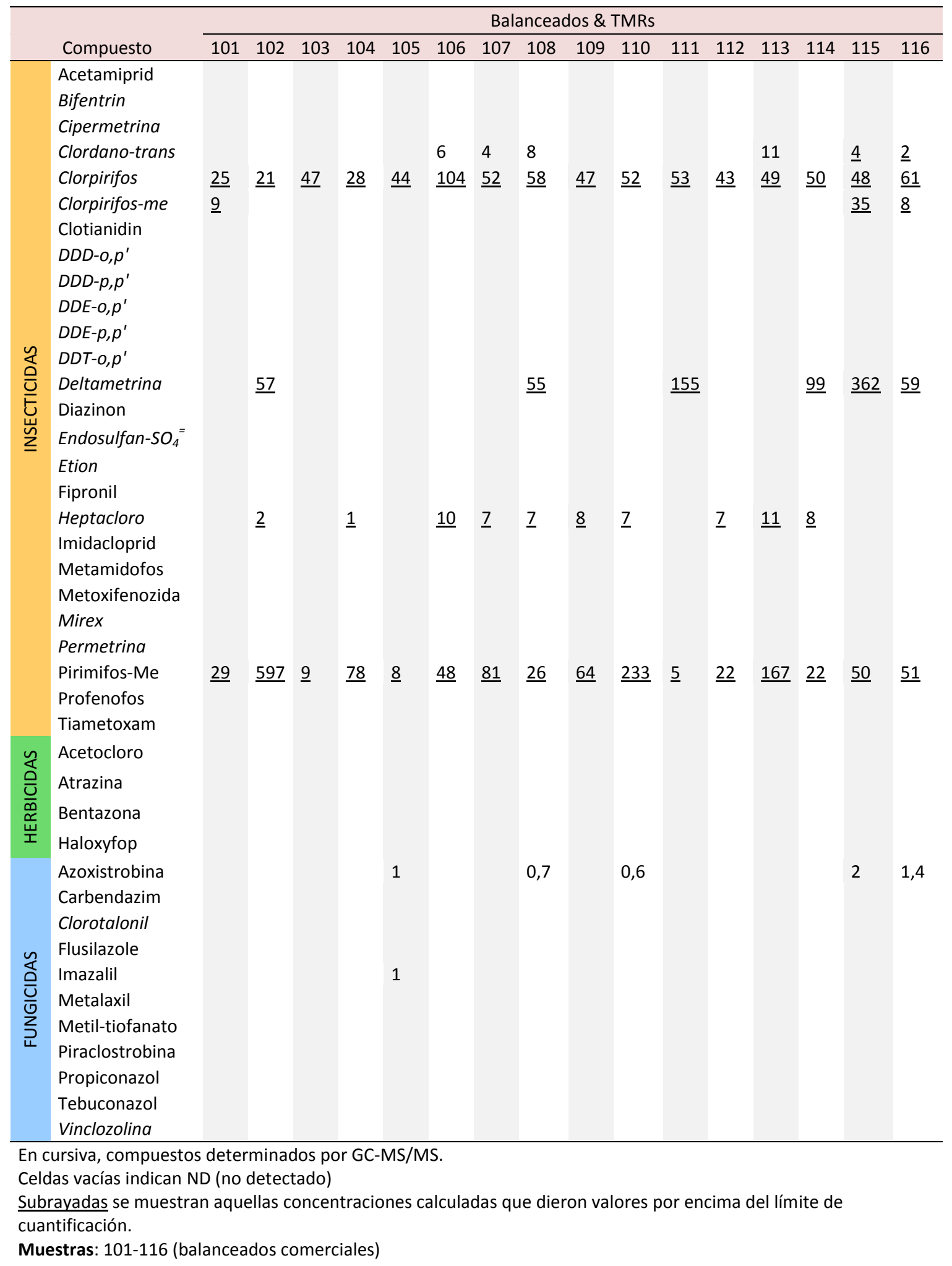


Tabla S4-13. Concentraciones ( $\mu \mathrm{g} / \mathrm{kg}$ mat.seca) de los plaguicidas detectados en las muestras clasificadas como balanceados y TMRs. Proyecto ANPCYT-PICT.

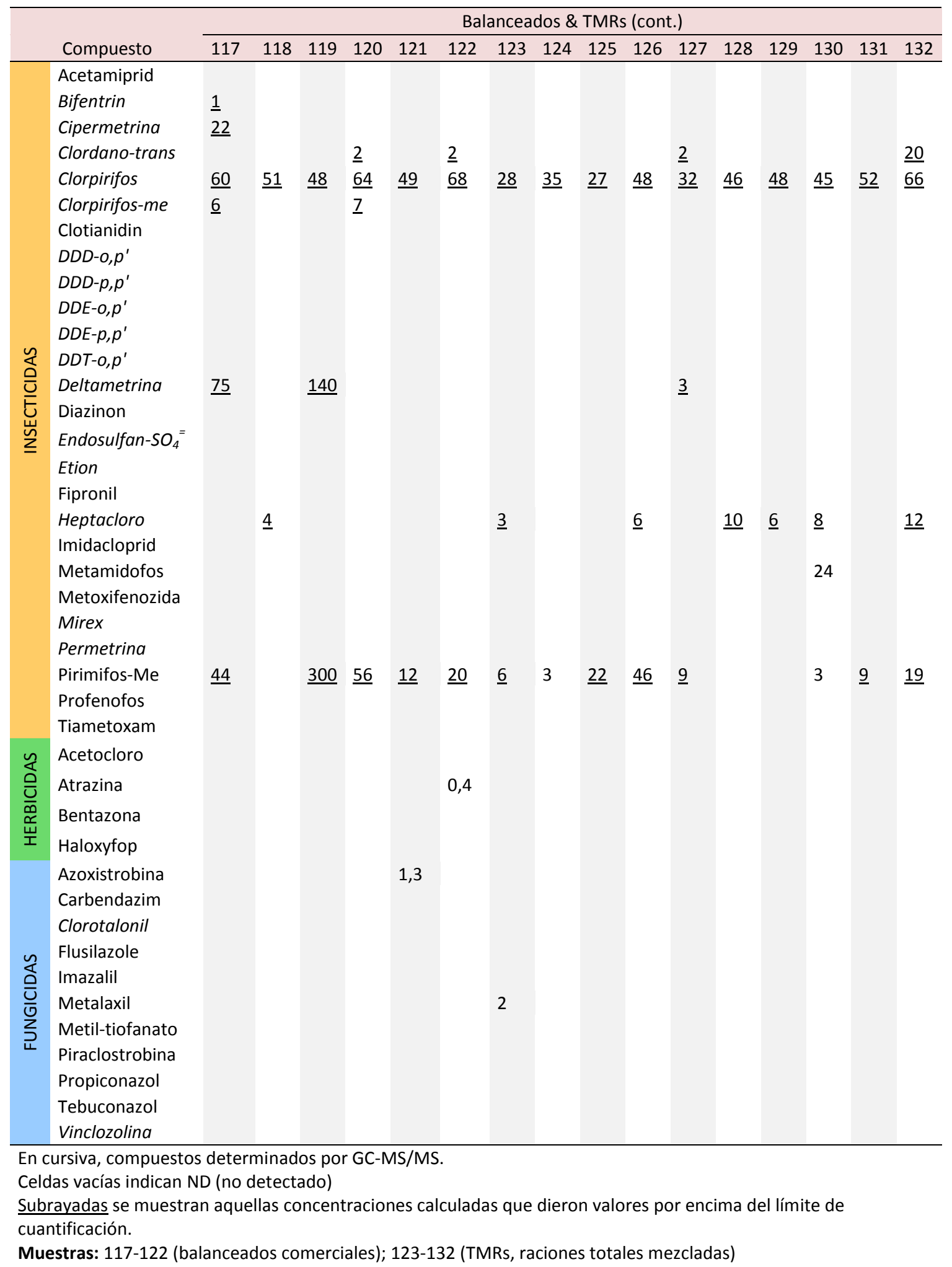


Tabla S4-14. Concentraciones ( $\mu \mathrm{g} / \mathrm{kg}$ mat.seca) de los plaguicidas detectados en las muestras clasificadas como oleaginosas y derivados. Proyecto ANPCyT-PICT.

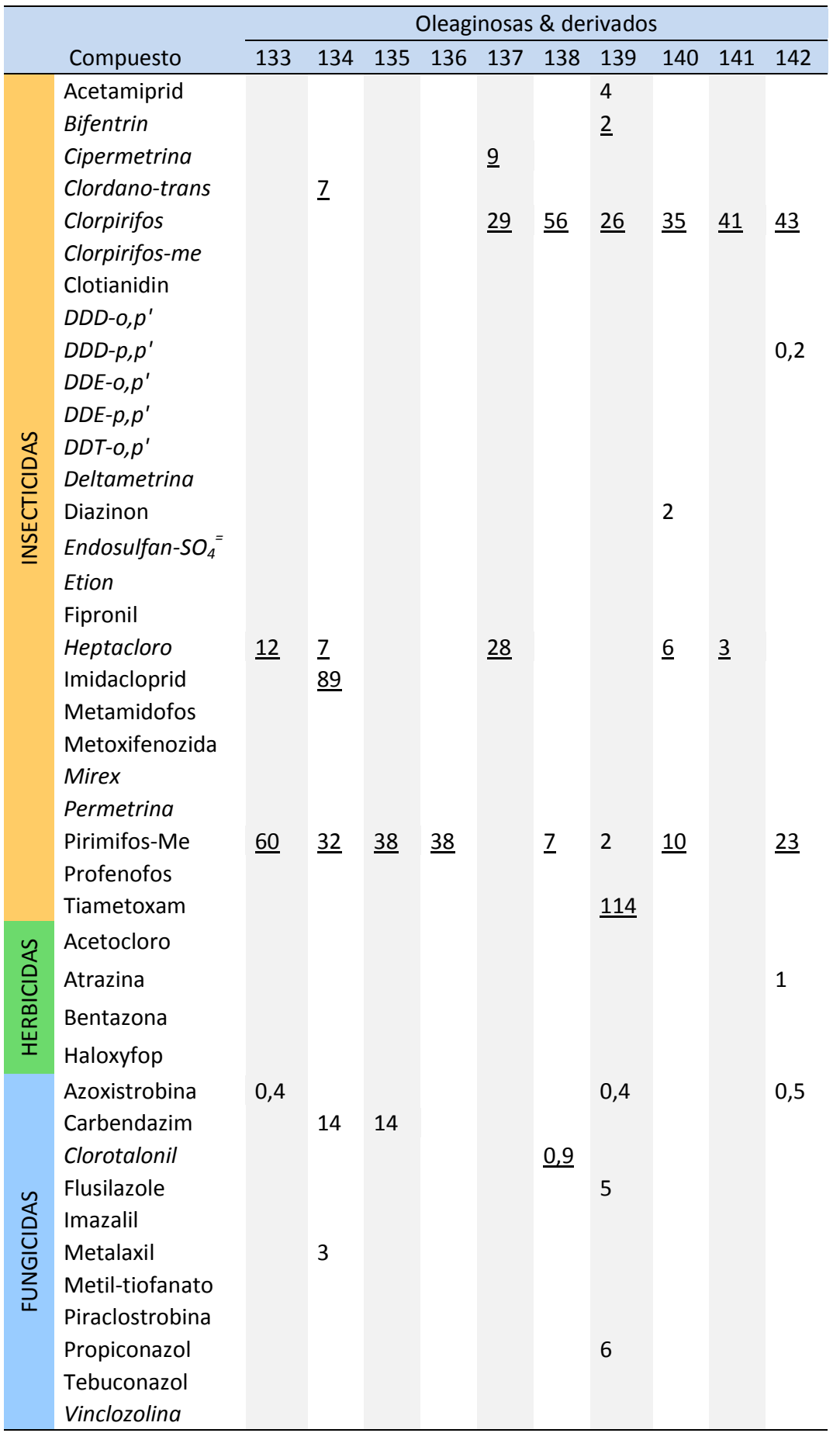

En cursiva, compuestos determinados por GC-MS/MS.

Celdas vacías indican ND (no detectado)

Subrayadas se muestran aquellas concentraciones calculadas que dieron valores por encima del límite de cuantificación.

Muestras: 133-136 (semillas de algodón); 137 (permeado de suero);

138-142 (expeller de soja) 


\section{CAPÍTULO 5}

\section{1) Resultados micotoxinas en piensos por QuEChERS-UHPLC-MS/MS}

Tabla S5-1: Concentraciones halladas ( $\mu \mathrm{g} / \mathrm{kg}$ mat. seca) de las micotoxinas analizadas por UHPLC-MS/MS en las muestras analizadas clasificadas como Forrajes.

\begin{tabular}{|c|c|c|c|c|c|c|c|c|c|c|c|c|c|c|c|c|c|c|c|c|}
\hline & \multicolumn{20}{|c|}{ Forrajes } \\
\hline & 1 & 2 & 3 & 4 & 5 & 6 & 7 & 8 & 9 & 10 & 11 & 12 & 13 & 14 & 15 & 16 & 17 & 18 & 19 & 20 \\
\hline ENB & & 2 & & & 0,4 & 10 & 1 & & & 0,3 & & & 3 & & & & & 0,2 & 1 & \\
\hline ENB1 & & & & & & & & & & & & & & & & & & & 4 & 2 \\
\hline ENA & & & & & & & & & & & & & & & & & & & & \\
\hline ENA1 & & 2 & & & & & & & & & & & & & & & & & & \\
\hline CPA & & & & & & & & & & & & & & & & & & & & \\
\hline E-corN & & & & & & & & & & & & & & & & & & & & \\
\hline E-crisN & & & & & & & & & & & & & & & & & & & & \\
\hline E-crip & & & & & & & & & & & & & & & & & & & & \\
\hline E-cris & & & & & & & & & & & & & & & & & & & & \\
\hline E-met & & & & & & & & & & & & & & & & & & & & \\
\hline E-sin & & & & & & & & & & & & & & & & & & & & \\
\hline 15ADON & & & & & & & & & & & & & & & & & & & & \\
\hline 3ADON & & & & & & & & & & & & & & & & & & & & \\
\hline DON & & & & 167 & & & & & & & & & & & & & & & & \\
\hline DAS & & & & & & & & 10 & & 16 & & & & & & & & & & \\
\hline H-T2 & & & & & & & & & & & & & & & & & 12 & & & \\
\hline NIV & & & & & & & & & & & & & & & & & & & & \\
\hline T-2 & & & & & & & & & & & & & & & & & & & & \\
\hline FB1 & & 457 & & & $\underline{81}$ & & 15 & & $\underline{1414}$ & 9 & $\underline{139}$ & $\underline{363}$ & $\underline{296}$ & $\underline{1573}$ & $\underline{69}$ & $\underline{1021}$ & & $\underline{2294}$ & $\underline{46}$ & 23 \\
\hline FB2 & & 130 & & & 54 & & & & $\underline{459}$ & & 91 & $\underline{400}$ & 68 & $\underline{1289}$ & 30 & $\underline{513}$ & & $\underline{1010}$ & & \\
\hline FB3 & & $\underline{50}$ & & & & & & & $\underline{171}$ & & & & $\underline{44}$ & $\underline{129}$ & & $\underline{136}$ & & $\underline{264}$ & & \\
\hline ZEA & $\underline{117}$ & 191 & 1 & & 23 & 4 & 3 & $\underline{551}$ & 21 & $\underline{221}$ & $\underline{3073}$ & $\underline{789}$ & $\underline{237}$ & $\underline{405}$ & 34 & 3 & 42 & 24 & $\underline{222}$ & 19 \\
\hline$\alpha-Z O L$ & & & & & & & & & & & & & & & & & & & & \\
\hline$\beta-Z O L$ & & & & & & & & & & $\underline{14}$ & & & & & & & & & & \\
\hline $\mathrm{AOH}$ & & $\underline{225}$ & & & & $\underline{83}$ & & $\underline{183}$ & 17 & $\underline{1804}$ & $\underline{44}$ & & $\underline{603}$ & $\underline{42}$ & & & $\underline{753}$ & 17 & $\underline{269}$ & \\
\hline AME & & 103 & & & 4 & $\underline{221}$ & 1 & $\underline{24}$ & $\underline{7}$ & $\underline{347}$ & $\underline{21}$ & $\underline{11}$ & $\underline{128}$ & 5 & 2 & $\underline{7}$ & $\underline{198}$ & $\underline{7}$ & $\underline{73}$ & $\underline{7}$ \\
\hline TEN & $\underline{71}$ & $\underline{70}$ & & $\underline{39}$ & & $\underline{37}$ & & $\underline{42}$ & & $\underline{92}$ & & & & & & & $\underline{66}$ & & $\underline{97}$ & 4 \\
\hline TeA & & & & & & & & $\underline{388}$ & & $\underline{3625}$ & & & & & & & & & & $\underline{623}$ \\
\hline AFB1 & & & & & & & & & & & & & & & & & & & & \\
\hline AFB2 & & & & & & & & & & & & & & & & & & & & \\
\hline AFG1 & & & & & & & & & & & & & & & & & & & & \\
\hline AFG2 & & & & & & $\underline{25}$ & & & & & & & & & & & & & & \\
\hline BEA & 4 & 100 & & & $\underline{52}$ & 14 & $\underline{60}$ & 2186 & 40 & 4437 & 64 & 123 & 61 & 64 & 22 & 81 & 162 & 24 & 145 & 42 \\
\hline CIT & & & & & & $\underline{28}$ & & & & & & & & & & & & & & \\
\hline MPA & & & & & & & & & & & & & & & & & & & & \\
\hline GLIO & & & & & & & & & & & & & & & $\underline{162}$ & & & & & \\
\hline ROQ-C & & & & & & & & & & & & & & & & & & & & 127 \\
\hline STE & $\underline{12}$ & $\underline{2}$ & $\underline{2}$ & $\underline{1}$ & & $\underline{1}$ & & $\underline{1}$ & & $\underline{2}$ & $\underline{25}$ & $\underline{2}$ & & $\underline{5}$ & $\underline{4}$ & & & & $\underline{2}$ & $\underline{8}$ \\
\hline
\end{tabular}

Eniatinas - Alcaloides del ergot - Tricotecenos - Fumonisinas - Zearalenona - Toxinas de Alternaria - Aflatoxinas - Misceláneas Celdas vacías indican ND (no detectado); Subrayadas se muestran aquellas concentraciones calculadas que dieron valores por encima del límite de cuantificación.

Micotoxinas: Eniatina B (ENB), Eniatina B1 (ENB1), Eniatina A (ENA), Eniatina A1 (ENA1), Ác. Ciclopiazónico (CPA), Ergocorninina (E-corN), Ergocristinina (E-crisN), Ergocriptina (E-crip), Ergocristina (E-cris), Ergometrina (E-met), Ergosina (E-sin), 15-ADON (15-acetil deoxinivalenol), 3ADON (3-acetil deoxinivalenol), Deoxinivalenol (DON), Diacetoxyscirpenol (DAS), Toxina HT2 (HT2), Nivalenol (NIV), Toxina T-2 (T2), Fumonisina B1 (FB1), Fumonisina B2 (FB2), Fumonisina B3 (FB3), Zearalenona (ZEA), $\alpha$-zearalenol ( $\alpha$-ZOL), $\beta$-zearalenol ( $\beta$-ZOL), Alternariol (AOH), Alternariolmetileter (AME), Tentoxina (TEN), Ác. Tenuazónico (TeA), Aflatoxina B1 (AFB1), Aflatoxina B2 (AFB2), Aflatoxina G1 (AFG1), Aflatoxina G2 (AFG2), Beauvericina (BEA), Citrinina (CIT), Ác. Micofenólico (MPA), Gliotoxina (GLIO), Roquefortina C (ROQ-C), Esterigmatocistina (STE).

Muestras: 1-4 (pasturas de alfalfa), 5-6 (henos de alfalfa), 7 (pastura de cebada), 8-16 (silos de maíz), 17-20 (silos de sorgo). 
Tabla S5-2: Concentraciones halladas ( $\mu \mathrm{g} / \mathrm{kg}$ mat. seca) de las micotoxinas analizadas por UHPLC-MS/MS en las muestras analizadas clasificadas como Cereales \& derivados.

\begin{tabular}{|c|c|c|c|c|c|c|c|c|c|c|c|c|}
\hline & & & & & & reales & deriva & & & & & \\
\hline & 21 & 22 & 23 & 24 & 25 & 26 & 27 & 28 & 29 & 30 & 31 & 32 \\
\hline ENB & & & 0,3 & & 0,2 & & 1 & 0,4 & 11 & 1 & 1 & \\
\hline ENB1 & & & & & & & & & $\underline{13}$ & & & \\
\hline ENA & & & & & & & & & 2 & & & \\
\hline ENA1 & & & & & & & & & $\underline{9}$ & & & \\
\hline CPA & & $\underline{30}$ & & & & & $\underline{12}$ & $\underline{17}$ & & & & \\
\hline E-corN & & & & & & & & & & & & \\
\hline E-crisN & & & & & & & & & & & & \\
\hline E-crip & & & & & & & & & & & & \\
\hline E-cris & & & & & & & & & & & & \\
\hline E-met & & & & & & & & & & & & \\
\hline E-sin & & & & & & & & & & & & \\
\hline 15ADON & $\underline{274}$ & & & & & & & $\underline{102}$ & & & & $\underline{367}$ \\
\hline 3ADON & $\underline{136}$ & & & & & & & & & & & $\underline{276}$ \\
\hline DON & & 60 & 61 & 78 & 123 & 36 & 89 & & & & & \\
\hline DAS & & & & & & & & & & & & \\
\hline H-T2 & & & & & & & & & & & & \\
\hline NIV & & & & & & & & & & $\underline{682}$ & & \\
\hline T-2 & & & & & & & & & & & & \\
\hline FB1 & $\underline{5918}$ & $\underline{1002}$ & $\underline{3034}$ & $\underline{1058}$ & $\underline{3062}$ & $\underline{1255}$ & $\underline{2547}$ & $\underline{3586}$ & $\underline{2893}$ & $\underline{5833}$ & $\underline{6498}$ & $\underline{27996}$ \\
\hline FB2 & $\underline{1812}$ & $\underline{263}$ & 814 & $\underline{268}$ & $\underline{538}$ & $\underline{416}$ & $\underline{802}$ & $\underline{976}$ & $\underline{1002}$ & $\underline{1821}$ & $\underline{1969}$ & $\underline{5557}$ \\
\hline FB3 & $\underline{596}$ & $\underline{151}$ & $\underline{350}$ & $\underline{118}$ & $\underline{335}$ & $\underline{156}$ & $\underline{244}$ & $\underline{364}$ & $\underline{240}$ & $\underline{652}$ & $\underline{717}$ & $\underline{2099}$ \\
\hline ZEA & $\underline{225}$ & 4 & 11 & 3 & 10 & 11 & 25 & $\underline{218}$ & $\underline{636}$ & $\underline{551}$ & $\underline{469}$ & $\underline{541}$ \\
\hline$\alpha-Z O L$ & & & & & & & & & $\underline{114}$ & $\underline{44}$ & $\underline{36}$ & \\
\hline$\beta-Z O L$ & 17 & & & & & & & & $\underline{50}$ & $\underline{228}$ & $\underline{208}$ & \\
\hline $\mathrm{AOH}$ & $\underline{44}$ & 10 & 9 & $\underline{26}$ & 7 & & & 21 & $\underline{174}$ & 16 & 15 & \\
\hline AME & $\underline{16}$ & 3 & 1 & $\underline{5}$ & 1 & 2 & 0,3 & 5 & $\underline{52}$ & 4 & $\underline{7}$ & 1 \\
\hline TEN & & & & 5 & & & & & $\underline{70}$ & & & \\
\hline TeA & & & & & & & & & & & & \\
\hline AFB1 & 2 & $\underline{17}$ & 1 & $\underline{15}$ & & & 2 & $\underline{19}$ & & & & \\
\hline AFB2 & & & & 1 & & & & & & & & \\
\hline AFG1 & & & & 3 & & & & & & & & \\
\hline AFG2 & & & & & & & & & & & & \\
\hline BEA & $\underline{36}$ & 4 & $\underline{19}$ & $\underline{24}$ & $\underline{33}$ & $\underline{22}$ & 9 & $\underline{39}$ & $\underline{623}$ & $\underline{68}$ & $\underline{72}$ & $\underline{12}$ \\
\hline CIT & & & & & & & & & & & & \\
\hline MPA & & & & & & & $\underline{14}$ & & & & & \\
\hline GLIO & & & & & & & & & & & & \\
\hline ROQ-C & & & & & & & & & & & & \\
\hline STE & & & 1 & & & & 3 & & 1 & 1 & & \\
\hline
\end{tabular}

Eniatinas - Alcaloides del ergot - Tricotecenos - Fumonisinas - Zearalenona - Toxinas de Alternaria - Aflatoxinas - Misceláneas Celdas vacías indican ND (no detectado); Subrayadas se muestran aquellas concentraciones calculadas que dieron valores por encima del límite de cuantificación.

Micotoxinas: Eniatina B (ENB), Eniatina B1 (ENB1), Eniatina A (ENA), Eniatina A1 (ENA1), Ác. Ciclopiazónico (CPA), Ergocorninina (E-corN), Ergocristinina (E-crisN), Ergocriptina (E-crip), Ergocristina (E-cris), Ergometrina (E-met), Ergosina (E-sin), 15-ADON (15acetil deoxinivalenol), 3-ADON (3-acetil deoxinivalenol), Deoxinivalenol (DON), Diacetoxyscirpenol (DAS), Toxina HT2 (HT2), Nivalenol (NIV), Toxina T-2 (T2), Fumonisina B1 (FB1), Fumonisina B2 (FB2), Fumonisina B3 (FB3), Zearalenona (ZEA), $\alpha-$ zearalenol ( $\alpha-Z O L)$, $\beta$-zearalenol ( $\beta$-ZOL), Alternariol (AOH), Alternariolmetileter (AME), Tentoxina (TEN), Ác. Tenuazónico (TeA), Aflatoxina B1 (AFB1), Aflatoxina B2 (AFB2), Aflatoxina G1 (AFG1), Aflatoxina G2 (AFG2), Beauvericina (BEA), Citrinina (CIT), Ác. Micofenólico (MPA), Gliotoxina (GLIO), Roquefortina C (ROQ-C), Esterigmatocistina (STE).

Muestras: 21-27 (maíz molido),28-29 (trigo molido), 30-31 (burlanda de maíz), 32 (gluten). 
Tabla S5-3: Concentraciones halladas ( $\mu \mathrm{g} / \mathrm{kg}$ mat. seca) de las micotoxinas analizadas por UHPLC-MS/MS en las muestras analizadas clasificadas como Balanceados y TMRs.

\begin{tabular}{|c|c|c|c|c|c|c|c|c|c|c|c|c|c|}
\hline & \multicolumn{13}{|c|}{ Balanceados \& TMRs } \\
\hline & 33 & 34 & 35 & 36 & 37 & 38 & 39 & 40 & 41 & 42 & 43 & 44 & 45 \\
\hline ENB & 13 & 8 & 11 & 2 & 2 & 3 & $\underline{89}$ & 308 & 7 & 1 & 2 & & \\
\hline ENB1 & $\underline{14}$ & $\underline{10}$ & $\underline{14}$ & & & & $\underline{105}$ & $\underline{419}$ & 7 & & & & \\
\hline ENA & 1 & 1 & 2 & & & & & $\underline{117}$ & 1 & & & & \\
\hline ENA1 & $\underline{10}$ & $\underline{6}$ & $\underline{9}$ & & & 2 & $\underline{62}$ & $\underline{373}$ & 4 & & 3 & & \\
\hline CPA & & & & & $\underline{7}$ & $\underline{10}$ & & & $\underline{15}$ & & & & \\
\hline E-corN & & & & & & & & & 3 & & & & \\
\hline E-crisN & & & & & & & & & 2 & & & & \\
\hline E-crip & & & & & & & & & $\underline{6}$ & & & & \\
\hline E-cris & & & & & & & & & 5 & & & & \\
\hline E-met & & & & & & & & & 3 & & & & \\
\hline$E-\sin$ & & & & & & & & & $\underline{4}$ & & & & \\
\hline 15ADON & & & & & & & & & $\underline{63}$ & & & & \\
\hline 3ADON & $\underline{57}$ & & $\underline{54}$ & & & & & & $\underline{58}$ & & & & \\
\hline DON & & & & 73 & & & & & & & & & \\
\hline DAS & & & & & & & & & & & & & \\
\hline H-T2 & & & & & & & & 21 & & & & & \\
\hline NIV & & & & & & & & & 470 & 232 & & & \\
\hline T-2 & & & & & & & & $\underline{19}$ & & & & & \\
\hline FB1 & $\underline{211}$ & $\underline{213}$ & $\underline{616}$ & $\underline{523}$ & $\underline{1835}$ & 3427 & & $\underline{35}$ & $\underline{1685}$ & $\underline{1189}$ & $\underline{1208}$ & $\underline{1255}$ & $\underline{1067}$ \\
\hline FB2 & 59 & 70 & $\underline{143}$ & $\underline{131}$ & $\underline{443}$ & 1054 & & & $\underline{694}$ & $\underline{414}$ & 348 & $\underline{695}$ & $\underline{624}$ \\
\hline FB3 & & 35 & $\underline{86}$ & $\underline{61}$ & $\underline{224}$ & $\underline{434}$ & & & $\underline{176}$ & $\underline{133}$ & 183 & $\underline{145}$ & $\underline{120}$ \\
\hline ZEA & 19 & $\overline{16}$ & 21 & 7 & 23 & 31 & $\underline{1018}$ & $\underline{5015}$ & $\underline{96}$ & $\underline{365}$ & 24 & $\underline{66}$ & 45 \\
\hline$\alpha-Z O L$ & & & & & & & $\underline{264}$ & $\underline{1349}$ & & & & & \\
\hline$\beta$-ZOL & & & & & & & & $\underline{326}$ & & & & & \\
\hline $\mathrm{AOH}$ & $\underline{200}$ & $\underline{220}$ & $\underline{275}$ & $\underline{148}$ & $\underline{32}$ & $\underline{66}$ & $\underline{101}$ & $\underline{361}$ & $\underline{104}$ & 17 & 24 & $\underline{29}$ & $\underline{42}$ \\
\hline AME & $\underline{52}$ & $\underline{57}$ & $\underline{54}$ & $\underline{44}$ & $\underline{8}$ & $\underline{18}$ & $\underline{43}$ & $\underline{197}$ & $\underline{35}$ & $\underline{6}$ & $\underline{5}$ & $\underline{10}$ & $\underline{8}$ \\
\hline TEN & $\underline{87}$ & $\underline{97}$ & $\underline{68}$ & $\underline{111}$ & $\underline{17}$ & $\underline{14}$ & $\underline{27}$ & $\underline{9}$ & $\underline{36}$ & $\underline{28}$ & $\underline{21}$ & & $\underline{44}$ \\
\hline TeA & $\underline{320}$ & & $\underline{233}$ & $\underline{486}$ & & & & $\underline{445}$ & & & & & \\
\hline AFB1 & 1 & 2 & 3 & 2 & 1 & & & & & & & & \\
\hline AFB2 & & & & & & & & & & & & & \\
\hline AFG1 & & & & & & & & & & & & & \\
\hline AFG2 & & & & & & & & & & & & & \\
\hline BEA & $\underline{11}$ & $\underline{12}$ & $\underline{11}$ & 24 & $\underline{15}$ & $\underline{67}$ & $\underline{1052}$ & $\underline{1392}$ & $\underline{69}$ & $\underline{39}$ & $\underline{26}$ & $\underline{608}$ & $\underline{539}$ \\
\hline CIT & & & & & & & & & & & $\underline{56}$ & & \\
\hline MPA & & & & & & & & & & & $\underline{22}$ & & \\
\hline GLIO & & & & & & & & & & & & & \\
\hline ROQ-C & & & & & & & & & & 104 & & & \\
\hline STE & & & & & & & & & & & & $\underline{7}$ & $\underline{4}$ \\
\hline
\end{tabular}

Eniatinas - Alcaloides del ergot - Tricotecenos - Fumonisinas - Zearalenona - Toxinas de Alternaria - Aflatoxinas - Misceláneas Celdas vacías indican ND (no detectado); Subrayadas se muestran aquellas concentraciones calculadas que dieron valores por encima del límite de cuantificación.

Micotoxinas: Eniatina B (ENB), Eniatina B1 (ENB1), Eniatina A (ENA), Eniatina A1 (ENA1), Ác. Ciclopiazónico (CPA), Ergocorninina (E-corN), Ergocristinina (E-crisN), Ergocriptina (E-crip), Ergocristina (E-cris), Ergometrina (E-met), Ergosina (E-sin), 15-ADON (15acetil deoxinivalenol), 3-ADON (3-acetil deoxinivalenol), Deoxinivalenol (DON), Diacetoxyscirpenol (DAS), Toxina HT2 (HT2), Nivalenol (NIV), Toxina T-2 (T2), Fumonisina B1 (FB1), Fumonisina B2 (FB2), Fumonisina B3 (FB3), Zearalenona (ZEA), $\alpha-$ zearalenol ( $\alpha-Z O L)$, $\beta$-zearalenol ( $\beta$-ZOL), Alternariol (AOH), Alternariolmetileter (AME), Tentoxina (TEN), Ác. Tenuazónico (TeA), Aflatoxina B1 (AFB1), Aflatoxina B2 (AFB2), Aflatoxina G1 (AFG1), Aflatoxina G2 (AFG2), Beauvericina (BEA), Citrinina (CIT), Ác. Micofenólico (MPA), Gliotoxina (GLIO), Roquefortina C (ROQ-C), Esterigmatocistina (STE).

Muestras: 33-42 (balanceados comerciales), 43-45 (TMRs, raciones totales mezcladas). 
Tabla S5-4. Concentraciones halladas ( $\mu \mathrm{g} / \mathrm{kg}$ mat. seca) de las micotoxinas analizadas por UHPLC-MS/MS en las muestras analizadas clasificadas como Oleaginosas \& derivados.

\begin{tabular}{|c|c|c|c|c|c|c|c|c|c|}
\hline & \multicolumn{9}{|c|}{ Oleaginosas \& derivados } \\
\hline & 46 & 47 & 48 & 49 & 50 & 51 & 52 & 53 & 54 \\
\hline ENB & 0,5 & & 4 & & 6 & 9 & 1 & & 2 \\
\hline ENB1 & & & 5 & & 7 & $\underline{13}$ & & & 4 \\
\hline ENA & & & & & & 1 & & & \\
\hline ENA1 & & & 2 & & $\underline{6}$ & $\underline{9}$ & & & 4 \\
\hline CPA & & & & & & & & & \\
\hline E-corN & & & & & & & & & \\
\hline E-crisN & & & & & & & & & \\
\hline E-crip & & & & & & & & & \\
\hline E-cris & & & & & & & & & \\
\hline E-met & & & & & & & & & \\
\hline E-sin & & & & & & & & & \\
\hline 15-ADON & & & & & & & & $\underline{1175}$ & \\
\hline 3-ADON & & & & & & & & & \\
\hline DON & 72 & & & & & & & & \\
\hline DAS & & & $\underline{26}$ & $\underline{29}$ & & & & & \\
\hline H-T2 & & & & & & & & & \\
\hline NIV & & & & & & & & & \\
\hline T-2 & & & & & & & & & \\
\hline FB1 & & & $\underline{28}$ & $\underline{35}$ & $\underline{316}$ & 21 & $\underline{96}$ & $\underline{83}$ & \\
\hline FB2 & & & & & 71 & & 23 & 38 & \\
\hline FB3 & & & & & $\underline{45}$ & & & & \\
\hline ZEA & $\underline{85}$ & 1 & $\underline{244}$ & $\underline{953}$ & & 15 & $\underline{1951}$ & $\underline{92}$ & $\underline{3550}$ \\
\hline$\alpha-Z O L$ & & & & & & & $\underline{181}$ & & $\underline{497}$ \\
\hline$\beta-Z O L$ & & & & $\underline{54}$ & & & & & 263 \\
\hline $\mathrm{AOH}$ & $\underline{260}$ & & $\underline{2857}$ & $\underline{1383}$ & 15 & & $\underline{140}$ & $\underline{73}$ & $\underline{258}$ \\
\hline AME & $\underline{81}$ & & $\underline{531}$ & $\underline{348}$ & 3 & 3 & $\underline{52}$ & $\underline{21}$ & $\underline{95}$ \\
\hline TEN & $\underline{60}$ & & $\underline{175}$ & $\underline{167}$ & $\underline{27}$ & $\underline{26}$ & $\underline{43}$ & & $\underline{26}$ \\
\hline TeA & & & $\underline{8017}$ & $\underline{9536}$ & & & & & 1052 \\
\hline AFB1 & & & & & & & & & \\
\hline AFB2 & 1 & & & & & & & & \\
\hline AFG1 & & & & & & & & & \\
\hline AFG2 & & & & & & & & & \\
\hline BEA & $\underline{874}$ & 4 & $\underline{6234}$ & $\underline{6364}$ & $\underline{9}$ & $\underline{7}$ & $\underline{623}$ & $\underline{26}$ & $\underline{3117}$ \\
\hline CIT & & & & & & & $\underline{68}$ & & \\
\hline MPA & & & & & & 10 & & & \\
\hline GLIO & & & & & & & & & \\
\hline ROQ-C & & & & & & & & & \\
\hline STE & & $\underline{1}$ & $\underline{9}$ & $\underline{2}$ & & & 1 & & \\
\hline
\end{tabular}

Eniatinas - Alcaloides del ergot - Tricotecenos - Fumonisinas - Zearalenona - Toxinas de Alternaria - Aflatoxinas - Misceláneas Celdas vacías indican ND (no detectado); Subrayadas se muestran aquellas concentraciones calculadas que dieron valores por encima del límite de cuantificación.

Micotoxinas: Eniatina B (ENB), Eniatina B1 (ENB1), Eniatina A (ENA), Eniatina A1 (ENA1), Ác. Ciclopiazónico (CPA), Ergocorninina (E-corN), Ergocristinina (E-crisN), Ergocriptina (E-crip), Ergocristina (E-cris), Ergometrina (E-met), Ergosina (E-sin), 15-ADON (15acetil deoxinivalenol), 3-ADON (3-acetil deoxinivalenol), Deoxinivalenol (DON), Diacetoxyscirpenol (DAS), Toxina HT2 (HT2), Nivalenol (NIV), Toxina T-2 (T2), Fumonisina B1 (FB1), Fumonisina B2 (FB2), Fumonisina B3 (FB3), Zearalenona (ZEA), $\alpha-$ zearalenol ( $\alpha-Z O L)$, $\beta$-zearalenol ( $\beta$-ZOL), Alternariol (AOH), Alternariolmetileter (AME), Tentoxina (TEN), Ác. Tenuazónico (TeA), Aflatoxina B1 (AFB1), Aflatoxina B2 (AFB2), Aflatoxina G1 (AFG1), Aflatoxina G2 (AFG2), Beauvericina (BEA), Citrinina (CIT), Ác. Micofenólico (MPA), Gliotoxina (GLIO), Roquefortina C (ROQ-C), Esterigmatocistina (STE).

Muestras: 46-49 (semillas de algodón), 50-52 (expellers de soja), 53 (expeller de gorasol), 54 (poroto de soja). 
BIBLIOGRAFÍA 


\section{BIBLIOGRAFÍA}

1. Dhaliwal GS, Jindal V, Dhawan AK (2010) Insect Pest Problems and Crop Losses: Changing Trends. Indian J Ecol 37: 1-7.

2. CIPF/FAO/WHO (2016) NIMF N ${ }^{\circ}$ : Glosario de términos fitosanitarios. Normas Internacionales para Manejo de Fitosanitarios. Producido por la Secretaría de la Convención Internacional de Protección Fitosanitaria. Disponible en http://www.fao.org/search/NIMF 5 (Accedido Septiembre 2018).

3. FAO/OMS (2015) Código Internacional de Conductas para la Gestión de Plaguicidas. Organización de las Naciones Unidas para la Alimentación y la Agricultura (FAO), Organización Mundial de la Salud (OMS), Roma.

4. Rivero M (2012) Manual para la aplicación de fitosanitarios. Servicio Nacional de Sanidad y Calidad Agroalimentaria (SENASA). Buenos Aires, Argentina.

5. Codex Alimentarius (2018) Residuos de plaguicidas en los alimentos y piensos. Glosario de términos. Disponible en: http://www.fao.org/fao-who-codexalimentarius/codex-texts/dbs/pestres/glossary/es/ (Accedido Agosto 2018).

6. Arregui C, Bertolaccini I, Herzog L, Sánchez D, Scotta R (2007) Manejo de plagas, enfermedades y malezas en cultivos extensivos. $1^{\circ} \mathrm{ed}$. Universidad Nacional del Litoral, Santa Fe, Argentina.

7. Fishel F (2010) Pesticide Formulations. Document PI-231, Agronomy Department, University of Florida (UF), Institute of Food and Agricultural Sciences (IFAS). Disponible en: http://edis.ifas.ufl.edu (Accedido Agosto 2018).

8. Cid R (2014) Cap. 1: Procedimientos de protección de cultivos. In, Aplicación eficiente de fitosanitarios. Ediciones INTA, Buenos Aires, Argentina.

9. Fishel F (2005) Pesticide-Organism Interactions. Document PI-43, Agronomy Department, University of Florida (UF), Institute of Food and Agricultural Sciences (IFAS). Disponible en: http://edis.ifas.ufl.edu (Accedido Febrero 2018).

10. Organización Mundial de la Salud (2018) OMS Datos y cifras http://www.who.int/es/news-room/factsheets/detail/pesticide-residues-in-food (Accedido Agosto 2018).

11. Stephenson GR, Solomon KR, Carazo Rojas E (2013) Cap. 4: Selección, formulación y aplicación de plaguicidas. In, Plaguicidas y ambiente. Editorial Universidad de Costa Rica, San José, Costa Rica.

12. SENASA, Servicio Nacional de Sanidad y Calidad Agroalimentaria. (2010) Resolución $N^{\circ} 934$, Productos agropecuarios: Requisitos que deben cumplir los productos y subproductos agropecuarios para consumo interno.

13. University of Hertfordshire: Pesticide Properties DataBase (PPDB). https://sitem.herts.ac.uk/aeru/ppdb/en/. Accedido Agosto 2018.

14. PAN (2018) Pesticide Action Network (PAN) Data Base. http://www.pesticideinfo.org/Search_Chemicals.jsp (Accedido Agosto 2018).

15. IRAC (2016) Modo de Acción de Insecticidas y Acaricidas. Insecticide Resistance Action Committee (IRAC). Disponible en http://www.irac-online.org/modes-of-action/ (Accedido agosto 2018).

16. WSSA (2018) Modo de Acción de Herbicidas, Resumen. Weed Science Society of America (WSSA). Disponible en http://wssa.net/wp-content/uploads/WSSA-Mechanism-of-Action.pdf (Accedido agosto 2018).

17. FRAC (2018) Modo de Acción de Fungicidas. Fungicide Resistance Action Committee (FRAC). Disponible en http://www.phi-base.org/images/fracCodeList.pdf (Accedido agosto 2018).

18. Beldoménico HR, García SR, De Jesús JJ, Repetti MR (2012) Residuos de plaguicidas, Material de Estudio para la asignatura Residuos Químicos Contaminantes de los Alimentos, Facultad de Ingeniería Química, Universidad Nacional del Litoral. Apunte impreso, accesible en Librería CEIQ-FIQ-UNL. Versión consultada: Revisión 2do. Cuatrimestre de 2012, 1-159.

19. Carvalho FP (2017) Pesticides, environment, and food safety. Food Energy Secur 6: 48-60.

20. Briggs SA (1992) Basic Guide to Pesticides: Their Characteristics and Hazards. 1 Ed. Taylor \& Francis, Washington, DC. 
21. Muñoz-Quezada MT, Lucero BA, Barr DB, Steenland K, Levy K, Ryan PB, Iglesias V, Alvarado S, Concha C, Rojas E, et al. (2013) Neurodevelopmental effects in children associated with exposure to organophosphate pesticides: A systematic review. NeuroToxicology 39: 158-168.

22. Horton MK, Kahn LG, Perera F, Barr DB, Rauh V (2012) Does the home environment and the sex of the child modify the adverse effects of prenatal exposure to chlorpyrifos on child working memory? Neurotoxicol Teratol 34: 534-541.

23. Berkowitz GS, Wetmur JG, Birman-Deych E, Obel J, Lapinski RH, Godbold JH, Holzman IR, Wolff MS (2004) In utero pesticide exposure, maternal paraoxonase activity, and head circumference. Environ Health Perspect 112: 388-391.

24. Engel SM, Berkowitz GS, Barr DB, Teitelbaum SL, Siskind J, Meisel SJ, Wetmur JG, Wolff MS (2007) Prenatal Organophosphate Metabolite and Organochlorine Levels and Performance on the Brazelton Neonatal Behavioral Assessment Scale in a Multiethnic Pregnancy Cohort. Am J Epidemiol 165: 13971404.

25. Eskenazi B, Marks AR, Bradman A, Harley K, Barr DB, Johnson C, Morga N, Jewell NP (2007) Organophosphate pesticide exposure and neurodevelopment in young Mexican-American children. Environ Health Perspect 115: 792-798.

26. Blair A, Ritz B, Wesseling C, Beane Freeman L (2015) Pesticides and human health. Occup Environ Med 72: 81-82.

27. Mostafalou S, Abdollahi M (2013) Pesticides and human chronic diseases: Evidences, mechanisms, and perspectives. Toxicol Appl Pharmacol 268: 157-177.

28. IPCS (2002) International Programme on Chemical Safety (IPCS). Global assessment of the state-ofthe-science of endocrine disruptors. World Health Organization (WHO), International Labour Organisation (ILO), United Nations Environment Programme (UNEP), 2002. Disponible en: http://www.who.int/ipcs/publications/new_issues/endocrine_disruptors/en/ Accedido Agosto 2018.

29. CCE (1999) Comisión de las Comunidades Europeas. Estrategia comunitaria en materia de alteradores endocrinos. Comunicación de la comisión al consejo y al parlamento Europeo. COM(1999)706 final. Bruselas.

30. Groshart C, Okkerman PC (2000) Towards the establishment of a priority list of substances for further evaluation of their role in endocrine disruption: preparation of a candidate list of substances as a basis for priority setting, Final report. BKH Consulting Engineers in association with TNO Nutrition and Food Research, The Netherlands.

31. Weselak M, Arbuckle TE, Foster W (2007) Pesticide Exposures and Developmental Outcomes: The Epidemiological Evidence. J Toxicol Environ Health B 10: 41-80.

32. Kalliora C, Mamoulakis C, Vasilopoulos E, Stamatiades GA, Kalafati L, Barouni R, Karakousi T, Abdollahi M, Tsatsakis A (2018) Association of pesticide exposure with human congenital abnormalities. Toxicol Appl Pharmacol 346: 58-75.

33. Petrakis D, Vassilopoulou L, Mamoulakis C, Psycharakis C, Anifantaki A, Sifakis S, Docea A, Tsiaoussis J, Makrigiannakis A, Tsatsakis A (2017) Endocrine Disruptors Leading to Obesity and Related Diseases. Int J Environ Res Public Health 14: 1282.

34. IARC (2018) International Agency for Research on Cancer. Monographs on the evaluation of Carcinogenic Risks to Humans. World Health Organization (WHO). Disponible en: http://monographs.iarc.fr/ENG/Classification/. Accedido Agosto 2018.

35. Menegaux F (2006) Household exposure to pesticides and risk of childhood acute leukaemia. Occup Environ Med 63: 131-134.

36. Vazquez MA, Maturano E, Etchegoyen A, Difilippo FS, Maclean B (2017) Association between Cancer and Environmental Exposure to Glyphosate. Int J Clin Med 08: 73-85.

37. Boada LD, Zumbado M, Henríquez-Hernández LA, Almeida-González M, Álvarez-León EE, Serra-Majem L, Luzardo OP (2012) Complex organochlorine pesticide mixtures as determinant factor for breast cancer risk: a population-based case-control study in the Canary Islands (Spain). Environmental Health 11:.

38. Felsot AS (2011) Pesticides \& Health, Myths vs. Realities. American Council on Science and Health. 
39. FAO (2017) Presentación y evaluación de los datos sobre residuos de plaguicidas para la estimación de los límites máximos de residuos de plaguicidas en alimentos y piensos. Publicaciones FAO, Roma.

40. OCDE (2009) Organisation for Economic Co-operation and Development. Guidance document on the definition of residue. Series on testing and assessment $N^{\circ} 63$ and series on pesticides $N^{\circ} 31$. ENV/JM/MONO(2009)30.

41. Dujardin B (2012) Complex Residue Definitions, Possibilities for simplification. Pesticides Unit, EFSA. Lecture at 9th European Pesticide Residue Workshop, Vienna, Austria, 27 June 2012.

42. Truchot E (2012) How to improve pesticide residue definitions. Lecture at 9th European Pesticide Residue Workshop, Vienna, Austria, 27 June 2012.

43. Poisot AS, Speedy A, Kueneman E (2004) Good Agricultural Practices - a working concept. Background paper for the FAO Internal Workshop on Good Agricultural Practices. Rome, Italy 27-29 October 2004. Disponible en http://www.fao.org/tempref/docrep/fao/010/ag856e/ag856e00.pdf (Accedido Agosto 2018).

44. European Food Safety Authority (2014) The 2012 European Union Report on pesticide residues in food. EFSA Journal 12:.

45. Medina-Pastor P, Valverde A, Pihlström T, Masselter S, Gamon M, Mezcua M, Rodríguez-Torreblanca C, Fernández-Alba AR (2011) Comparative Study of the Main Top-down Approaches for the Estimation of Measurement Uncertainty in Multiresidue Analysis of Pesticides in Fruits and Vegetables. J Agric Food Chem 59: 7609-7619.

46. SAGPyA (1999) Secretaría de Agricultura, Ganadería, Pesca y Alimentación. Resolución 350/99 'Manual de Procedimientos, Criterios y Alcances para el Registro de Productos Fitosanitarios en la República Argentina'. Disponible en http://servicios.infoleg.gob.ar/infoleg/nternet/anexos/5500059999/59812/norma.htm (Accedido Agosto 2018).

47. SENASA, Servicio Nacional de Sanidad y Calidad Agroalimentaria. (2011) Resolución N 559, Productos veterinarios: límites de residuos en alimentos de origen animal.

48. SENASA, Servicio Nacional de Sanidad y Calidad Agroalimentaria. (2012) Resolución $N^{\circ} 608$, Productos alimenticios: Límites Máximos de Residuos.

49. MERCOSUR (1994) Resolución GMC N²3, Residuos de plaguicidas en productos agrícolas. Mercado Común del Sur. http://www.mercosur.int/innovaportal/v/3097/2/innova.front/resoluciones-1994 (Accedido Agosto 2018).

50. ANMAT (2014) Código Alimentario Argentino. Cap VIII Alimentos Lácteos. Administración Nacional de Medicamentos, Alimentos y Tecnología Médica Ministerio de Salud de la Nación, Argentina. Disponible en http://www.anmat.gov.ar/alimentos/normativas_alimentos_caa.asp (Accedido Agosto 2018).

51. ANMAT (2012) Código Alimentario Argentino. Cap XII Bebidas hídricas. Administración Nacional de Medicamentos, Alimentos y Tecnología Médica Ministerio de Salud de la Nación, Argentina.

Disponible en http://www.anmat.gov.ar/alimentos/normativas_alimentos_caa.asp (Accedido Agosto 2018).

52. Prov. de Santa Fe (1994) Ley № 11.220, Prestación y regulación de los servicios sanitarios. Legislatura de la Provincia de Santa Fe, Argentina. Disponible en

https://www.santafe.gov.ar/normativa/item.php?id=107685\&cod=b2adee89ade10409c3937bc9f49b 55e5 (Accedido Agosto 2018).

53. EPA (2018) Environmental Protection Agency (EPA), Washington, DC, United States of America (USA). Disponible en: https://www.epa.gov/ (Accedido Agosto 2018).

54. Comisión Europea (2009) Reglamento (CE) N 1107/2009 del Parlamento Europeo y del Consejo relativo a la comercialización de productos fitosanitarios. Diario Oficial de la Comunidad Europea 061: 1-50.

55. Comisión Europea (2005) Reglamento CE N³96, Relativo a los Límites Máximos de Residuos de plaguicidas en alimentos y piensos de origen vegetal y animal. Diario Oficial de la Comunidad Europea 063: 1-16.

56. Rubinstein H, Theumer M (2011) Cap. 3: Principales micotoxinas. In Ramos A (ed.), Micotoxinas y micotoxicosis pp 45-72. A. Madrid Vicente Ediciones, España. 
57. Marín Sillué S, Sanchis Almenar V, Ramos Girona AJ (2011) Cap. 4: Factores ecofisiológicos que condicionan el crecimiento fúngico y la producción de micotoxinas. In Ramos AJ (ed.), Micotoxinas y Micotoxicosis pp 73-93. A. Madrid Vicente Ediciones, España.

58. Bullerman LB (2003) Mycotoxins, Classifications. In, Encyclopedia of Food Sciences and Nutrition pp 4080-4089. Elsevier.

59. Turner NW, Subrahmanyam S, Piletsky SA (2009) Analytical methods for determination of mycotoxins: A review. Anal Chim Acta 632: 168-180.

60. Alshannaq A, Yu J-H (2017) Occurrence, Toxicity, and Analysis of Major Mycotoxins in Food. Int J Environ Res Public Health 14: 632.

61. Arranz I, Mischke C, Stroka J, Sizoo E, van Egmond H, Neugebauer M (2007) Liquid chromatographic method for the quantification of zearalenone in baby food and animal feed: interlaboratory study. $J$ AOAC Int 90: 1598-1609.

62. Freire L, Sant'Ana AS (2018) Modified mycotoxins: An updated review on their formation, detection, occurrence, and toxic effects. Food Chem Toxicol 111: 189-205.

63. Berthiller F, Maragos CM, Dall'Asta C (2015) Chapter 1. Introduction to Masked Mycotoxins. In Dall'Asta C, Berthiller F (eds.), Issues in Toxicology pp 1-13. Royal Society of Chemistry, Cambridge.

64. Pereira VL, Fernandes JO, Cunha SC (2014) Mycotoxins in cereals and related foodstuffs: A review on occurrence and recent methods of analysis. Trends Food Sci Technol 36: 96-136.

65. Righetti L, Paglia G, Galaverna G, Dall'Asta C (2016) Recent Advances and Future Challenges in Modified Mycotoxin Analysis: Why HRMS Has Become a Key Instrument in Food Contaminant Research. Toxins 8: 361.

66. Berthiller F, Crews C, Dall'Asta C, Saeger SD, Haesaert G, Karlovsky P, Oswald IP, Seefelder W, Speijers G, Stroka J (2013) Masked mycotoxins: A review. Mol Nutr Food Res 57: 165-186.

67. Gruber-Dorninger C, Novak B, Nagl V, Berthiller F (2017) Emerging Mycotoxins: Beyond Traditionally Determined Food Contaminants. Journal of Agricultural and Food Chemistry 65: 7052-7070.

68. Vaclavikova M, Malachova A, Veprikova Z, Dzuman Z, Zachariasova M, Hajslova J (2013) 'Emerging' mycotoxins in cereals processing chains: Changes of enniatins during beer and bread making. Food Chem 136: 750-757.

69. EFSA Panel on Contaminants in the Food Chain (CONTAM) (2014) Scientific Opinion on the risks to human and animal health related to the presence of beauvericin and enniatins in food and feed: Beauvericin and enniatins in food and feed. EFSA Journal 12: 3802.

70. Nichea M, Palacios S, Chiacchiera S, Sulyok M, Krska R, Chulze S, Torres A, Ramirez M (2015) Presence of Multiple Mycotoxins and Other Fungal Metabolites in Native Grasses from a Wetland Ecosystem in Argentina Intended for Grazing Cattle. Toxins 7: 3309-3329.

71. EFSA Panel on Contaminants in the Food Chain (CONTAM) (2011) Scientific Opinion on the risks for animal and public health related to the presence of Alternaria toxins in feed and food: Alternaria toxins in feed and food. EFSA Journal 9: 2407.

72. Krska R, Sulyok M, Berthiller F, Schuhmacher R (2017) Mycotoxin testing: From Multi-toxin analysis to metabolomics. JSM Mycotoxins 67: 11-16.

73. MERCOSUR (2002) Resolución N²5/02. Reglamento técnico MERCOSUR sobre límites máximos de aflatoxinas admisibles en leche, maní y maíz.

74. ANVISA (2011) Resolução RDC N 7, de 18 de Fevreiro de 2011 Dispõe sobre limites máximos tolerados (LMT) para micotoxinas em alimentos. Ministério da Saúde, Republica Federativa Do Brasil.

75. van Egmond HP, Jonker MA (2003) Reglamentos a nivel mundial para las micotoxinas en los alimentos y en las raciones. FAO 1-60.

76. Comisión Europea (2010) Reglamento EU No 165/2010 de la Comisión que modifica, en lo que respecta a las aflatoxinas, el Reglamento CE no 1881/2006 por el que se fija el contenido máximo de determinados contaminantes en los productos alimenticios. Diario Oficial de la Comunidad Europea L 50: 8-12.

77. Comisión Europea (2006) Recomendación CE/576/2006 de la Comisión del 17 de agosto de 2006 sobre la presencia de deoxinivalenol, zearalenona, ocratoxina A, toxinas T-2 y HT-2 y fumonisinas en productos destinados a la alimentación animal. Diario Oficial de la Comunidad Europea 229: 7-9. 
78. Comisión Europea (2002) Directiva 2002/32/CE del Parlamento Europeo y del Consejo, de 7 de mayo de 2002, sobre sustancias indeseables en la alimentación animal. Diario Oficial de la Comunidad Europea 036: 3-14.

79. Jestoi M (2008) Emerging Fusarium Mycotoxins Fusaproliferin, Beauvericin, Enniatins, And Moniliformin, A Review. Crit Rev Food Sci Nutr 48: 21-49.

80. Ministerio de Producción (2018) Datos de producción primaria. Dirección Nacional Láctea, Secretaría de Agroindustria, Ministerio de Producción. Disponible en https://www.agroindustria.gob.ar/sitio/areas/ss_lecheria/estadisticas/_01_primaria/index.php (Accedido Agosto 2018).

81. OCLA (2018) Datos estadísticos. Observatorio de la Cadena Láctea Argentina. Disponible en http://www.ocla.org.ar (Accedido Agosto 2018).

82. Cardin R, Iturregui ME (2016) Informe de cadenas de valor. Ministerio de Hacienda y Finanzas Públicas. República Argentina. Diciembre de 2016.

83. Fox PF, McSweeney PLH (1998) Dairy chemistry and biochemistry. Blackie Academic \& Professional, London; New York.

84. Walstra P, Wouters JTM, Geurts TJ (2006) Dairy science and technology. CRC/Taylor \& Francis, Boca Raton.

85. Alais C, Lacasa Godina A (2003) Ciencia de la leche: principios de técnica lechera. Reverté, Barcelona.

86. Fischer WJ, Schilter B, Tritscher AM, Stadler RH (2011) Contaminants of milk and dairy products: contamination resulting from farm and dairy practices. In, Encyclopedia of Dairy Sciences pp 887-897. Elsevier.

87. van Asselt ED, van der Fels-Klerx HJ, Marvin HJP, van Bokhorst-van de Veen H, Groot MN (2017) Overview of Food Safety Hazards in the European Dairy Supply Chain: Food safety hazards in the dairy chain.... Comprehensive Reviews in Food Science and Food Safety 16: 59-75.

88. Blüthgen A, Tuinstra L (1997) Cap. 7 Pesticides. In, Residues and Contaminants in Milk and Milk Products pp 54-64. International Dairy Federation, Bruselas, Bélgica.

89. Flores-Flores ME, Lizarraga E, López de Cerain A, González-Peñas E (2015) Presence of mycotoxins in animal milk: A review. Food Control 53: 163-176.

90. Mao J, Zheng N, Wen F, Guo L, Fu C, Ouyang H, Zhong L, Wang J, Lei S (2018) Multi-mycotoxins analysis in raw milk by ultra high performance liquid chromatography coupled to quadrupole orbitrap mass spectrometry. Food Control 84: 305-311.

91. Fink-Gremmels J (2008) Mycotoxins in cattle feeds and carry-over to dairy milk: A review. Food Addit Contam Part A 25: 172-180.

92. van Egmond HP, Svensson UK, Fremy JM (1997) Cap. 10 Mycotoxins. In, Residues and Contaminants in Milk and Milk Products pp 79-88. International Dairy Federation, Bruselas, Bélgica.

93. OCDE (2013) Organisation for Economic Co-operation and Development. Guidance document on residues in livestock. ENV/JM/MONO(2013)8.

94. Galetto A (2018) Diagnóstico competitivo del sector lácteo argentino. Observatorio de la Cadena Láctea Argentina (OCLA). Disponible en http://www.ocla.org.ar/contents/news/details/12305295diagnostico-competitivo-del-sector-lacteo-argentino (Accedido Agosto 2018).

95. Gaggiotti M (2008) Tabla de Composición Química de Alimentos para Rumiantes. laboratorio de producción animal. Instituto Nacional de Tecnología Agropecuaria EEA Rafaela, Santa Fe, Argentina. Ediciones INTA.

96. Walorczyk S (2008) Development of a multi-residue method for the determination of pesticides in cereals and dry animal feed using gas chromatography-tandem quadrupole mass spectrometry. $J$ Chromatogr A 1208: 202-214.

97. Binder EM, Tan LM, Chin LJ, Handl J, Richard J (2007) Worldwide occurrence of mycotoxins in commodities, feeds and feed ingredients. Anim Feed Sci Technol 137: 265-282.

98. Kabak B, Dobson ADW, Var I (2006) Strategies to Prevent Mycotoxin Contamination of Food and Animal Feed: A Review. Crit Rev Food Sci Nutr 46: 593-619.

99. Neme K, Mohammed A (2017) Mycotoxin occurrence in grains and the role of postharvest management as a mitigation strategies. A review. Food Control 78: 412-425. 
100. Imamoglu H, Oktem Olgun E (2016) Analysis of Veterinary Drug and Pesticide Residues Using the Ethyl Acetate Multiclass/Multiresidue Method in Milk by Liquid Chromatography-Tandem Mass Spectrometry. J Anal Methods Chem 2016: 1-17.

101. Lozano A, Kiedrowska B, Scholten J, de Kroon M, de Kok A, Fernández-Alba AR (2016) Miniaturisation and optimisation of the Dutch mini-Luke extraction method for implementation in the routine multiresidue analysis of pesticides in fruits and vegetables. Food Chem 192: 668-681.

102. Bedi J, Gill J, Kaur P, Aulakh R (2018) Pesticide residues in milk and their relationship with pesticide contamination of feedstuffs supplied to dairy cattle in Punjab (India). J Anim Feed Sci 27: 18-25.

103. Gilbert J, Anklam E (2002) Validation of analytical methods for determining mycotoxins in foodstuffs. Trends Analyt Chem 21: 468-486.

104. Şenyuva HZ, Gilbert J (2010) Immunoaffinity column clean-up techniques in food analysis: A review. J Chromatogr B 878: 115-132.

105. Anastassiades M, Lehotay SJ, Stajnbaher D, Schenck FJ (2003) Fast and easy multiresidue method employing acetonitrile extraction/partitioning and 'dispersive solid-phase extraction' for the determination of pesticide residues in produce. J AOAC Int 86: 412-431.

106. Rejczak T, Tuzimski T (2017) QuEChERS-based extraction with dispersive solid phase extraction cleanup using PSA and ZrO 2 -based sorbents for determination of pesticides in bovine milk samples by HPLC-DAD. Food Chem 217: 225-233.

107. Lehotay SJ, Mastovská K, Yun SJ (2005) Evaluation of two fast and easy methods for pesticide residue analysis in fatty food matrixes. J AOAC Int 88: 630-638.

108. Anastassiades M, Scherbaum E, Tadelen B, tajnbaher D (2007) Recent Developments in QuEChERS Methodology for Pesticide Multiresidue Analysis. In Ohkawa H, Miyagawa H, Lee PW (eds.), Pesticide Chemistry pp 439-458. Wiley-VCH Verlag GmbH \& Co. KGaA, Weinheim, Germany.

109. AOAC International (2007) AOAC Official Method 2007.01. Pesticide Residues in Foods by Acetonitrile Extraction and Partitioning with Magnesium Sulfate Gas Chromatography/Mass Spectrometry and Liquid Chromatography/Tandem Mass Spectrometry First Action 2007.

110. European Stantards (2008) EN 15662.2008. Foods of Plant Origin- Determination of Pesticide Residues Using GC-MS and/or LC-MS/MS Following Acetonitrile Extraction and Partitioning and Cleanup by Dispersive SPE, QuEChERS Method.

111. Filigenzi MS, Ehrke N, Aston LS, Poppenga RH (2011) Evaluation of a rapid screening method for chemical contaminants of concern in four food-related matrices using QuEChERS extraction, UHPLC and high resolution mass spectrometry. Food Addit Contam Part A 28: 1324-1339.

112. Aguilera-Luiz MM, Plaza-Bolaños P, Romero-González R, Martínez Vidal JL, Frenich AG (2011) Comparison of the efficiency of different extraction methods for the simultaneous determination of mycotoxins and pesticides in milk samples by ultra high-performance liquid chromatography-tandem mass spectrometry. Analytical and Bioanalytical Chemistry 399: 2863-2875.

113. Jeong I-S, Kwak B-M, Ahn J-H, Jeong S-H (2012) Determination of pesticide residues in milk using a QuEChERS-based method developed by response surface methodology. Food Chem 133: 473-481.

114. De Dominicis E, Commissati I, Suman M (2012) Targeted screening of pesticides, veterinary drugs and mycotoxins in bakery ingredients and food commodities by liquid chromatography-high-resolution single-stage Orbitrap mass spectrometry: Screening of contaminants in bakeries by LC-HRMS. J Mass Spectrom 47: 1232-1241.

115. dos Anjos MR, Castro IM de, Souza M de LM de, de Lima VV, de Aquino-Neto FR (2016) Multiresidue method for simultaneous analysis of aflatoxin $M_{1}$, avermectins, organophosphate pesticides and milbemycin in milk by ultra-performance liquid chromatography coupled to tandem mass spectrometry. Food Addit Contam Part A 33: 995-1002.

116. Golge O, Koluman A, Kabak B (2018) Validation of a Modified QuEChERS Method for the Determination of 167 Pesticides in Milk and Milk Products by LC-MS/MS. Food Anal Methods 11: 1122-1148.

117. Jadhav MR, Pudale A, Raut P, Utture S, Ahammed Shabeer TP, Banerjee K (2019) A unified approach for high-throughput quantitative analysis of the residues of multi-class veterinary drugs and pesticides in bovine milk using LC-MS/MS and GC-MS/MS. Food Chem 272: 292-305. 
118. Braun D, Ezekiel CN, Abia WA, Wisgrill L, Degen GH, Turner PC, Marko D, Warth B Unraveling Early-Life Mycotoxin Exposures via LC-MS/MS Breast Milk Analysis. ChemRxiv.

119. Tsiplakou E, Anagnostopoulos CJ, Liapis K, Haroutounian SA, Zervas G (2010) Pesticides residues in milks and feedstuff of farm animals drawn from Greece. Chemosphere 80: 504-512.

120. Romero-González R, Garrido Frenich A, Martínez Vidal JL, Prestes OD, Grio SL (2011) Simultaneous determination of pesticides, biopesticides and mycotoxins in organic products applying a quick, easy, cheap, effective, rugged and safe extraction procedure and ultra-high performance liquid chromatography-tandem mass spectrometry. J Chromatogr A 1218: 1477-1485.

121. Marchis D, Ferro GL, Brizio P, Squadrone S, Abete MC (2012) Detection of pesticides in crops: A modified QuEChERS approach. Food Control 25: 270-273.

122. Walorczyk S, Drożdżyński D (2012) Improvement and extension to new analytes of a multi-residue method for the determination of pesticides in cereals and dry animal feed using gas chromatographytandem quadrupole mass spectrometry revisited. J Chromatogr A 1251: 219-231.

123. Dzuman Z, Zachariasova M, Lacina O, Veprikova Z, Slavikova P, Hajslova J (2014) A rugged highthroughput analytical approach for the determination and quantification of multiple mycotoxins in complex feed matrices. Talanta 121: 263-272.

124. Mol J, de Rijk T, van Egmond H, de Jong J (2014) Mycotoxins and pesticides in straws and hay used as animal feed. RIKILT Wageningen UR (University \& research centre).

125. Zachariasova M, Dzuman Z, Veprikova Z, Hajkova K, Jiru M, Vaclavikova M, Zachariasova A, Pospichalova M, Florian M, Hajslova J (2014) Occurrence of multiple mycotoxins in European feedingstuffs, assessment of dietary intake by farm animals. Anim Feed Sci Technol 193: 124-140.

126. Dzuman Z, Zachariasova M, Veprikova Z, Godula M, Hajslova J (2015) Multi-analyte high performance liquid chromatography coupled to high resolution tandem mass spectrometry method for control of pesticide residues, mycotoxins, and pyrrolizidine alkaloids. Anal Chim Acta 863: 29-40.

127. Zhang Z, Feng M, Zhu K, Han L, Sapozhnikova Y, Lehotay SJ (2016) Multiresidue Analysis of Pesticides in Straw Roughage by Liquid Chromatography-Tandem Mass Spectrometry. J Agric Food Chem 64: 6091-6099.

128. León N, Pastor A, Yusà V (2016) Target analysis and retrospective screening of veterinary drugs, ergot alkaloids, plant toxins and other undesirable substances in feed using liquid chromatography-high resolution mass spectrometry. Talanta 149: 43-52.

129. da Luz SR, Pazdiora PC, Dallagnol L, Dors GC, Chaves FC (2017) Mycotoxin and fungicide residues in wheat grains from fungicide-treated plants measured by a validated LC-MS method. Food Chem 220: 510-516.

130. Ren Y, Zhang Y, Shao S, Cai Z, Feng L, Pan H, Wang Z (2007) Simultaneous determination of multicomponent mycotoxin contaminants in foods and feeds by ultra-performance liquid chromatography tandem mass spectrometry. J Chromatogr A 1143: 48-64.

131. Schenck F, Casanova J (1999) Rapid screening for organochlorine and organophosphorus pesticides in milk using $\mathrm{C} 18$ and graphitized carbon black solid phase extraction cleanup. J Environ Sci Health part $B$ 34: 349-362.

132. Maldaner L, Santana CC, Jardim ICSF (2008) HPLC Determination of Pesticides in Soybeans using Matrix Solid Phase Dispersion. J Liq Chromatogr Relat Technol 31: 972-983.

133. Hunter RE, Riederer AM, Ryan PB (2010) Method for the Determination of Organophosphorus and Pyrethroid Pesticides in Food via Gas Chromatography with Electron-Capture Detection. J Agric Food Chem 58: 1396-1402.

134. Fagnani R, Beloti V, Battaglini APP, Dunga K da S, Tamanini R (2011) Organophosphorus and carbamates residues in milk and feedstuff supplied to dairy cattle. Pesq Vet Bras 31: 598-602.

135. Selvi C, Paramasivam M, Rajathi DS, Chandrasekaran S (2012) Multiresidue Analysis of Organochlorine Pesticides in Milk, Egg and Meat by GC-ECD and Confirmation by GC-MS. Bull Environ Contam Toxicol 89: 1051-1056.

136. Aresta A, Cioffi N, Palmisano F, Zambonin CG (2003) Simultaneous Determination of Ochratoxin A and Cyclopiazonic, Mycophenolic, and Tenuazonic Acids in Cornflakes by Solid-Phase Microextraction Coupled to High-Performance Liquid Chromatography. J Agric Food Chem 51: 5232-5237. 
137. Chan D, MacDonald SJ, Boughtflower V, Brereton P (2004) Simultaneous determination of aflatoxins and ochratoxin $A$ in food using a fully automated immunoaffinity column clean-up and liquid chromatography-fluorescence detection. J Chromatogr A 1059: 13-16.

138. Vallealgarra F, Medina A, Gimenoadelantado J, Llorens A, Jimenez M, Mateo R (2005) Comparative assessment of solid-phase extraction clean-up procedures, GC columns and perfluoroacylation reagents for determination of type B trichothecenes in wheat by GC-ECD. Talanta 66: 194-201.

139. Shundo L, Sabino M (2006) Aflatoxin M1 in milk by immunoaffinity column cleanup with TLC/HPLC determination. Braz J Microbiol 37: 164-167.

140. Pussemier L, Piérard J-Y, Anselme M, Tangni EK, Motte J-C, Larondelle Y (2006) Development and application of analytical methods for the determination of mycotoxins in organic and conventional wheat. Food Addit Contam 23: 1208-1218.

141. Oldenburg E, Ellner F (2005) Fusarium mycotoxins in forage maize - Detection and evaluation. Mycotoxin Res 21: 105-107.

142. Picó Y, Blasco C, Font G (2004) Environmental and food applications of LC-tandem mass spectrometry in pesticide-residue analysis: An overview: LC-Tandem Mass Spectrometry in Pesticide-Residue Analysis. Mass Spectrom Rev 23: 45-85.

143. Wong JW, Wang J, Chow W, Carlson R, Jia Z, Zhang K, Hayward DG, Chang JS (2018) Perspectives on Liquid Chromatography-High-Resolution Mass Spectrometry for Pesticide Screening in Foods. J Agric Food Chem 66: 9573-9581.

144. Martínez-Domínguez G, Romero-González R, Arrebola FJ, Garrido Frenich A (2016) Multi-class determination of pesticides and mycotoxins in isoflavones supplements obtained from soy by liquid chromatography coupled to Orbitrap high resolution mass spectrometry. Food Control 59: 218-224.

145. Sancho JV, Ibáñez M (2015) Multiresidue Analysis of Pesticides: LC-MS/MS versus LC-HRMS. In, Fast Liquid Chromatography-Mass Spectrometry Methods in Food and Environmental Analysis pp 381419. Imperial College Press.

146. Veprikova Z, Vaclavikova M, Lacina O, Dzuman Z, Zachariasova M, Hajslova J (2012) Occurrence of mono- and di-glycosylated conjugates of T-2 and HT-2 toxins in naturally contaminated cereals. World Mycotoxin J 5: 231-240.

147. Jia W, Chu X, Ling Y, Huang J, Chang J (2014) Multi-mycotoxin analysis in dairy products by liquid chromatography coupled to quadrupole orbitrap mass spectrometry. J Chromatogr A 1345: 107-114.

148. Amelin V, Korotkov A, Andoralov A (2016) Identification and Determination of 492 Contaminants of Different Classes in Food and Feed by High-Resolution Mass Spectrometry Using the Standard Addition Method. J AOAC Int 99: 1600-1618.

149. IARC (2012) Chemical agents and related occupations. WHO IARC monographs on the evaluation of carcinogenic risk to humans. Volume $100 \mathrm{~F}$.

150. Creppy EE (2002) Update of survey, regulation and toxic effects of mycotoxins in Europe. Toxicol Lett 127: 19-28.

151. López C., Ramos L., Ramadán S., Bulacio L. (2003) Presence of aflatoxin M1 in milk for human consumption in Argentina. Food Control 14: 31-34.

152. Prandini A, Tansini G, Sigolo S, Filippi L, Laporta M, Piva G (2009) On the occurrence of aflatoxin M1 in milk and dairy products. Food Chem Toxicol 47: 984-991.

153. Patterson DSP, Glancy EM, Roberts BA (1980) The carry over of aflatoxin M1 into the milk of cows fed rations containing a low concentration of aflatoxin B1. Food Cosmet Toxicol 18: 35-37.

154. van Egmond HP (1983) Mycotoxins in dairy products. Food Chem 11: 289-307.

155. Black RD, McVey DS, Oehme FW (1992) Immunotoxicity in the bovine animal: a review. Vet Hum Toxicol 34: 438-442.

156. Signorini ML, Gaggiotti M, Molineri A, Chiericatti CA, Zapata de Basílico ML, Basílico JC, Pisani M (2012) Exposure assessment of mycotoxins in cow's milk in Argentina. Food Chem Toxicol 50: 250257.

157. Alonso VA, Monge MP, Larriestra A, Dalcero AM, Cavaglieri LR, Chiacchiera SM (2010) Naturally occurring aflatoxin $\mathrm{M} 1$ in raw bulk milk from farm cooling tanks in Argentina. Food Addit Contam Part A 27: 373-379. 
158. García Londoño VA, Boasso AC, de Paula MCZ, Garcia LP, Scussel VM, Resnik S, Pacín A (2013) Aflatoxin M1 survey on randomly collected milk powder commercialized in Argentina and Brazil. Food Control 34: 752-755.

159. Scaglioni P., Becker-Algeri T, Drunkler D, Badiale-Furlong E (2014) Aflatoxin B1 and M1 in milk. Anal Chim Acta 829: 68-74.

160. Picinin LCA, Cerqueira MMOP, Vargas EA, Lana ÂMQ, Toaldo IM, Bordignon-Luiz MT (2013) Influence of climate conditions on aflatoxin M1 contamination in raw milk from Minas Gerais State, Brazil. Food Control 31: 419-424.

161. Santili ABN, de Camargo AC, Nunes R de SR, Gloria EM da, Machado PF, Cassoli LD, Dias CT dos S, Calori-Domingues MA (2015) Aflatoxin M1 in raw milk from different regions of São Paulo state, Brazil. Food Addit Contam Part B 8: 207-214.

162. Diaz GJ, Espitia $E$ (2006) Occurrence of aflatoxin $M_{1}$ in retail milk samples from Bogotá, Colombia. Food Addit Contam 23: 811-815.

163. Li S, Min L, Wang P, Zhang Y, Zheng N, Wang J (2017) Aflatoxin M1 contamination in raw milk from major milk-producing areas of China during four seasons of 2016. Food Control 82: 121-125.

164. Bilandžić $N$, Varenina I, Solomun Kolanović $B$, Božić Luburić $Đ$, Varga I, Želježić $B$, Cvetnić L, Benić $M$, Tanković S, Cvetnić $Z$ (2017) Occurrence of aflatoxin M1 in raw cow, goat and sheep milk during spring and autumn in Croatia during 2016. Toxin Reviews 36: 290-296.

165. Flores-Flores ME, González-Peñas E (2018) Short communication: Analysis of mycotoxins in Spanish milk. J Dairy Sci 101: 113-117.

166. Campone L, Piccinelli AL, Celano R, Pagano I, Di Sanzo R, Carabetta S, Russo M, Rastrelli L (2018) Occurrence of aflatoxin M1 in milk samples from Italy analysed by online-SPE UHPLC-MS/MS. Nat Prod Res 32: 1803-1808.

167. Shuib NS, Makahleh A, Salhimi SM, Saad B (2017) Determination of aflatoxin M1 in milk and dairy products using high performance liquid chromatography-fluorescence with post column photochemical derivatization. J Chromatogr A 1510: 51-56.

168. Asghar MA, Ahmed A, Asghar MA (2018) Aflatoxin M1 in fresh milk collected from local markets of Karachi, Pakistan. Food Addit Contam Part B 11: 167-174.

169. Shephard GS, Berthiller F, Burdaspal PA, Crews C, Jonker MA, Krska R, Lattanzio VMT, MacDonald S, Malone RJ, Maragos C, et al. (2013) Developments in mycotoxin analysis: an update for 2011-2012. World Mycotoxin J 6: 3-30.

170. Anklam E, Stroka J, Boenke A (2002) Acceptance of analytical methods for implementation of EU legislation with a focus on mycotoxins. Food Control 13: 173-183.

171. Huang LC, Zheng N, Zheng BQ, Wen F, Cheng JB, Han RW, Xu XM, Li SL, Wang JQ (2014) Simultaneous determination of aflatoxin $M 1$, ochratoxin $A$, zearalenone and $\alpha$-zearalenol in milk by UHPLC-MS/MS. Food Chem 146: 242-249.

172. Beltrán E, Ibáñez M, Sancho JV, Cortés MÁ, Yusà V, Hernández F (2011) UHPLC-MS/MS highly sensitive determination of aflatoxins, the aflatoxin metabolite $M 1$ and ochratoxin $A$ in baby food and milk. Food Chem 126: 737-744.

173. Beltrán $E$, Ibáñez $M$, Sancho JV, Hernández $F$ (2009) Determination of mycotoxins in different food commodities by ultra-high-pressure liquid chromatography coupled to triple quadrupole mass spectrometry. Rapid Commun Mass Spectrom 23: 1801-1809.

174. Campone L, Piccinelli AL, Celano R, Pagano I, Russo M, Rastrelli L (2016) Rapid and automated analysis of aflatoxin $\mathrm{M} 1$ in milk and dairy products by online solid phase extraction coupled to ultra-highpressure-liquid-chromatography tandem mass spectrometry. J Chromatogr A 1428: 212-219.

175. Flores-Flores ME, González-Peñas E (2017) An LC-MS/MS method for multi-mycotoxin quantification in cow milk. Food Chem 218: 378-385.

176. Chen W, Hsu H, Chen C (2011) Measurement of Aflatoxin M1 in Milk by Ultra-High-Performance Liquid Chromatography/Tandem Mass Spectrometry. J AOAC Int 94: 872-877.

177. Berthiller F, Burdaspal PA, Crews C, Iha MH, Krska R, Lattanzio VMT, MacDonald S, Malone RJ, Maragos C, Solfrizzo M, et al. (2014) Developments in mycotoxin analysis: an update for 2012-2013. World Mycotoxin Journal 7: 3-33. 
178. Chen D, Cao X, Tao Y, Wu Q, Pan Y, Huang L, Wang X, Wang Y, Peng D, Liu Z, et al. (2012) Development of a sensitive and robust liquid chromatography coupled with tandem mass spectrometry and a pressurized liquid extraction for the determination of aflatoxins and ochratoxin $A$ in animal derived foods. J Chromatogr A 1253: 110-119.

179. Sorensen L, Elbak T (2005) Determination of mycotoxins in bovine milk by liquid chromatography tandem mass spectrometry. J Chromatogr B 820: 183-196.

180. Cavaliere C, Foglia P, Pastorini E, Samperi R, Laganà A (2006) Liquid chromatography/tandem mass spectrometric confirmatory method for determining aflatoxin M1 in cow milk. J Chromatogr A 1101: 69-78.

181. Biancardi A, Piro R, Dall'asta C, Galaverna G (2013) A simple and reliable liquid chromatographytandem mass spectrometry method for the determination of aflatoxin $\mathrm{M}_{1}$ in milk. Food Addit Contam Part A 30: 381-388.

182. Campone L, Piccinelli AL, Celano R, Russo M, Rastrelli L (2013) Rapid analysis of aflatoxin M1 in milk using dispersive liquid-liquid microextraction coupled with ultrahigh pressure liquid chromatography tandem mass spectrometry. Anal Bioanal Chem 405: 8645-8652.

183. Rubert J, Soler C, Mañes J (2012) Application of an HPLC-MS/MS method for mycotoxin analysis in commercial baby foods. Food Chem 133: 176-183.

184. Zhang K, Wong JW, Hayward DG, Vaclavikova M, Liao C-D, Trucksess MW (2013) Determination of Mycotoxins in Milk-Based Products and Infant Formula Using Stable Isotope Dilution Assay and Liquid Chromatography Tandem Mass Spectrometry. J Agric Food Chem 61: 6265-6273.

185. Wang H, Zhou X-J, Liu Y-Q, Yang H-M, Guo Q-L (2011) Simultaneous Determination of Chloramphenicol and Aflatoxin $\mathrm{M}_{1}$ Residues in Milk by Triple Quadrupole Liquid Chromatography-Tandem Mass Spectrometry. J Agric Food Chem 59: 3532-3538.

186. Rubert J, León N, Sáez C, Martins CPB, Godula M, Yusà V, Mañes J, Soriano JM, Soler C (2014) Evaluation of mycotoxins and their metabolites in human breast milk using liquid chromatography coupled to high resolution mass spectrometry. Anal Chim Acta 820: 39-46.

187. Demonte LD, Michlig N, Gaggiotti M, Adam CG, Beldoménico HR, Repetti MR (2018) Determination of glyphosate, AMPA and glufosinate in dairy farm water from Argentina using a simplified UHPLCMS/MS method. Sci Total Environ 645: 34-43.

188. Di Renzo J, Casanoves F, Balzarini M, González L, Tablada M, Robledo C InfoStat version 2012. InfoStat Group, FCA, Universidad Nacional de Córdoba, Argentina. http://www.infostat.com.ar.

189. Comisión Europea (2002) Decisión CE N 657/2002 de la Comisión por la que se aplica la Directiva 96/23/CE del Consejo en cuanto al funcionamiento de los métodos analíticos y la interpretación de los resultados. Diario Oficial de la Comunidad Europea L 221: 8-36.

190. Comisión Europea (2015) SANTE 11495/2015 Guidance document on analytical quality control and method validation procedures for pesticide residues and analysis in food and feed.

191. Mertzig K, Hardebusch B, Obrecht K, Lippold K (2012) Comparison of three different MRM methods for analysing pesticide residues in milk (Presentación en congreso). 12th European Pesticide Residue Workshop (EPRW, Viena).

192. Brackett RE, Marth EH (1982) Association of aflatoxin M1 with casein. Zeitschrift fur LebensmittelUntersuchung und -Forschung 174: 439-441.

193. Lacina O, Zachariasova M, Urbanova J, Vaclavikova M, Cajka T, Hajslova J (2012) Critical assessment of extraction methods for the simultaneous determination of pesticide residues and mycotoxins in fruits, cereals, spices and oil seeds employing ultra-high performance liquid chromatography-tandem mass spectrometry. J Chromatogr A 1262: 8-18.

194. Horne DS (2006) Casein micelle structure: Models and muddles. Curr Opin Colloid Interface Sci 11: 148-153.

195. Martins JG, Amaya Chávez A, Waliszewski SM, Colín Cruz A, García Fabila MM (2013) Extraction and clean-up methods for organochlorine pesticides determination in milk. Chemosphere 92: 233-246.

196. Raza N, Kim K-H (2018) Quantification techniques for important environmental contaminants in milk and dairy products. Trends Analyt Chem 98: 79-94.

197. LMR de plaguicidas. CODEXALIMENTARIUS FAO-WHO. 
198. Administración Nacional de Medicamentos, Alimentos y Tecnología Médica, ANMAT.

199. Reglamento (CE) n 396/2005 del Parlamento Europeo y del Consejo, de 23 de febrero de 2005 relativo a los límites máximos de residuos de plaguicidas en alimentos y piensos de origen vegetal y animal y que modifica la Directiva 91/414/CEE del ConsejoTexto pertinente a efectos del EEE.

200. Global MRL Database: PESTICIDES.

201. Bennett DA, Chung AC, Lee SM (1997) Multiresidue method for analysis of pesticides in liquid whole milk. J AOAC Int 80: 1065-1077.

202. Chen AW, Fink JM, Letinski DJ (1996) Analytical Methods To Determine Residual Cypermethrin and Its Major Acid Metabolites in Bovine Milk and Tissues. Journal of Agricultural and Food Chemistry 44: 3534-3539.

203. Pagliuca G, Serraino A, Gazzotti T, Zironi E, Borsari A, Rosmini R (2006) Organophosphorus pesticides residues in Italian raw milk. Journal of Dairy Research 73: 340.

204. Khay S, Abd El-Aty AM, Choi J-H, Shin E-H, Shin H-C, Kim J-S, Chang B-J, Lee C-H, Shin S-C, Jeong JY, et al. (2009) Simultaneous determination of pyrethroids from pesticide residues in porcine muscle and pasteurized milk using GC. J Sep Sci 32: 244-251.

205. Goulart S, Dequeiroz M, Neves A, Dequeiroz J (2008) Low-temperature clean-up method for the determination of pyrethroids in milk using gas chromatography with electron capture detection. Talanta 75: 1320-1323.

206. Salas JH, González MM, Noa M, Pérez NA, Díaz G, Gutiérrez R, Zazueta H, Osuna I (2003) Organophosphorus Pesticide Residues in Mexican Commercial Pasteurized Milk. Journal of Agricultural and Food Chemistry 51: 4468-4471.

207. LeDoux M (2011) Analytical methods applied to the determination of pesticide residues in foods of animal origin. A review of the past two decades. J Chromatogr A 1218: 1021-1036.

208. Dagnac T, Garcia-Chao M, Pulleiro P, Garcia-Jares C, Llompart M (2009) Dispersive solid-phase extraction followed by liquid chromatography-tandem mass spectrometry for the multi-residue analysis of pesticides in raw bovine milk. J Chromatogr A 1216: 3702-3709.

209. Ciscato, CHP, Barbosa, CM, Gebara, AB, Osawka, AS (2018) Dietary Milk Consumption and the Pesticide Residues. Exposure from Pasteurized and UHT samples. Adv Clin Toxicol 3:.

210. Zacharia, James Identity, Physical and Chemical Properties of Pesticides. In Stoytcheva, Margarita (ed.), Pesticides in the Modern World - Trends in Pesticides Analysis. INTECH Open Access Publisher.

211. Villaamil Lepori, Edda, Bovi Mitre, Graciela, Nassetta, Mirtha (2013) Situación actual de la contaminación por plaguicidas en Argentina. Rev Int Contam Ambient 29: 25-43.

212. Lorenzatti E, Maitre M, Lenardon A (2003) Evaluación de la contaminación con plaguicidas en productos lácteos. Revista FAVE - Ciencias Veterinarias 2: 49-56.

213. Lorenzatti E, Maitre M, Marino F, Masin C, Rodríguez A, Lenardón A (2016) Contaminación ambiental por plaguicidas: análisis de residuos y experimentos de laboratorio. EdicionesUNL, Santa Fe, Argentina.

214. Ruiz, AE, Wierna, N, Bovi Mitre, G (2008) Plaguicidas organoclorados en leche cruda comercializada en Jujuy (Argentina). Revista de Toxicología 25: 61-66.

215. Avancini RM, Silva IS, Rosa ACS, Sarcinelli P de N, de Mesquita SA (2013) Organochlorine compounds in bovine milk from the state of Mato Grosso do Sul - Brazil. Chemosphere 90: 2408-2413.

216. Luzardo OP, Almeida-González M, Henríquez-Hernández LA, Zumbado M, Álvarez-León EE, Boada LD (2012) Polychlorobiphenyls and organochlorine pesticides in conventional and organic brands of milk: Occurrence and dietary intake in the population of the Canary Islands (Spain). Chemosphere 88: 307315.

217. Nag SK, Raikwar MK (2008) Organochlorine Pesticide Residues in Bovine Milk. Bull Environ Contam Toxicol 80: 5-9.

218. Programa de las Naciones Unidas para el Medio Ambiente (2009) Convenio de Estocolmo sobre contaminantes orgánicos persistentes. Perfil de riesgo del endosulfan.

219. SENASA, Servicio Nacional de Sanidad y Calidad Agroalimentaria. (2017) Resultados del Plan CREHA Animal 2017. Accesible en: 
http://www.senasa.gob.ar/sites/default/files/ARBOL_SENASA/ANIMAL/ABEJAS/PROD_PRIMARIA/PLA N_CREHA/CTROL_RES/res_res_2017_pag_web.pdf.

220. SENASA, Servicio Nacional de Sanidad y Calidad Agroalimentaria. Lista de Establecimientos con Antecedentes de Residuos (EAR). Productos Leche $N^{\circ}$ 03/2017. Accesible en http://www.senasa.gob.ar/sites/default/files/ARBOL_SENASA/ANIMAL/ABEJAS/PROD_PRIMARIA/PLA N_CREHA/CTROL_RES/ear_03-17_productos.pdf.

221. Handford CE, Elliott CT, Campbell K (2015) A review of the global pesticide legislation and the scale of challenge in reaching the global harmonization of food safety standards: Global Harmonization of Pesticide Legislation. Integr Environ Assess Manag 11: 525-536.

222. Wattiaux M, Howard T (1995) Cap. 3: Feeds for dairy cows. In, Dairy essentials : nutrition and feeding, reproduction and genetic selection, lactation and milking, raising dairy heifers pp 21-24. Madison, Wis. : The Babcock Institute for International Dairy Research and Development.

223. Panseri S, Biondi PA, Vigo D, Communod R, M. L (2013) Occurrence of Organochlorine Pesticides Residues in Animal Feed and Fatty Bovine Tissue. In Muzzalupo I (ed.), Food Industry. InTech.

224. U.S. Code of Federal Regulations (CFR), Title 40, Part 180. Tolerances and exceptions for pesticide chemical residues in food. https://ecfr.io/Title-40/pt40.26.180. Accedido Agosto 2018.

225. (2002) Directiva 2002/32/CE del Parlamento Europeo y del Consejo, de 7 de mayo de 2002 sobre sustancias indeseables en la alimentación animal.

226. MAFF, Ministry of Agriculture, Forestry and Fisheries of Japan, 2006, Regulation values of pesticides; http://www.famic.go.jp/ffis/feed/r_safety/r_feeds_safety21.html. Accedido Abril 2018.

227. Tienstra M, Portolés T, Hernández F, Mol JGJ (2015) Fast gas chromatographic residue analysis in animal feed using split injection and atmospheric pressure chemical ionisation tandem mass spectrometry. J Chromatogr A 1422: 289-298.

228. Silva LCC da, Beloti V, Tamanini R, Pontes Netto D (2014) Milk contamination by organophosphorus and carbamate residues present in water and animal feedstuff. Semina: Ciências Agrárias 35: 2485.

229. Joint FAO/WHO Food Standards Programme (2006) CODEX Classification of food and animal feed. Draft Revision-1.

230. Alder L, Greulich K, Kempe G, Vieth B (2006) Residue analysis of 500 high priority pesticides: Better by GC-MS or LC-MS/MS? Mass Spectrometry Reviews 25: 838-865.

231. Chamkasem N, Ollis LW, Harmon T, Lee S, Mercer G (2013) Analysis of 136 Pesticides in Avocado Using a Modified QuEChERS Method with LC-MS/MS and GC-MS/MS. J Agric Food Chem 61: 23152329.

232. Cravzov A, Traskauskas C, Delfino M (2001) Pesticides in cotton seeds and ginning trash. Departamento de Quimica, Facultad de Agroindustrias, UNNE Roque S Peña, Chaco.

233. Ciscato C, Barbosa C, Gebara A, Ozawa K (2018) Dietary Milk Consumption and the Pesticide Residues Exposure from Pasteurized and UHT samples. Adv Clin Toxicol 3: 3-7.

234. European Food Safety Authority (2017) The 2015 European Union report on pesticide residues in food. EFSA Journal 15:.

235. Maggioni DA, Signorini ML, Michlig N, Repetti MR, Sigrist ME, Beldomenico HR (2017) Comprehensive estimate of the theoretical maximum daily intake of pesticide residues for chronic dietary risk assessment in Argentina. Journal of Environmental Science and Health, Part B 52: 256-266.

236. European Food Safety Authority (EFSA) (2009) Refined risk assessment regarding certain MRLs of concern for the active substance pirimiphos-methyl. EFSA Journal 7:.

237. European Food Safety Authority (2011) Risk assessment for pirimiphos-methyl residues resulting from cross-contamination: Risk assessment for pirimiphos-methyl residues resulting from crosscontamination. EFSA Journal 9: 2436.

238. Arregui MC, Sánchez D, Althaus R, Scotta RR, Bertolaccini I (2010) Assessing the risk of pesticide environmental impact in several Argentinian cropping systems with a fuzzy expert indicator. Pest Management Science 66: 736-740.

239. Potocarrero R, Aparicio V, de Gerónimo E, Morales C, Lizondo M (2014) Presencia de ametrina y atrazina en los sistemas hídricos superficiales y subterráneos del este cañero de la provincia de Tucumán. (Publicación on-line INTA) 
https://inta.gob.ar/sites/default/files/intapresencia_de_ametrina_y_atrazina_en_los_sistemas_hidric os_superficiales_y_subtenarraneos_en_el_este_canero_de_la_provincia_de_tucuman.pdf.

240. Reynoso L, Andriulo A (2008) Estado actual de la calidad del agua en la cuenca del arroyo pergamino. INTA. Estación Experimental Agropecuaria Pergamino. (Publicación on-line INTA) http://inta.gob.ar/ 12/4/2013.

241. Hang S, Andriulo A, Sasal C, Nassetta M, Portela M, Cañas A (2010) Integral Study of atrazine behavior in field lysimeters in Argentinean humid pampas soils. Chilean Journal of Agricultural Research 70: 104-112.

242. Bedmar F, Gianelli V, Angelini H, Viglianchino L (2015) Riesgo de contaminación del agua subterránea con plaguicidas en la cuenca del arroyo El Cardalito, Argentina. Revista de Investigaciones Agropecuarias - INTA 41:.

243. Gonzalez M, Miglioranza KSB, Aizpún JE, Isla FI, Peña A (2010) Assessing pesticide leaching and desorption in soils with different agricultural activities from Argentina (Pampa and Patagonia). Chemosphere 81: 351-358.

244. Etchegoyen M, Ronco A, Almada P, Abelando M, Marino D (2017) Occurrence and fate of pesticides in the Argentine stretch of the Paraguay-Paraná basin. Environmental Monitoring and Assessment 189:.

245. Subsecretaría de Recursos Hídricos de la Nación (República Argentina) (2003) Desarrollos de niveles guia nacionales de calidad de agua ambiente correspondientes a atrazina. Diciembre 2003. https://www.argentina.gob.ar/sites/default/files/ documento20.pdf.

246. Pohanish RP, Sittig M (2015) Sittig's handbook of pesticides and agricultural chemicals.

247. Gupta PK (2018) Toxicity of Fungicides. In, Veterinary Toxicology pp 569-580. Elsevier.

248. Wu Y, Miao H, Fan S (2011) Separation of Chiral Pyrethroid Pesticides and Application in Pharmacokinetics Research and human Exposure Assessment. In Stoytcheva M (ed.), Pesticides in the modern world: effects of pesticides exposure. Intech, Croatia.

249. Bradbury SP, Coats JR (1989) Toxicokinetics and toxicodynamics of pyrethroid insecticides in fish. Environmental Toxicology and Chemistry 8: 373-380.

250. Maggioni DA, Signorini ML, Michlig N, Repetti MR, Sigrist ME, Beldomenico HR (2018) National shortterm dietary exposure assessment of a selected group of pesticides in Argentina. Journal of Environmental Science and Health, Part B 1-13.

251. Karabasanavar N, Singh S, Ahmad A, Singh S, Rao V (2015) Monitoring of Animal Feed and Fodder Samples for Endosulphan Residues. J Vet Pub HIth 13: 119-122.

252. Lozowicka B, Kaczynski P, Paritova a. e., Kuzembekova GB, Abzhalieva AB, Sarsembayeva NB, Alihan K (2014) Pesticide residues in grain from Kazakhstan and potential health risks associated with exposure to detected pesticides. Food Chem Toxicol 64: 238-248.

253. Abbasi NA, Malik RN, Frantz A, Jaspers VLB (2016) A review on current knowledge and future prospects of organohalogen contaminants (OHCs) in Asian birds. Science of The Total Environment 542: 411-426.

254. Ministerio de Salud de la Nación (República Argentina) (2015) Químicos prohibidos y restringidos en Argentina. http://www.msal.gob.ar.

255. Bryden WL (2012) Mycotoxin contamination of the feed supply chain: Implications for animal productivity and feed security. Anim Feed Sci Technol 173: 134-158.

256. Covarelli L, Beccari G, Prodi A, Generotti S, Etruschi F, Meca G, Juan C, Mañes J (2015) Biosynthesis of beauvericin and enniatins in vitro by wheat Fusarium species and natural grain contamination in an area of central Italy. Food Microbiology 46: 618-626.

257. Blesa J, Marín R, Lino CM, Mañes J (2012) Evaluation of enniatins A, A1, B, B1 and beauvericin in Portuguese cereal-based foods. Food Addit Contam Part A 29: 1727-1735.

258. Beccari G, Caproni L, Tini F, Uhlig S, Covarelli L (2016) Presence of Fusarium Species and Other Toxigenic Fungi in Malting Barley and Multi-Mycotoxin Analysis by Liquid Chromatography-HighResolution Mass Spectrometry. J Agric Food Chem 64: 4390-4399.

259. Wambacq E, Vanhoutte I, Audenaert K, De Gelder L, Haesaert G (2016) Occurrence, prevention and remediation of toxigenic fungi and mycotoxins in silage: a review: Fungi and mycotoxins in silage. $J \mathrm{Sci}$ Food Agric 96: 2284-2302. 
260. Gallo A, Giuberti G, Frisvad J, Bertuzzi T, Nielsen K (2015) Review on Mycotoxin Issues in Ruminants: Occurrence in Forages, Effects of Mycotoxin Ingestion on Health Status and Animal Performance and Practical Strategies to Counteract Their Negative Effects. Toxins 7: 3057-3111.

261. Pinotti L, Ottoboni M, Giromini C, Dell'Orto V, Cheli F (2016) Mycotoxin Contamination in the EU Feed Supply Chain: A Focus on Cereal Byproducts. Toxins 8: 45.

262. European Commission Decision C 2453 (2015) Horizon 2020 Work Programme 2014-2015. 9. Food security, sustainable agriculture and forestry, marine and maritime and inland water research and the bioeconomy.

263. Comisión Europea (2006) Reglamento CE N 401/2006 de la Comisión por el que se establecen los métodos de muestreo y de análisis para el control oficial del contenido de micotoxinas en los productos alimenticios. Diario Oficial de la Comunidad Europea L 221: 8-36.

264. Amigot SL, Fulgueira CL, Bottai H, Basílico JC (2006) New parameters to evaluate forage quality. Postharvest Biol Technol 41: 215-224.

265. Pereyra MLG, Alonso VA, Sager R, Morlaco MB, Magnoli CE, Astoreca AL, Rosa CAR, Chiacchiera SM, Dalcero AM, Cavaglieri LR (2008) Fungi and selected mycotoxins from pre- and postfermented corn silage. Journal of Applied Microbiology 104: 1034-1041.

266. Pereyra MLG, Chiacchiera SM, Rosa CAR, Sager R, Dalcero AM, Cavaglieri LR (2012) Fungal and mycotoxin contamination in mixed feeds: Evaluating risk in cattle intensive rearing operations (Feedlots). Rev Bras Med Vet 34: 311-318.

267. Pacin AM, Ciancio Bovier E, González HHL, Whitechurch EM, Martínez EJ, Resnik SL (2009) Fungal and Fumonisins Contamination in Argentine Maize ( Zea mays L.) Silo Bags. J Agric Food Chem 57: 27782781.

268. Cendoya E, Monge MP, Palacios SA, Chiacchiera SM, Torres AM, Farnochi MC, Ramirez ML (2014) Fumonisin occurrence in naturally contaminated wheat grain harvested in Argentina. Food Control 37: 56-61.

269. Garrido CE, Hernández Pezzani C, Pacin A (2012) Mycotoxins occurrence in Argentina's maize (Zea mays L.), from 1999 to 2010. Food Control 25: 660-665.

270. Martins J, Zitelli S, Zapata de Basílico ML, Basílico JC (2002) Evolución de especies de Fusarium en los estadíos de formación del grano de maíz y determinación de Fusaproliferina y Beauvericina. FABICIB 6: 205-212.

271. Basílico MLZ, Pose G, Ludemann V, Fernández Pinto VE, Aríngoli EE, Ritieni A, Basílico JC (2010) Fungal diversity and natural occurrence of fusaproliferin, beauvericin, deoxynivalenol and nivalenol in wheat cultivated in Santa Fe Province, Argentina. Mycotox Res 26: 85-91.

272. European Food Safety Authority (2011) Scientific Opinion on the risks for animal and public health related to the presence of Alternaria. EFSA Journal 9: 2407.

273. Streit E, Schatzmayr G, Tassis P, Tzika E, Marin D, Taranu I, Tabuc C, Nicolau A, Aprodu I, Puel O, et al. (2012) Current Situation of Mycotoxin Contamination and Co-occurrence in Animal Feed-Focus on Europe. Toxins 4: 788-809.

274. Madege R, Audenaert K, Kimanya M, Tiisekwa B, De Meulenaer B, Bekaert B, Landschoot S, Haesaert G (2018) Control of Fusarium verticillioides (Sacc.) Nirenberg and Fumonisins by Using a Combination of Crop Protection Products and Fertilization. Toxins 10: 67.

275. D'Mello F, Macdonald AMC, Postel D, Dijksma W, Dujardon A, Placinta C (1998) Pesticide use and mycotoxin production in Fusarium and Aspergillus phytopathogens. Eur J Plant Pathol 104: 741-751. 
